ANTONIO FABIANO DE OLIVEIRA

\title{
AVALIAÇÃO CRÍTICA DO REVESTIMENTO DE CROMO DURO EM CILINDROS DE LAMINAÇÃO A FRIO
}

São Paulo

2019 


\section{AVALIAÇÃO CRÍTICA DO REVESTIMENTO DE CROMO DURO EM CILINDROS DE LAMINAÇÃO A FRIO}

Tese a ser apresentada à Escola Politécnica da Universidade de São Paulo para obtenção do Título de Doutor em Ciências.

Área de concentração:

Engenharia Metalúrgica e de Materiais

Orientador:

Prof. Dr. Guilherme Frederico Bernardo Lenz e Silva

São Paulo

2019 
Este exemplar foi revisado e alterado em relação à versão original, sob responsabilidade única do autor e com a anuência de seu orientador.

São Paulo, 14 de janeiro de 2019.

\author{
Antonio Fabiano de Oliveira \\ Autor
}

Prof. Dr. Guilherme Frederico Bernardo Lenz e Silva Orientador

Catalogação-na-publicação

Oliveira, Antonio Fabiano de

Avaliação crítica do revestimento de cromo duro em cilindros de laminação a frio / A. F. Oliveira -- versão corr. -- São Paulo, 2019. $281 \mathrm{p}$.

Tese (Doutorado) - Escola Politécnica da Universidade de São Paulo. Departamento de Engenharia Metalúrgica e de Materiais.

1.Rugosidade 3D 2.Texturização 3.Cromagem 4.Laminação 5.Agrupamento I.Universidade de São Paulo. Escola Politécnica. Departamento de Engenharia Metalúrgica e de Materiais II.t. 

À Deus, minha esposa, meus filhos, meus pais (in memorian), minha tia e meus irmãos. 


\section{AGRADECIMENTOS}

Para meu Deus, em quem deposito toda minha vida.

Para minha amada esposa e amiga Cássia e aos meus queridos filhinhos, Pietro e Gael.

Para meus Pais Antonio Cândido (in memorian), minha mãe Elizabete (in memorian), que sempre foram minhas fontes de exemplo, inspiração, respeito e devoção. O meu muito obrigado, por tudo que fizeram por mim.

Para minha querida tia Edith, minha segunda mãe, que sempre me ensinou o caminho da verdade, da lealdade e do estudo.

Para meus irmãos e amigos, Andréa, Anestal, Carla, Rogério, Eduardo, Marcos e todos meus sobrinhos e sobrinhas.

Para meu sogro Zé do montão, minha sogra De Lourdes, meus cunhados Suzy e Ricardo.

Para o Prof. Dr. Guilherme Frederico Bernardo Lenz e Silva, que me ajudou a tornar este sonho do doutorado em realidade, contribuiu enormemente nos resultados obtidos através das várias reuniões.

Para o Prof. Dr. Ronald Plaut pelo apoio, críticas e sugestões, e torná-la mais consistente.

Para o Ricardo Lívio (CRC), pelo apoio e incentivo.

Para os amigos Prof. Dr. Cleyton de Carvalho Carneiro (PMI-USP Santos) pela enorme ajuda na elaboração e interpretação dos dados através do mapeamento auto organizável SOM, Dr. Eduardo Nunes (GM), e a Profa. Dra. Izabel Machado e todo o pessoal do LFS da Mecânica da USP, pela disponibilização do interferômetro 3D e ao Prof. Dr. José Fontebasso Neto, da Universidade Católica de Santos, pelo enorme apoio na utilização do SPSS. 
Para os amigos da Usiminas Célio, Michel, Cristiano, Luis Fernando, Marcelo, Vinícius, e da CRC do Sul, Cleberson pelo apoio técnico.

Enfim, a todos que direta e indiretamente me apoiaram e acreditaram neste projeto. 


\section{EPÍGRAFE}

"O valor de praticar com rigor, por algum tempo, uma ciência rigorosa, não está propriamente em seus resultados: pois eles sempre serão uma gota ínfima, ante o mar de coisas dignas de saber. Mas isso produz um aumento de energia, de capacidade dedutiva, de tenacidade; aprende-se a alcançar um fim de modo pertinente. Neste sentido é valioso, em vista de tudo que fará depois, de ter sido homem da ciência ".

Friedrich Nietzche (1844-1900) 


\section{RESUMO}

O presente trabalho analisou o comportamento tribológico do revestimento superficial cromo duro, aplicado em cilindros de laminação e sua influência durante o processo de laminação a frio, para ligas de aço, cobre e alumínio.

Iniciou-se o processo com a análise dos mecanismos de desgaste que ocorrem em cilindros de laminação. Em função das dimensões dos cilindros de laminação, foram produzidas réplicas obtidas em vários cilindros de laminação em diferentes empresas, antes e após a campanha dos cilindros de laminação. Consideramos no processo de amostragem, 3 tipos de acabamento do cilindro: texturizado, jateado e retificado. E ainda, cilindro sem e com revestimento de cromo.

A estrutura da Texturização Shot Blaster (SBT) não atende todos os requisitos relacionados ao produto acabado. A camada de cromo duro, aplicado sobre estes cilindros de laminação SBT, melhora a qualidade da superfície da chapa, sendo de interesse para aquelas siderúrgicas que não têm outra alternativa às novas estruturas de superfície, podendo ser obtidas pelos métodos: Electro Discharge Texturing (EDT), Laser Texturing (LT), Electro Beam Texturing (EBT).

A função das superfícies geradas, obtidas por estes métodos diferentes vai influenciar as propriedades tribológicas durante os processos de laminação e deformação de chapa. Por outro lado, pode aumentar o custo final do produto ou exigem grandes investimentos para obtenção de tais métodos.

Palavras-chave: Rugosidade 3D. Texturização. Cromagem. Laminação. Agrupamento. 


\section{ABSTRACT}

The present work analyzed the tribological behavior of the hard chrome surface coating applied in rolling cylinders and their influence during the cold rolling process for steel, copper and aluminum alloys.

The process started by analyzing the wear mechanisms that occur in work rolls. In function on the dimensions of the work rolls, replicas were obtained from several rolls and in different companies, before and after the roll chance. We consider in the sampling process, three types of work rolls finish: texturing, shot blasted and rectified. And still, work rolls without and with chrome coating.

The Texture Shot Blaster (SBT) structure is not available in all respects related to the finished product. The hard chromium layer applied to these SBT rollers improves the surface quality of the sheet and is of interest to steel parts that are not of good capacity: EDT Textures, Laser texturing (LT), electrical beam texturization (EBT).

The function of the generated surfaces obtained by these different methods is going to influence the tribological properties during the subsequent forming processes. On the other hand, they can increase the product final cost or require large investments to obtain such methods.

Key words: 3D finishing. Tribology. Deposit Chrome. Rolling. Cluster analysis. 


\section{LISTA DE FIGURAS}

Figura 1- 1. Resumo dos processos realizados numa usina siderúrgica, a partir do minério até o produto final.

Figura 1-2. Métodos de texturização de cilindros de trabalho. Métodos estocásticos (SBT, EDT e Pretex) e métodos determinísticos (LT e EBT).

Figura 1-3. Ilustração esquemática do mecanismo dos vales de lubrificação hidrostática.

Figura 2-1. Número de publicações sobre rugosidade de superfícies. .38

Figura 2-2. Superfície efetiva da superfície de um material 39

Figura 2-3. Perfil real cortado por um plano perpendicular. 40

Figura 2-4. Perfil efetivo

Figura 2-5. A1 e A2 são áreas acima da linha média = A3 área abaixo da linha média.

Figura 2-6. Elemento do perfil

Figura 2-7. Rugosidade $R_{\text {máx }}$ definido pela rugosidade parcial $\mathrm{Zp}$ (neste caso

$\left.\mathrm{Z}_{3}\right)$

Figura 2-8. Rugosidade $\mathrm{R}_{\text {máx }}$ definido pela rugosidade parcial Zv (neste caso $\left.\mathrm{Z}_{3}\right)$ 45

Figura 2-9. Parâmetro de rugosidade Ra .46

Figura 2-10. Rugosidade Rmáx definido pela rugosidade parcial .48

Figura 2-11. Rugosidade parcial $Z_{i}$, para definir $R_{c}$ .50

Figura 2-12. Rugosímetro de contato portátil .54

Figura 2-13. Superfície iluminada em microscópio .55

Figura 2-14. Característica da textura primária .56

Figura 2-15. Exemplo de imagem adequada para a abordagem estatística 62

Figura 2-16. Exemplo de imagem adequada para a abordagem estrutural. 62

Figura 2-17. Rugosímetro 3D não contato. 282 
Figura 3-1. Desenho esquemático de um trem de laminação a frio .71

Figura 3- 2. Velocidades e forças de atrito durante o processo de laminação .......72

Figura 3-3. Processo de jateamento de granalha de aço ...................................75

Figura 3-4. Desenho esquemático da irradiação com laser no material ..................76

Figura 3-5. Equipamento para realizar a texturização por descarga elétrica...........77

Figura 3-6. Retífica utilizada para realizar usinagem nos cilindros ........................79

Figura 3- 7. As figuras indicam a laminação de acabamento em diferentes graus de redução para 4 métodos de texturização SBT, EDT, EBT e LT.

Figura 3- 8. Grau de redução na laminação de acabamento em função do grau de transferência da rugosidade para a chapa metálica

Figura 3- 9. Lavador de gases da cromagem de cilindros na planta CRC Mauá....84

Figura 3- 10. Variação dos parâmetros de rugosidade (a) Ra e (b) Pc em função do tipo de texturização. $\diamond$ Com revestimento de cromo. Sem revestimento de cromo.

Figura 3- 11. Ensaios tipo bloco-sobre-anel comparando cilindros revestidos e não revestidos: (a) Tribômetro; (b e c) coeficiente de atrito em função do número de rotações para pressões de contato de 3,3 $\mathrm{MPa}$ e $11 \mathrm{MPa}$; (d) taxa de desgaste.

Figura 3- 12. Variação do coeficiente de atrito em função da espessura do revestimento de cromo duro.

Figura 3- 13. Variação do coeficiente de atrito em função de diferentes modificações superficiais: sem modificação superficial (SM), com revestimento de cromo duro $(C)$, texturizadas por jateamento de granalha de aço $(\mathrm{T})$ e texturizadas com posterior revestimento de cromo duro.

Figura 3- 14. Desgaste do contra-corpo para diferentes modificações superficiais (a) sem modificação superficial (b) revestida com cromo duro (c) texturizada (d) Texturizada com posterior revestimento de cromo duro 
Figura 3- 15. Taxa de desgaste em função das diferentes modificações superficiais (SM) sem modificação superficial (C) revestida com cromo duro (T) texturizada (TC) Texturizada com posterior revestimento de cromo duro.

Figura 3- 16. Comparação dos valores de Ra do revestimento e do substrato em função da espessura do revestimento.

Figura 3- 17. Microscopia ótica da seção transversal de amostra revestida com $\mathrm{NiP}$ e $\mathrm{Ra}=2,46 \mu \mathrm{m}$.

Figura 3- 18. Tribômetro com a configuração de cilindro de contato transversal. ..92

Figura 4-1. Visualização de um item de dado com valores aleatórios através de um gráfico de barras $(A)$ e da curva de Andrews $(B)$

Figura 4-2. Visualização de um item de dado com valores aleatórios usando polígonos

Figura 4-3. Conjunto de dados para o qual algoritmos baseados em métricas de distância apresentam desempenhos ruins. Possíveis análises revelam 2 retângulos e 4 linhas, uma figura humanoide, etc.

Figura 4-4. Classificação simplificada dos métodos de agrupamento

Figura 4-5. Ilustração do critério de ligação simples e ligação completa. Supondo-se dois agrupamentos pré-existentes A e B, a ligação simples define a distância entre os dois grupos como a menor dentre todas as distâncias entre os pares de objetos $(x, y)$.

Figura 4-6. Dendrogramas obtidos segundo os critérios de ligação simples e completa. Em (A) um conjunto hipotético de objetos com sua matriz de distâncias $D$ descrita em $(B)$, sem consideração de escala. Pelo critério de ligação simples (C), os grupos $\{4\}$ e $\{5\}$ são.

Figura 4-7. O k-means é sensível à posição inicial dos centróides: à esquerda vê-se um agrupamento indevido se comparado ao obtido na figura à direita, o que pode ser verificado pelo erro total obtido. ....109

Figura 5-1. Em (A) uma representação das várias regiões corticais especializadas no cérebro humano. Em (B) uma imagem 
projetada sobre a retina de um macaco (esquerda) é mapeada sobre seu córtex cerebral primário, o qual mantém as relações topológicas da imagem.

Figura 5-2. Representação do córtex tonotópico de um gato onde os estímulos sonoros provocaram sensibilização no córtex conforme altura das notas: a organização dos neurônios representa ordenação topológica dos sinais de entrada.

Figura 5-3. Diferentes configurações de arranjo para o SOM em $\mathfrak{R}^{2}$. Em (A) vêse a vizinhança retangular enquanto em (B) observa-se uma vizinhança hexagonal.

Figura 5-4. Todos os neurônios do arranjo, representados por vetores de pesos sinápticos $\mathrm{mi}=[\mathrm{mi} 1, \ldots, \mathrm{miD}], \mathrm{i}=1, \ldots, 24$, recebem o mesmo dado de entrada.

Figura 5-5. llustração da adaptação dos pesos de um SOM para a apresentação de um único padrão em 2. Em (A) uma representação da função $h_{c i}$ sobre um mapa bidimensional cuja projeção pode ser vista em (B).

Figura 5-6. A grade elástica do SOM com inicialização linear dos vetores de pesos dos neurônios sobre um conjunto de dados artificiais em $\mathfrak{R} 3$. A grade inicial é alinhada com o plano gerado pelos eixos de maior variância do conjunto de dados.

Figura 5-7. A "grade elástica" já adaptada sobre os dados da Figura 5-5. As quatro últimas figuras ilustram a superfície formada pela grade sob alguns pontos de vista.

Figura 5-8. O problema do caixeiro-viajante para 51 cidades. Em (A) o SOM apresenta um resultado inferior se comparado ao método KNIES (B). Em (C) o caminho ótimo (com menor custo) obtido por métodos de otimização. Nota-se que o SOM opera com um número $\mathrm{d}$.

Figura 5-9. Diferentes formatos para o arranjo SOM 122

Figura 6-1. Processo de Formação de Agrupamentos 
Figura 6-2. Método das Médias das Distâncias

Figura 6-3. Método da Ligação Simples ou do Vizinho mais Próximo... 133

Figura 6-4. Método da Ligação Completa ou do Vizinho mais Distante. 134

Figura 6-5. Método do Centroide 136

Figura 6-6. Processo de Divisão de um Conjunto através das Técnicas de Partição 137

Figura 6-7. Ilustração do Método K-Médias. Agrupamento de cores padrão RGB. 139

Figura 7-1. Categorias dos objetivos das técnicas de análise multivariada. 142

Figura 7-2. Objetivos da técnica de Análise Multivariada da Variância (MANOVA) 143

Figura 7-3. Objetivos da aplicação da técnica de Análise de Regressão 144

Figura 8- 1. Plano de amostragem - Etapa 1 154

Figura 8-2. Amostragem da aplicação de resina na mesa do cilindro 155

Figura 8-3. Região de amostragem da resina na mesa do cilindro de laminação. 156

Figura 8-4. Desenho esquemático do cone de laminação e campanha do cilindro 158

Figura 8- 5. Plano de amostragem - Etapa 1 159

Figura 8- 6. Plano de amostragem - Etapa 2 160

Figura 8- 7. Análise de réplica através do Interferômetro $\mathrm{CCl}$.............................162

Figura 8-8. Processo de cromagem de cilindros 165

Figura 8- 9. Unidade de cromagem da CRC Mauá 165

Figura 8- 10. Processo de limpeza e cromagem do cilindro de laminação a frio..167

Figura 8- 11. Altura média aritmética da superfície 168

Figura 8- 12. Altura máxima entre o maior pico e o maior vale 169

Figura 8- 13. Rugosidade média quadrática. 170

Figura 8-14. Curvas de distribuição Skewness. 171

Figura 8-15. Curvas de distribuição Curtose 172 


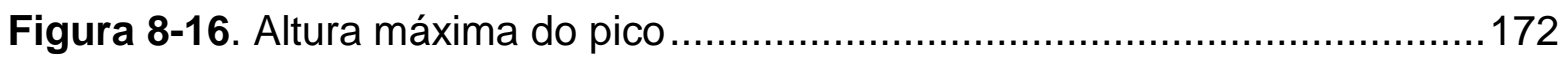

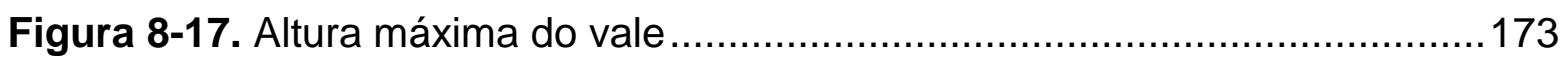

Figura 8-18. Diagrama esquemática do volume de material e do volume vazio de uma superfície ..................................................................174

Figura 9- 1. Distribuição simétrica e assimétrica ............................................189

Figura 9- 2. Gráfico de dispersão para 2 clusters.............................................194

Figura 9- 3. Gráfico de dispersão para 3 Clusters..........................................195

Figura 9- 4. Gráfico de dispersão para 5 Clusters............................................196

Figura 9- 5. Gráfico de dispersão para 10 Clusters........................................197

Figura 9- 6. Gráfico de dispersão para 15 Clusters.........................................198

Figura 9- 7. Cálculo para definição do índice de David-Bouldin ..........................200

Figura 9- 8. Matrix U (matriz da distância unificada) .......................................201

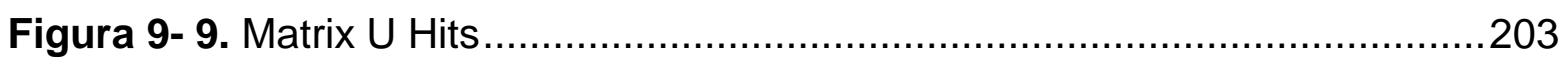

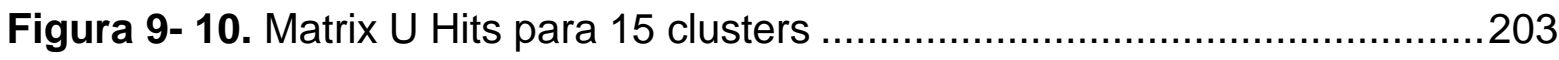

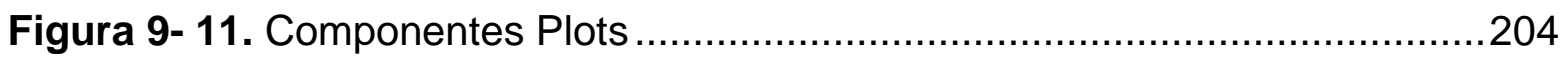

Figura 9- 12. Resultado das componentes principais .......................................249

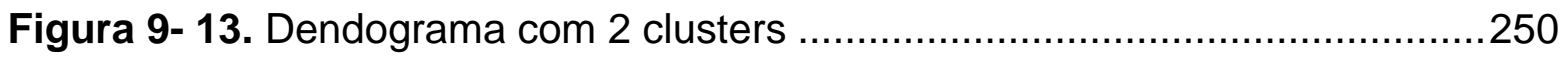

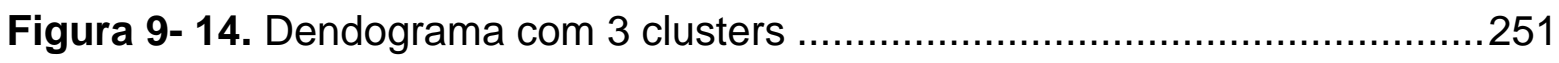

Figura 9- 15. Dendograma com 5 clusters ..................................................252

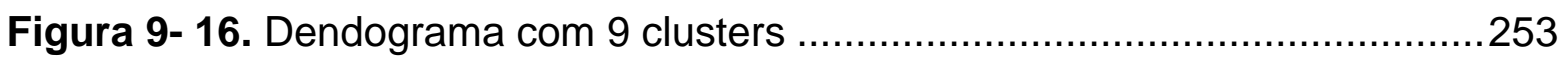

Figura 9- 17. Gráfico de cubo dos materiais aço x cobre (modelo) ......................259

Figura 9- 18. Gráfico de cubo dos materiais aço x cobre (real) ..........................260

Figura 9- 19. Gráfico de cubo dos materiais aço x alumínio (modelo)...................261

Figura 9- 20. Gráfico de cubo dos materiais aço x alumínio (real) ......................262 


\section{LISTA DE TABELAS}

Tabela 2-1. Seleção de comprimento e amostragem .......................................42

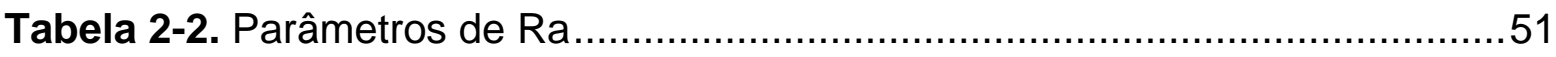

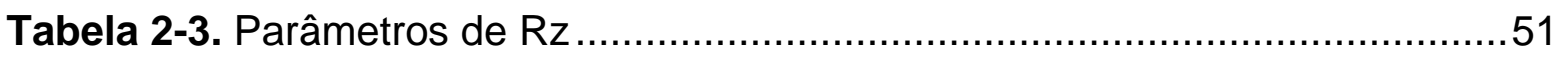

Tabela 2-4. Parâmetros de Ra (JIS B0601, 1994)........................................52

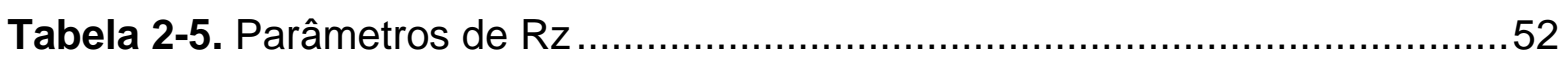

Tabela 2-6. Parâmetros de Ra (JIS B0601, 2001)..........................................52

Tabela 2-7. Parâmetros de Rz (JIS B0601, 2001).....................................53

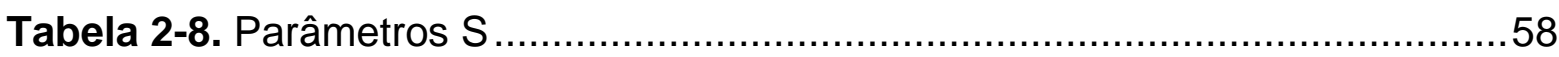

Tabela 3- 1. Resultados de dureza do cromo duro encontrados na literatura ........84

Tabela 7- 1. Matriz utilizada para regressão linear múltipla ............................146

Tabela 7- 2. Anova para regressão linear múltipla......................................150

Tabela 8-1. Coeficiente de correlação da réplica.............................................161

Tabela 9- 1. Análise regressão multivariada para equação $9.1 \ldots \ldots \ldots \ldots \ldots \ldots \ldots \ldots . . . \ldots 17$

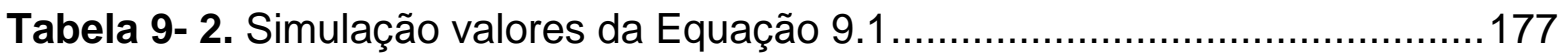

Tabela 9- 3. Análise regressão multivariada para equação 9.2 ...........................178

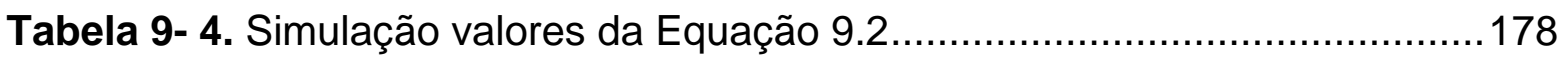

Tabela 9- 5. Análise regressão multivariada para equação 9.3 .........................179

Tabela 9- 6. Simulação valores da Equação 9.3 .....................................179

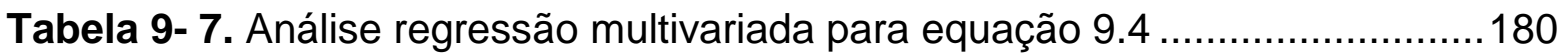

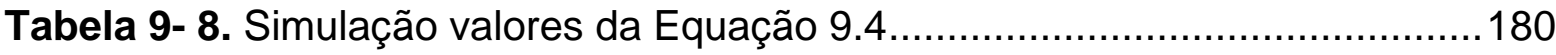

Tabela 9- 9. Análise regressão multivariada para equação 9.5 ........................181

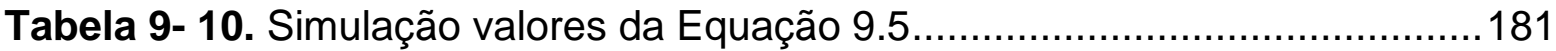

Tabela 9- 11. Análise regressão multivariada para equação 9.6 ......................182

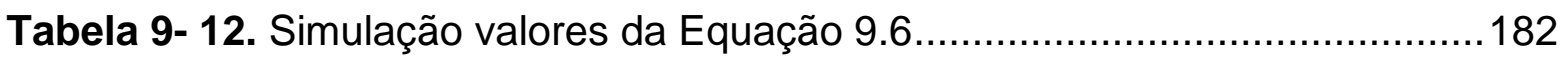

Tabela 9- 13. Análise regressão multivariada para equação 9.7 ........................183

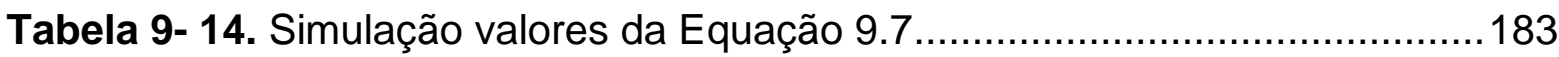


Tabela 9- 15. Análise regressão multivariada para equação 9.8 184

Tabela 9- 16. Simulação valores da Equação 9.8.............................................184

Tabela 9- 17. Análise regressão multivariada para equação 9.9 ……..................185

Tabela 9- 18. Simulação valores da Equação 9.9...........................................185

Tabela 9- 19. Análise regressão multivariada para equação 9.10 ….................... 186

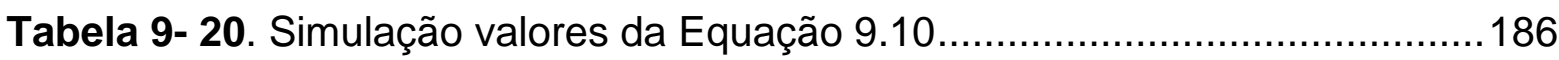

Tabela 9- 21. Resumo das equações de regressão linear multivariada ...............188

Tabela 9- 22. Tabela de frequências das variáveis ...........................................190

Tabela 9- 23. Tabela de frequências com correção assimetria............................190

Tabela 9- 24. Média e desvio padrão das variáveis ..........................................191

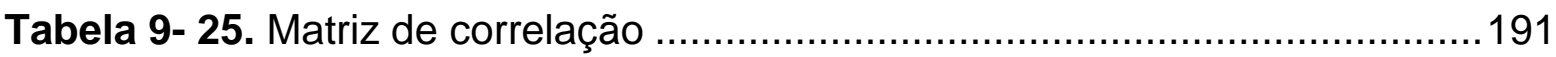

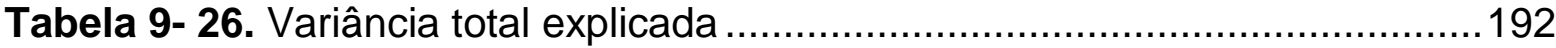

Tabela 9- 27. Matriz de componente ........................................................192

Tabela 9- 28. Centro de cluster inicial............................................................193

Tabela 9- 29. Distância entre os centróides dos clusters....................................193

Tabela 9- 30. Número de casos em cada cluster..............................................193

Tabela 9- 31. Resultado das equações de regressão linear múltipla....................205

Tabela 9- 32. Cluster com 2 componentes ...................................................205

Tabela 9- 33. Cluster com 3 componentes ................................................206

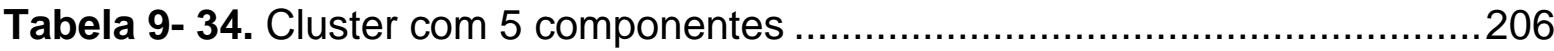

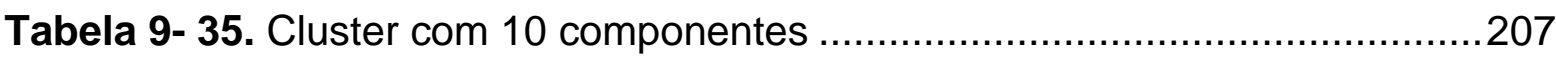

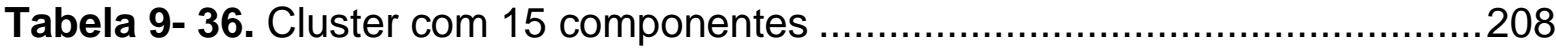

Tabela 9- 37. Parametrização das variáveis processo I ........................................209

Tabela 9- 38. Parametrização das variáveis processo II ......................................209

Tabela 9- 39. Resultados parametrização para 2 clusters ...................................210

Tabela 9- 40. Resultados parametrização para 3 clusters .................................210

Tabela 9- 41. Resultados parametrização para 5 clusters ..................................211

Tabela 9- 42. Resultados parametrização para 10 clusters ................................212

Tabela 9- 43. Resultados parametrização para 15 clusters ................................213 
Tabela 9- 44. Superfície do cilindro jateado e cromado - chapa aço (início) ........214

Tabela 9- 45. Curva Abbott - cilindro jateado e cromado - chapa aço (início) ......215

Tabela 9- 46. Superfície do cilindro jateado e cromado - chapa aço (meio) .........215

Tabela 9- 47. Curva Abbott - cilindro jateado e cromado - chapa aço (meio) .......216

Tabela 9- 48. Superfície do cilindro jateado e cromado - chapa aço (final) ..........216

Tabela 9- 49. Curva Abbott - cilindro jateado e cromado - chapa aço (final) ........217

Tabela 9- 50. Superfície do cilindro jateado e não cromado - chapa aço (início)..217

Tabela 9- 51. Curva Abbott - cilindro jateado e não cromado - chapa aço (início)218

Tabela 9- 52. Superfície do cilindro jateado e não cromado - chapa aço (meio) ..218

Tabela 9- 53. Curva Abbott - cilindro jateado e não cromado - chapa aço (meio) 219

Tabela 9- 54. Superfície do cilindro jateado e não cromado - chapa aço (final) ...219

Tabela 9- 55. Curva Abbott - cilindro jateado e não cromado - chapa aço (final) .220

Tabela 9- 56. Superfície do cilindro retificado e cromado - chapa aço (início)......220

Tabela 9- 57. Curva Abbott - cilindro retificado e cromado - chapa aço (início)....221

Tabela 9- 58. Superfície do cilindro retificado e cromado - chapa aço (meio) ......221

Tabela 9- 59. Curva Abbott - cilindro retificado e cromado - chapa aço (meio) ....222

Tabela 9- 60. Superfície do cilindro retificado e cromado - chapa aço (final) .......222

Tabela 9- 61. Curva Abbott - cilindro retificado e cromado - chapa aço (final)......223

Tabela 9- 62. Superfície do cilindro retificado e não-cromado - chapa aço (início)

Tabela 9- 63. Curva Abbott - cilindro retificado e não-cromado - chapa aço (início)

Tabela 9- 64. Superfície do cilindro retificado e não-cromado - chapa aço (meio)

Tabela 9- 65. Curva Abbott - cilindro retificado e não-cromado - chapa aço (meio) 225

Tabela 9- 66. Superfície do cilindro retificado e não-cromado - chapa aço (final) 225

Tabela 9- 67. Curva Abbott - cilindro retificado e não-cromado - chapa aço (final) .226

Tabela 9- 68. Superfície do cilindro texturizado e cromado - chapa aço (início)...226 
Tabela 9- 69. Curva Abbott - cilindro texturizado e cromado - chapa aço (início).227

Tabela 9- 70. Superfície do cilindro texturizado e cromado - chapa aço (meio) ...227

Tabela 9- 71. Curva Abbott - cilindro texturizado e cromado - chapa aço (meio) .228

Tabela 9- 72. Superfície do cilindro texturizado e cromado - chapa aço (final) ....228

Tabela 9- 73. Curva Abbott - cilindro texturizado e cromado - chapa aço (final)...229

Tabela 9- 74. Superfície do cilindro texturizado e não-cromado - chapa aço (início)

Tabela 9- 75. Curva Abbott - cilindro texturizado e não-cromado - chapa aço (início)

Tabela 9- 76. Superfície do cilindro texturizado e não-cromado - chapa aço (meio)

Tabela 9- 77. Curva Abbott - cilindro texturizado e não-cromado - chapa aço (meio)

Tabela 9- 78. Superfície do cilindro texturizado e não-cromado - chapa aço (final)

Tabela 9- 79. Curva Abbott - cilindro texturizado e não-cromado - chapa aço (final)

Tabela 9- 80. Superfície do cilindro retificado e cromado - chapa cobre (início) ..232

Tabela 9- 81. Curva Abbott - cilindro retificado e cromado - chapa cobre (início).233

Tabela 9- 82. Superfície do cilindro retificado e cromado - chapa cobre (meio) ...233

Tabela 9- 83. Curva Abbott - cilindro retificado e cromado - chapa cobre (meio) .234

Tabela 9- 84. Superfície do cilindro retificado e cromado - chapa cobre (final) ....234

Tabela 9- 85. Curva Abbott - cilindro retificado e cromado - chapa cobre (final) ..235

Tabela 9- 86. Superfície do cilindro retificado e não-cromado - chapa cobre (início)

Tabela 9- 87. Curva Abbott - cilindro retificado e não-cromado - chapa cobre (início)

Tabela 9- 88. Superfície do cilindro retificado e não-cromado - chapa cobre (meio) .236

Tabela 9- 89. Curva Abbott - cilindro retificado e não-cromado - chapa cobre (meio) 
Tabela 9- 90. Superfície do cilindro retificado e não-cromado - chapa cobre (final)

Tabela 9- 91. Curva Abbott - cilindro retificado e não-cromado - chapa cobre (final)

Tabela 9- 92. Superfície do cilindro retificado e cromado - chapa alumínio (início)

Tabela 9- 93. Curva Abbott - cilindro retificado e cromado - chapa alumínio (início)

Tabela 9- 94. Superfície do cilindro retificado e cromado - chapa alumínio (meio)

Tabela 9- 95. Curva Abbott - cilindro retificado e cromado - chapa alumínio (meio)

Tabela 9- 96. Superfície do cilindro retificado e cromado - chapa alumínio (final) 240

Tabela 9- 97. Curva Abbott - cilindro retificado e cromado - chapa alumínio (final)

Tabela 9- 98. Superfície do cilindro retificado e não-cromado chapa alumínio (início)

Tabela 9- 99. Curva Abbott cilindro retificado não-cromado-chapa alumínio (início)

Tabela 9- 100. Superfície do cilindro retificado e não-cromado chapa alumínio (meio)

Tabela 9- 101. Curva Abbott-cilindro retificado não-cromado-chapa alumínio (meio)

Tabela 9- 102. Superfície do cilindro retificado não-cromado chapa alumínio (final)

Tabela 9- 103. Curva Abbott-cilindro retificado não-cromado-chapa alumínio (final)

Tabela 9- 104. Resultado dos parâmetros de processo - interferômetro 245

Tabela 9- 105. Posição da campanha de cada critério de laminação 246

Tabela 9- 106. Tabela de avaliação dos principais componentes. 247

Tabela 9- 107. Matriz de autovetores 248 
Tabela 9- 108. Matriz de scores dos critérios de laminação ………....................248

Tabela 9- 109. Critérios de seleção das interações ...........................................254

Tabela 9- 110. Resultados das equações de regressão ......................................254

Tabela 9- 111. Experimento fatorial para máxima campanha do cilindro .............258

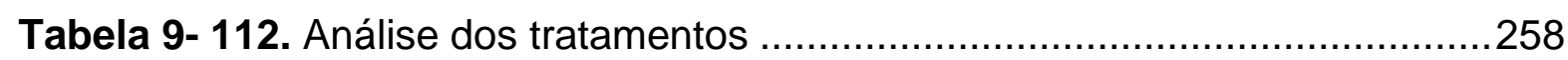




\section{LISTA DE GRÁFICOS}

Gráfico 9- 1. Análise das principais componentes pela variância........................247

Gráfico 9- 2. Interações para máxima campanha dos cilindros ..........................255

Gráfico 9- 3. Interações para mínima campanha dos cilindros..........................256

Gráfico 9- 4. Interação para média campanha dos cilindros .............................257 


\section{LISTA DE ABREVIAÇÕES}

$\mathbf{E}_{0}$ espessura da chapa antes de atravessar os cilindros.

Ef espessura da chapa depois de atravessar os cilindros.

I largura da chapa.

b largura da chapa após atravessar o cilindro

MEV microscópio eletrônico de varredura

Ve velocidade da chapa antes de atravessar os cilindros.

Vf velocidade da chapa depois de atravessar os cilindros.

Ra parâmetro de rugosidade bidimensional relativo à rugosidade aritmética média

$\mathbf{R z}$ parâmetro de rugosidade bidimensional relativo à altura máxima do pico

Pc: parâmetro de rugosidade bidimensional relativo ao número de picos

$\mathbf{R}_{\max }$ parâmetro de rugosidade bidimensional relativo a altura máxima do perfil

Sq Parâmetro de rugosidade tridimensional relativo a rugosidade superficial quadrática média.

Rt Distância entre o mais elevado pico e o vale mais baixo

$\mathbf{R z}$ Valor médio da altura absoluta de cinco picos mais altos e a profundidade dos cinco vales mais profundos

$\mathrm{J}$ Jateamento

C revestimento de cromo duro

EDT texturização por descargas elétricas

$\boldsymbol{R}$ retificado

Im comprimento de medição

Sm Média do espaçamento entre picos

$\%$ Porcentagem

$<$ Menor

a Alfa

2D Bidimensional

3D Tridimensional 


\section{SUMÁRIO}

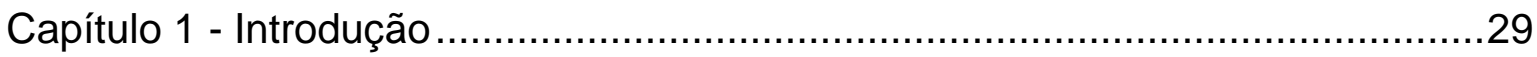

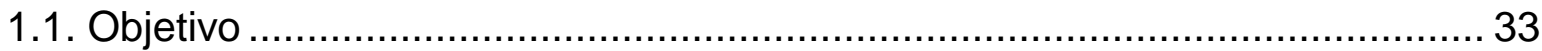

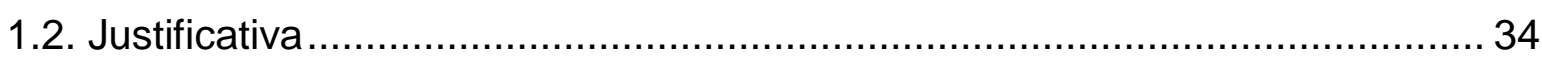

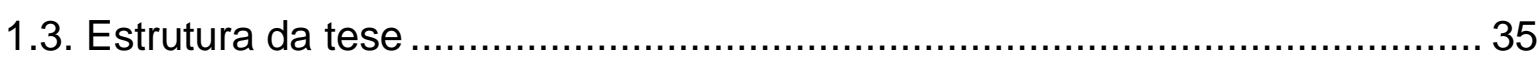

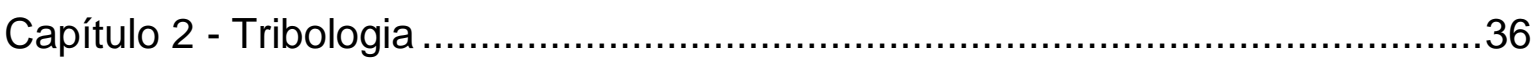

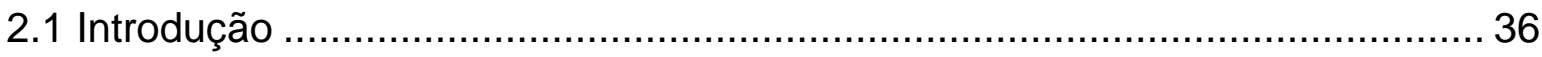

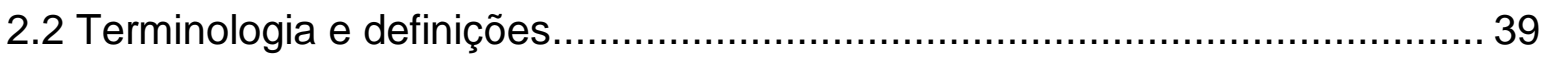

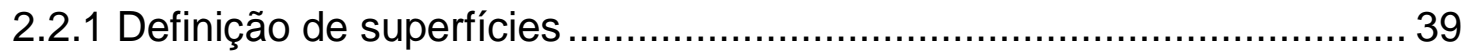

2.2.2 Definição de perfil de rugosidade ..................................................... 40

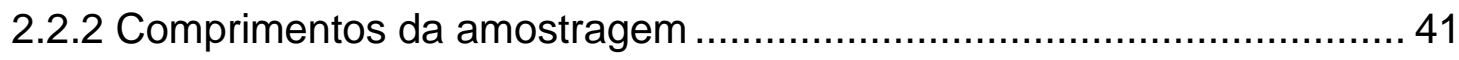

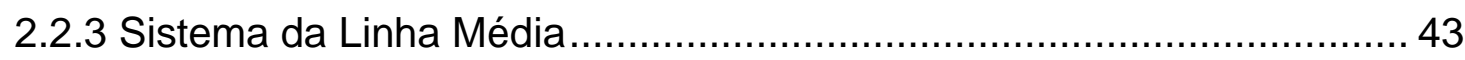

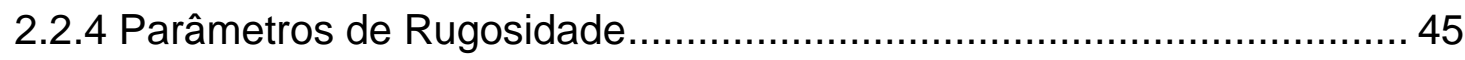

2.2.4.1 Rugosidade média dos valores absolutos (Ra) ……………………..... 46

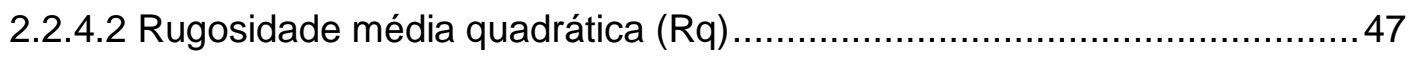

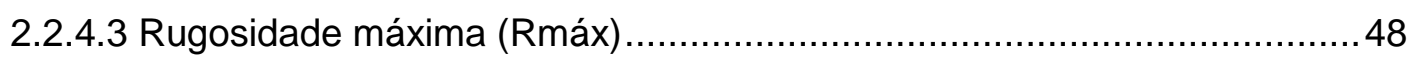

2.2.4.4 Rugosidade média da distância entre o pico mais alto e o mais baixo do

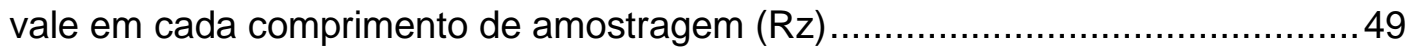

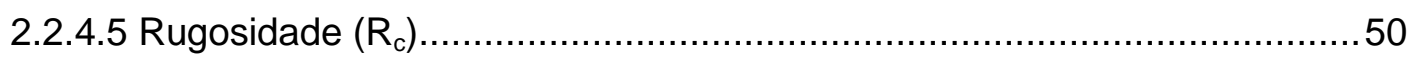

2.2.4.6. Apresentação da evolução das normas de rugosidade ...........................51

2.3. Métodos de medição de rugosidade ....................................................... 53

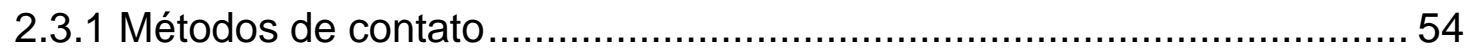

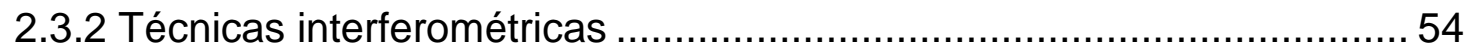

2.4 Nova abordagem para caracterização de superfícies …………………....... 55

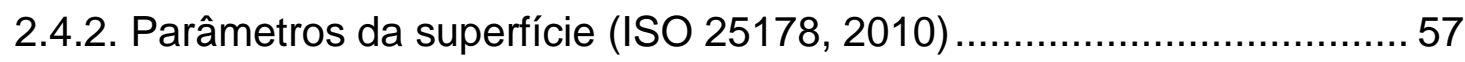

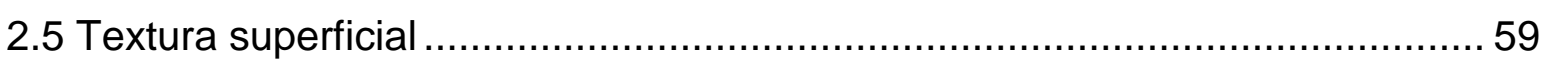

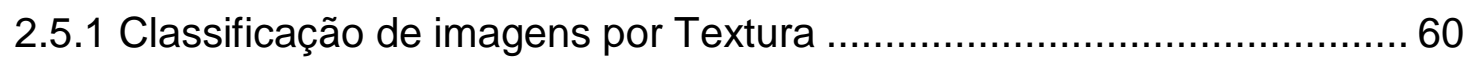

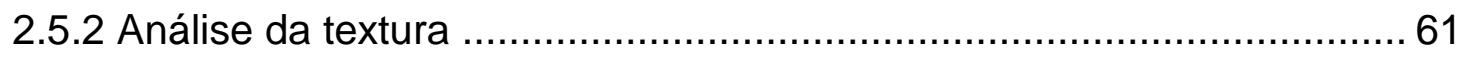

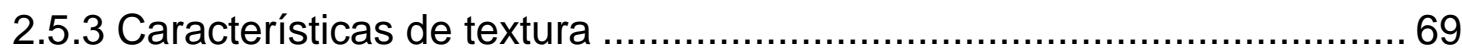

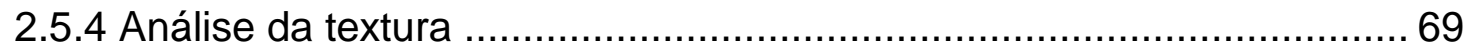

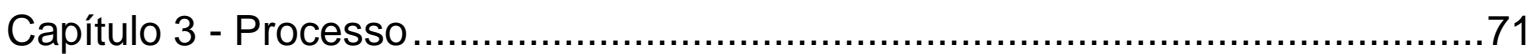

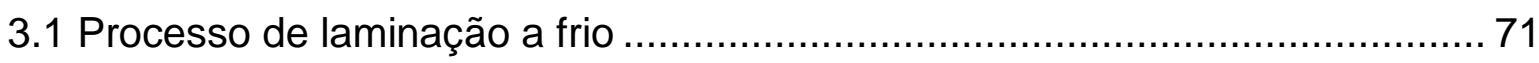

3.1.1 Texturização aplicada à laminação a frio ........................................... 73 
3.1.2 Texturização de cilindros de laminação e o efeito do grau de redução. 79

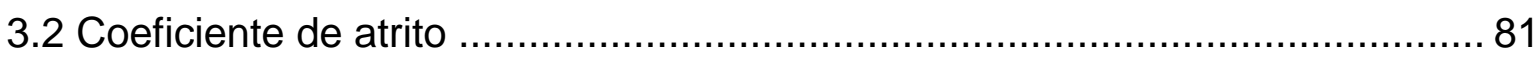

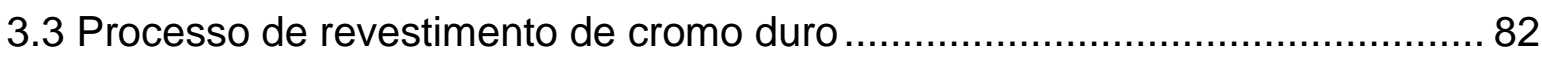

3.3.1 Performance do revestimento de cromo .......................................... 88

Capítulo 4 - Mineração de dados ...................................................................93

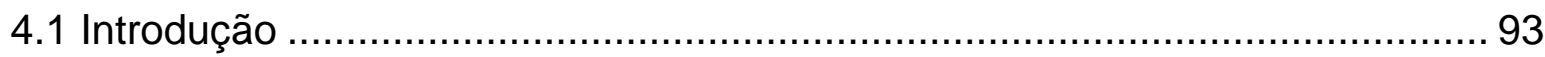

4.1.1 Métodos simples de visualização .................................................. 97

4.1.2 Métodos de Agrupamento .......................................................... 100

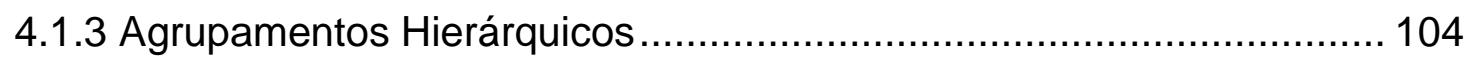

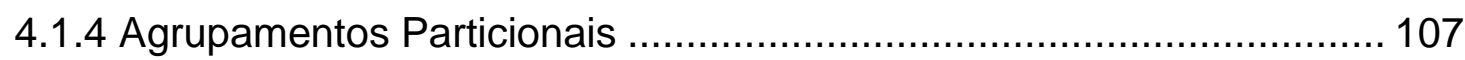

Capítulo 5 - Mapas Auto Organizáveis .......................................................110

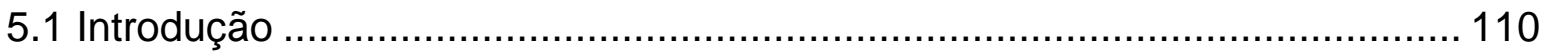

5.2 Modelo Formal do SOM …............................................................ 110

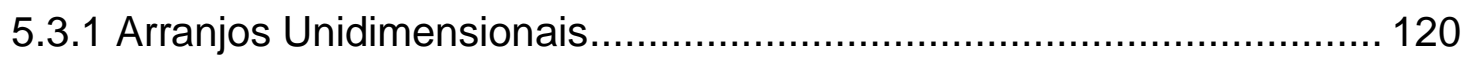

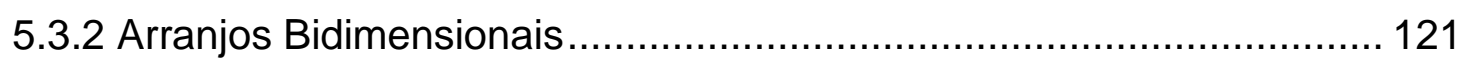

Capítulo 6 - Análise de agrupamento - Cluster................................................123

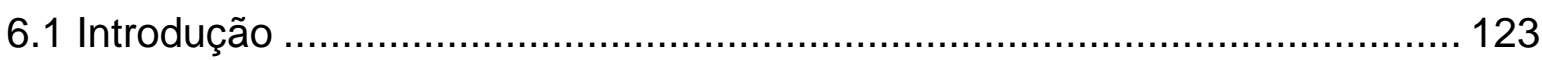

6.2 Coeficientes de Similaridade e de Dissimilaridade .................................... 125

6.3 Coeficientes Utilizados para Variáveis Quantitativas ................................. 126

6.4 Coeficientes Utilizados para Variáveis Qualitativas.................................... 129

6.5 Técnicas de Formação de Agrupamentos ............................................... 129

6.6 Técnicas Hierárquicas e de Partição para a Análise de Agrupamentos ........ 130

6.6.1 Método das Médias das Distâncias (Average Linkage)...................... 131

6.6.2 Método da Ligação Simples (Single Linkage) .................................. 132

6.6.3 Método da Ligação Completa (Complete Linkage) ............................ 134

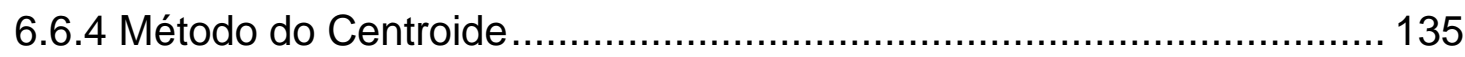

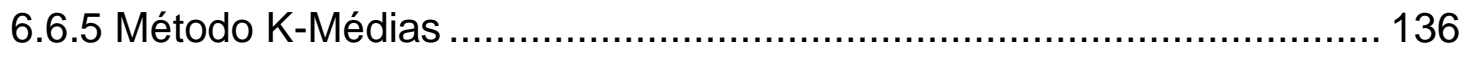

Capítulo 7 - As técnicas estatísticas de análise multivariada .............................141

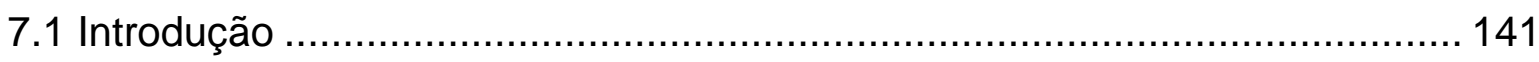

7.2 Objetivos de aplicação das técnicas estatísticas de análise multivariada ..... 142

7.3 Análise Multivariada da Variância (MANOVA) ............................................. 143

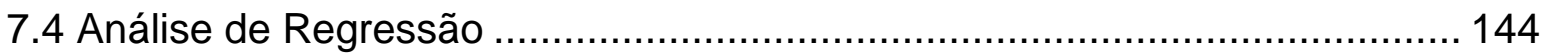

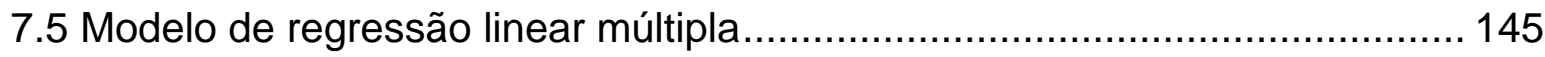

7.5 Significância do modelo de regressão múltipla ............................................. 148 
7.5 Coeficiente de determinação. 151

7.5 Testes de significância para os coeficientes de regressão. 152

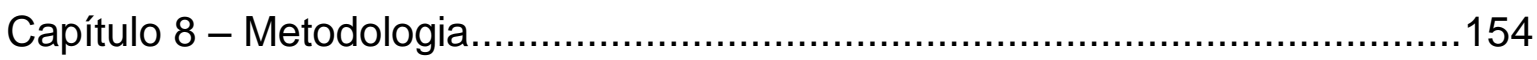

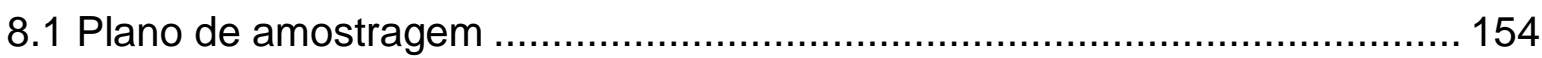

8.2.1 Validação da réplica através de método comparativo ............................... 161

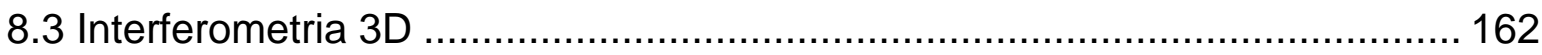

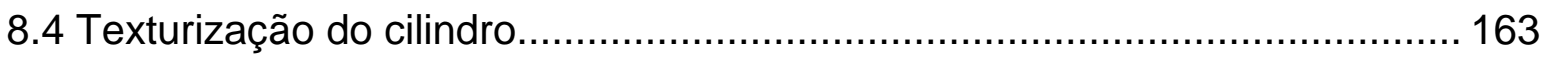

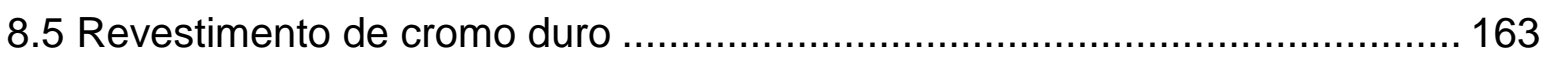

8.6 Parâmetros processo de cromagem ................................................ 164

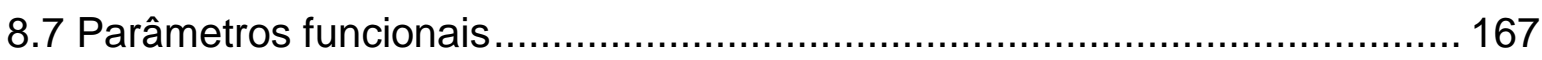

8.7.1 Parâmetro de amplitude Sa........................................................ 167

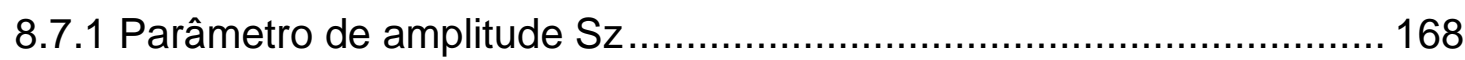

8.2.3 Parâmetro de amplitude Sq......................................................... 169

8.2.3 Parâmetro de amplitude Ssk ...................................................... 170

8.2.4 Parâmetro de amplitude Sku......................................................... 171

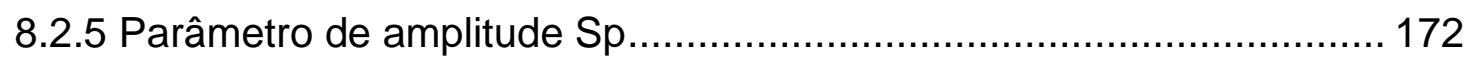

8.2.6 Parâmetro de amplitude Sv....................................................... 173

8.2.7 Índice de volume de material e do volume vazio................................ 173

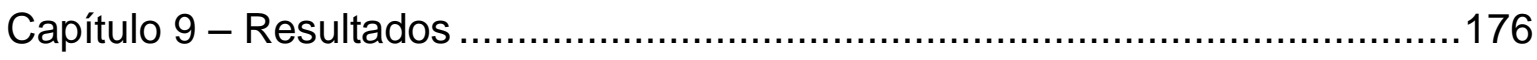

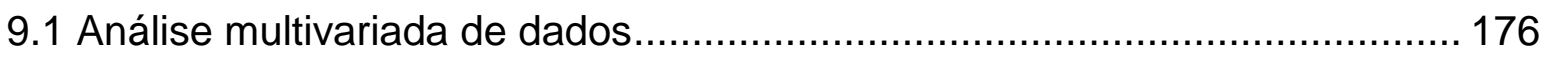

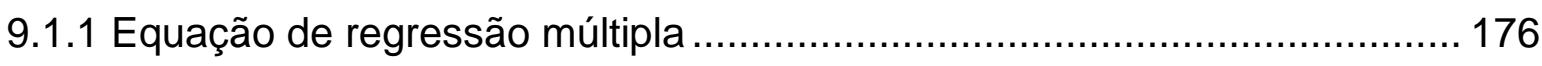

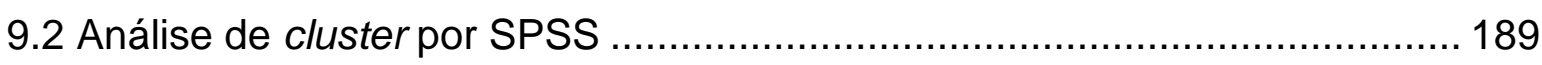

9.2.1 Análise de frequências das componentes........................................ 189

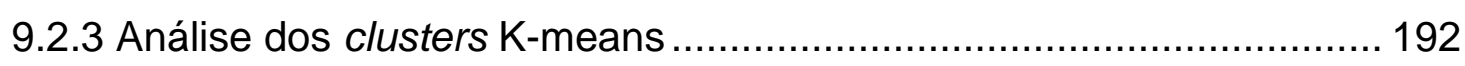

9.2.4 Análise dos gráficos scatters 3D ................................................... 194

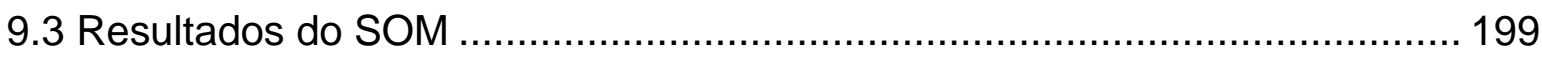

9.3.1 Matriz da Distância Unificada (Matriz-U) ......................................... 200

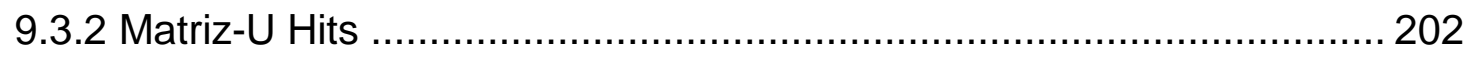

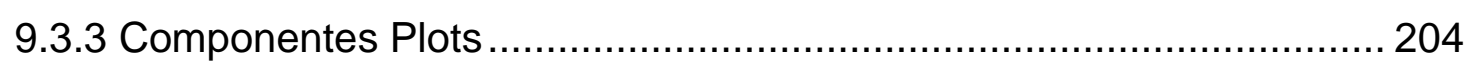

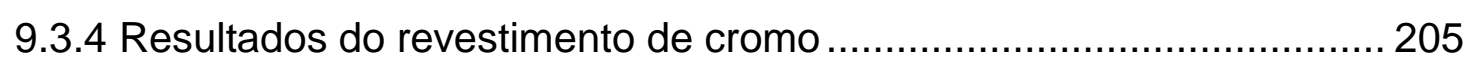

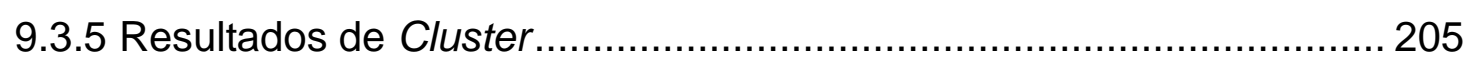

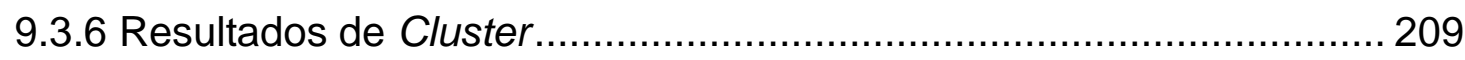

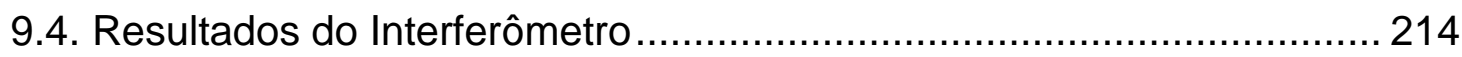

9.5. Resultados do software estatístico Portal Action ................................ 246 


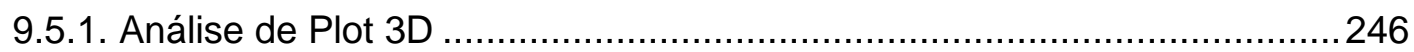

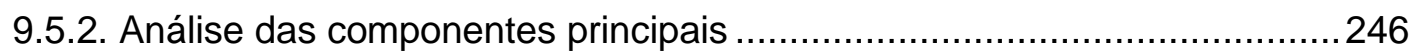

9.5.3. Análise de agrupamento - método hierárquico .....................................250

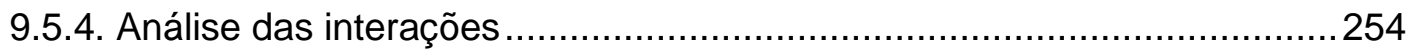

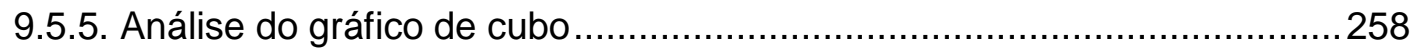

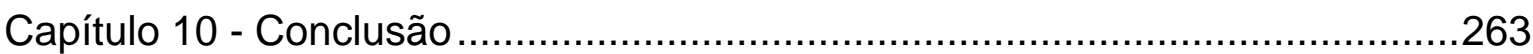

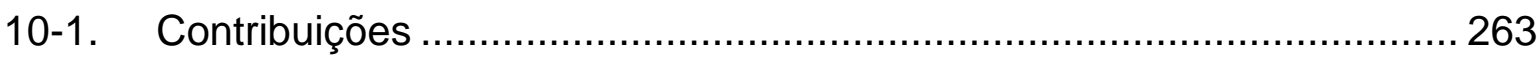

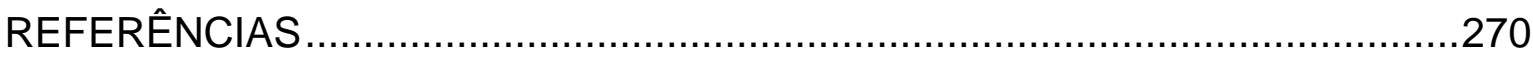





\section{Capítulo 1 - Introdução}

Um dos principais processos de produção de aço adotados pelas empresas no mundo é o processo de laminação, por permitir trabalhar grande volume de material. Os cilindros utilizados no processo de laminação devem permitir a obtenção de laminados com elevados padrões de qualidade. Os laminados devem apresentar níveis adequados de resistência mecânica, planicidade, topografia superficial, espessura de chapa, no atendimento a consumidores cada vez mais exigentes nas indústrias automobilística, linha branca, dentre outros. (MENDES, 2007).

A laminação a frio é uma etapa do processo siderúrgico, conforme FIGURA 1-1, e é baseada em um processo de conformação mecânica, no qual a chapa, podendo ser aço, cobre ou alumínio, é deformada plasticamente, quando o mesmo passa através de cilindros de trabalho, a uma determinada velocidade, tração e compressão (DIETER, 1988).

Figura 1- 1. Resumo dos processos realizados numa usina siderúrgica, a partir do minério até o produto final.

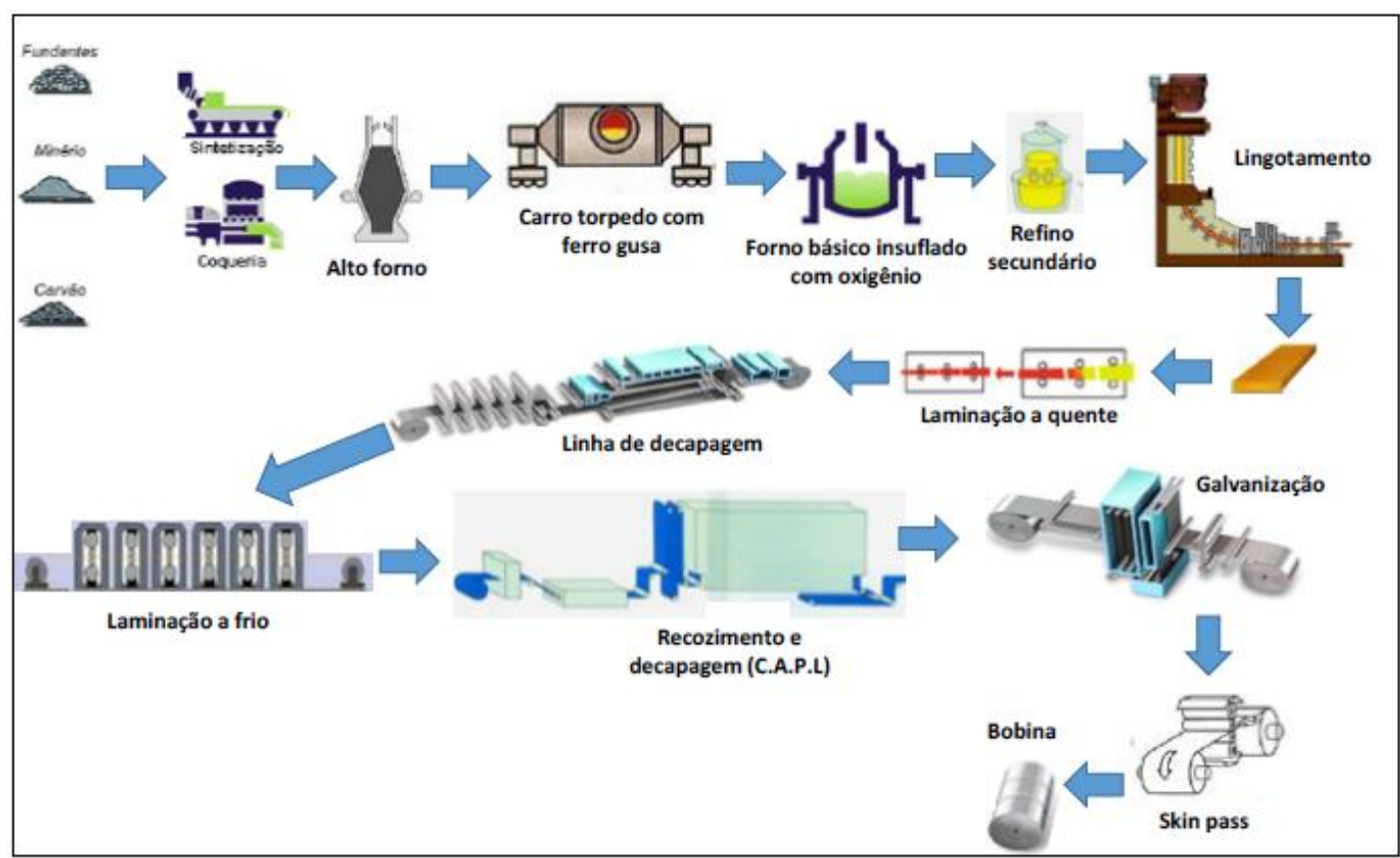

Fonte: (Rizzo, 2005). 
O processo de laminação opera com níveis elevados de carga, causando solicitações severas nos cilindros de laminação e, consequentemente, levando ao desgaste dos cilindros de laminação. Em função da exigência dos consumidores de produtos laminados a frio, é comum aos produtores a necessidade de produzir o material laminado com uma textura superficial pré-definida, sendo que esta textura é transmitida à chapa pelos cilindros de laminação (ELKOCA, 2008).

A textura superficial usada em laminação a frio consiste de modificações superficiais feitas na topografia do cilindro de trabalho, geralmente levando a acabamentos de dimensões micrométricas. Estas modificações podem ser feitas de forma a produzir um padrão de textura superficial com caráter aleatório, utilizando por exemplo, as técnicas por SBT ou EDT (PAWELSKI et al., 1994; SIMÃO, ASPINWALL, 1999), conforme FIGURA 1-2.

Uma outra possibilidade, é a produção de padrões de texturas determinísticas, de forma que a topografia seja constituída de arranjos regulares de protuberâncias ou depressões nas superfícies. Várias técnicas podem ser utilizadas na texturização superficial determinística (COSTA, H.; HUTCHINGS, I., 2015), sendo que a mais utilizada e conhecida é a LT, conforme FIGURA 1-2 (HILGENBERG; STEINHOFF, 2015).

Figura 1-2. Métodos de texturização de cilindros de trabalho. Métodos estocásticos (SBT, EDT e Pretex) e métodos determinísticos (LT e EBT).

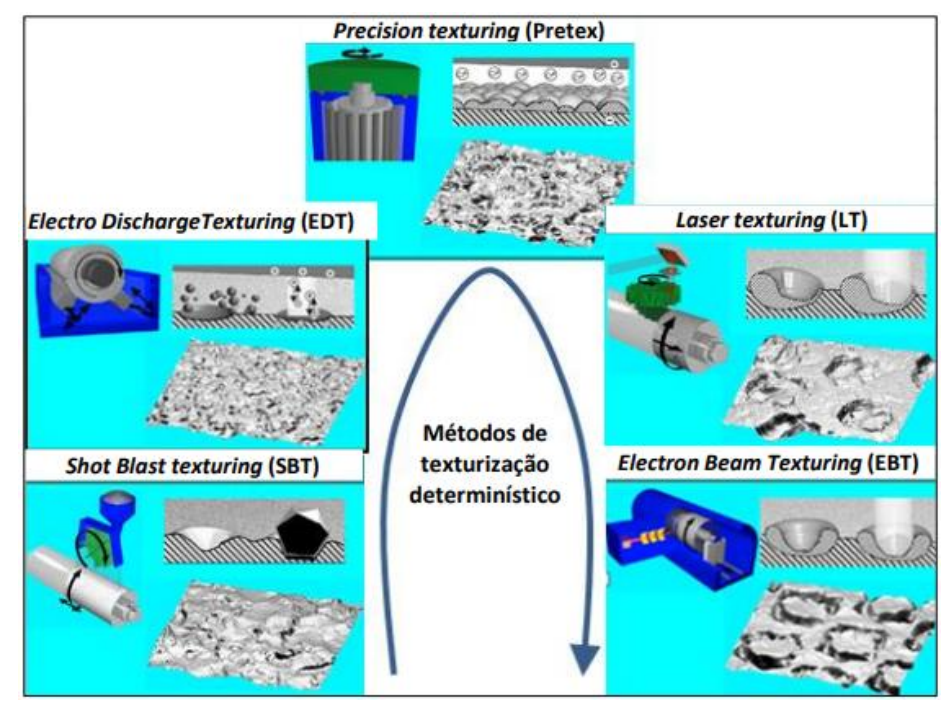


Fonte: (J. Staeves, 1998).

Tribologicamente a texturização superficial do cilindro pode apresentar várias vantagens. Uma delas é a possibilidade de acumular debris no interior das depressões (geralmente na forma de "bolsas") que constituem a textura, evitando que estas partículas permaneçam na região de contato e reduzindo o desgaste abrasivo das superfícies (BECKER; LUDEMA, 1999; ZUM GAHR; MATHIEU; BRYLKA, 2007). Além disso, a presença dos bolsas pode servir de reservatório para o lubrificante, no caso de contato com alta deformação plástica (STEINHOFF; K; RASP, W; PAWELSKI, 1996). O lubrificante utilizado no processo de laminação pode ainda formar um filme fino entre o cilindro e a chapa laminada, propiciando um regime de lubrificação chamado de elasto-hidrodinâmico, garantindo um filme de lubrificante entre as superfícies.

Com a utilização do cilindro texturizado, cria-se um campo de tensões que resulta na penetração de lubrificante no interior das bolsas das texturas e, com a evolução da deformação do produto laminado, ocorre um aumento das áreas efetivas de contato, chapa e cilindro, expulsando o lubrificante do interior dos bolsas $(\mathrm{BECH}$; BAY; ERIKSEN, 1998). É possível encontrar na literatura, estudos que mostram que a textura superficial não possui resistência mecânica suficiente, para suportar sistemas com elevadas cargas. As áreas mais altas da topografia suportam uma maior proporção da carga aplicada do que as áreas mais baixas do relevo, elevando a possibilidade de desgaste nestas áreas (FLETCHER et al., 2000). É de grande importância compreender e também controlar os fenômenos associados à lubrificação, a fim de reduzir o atrito e melhorar a qualidade de superfície da peça, conforme ilustrada na FIGURA 1-3. 
Figura 1-3. llustração esquemática do mecanismo dos vales de lubrificação hidrostática.

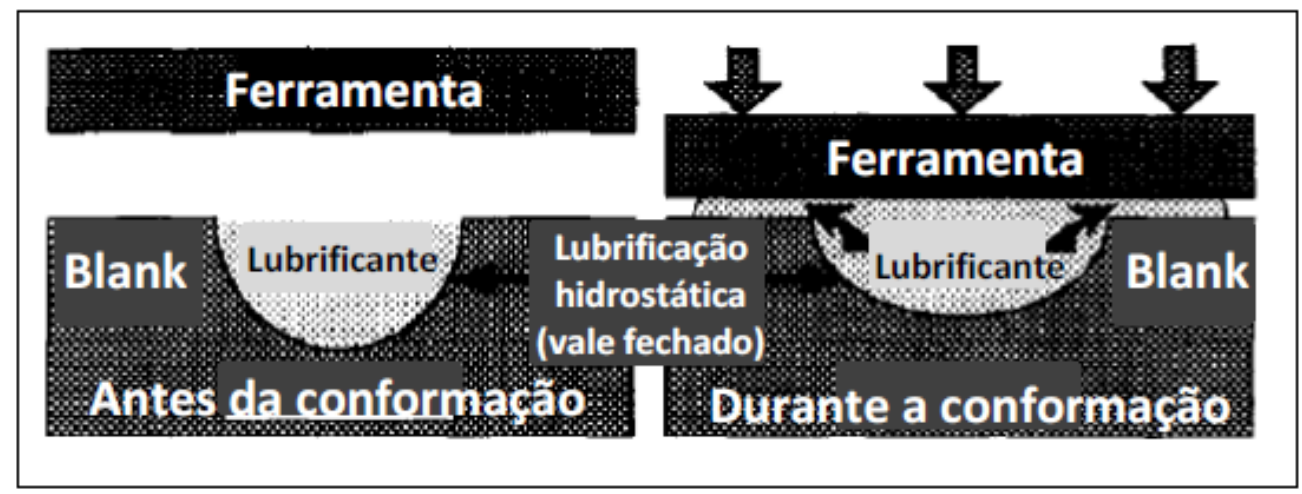

Fonte: (Pawelski et. Al, 1994).

No caso da laminação a frio, durante as primeiras etapas da laminação, alguns picos se fraturam facilmente se tornando debris (SIMÃO; ASPINWALL, 1999). Para evitar a fácil remoção da textura superficial, normalmente utiliza-se a técnica de tratamento de superfície conhecida como, deposição de cromo duro. O Cromo duro é um revestimento metálico eletrodepositado largamente utilizado pela indústria de laminação a frio, a fim de obter altos níveis de dureza na superfície do cilindro, manter a topografia original do cilindro, aumentar a resistência ao desgaste e corrosão da textura superficial do cilindro e baixo coeficiente de atrito entre a chapa e o cilindro (BODGER; MCGRANN; SOMERVILLE, 1997). Portanto, com o revestimento de cromo e, consequente elevação da dureza superficial em cilindros de laminação, é possível aumentar a capacidade de tonelagem ou também conhecido como campanha, que é a quantidade de material laminado pelo cilindro (SIMÃO; ASPINWALL, 1999). 


\subsection{Objetivo}

Avaliar comportamento tribológico dos cilindros de trabalho durante o processo de laminação a frio, para chapas de aço, cobre e alumínio, a partir da aplicação do revestimento de cromo duro, na superfície do cilindro, utilizando o método de agrupamentos de variáveis, sendo:

- Avaliar a influência do revestimento de cromo em relação à performance dos parâmetros de rugosidade: $\mathrm{S}_{\mathrm{a}}, \mathrm{S}_{\mathrm{q}}, \mathrm{S}_{\mathrm{sk}}, \mathrm{S}_{\mathrm{ku}}, \mathrm{S}_{\mathrm{p}}, \mathrm{S}_{\mathrm{v}}, \mathrm{V}_{\mathrm{mp}}, \mathrm{V}_{\mathrm{mc}}, \mathrm{V}_{\mathrm{vc}}, \mathrm{V}_{\mathrm{vv}}$;

- Avaliar a influência do revestimento de cromo em função do tipo de chapa de aço laminada (aço, cobre e alumínio).

- Avaliar o mecanismo de agrupamento aplicado pelas ferramentas SPSS e SOM, em função dos parâmetros de rugosidade e condições de processo de laminação.

- Avaliar a influência do revestimento de cromo em relação aos aspectos de qualidade da chapa, utilizando como referência a performance dos parâmetros de rugosidade.

- Avaliar a inter-relação dos parâmetros de rugosidade 3D e aplicações típicas, na busca de limites operacionais do processo de laminação. 


\subsection{Justificativa}

A qualidade superficial de qualquer material deve estar devidamente adequada ao tipo de aplicação ou solicitação, não sendo uma decisão relativamente simples, devido a isso, a importância do estudo do acabamento superficial dos cilindros de laminação e consequente da chapa laminada, à medida que crescem as exigências de qualidade de produtos manufaturados.

Além disso, a caracterização com mais exatidão da superfície das chapas tornouse cada vez mais importante nos últimos anos (Unfer et. al., 2012). A rugosidade da chapa influencia em particular no processo de estampagem e na aparência da pintura sobre o produto final (Pfestorf et. al., 1998). Segundo Weidel e Engel, é evidente que a caracterização tradicional da rugosidade em $2 \mathrm{D}$ não seria mais suficiente para caracterizar esse efeito (Weidel et. al., 2006). A tribologia no processo de conformação não pode ser descrita usando somente os parâmetros convencionais medidos em 2D (Weidel et. al., 2006). Assim, torna-se essencial o desenvolvimento de novos parâmetros relativos à superfície das chapas, empregando a medição efetuada em 3D (Pfestorf et. al., 1998). Uma grande vantagem dos parâmetros medidos em 3D é a mais precisa descrição da superfície, principalmente em uma aplicação industrial (Pfestorf et. al., 1998). Quando se observa os resultados das medições 2D, por exemplo, nota-se que um orifício oriundo de um ponto de corrosão é indistinguível de um risco. Ambas as falhas aparecem como sendo um vale no perfil (Weidel et. al., 2006).

Entretanto, a produção das superfícies com alto grau de acabamento exige, em geral, custo de fabricação mais elevado. Dependendo do tipo de processo de fabricação, obtêm-se os mais variados acabamentos para as superfícies. Existe, todavia, um único parâmetro que define o grau de acabamento de superfícies, que é denominado rugosidade. Sua medição gera um valor quantitativo estabelecido através de comparações com padrões convencionais, utilizando instrumentos que geram informações a partir de leituras de natureza bidimensional.

A presente tese apresenta uma nova abordagem, com a classificação de acabamentos de superfícies dos cilindros considerando a avaliação de sua textura topográfica, conhecida como rugosidade tridimensional ou 3D. Atendendo a este 
quesito, os parâmetros e variáveis utilizados na análise, foram obtidas da utilização e leitura de um interferômetro, que utiliza feixe de luz, capaz de detectar micro variações volumétricas na superfície da chapa.

\subsection{Estrutura da tese}

No Capítulo 1 uma introdução do tema a ser abordado ao longo da tese.

No Capítulo 2 apresenta uma revisão teórica de tribologia, além de terminologias, definições e parâmetros para avaliação da rugosidade 2D e 3D.

No Capítulo 3 apresenta-se os processos de laminação a frio e de cromagem de cilindros, apresentando métodos convencionais e modernos de texturização de cilindros.

No Capítulo 4 detalha a técnica utilizada para mineração de dados, mostrando os padrões de similaridades e diferenças, de produzir regras e resumos, a partir dos dados.

No Capítulo 5 apresenta-se o SOM (Self-Organising Maps), um tipo de rede neural artificial baseada em aprendizado competitivo e não supervisionado, conhecido como Mapa auto organizável de Kohonen.

No Capítulo 6 apresenta-se a análise de agrupamentos - Cluster e suas técnicas e algoritmos de formação de grupos, que visa separar os objetos em grupos similares.

No Capítulo 7 apresenta-se o método de agrupamento de variáveis através do software SPSS, através do método k-means não paramétrico.

No Capítulo 8 são apresentadas as metodologias desenvolvidas e aplicadas neste trabalho.

No Capítulo 9 os resultados encontrados, a partir das técnicas utilizadas.

No Capítulo 10 a conclusão do trabalho. 


\section{Capítulo 2 - Tribologia}

\subsection{Introdução}

A palavra tribologia é derivada das palavras grega TRIBOS que significa atrito, e LOGOS que significa estudo, de forma que uma tradução literal significa Estudo do Atrito, ou a ciência que estuda o Atrito (HALLING, 1983). Tribologia é definida como "A ciência e a tecnologia da interação entre superfícies com movimento relativo e dos assuntos e práticas relacionadas". A palavra tribologia, em sua atual conotação, surgiu pela primeira vez na Inglaterra, em 1966, em um relatório do Departamento de Educação e Ciência. Embora a palavra seja nova, o assunto a que se refere não o é, incluindo os tópicos relativos ao atrito, desgaste e lubrificação (HALLING, 1983). A invenção da roda, ilustra bem a preocupação do homem em reduzir o atrito nos movimentos de rotação e consequentemente de translação, e essa invenção é anterior a qualquer registro histórico existente. A necessidade de nosso envolvimento com problemas tribológicos de atrito e desgaste é perfeitamente justificável, pois esses fenômenos afetam quase todos os aspectos de nossa vida (HALLING, 1983).

A Tribologia desempenhou um papel central nos primórdios da evolução tecnológica. Reduzir a fricção, com uso da roda possibilitou ao homem ir mais longe e mais rápido. A lubrificação de trenós possibilitou o transporte de blocos de construção, possibilitando-se assim, erguer construções ainda maiores. Junto com um conhecimento tribológico, o uso do metal como material de construção e o óleo como lubrificante, ampliaram o caminho para a revolução industrial e possibilitaram novas invenções como, rolamentos e engrenagens, capazes de suportar cargas elevadas, com baixo atrito. Esses foram os componentes imprescindíveis para o desenvolvimento de equipamentos e máquinas de alta potência (HOLMBERG, et al., 2009).

$\mathrm{Na}$ grande maioria das interfaces de relevância tecnológica, ocorre o contato entre as rugosidades das superfícies. Consequentemente, a importância da investigação de um contato de uma simples rugosidade nos estudos das propriedades 
mecânicas e dos fundamentos tribológicos de superfícies tem sido amplamente reconhecido. (BHUSHAN, 1999).

Por mais de meio século muito tem se discutido, avaliado, definido e contemplado sobre a noção de tecnologia da superfície e tem se concluído que ninguém tem todos os dados para definir precisamente a "funcionabilidade" de uma superfície de uma peça para predizer como ela irá se comportar e por quanto tempo. (CLARK e GRANT, 1992). Superfícies típicas que requerem aspectos funcionais estão em sistemas que incluem rolamento, deslizamento, reflexão de luz, contato elétrico, estampagem, dentre outras.

Dentro da área de tribologia, especificamente na subárea de laminação, a preocupação dos tribologistas é com o que acontece quando duas superfícies sólidas deslizam uma sobre a outra, com e sem lubrificação. Eles frequentemente medem e comparam a textura e os parâmetros de rugosidade da superfície, antes e após um processo de desgaste, como também em estágios intermediários.

Entendendo a relação entre as propriedades do desgaste e a textura da superfície, torna-se possível chegar à otimização da especificação da sua textura e do processo de manufatura para várias necessidades funcionais da superfície a ser gerada. (AMERICAN SOCIETY FOR METALS, 1992).

O estudo da textura de superfícies é uma área ativa da pesquisa acadêmica bem como da prática industrial, e é comumente referida como metrologia de superfícies. Conforme estudo feito por Thomas (1999), o número de publicações sobre rugosidade de superfícies tem crescido muito nos últimos anos conforme mostra a FIGURA 2.1. 
Figura 2-1. Número de publicações sobre rugosidade de superfícies.

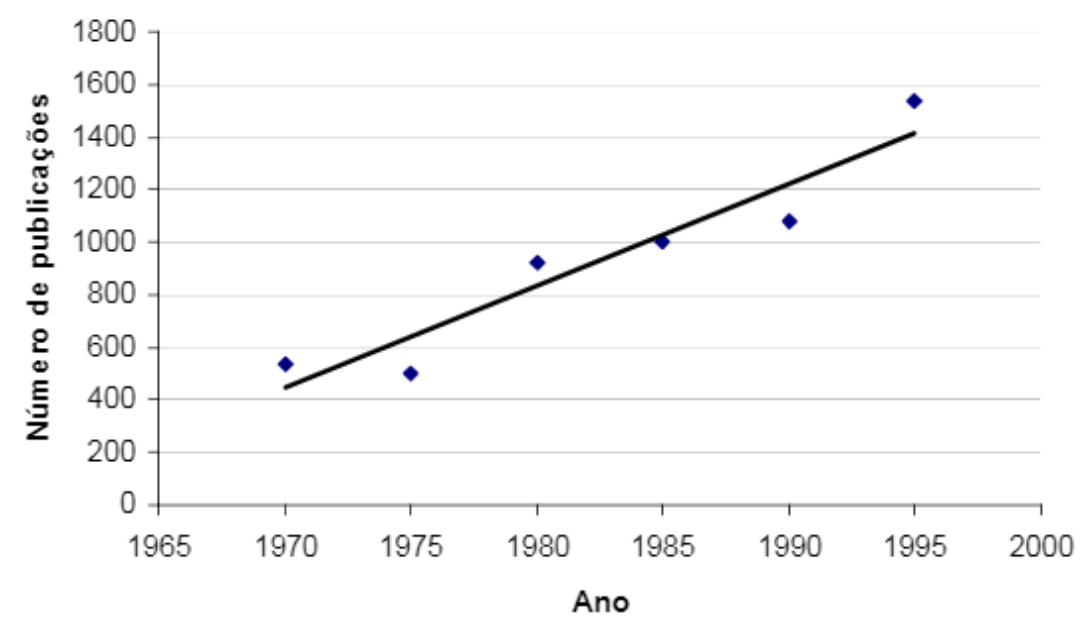

Fonte: (THOMAS, R. T. 1999).

Com a proliferação dos parâmetros de acabamentos de superfícies nas últimas décadas é surpreendente ver contínuos esforços sendo colocados no desenvolvimento de mais métodos para avaliação de superfícies. Importantes informações sobre propriedades funcionais das superfícies podem ser extraídas da curva básica desenvolvida por Abbott e Firestone.

O processo da técnica de medição de superfície por apalpador (stylus) para avaliação de superfícies tem sido usado pela indústria por mais de 50 anos. Basicamente, este método determina parâmetros que dão uma rápida e clara caracterização da superfície.

Nos anos recentes, quando microprocessadores foram introduzidos na metrologia de superfícies, e perfis completos puderam ser armazenados, novas formas foram encontradas para avaliar o perfil pela curva Abbott-Firestone.

Com o desenvolvimento de perfilometros tridimensionais, um novo grupo de parâmetros em três dimensões foram desenvolvidos, de modo que engenheiros de manufatura não são somente capazes de caracterizar as superfícies com muito mais detalhes, mas também são capazes de desenvolver e testar superfícies visando a sua funcionabilidade. Ou seja, serem produzidas, controladas e testadas de acordo com a função que irão desempenhar na aplicação. 


\subsection{Terminologia e definições}

O melhor entender ao uso dos termos, ou seja, especificar algumas expressões e palavras que são geralmente usadas em contextos específicos.

\subsubsection{Definição de superfícies}

A superfície geométrica ou ideal, prescrita no projeto, é aquela em que não existem erros de forma e acabamento. A superfície real é a que limita o corpo e o separa do meio que o envolve (DIN 4762, 1989) (ISO 4287, 1997). Já a superfície efetiva é a forma aproximada da superfície real de uma peça, sendo a superfície apresentada e analisada pelo aparelho de medição. É importante esclarecer que existem diferentes sistemas e condições de medição que apresentam, portanto, diferentes superfícies efetivas. A FIGURA 2-2 apresenta um exemplo do aspecto de uma superfície efetiva obtida através de um rugosímetro, para ilustrar os picos e vales em micrometros.

Figura 2-2. Superfície efetiva da superfície de um material 


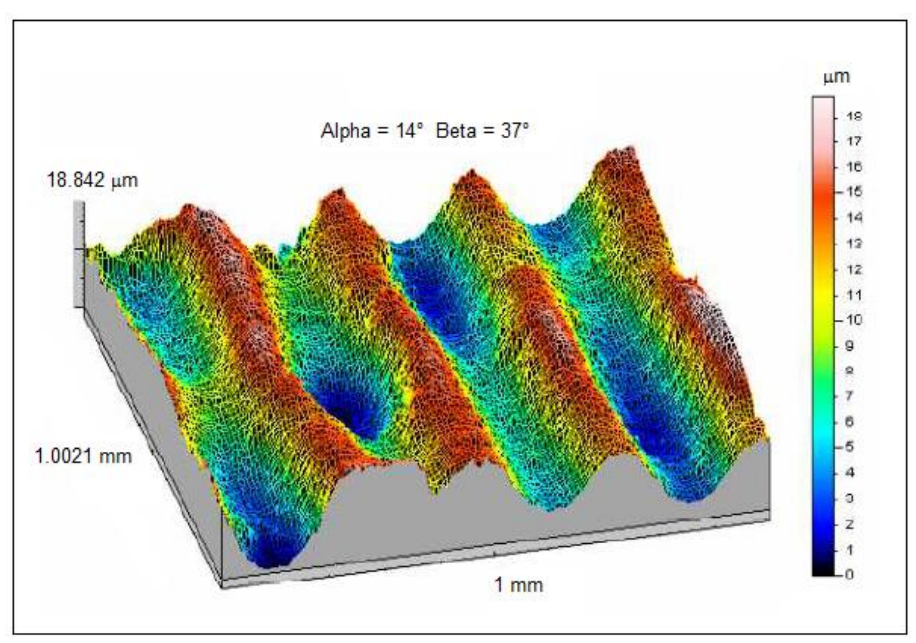

Fonte: (Imagem rugosímetro Lamed RU 001).

\subsubsection{Definição de perfil de rugosidade}

Para se definir a rugosidade utiliza-se um conceito que é o perfil geométrico, que consiste na interseção da superfície geométrica com um plano perpendicular mostrado na FIGURA 2-3. Os critérios de avaliação são feitos por análise de superfície de perfil. Por exemplo, uma superfície plana perfeita, cortada por um plano perpendicular, originará um perfil geométrico que será uma linha reta. Outro perfil importante dentro desta conceituação é o chamado perfil real, que está definido como a interseção da superfície real com um plano perpendicular, resultando em uma linha irregular.

Figura 2-3. Perfil real cortado por um plano perpendicular

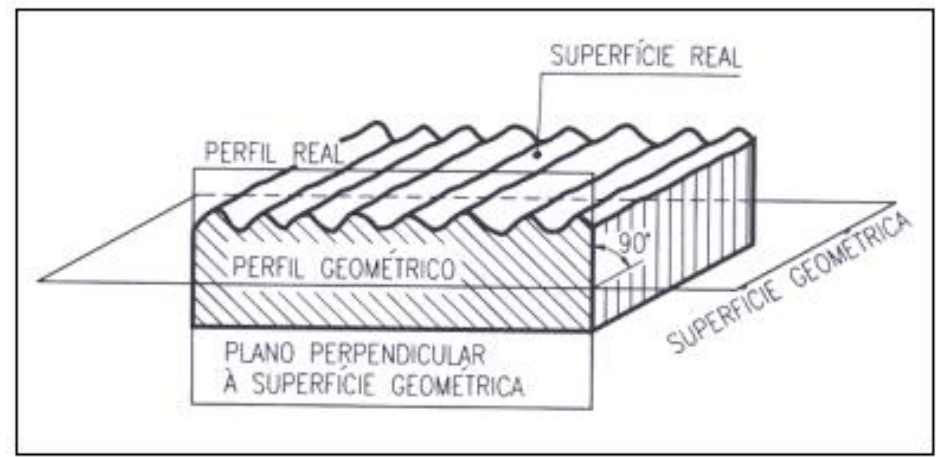

Fonte: (GONZALES, 1992). 
O perfil efetivo é a porção do perfil, apalpado (por contato) durante o processo de medição de uma superfície. O perfil efetivo contém os principais desvios, que são classificados em: forma, ondulação e rugosidade e são apresentados na norma DIN 4768 (1990).

Cabe ser destacado o conceito de orientação das irregularidades. A rugosidade é classificada como perfil periódico quando os sulcos têm direções definidas, e como perfil aperiódico quando os sulcos não têm direções definidas. Dentro deste contexto é definido um sistema de coordenadas para o parâmetro do estado da superfície (ABNT ISO 4287, 2002).

Essas orientações do sulco da superfície podem acontecer de duas formas: causadas pelo processo de produção, que são as impressões deixadas pela ferramenta e que se define como textura primária ou causadas por vibrações ou deflexões do sistema de produção ou pelo tratamento térmico, chamada de textura secundária.

Outro perfil definido pelas normas DIN 4777 (1990) e ISO 3274 (1997) é o de rugosidade "R", que consegue mostrar todos os desvios a partir da linha média.

\subsubsection{Comprimentos da amostragem}

A rugosidade é medida a partir de uma série de comprimentos (comprimento de referência ou cut-off) de amostragem. O comprimento de amostragem nos aparelhos eletrônicos, chamado de cut-off, não deve ser confundido com a distância total percorrida pelo apalpador sobre a superfície.

A FIGURA 2-4 apresenta a profundidade do perfil $\mathrm{Pt}$, que é a distância entre retas paralelas que limitam o perfil $P$, dentro do comprimento de medição $I m$, sendo que esta deve ser a menor possível. O tamanho do comprimento de medição Im deve ser indicado, e o perfil $P$ é o gráfico dos desvios da reta média, dentro do comprimento de medição Im.

Figura 2-4. Perfil efetivo 


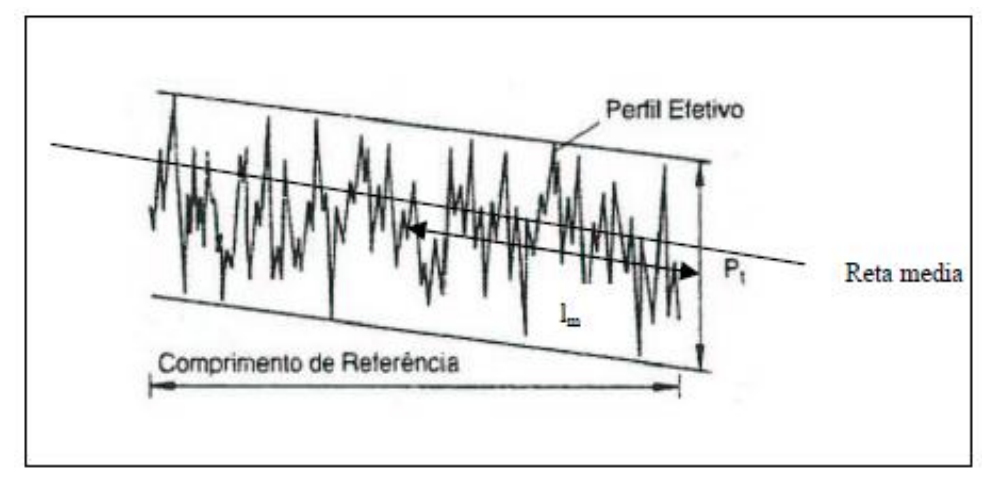

Fonte: (ALVES, 2006).

Antes da medição da rugosidade existe uma avaliação do mensurando para determinar a seleção do comprimento. Essa seleção considera as variáveis de perfil: se periódico ou aperiódico e parâmetros de medição Ra ou Rz. A partir dessa avaliação se determina o comprimento que será medido no mensurando. Segundo a norma DIN 4768 (1990) e ISO 4288 (1996) devem ser considerados os comprimentos de amostragem apresentados na TABELA 2-1.

Tabela 2-1. Seleção de comprimento e amostragem

\begin{tabular}{|c|c|c|c|c|}
\hline $\begin{array}{c}\text { Perfis } \\
\text { Periódicos }\end{array}$ & \multicolumn{2}{|c|}{$\begin{array}{c}\text { Perfis } \\
\text { Aperiódicos }\end{array}$} & $\begin{array}{c}\text { Comprimento } \\
\text { de } \\
\text { amostragem }\end{array}$ & $\begin{array}{c}\text { Comprimento de } \\
\text { medição } \\
\text { Unitário/ total }\end{array}$ \\
\hline $\begin{array}{c}\text { Distância } \\
\text { entre sulcos } \\
\text { Sm }(\mathrm{mm})\end{array}$ & $\begin{array}{c}\mathrm{R}_{z} \\
(\mu \mathrm{m})\end{array}$ & $\begin{array}{c}\mathrm{Ra} \\
(\mu \mathrm{m})\end{array}$ & $\lambda_{\mathrm{c}(\mathrm{mm})}$ & $1_{\mathrm{e}(\mathrm{mm})}$ \\
\hline$>0,01$ até 0,04 & até 0,1 & até 0,02 & 0,08 & $0,08 / 0,4$ \\
\hline$>0,04$ até 0,13 & $>0,04$ até 0,13 & até 0,13 & 0,25 & $0,25 / 1,25$ \\
\hline$>0,13$ até 0,4 & $>0,04$ até 0,13 & $>0,02$ até 0,1 & 0,8 & $0,8 / 4$ \\
\hline$>0,4$ até 1,3 & $>0,04$ até 0,13 & $>2$ até 10 & 2,5 & $2,5 / 12,5$ \\
\hline$>1,3$ até 4 & $>50$ & $>10$ & 8 & $8 / 40$ \\
\hline
\end{tabular}

Fonte: (GONZALES, 1992). 


\subsubsection{Sistema da Linha Média}

No sistema da linha média, todas as grandezas da medição da rugosidade são definidas a partir da definição que a linha média é a linha paralela à direção geral do perfil, no comprimento da amostragem, de tal modo que a soma das áreas superiores, compreendidas entre ela e o perfil efetivo, seja igual à soma das áreas inferiores, no comprimento da amostragem (le), conforme FIGURA 2-5.

Figura 2-5. A1 e A2 são áreas acima da linha média = A3 área abaixo da linha média.

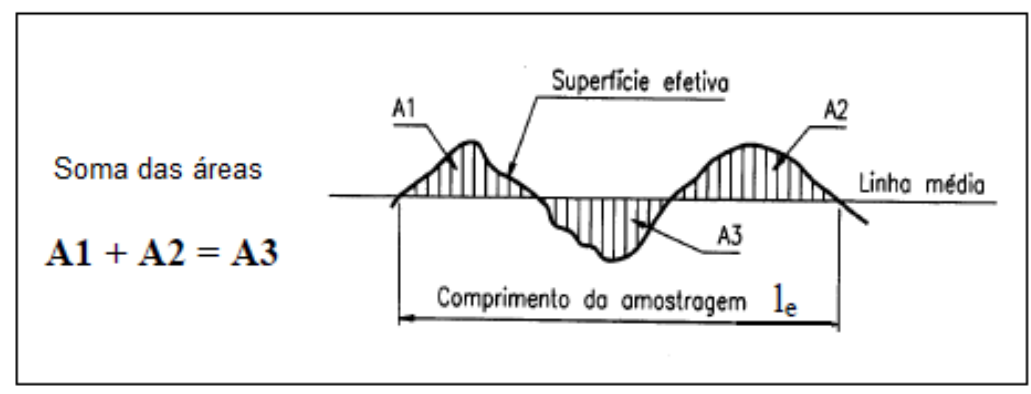

Fonte: (GONZALES, 1991).

O elemento de perfil, como se vê na FIGURA 2-6, traz a porção positiva no trecho $(Z p)$, e a porção negativa no trecho final $(Z v)$. O comprimento de amostragem $(Z p+$ $\mathrm{Z} v=\mathrm{Z} \mathrm{t}$ ) deve ser considerado como um pico de perfil somado a um vale de perfil. Os picos e os vales do perfil de avaliação são considerados apenas uma vez no início a cada comprimento de amostragem.

Figura 2-6. Elemento do perfil 


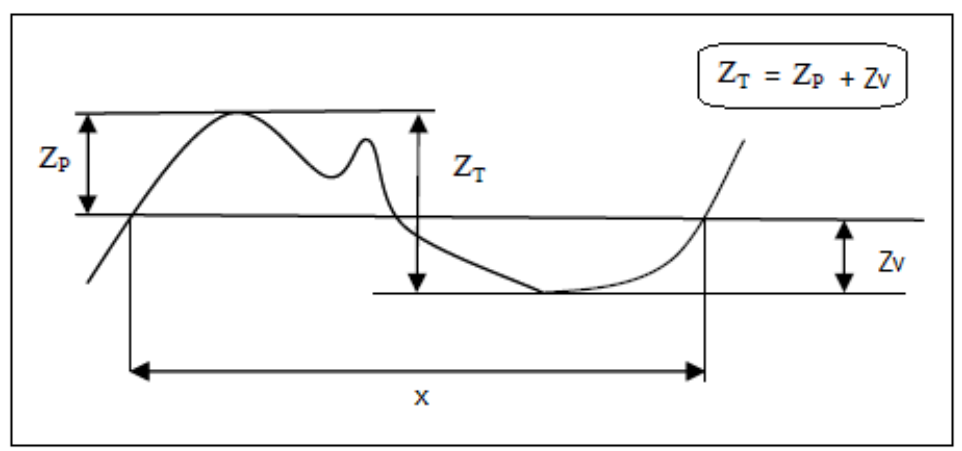

Fonte: (NBR 4287, 2002).

A norma NBR ISSO 4287 (2002) define parâmetros conforme nas FIGURA 2.7 e 2.8:

- $(Z p)$ altura de pico do perfil: "distância entre o eixo $X$ e o ponto mais alto dos pontos do perfil".

- $(Z v)$ profundidade do vale do perfil: "distância entre o eixo $\mathrm{X}$ e o ponto mais baixo dos vales do perfil";

- (Zt) altura de um elemento de perfil: "soma da altura do pico e profundidade do vale de um elemento do perfil".

Figura 2-7. Rugosidade $R_{\text {máx }}$ definido pela rugosidade parcial $Z p$ (neste caso $Z_{3}$ ) 


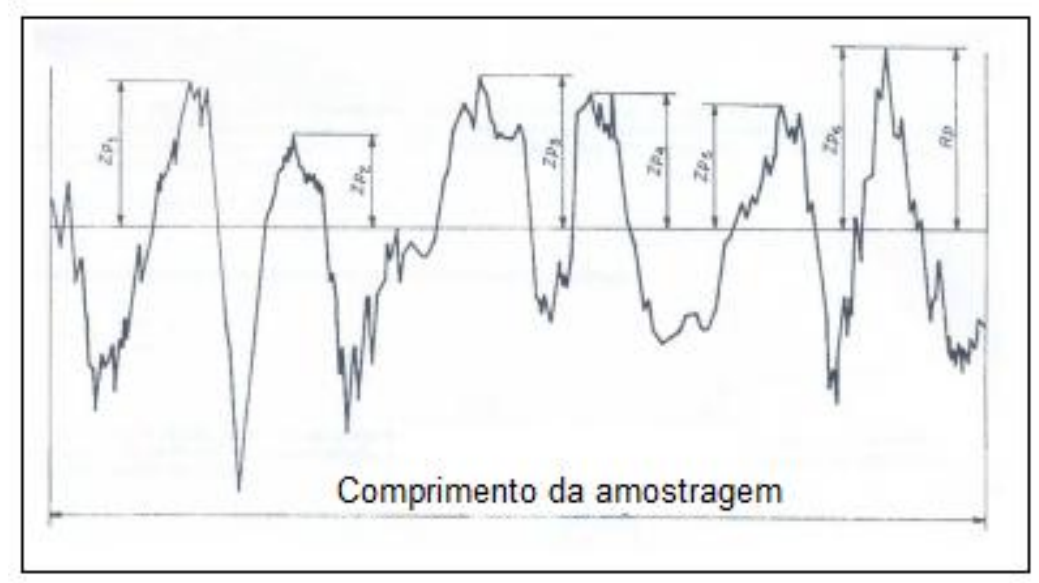

Fonte: (NBR 4287, 2002).

A maior altura dos picos do perfil $(Z p)$ no comprimento de amostragem juntamente com o perfil ( $\mathrm{Zv}$ ), que é a maior profundidade do vale do perfil no comprimento de amostragem se unem para formar o sistema $M$, o qual compõe as bases para a formação dos parâmetros de rugosidade (NBR ISO 4287, 2002).

Figura 2-8. Rugosidade $R_{\text {máx }}$ definido pela rugosidade parcial $Z v$ (neste caso $Z_{3}$ )

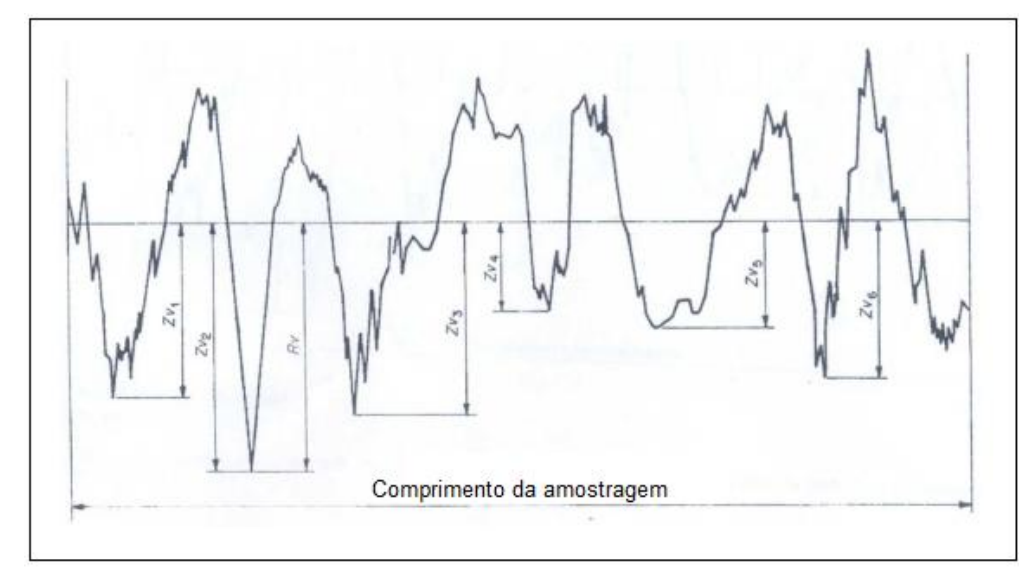

Fonte: (NBR 4287, 2002).

\subsubsection{Parâmetros de Rugosidade}

Os parâmetros de rugosidade existentes são valores numéricos resultantes de integrações ou de operações matemáticas simples de perfis amostrais de 
superfícies. Logo, são representações sujeitas a diversos erros de medição e interpretação.

Contudo, sua praticidade é inegável: é extremamente útil dispor de valores numéricos para comparação e análise de superfícies, seja para resumir diversas informações contidas em uma superfície tridimensional, ou mesmo para separar e classificar superfícies distintas, geradas por diferentes processos de fabricação.

\subsubsection{Rugosidade média dos valores absolutos (Ra)}

Segundo as normas técnicas: "Rugosidade média $\mathrm{Ra}$ - Roughness Average é o valor médio aritmético de todos os desvios do perfil de rugosidade da linha média dentro do comprimento de medição "Im", utiliza a Equação 2.1, (DIN 4762, 1989 DIN 4768, 1990; ISO 4278, 1997), conforme FIGURA 2-9.

$$
R_{a}=\sqrt{\frac{1}{l_{m} \int_{0}^{1}|y(x)| d x}}
$$

Definição dos parâmetros:

Im = comprimento de medição.

$y(x)=$ são os desvios do perfil de rugosidade.

CLA (Center Line Average), significa centro da linha média.

Figura 2-9. Parâmetro de rugosidade $R a$ 


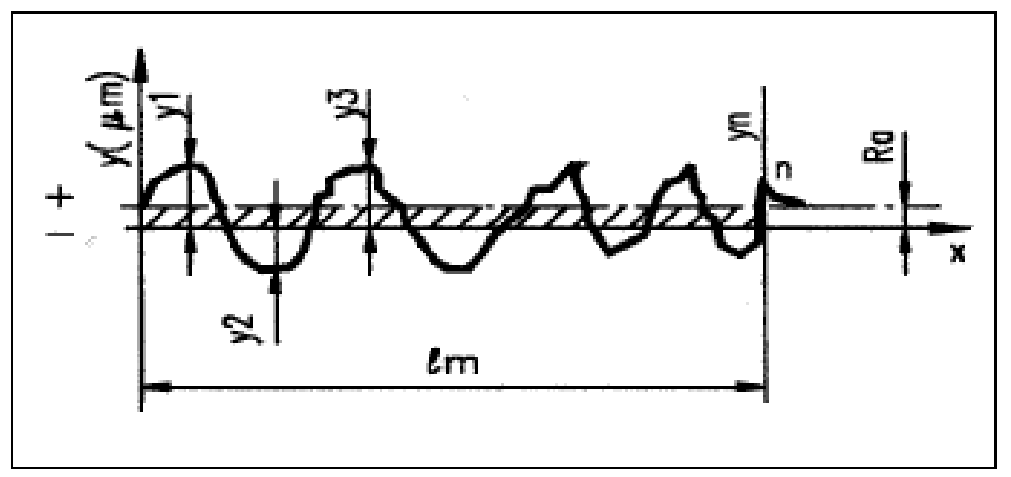

Fonte: (Gonzalez, 1991).

O parâmetro Ra pode ser usado nos seguintes casos: quando for necessário o controle contínuo da rugosidade nas linhas de produção e em superfícies em que o acabamento apresenta sulcos de usinagem bem orientados (torneamento, fresagem, etc.). O Ra é o parâmetro de medição mais usado, aplicável na maioria dos processos de fabricação e, devido sua grande utilização, quase todos os equipamentos apresentam esse parâmetro. Observa-se que os riscos superficiais inerentes ao processo não alteram muito seu valor, para maioria das superfícies.

Entretanto, esse parâmetro possui desvantagens, pois o valor de Ra em um comprimento de amostragem indica a média da rugosidade. Por isso, se um pico ou vale não típico aparecer na superfície, o valor da média não sofrerá grande alteração ocultando o defeito.

\subsubsection{Rugosidade média quadrática $(\mathrm{Rq})$}

A rugosidade média quadrática é o valor médio quadrático de todos os desvios do perfil de rugosidade $\mathrm{Rq}$ da reta média dentro do comprimento de medição Im. (DIN 4762, 1989).

$R_{q}=\sqrt{\frac{1}{l_{m} \int_{0}^{1} y^{2}(x) d x}}$ 
Definição dos parâmetros;

$y(x)=$ desvios do perfil de rugosidade.

Im = comprimento de medição.

\subsubsection{Rugosidade máxima (Rmáx)}

A rugosidade máxima (Rmáx) é o maior valor de rugosidade obtido dentre a avaliação de cinco comprimentos de medição unitários le (DIN 4762, 1989), ou seja, a rugosidade máxima está definida como o maior valor das rugosidades parciais ( $\mathrm{Z} i)$ que se apresenta no percurso de medição $(\mathrm{Im})$. Por exemplo, na FIGURA 2-10, o maior valor parcial é o Z3, que está localizado no $3^{0}$ cut off, e que corresponde à rugosidade Rmáx.

Figura 2-10. Rugosidade Rmáx definido pela rugosidade parcial

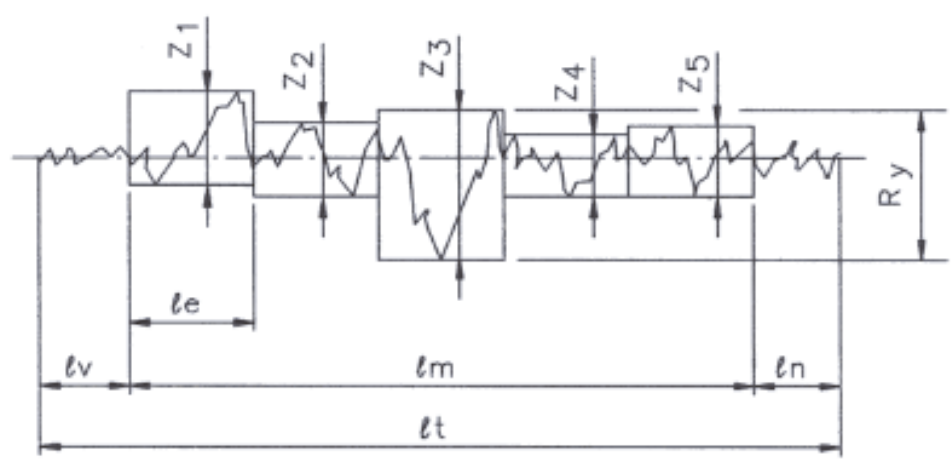

Fonte: (DIN 4762, 1989).

O parâmetro Rmáx pode ser empregado para avaliar, por exemplo, superfícies de vedação, assentos de anéis de vedação, superfícies dinamicamente carregadas, tampões em geral, parafusos altamente carregados, superfícies de deslizamento em que o perfil efetivo é periódico. 
Assim, uma das vantagens da utilização do parâmetro Rmáx é informar sobre a máxima deterioração da superfície da peça. A fácil obtenção, quando o equipamento de medição fornece o gráfico da superfície, é também uma das vantagens, assim como a alta aplicabilidade na maioria das superfícies, pois fornece informações complementares ao parâmetro Ra (que dilui o valor dos picos e vales). Porém, há algumas desvantagens do Rmáx, como o fato de nem todos os equipamentos fornecerem este parâmetro. Para avaliá-lo por meio de um gráfico é preciso ter certeza de que o perfil registrado é um perfil de rugosidade.

O parâmetro Rmáx também pode dar uma imagem errada da superfície, pois avalia erros que, muitas vezes, não representam a superfície como um todo. Por exemplo, um risco causado após uma usinagem, que não caracteriza o processo, individualmente, não apresenta informação suficiente a respeito da superfície, isto é, não informa a rugosidade real da superfície.

\subsubsection{Rugosidade média da distância entre o pico mais alto e o mais baixo do vale em cada comprimento de amostragem $(R z)$}

A rugosidade média $(R z)$, corresponde à média aritmética dos cinco valores de rugosidade parcial $Z_{1}$ a $Z_{5}$. A rugosidade parcial $(Z i)$ é a soma dos valores absolutos das ordenadas dos pontos de maior afastamento, acima e abaixo da linha média, existentes no comprimento de amostragem (cut off). Este valor corresponde à altura entre os pontos máximo e mínimo do perfil, no comprimento de amostragem (Im).

$$
R_{z}=\frac{1}{5} \sum_{i=1}^{5}\left(y_{p}\right)+\frac{1}{5} \sum_{i=1}^{5}\left(y_{v}\right)
$$

Sendo,

$\mathrm{y}_{\mathrm{p}}=$ desvios positivos do perfil de rugosidade

$\mathrm{y}_{\mathrm{v}}=$ desvios negativos do perfil de rugosidade 
O parâmetro $R_{z}$ pode ser empregado nos casos de pontos isolados que não influenciam na função da peça a ser controlada. Por exemplo, em superfícies de apoio e de deslizamento, em ajustes prensados e em superfícies onde o perfil é periódico e conhecido.

Existem algumas vantagens na utilização desse parâmetro, como informar a distribuição média da superfície vertical e os perfis periódicos que definem muito bem essa superfície.

\subsubsection{Rugosidade $\left(R_{c}\right)$}

O parâmetro $R_{c}$ é o valor médio aritmético das amplitudes de todos os picos e vales.

Figura 2-11. Rugosidade parcial $Z_{i}$, para definir $R_{c}$

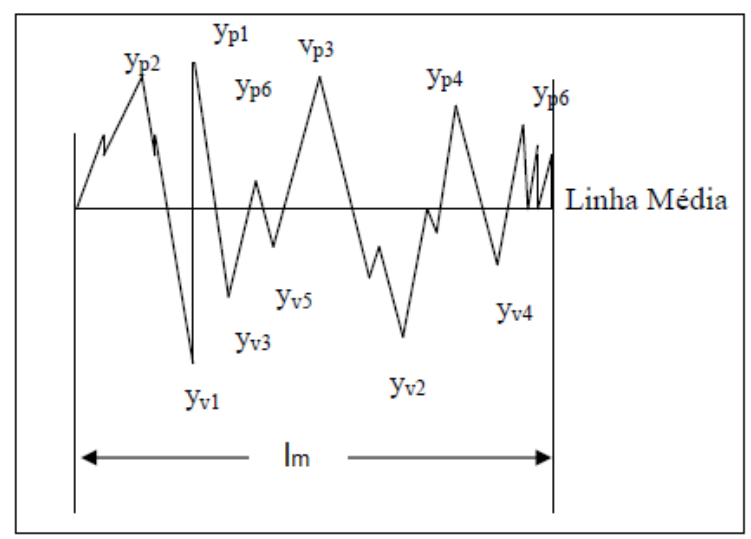

Fonte: (DIN 4762, 1989).

$R_{z}=\frac{1}{n} \sum_{i=1}^{\mathrm{n}}\left(y_{p i}\right)+\frac{1}{m} \sum_{i=1}^{m}\left(y_{v i}\right)$

ypi $=$ desvios dos picos de rugosidade

yvi $=$ desvios dos vales de rugosidade 


\subsubsection{Apresentação da evolução das normas de rugosidade}

Nas Tabelas, a seguir, procurou-se mostrar um comparativo entre os parâmetros mais usados ( $R a$ e $R z$ ) para se analisar a evolução desses parâmetros e estabelecer um comparativo. E pela norma japonesa-JIS, evidenciou-se a evolução desses parâmetros de 1982 a 2001.

O comparativo entre as normas apresentadas faz referência aos anos de 1982, 1994 e 2001, e mostra que existiu uma grande evolução para o comprimento da amostragem, diminuindo muito o tamanho do Cut off $(\lambda \mathrm{c}) \mathrm{em}(\mathrm{mm})$ como visto na TABELA 2-2 comparada com as demais Tabelas 2-4 e 2-6, para o parâmetro Ra, TABELA 2-3 comparada com as demais TABELAS 2-5 e 2-7, para o parâmetro Rz. Este fato aconteceu devido a um grande avanço em termos de instrumentos de medição e de normas. O outro avanço foi à diminuição do comprimento total (Im) na amostra de superfície, esse comprimento vem diminuindo ao longo do tempo e mostrando a exatidão e avanço dos equipamentos para executar tais medições.

Tabela 2-2. Parâmetros de Ra

\begin{tabular}{|c|c|c|c|}
\hline $\begin{array}{c}\text { Faixa para leitura } \mathrm{R}_{\mathrm{a}} \\
(\mu \mathrm{m})\end{array}$ & $\begin{array}{c}\text { Cut off }\left(\lambda_{\mathrm{c}}\right) \\
(\mathrm{mm})\end{array}$ & $\begin{array}{c}\text { Comprimento de } \\
\text { amostragem }(1)\end{array}$ & $\begin{array}{c}\text { Comprimento de } \\
\text { Avaliação }\left(\mathrm{l}_{\mathrm{m}}\right)\end{array}$ \\
\hline $\mathrm{R}_{\mathrm{a}} \leq 12,5$ & 0,8 & 2.5 & 2,4 ou maior \\
\hline $12,5<\mathrm{R}_{\mathrm{a}} \leq 100,0$ & 2,5 & 8 & 7,5 ou maior \\
\hline
\end{tabular}

Fonte: (JIS B0601, 1982).

Tabela 2-3. Parâmetros de $\mathrm{Rz}$

\begin{tabular}{|c|c|}
\hline $\begin{array}{c}\text { Faixa para leitura } \mathrm{R}_{z} \\
(\mu \mathrm{m})\end{array}$ & $\begin{array}{c}\text { Comprimento de } \\
\text { amostragem }(1)\end{array}$ \\
\hline $\mathrm{R}_{\mathrm{z}} \leq 0,8$ & 0,25 \\
\hline $0,8<\mathrm{R}_{z} \leq 6,3$ & 0,8 \\
\hline $6,3 \leq \mathrm{R}_{\mathrm{z}} \leq 12,5$ & 2,5 \\
\hline $25<\mathrm{R}_{z} \leq 100,0$ & 8 \\
\hline $100<\mathrm{R}_{\mathrm{z}} \leq 12,5$ & 25 \\
\hline
\end{tabular}


Fonte: (JIS B0601, 1982).

Tabela 2-4. Parâmetros de Ra (JIS B0601, 1994).

\begin{tabular}{|c|c|c|c|}
\hline $\begin{array}{c}\text { Faixa para leitura } \mathrm{R}_{\mathrm{a}} \\
(\mu \mathrm{m})\end{array}$ & $\begin{array}{c}\text { Cut off }\left(\lambda_{\mathrm{c}}\right) \\
(\mathrm{mm})\end{array}$ & $\begin{array}{c}\text { Comprimento de } \\
\text { amostragem (1) }\end{array}$ & $\begin{array}{c}\text { Comprimento de } \\
\text { Avaliação }\left(1_{\mathrm{m}}\right)\end{array}$ \\
\hline $0,006<\mathrm{R}_{\mathrm{a}} \leq 0,02$ & 0,08 & 0,08 & 0,4 \\
\hline $0,002<\mathrm{R}_{\mathrm{a}} \leq 0,1$ & 0,25 & 0,25 & 1,25 \\
\hline $0,1<\mathrm{R}_{\mathrm{a}} \leq 2,0$ & 0.8 & 0,8 & 12,5 \\
\hline $2,0<\mathrm{R}_{\mathrm{a}} \leq 10,0$ & 2.5 & 2,5 & 40 \\
\hline $10,0<\mathrm{R}_{\mathrm{a}} \leq 80,0$ & 8 & 8 & \\
\hline
\end{tabular}

Fonte: (JIS B0601, 1994).

Tabela 2-5. Parâmetros de $\mathrm{Rz}$

\begin{tabular}{|c|c|c|c|}
\hline $\begin{array}{c}\text { Faixa para leitura } \mathrm{R}_{z} \\
(\mu \mathrm{m})\end{array}$ & $\begin{array}{c}\text { Cut off }\left(\lambda_{\mathrm{c}}\right) \\
(\mathrm{mm})\end{array}$ & $\begin{array}{c}\text { Comprimento de } \\
\text { amostragem }(1)\end{array}$ & $\begin{array}{c}\text { Comprimento de } \\
\text { Avaliação }\left(1_{\mathrm{m}}\right)\end{array}$ \\
\hline $0,025<\mathrm{R}_{z} \leq 0,10$ & 0,08 & 0,08 & 0,4 \\
\hline $0,10<\mathrm{R}_{\mathrm{z}} \leq 0,50$ & 0,25 & 0,25 & 1,25 \\
\hline $0,50<\mathrm{R}_{z} \leq 10,0$ & 0.8 & 0,8 & 4 \\
\hline $10,0<\mathrm{R}_{z} \leq 50,0$ & 2.5 & 2,5 & 40 \\
\hline $50,0<\mathrm{R}_{z} \leq 200,0$ & 8 & 8 & \\
\hline
\end{tabular}

Fonte: (JIS B0601, 1994).

Tabela 2-6. Parâmetros de Ra (JIS B0601, 2001).

\begin{tabular}{|c|c|c|c|}
\hline $\begin{array}{c}\text { Faixa para leitura } \mathrm{R}_{\mathrm{a}} \\
(\mu \mathrm{m})\end{array}$ & $\begin{array}{c}\text { Cut off }\left(\lambda_{\mathrm{c}}\right) \\
(\mathrm{mm})\end{array}$ & $\begin{array}{c}\text { Comprimento de } \\
\text { amostragem }(1)\end{array}$ & $\begin{array}{c}\text { Comprimento de } \\
\text { Avaliação }\left(\mathrm{l}_{\mathrm{m}}\right)\end{array}$ \\
\hline $0,006<\mathrm{R}_{\mathrm{a}} \leq 0,02$ & 0,08 & 0,08 & 0,4 \\
\hline $0,024<\mathrm{R}_{\mathrm{a}} \leq 0,1$ & 0,25 & 0,25 & 1,25 \\
\hline $0,1<\mathrm{R}_{\mathrm{a}} \leq 2,0$ & 0.8 & 0,8 & 4 \\
\hline $2,0<\mathrm{R}_{\mathrm{a}} \leq 10,0$ & 2.5 & 2,5 & 40 \\
\hline $10,0<\mathrm{R}_{\mathrm{a}} \leq 80,0$ & 8 & 8 & \\
\hline
\end{tabular}

Fonte: (JIS B0601, 2001). 
Tabela 2-7. Parâmetros de Rz (JIS B0601, 2001).

\begin{tabular}{|c|c|c|c|}
\hline $\begin{array}{c}\text { Faixa para leitura } \mathrm{R}_{z} \\
(\mu \mathrm{m})\end{array}$ & $\begin{array}{c}\text { Cut off }\left(\lambda_{\mathrm{c}}\right) \\
(\mathrm{mm})\end{array}$ & $\begin{array}{c}\text { Comprimento de } \\
\text { amostragem }(1)\end{array}$ & $\begin{array}{c}\text { Comprimento de } \\
\text { Avaliação }\left(\mathrm{l}_{\mathrm{m}}\right)\end{array}$ \\
\hline $0,025<\mathrm{R}_{z} \leq 0,10$ & 0,08 & 0,08 & 0,4 \\
\hline $0,10<\mathrm{R}_{z} \leq 0,5$ & 0,25 & 0,25 & 1,25 \\
\hline $0,5<\mathrm{R}_{z} \leq 10$ & 0.8 & 0,8 & 4 \\
\hline $10<\mathrm{R}_{z} \leq 50$ & 2.5 & 2,5 & 12,5 \\
\hline $50<\mathrm{R}_{z} \leq 200$ & 8 & 8 & 40 \\
\hline
\end{tabular}

Fonte: (JIS B0601, 2001).

\subsection{Métodos de medição de rugosidade}

Com o desenvolvimento tecnológico, os métodos de medição de rugosidade superficial foram se expandindo e estão divididos em dois grandes grupos: métodos de contato e os de não contato.

Entre estas opções para a avaliação da rugosidade, a indústria, ainda, prefere a primeira opção. Isto é, os métodos de contato que utilizam um perfil apresentado por um plano de corte da superfície para tomar como amostra representativa e realizar a avaliação.

Para a avaliação da rugosidade, um importante passo é a definição do tipo de medição, pois existem diferenças de metodologia cada tipo de equipamento. No caso dos microscópios são feitas medições considerando áreas quadradas com tamanhos pré-determinados, já na medição por interferômetro as leituras têm as determinações dos equipamentos de contato. 


\subsubsection{Métodos de contato}

Os métodos de contato têm uma utilização muito grande na indústria de uma forma geral, são executados tocando a superfície de medição e são normalmente realizados pelos rugosímetros, que registram o perfil de corte da superfície.

O método de medição se refere ao levantamento de perfis por medição de contato com apalpadores, conforme FIGURA 2-12. Esse método consiste em apalpar a peça perpendicularmente as linhas de usinagem e à superfície, obtendo um corte no perfil da peça, permitindo que o perfil real seja obtido em um registrador gráfico e que sejam calculados os valores de rugosidade pelo processador do rugosímetro.

Figura 2-12. Rugosímetro de contato portátil

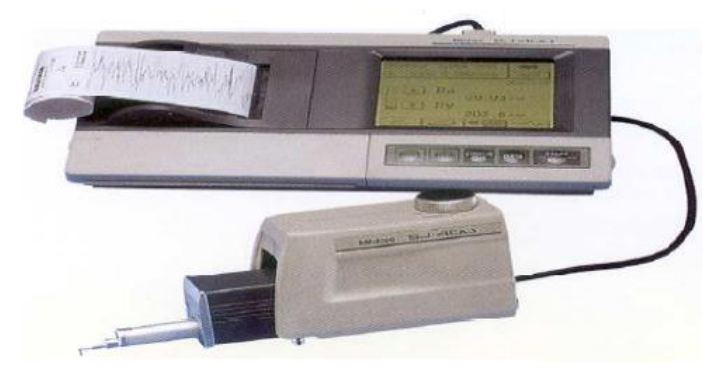

Fonte: (UHGM Metrology).

\subsubsection{Técnicas interferométricas}

Apesar das técnicas interferométricas, de um modo geral, não representarem novidade no campo da mecânica experimental, estas vêm sendo desenvolvidas, mostrando mais flexibilidade e facilidades para a medição.

A exatidão da técnica é uma característica importante, pois, dependendo das configurações utilizadas, é possível realizar medidas considerando desde centésimos até centenas de micrometros. Com essas inovações, aumentou-se o interesse por essas técnicas, talvez a de maior impacto seja a integração destas com sistemas de processamento de imagens, em substituição aos filmes tradicionalmente usados. 
Dentre as técnicas interferométricas existentes, a técnica de speckle (RASTOGI, 2000) se destaca por possuir uma ampla faixa de exatidão, e por não ter exigências rigorosas quanto à resolução do meio de gravação. A técnica passou a se chamar então Interferometria Digital de Padrões de Speckle (DHANASEKAR e RAMAMOORTHY, 2007).

Essa técnica se define quando uma superfície rugosa é iluminada com luz coerente, a informação do micro relevo superficial é percebida a partir do espalhamento da onda em uma imagem. Portanto, a dependência aleatória entre a rugosidade superficial e as coordenadas espaciais é transformada num conjunto de pequenas manchas claras e escuras tanto no plano da imagem quanto em qualquer plano intermediário localizado entre a superfície iluminada e o plano da imagem, conforme FIGURA 2-14.

Figura 2-13. Superfície iluminada em microscópio

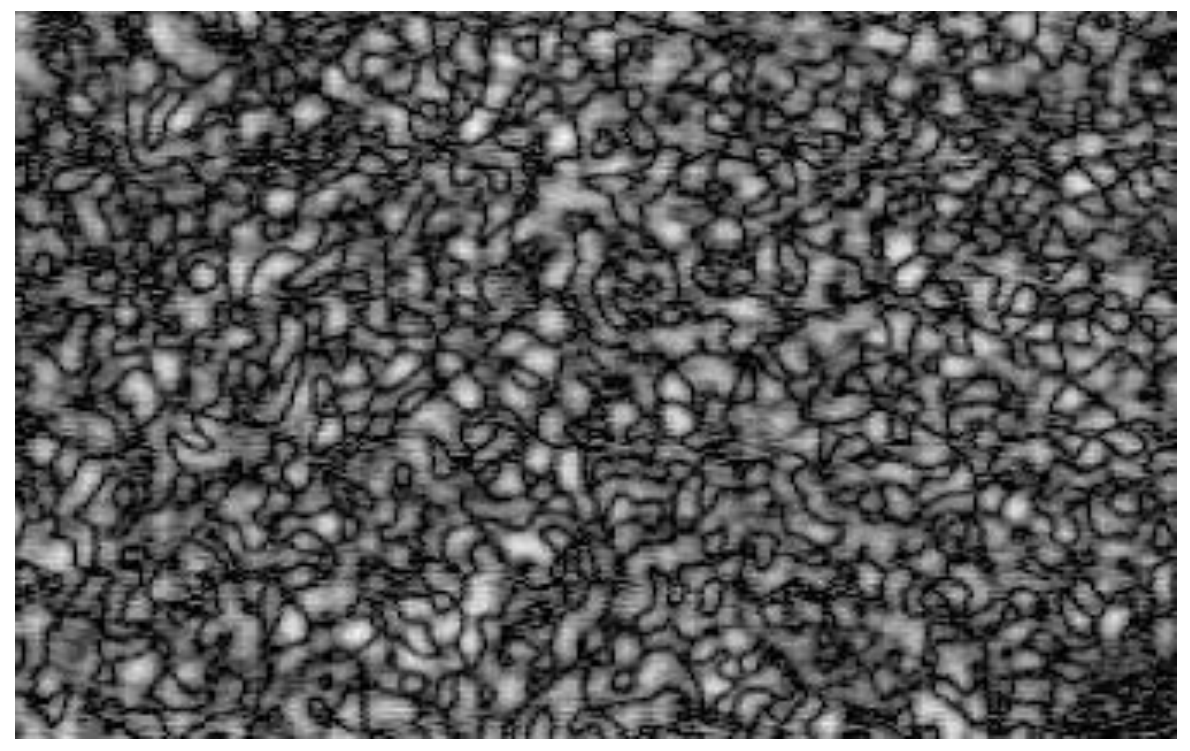

Fonte: (DHANASEKAR e RAMAMOORTHY, 2007).

\subsection{Nova abordagem para caracterização de superfícies}

Houve uma evolução na caracterização e medição de superfícies em Engenharia, isso se deu a partir de um método integrado 3D (STOUT et al., 1993). Em 2002, um grupo de trabalho foi criado para desenvolver padrões de textura de superfície de 
área, a atual norma (ISO 25178, 2010). Com a crescente pesquisa na área gerouse um documento intitulado Surf Stand, que formou a base para a rugosidade tridimensional (BLUNT e JIANG, 2003).

A definição de textura primária da superfície está baseada no perfil, isto se dá para assegurar a coerência das irregularidades do mesmo. Esta ideia não está necessariamente relacionada com os dados da superfície, enquanto os erros de forma, sempre são especificados em paralelo à superfície (ISO 1101, 2004).

Entretanto o perfil da textura da superfície como na FIGURA 2-15 geralmente, têm sistemas de coordenadas diferentes, consequentemente não fazem parte de uma única especificação coerente, pois não se avaliava a direção da textura juntamente com a direção da forma, e se aplicam sistemas de coordenadas diferentes.

Figura 2-14. Característica da textura primária

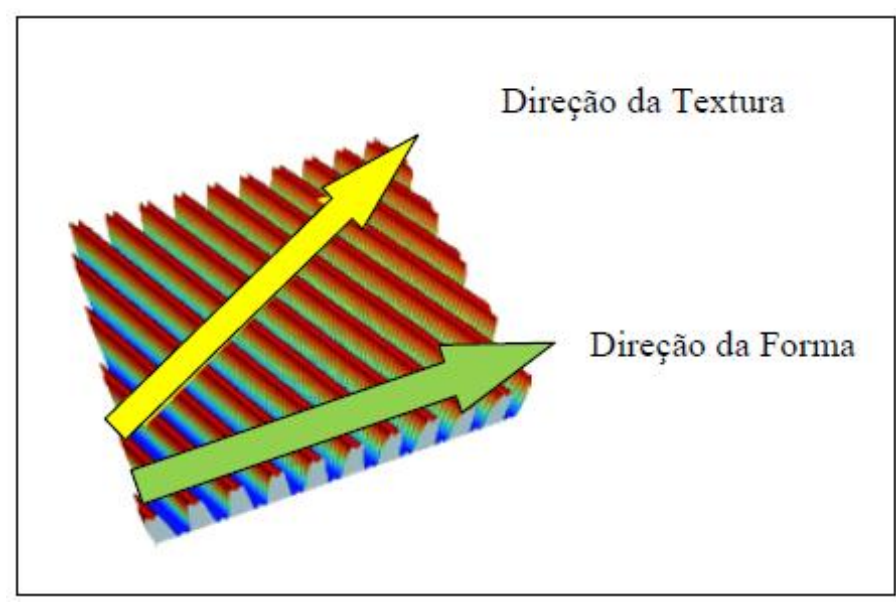

Fonte: (JIANG, 2006).

A nova classificação incorpora o conceito da textura e seu direcionamento para a medição e avaliação da rugosidade, essa nova abordagem foi contemplada pelo sistema de coordenadas unificado e foi estabelecida para a textura da superfície e medição pela (ISO 25178-3, 2010). Portanto, a textura superficial é agora parte de um sistema coerente (JIANG, 2006). A partir disso todas as superfícies são compostas por uma coleção de atributos que determinam as características que compõem sua textura. A organização dessas características da superfície, os tipos 
de formas e tamanhos e a capacidade de caracterizar a geometria da superfície de forma adequada torna-se fundamental para a otimização e controle dessas superfícies.

Esses atributos não possuem parâmetros específicos definidos, mas existe uma variedade de técnicas de reconhecimento de padrões que podem ser utilizados para sua caracterização, dentro da mesma escala. O processo de caracterização consiste em cinco fases:

I. Seleção do tipo de textura: é importante observar o tipo de atributo da função de textura da superfície que está sendo avaliada.

II. Segmentação: a segmentação é usada para determinar as regiões da superfície de mesma escala, que definem essas características.

III. Determinação das características significativas: os descritores e/ou parâmetros estatísticos não interagem com todos os atributos da mesma maneira, características diferentes interagem de forma diferente. Assim, é essencial determinar os atributos que são funcionalmente importantes daqueles que não são. Para cada superfície determinada, é necessário um processo de segmentação que identifique as características significativas e não significativas.

IV. Seleção dos atributos: uma vez que o conjunto significativo de atributos tenha sido determinado, é necessário definir quais os atributos são mais adequados para a caracterização.

V. Estatísticas do atributo: os atributos são construídos a partir dos cálculos estatísticos adequados para definir as características significativas, ou um parâmetro, ou, alternativamente, um histograma de valores dos atributos.

\subsubsection{Parâmetros da superfície (ISO 25178, 2010)}

Parâmetros de textura foram desenvolvidos de acordo com suas propriedades e divididos em dois grupos de parâmetros chamados "campo" e "característica". 
1. Parâmetros de campo: são baseados em estatísticas, e são utilizados para classificar as médias, desvios e características específicas de uma superfície de mesma escala.

2. Parâmetros de característica: determinam um novo conceito para a textura da superfície e são definidos por meio de subconjuntos de características prédefinidas a partir de uma superfície de mesma escala, usando a segmentação como base para o reconhecimento de padrões (JIANG, 2006). Este conceito dominante permitiu examinar as características topográficas. Os parâmetros definidos em BLUNT e JIANG (2003) formam a base para uma especificação técnica ISO para a textura da superfície de área (ISO 25178, 2010).

Os parâmetros de características são divididos em dois grupos os parâmetros-S e os parâmetros-V. Os parâmetros-S dependem da amplitude da altura e espaçamento de frequência, para descrever a amplitude e a informação espacial. $O$ parâmetros- $V$ fornecem informações volumétricas, baseadas na curva de AbbottFirestone.

O grupo de parâmetros-S contém 12 parâmetros e é dividido em quatro tipos básicos: amplitude, espaciais, híbridos e diversos. Eles espelham os parâmetros do perfil, usados nas medições de rugosidade. Estes são convencionalmente adotados pela indústria. Os parâmetros referem-se ao espaçamento e às propriedades espaciais das superfícies, conforme TABELA 2-8.

O grupo de parâmetro- $V$ é projetado para avaliar as características funcionais topográfica da superfície através da análise do volume do material e volume vazio de uma superfície de mesma escala. A metodologia de obtenção dos parâmetros é dividir uma superfície em três zonas de altura, o pico, o núcleo e as zonas de vale, e depois fazer cálculos de volume com base nas três zonas. A divisão em três zonas foi originalmente derivada da DIN 4476, como uma solução prática para os problemas.

Tabela 2-8. Parâmetros S

Parâmetros de $\quad$ - Desvio médio quadrático da altura - Sq 


\begin{tabular}{cl}
\hline amplitude & - Assimetria - Ssk \\
& - Curtose - Sku \\
& - Altura máxima da superfície externa $-\mathrm{Sz}$ \\
& - Altura máxima do pico $-\mathrm{Sp}$ \\
& - Altura máxima do vale $-\mathrm{Sv}$ \\
& - Média aritmética da altura - Sa \\
\hline Parâmetros espaciais & - Auto correlação do decaimento mais rápido do comprimento - Sal \\
& - Relação do aspecto na textura - Str \\
\hline Parâmetros híbridos & - Razão da área interfacial desenvolvida - Sdr \\
& Sdqu médio da inclinação do quadrado da textura superficial - \\
\hline Parâmetros diversos & - Direção da textura na superfície da textura - Std \\
\hline
\end{tabular}

Fonte: BLUNT e JIANG (2003).

Esse formato de avaliação está sendo usado, como exemplo, na melhoria de próteses (BLUNT et al., 2009) e se concentrou no desgaste dos materiais e simulações de desgastes. As medições da superfície 3D foram feitas em nove locais, na respectiva prótese, usando interferometria, e os valores médios e as incertezas foram medidas.

Este estudo de caso mostrou a capacidade para pré-selecionar materiais e analisar os desgastes das superfícies e a possibilidade de evitá-los. Os autores mostraram os parâmetros de rugosidade utilizados na superfície 3D que os auxiliou na compreensão de sua relação com o desgaste da superfície.

\subsection{Textura superficial}

Uma das primeiras dificuldades que se tem quando se estuda textura, é obter uma definição única. (HARALICK et al., 1973) caracterizam textura a partir dos coeficientes de uniformidade, densidade, aspereza, regularidade, intensidade, dentre outras características. SKLANSKY (1978) afirma que, "uma região de uma imagem apresenta uma textura única, se o conjunto de características ou outras propriedades locais da imagem forem constantes ou aproximadamente periódicas". 
WILSON e SPANN (1988) definem que "regiões de textura são padrões espacialmente estendidos baseados na maior ou menor repetição precisa de alguma unidade celular". JAIN (1989), evidencia que "o termo textura geralmente se refere à repetição de elementos básicos de textura chamados texels". O texel contém vários pixels, cuja colocação pode ser aleatória, quase-periódica ou periódica. Nas texturas naturais, a distribuição desses pixels é geralmente aleatória, ao passo que texturas artificiais é frequentemente determinística ou periódica. A partir desse entendimento, uma textura pode ser caracterizada como áspera, fina, suave, granulada, ondulada, irregular, regular ou linear.

Em 1990, o IEEE Standard - Institute of Electrical and Electronics Engineers Standards, define que "textura é um atributo representando o arranjo espacial dos níveis de cinza dos pixels em uma região". GONZALEZ e WOODS (1992) afirmam que o ser humano intuitivamente percebe a textura a partir das propriedades que constituem essa textura como: suavidade, aspereza e regularidade.

CONCl et al. (2008) afirmam que "textura consiste em todas as formas associadas à impressão de rugosidade e contraste criados pela variação tonal ou pela repetição de padrões visuais sobre uma região".

\subsubsection{Classificação de imagens por Textura}

As classificações de imagens baseadas em características texturais têm sido amplamente utilizadas no meio científico e industrial. A textura pode ser definida como um padrão estatístico local no domínio de observação e de interesse (SENGUR et al., 2007).

A textura é frequentemente usada como um descritor regional em análise de imagem. A análise de textura é uma área de pesquisa importante com aplicações em bibliotecas digitais, bancos de dados multimídia, imagens médicas, robótica, sensoriamento remoto, controle de qualidade, automotiva, linha branca, etc. (YANG e LIU, 2002; BASHAR et al., 2003). 
A extração de características da textura se baseia num modelo matemático elaborado, incluindo, matrizes de co-ocorrência de nível de cinza, funções de auto correlação, campos aleatórios, filtros Gabor, Wavelets, etc. Tais modelos, normalmente, possuem exigências computacionais elevadas (PASCHOS e PETROU, 2003).

Em (PEDRINI e SCHUWARTZ, 2008) utiliza-se extração de características de textura para recuperação de imagens. O descritor de textura proposto usa variância e propriedades de luminescência.

(MARTINS et al., 2002) propuseram um método baseado em uma rede neural híbrida SOM (Self-Organising Maps) e LVQ (Learning Vector Quantization), para classificação de imagens de sensoriamento remoto a partir dos atributos de textura, extraídos com uso de filtros de Gabor. Em (SHIBA et al., 2005), apresenta-se um método baseado em árvores de decisão, para classificação de imagens de sensoriamento remoto descritas pelas três bandas do sistema de cores RBG. (ALVES e ARAUJO, 2006) fizeram uma análise comparativa do desempenho de dois diferentes modelos de redes neurais, na classificação de imagens digitais a partir de suas texturas, caracterizadas por descritores estatísticos de primeira e de segunda ordem.

\subsubsection{Análise da textura}

(PEDRINI e SCHWARTZ, 2008) distinguem quatro tipos de abordagem baseadas em: processamento de sinais (decomposição de valor singular, espectro de Fourier, Transformada de Wavelet); geometria (unidade de textura, codificação de características de textura); modelos paramétricos (campos aleatórios de Markov) e estatísticos (distribuição de níveis de cinza, matriz de co-ocorrência, matriz de comprimento ocorridas de cinza, função de auto correlação, matriz da diferença dos tons de cinza da vizinhança).

Neste contexto, para melhor entendimento, consideram as seguintes abordagens: 
1 - Estatística: é definida por um conjunto de medidas extraídas do padrão. Esta se caracteriza por descrever rugosidade, aspereza, suavidade, regularidade e quantificar essas características por meio de medidas, sem procurar analisar a estrutura hierárquica da textura. Nesta abordagem a análise de interesse, sendo adequada para imagens semelhantes à apresentada na FIGURA 2-16.

Figura 2-15. Exemplo de imagem adequada para a abordagem estatística

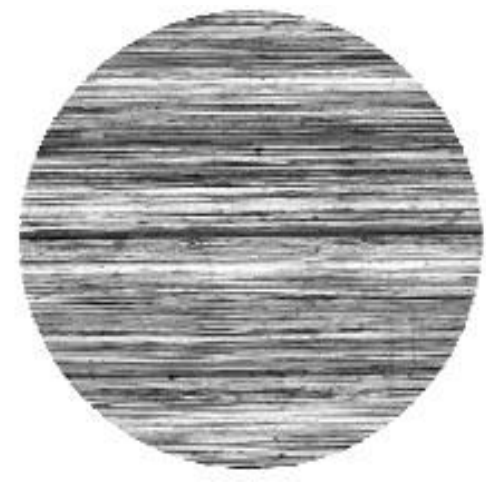

Fonte: (PEDRINI e SCHWARTZ, 2008).

2 - Estrutural: tem por objetivo estabelecer um relacionamento de vizinhança dos elementos de textura e seu posicionamento em relação aos demais, englobando os seguintes elementos: a homogeneidade, que define a regularidade; o número de elementos por unidade espacial, que define a densidade e o relacionamento de vizinhança dos elementos de textura e seu posicionamento em relação aos demais, que define a conectividade. Esta abordagem é apropriada para análise de imagens que possuem regiões que podem ser distinguidas por propriedades texturais ou de cor, tal como, a imagem apresentada na FIGURA 2-17.

Figura 2-16. Exemplo de imagem adequada para a abordagem estrutural 


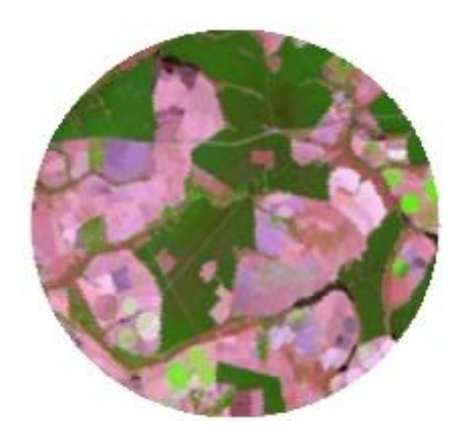

Fonte: (SIDOROVA, 2010).

Considerando as possíveis abordagens, destacam-se a seguir alguns artigos relacionados à classificação e textura em diversas aplicações:

(SIDOROVA, 2010) apresenta um algoritmo de clustering baseado em histogramas, levando-se em consideração as características estatísticas de texturas das imagens. $O$ algoritmo permite a adição de clustering falsos, que ocorrem nos limites dos objetos com diferentes texturas, reduzindo significativamente seu número. Os clusters são analisados estimando-se sua separabilidade no espaço vetorial multidimensional de características e no contexto da imagem. A aplicação do algoritmo tem como objetivo, o reconhecimento automatizado de cobertura de áreas, utilizando-se, para isso, de fotografias aéreas de paisagens florestais. A comparação dos mapas de clustering e mapas esquemáticas de levantamento terrestre mostram uma boa compatibilidade.

A abordagem exposta em (SIM et al.,2004) mostra um algoritmo simples para recuperação de imagens baseadas em texturas. O descrito proposto é obtido, primeiramente, pelo cálculo do espectro de potência de uma imagem de textura original para invariância de translação, e então a imagem do espectro de potência é normalizada para a invariância de escala. $O$ algoritmo proposto é mais simples do que os algoritmos convencionais em termos de complexidade computacional. A efetividade do descrito proposto, para recuperação de textura invariável, é mostrada com vários conjuntos de dados de textura, comparando sua exatidão de recuperação, seu tamanho e sua complexidade com os dos descritores convencionais. 
Em (PALM, 2004), apresentam-se matrizes de co-ocorrência para classificação da textura de cor. O ganho das informações das novas matrizes é mostrado quantitativamente usando a distância de Kolmogorov, e através de experimentos de qualificação extensiva em dois conjuntos de dados. São avaliadas as combinações de cor em RGB e LUV e as texturas, e é demonstrada a existência de padrões de cor pura de intensidade independente.

(MÜNZENMAYER et al., 2005) consideram que os algoritmos de textura de imagem vêm sendo melhorados há alguns anos. No entanto, os resultados desses algoritmos ainda estão sob considerável influência das condições de iluminação, sobre as quais as imagens são capturadas. É fortemente desejável que se reduza a influência da iluminação tanto quanto possível para se obter resultados de classificação estáveis e satisfatórios. Nesse artigo, é apresentada a análise de um algoritmo para avaliar a textura por meio das características do histograma de soma-e-diferença, com relação às mudanças de iluminação. Baseado nessa análise é proposto um conjunto de características, considerando o fator da influência da iluminação sobre a maioria das características originais. Os autores concluem esse artigo com uma avaliação quantitativa e experimental em amostras de imagens reais e artificiais.

Em (XIA et al., 2006), os autores entendem que a análise Multifractal tem se tornado popular em aplicações de segmentação de imagem, está baseada em contagem de caixas (box-counting). Porém, apesar de sua eficiência computacional, o esquema de partição regular usado por vários métodos intrínsecos de contagem de caixa, produz resultados menos precisos. Os autores propõem, portanto, um algoritmo para estimar a dimensão Multifractal, baseado na morfologia matemática e em um conjunto de novos descritores multifractais, nomeados Morphological Multifractal Exponents. Estes descritores são definidos para caracterizar as propriedades de escalas locais de texturas. É utilizada uma série de elementos de estruturas cúbicas e um esquema de dilatação interativa, de forma que as complexidades computacionais das operações morfológicas podem ser tremendamente reduzidas. O algoritmo proposto e os métodos baseados em contagem de caixa têm sido aplicados à segmentação de mosaicos de textura e imagens reais. Os resultados comparativos demonstram que a estimativa da 
dimensão multifractal morfológica pode diferenciar imagens de textura mais efetivamente e pode prover segmentações mais robustas.

Em (CONCl et al., 2001), é apresentado o método Differential Box-Counting (CDC) que faz referência à contagem de $\mathrm{D}$-cubos para determinar a dimensão fractal em texturas de imagens multidimensionais. O método Differential Box-Counting é o mais adequado para obter este descritor de textura, pois permite o cálculo da dimensão fractal em qualquer dimensão.

(CARKACIO e YARMAN, 2003) apresentaram um descritor de textura genérico Statistical Analysis of Structural information (SASI) para representação de textura. O descritor está baseado em estatísticas de coeficientes de auto correlação, calculadas sobre janelas nas imagens. $O$ descritor define um conjunto de janelas para extrair e medir várias propriedades estruturais de textura usando multiresolução21 espacial.

Devido à flexibilidade no desenho das janelas, o descritor atinge maiores taxas de recuperação média em comparação com outros descritores como os filtros de Gabor. No entanto, o preço deste desempenho é o aumento da complexidade computacional.

(CUl et al., 2006) propõem um conjunto de características invariantes à rotação e à escala baseados em transformada de Radon e na análise de multiescala. A Transformada de Radon é usada para projetar a imagem ao espaço 1-D, desta forma as linhas da matriz de projeção são transformadas por uma transformada wavelet 1-D adaptável, assim a matriz de características invariantes à escala é derivada no domínio Wavelet Radon. A análise Multiescala é empregada para a matriz de características, e os valores de energia em diferentes escalas são provados não somente serem invariantes à escala e à rotação da imagem, mas também refletem as diferentes distribuições de energia da imagem de textura em diferentes escalas. Na fase de classificação, um classificador de Mahalanobis é usado para classificar 25 classes de texturas naturais distintas. A classificação é realizada pela técnica de agrupamento de regiões a partir de uma medida de similaridade entre elas. A medida de similaridade utilizada consiste na distância de Mahalanobis entre a classe de interesse e as regiões candidatas à relação de 
pertinência com esta classe. Portanto, cada região será classificada a uma dada classe de interesse baseada na minimização da distância de Mahalanobis. Os autores apresentam resultados experimentais, que mostram que a taxa de reconhecimento média para rotação conjunta, e invariância de escala do método de classificação proposto, pode ser de 92,2\%.

(CHARALAMPIDIS e KASPARIS, 2002) introduzem um conjunto de características invariantes à rotação para segmentação e classificação de textura, baseado na extensão das características de dimensão fractal (Fractal Dimension - FD). A FD extrai informação de aspereza das imagens, considerando todas as escalas disponíveis de uma vez. Os autores consideram uma única escala de cada vez, de forma que texturas com propriedades dependentes de escala são caracterizadas satisfatoriamente. Características de escala única são combinadas com características de escala múltipla para uma representação textural mais completa. São empregados wavelets para a computação de características aproximadas de escala única e múltipla, por causa de sua eficiência para extrair informação para resoluções diferentes. As características são extraídas em direções múltiplas usando wavelets direcional, e o vetor de característica é finalmente transformado para um vetor de características invariantes à rotação, que retém a informação direcional da textura. Um algoritmo K-means interativo é usado para segmentação. O método obteve excelente desempenho para a segmentação de texturas.

(RUSHING, 2002) descreve um novo tipo de característica de textura baseado em regras de associação. Regras de associação têm sido usadas em aplicações como análise de Mercado, para capturar relações presentes entre itens nos grandes conjuntos de dados. Os autores demonstram que regras de associação podem ser adaptadas para capturar frequência de ocorrências de estruturas locais em imagens. A frequência de ocorrência de estruturas pode ser usada para caracterizar a textura. Os autores descrevem métodos para segmentação de imagens por textura baseados em regras de associação de características. Resultados da simulação, utilizando imagens retiradas de texturas naturais, mostram que as características de regras de associação têm um desempenho inferior à de outras técnicas. 
(HAMMOUCHE e POSTAIRE, 2006) propõem uma adaptação de medidas estatísticas de textura, visando descrever uma distribuição de espaço de observações multidimensionais. A ideia principal é, considerar os núcleos de agrupamentos, como domínios caracterizados pelas suas texturas específicas no espaço de dados. A distribuição dos pontos de dados é primeiramente descrita como um histograma multidimensional definido em uma ordem regular multidimensional de pontos de amostra. Para avaliar uma textura multidimensional localmente, é introduzida uma matriz de co-ocorrência que caracteriza a distribuição local dos pontos dos dados no espaço de dados multidimensional. Podem ser computadas várias características de textura local desta matriz de coocorrência. Tal matriz acumula informação de espaço e estatística na distribuição de dados nas vizinhanças dos pontos de amostras. São selecionadas características diferentes de textura. Os pontos nomeados a estas classes, considerados como os núcleos dos agrupamentos, tendem a formar componentes conectados no espaço de dados.

Em (AVCI, 2006), usa-se uma Rede Neural WNN-ANE Wavelet Neural Network based on Adaptive Norma para aumentar a efetividade dos algoritmos de extração de características invariante à escala Best Wavelet Statistical Features (WSF) e (Wavelet Co-occurrence Features (WCF). A eficiência do método proposto foi comprovada através de experimentos exaustivos realizados com texturas de Brodatz.

(ALEGRE et al., 2010) apresentam um método para desenvolver um controle de superfície acabada usando um sistema de visão computacional. O objetivo principal era o de criar um critério de aceitação para o controle de rugosidade de superfície, dividindo-as em baixa rugosidade - classe aceitável - e alta rugosidade - classe defeituosa. Foram usadas 143 imagens, e estas foram descritas a partir de três diferentes métodos: filtros locais de textura, quatro descritores de Haralick em matrizes de co-ocorrência e um vetor de 20 características obtido através da subbanda de uma transformada wavelet da imagem original. A classificação foi conduzida usando $\mathrm{k}-\mathrm{NN}$ e rede neural. A melhor taxa de erro de $4.0 \%$ com $\mathrm{k}-\mathrm{NN}$ foi alcançada usando-se descritores de textura. Com a rede neural, de oito camadas 
escondidas para os descritores Haralick com configuração otimizada, o resultado foi uma taxa de erro de $0.0 \%$.

(LESSMANN e WÜRTZ, 2008) observam que imagens geradas no cérebro ou em um computador requerem uma segmentação de imagens para serem compreendidas, sendo necessária sua partição em diferentes regiões, semanticamente conectadas que constituem um objeto físico. Esta tarefa é fundamental para o processo subsequente de análise da informação visual, e parece ser realizado pelo cérebro de forma bem fácil.

Entretanto, é um desafio bastante exigente para algoritmos de computador. Os autores apresentam redes neurais que processam as informações de contorno favorecendo contornos fechados. Os pesos conectivos são reconhecidos através das sequências de imagens reais. Assim, a segmentação é alcançada com base na cor, textura e informação de contorno.

(SENGUR et al., 2007) descrevem o uso de redes neurais Wavelet Packet Neural Networks (WPNN) para o problema de classificação de textura. O esquema proposto é composto de um extrator de características Wavelet Packet e um classificador multilayer perceptron. Características de energia e entropia são integradas ao extrator de característica Wavelet. Os estudos experimentais executados mostram a efetividade da estrutura WPNN. A taxa de sucesso global é aproximadamente de $95 \%$.

(ALEGRE et al., 2010) propõem a utilização de filtros de Gabor e matriz de covariância para produzir um conjunto de características que mostram os dados estatísticos de domínio da frequência aplicados às texturas. Os experimentos são conduzidos em 32 texturas do conjunto de dados de textura Brodatz. O resultado é obtido pela utilização de 24 filtros de Gabor, para gerar uma matriz covariância $24 \mathrm{x}$ 24 , com um resultado de $91,86 \%$ no reconhecimento. Os resultados experimentais mostram que os métodos combinados são melhores do que o uso das informações somente provenientes das matrizes de co-ocorrência. 


\subsubsection{Características de textura}

Em (HARALICK, 1979), foi proposta uma metodologia para descrição de texturas baseada em estatística. A abordagem estatística se caracteriza por descrever rugosidade, aspereza, suavidade, regularidade que quantificam essas características através de medidas. A extração de características se dá pela relação entre os níveis de cinza.

Esta abordagem estatística pode ser dividida em duas importantes vertentes: a abordagem de primeira ordem, na qual se extraem características a partir de histogramas de primeira ordem, e a abordagem de segunda ordem, que leva em conta o posicionamento relativo da ocorrência dos níveis de cinza. Entretanto, somente a abordagem de segunda ordem é utilizada por Haralick para descrição das texturas.

Lembrando que a textura cristalográfica, diferente da textura superficial, em termos básicos, trata-se da orientação preferencial dos grãos de um material policristalino (que é o caso dos aços) em relação à algum referencial plano e direcional, como por exemplo, a superfície da chapa ou a direção de laminação.

\subsubsection{Análise da textura}

Para a análise de primeira ordem, se avalia a distribuição de níveis de cinza na imagem utilizando histogramas. Assim, se procede para avaliar as probabilidades $\mathrm{P}(i)$ de ocorrência para cada característica na imagem, onde $i=0,1,2,3,4, \ldots \ldots \ldots . Z$, onde Z é o número de características. Para isso se utilizam parâmetros estatísticos de primeira ordem para a caracterização da textura, os exemplos são: média, variância, desvio padrão, simetria entre outros.

Para aplicação na textura se considera uma janela móvel com o pixel central circundado por pixels adjacentes. As medidas da distribuição dos níveis de cinza calculadas são atribuídas ao pixel central da janela. Como esta se move para o lado da imagem, usando cada pixel como ponto central, a cada nova posição são atribuídos valores relativos ao conjunto de pixels adjacentes. (PARKER, 1997) especifica dezessete propriedades locais, que incluem quatro momentos centrais dos níveis de cinza no interior da janela, e diferenças entre níveis de cinza médios 
e pixels vizinhos mais próximos. Essa abordagem não consegue extrair a relação do pixel com sua vizinhança, desconsiderando a distribuição espacial dos pixels na imagem que está sendo analisada. 


\section{Capítulo 3 - Processo}

\subsection{Processo de laminação a frio}

O processo de laminação a frio consiste em laminar chapas de aço, cobre ou alumínio através de um Laminador de tiras a frio, conforme FIGURA 3-1. Neste equipamento, as principais características a serem observadas nas chapas após laminadas são: rugosidade, dimensões, propriedades mecânicas. Estas estão diretamente relacionada ao desempenho dos cilindros durante a laminação. Este laminador consiste de um conjunto de cilindros de trabalho e apoio, posicionados no interior de uma cadeira de laminação, por onde passa a chapa a ser laminada, o qual consiste de cadeiras de laminadores responsáveis pela diminuição da espessura e pelo acabamento das tiras (MENDES, 2007).

Figura 3-1. Desenho esquemático de um trem de laminação a frio

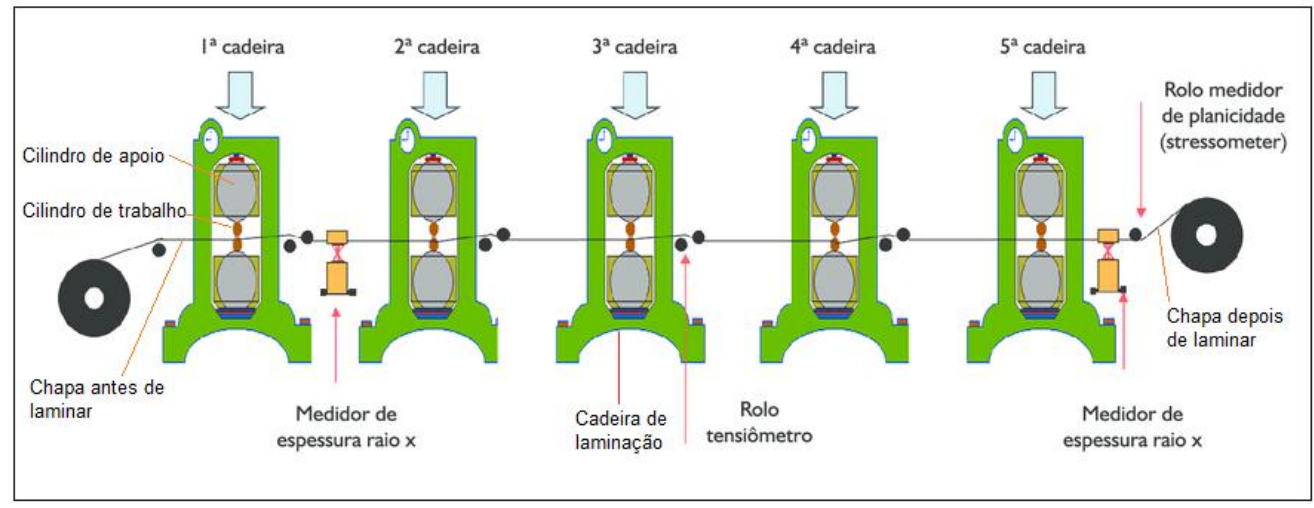

Fonte: (portal Usiminas - http://usiminas.com).

Em relação ao movimento da chapa laminada e dos cilindros, a diferença de velocidade da chapa laminada varia em relação a entrada e a saída da cadeira de laminação (DIETER, 1988). Uma chapa antes de entrar no conjunto de cilindros possui uma espessura inicial (E0) conforme FIGURA 3-2. O processo de deformação diminui a espessura da chapa para determina espessura final (Ef), na saída da cadeira do laminador. O processo de deformação da espessura da chapa, provoca um alongamento na mesma, sem alterar dimensões da largura da chapa. 
Neste caso, a variação de volume de material que atravessa os cilindros é nula e a quantidade de material que entra na cadeira do laminador é a mesma que sai, num mesmo intervalo de tempo, conforme EQUAÇÃO 3.1.

$E_{0} L V_{e}=E_{f} b V_{f}$

Eo espessura inicial da chapa

Ef espessura final da chapa

L largura inicial da chapa

Ve velocidade da chapa antes de atravessar os cilindros

b representa a largura da chapa após atravessar o cilindro

Vf representa a velocidade da chapa depois de atravessar os cilindros

Figura 3- 2. Velocidades e forças de atrito durante o processo de laminação

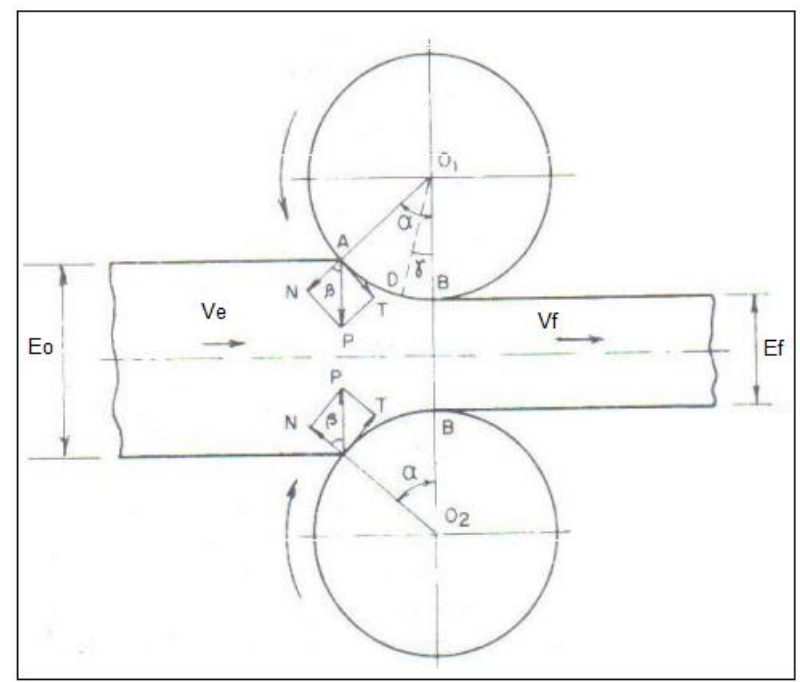

Fonte: (DIETER, 1988).

Devido à variação nula de volume que atravessa os cilindros, a velocidade de saída da chapa deve ser maior que a de entrada. Portanto, a velocidade de entrada da chapa deve aumentar continuamente até a velocidade de saída. Nota-se que a velocidade da chapa antes da entrada nos cilindros é menor do que a velocidade 
periférica dos cilindros. Portanto, com o aumento da velocidade da chapa laminada, a mesma se iguala à velocidade do cilindro no ponto de contato entre chapa e cilindro, chamado ponto neutro, cuja velocidade relativa entre a chapa e o cilindro é nula. Após o ponto neutro, a velocidade da chapa laminada é superior à velocidade periférica do cilindro e a velocidade relativa volta a aumentar, só que no sentido de se afastar do ponto neutro, gerando assim a mudança de sentido da velocidade relativa a partir do ponto neutro (MENDES, 2007).

Em consequência do movimento relativo entre chapa e cilindro, as forças de atrito também mudam de sentido no ponto neutro. Entre a entrada e o ponto neutro, a velocidade do cilindro é mais lenta e a força de atrito atua no sentido de empurrar a chapa. Após o ponto neutro, a velocidade da chapa é maior e o sentido da força de atrito é contrário ao da saída da chapa (MENDES, 2007). Essas relações de força e atrito, provocam desgastes nos cilindros de laminação, sendo determinante para a performance da campanha dos cilindros durante o processo de laminação.

\subsubsection{Texturização aplicada à laminação a frio}

As superfícies texturizadas desempenham um importante papel na fabricação dos materiais para diversas aplicações e segmentos do mercado que estes cilindros como matéria prima. $\mathrm{Na}$ indústria automotiva, por exemplo, os vales formados pela superfície texturizada dos cilindros, durante o processo de conformação, além de serem um bom reservatório para óleo lubrificante, ajudam a produzir uma refletividade uniforme após a pintura (UTSCH; VINKE, 2005), por exemplo, descreve em seu trabalho que a influência da rugosidade da superfície do metalbase diminui com aumento da espessura da camada de tinta aplicada em partes automotivas. Afirma também que o brilho aparente da superfície dos painéis automotivos pintados melhora com o aumento da quantidade de picos na superfície e sugere faixa ideal de rugosidade média, representado pelo parâmetro $\mathrm{Ra}$, de 0,5 a 2,4 $\mu \mathrm{m}$. O parâmetro de rugosidade $\mathrm{Ra}$, é definido pela norma (ISO 4287, 1997) como sendo a média aritmética das alturas de um perfil.

Além de proporcionar uma otimização estética do produto laminado, (LO e HORNG, 1999) mostraram que texturização afeta o comportamento tribológico 
durante o processo de laminação da chapa, onde a presença de bolsas serve de reservatório de lubrificante como fonte secundária de lubrificante no contato.

Assim, cada aplicação exige uma diferente condição de rugosidade superficial. Para atingir os melhores resultados é então necessário dominar processo de transferência de rugosidade do cilindro para a tira, necessários à confecção do produto solicitado. Neste contexto são apresentados alguns estudos de transferência de rugosidade durante a laminação.

O trabalho de (XIE; JIANG e YUEN, 2011) afirma que além da proporção de redução da chapa, da velocidade de laminação e da espessura da chapa, a rugosidade inicial da chapa também interfere no fluxo do material durante a laminação. Geralmente, a rugosidade da tira laminada diminui com o aumento da redução. Além disso, cilindros de trabalho mais rugosos criam chapas mais rugosas. A maior dificuldade de se chegar a uma clara conclusão sobre os eventos que ocorrem durante a laminação, é a falta de visualização das interações tribológicas entre a superfície e o cilindro.

(BUSCH et al., 1987) estudaram a transferência de rugosidade durante a laminação de aço baixo carbono micro ligado e aço baixo carbono, utilizando cilindros texturizados de duas diferentes maneiras: retificado por rebolo rugoso e texturizados por jateamento de granalha. Durante o estudo, concluíram que a transferência da rugosidade equivale a um mecanismo de identação e que, materiais mais duros (chapa), para a mesma carga e velocidade de laminação apresentaram menor taxa de transferência da rugosidade do cilindro para a tira. Outra constatação foi que para manter a mesma taxa de transferência de rugosidade, utilizando cilindros de maior diâmetro, é necessário aumentar a carga de laminação. Além disto, a transferência de rugosidade depende da carga de laminação e da tensão vertical na "mordida do cilindro". Logo, pequeno diâmetro de cilindro para uma mesma carga de laminação implica em menor comprimento de contato e tensão vertical na mordida muito maior.

Já que a textura superficial da chapa é obtida durante a laminação, o produto final apresenta a mesma textura superficial em ambos os lados da tira, caso os dois cilindros do par forem texturizados. Utilizando cilindros com rugosidades diferentes, 
ou seja, na posição superior diferente do cilindro na posição inferior, pode-se transferir uma textura superficial diferenciada para a chapa. Por exemplo, texturas com vales ou micro cavidades podem ser impressas na tira para reter o lubrificante, diminuindo consequentemente $o$ atrito entre a chapa e a ferramenta durante a estampagem, possibilitando uma estampagem mais profunda (CORTÊS, 2009).

Existem na atualidade inúmeras técnicas de texturização superficial (COSTA, H. L.; HUTCHINGS, I. M., 2015). A seguir, algumas das técnicas mais utilizadas nas indústrias que trabalham com laminação a frio.

Cada técnica de texturização tem suas particularidades, apresentando diferentes resultados: distribuições de cavidades ou vales, faixas de rugosidade, densidades de picos, homogeneidade e reprodutibilidade (SIMÃO et al., 1994; SUN et al., 2006).

\section{1.) Texturização por jato de granalha}

As granalhas de aço são projetadas por uma roda centrifugadora (turbina) contra a superfície do cilindro de laminação. O impacto destas granalhas na superfície da mesa do cilindro de trabalho do laminador, gera uma deformação local, provocando aparecimento de micro cavidades. Controlando a força, o diâmetro e a quantidade das granalhas projetadas, pode-se conseguir a rugosidade final objetivada (DEUTSCHER, 1995), conforme FIGURA 3-3. Resultados obtidos por (SUN et al., 2006) mostraram que para o método de texturização por jato de granalha ocorre uma grande variação da rugosidade, com esparsa e desigual distribuição da textura, a qual resulta em transferência da rugosidade menor que $70 \%$.

Figura 3-3. Processo de jateamento de granalha de aço 


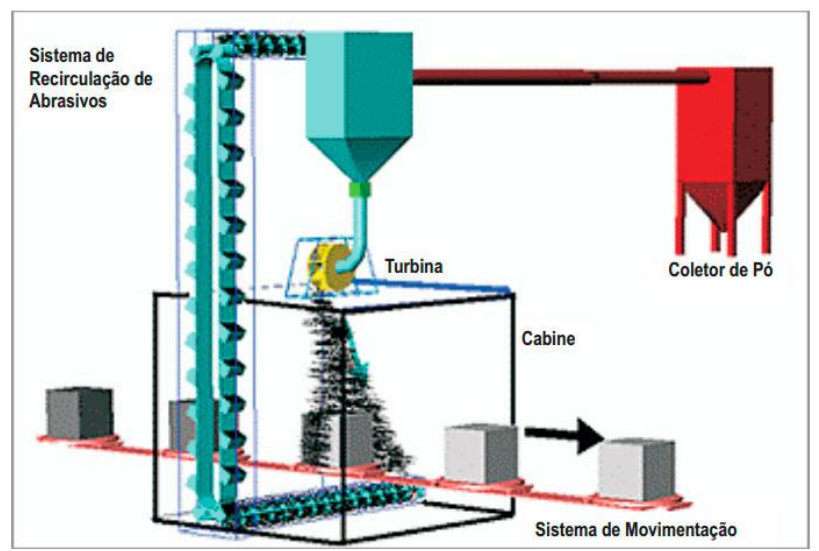

Fonte: (DEUTSCHER, 1995).

\section{2.) Texturização por feixe de laser}

O método de texturização por feixe de laser utilizado na indústria de laminação, consiste em um feixe de laser irradiar na superfície do cilindro, o qual passa por uma roda dentada que interrompe sua passagem intermitentemente. Em cada ponto iluminado ocorre uma microcratera localizada da superfície do material formando micro cavidades. A velocidade da roda dentada e o diâmetro do feixe a laser é que definem a rugosidade final da superfície do cilindro, conforme FIGURA 3-4 (SUN et al., 2006).

Na texturização a laser a transferência da rugosidade é em torno de $50 \%$ e que, só é possível transferir $25 \%$ da altura dos picos formados, pois o mesmo fica achatado na extremidade superior (DEUTSCHER, 1995). A vantagem deste processo é sua elevada homogeneidade superficial. Fazendo programações em um sistema micro processado, é possível obter qualquer padrão de textura, inclusive desenhos. Novos sistemas de laser conseguem alterar formatos e dimensões das crateras formadas melhorando a taxa de transferência da rugosidade do cilindro. Porém, o custo do equipamento e o elevado tempo para texturização, prejudicam o desempenho do processo (DEUTSCHER, 1995).

Figura 3-4. Desenho esquemático da irradiação com laser no material 


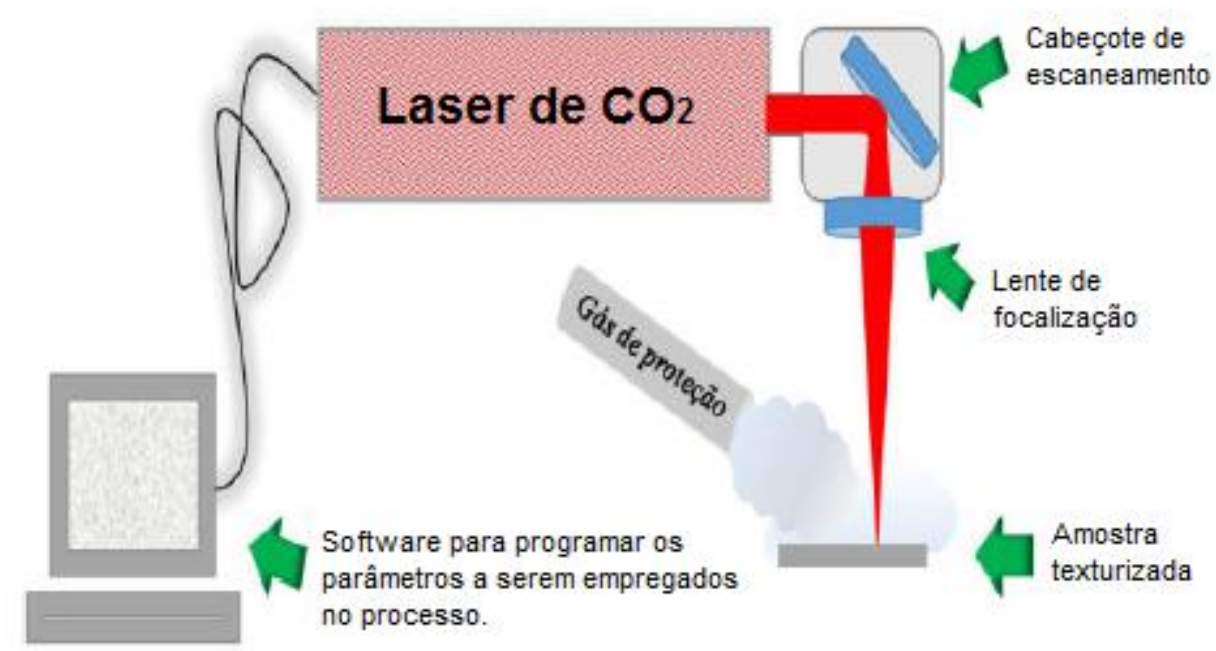

Fonte: (L. S., Yamin, 2017).

\section{3.) Método de texturização por descargas elétricas}

Utiliza eletrodos posicionados longitudinalmente à superfície do cilindro, que fica imerso em um meio dielétrico. Descargas elétricas são induzidas entre o eletrodo (anodo) e o cilindro (catodo), provocando eletroerosão em sua superfície. A combinação da corrente, tensão e frequência de oscilação definem a condição final do cilindro texturizado (SIMÃO et al., 1994). A FIGURA 3-5, mostra de forma esquemática o processo de texturização por descargas elétricas.

Figura 3-5. Equipamento para realizar a texturização por descarga elétrica

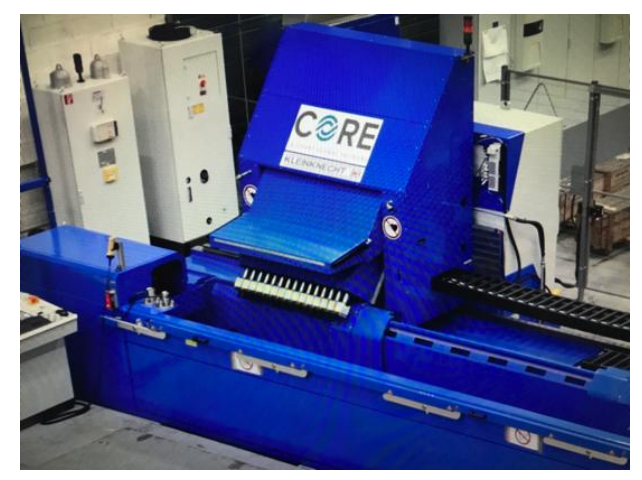

Fonte: Autor (cortesia da empresa: CORE E-text Machine). 
Verifica-se que a taxa de transferência de rugosidade é alta, em torno de $80 \%$ e a textura é bem homogênea e repetitiva. Além disso, após laminação de 1.750 toneladas de material, ocorreu somente uma perda de rugosidade do cilindro em torno de $18 \%$ (SIMÃO et al., 1994).

O sistema apresenta maior homogeneidade quando aplicado em grandes áreas e boa repetibilidade se comparado com processo de texturização por jato de granalha. É possível alterar parâmetros de processamento como corrente e tensão dos eletrodos, ou até mesmo alterar o tipo de material do eletrodo para se obter a combinação rugosidade e densidade de picos desejados (CORTÊS, 2009). Entretanto este método produz somente texturas aleatórias enquanto que com o método a laser é possível prever a topografia final do cilindro.

\section{4.) Método de texturização por usinagem (SCRATCH)}

Retificadora, ou retífica, são máquinas operatrizes altamente especializadas em retificar e polir peças e componentes cilíndricos ou planos.

Os cilindros de laminação têm suas medidas de acabamento retificada numa retífica. Outro exemplo seriam os corpos como barramentos e prismas de precisão das próprias máquinas operatrizes que são acabados em suas medidas finais por retíficas planas e cilíndricas. São altamente especializadas na atividade de tornar reto ou exato, dispor em linha reta, corrigir e polir peças e componentes cilíndricos ou planos, apresentado na FIGURA 3-6.

O processo de retificação é executado por ferramentas chamadas de esmeratrizes ou rebolos, que são pedras fabricadas com materiais abrasivos cujos formatos podem ser cilíndricos, ovalizados, esféricos, etc.

Em geral, os rebolos são presos a eixos (pontas montadas) e giram em altíssima rotação. Dessa forma, o componente a ser retificado é montado num suporte, numa mesa coordenada ou num eixo, e recebe o atrito do rebolo, que vai retirando o material em quantidades muito pequenas, até chegar ao ponto ou dimensão determinada pelo projeto. 
Figura 3-6. Retífica utilizada para realizar usinagem nos cilindros

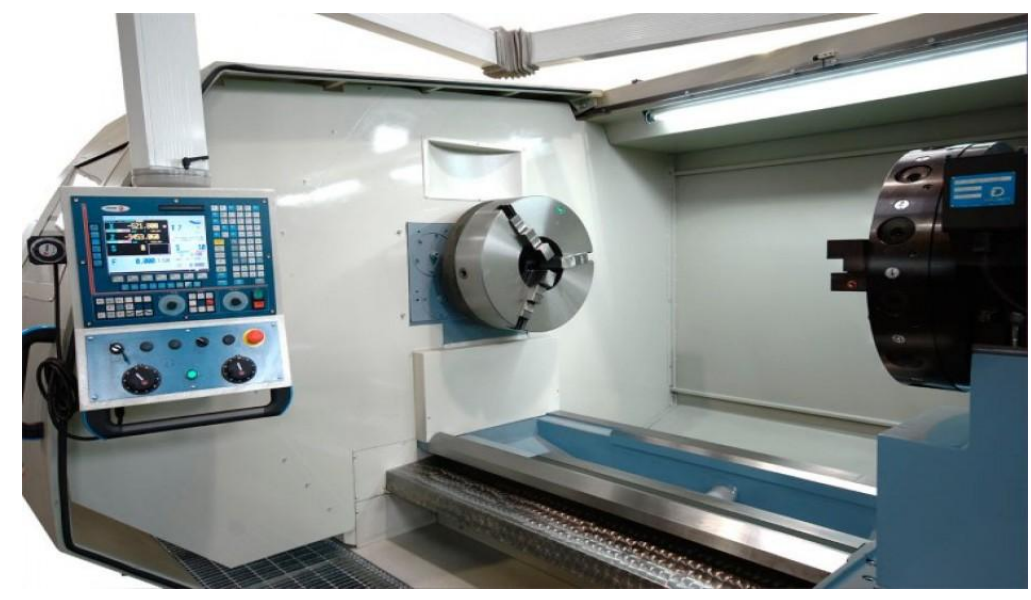

Fonte: (Portal Proeminente - http://proeminente.com).

\subsubsection{Texturização de cilindros de laminação e o efeito do grau de redução}

Após o processo de texturização nos cilindros de laminação, a rugosidade dos mesmos será transferida para a chapa metálica durante o processo da laminação a frio. Estudos efetuados por (PAWELSKI et. al., 1994), relativos à transferência da rugosidade de diferentes cilindros texturizados sobre a chapa metálica, em termos dos graus de redução, encontram-se resumidos na FIGURA 3.7.

Figura 3- 7. As figuras indicam a laminação de acabamento em diferentes graus de redução para 4 métodos de texturização SBT, EDT, EBT e LT. 

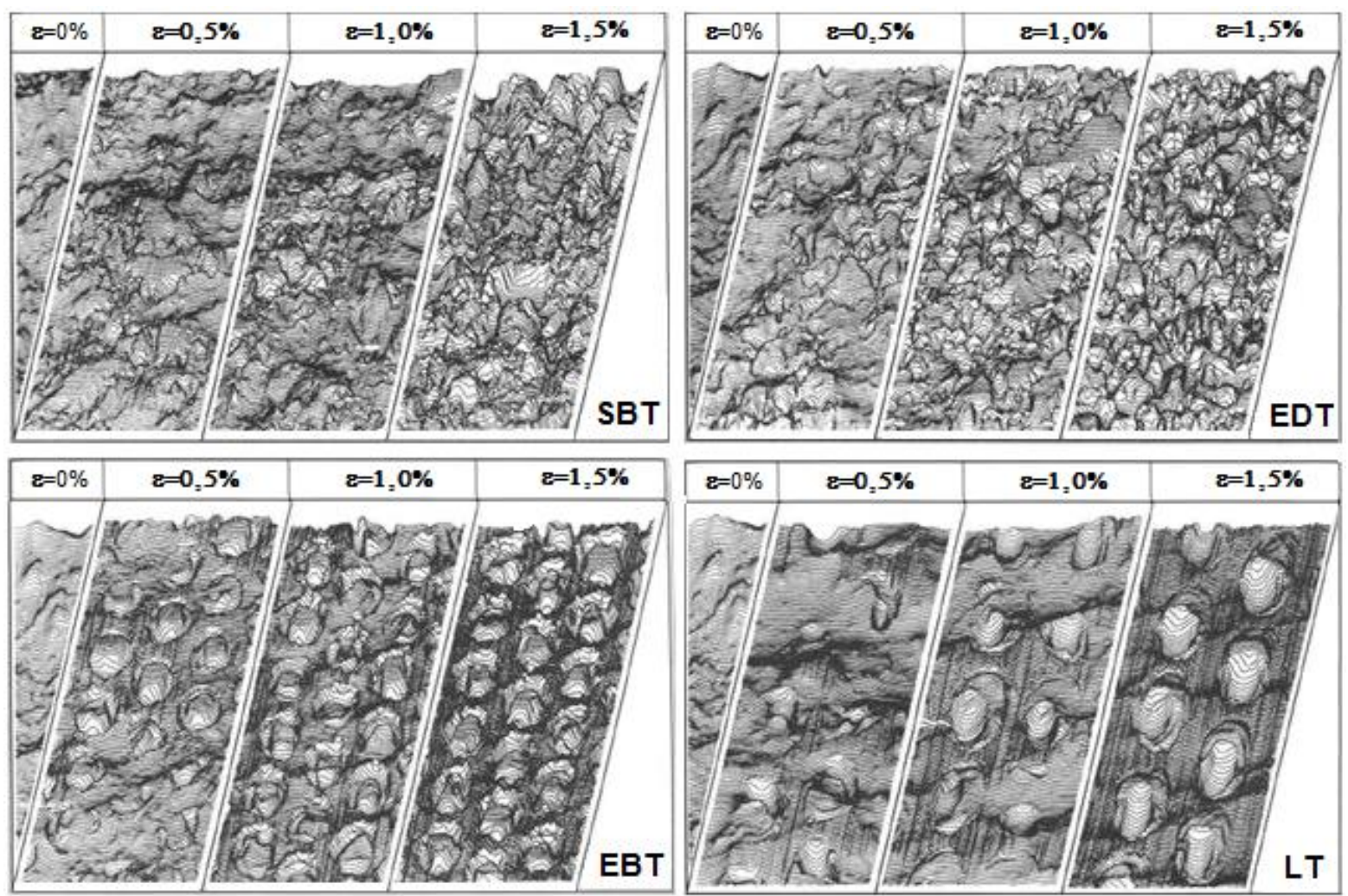

Fonte: (PAWELSKI et al.,1994).

A FIGURA 3-8 demonstra claramente que a intensidade de transferência de rugosidade ocorrida do cilindro para a chapa, depende do grau de redução aplicada na cadeira durante o processo de laminação. Estas reduções, possuem um limite na transferência da rugosidade. A melhor condição para o processo e a aplicação, seria buscar o "ponto ótimo" ou um ponto de equilíbrio entre o processo e a aplicação.

Figura 3- 8. Grau de redução na laminação de acabamento em função do grau de transferência da rugosidade para a chapa metálica 


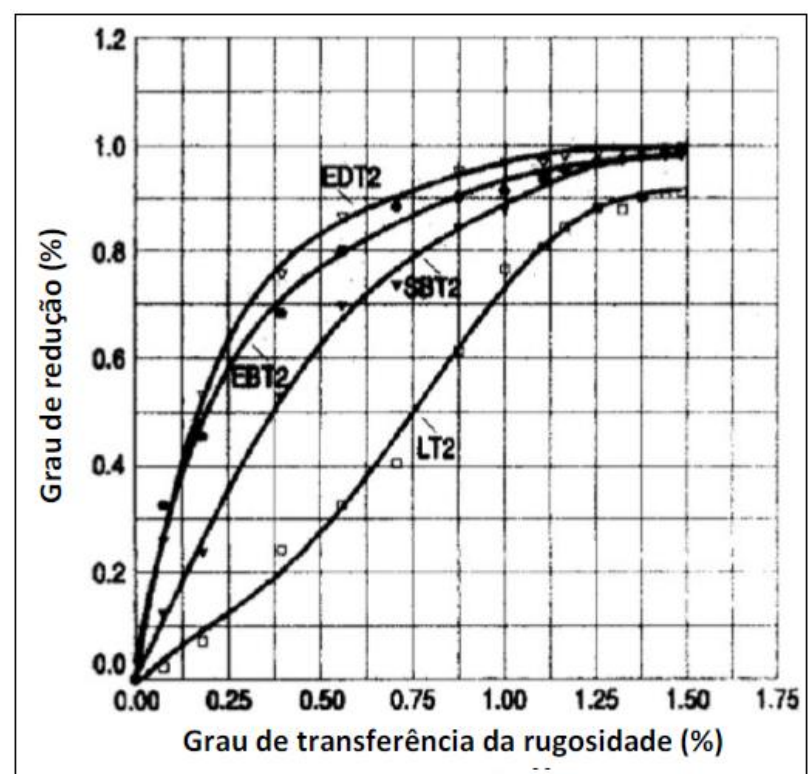

Fonte: (Pawelski et al, 1994).

Outro aspecto importante apontado por (PAWELSKI, 1994) apresentado na FIGURA 3-8, é a existência de um nível de saturação na transferência da rugosidade em diferentes métodos de texturização (SBT, EDT, EBT e LT), a partir do grau de redução da laminação a frio de chapas metálicas.

\subsection{Coeficiente de atrito}

O atrito e a resistência desenvolvida por um corpo em contato com outro ou outros, quando estes realizam ou tendem a realizar um movimento relativo entre si. Do ponto de vista energético, o atrito é a conversão de energia cinética em outra forma de energia, por exemplo: térmica, acústica, elétrica. Essa energia depende da natureza dos corpos envolvidos e do tribofilme formado entre eles. Os dois principais mecanismos de atrito são a adesão e a deformação plástica. Em princípio, a energia de atrito é dissipada na deformação das camadas superficiais por mecanismos elástico, plástico e viscoelástico e pela formação de trincas nessas camadas. Pode ainda haver a participação de outros corpos em contato com ambas as superfícies, como é o caso dos lubrificantes (HOLMBERG et al., 2009). 
O coeficiente de atrito (grandeza adimensional) representado quase sempre pela letra $\mu$, conforme EQUAÇÃO 3.2, que representa o coeficiente de atrito relaciona a força de atrito com a força normal entre os corpos. Esse coeficiente também depende da natureza dos corpos em contato uns com os outros (HOLMBERG, et al., 2009).

$\mu=\frac{F}{N}$

Podem-se dividir as forças de atrito em dois grupos: as forças de atrito estático e cinético. A força de atrito estático, pode ser caracterizada, pelo atrito entre corpos que não realizam movimento relativo entre si. Já a força de atrito cinético, que também leva o nome de força de atrito dinâmico, é a força característica gerada a partir do contato entre corpos que apresentam movimento relativo entre si (BAYER, 1994). De uma maneira moderna, pode-se descrever o atrito como uma variável que depende de parâmetros que envolvem o tribossitema como: velocidade relativa, pressão de contato, presença de lubrificantes, umidade, temperatura, filmes superficiais e propriedades dos substratos (BAYER, 1994).

O atrito microscópico é causado pela quebra de ligações entre átomos que podem estar fortemente ligados ou apenas em contato por microssaliências na superfície do material. Por mais "liso" que o material possa parecer a olho nu, ainda existem microasperezas superficiais na escala microscópica (KIM, 1991). A quebra dessas microligações ocorre depois de uma deformação plástica em um ponto de contato entre as superfícies em que as ligações são mais fracas (KIM, 1991). Novos métodos de análise de superfície, assim como métodos de análise de forças atômicas, abriram um novo caminho para que se estude o atrito e suas forças em escala molecular, também o avanço dos processadores e programas de computador, ajudam a simular as relações atômicas entre os objetos em contato e a forma com que adquirem movimento relativo entre si (HOLMBERG et al., 2009).

\subsection{Processo de revestimento de cromo duro}


O cromo duro é obtido por eletrodeposição a partir de uma solução contendo ácido crômico e um ânion catalisador (NEWBY, 1994). Comercialmente existem três tipos de soluções para a deposição do cromo duro: convencional, catalisadores mistos e soluções livres de fluoretos.

Em todas as três diferentes soluções utiliza-se o Trióxido de cromo ( $\mathrm{CrO} 3)$ como fonte de cromo e os íons de sulfetos $\mathrm{SO}_{4}^{-2}$ como catalisador. Para a solução com catalisadores mistos utilizam-se como catalisador secundário íons de flúor e em soluções livres de fluoretos acrescenta-se uma espécie orgânica (NEWBY, 1994). Antes da deposição do cromo duro, é necessária a remoção de sujeira e filmes passivos na superfície da peça (cilindro) a ser submetida ao processo de cromagem. Para isto usa-se um procedimento de limpeza química e em algumas situações, a limpeza eletroquímica. $O$ ataque químico do metal da peça a ser cromada, antes da deposição assegura a boa adesão do revestimento de cromo na superfície da peça (cilindro) (NEWBY, 1994).

Este processo anterior a aplicação do cromo duro no cilindro, ocorre em três etapas. Inicia-se num tanque de enxague, onde ocorre a limpeza manual na superfície da mesa do cilindro, com um detergente alcalino para ajudar na remoção de resíduos de óleo e graxa. Na sequência, ocorre uma limpeza química e posteriormente uma limpeza eletroquímica. Todo o processo de limpeza manual e química, é realizado utilizando-se detergente alcalino para remoção de óleos e graxas. Em seguida, realiza-se a limpeza eletroquímica, que além do detergente alcalino em determinada concentração, tempo e temperatura. A reação eletrolítica ocorre durante este período, contribuindo para a remoção dos óleos e graxas na superfície da mesa do cilindro, provocando um ataque no metal-base do mesmo, sendo, decisivo para a performance da adesão do cromo. O tempo total gasto para estas 3 etapas de processo de limpeza varia em função do diâmetro do cilindro e do parâmetro de rugosidade, entre 15 a 30 minutos. (NEWBY, 1994)

Posterior a esta etapa de limpeza, inicia-se o processo de cromagem, em 3 etapas: homogeneização do cilindro em relação a temperatura do banho, limpeza anódica do cilindro imerso no banho e a cromagem do cilindro que ocorre através de uma reação catódica, com uma camada de cromo proporcional à aplicação do cilindro durante o processo de laminação. Em geral, a dureza do cromo dura varia entre 
850 e $1100 \mathrm{kgf} / \mathrm{cm}^{2}$. A TABELA 3-1 detalha valores para o cromo duro de alguns estudos da literatura. Usualmente na indústria de laminação é utilizado um banho livre de fluoretos obtendo dureza entre 1100 e $1200 \mathrm{Kgf} / \mathrm{mm}^{2}$.

Tabela 3- 1. Resultados de dureza do cromo duro encontrados na literatura

\begin{tabular}{l|c}
\hline \multicolumn{1}{c|}{ Tipo de Solução } & Microdureza $\left(\mathrm{Kgf} / \mathrm{mm}^{2}\right)$ \\
\hline Solução convencional & $600-1100$ \\
\hline Solução convencional & $840-995$ \\
\hline Solução convencional & $800-1200$ \\
\hline Livre de fluoretos & $1093-1150$ \\
\hline
\end{tabular}

Fonte: (NEWBY, 1994).

Apesar de ser amplamente utilizado pela indústria siderúrgica e segmentos similares, o processo de obtenção de cromo duro utiliza, como fonte do mineral, o cromo hexavalente. Os compostos do cromo hexavalente penetram através das membranas biológicas e são reduzidos a cromo trivalente podendo causar danos à estrutura celular do ser humano. Estes compostos são irritantes e corrosivos, e as partes mais atingidas são a pele e o sistema respiratório, podendo causar ulcerações e até perfuração no septo nasal. A intoxicação torna-se séria quando há adsorção pelo trato intestinal (SILVA et al., 2008). Desta forma, as principais unidades de cromagem de cilindros de laminação a frio do Brasil são constituídas de unidades de tratamentos ambientais, possuindo lavadores de gases oriundos do banho de cromo, com monitoramento periódico das emissões de gases da chaminé, controle de saúde ocupacional dos operadores de produção, tratamento dos resíduos, conforme FIGURA 3-8.

Figura 3- 9. Lavador de gases da cromagem de cilindros na planta CRC Mauá. 


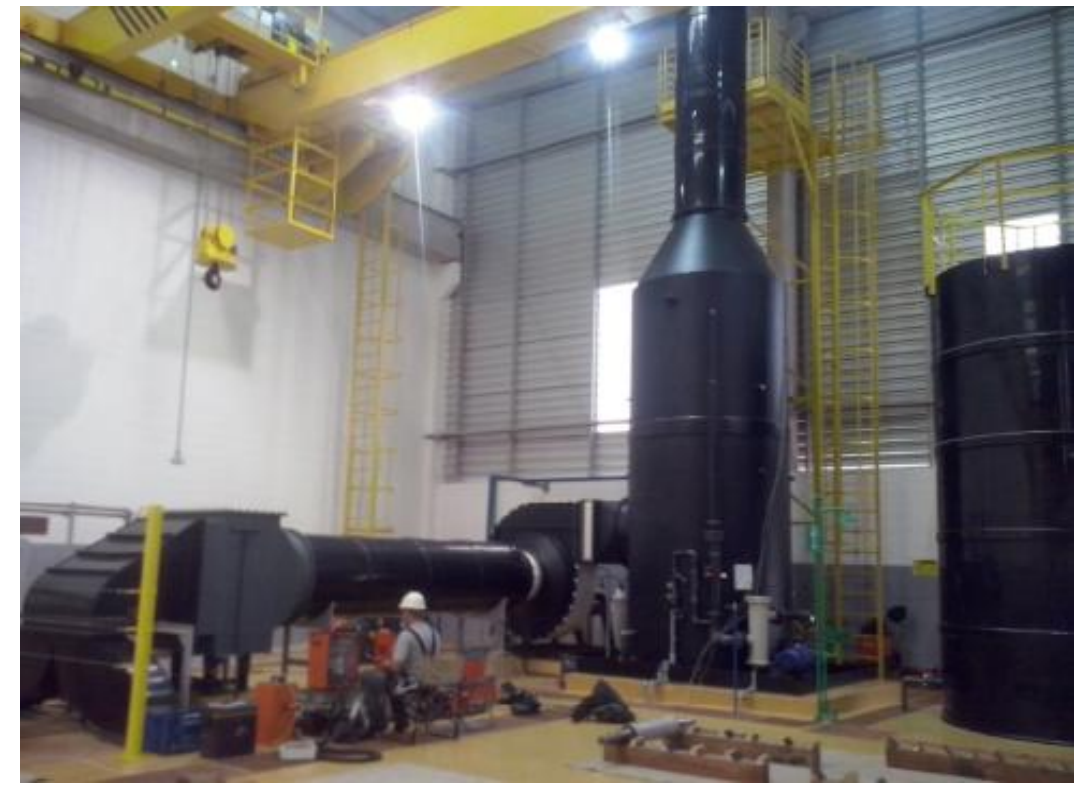

Fonte: (Autor - cortesia da empresa: CRC dos Sul Mauá).

Além de elevar a dureza a superfície do cilindro, o revestimento de cromo duro proporciona uma estabilização dos parâmetros topográficos obtidos na texturização. Em alguns casos, onde os parâmetros de rugosidade são obtidos através de algum método de texturização, pode haver um inexpressivo aumento de rugosidade aparente. (CHIU et al., 2002; BOLELLI et al., 2006; EL-AMOUSH et al., 2011; DE MELLO, GONÇALVES JR e COSTA, 2013)

Para efeito comparativo, os autores (SIMÃO e ASPINWALL, 1999) produziram 11 diferentes padrões de textura superficial com a técnica de texturização por descargas elétricas e posteriormente revestimento com cromo duro. Nomearam as diferentes texturas de "A" a "K" e, realizaram medições dos parâmetros de topografia Ra e Pc após a texturização e após o revestimento de cromo. $O$ parâmetro Pc é definido pela (ISO 4287, 1997) e representa o número médio de picos pelo comprimento de amostragem. Os dados para os parâmetros de rugosidade $\mathrm{Ra}$ e $\mathrm{Pc}$ com e sem revestimento com cromo são mostrados na FIGURA 3-10 (a) e (b) respectivamente. 
Figura 3- 10. Variação dos parâmetros de rugosidade (a) Ra e (b) Pc em função do tipo de texturização. $\diamond$ Com revestimento de cromo. Sem revestimento de cromo.

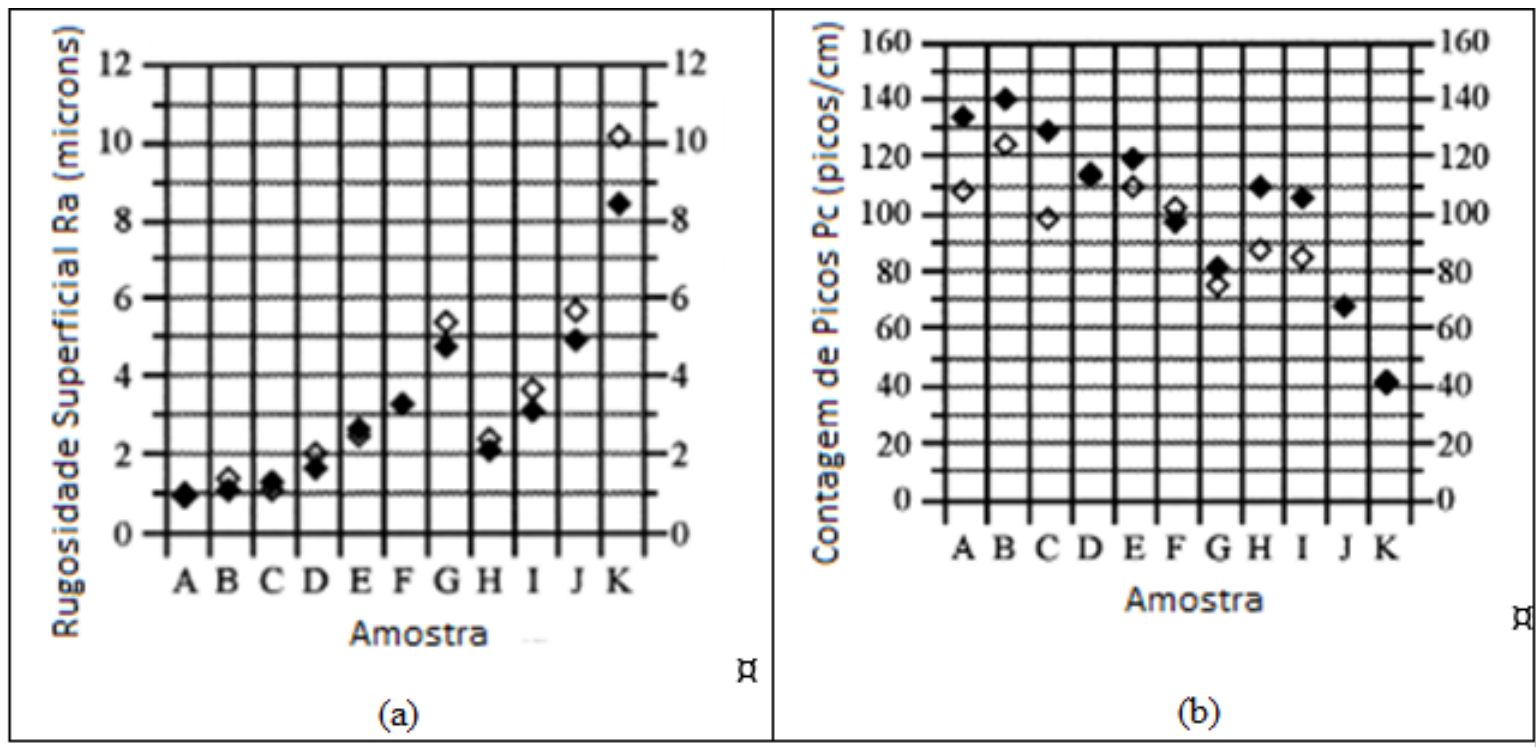

Fonte: (SIMÃO; ASPINWALL, 1999).

Os resultados mostraram que a maioria das amostras com revestimentos de cromo duro apresentavam valores um pouco maiores de rugosidade média da superfície, além de uma contagem de picos ligeiramente menor. A provável razão para esse fato deve-se ao detalhe de alguns picos e vales menores serem recobertos e "ocultados" pelo revestimento de cromo. Com as superfícies mais grosseiras, os picos e vales são maiores e mais amplos, o suficiente para acomodar a fina camada de cromo, variando de 3 a $8 \mu \mathrm{m}$, conseguindo assim manter aproximadamente os mesmos valores de $\mathrm{Pc}$, enquanto ocorre um pequeno aumento da rugosidade superficial $\mathrm{Ra}$.

Alguns trabalhos mostram que a adição do revestimento de cromo duro em amostras de aço ferramenta AISI H13 não altera o coeficiente de atrito. Por exemplo, a FIGURA 3-11 compara os coeficientes de atrito de amostras revestidas e não revestidas utilizando ensaios tipo bloco sobre cilindro. Porém, as amostras revestidas com cromo duro sofreram uma flutuação do coeficiente de atrito, que foi apontada como início do ponto de colapso do revestimento, que com sua ruptura produz debris na área de contato. Além disso, o estudo mostra que o aumento da 
pressão de contato de 3,3 MPa para $11 \mathrm{MPa}$ reduziu o coeficiente de atrito tanto para amostras revestidas com cromo duro quanto para amostras sem revestimento. Para pressões de contato de 3,3 a 7,2 MPa a taxa de desgaste para amostras revestidas foi de aproximadamente $0,28 \mathrm{mg} / \mathrm{MPa}$, enquanto que para amostras sem revestimentos a taxa de desgaste foi de aproximadamente $6,15 \mathrm{mg} / \mathrm{MPa}$ (CHIU et al., 2002).

Figura 3- 11. Ensaios tipo bloco-sobre-anel comparando cilindros revestidos e não revestidos: (a) Tribômetro; (b e c) coeficiente de atrito em função do número de rotações para pressões de contato de 3,3 MPa e $11 \mathrm{MPa}$; (d) taxa de desgaste.

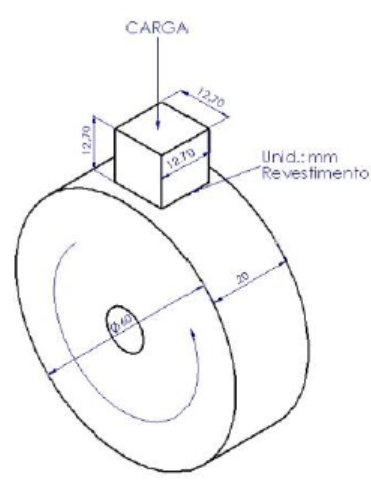

(a)

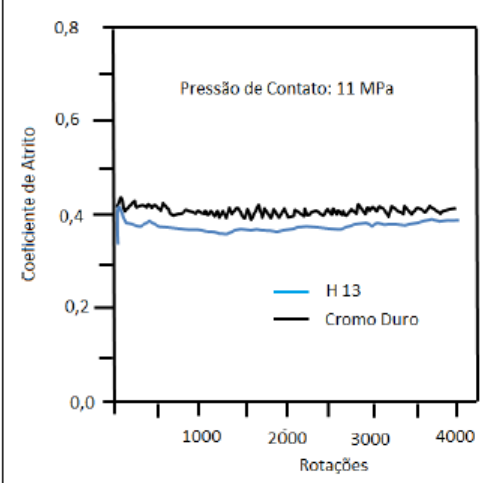

(c)

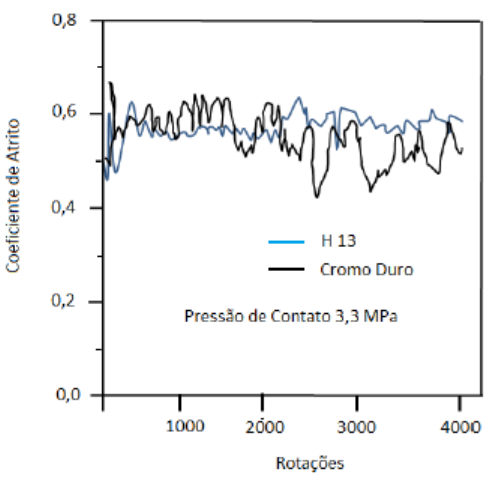

(b)

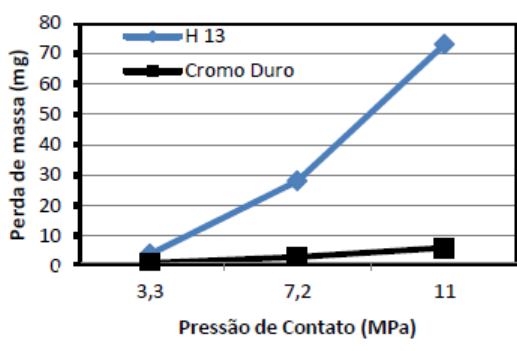

(d)

Fonte: (CHIU et al., 2002). 


\subsubsection{Performance do revestimento de cromo}

(EL-AMOUSH et al., 2011) utilizaram um Tribômetro pino-sobre-disco para avaliar o comportamento tribológico de revestimentos de cromo duro. Utilizou-se velocidade de deslizamento de $11 \mathrm{~cm} / \mathrm{s}$, carga de normal de $5 \mathrm{~N}$, esferas de aço 1010 de 6 $\mathrm{mm}$ de diâmetro como contra-corpos, diâmetro da pista de deslizamento de $5 \mathrm{~mm}$ e distância de deslizamento de 40, 80, 120 e 160 m. O revestimento de cromo duro reduziu o coeficiente de atrito em aproximadamente 9 vezes. Apesar de relatarem a redução do coeficiente de atrito, os autores não explicaram o motivo desta redução, apenas afirmaram que o revestimento age como lubrificante. Foram realizados testes para espessuras do revestimento de cromo de 0, 8, 13 e $18 \mu \mathrm{m}$. É possível observar na FIGURA 3-12, que entre cada espessura do revestimento 0 comportamento do coeficiente de atrito foi adotado como linear pelos autores, o que pode levar a uma ligeira confusão na interpretação dos resultados.

Figura 3- 12. Variação do coeficiente de atrito em função da espessura do revestimento de cromo duro.

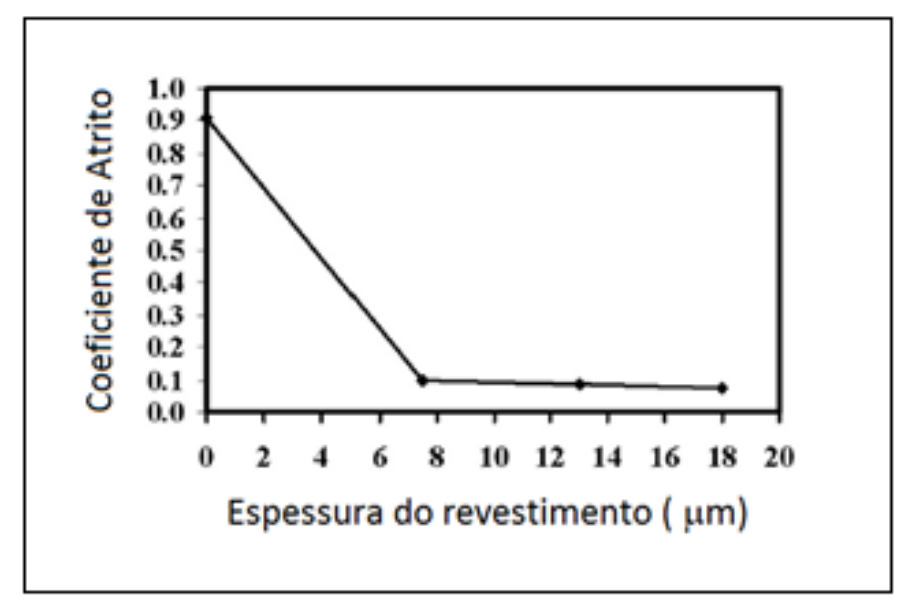

Fonte: (EL-AMOUSH et al., 2011).

Amostras de aço VC-9 foram ensaiadas (utilizado pela indústria de laminação) em um tribômetro (DE MELLO; GONÇALVES JR e COSTA, 2013), configurado para 
ensaios de deslizamento alternado com frequência de $2 \mathrm{~Hz}$, pista de deslizamento de 10 mm, utilizando como contra-corpo esferas de aço AISI 52100 e carga normal de $1 \mathrm{~N}$ por $1 \mathrm{~h}$. Os ensaios foram conduzidos em amostras sem modificação superficial (SM), com revestimento de cromo duro (C), texturizadas por jateamento de granalha de aço $(\mathrm{T})$ e texturizadas com posterior revestimento de cromo duro (TC). A vantagem do ensaio de deslizamento alternado utilizado é promover a inversão do sentido da força, assim como ocorre na operação de laminação. Para o sistema tribológico utilizado, não houve alteração significativa do coeficiente de atrito em função das diferentes modificações superficiais FIGURA 3-13, de acordo com o também observado por (CHIU et al., 2002)

Figura 3- 13. Variação do coeficiente de atrito em função de diferentes modificações superficiais: sem modificação superficial (SM), com revestimento de cromo duro $(\mathrm{C})$, texturizadas por jateamento de granalha de aço $(\mathrm{T})$ e texturizadas com posterior revestimento de cromo duro.

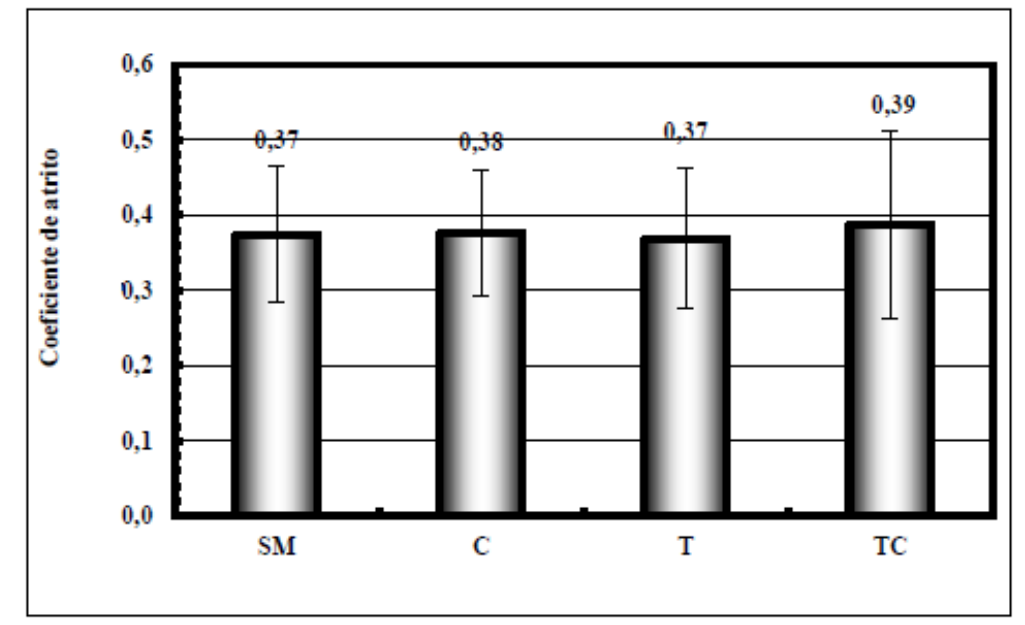

Fonte: (DE MELLO; GONÇALVES JR; COSTA, 2013).

Apesar de não provocar diferenças significativas no coeficiente de atrito, o revestimento de cromo duro promoveu uma redução significativa no desgaste do contra-corpo de AISI 52100, conforme pode ser observado qualitativamente na FIGURA 3-14 e quantitativamente na FIGURA 3-15. 
Figura 3- 14. Desgaste do contra-corpo para diferentes modificações superficiais (a) sem modificação superficial (b) revestida com cromo duro (c) texturizada (d) Texturizada com posterior revestimento de cromo duro.

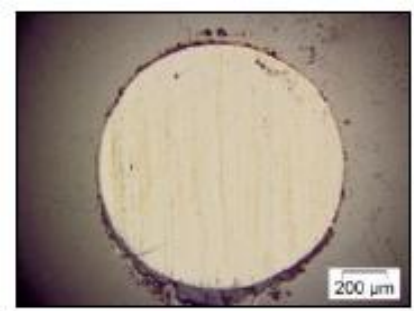

(a)

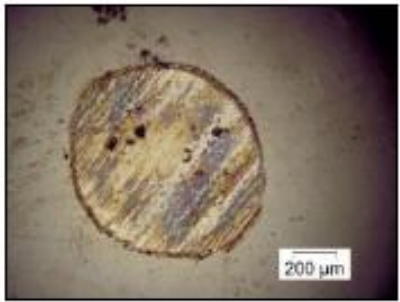

(b)

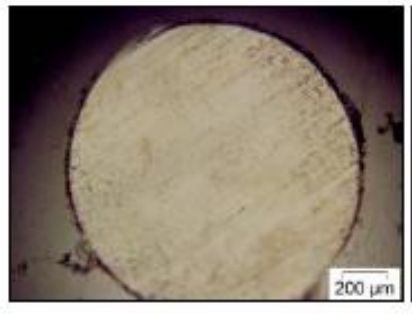

(c)

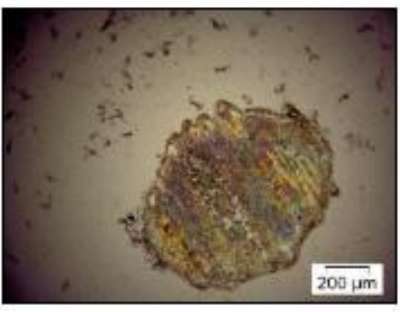

(d)

Fonte: (DE MELLO; GONÇALVES JR; COSTA, 2013).

Figura 3- 15. Taxa de desgaste em função das diferentes modificações superficiais (SM) sem modificação superficial (C) revestida com cromo duro (T) texturizada (TC) Texturizada com posterior revestimento de cromo duro.

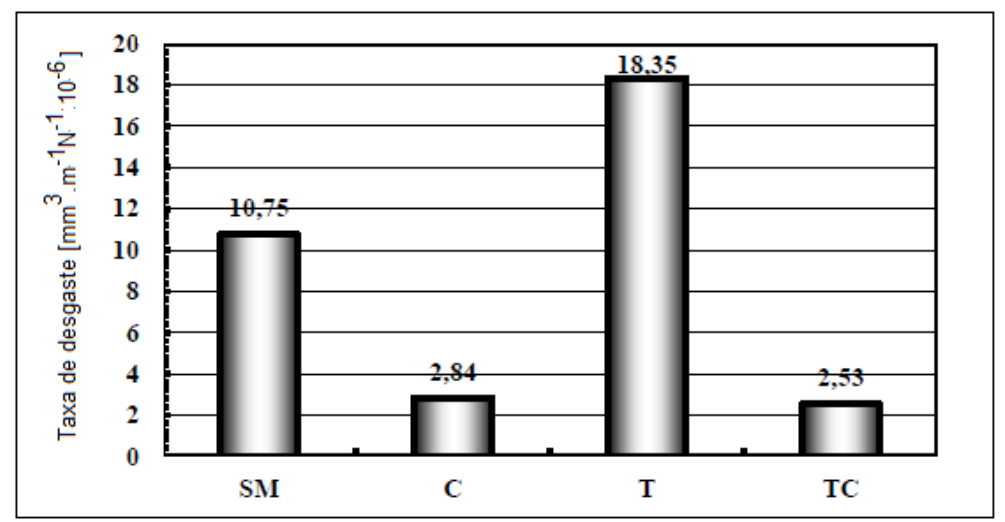

Fonte: (DE MELLO; GONÇALVES JR; COSTA, 2013).

A adição do revestimento promoveu a formação de uma tribocamada no contracorpo constituída de cromo e oxigênio, enquanto em corpos sem o revestimento de 90 
cromo duro ocorreu a formação de uma tribocamada constituída de ferro e oxigênio nas amostras, reduzindo o desgaste do contra-corpo, conforme FIGURA 3-16 (DE MELLO; GONÇALVES JR; COSTA, 2013). Além de proteger o contra-corpo, a deposição de cromo duro mostrou-se eficaz para reduzir a taxa de desgaste do corpo.

Figura 3- 16. Comparação dos valores de Ra do revestimento e do substrato em função da espessura do revestimento.

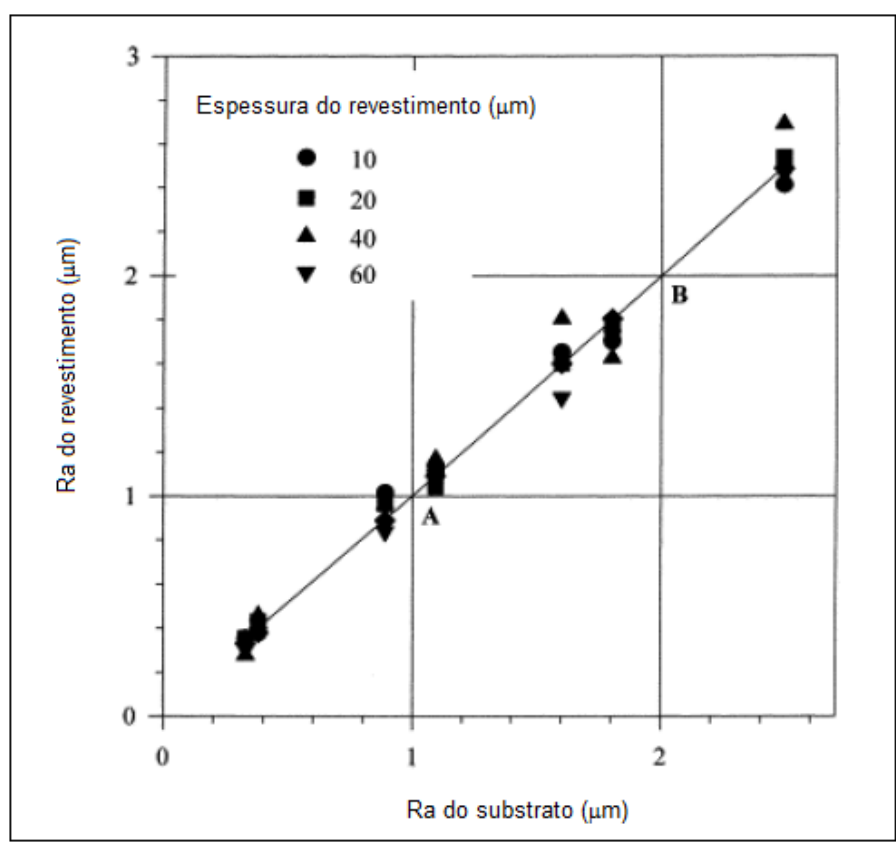

Fonte: (TAHERI; OGUOCHA; YANNA COPOULOS, 2001).

O efeito anterior é mais evidente na microscopia ótica mostrada na FIGURA 3-17, que mostra que o revestimento acompanha a ondulação da superfície (TAHERI; OGUOCHA; YANNA COPOULOS, 2001). 
Figura 3- 17. Microscopia ótica da seção transversal de amostra revestida com NiP e $\mathrm{Ra}=2,46 \mu \mathrm{m}$.

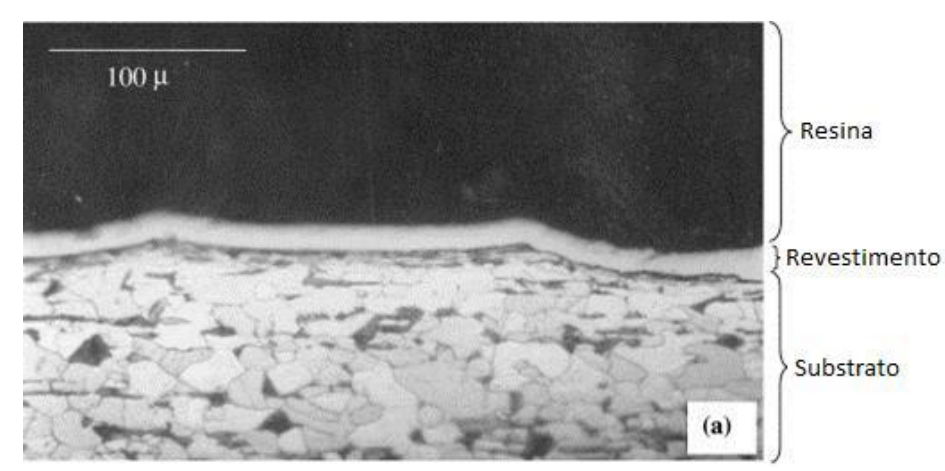

Fonte: (TAHERI; OGUOCHA; YANNA COPOULOS, 2001).

Atrito e desgaste foram estudados utilizando um tribômetro com a configuração de cilindro de contato transversal FIGURA 3-18. Como contra-corpo utilizou-se aço AISI 52100 (750 HV, localizado na posição 5 da Figura), o substrato utilizado para o revestimento foi de aço AISI M2 temperado e revenido $(880 \mathrm{HV})$, diâmetro de 60 $\mathrm{mm}, 159 \mathrm{rpm}$, velocidade de deslizamento de $0,5 \mathrm{~m} / \mathrm{s}$, carga normal de 2 a $35 \mathrm{~N} \mathrm{e}$ duração de teste de 4 min a $30 \mathrm{~h}$ correspondendo a uma distância de deslizamento de 120 a $54.000 \mathrm{~m}$. No trabalho foi avaliado o comportamento tribológico de amostras com o revestimento de $\mathrm{NiP}\left(577 \mathrm{Kgf} / \mathrm{mm}^{2}\right)$, amostras com o revestimento com posterior tratamento térmico $\left(974 \mathrm{Kgf} / \mathrm{mm}^{2}\right)(\mathrm{NiP} \mathrm{HT})$ e amostras apenas sem revestimento (RAMALHO; MIRANDA, 2005).

Figura 3- 18. Tribômetro com a configuração de cilindro de contato transversal.

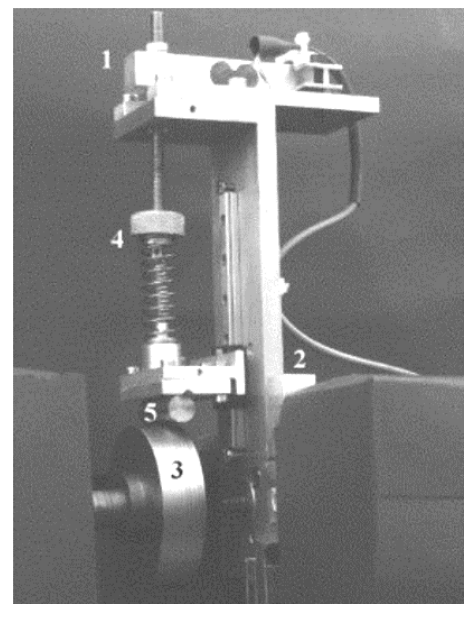

Fonte: (RAMALHO; MIRANDA, 2005). 


\section{Capítulo 4 - Mineração de dados}

\subsection{Introdução}

Nas últimas duas décadas, a humanidade tem se deparado com um problema que aumenta exponencialmente em complexidade: a mineração de dados (data mining). Este termo envolve a atividade de aplicar técnicas específicas sobre conjuntos de dados, com o objetivo de revelar padrões, similaridades e diferenças, de produzir regras e resumos, a partir destes dados (FAYYAD et al., 1996). É notório que a capacidade de geração, obtenção e armazenamento de dados já ultrapassou, em muito, a capacidade humana de analisar e obter informação relevante destes mesmos dados, os quais tendem a ser acondicionados em bases de dados através de ferramentas cada vez mais sofisticadas e eficientes. Além disso, o advento da Internet, aliada a seu crescimento vertiginoso, tem massificado o acesso à informação e colocado um volume imenso de dados disponível a praticamente qualquer pessoa em qualquer ponto da Terra.

Da associação entre estes dois fatores emerge um cenário desafiador, voltado para a descoberta de novos conhecimentos e para a recuperação de informações relevantes. O volume crescente de dados gerados e disponibilizados por governos, empresas, universidades e pessoas físicas, traz uma dificuldade crescente para responder a perguntas como:

- "O que se pode extrair de informação a partir destes dados?"

- "Quais os agrupamentos (clusters) existentes nestes dados?"

- "O que torna estes agrupamentos semelhantes (ou distintos) entre si?"

Considere, também, os casos em que as informações são disponibilizadas em forma textual, como é o caso de grande parte do material existente na Internet. Atualmente, seria extremamente difícil, senão impossível, catalogar esta informação por meios manuais, e ferramentas tradicionais de recuperação de informação, que tentam recuperar textos cujos conteúdos estejam associados a um determinado assunto, frequentemente produzem resultados insatisfatórios. É 
comum, num processo de recuperação de informação, serem obtidas imensas quantidades de obras de valor desconhecido e questionável (LAGUS, 2000). Atender a este novo problema significa responder a mais uma questão, consideravelmente mais difícil:

- "Quais são as outras informações disponíveis e úteis relacionadas a este assunto?"

A resposta a esta última questão tem sido abordada por um novo termo na literatura, a mineração de textos (text mining) (LAGUS, 2000). A mineração de textos envolve a aplicação de técnicas e ferramentas, notadamente com uso de redes neurais, nos problemas de organização, classificação e agrupamento de dados em forma textual.

Neste cenário já complexo, considere ainda a possibilidade de haver dados incorretos, inverídicos e contraditórios nos conjuntos, o que amplia ainda mais o elenco de dificuldades e desafios a serem superados.

Aparentemente, a capacidade do cérebro humano em simplificar, generalizar, formular hipóteses e testá-las, sem um tutor para indicar o caminho correto a seguir, parece ter sido a força motriz das realizações humanas desde sua existência. Tem sido notável como o ser humano lidou com tais dificuldades até o momento. Infelizmente, esta capacidade parece estar cada vez mais aquém das necessidades para lidar com volumes tão grandes de dados. Faz-se necessário, cada vez mais, a utilização de ferramentas e métodos capazes de operar sobre dados multidimensionais, capazes de comparar e classificar conjuntos de dados tão volumosos que inviabilizariam a simples leitura destes, capazes de simplificar e evidenciar aspectos relevantes de conjuntos de dados que, de outra forma, estariam ocultos sob o grande volume de dados. Faz-se necessária a pesquisa e a descoberta de formas mais eficientes de responder às perguntas, sejam elas dirigidas pela disponibilidade de dados, sejam elas orientadas a um contexto ou assunto em particular.

O interesse crescente da comunidade científica em torno de métodos automáticos para análise de dados ou, no mínimo, auxiliados por computador, tem gerado diversos textos cujo objetivo central é a discussão de métodos capazes de obter 94 
informações relevantes do imenso volume de dados disponíveis, como por exemplo (FAYYAD et al., 1996; MICHALSKI et al., 1998), referências importantes para uma introdução à mineração de dados.

A utilização de estratégias baseadas em modelos comportamentais do cérebro ou fundamentadas na teoria de probabilidades parece ser um caminho bastante promissor e direcionou este trabalho para o estudo do modelo, o Mapa AutoOrganizável de Kohonen (SOM: Self-Organizing Maps) na tentativa de responder, pelo menos em parte, às quatro perguntas formuladas anteriormente.

A escolha desta ferramenta SOM baseou-se num conjunto de características apresentadas, dentre as quais destacam-se:

- Capacidade de operar com conjuntos volumosos de dados;

- Capacidade de operar com dados representados por um grande número de características (alta dimensionalidade);

- Utilização de aprendizado não supervisionado;

- Capacidade de realizar projeção de dados, reduzindo assim a dimensionalidade do conjunto de dados;

- Capacidade de realizar redução de dados, diminuindo a quantidade de dados exibidos pela ferramenta;

- Possibilidade de avaliação gráfica dos resultados obtidos;

- Algoritmos relativamente simples e rápidos;

- Capacidade de generalização do modelo, de forma a possibilitar a representação de dados não disponíveis no momento do treinamento.

O modelo SOM é aplicado ao problema de recuperação de informação textual, que consiste, na codificação e recuperação de documentos considerando-se a similaridade dos conteúdos. 
A estratégia proposta envolve um modelo hierárquico, originalmente proposto por (HONKELA et al., 1996). Nesta estratégia, um mapa SOM, previamente adaptado e representando o contexto médio das palavras existentes no corpo de texto, gera um conjunto de vetores representando cada documento de texto. Estes vetores, uma espécie de "assinatura estatística" dos documentos, são usados para adaptar um segundo mapa SOM, que representa então a similaridade contextual dos documentos.

Retornando ao conjunto de atividades associado ao primeiro conceito de mineração de dados apresentado previamente, ele deve ser precedido por atividades essenciais que vão desde o próprio entendimento do domínio da aplicação e de seus objetivos até a interpretação dos resultados. As etapas anteriores ao processo de mineração, mais especificamente, a remoção de ruído, a escolha de variáveis relevantes, a manipulação de valores ausentes e a escolha do método de mineração adequado (considerando o objetivo proposto: classificação, regressão, modelagem etc.) devem receber atenção especial e jamais serem relegadas a papel menos importante, pois os métodos de mineração são fiéis ao raciocínio GIGO (Garbage In Garbage Out). Sem estes cuidados corre-se o risco de obter resultados pouco confiáveis, pois padrões e regras potencialmente inválidas ou sem interpretação adequada podem emergir. (FAYYAD et al., 1996).

Há diversos métodos aplicados na mineração de dados vindos de várias áreas do conhecimento e termos como "análise exploratória de dados" (JAIN \& DUBES, 1988; TUKEY, 1977), "análise de agrupamentos" (EVERITT, 1993) ou "classificação automática" (COSTA, 1999), "reconhecimento de padrões" (DUDA et al. 2000; BISHOP, 1995), "aprendizado de máquina" (MICHALSKI et al. 1998) e outros (FAYYAD et al., 1996) são frequentemente usados para referir-se a tais métodos. Nesta tese optou-se por uma taxonomia baseada na idéia de (KASKI, 1997; SVENSÉN, 1998) de que, na mineração de dados multidimensionais, só terão utilidade método capaz de revelar a estrutura inerente do conjunto de dados, pois em última instância é exatamente a relação de similaridade/dissimilaridade o que se busca entender. Pode-se dividir os métodos em conjuntos conforme a maneira de exibir a estrutura topológica dos dados: 
(a) Métodos simples de visualização: capazes de gerar gráficos e resumos rápidos do comportamento dos dados e úteis para análise preliminar à mineração de dados.

(b) Métodos de agrupamento: Tem o objetivo de descobrir agrupamentos de dados com características semelhantes entre si.

(c) Métodos de projeção: baseados na idéia de projetar os dados de seu espaço original para um espaço de menor dimensão procurando revelar a estrutura topológica dos dados.

(d) Métodos baseados em modelos gerativos: onde os pontos no espaço de dados são entendidos como sendo gerados por um modelo que representa a função de distribuição de probabilidade dos dados.

\subsubsection{Métodos simples de visualização}

A maioria dos métodos simples para visualização de dados multidimensionais propostos na literatura baseiam-se em gráficos ou cálculos matemáticos que, de alguma forma, representam ou resumem características dos conjuntos de dados. Como exemplo, (TUKEY, 1977) propõe, dentre vários métodos gráficos e numéricos, o cálculo de um resumo de cinco números para conjuntos de dados: o maior e menor valores, a média e o $1^{\circ}$ e $3^{\circ}$ quartis. A ideia geral destes métodos simples consiste em plotar gráficos (em geral bidimensionais) com os atributos dos dados diretamente relacionados entre si, ou então algum resumo matemático destes, como médias, logaritmos, potências etc. Estes gráficos formariam uma espécie de "descrição sucinta" dos conjuntos de dados cuja análise preliminar possibilitaria um melhor entendimento dos dados e evitaria a aplicação negligente de técnicas de mineração de dados, o que muitas vezes leva a resultados sem sentido (FAYYAD et al. 1996; EVERITT, 1993).

Uma divisão simplista feita por (EVERITT, 1993), e aqui resumida, classifica estes métodos em:

- histogramas e gráficos, relacionando atributos ou resumos destes entre si; e 
- representações icônicas, onde normalmente associa-se um atributo do dado a um atributo de uma figura que o representará.

(JAIN \& DUBES, 1988) diferenciam as representações icônicas de métodos de projeção não lineares afirmando que enquanto estes tentam preservar a estrutura dos dados num gráfico com apenas duas coordenadas (dos atributos mais relevantes, normalmente), representações icônicas tentam preservar esta mesma estrutura através de uma figura controlada por todos os atributos. A grosso modo, entretanto, pode-se considerar as representações icônicas como uma espécie de projeção não linear dos dados.

Um método bastante simples é a visualização de todas as dimensões (ou daquelas selecionadas) como um gráfico de barras, onde cada barra representa uma dimensão, conforme ilustrado na FIGURA 4-1A. A FIGURA 4-1B representa o mesmo objeto $\mathbf{v}=[\mathrm{V} 1, \ldots, \mathrm{VD}]$ pela "curva de Andrews" (ANDREWS, 1972), obtida através do cálculo da função

$f(v, t)=\frac{1}{\sqrt{2}} v_{1}+v_{2} \operatorname{sen}(t)+v_{3} \cos (t)+v_{4} \operatorname{sen}(2 t)+v_{5} \cos (2 t)+\cdots$

Sobre o intervalo $-\pi<t<\pi$ e, $D=10$ no exemplo. Cada componente $v_{i}$ é um atributo do objeto. Uma propriedade interessante desta função é a preservação da relação de vizinhança topológica entre os objetos no sentido de que dois pontos próximos no espaço de entrada serão representados por curvas próximas para todos os valores de $t$ (EVERITT, 1993).

Figura 4-1. Visualização de um item de dado com valores aleatórios através de um gráfico de barras $(A)$ e da curva de Andrews $(B)$ 


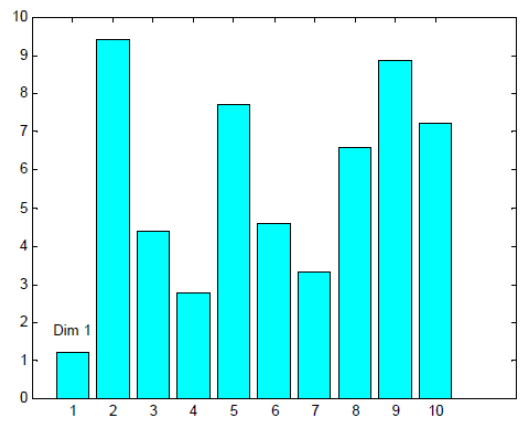

(A)

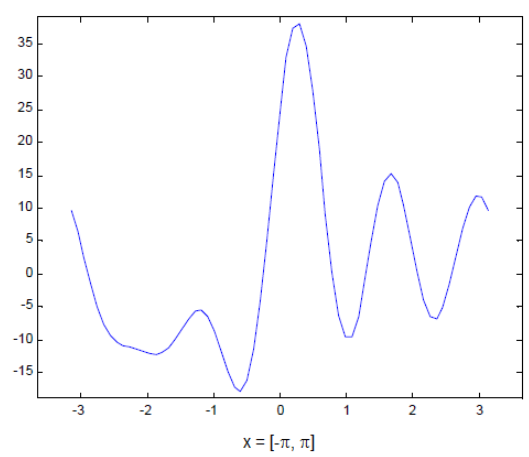

(B)

Fonte: (EVERITT, 1993).

Várias curvas de Andrews diferentes podem ser construídas com a simples permutação das variáveis. Como, em geral, as baixas frequências $\left(v_{1}, v_{2}, v_{3}\right)$ são mais evidenciadas no gráfico, seria interessante associá-las com os atributos mais importantes dos objetos sendo representados (EVERITT, 1993). Infelizmente, esta informação não é, em geral, previamente conhecida.

Outras possibilidades incluem a representação dos dados através de figuras poligonais e as "faces de Chernoff" (CHERNOFF, 1973), cujos exemplos podem ser vistos na FIGURA 4-2. Os ícones poligonais podem ser gerados com todas as dimensões, caso em que tem seu uso limitado dada a sobreposição de figuras ou ainda, pode-se escolher duas delas (as mais importantes) para posicionar o centro da figura num plano cartesiano, gerando um gráfico de dispersão ou scatterplot (EVERITT, 1993; KASKI, 1997).

Figura 4-2. Visualização de um item de dado com valores aleatórios usando polígonos 


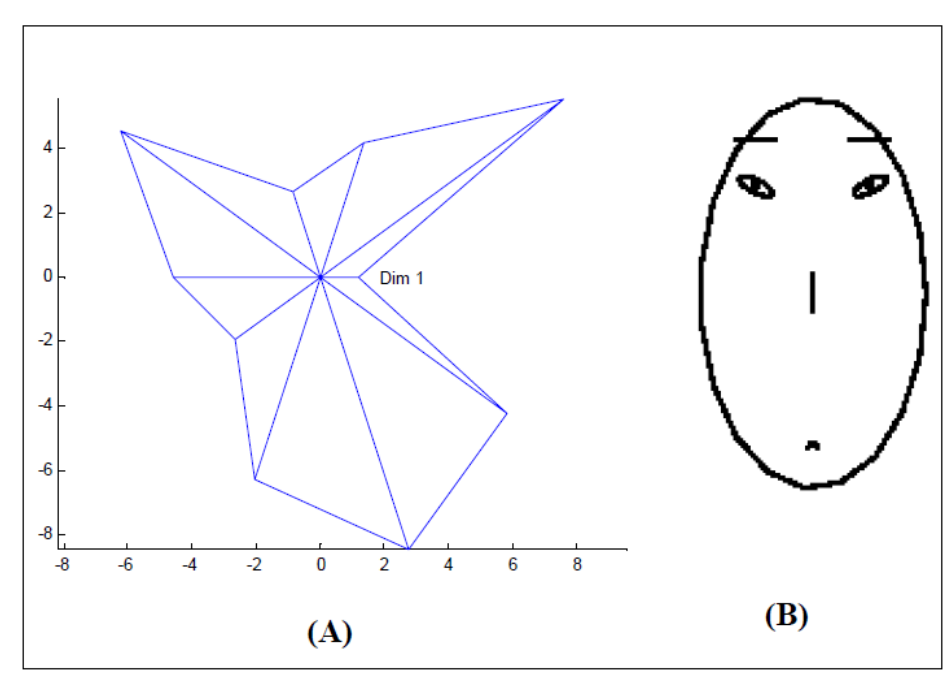

Fonte: (EVERITT, 1993; KASKI, 1997).

As faces de Chernoff são geradas com cada dimensão dos dados controlando uma característica da face, como a largura e curvatura da boca, a separação entre os olhos etc. $O$ autor argumenta que sua utilização se presta para avaliar dados em $\mathfrak{R}^{D}$ considerando $D \leq 18$.

Embora interessantes e com valor histórico, a capacidade de visualizar relações entre os dados através dos métodos citados degenera rapidamente à medida que aumenta o número de dimensões. À exceção do resumo de cinco números, nenhum dos outros métodos executa redução de dados, ou seja, se o conjunto de entrada for numeroso, a figura resultante da visualização de todos os dados individuais será provavelmente incompreensível (KASKI, 1997). Embora seja possível identificar a presença de agrupamentos em algumas situações, estes métodos devem ser tomados apenas como ferramentas adicionais capazes de auxiliar na tarefa de mineração de dados (EVERITT, 1993; JAIN \& DUBES, 1988).

\subsubsection{Métodos de Agrupamento}

A tarefa de reunir objetos semelhantes em grupos é um processo usualmente adotado pelo ser humano ao longo da história da humanidade, podendo inclusive ser associado à própria criação da linguagem. As palavras podem ser interpretadas 
como rótulos associados a conjuntos de objetos semelhantes. Tomando apenas adjetivos como exemplo, as palavras "feroz", "saboroso", "venenoso", etc., são rótulos que determinam a própria capacidade de adaptação ao meio, ao permitir classificar e discriminar agentes e objetos do meio.

Considera-se agrupamento uma região do $D$-espaço (espaço $D$-dimensional que congrega os $D$ atributos) com densidade de pontos relativamente elevada $\mathrm{e}$ separada de outras regiões densas por regiões com baixa densidade (EVERITT, 1993). Pode-se entender, resumidamente, que métodos de agrupamento são aqueles que buscam dividir um conjunto de objetos não rotulados em grupos (partições) de forma que os objetos de cada grupo tenham mais semelhanças entre si do que em relação aos objetos de qualquer outro grupo. Neste processo necessariamente não supervisionado, segundo (COSTA, 1999), tanto o número ótimo de grupos como as características particulares revelando semelhanças (ou diferenças) devem ser determinados pelo próprio processo (EVERITT, 1993).

Esta característica aponta para métodos não triviais, uma vez que a quantidade de formas possíveis de criar $K$ partições para um grupo de $N$ objetos pode ser assustadoramente grande, tornando a busca exaustiva por um particionamento ótimo computacionalmente proibitiva, ao menos atualmente. $\mathrm{O}$ valor exato para este número de formas possíveis quando $K$ é conhecido é dado pelo número de Stirling do segundo tipo (JAIN \& DUBES, 1988):

$S(N, K)=\frac{1}{K !} \sum_{i=1}^{k}(-1)^{k-i}\left(\begin{array}{c}k \\ i\end{array}\right) i^{N}$

Sendo,

$\mathbf{N}$ objetos

K partições

K! Fatorial

Caso $K$ seja desconhecido (o que é normalmente o caso), este número de possibilidades é ainda maior, pois é dado por um somatório de números de Stirling (COSTA, 1999): 


$$
\sum_{i=1}^{P} S(N, l)
$$

Onde $P$ é o número máximo de partições, previamente arbitrado. Este somatório é também conhecido como número de Bell.

Deve ser claro que o conceito de similaridade entre os pontos no $D$-espaço está diretamente relacionado ao tipo de métrica considerada. A escolha da métrica afeta diretamente a quantidade e a forma de grupos encontrados pelos algoritmos de agrupamento, pois aspectos da estrutura do espaço podem ser levados em consideração durante o processo conforme a métrica (COSTA, 1999; JAIN et al., 1999). É patente, pois, a dificuldade na escolha da métrica quando não se tem informação prévia sobre o conjunto de dados a ser analisado. O risco é o de que o algoritmo "encontre grupos segundo sua ótica", ou seja, pode-se procurar (e encontrar) grupos com formas previamente supostas onde estes, de fato, não existam ou, então, deixar de encontrar agrupamentos cuja discriminação fica obscurecida pela métrica adotada.

A FIGURA 4-3 ilustra um caso em que algoritmos baseados em distância (como é o caso do SOM, que utiliza distância euclidiana) têm péssimo desempenho, pois é um exemplo onde um intérprete humano utiliza-se de muito mais informação prévia do que aquela disponibilizada ao algoritmo, no caso, apenas a distância entre pontos. A este método de agrupamento (MICHALSKI \& KAUFMAN, 1998) denominam métodos de agrupamento conceitual: é fácil observar retângulos no exemplo da figura porque o ser humano conhece previamente o conceito de um retângulo, sendo direta, portanto, a associação. Um conceito é definido como sendo um conjunto de objetos que possuem um conjunto de propriedades que os diferenciam de outros conceitos, o que vem a ser uma descrição muito semelhante, senão idêntica, ao próprio conceito de agrupamento). 
Figura 4-3. Conjunto de dados para o qual algoritmos baseados em métricas de distância apresentam desempenhos ruins. Possíveis análises revelam 2 retângulos e 4 linhas, uma figura humanoide, etc.

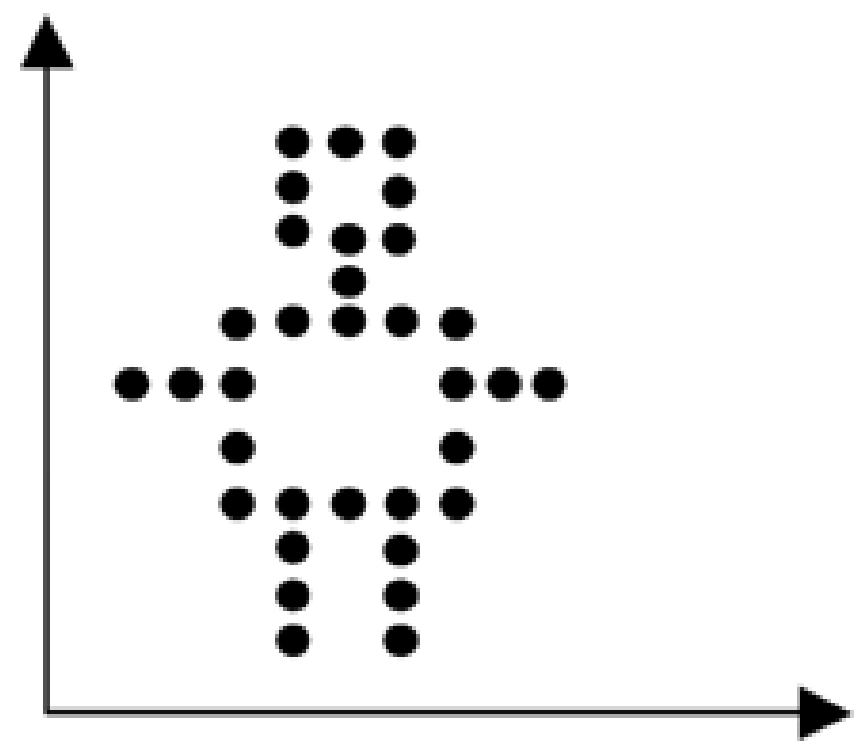

Fonte: (KUBAT et al., 1998).

Para que um algoritmo obtenha resultados semelhantes ele deverá basear-se num banco de conceitos previamente informado, ou então possuir algum método para adquirir (aprender) tais conceitos.

A FIGURA 4-4 apresenta uma hierarquia simplificada dos métodos de agrupamento propostos na literatura.

Figura 4-4. Classificação simplificada dos métodos de agrupamento. 


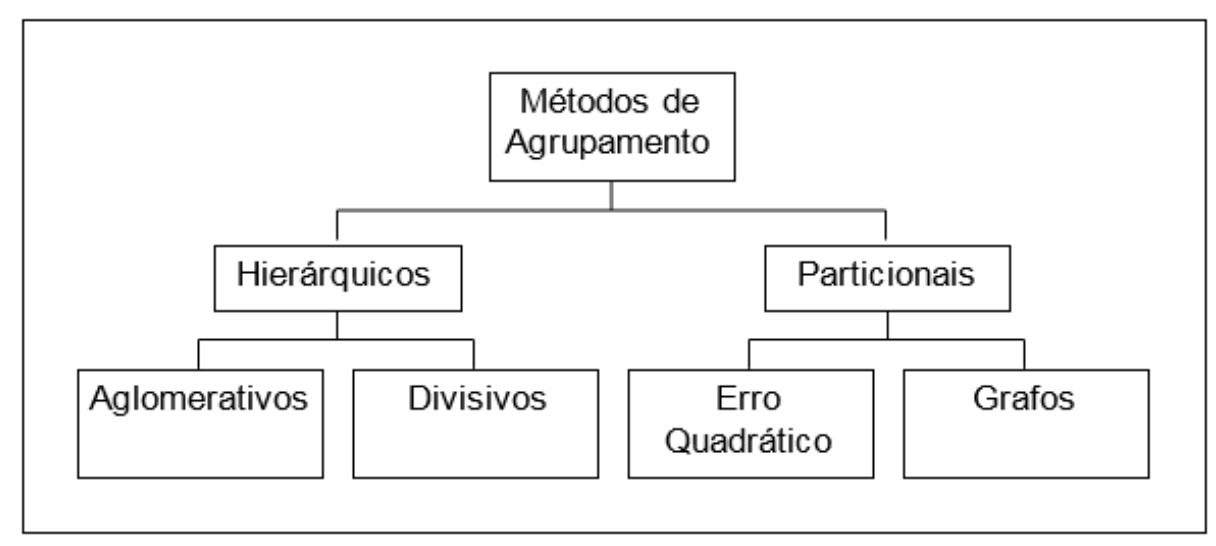

Fonte: (JAIN et al., 1999).

Entretanto, deve-se levar em consideração algumas características que independem da taxionomia proposta, qualquer que seja ela. Por exemplo, os métodos podem fazer com que um objeto pertença exclusivamente a um agrupamento, isto é, a intersecção de agrupamentos é vazia ou então, utilizar conceitos de lógica nebulosa para associar graus de pertinência dos objetos para com os conjuntos. Métodos podem considerar todos os atributos dos objetos simultaneamente durante o processo de agrupamento (métodos politéticos) ou então considerar cada atributo individual e sequencialmente (monotéticos). Também um método pode considerar todo o conjunto de objetos simultaneamente (métodos não incrementais) ou então tomar pequenas porções ao longo do processo (incrementais), sendo esta uma característica importante no processo de mineração de dados face aos imensos conjuntos de dados comumente observados.

\subsubsection{Agrupamentos Hierárquicos}

Os métodos hierárquicos, de modo geral, tratam o conjunto de dados como uma estrutura de partições, cada uma correspondendo a um agrupamento, hierarquicamente organizadas segundo a similaridade entre seus objetos. Os métodos divisivos consideram a princípio a existência de uma única partição (o próprio conjunto de dados) e atuam subdividindo esta partição em uma série de partições aninhadas. Já os métodos aglomerativos partem do oposto, fundindo 
agrupamentos individuais (inicialmente cada grupo contém um único objeto) em partições maiores até a obtenção de uma única partição contendo todos os objetos do conjunto.

Algoritmos hierárquicos aglomerativos (mais eficientes e representativos que os divisivos, segundo (COSTA, 1999) geralmente trabalham com uma matriz de distâncias $D$ representando a similaridade (ou a dissimilaridade) entre todos os possíveis pares de $\mathrm{N}$ objetos do conjunto de dados. Esta matriz $\mathrm{D}$ de elementos $\mathrm{dij}$ $(\mathrm{i}, \mathrm{j}=1, \ldots, \mathrm{N})$ é, portanto, simétrica de diagonal nula e ordem $\mathrm{N}$, sendo usada para decidir quais grupos serão fundidos entre si. Em geral, unem-se dois ou mais grupos que apresentam a menor "distância" entre si. A distância entre dois grupos é normalmente avaliada segundo os critérios de ligação simples ou ligação completa (complete link).

A ideia destes critérios é ilustrada na Figura 4-5, e é mais facilmente entendida supondo-se, inicialmente, dois agrupamentos quaisquer já existentes, A e B, e uma matriz $\mathrm{D}$ de distâncias entre todos os pares de objetos. $O$ critério de ligação simples define $d_{A B}$ como a menor distância entre todos os pares $(x, y)$ de objetos onde $x \in \mathrm{A}$ e $y \in \mathrm{B}$. Após calculadas as distâncias entre os agrupamentos conforme os critérios já descritos, os algoritmos promovem a união dos agrupamentos com a menor distância entre si.

Figura 4-5. llustração do critério de ligação simples e ligação completa. Supondose dois agrupamentos pré-existentes A e B, a ligação simples define a distância entre os dois grupos como a menor dentre todas as distâncias entre os pares de objetos $(x, y)$. 


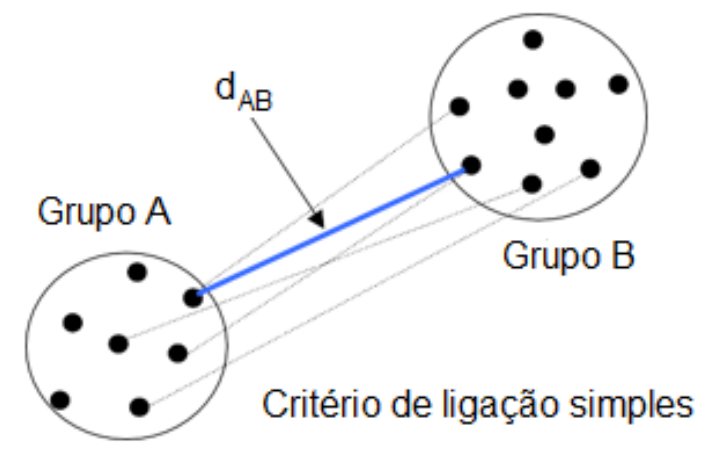

(A)

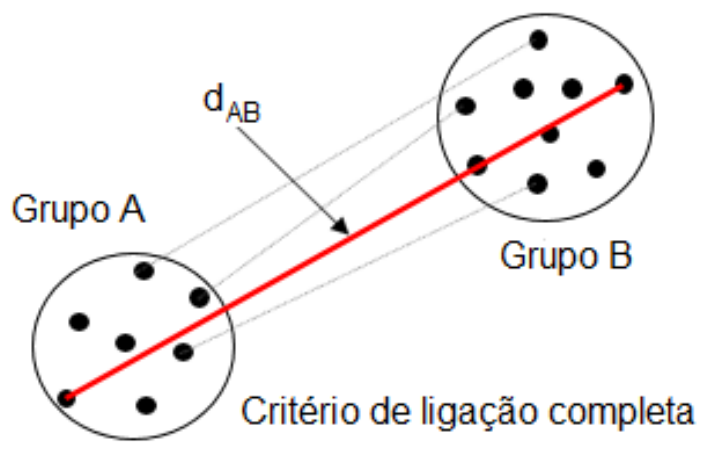

(B)

Fonte: (JAIN et al., 1999).

O critério de ligação completa define a distância entre os dois grupos como sendo a maior distância dentre todas as distâncias entre os mesmos pares de objetos $(x, y)$. A saída típica destes algoritmos é um dendrograma conforme FIGURA 4-6, uma espécie de grafo de árvore que representa as junções sucessivas das partições e que pode gerar agrupamentos diferentes conforme o nível em que é seccionada.

Figura 4-6. Dendrogramas obtidos segundo os critérios de ligação simples e completa. Em (A) um conjunto hipotético de objetos com sua matriz de distâncias $D$ descrita em (B), sem consideração de escala. Pelo critério de ligação simples (C), os grupos $\{4\}$ e $\{5\}$ são 


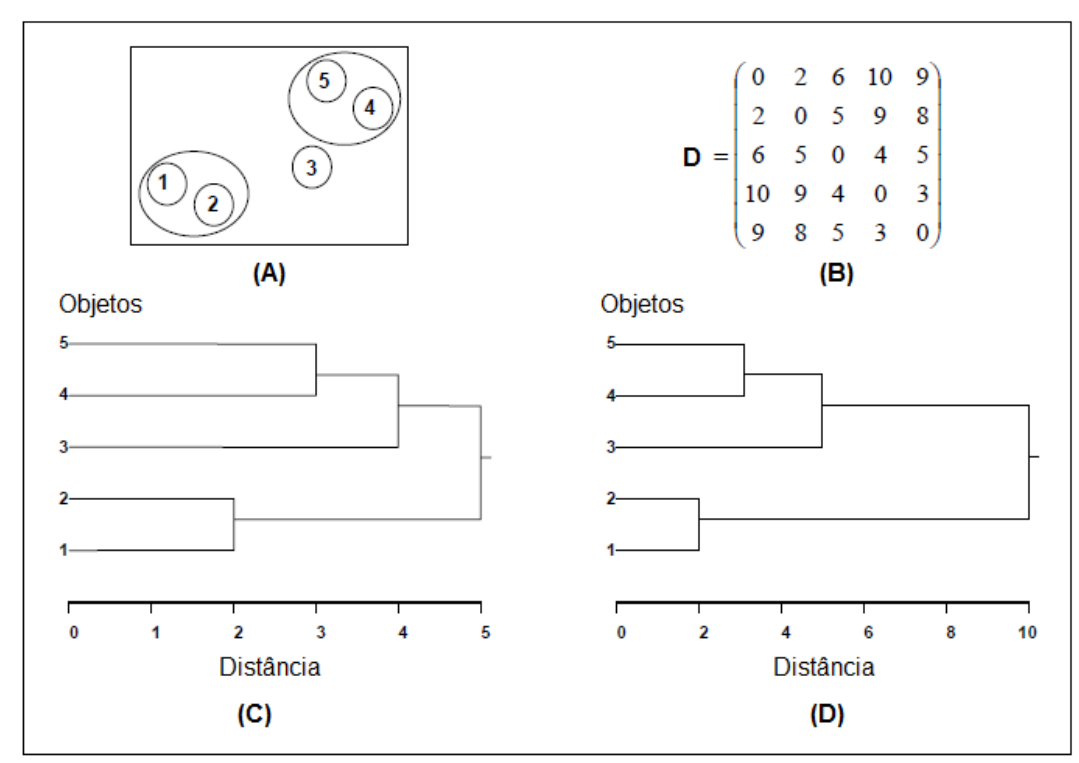

Fonte: (Everitt,1993).

De acordo com (JAIN et al., 1999), o critério de ligação simples possui a característica de produzir agrupamentos com tendência hiperelipsoidal, ao passo que o critério de ligação completa forma agrupamentos mais compactos com tendência hiperesférica. Técnicas hierárquicas são comuns onde se necessita gerar uma taxionomia facilmente obtida pelo dendrograma (por exemplo nas áreas de biologia e ciências sociais), mas são impraticáveis quando o número de objetos é elevado (JAIN \& DUBES, 1988), o que infelizmente é comum nos processos de mineração de dados.

\subsubsection{Agrupamentos Particionais}

Os métodos particionais ou não-hierárquicos, dividem o conjunto dos $N$ objetos em $K$ agrupamentos sem relacioná-los hierarquicamente entre si, como o fazem métodos hierárquicos. Normalmente, as partições são obtidas pela otimização de um critério definido local (sobre um subconjunto de objetos) ou globalmente (sobre todo o conjunto) na forma de uma função-objetivo. Sua maior vantagem é poder atuar sobre conjuntos com elevado número de objetos, pois tais métodos em geral têm complexidade $O(N), N$ = número de objetos do conjunto de dados. Por outro lado, possuem uma séria restrição relacionada às funções- objetivo usadas que, 
em geral, assumem que $K$ é conhecido. Assim, uma escolha errada de $K$ provoca a imposição deste número de agrupamentos ao conjunto.

Um dos métodos mais conhecidos, o k-means (MACQUEEN, 1967), emprega como função- objetivo o erro quadrático total definido genericamente para um certo número $K$ de agrupamentos por

$e_{k}^{2}=\sum_{j=1}^{K} \sum_{i=1}^{N}\left\|v_{i}^{(j)}-c_{j}\right\|^{2}$

Onde $v_{i}^{(j)}$ é o $i$-ésimo objeto pertencente ao j-ésimo agrupamento, o qual tem $\mathrm{cj}$ como seu centroide. Repare que cada objeto pertence ao agrupamento cujo centroide está mais próximo de si, sendo que nj é o número de objetos do j-ésimo agrupamento. O centroide do j-ésimo agrupamento vai ser o vetor médio dos $\mathrm{n}_{\mathrm{j}}$ objetos que pertencem ao j-ésimo agrupamento em um dado instante:

$c_{j}=v^{-(j)}=\frac{1}{n_{j}} \sum_{i=1}^{n_{j}} v_{i}^{(j)}$

O k-means recebe como entrada um número $K$ de agrupamentos e atribui aleatoriamente um objeto como sendo o centroide inicial de cada agrupamento. Sucessivamente, cada objeto é associado ao agrupamento mais próximo e o centroide de cada agrupamento é então recalculado levando-se em conta o novo conjunto de objetos a ele pertencentes.

Repare que, com isso, os centróides não mais se restringem a serem um subconjunto de objetos, pois podem estar localizados onde não há nenhum objeto. O algoritmo pára quando, tipicamente, há poucas trocas de objetos entre grupos ou quando um valor estipulado como erro mínimo é atingido. Opcionalmente, após uma estabilização, grupos podem ser fundidos ou então divididos segundo critérios estabelecidos, quando então o processo de associação dos objetos aos novos grupos reinicia. Além da escolha do número $K$ de centróides, um dos principais problemas do k-means é justamente a escolha inicial dos centróides, como mostra a FIGURA 4-7. Nesta figura representa-se um conjunto $\mathrm{V}=\{A, B, C, D, E, F, G\}$ de 108 
objetos num plano bidimensional e aplica-se o algoritmo $k$-means com $K=3$ agrupamentos. Se os centróides destes forem tomados inicialmente pelos padrões $\{A, B, C\}$, será obtido o resultado ilustrado à esquerda, bastante inconveniente se comparado ao erro total obtido na ilustração à direita, gerada tomando-se os padrões $\{A, D, F\}$ como centróides iniciais.

Figura 4-7. O k-means é sensível à posição inicial dos centróides: à esquerda vêse um agrupamento indevido se comparado ao obtido na figura à direita, o que pode ser verificado pelo erro total obtido.

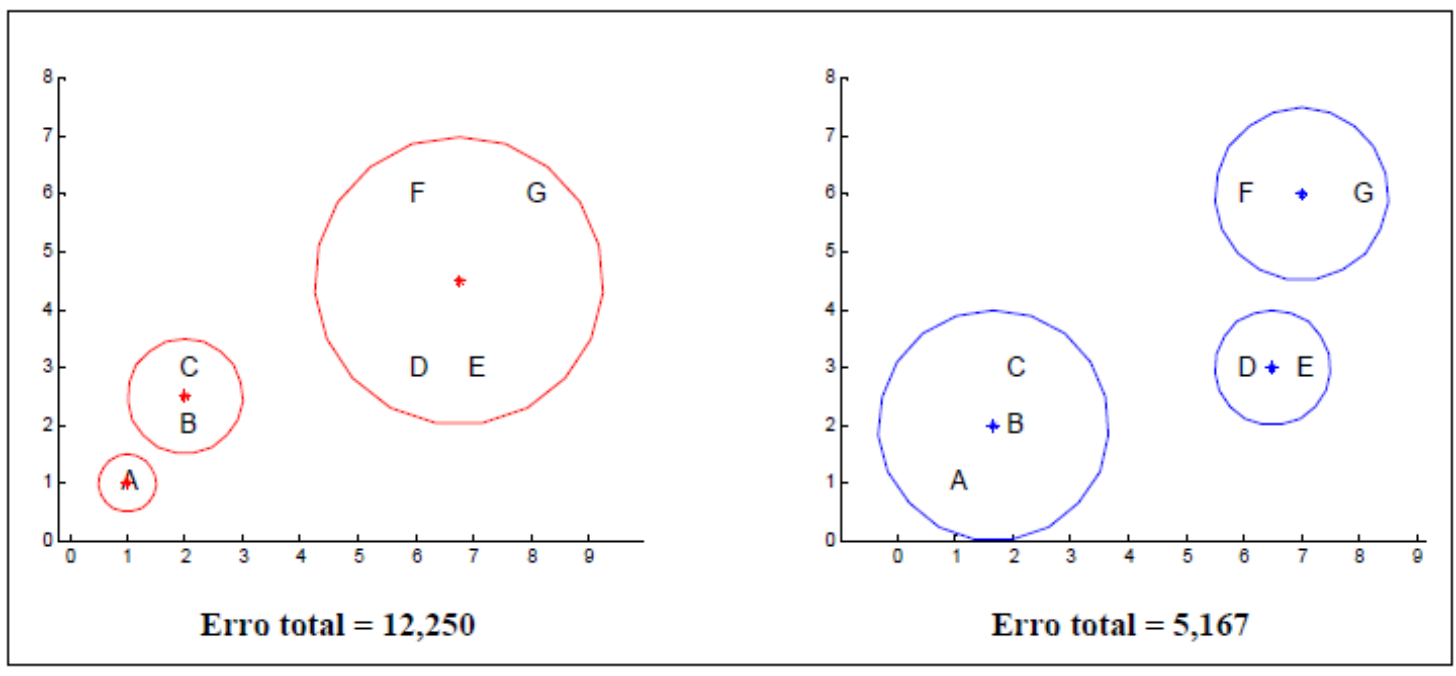

Fonte: (JAIN et al., 1999). 


\section{Capítulo 5 - Mapas Auto Organizáveis}

\subsection{Introdução}

O Mapa Auto Organizável de Kohonen (SOM) (KOHONEN, 1997) é um tipo de rede neural artificial baseada em aprendizado competitivo e não supervisionado, sendo capaz de mapear um conjunto de dados, de um espaço de entrada contido em $\mathfrak{R}^{D}$, em um conjunto finito de neurônios organizados em um arranjo normalmente unidimensional ou bidimensional. As relações de similaridade entre os neurônios (e, por extensão, entre os dados) podem ser observadas através das relações estabelecidas entre os vetores de pesos dos neurônios, os quais também estão contidos em $\Re^{D}$.

Ao realizar esta projeção não linear, o algoritmo tenta preservar ao máximo a topologia do espaço original, ou seja, procura fazer com que neurônios vizinhos no arranjo apresentem vetores de pesos que retratem as relações de vizinhança entre os dados. Para tanto, os neurônios competem para representar cada dado, e o neurônio vencedor tem seu vetor de pesos ajustados na direção do dado. Esta redução de dimensionalidade com preservação topológica, permite ampliar a capacidade de análise de agrupamentos dos dados pertencentes a espaços de elevada dimensão.

O SOM é certamente um dos principais modelos de redes neurais artificiais na atualidade e é utilizado numa diversidade de aplicações que dificilmente seriam contidas numa simples obra. Há milhares de publicações sobre o SOM introduzido por (KOHONEN, 1996) e sua referência mais completa talvez seja Kohonen (1997).

\subsection{Modelo Formal do SOM}

Conforme ilustrado na FIGURA 5-1, evidências biológicas têm mostrado que as células do córtex cerebral dos mamíferos organizam-se de forma altamente estruturada em suas funções, resultando em regiões do cérebro especificamente capacitadas no processamento sensorial de sinais como visão, audição, controle 110 
motor, linguagem, etc. (VAN HULLE, 2000; KOHONEN, 1997). Isso significa que os neurônios se tornam sensíveis a determinados estímulos em particular e a outros, não, especializando-se no "processamento" de um determinado sinal, o que pode ser explicado pela separação dos canais nervosos que ligam os órgãos sensoriais ao cérebro. Em particular, a ordem física dos sinais percebidos pelo tecido dos órgãos sensoriais é projetada no córtex cerebral primário em ordem semelhante, resultando num mapeamento que preserva a ordem topológica do sinal recebido, embora com algumas transformações (VAN HULLE, 2000).

Figura 5-1. Em (A) uma representação das várias regiões corticais especializadas no cérebro humano. Em (B) uma imagem projetada sobre a retina de um macaco (esquerda) é mapeada sobre seu córtex cerebral primário, o qual mantém as relações topológicas da imagem.

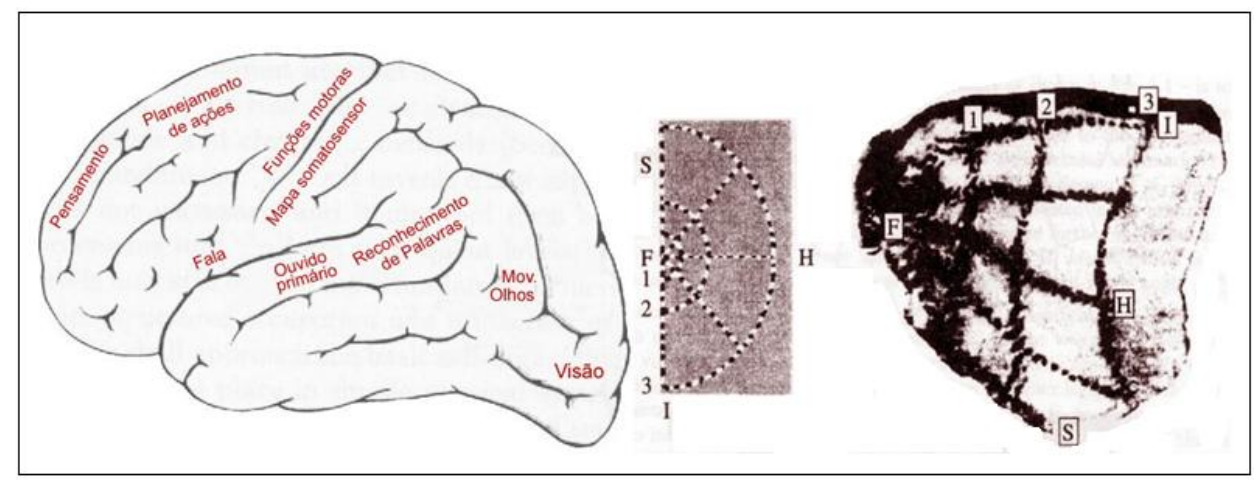

Fonte: (A) reproduzida de (KOHONEN 1997, pg 79). (B) reproduzida de (VAN HULLE, 2000, pg 4).

Entretanto, analisando-se mais especificamente estas regiões especializadas, há evidências de uma organização um pouco mais abstrata e complexa, ainda não totalmente compreendida: suas células organizam-se e tornam-se sensíveis aos estímulos de acordo com uma ordem topológica que especifica uma relação de similaridade entre os sinais de entrada. Assim, os neurônios exibem uma ordenação física tal que estímulos semelhantes no espaço de dados são processados por neurônios fisicamente próximos entre si no córtex cerebral. Nota- 
se que não existe nenhum "movimento" de neurônios, apenas seus parâmetros são ajustados para que tal comportamento ocorra. Assim é, por exemplo, com o córtex auditivo: os neurônios desta região tornam-se sensíveis aos estímulos sonoros numa ordem topológica que reflete a variação tonal do sinal sonoro, fato simulado em (KOHONEN, 1982) e representado na FIGURA 5-2.

Figura 5-2. Representação do córtex tonotópico de um gato onde os estímulos sonoros provocaram sensibilização no córtex conforme altura das notas: a organização dos neurônios representa ordenação topológica dos sinais de entrada.

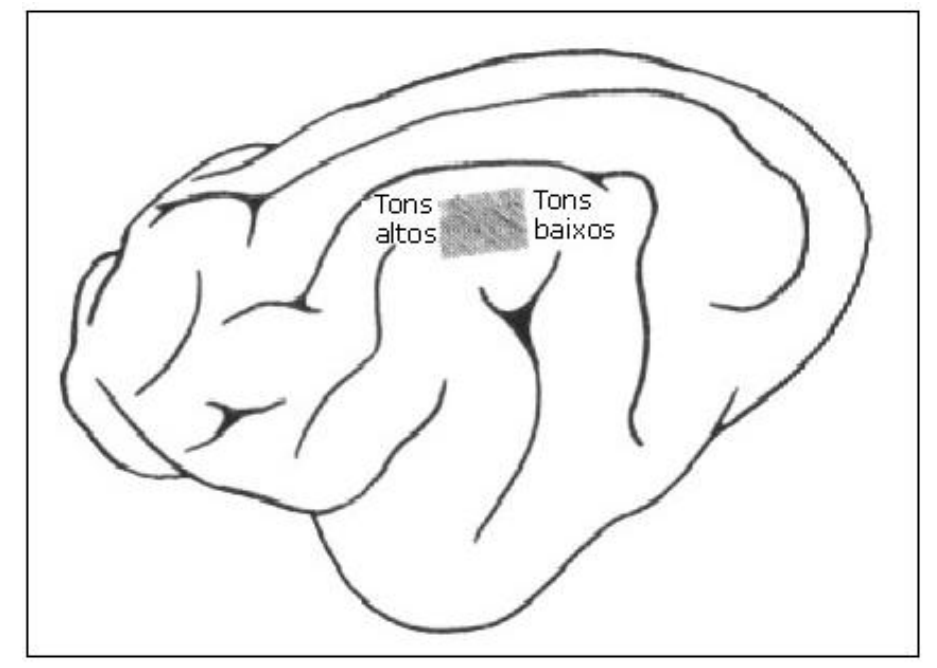

Fonte: (KOHONEN, 1997).

A formação de mapeamentos topologicamente corretos é atribuída a uma diversidade de mecanismos, dos quais um em particular, a auto-organização, recebeu bastante atenção da comunidade acadêmica devido a suas fortes evidências biológicas. Isto levou à proposição de vários modelos de mapas topográficos, ou mapas topologicamente corretos. Duas variantes são pesquisadas: modelos baseados em gradiente e modelos baseados em aprendizado competitivo (VAN HULLE, 2000). Esta última vertente, embora menos relacionada com os fundamentos biológicos, foi muito mais pesquisada e é nela que baseia- se o SOM. O aprendizado competitivo, sob a ótica de uma rede neural artificial, tem o sentido de quantização vetorial e pode ser sucintamente descrito desta forma: 
- Um conjunto de dados representados por vetores no espaço $\mathfrak{R}^{D}$ é apresentado, em ordem aleatória e de forma repetitiva, a uma rede composta por neurônios organizados segundo um arranjo específico, cada neurônio com o seu vetor de pesos no $\mathfrak{R}^{D}$;

- Para cada dado apresentado à rede, haverá uma competição entre todos os neurônios pelo direito de representá-lo, de forma que o neurônio cujo vetor de pesos for o mais próximo do dado, segundo uma métrica previamente definida, vence a competição. Este neurônio é chamado BMU (Best Matching Unit) e este passo é chamado de estágio competitivo (VAN HULLE, 2000, pg 16).

- O neurônio BMU é adaptado, isto é, seu vetor de pesos sinápticos é alterado no sentido de se aproximar ainda mais do dado apresentado, aumentando a probabilidade de que este mesmo neurônio volte a vencer numa subsequente apresentação do mesmo dado. Para viabilizar o requisito de que neurônios próximos no arranjo vençam para dados próximos no $\mathfrak{R}^{D}$, neurônios pertencentes a uma vizinhança do neurônio vencedor, de acordo com a especificação do arranjo, também terão seu vetor de pesos ajustado na direção do dado, embora com menor intensidade. A primeira regra é conhecida como WTA (Winner-Takes-All) (KASKI \& KOHONEN, 1997), e o passo de ajuste da vizinhança é chamado de estágio cooperativo (VAN HULLE, 2000, pg 16).

Fica evidente então que, a idéia fundamental é a de que neurônios próximos entre si no arranjo representem dados próximos entre si no espaço de dados. Representar um dado aqui significa ter um vetor de pesos que seja mais próximo do dado que qualquer outro vetor de pesos da rede neural. Com isso, a topologia dos dados no espaço original acabará sendo preservada, dentro do possível, pelo arranjo de neurônios em um espaço de menor dimensão.

As relações de similaridade entre os neurônios podem ser visualmente observadas contanto que a dimensão do arranjo seja $1 \leq P \leq 3$.

Seja o conjunto de entrada $\mathbf{V}=\left\{\mathbf{v}_{1}, \ldots, \mathbf{v}_{N}\right\}, \mathbf{V} \subseteq \mathfrak{R}^{D}$, de vetores $\mathbf{v}_{n}=\left[v_{n 1}, \ldots, v_{n D}\right]^{T} \in$ $\Re^{D}, \quad n=1, \ldots, N$, onde cada vetor $\mathbf{v}_{n}$ representa um dado (um ponto) no espaço $D$ dimensional, através de seus $D$ atributos. O SOM é definido por um conjunto de 
neurônios $i, i=1, \ldots, Q$, dispostos em um arranjo que define a vizinhança de cada neurônio, como pode ser visto na FIGURA 5-3 para as possibilidades mais utilizadas em $\Re^{2}$.

Figura 5-3. Diferentes configurações de arranjo para o SOM em $\Re^{2}$. Em (A) vê-se a vizinhança retangular enquanto em (B) observa-se uma vizinhança hexagonal.

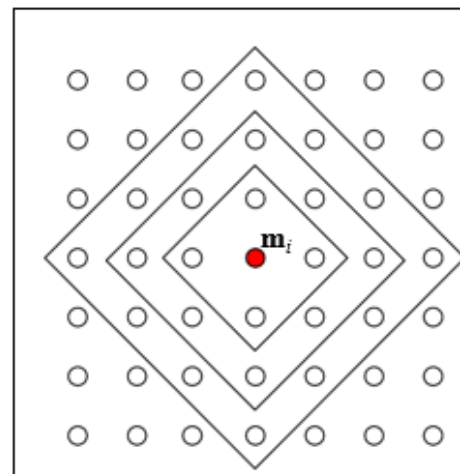

(A)

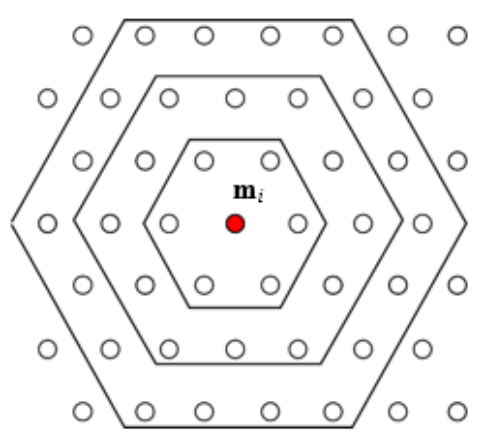

(B)

Fonte: (VAN HULLE, 2000).

Um neurônio é considerado vizinho de outro no arranjo conforme a configuração adotada, o que define a vizinhança imediata com 4 e 6 vizinhos nos arranjos retangular e hexagonal, respectivamente. $O$ formato do arranjo influencia diretamente a adaptação do SOM, sendo que o modelo hexagonal oferece tradicionalmente resultados "melhores" que o retangular.

Cada neurônio $i$ é representado por um vetor de pesos sinápticos $\mathbf{m}_{i}=\left[m_{i 1}, \ldots\right.$, $\left.m_{i]}\right]^{T} \in \mathfrak{R}^{D}$.

Todos os neurônios são conectados ao sinal de entrada ou dado recebido, conforme FIGURA 5-4. 
Figura 5-4. Todos os neurônios do arranjo, representados por vetores de pesos sinápticos $\mathrm{mi}=[\mathrm{mi} 1, \ldots, \mathrm{miD}], \mathrm{i}=1, \ldots, 24$, recebem o mesmo dado de entrada.

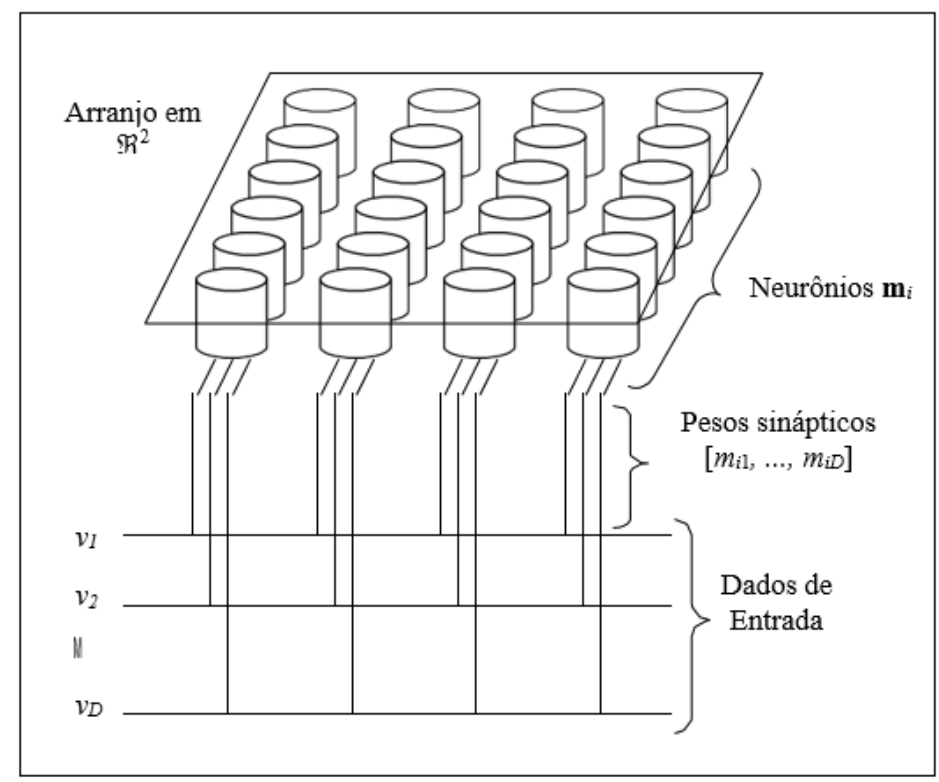

Fonte: (VAN HULLE, 2000).

Seja $\mathbf{v}_{n} \in \mathbf{V}$ um dado de entrada tomado aleatoriamente $(n \propto\{1, \ldots, N\})$ e apresentado à rede. Como todos os neurônios do arranjo recebem a mesma entrada $\mathbf{v}_{n}$ calcula-se a distância do vetor de pesos $\mathbf{m}_{i}$ de cada neurônio $i$ ao vetor $\mathbf{v}_{n}$ de acordo com uma métrica, que no caso da distância euclidiana é dada por:

$d\left(m_{i}, v_{n}\right)=\left\|m_{i}-v_{n}\right\|=\sqrt{\sum_{j=1}^{D}\left|m_{i j}-v_{n j}\right|^{2}}$

Calculadas todas as distâncias, é eleito um neurônio BMU de índice $c$ na forma:

$c=\arg \min \left\{\left\|m_{i}-v_{n}\right\|\right\}$

A proposta original de aprendizado competitivo diz que o neurônio BMU deve então ser adaptado para melhor representar o sinal de entrada segunda a regra WTA. Como já colocado, não apenas o neurônio que ganhou a competição é adaptado, mas também seus vizinhos, estabelecendo uma interação local entre os neurônios que, ao longo do aprendizado, promove a organização geral do mapa (KOHONEN, 
1997). O aprendizado, isto é, o novo valor do peso sináptico do i-ésimo neurônio no instante de tempo $(t+1)$, é definido por uma equação de adaptação dada por:

$m(t+1)=m_{i}(t)+\alpha(t) x\left(h_{c i}(t) x\left[m_{i}(t)-v_{n}(t)\right]\right.$

onde $t=0,1,2 \ldots$ é um número inteiro representando a coordenada discreta de tempo e $\alpha(\mathrm{t})$ define a taxa de aprendizado. O grau de adaptação do neurônio BMU e de seus vizinhos depende, portanto, da função de vizinhança, $h_{\mathrm{ci}}$ e da taxa de aprendizado $\alpha$. É necessário que $\mathrm{h}_{\mathrm{ci}}(\mathrm{t}) \rightarrow 0$ quando $\mathrm{t} \rightarrow \infty$, ou seja, a função deve reduzir o grau de vizinhança relativo ao neurônio BMU ao longo do treinamento para ocorrer a convergência do mapa. Tradicionalmente, também, $\alpha(t) \rightarrow 0$ quando $\mathrm{t} \rightarrow \infty$ (Kohonen, 1997, pg. 87).

Normalmente, $h_{c i}=h\left(\left\|r_{c}-r_{i}\right\|, t\right)$, com $r_{c}$ e $r_{i}$ representando as posições dos neurônios de índices $\mathrm{c}$ e $\mathrm{i}$ dentro do arranjo, indicando que quando $\left\|\mathbf{r}_{\mathrm{c}}-\mathbf{r}_{\mathrm{i}}\right\|$ aumenta, $h_{c i}$ sofre uma redução exponencial. A forma e o raio de $h_{c i}$ controlam a flexibilidade do mapa (KOHONEN, 1997). Se for escolhida uma função de vizinhança discreta, onde $h_{c i}=1$ caso 0 neurônio faça parte da região de vizinhança, e $h_{c i}=0$, caso contrário, temos o denominado SOM de produto interno. Entretanto, uma escolha típica para esta função quando o SOM é aplicado à mineração de dados é uma gaussiana da forma:

$h_{c i}=\exp \left(-\frac{\left\|r_{c}-r_{i}\right\|^{2}}{2 \sigma^{2}(t)}\right)$

O parâmetro $\sigma(t)$ define a largura da região de vizinhança, chamada raio de vizinhança. Normalmente $\sigma(t) \rightarrow 0$ quando $t \rightarrow \infty$. (Kohonen, 1997, pg. 87).

Figura 5-5. llustração da adaptação dos pesos de um SOM para a apresentação de um único padrão em 2. Em (A) uma representação da função $h_{c i}$ sobre um mapa bidimensional cuja projeção pode ser vista em (B). 


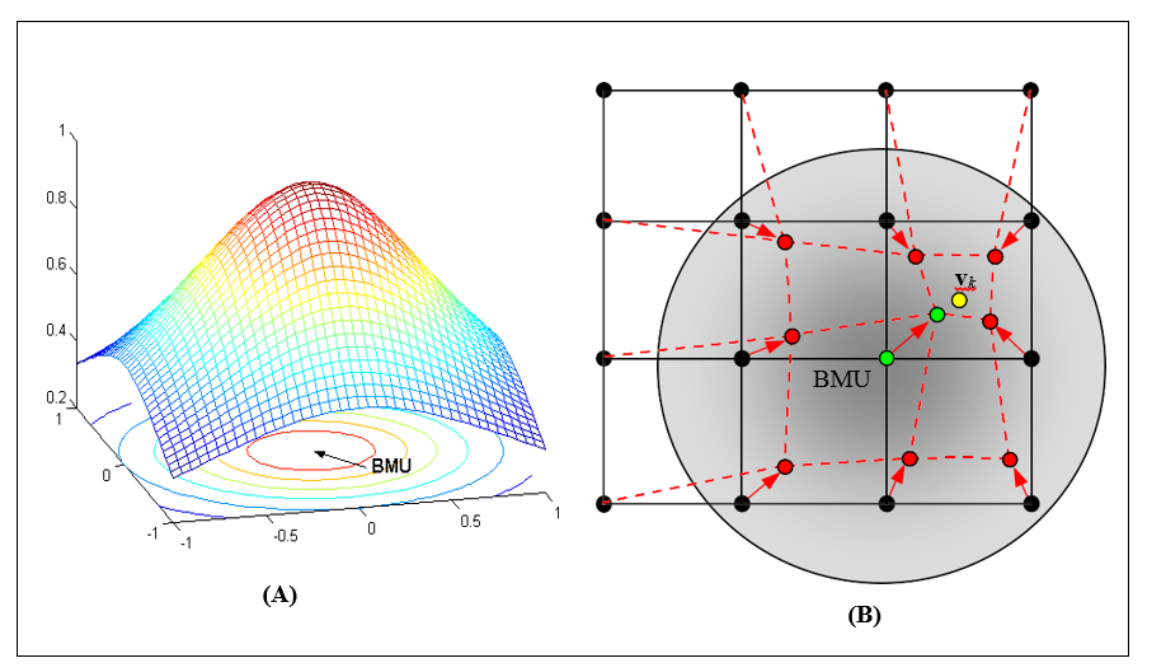

Fonte: (KOHONEN, 1997).

A FIGURA 5-5 representa $h_{c i}$ e sua influência na taxa de aprendizado dos neurônios na vizinhança do BMU. Observa-se que o neurônio que venceu a competição "arrasta" seus vizinhos na direção do objeto apresentado numa proporção que depende da gaussiana $h_{c i}$, isto é, os neurônios vizinhos tendem a se aproximar. Dessa forma, ao longo do aprendizado, estímulos semelhantes a $\mathbf{v}_{\boldsymbol{n}}$ serão percebidos por neurônios próximos entre si, o que acaba por promover a ordenação topológica dos neurônios da rede em relação aos dados no espaço original.

Figura 5-6. A grade elástica do SOM com inicialização linear dos vetores de pesos dos neurônios sobre um conjunto de dados artificiais em $\Re 3$. A grade inicial é alinhada com o plano gerado pelos eixos de maior variância do conjunto de dados. 

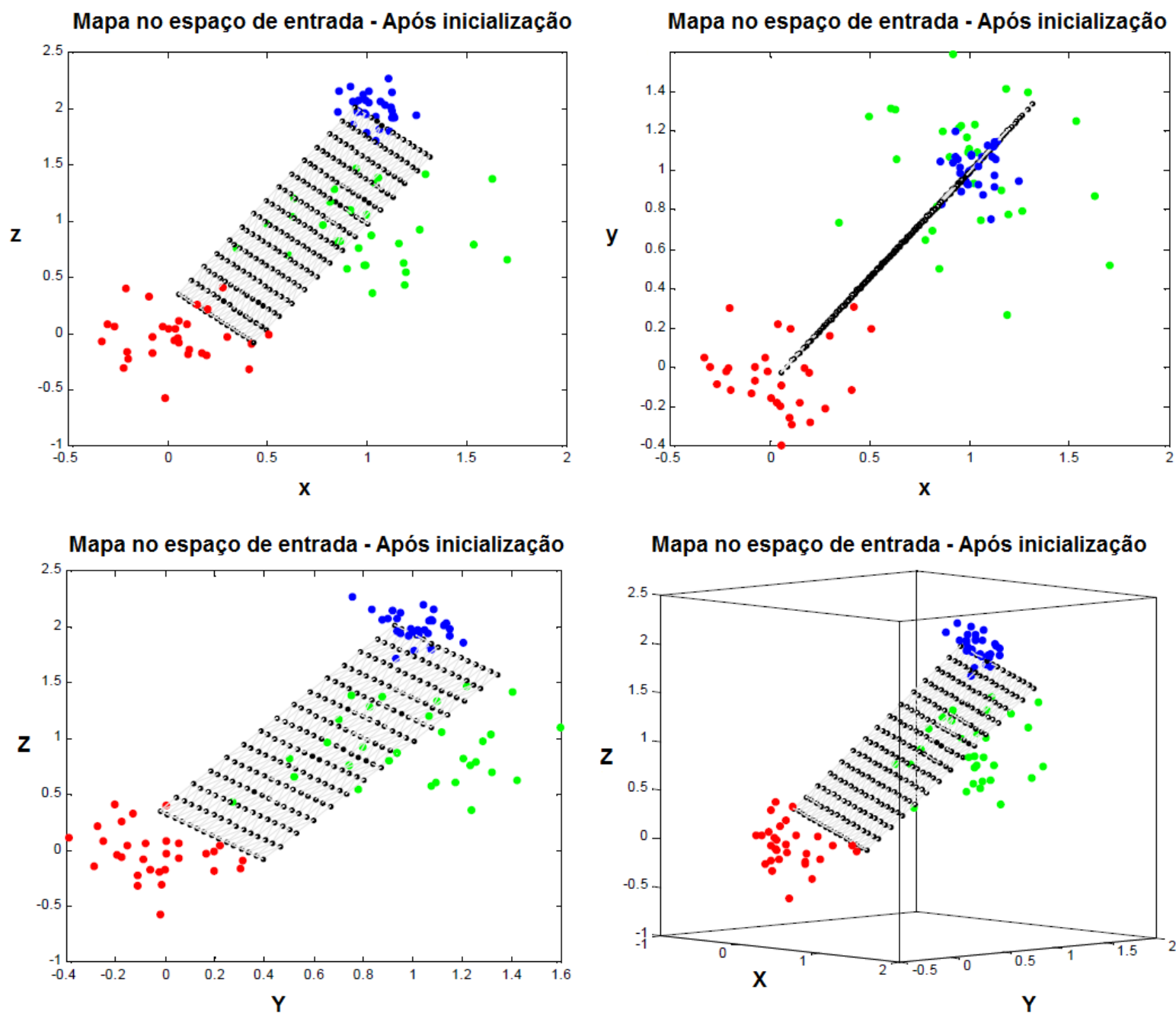

Fonte: (KOHONEN, 1997).

Numa interpretação bem pragmática, o SOM comporta-se como uma grade composta de neurônios ligados entre si por conexões elásticas, responsáveis por dobrar, comprimir ou esticar a grade de forma a representar, da melhor forma possível, o conjunto de dados no espaço original. Uma simulação deste comportamento é ilustrada na FIGURA 5-5 onde exemplifica-se a inicialização dos vetores de pesos da grade de neurônios, e na FIGURA 5-6, onde se pode observar a grade de neurônios já adaptada ao conjunto de dados a partir de diferentes pontos de vista.

É interessante de ser notada a deformação que a grade original sofre na tentativa de representar o conjunto de dados, sendo comprimida em regiões de alta 
densidade (pontos azuis) e distendida em regiões de baixa densidade (pontos verdes).

Figura 5-7. A "grade elástica" já adaptada sobre os dados da Figura 5-5. As quatro últimas figuras ilustram a superfície formada pela grade sob alguns pontos de vista.
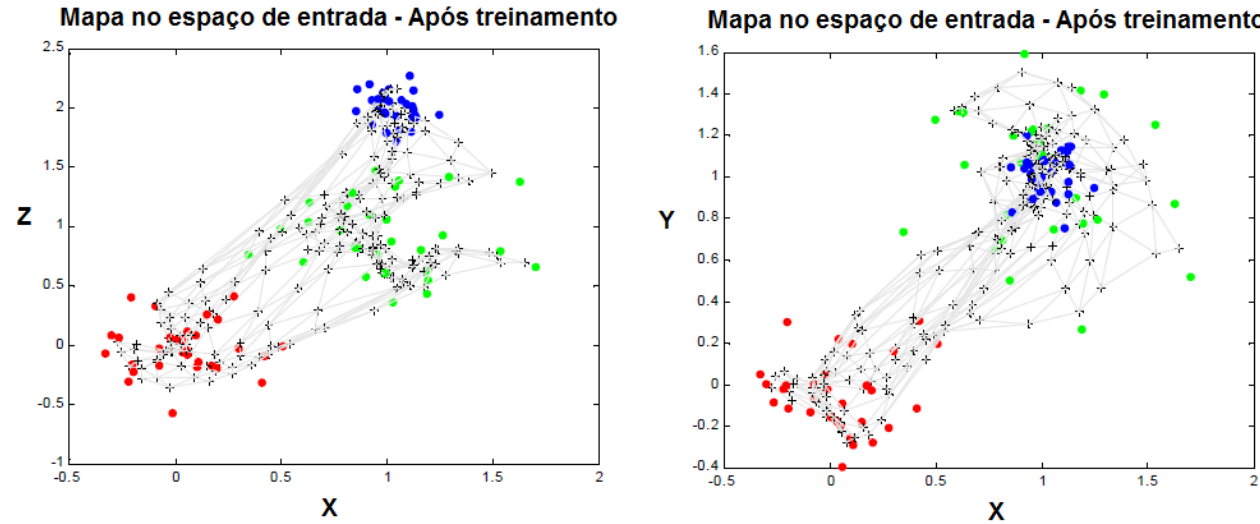

Mapa no espaço de entrada - Após treinamento

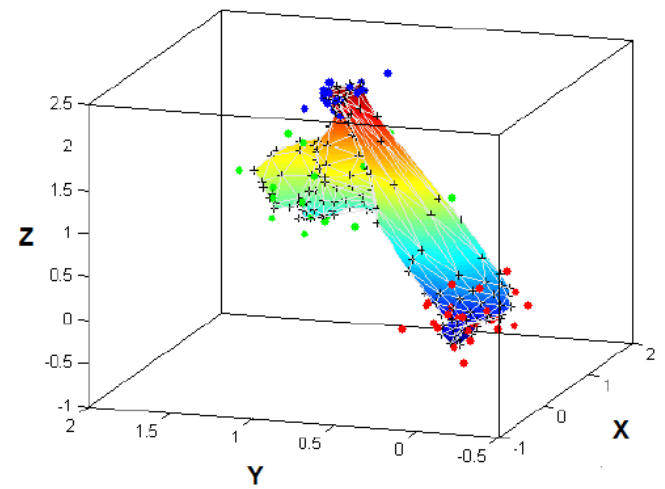

Mapa no espaço de entrada - Após treinamento
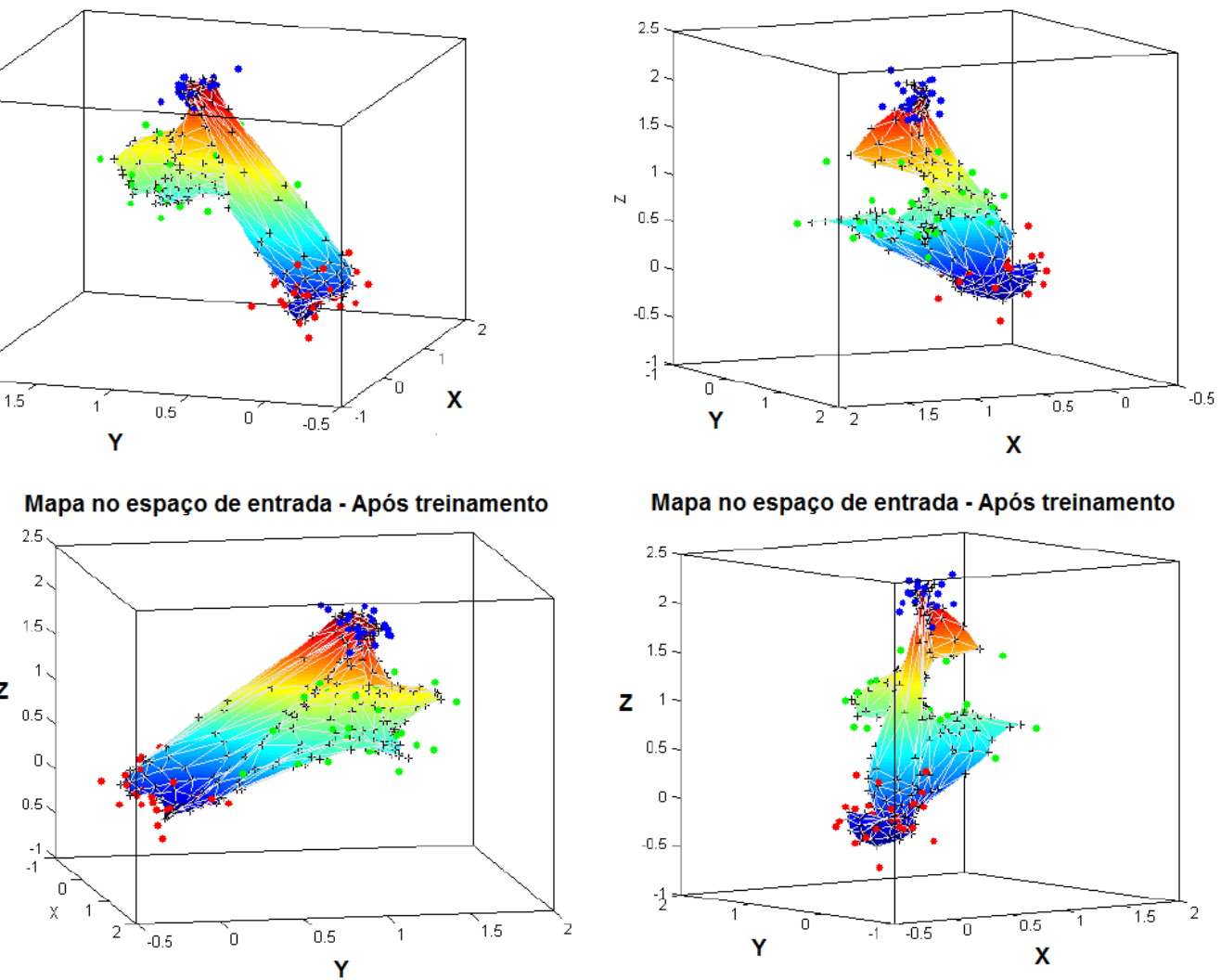

Mapa no espaço de entrada - Após treinamento

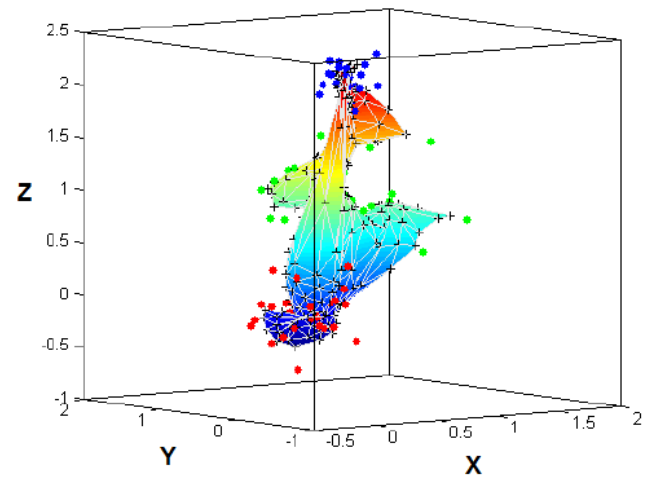

Fonte: (KOHONEN, 1997). 


\subsubsection{Arranjos Unidimensionais}

Embora seja a única configuração para a qual uma prova de convergência foi estabelecida (ERWIN et al. 1992), o arranjo unidimensional é pouco explorado na prática, tendo sido usado basicamente em demonstrações sobre o comportamento do SOM. Uma aplicação bastante interessante de mapas unidimensionais é apresentada em (ARAS et al.,1999) para a solução do problema do caixeiroviajante, onde uma versão do SOM unidimensional construtiva chamada KNIES (do original Kohonen Network Incorporating Explicit Statistics) é utilizada com resultados animadores.

O algoritmo inicia-se com um "anel" formado por poucos neurônios colocados próximos ao centro de massa do conjunto de cidades e é operado em 2 fases. A fase de atração é idêntica ao do algoritmo tradicional, onde o BMU e seus vizinhos são aproximados do sinal apresentado (neste caso, os sinais são cidades representadas por coordenadas em $\mathfrak{R}^{2}$ ). Na fase de repulsão, os neurônios que não participaram da fase de atração são afastados, de forma que as propriedades estatísticas globais do conjunto (média, variância etc.) permaneçam constantes.

O KNIES remove, ao final de seu ciclo, os neurônios que não sejam explicitamente responsáveis por alguma cidade, conforme ilustrado na FIGURA 5-8.

Figura 5-8. O problema do caixeiro-viajante para 51 cidades. Em (A) o SOM apresenta um resultado inferior se comparado ao método KNIES (B). Em (C) o caminho ótimo (com menor custo) obtido por métodos de otimização. Nota-se que o SOM opera com um número $\mathrm{d}$. 

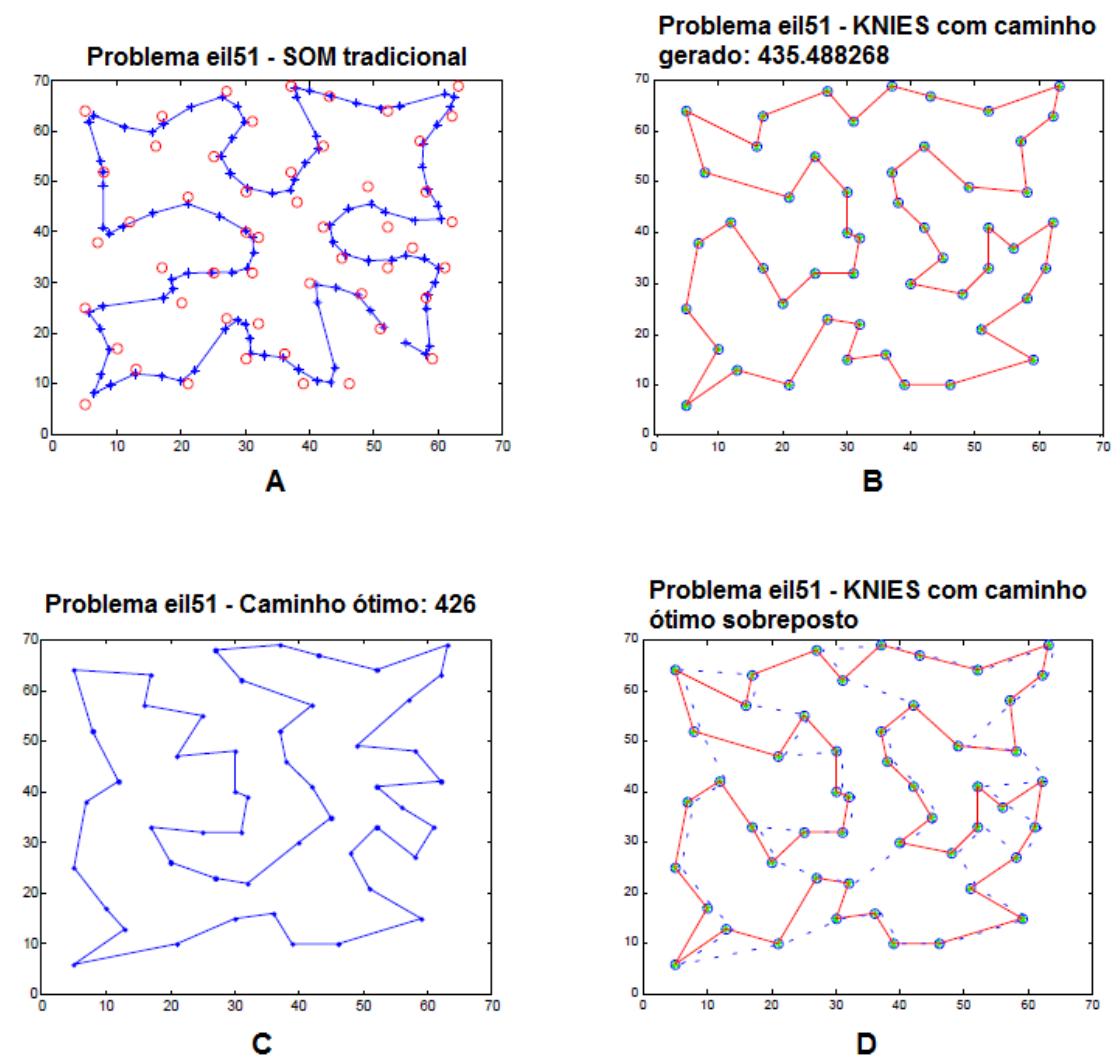

Fonte: (REINELT, 1991).

\subsubsection{Arranjos Bidimensionais}

Os arranjos bidimensionais possuem uma estrutura de vizinhança plana retangular ou hexagonal. Outras configurações possíveis são arranjos cilíndricos e toroidais (VESANTO et al., 2000). Estes dois últimos formatos do arranjo são pouco explorados e possuem um tratamento conservador por parte das ferramentas utilizadas nesta tese, sendo que o mapa toroidal foi escolhido como o arranjo referencial, e tomando-o como plano, conforme apresentado na FIGURA 5-9. 
Figura 5-9. Diferentes formatos para o arranjo SOM.
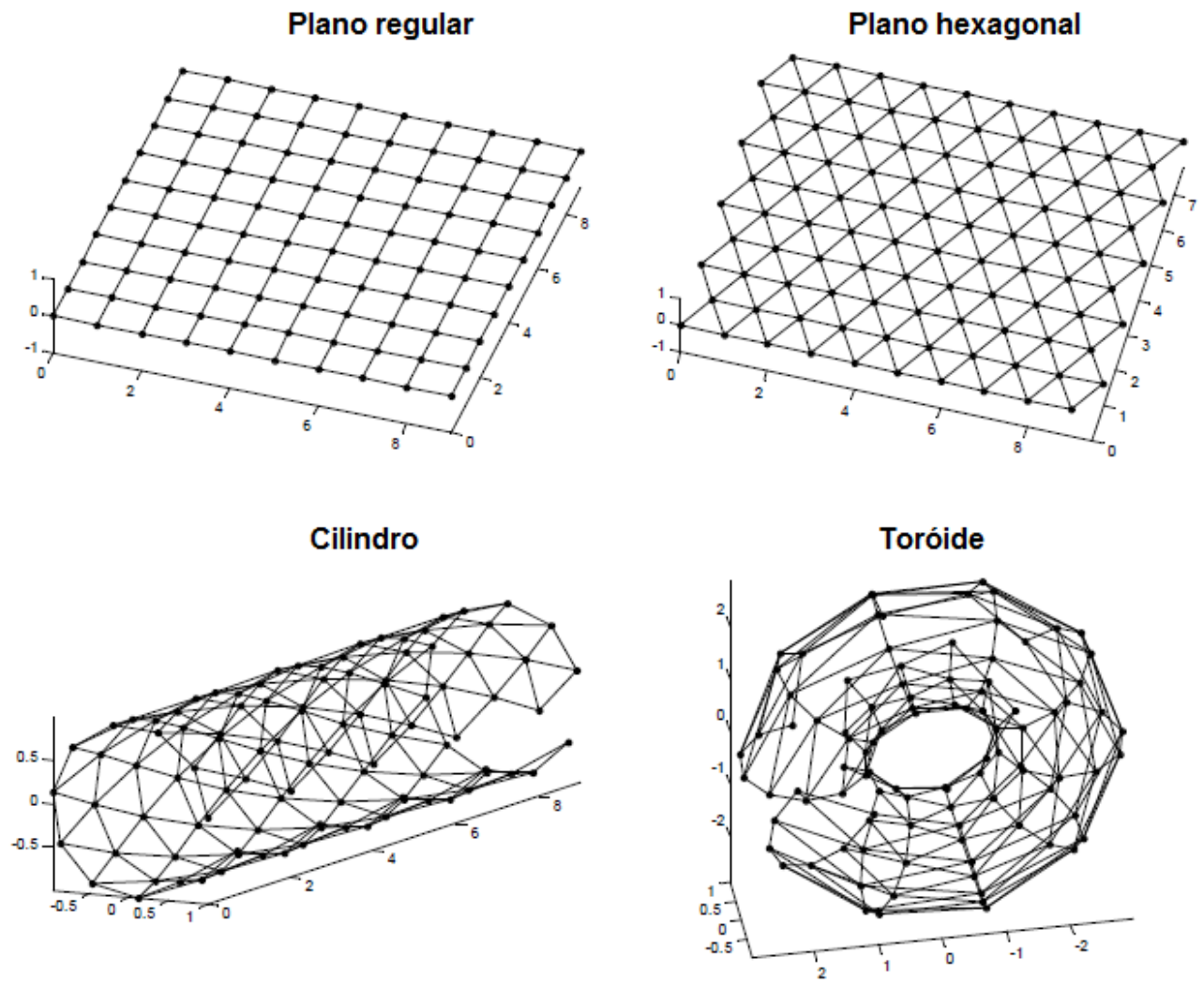

Fonte: (VESANTO et al. 2000). 


\section{Capítulo 6 - Análise de agrupamento - Cluster}

\subsection{Introdução}

A Análise de Agrupamentos é um conjunto variado de técnicas e algoritmos que objetivam identificar e agrupar objetos segundo a similaridade sobre algum atributo ou característica particular que possuem.

Segundo (EVERITT, 1974), o problema básico que a Análise de Agrupamentos pretende resolver é "dada uma amostra de "n" objetos (ou indivíduos), cada um deles segundo "p" variáveis, procurar um esquema de classificação que agrupe os objetos em " $g$ " grupos. Devem ser determinados também o número e as características desses grupos".

Segundo HAIR et al., 2005, de forma análoga, dizem que a Análise de Agrupamentos é uma técnica analítica para a criação de grupos de indivíduos que objetiva classificar uma amostra de objetos em um pequeno número de grupos mutuamente excludentes, com base nas similaridades entre eles.

De fato, os algoritmos voltados para a Análise de Agrupamentos buscam particionar um conjunto de dados formando subconjuntos, ou grupos, de tal forma que os indivíduos, ou observações, presentes em um grupo, tenham alto grau de similaridade entre eles, enquanto que indivíduos pertencentes a diferentes grupos tenham alto grau de dissimilaridade.

Existem diversas etapas que precisam ser seguidas na realização da Análise de Agrupamentos sobre um conjunto de dados. (SNEATH, 1967) apontou essa necessidade. (BASSAB et al., 1990) também propõem uma estrutura apropriada para a aplicação das técnicas de agrupamento, podendo ser decomposta nas etapas seguintes:

Definição de objetivos, critérios, escolha de variáveis e objetos;

Obtenção dos dados;

- Tratamento dos dados; 
- Escolha dos critérios de similaridade ou dissimilaridade;

- Adoção e execução de um algoritmo para o agrupamento;

- Apresentação dos resultados;

- Avaliação e interpretação dos resultados.

Nessa estrutura, as etapas não são independentes. Ao contrário, pode ser necessário voltar a etapas anteriores para se corrigir ou aprimorar etapas posteriores.

Nas primeiras etapas são definidos os objetivos que se pretendem alcançar com a utilização da Análise de Agrupamentos. Aqui também são conhecidas as variáveis de análise e suas características no contexto do estudo. As variáveis também são consideradas quanto à escala em que se encontram e se são variáveis quantitativas ou qualitativas, derivadas, compostas, discretas ou contínuas, nominais ou ordinais. Se necessário as variáveis podem ser padronizadas para que se tornem adimensionais.

Na segunda etapa são feitas as principais opções da Análise de Agrupamentos. Se não for um dos objetivos a criação de um número já determinado de agrupamentos, opta-se, pelas Técnicas Hierárquicas. Se um determinado número de agrupamentos se faz necessário, opta- se pelo uso das Técnicas de Partição ou não-Hierárquicas.

Uma vez escolhida qual técnica de partição que será utilizada é necessário definir a medida de distância, ou seja, o Coeficiente de Similaridade ou de Dissimilaridade.

$\mathrm{Na}$ terceira etapa aplicam-se diferentes algoritmos com o objetivo de se criarem agrupamentos preliminares. Diversos algoritmos podem ser utilizados até que se defina qual o mais adequado. Nesses casos, a experiência do pesquisador influi na definição da técnica a ser utilizada e isso é muito comum. Na criação dos agrupamentos, é importante que se diga, o que se quer garantir é que elementos pertencentes a um mesmo grupo apresentem comportamentos semelhantes e que elementos pertencentes a grupos diferentes apresentem comportamentos distintos. 


\subsection{Coeficientes de Similaridade e de Dissimilaridade}

Um conceito fundamental na Análise de Agrupamento reside na escolha de um critério para medir a distância entre objetos ou quantificar sua similaridade. Segundo (SNEATH e SOKAL, 1973), agrupar é constatar uma distância mínima ou de alta correlação dentro de um padrão. Como afirma (AZAMBUJA, 2005), para se construir um simples grupo a partir de um conjunto de elementos é necessário utilizar algum critério de proximidade ou tipo de medida que possibilite a comparação entre os componentes desse conjunto, tornando possível verificar se um dado elemento $A$ é mais parecido com $B$ do que com $C$.

É necessária a definição de um coeficiente de mensuração que quantifique a distância entre os objetos da análise e mostre o quanto dois elementos de um conjunto são similares.

Essa medida é chamada, como já citado anteriormente, de Coeficiente de Similaridade. É importante observar que é possível se estabelecer também o conceito e o termo Coeficiente de Dissimilaridade. O Coeficiente de Similaridade é aquele cujo maior valor observado represente a maior proximidade, como é o caso do Coeficiente de Correlação. O Coeficiente de Dissimilaridade indica que quanto maior for o valor observado menor é a proximidade e menos parecidos são aqueles objetos, como é o caso da Distância Euclidiana.

Alguns coeficientes se adaptam melhor a determinadas situações de estudo e análise. Também, como já citado anteriormente, os Coeficientes de Dissimilaridade são mais adequados para as variáveis quantitativas, e os de Similaridade para as variáveis qualitativas. Escolhido o coeficiente, torna-se possível construir a Matriz de Distâncias, que é de onde surgirão os grupos.

Toda característica, ou evento da natureza que apresente mais de uma realização possível, poderá ser representado através de uma variável, a qual se refere convencionalmente, ao conjunto de resultados possíveis de um fenômeno (AZAMBUJA, 2005). As variáveis são classificadas, dicotomicamente, em Qualitativas ou Quantitativas. 
Uma variável Quantitativa é aquela que apresenta como possíveis realizações números oriundos de uma contagem, de uma medição ou de uma apuração. As variáveis quantitativas podem ser discretas, se o conjunto de valores que ela pode assumir for um conjunto finito ou infinito enumerável, ou podem ser contínuas, se o conjunto de valores que ela pode assumir for um conjunto infinito não enumerável (BUSSAB e MORETTIN, 2003; AZAMBUJA, 2005).

\subsection{Coeficientes Utilizados para Variáveis Quantitativas}

A Distância Euclidiana é o Coeficiente de Dissimilaridade mais conhecido e mais utilizado para indicar a distância entre objetos de análise. Trata-se, objetivamente, da distância geométrica entre dois pontos no espaço. Cada observação é tomada como sendo um ponto e o cálculo do coeficiente representa a distância física entre cada uma delas.

Em termos matemáticos, tem-se:

$d_{(A)(B)}=\sqrt{\left(x_{1(A)}-x_{2(B)}\right)^{2}+\left(y_{1(A)}-y_{2(B)}\right)^{2}}$

Onde:

$d_{(A)(B)}$ é a Distância Euclidiana entre duas observações, A e B,

$X_{1(A)}, y_{1(A)}$ são as coordenadas do ponto $\mathrm{A} e$

$x_{2(B)}, y_{2(B)}$ são as coordenadas do ponto B.

Generalizando, tem-se:

$d_{(A)(B)}=\sqrt{\sum_{i=1}^{p}\left(x_{i(A)}-x_{i(B)}\right)^{2}}$

A Distância Euclidiana apresenta simplicidade de cálculo e a distância entre quaisquer dois objetos não é afetada pela inserção de outros objetos ao conjunto de dados de análise. No entanto é conveniente que os dados sejam padronizados 
para que se evitem erros provocados pelas diferenças de escala associadas a dimensões.

Algumas medidas derivadas da Distância Euclidiana podem ser definidas.

A Distância Euclidiana Média $d D E M_{(A)(B)}$, também muito utilizada na Análise de Agrupamentos é definida como:

$d D E M_{(A)(B)}=\sqrt{\frac{\sum_{i=1}^{p}\left(x_{1(A)}-x_{2(B)}\right)^{2}}{p}}$

Onde $p$ é o número de pontos considerados, como também nas demais fórmulas dessa seção.

A Distância Euclidiana Quadrática $d D E Q_{(A)(B)}$ é definida por:

$d D E Q_{(A x B)}=\frac{\sum_{i=1}^{p}\left(x_{1(A)}-x_{2(B)}\right)^{2}}{p}$

Essa distância é o quadrado da Distância Euclidiana, como o próprio nome diz, e é mais influenciada por aqueles objetos localizados a uma distância maior.

A Distância Manhattan $\operatorname{dMAN}_{(A)(B)}$ também chamada de Métrica Quarteirão, é outra medida utilizada na Análise de Agrupamentos. Ela é calculada através da soma do valor absolutos das diferenças entre as observações. Ela é definida como:

$d M A N_{(A)(B)}=\sum_{i=1}^{p} w_{i}\left|x_{i(A)}-x_{i(B)}\right|$

Onde:

$w_{i}$ é uma ponderação que pode ser aplicado a cada dupla de variáveis.

O Coeficiente de Gower (GOWER, 1969), dGOW $W_{(A)(B)}$ é baseado na proporção da variação em relação à maior discrepância possível entre as observações:

$$
d G O W_{(A)(B)}=-\log _{10}\left[1-\frac{1}{p} \sum_{i=1}^{p} \frac{x_{i(A)}-x_{i(B)}}{x_{i=M a x}-x_{i=M i n}}\right]
$$


O Coeficiente de Cattel, $d C A T_{(A)(B)}$ utiliza a Distância Euclidiana com variáveis padronizadas:

$$
d \operatorname{CAT}_{(A)(B)}=\frac{2\left(p-\frac{2}{3}\right)-d_{(A)(B)}}{2\left(p-\frac{2}{3}\right)+d_{(A)(B)}}
$$

Alguns coeficientes são baseados no fato do critério de similaridade assumir valores estritamente positivos. É o caso do Coeficiente de Canberra, do Coeficiente de Bray-Curtis e do Coeficiente de Sokal e Sneath, respectivamente definidos como:

$\operatorname{dCanberra~}_{(A)(B)}=\frac{1}{p} \sum_{i=1}^{p} \frac{\left|x_{i(A)}-x_{i(B)}\right|}{x_{i(A)}+x_{i(B)}}$

$d$ Bray $-\operatorname{Curtis}_{(A)(B)}=\sum_{i=1}^{p} \frac{\left|x_{i(A)}-x_{i(B)}\right|}{x_{i(A)}+x_{i(B)}}$

$d$ Sokal- Sneath $_{(A)(B)}=\left[\frac{1}{p} \sum_{i=1}^{p}\left(\frac{\left|x_{i(A)}-x_{i(B)}\right|}{x_{i(A)}+x_{i(B)}}\right)^{2}\right]^{\frac{1}{2}}$

Existem diversos coeficientes também trabalhados na Análise de Agrupamentos. Alguns ainda poderiam ser citados como a Distância de Minkowsky, a Distância de Chebyshev, dentre outros. Referências sobre os coeficientes citados e outros aqui não citados podem ser encontrados em (BASSAB et al., 1990; SNEATH e SOKAL, 1973). 


\subsection{Coeficientes Utilizados para Variáveis Qualitativas}

Uma variável é considerada qualitativa quando seu valor se apresenta como uma qualidade ou atributo. Segundo (BASSAB et al., 1990), é frequente o uso de critérios qualitativos na procura de elementos semelhantes, daí a necessidade de se definir coeficientes capazes de estabelecer o grau de similaridade entre objetos de análise. (AZAMBUJA, 2005), de forma análoga, diz que na área das Ciências Sociais, é frequente a utilização de técnicas estatísticas para a análise de variáveis qualitativas. A Análise de Agrupamento também aplica as técnicas nos dados qualitativos para gerar outros dados, ou seja, ela utiliza as variáveis qualitativas, e também as quantitativas, para subsidiar seus objetivos que se apresentam focalizados na identificação daqueles elementos que possuem uma mesma categoria de comportamento no conjunto das observações analisadas.

As variáveis dicotômicas são aquelas que podem assumir somente um valor (nominal ou ordinal), dentre dois valores possíveis. $\mathrm{O}$ fator $\mathrm{RH}$ do sangue, por exemplo, ou é positivo ou é negativo. O sexo, masculino ou feminino, também é outro exemplo. No entanto os valores dessas variáveis podem ser substituídos pelos números 1 e 0 para facilitar análises e representações gráficas, comuns na estatística. Quando isso ocorre essas variáveis ganham o nome de binárias.

\subsection{Técnicas de Formação de Agrupamentos}

O número de técnicas e algoritmos para a formação de agrupamentos é grande e diversificado. Um tipo de proposta de organização dessas técnicas é citado em (EVERITT 1974; BASSAB et al. 1990). Segundo os autores, pode-se dizer que existem três grandes famílias de técnicas voltadas para a formação de agrupamentos:

- Técnicas Hierárquicas, nas quais os objetos, ou observações, são classificados em grupos em diferentes etapas produzindo uma árvore de classificação; 
- Técnicas de Partição ou não-Hierárquica, nos quais os grupos obtidos produzem uma partição no conjunto de objetos;

- Técnicas de Cobertura, nos quais os grupos formados recobrem o conjunto de objetos embora possam também se sobrepor.

Neste trabalho foi utilizado somente a técnica de Partição ou não-Hierárquica. Escolher uma técnica em particular exige não somente o conhecimento de suas propriedades particulares como também sua adequação aos objetivos do pesquisador (BASSAB et al., 1990).

\subsection{Técnicas Hierárquicas e de Partição para a Análise de Agrupamentos}

A FIGURA 6-1 ilustra as Técnicas Hierárquicas que são utilizadas na Análise de Agrupamentos logo depois que ocorre a formação de um grupo, no momento de reconstrução da Matriz de Distâncias. Como cita (AZAMBUJA, 2005), cada um dos elementos que participarão do processo é considerado como um grupo e estará se juntando a outro elemento ou outro grupo de acordo com os valores calculados presentes na Matriz de Distâncias, que é atualizada cada vez que um agrupamento é feito. Ao final do processo, todos elementos são reunidos em um único grupo.

Figura 6-1. Processo de Formação de Agrupamentos 


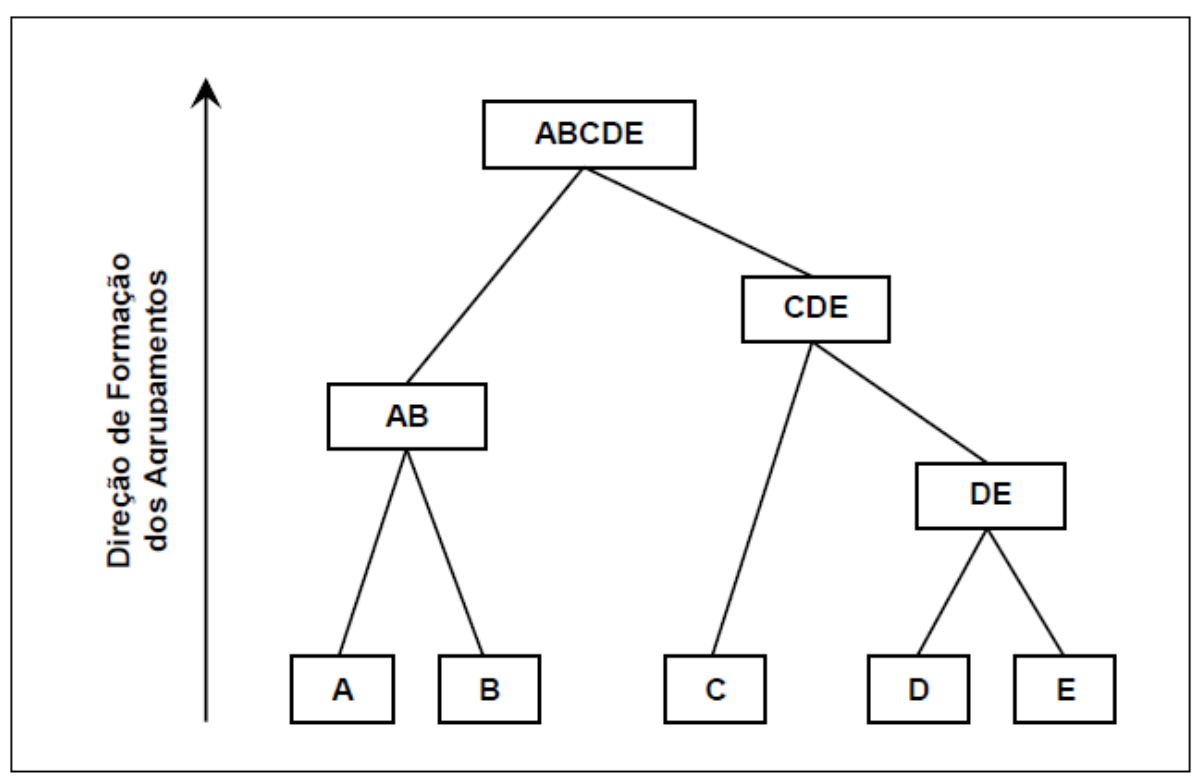

Fonte: (AZAMBUJA, 2005).

Nas técnicas hierárquicas não se sabe, preliminarmente, a quantidade de grupos que serão formados. Diferentes técnicas podem formar diferentes quantidades de grupos. Isso pode ser útil como levantamento preliminar, feito na fase exploratória da análise.

No contexto desse estudo serão trabalhas as seguintes técnicas, também chamadas na literatura de métodos hierárquicos:

- Método das Médias das Distâncias (Average Linkage)

- Método da Ligação Simples (Single Linkage)

- Método da Ligação Completa (Complete Linkage)

- Método do Centroide (Centroid Distance)

\subsubsection{Método das Médias das Distâncias (Average Linkage)}

Esse método foi apresentado no exemplo feito no início desse estudo com a finalidade de ilustrar a formação de agrupamentos. É uma técnica que possui facilidade e rapidez de cálculo, principalmente se comparada às outras técnicas. 
A FIGURA 6-2 ilustra o método aplicado a dois grupos com três elementos cada um.

Figura 6-2. Método das Médias das Distâncias

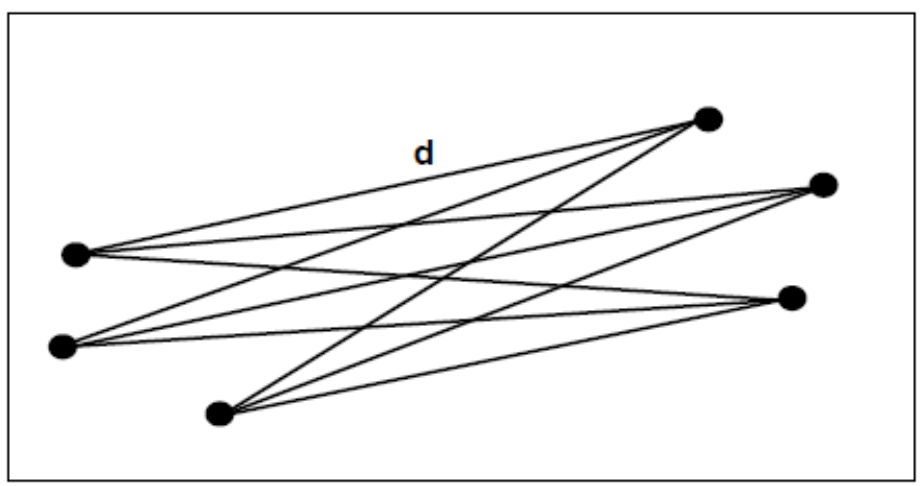

Fonte: (JOHNSON e WICHERN, 1998).

Como já visto, o Average Linkage utiliza a média das distâncias entre todos os pares de objetos da matriz de dados para se criar a matriz de distâncias. Baseando-se nela um grupo é formado e a matriz de distâncias é recalculada tomando-se esse grupo como novo elemento. Um novo agrupamento é formado e o processo continua até que apenas um grupo, contendo todos os elementos do conjunto de dados, seja criado.

Segundo (JOHNSON e WICHERN, 1998), esse método pode ser afetado se ocorrer mudança no coeficiente utilizado para os cálculos da matriz de distâncias, ainda que esse novo coeficiente mantenha a ordem dessas distâncias.

\subsubsection{Método da Ligação Simples (Single Linkage)}

Esse método também é conhecido como o Método do Vizinho mais Próximo ou Método da Distância Mínima. Ele define como similaridade entre dois grupos aquela formada pelos elementos mais parecidos. Em outras palavras, quando ele é aplicado para fornecer a distância entre conjuntos de elementos, ele seleciona a distância que corresponde à maior semelhança entre os elementos de grupos distintos. 
Para exemplificar, sejam os conjuntos A e B de objetos de análise. A distância entre eles será definida como:

$d_{(A)(B)}=\min \left\{d_{i j}, i \in A, j \in B\right\}$

A FIGURA 6-3 representa esse método de maneira ilustrativa.

Figura 6-3. Método da Ligação Simples ou do Vizinho mais Próximo

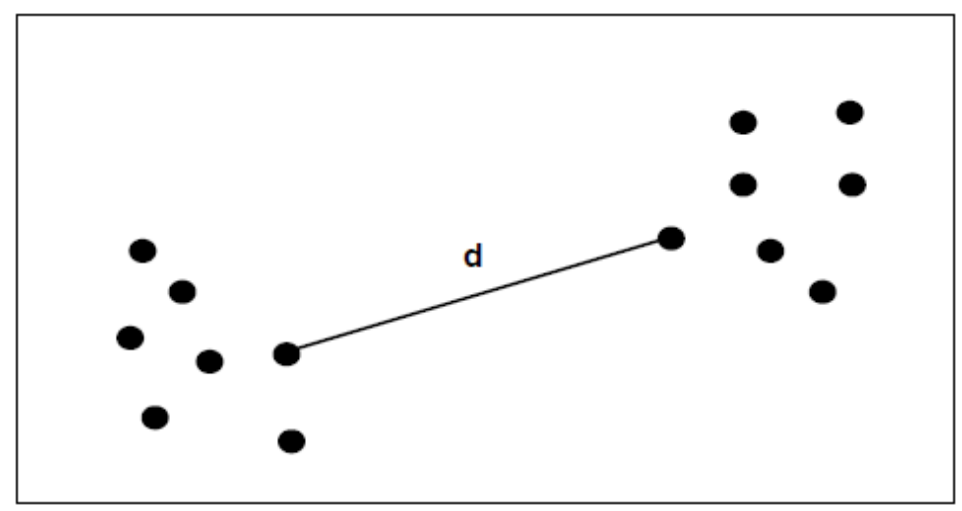

Fonte: (AZAMBUJA, 2005).

Se o coeficiente utilizado para o cálculo da matriz de distâncias for um coeficiente de similaridade, a maior semelhança será representada pela maior distância entre os elementos. Analogamente, se o coeficiente utilizado for de dissimilaridade a maior semelhança será a menor distância. 
Como esse método une grupos segundo uma distância mínima entre eles, os grupos formados tendem a ser menos homogêneos se comparados ao Método das Médias das Distâncias. Isso significa que em um mesmo grupo podem ser encontrados elementos bem distintos. Esse método tende a formar grupos com vários elementos enquanto isola outros elementos ainda não anexados (AZAMBUJA, 2005).

\subsubsection{Método da Ligação Completa (Complete Linkage)}

Esse método é também conhecido como o Método do Vizinho mais Distante. Nesse caso, a similaridade é definida pelos objetos de cada grupo que menos se parecem. Em outras palavras, quando ele é aplicado para fornecer a distância entre conjuntos de elementos, ele seleciona a distância que corresponde à maior diferença entre os elementos de grupos distintos.

Para exemplificar, assim como foi feito no método anterior, sejam os conjuntos $\mathrm{A} e$ $B$ de objetos de análise. A distância entre eles será definida como:

$d_{(A)(B)}=\operatorname{máx}\left\{d_{i j}, i \in A, j \in B\right\}$

É importante ressaltar que a fusão ainda é feita com os grupos mais similares, ou seja, que estão a uma menor distância. A FIGURA 6-4 ilustra esse método.

Figura 6-4. Método da Ligação Completa ou do Vizinho mais Distante. 


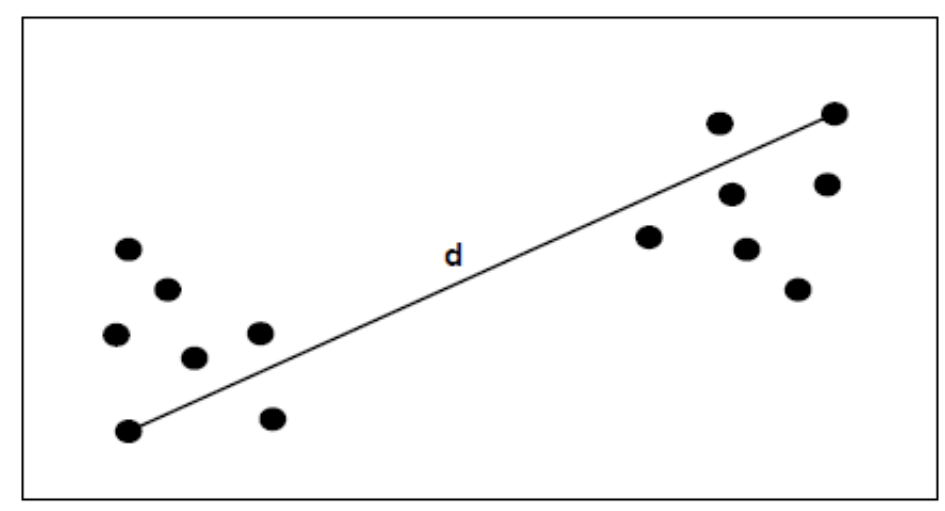

Fonte: (AZAMBUJA, 2005).

Cada vez que um novo elemento é adicionado a um grupo esse se torna mais distinto em relação aos outros. Esse método, como cita (AZAMBUJA, 2005; KRZANOWSKI e MARRIOT, 1995), é indicado para a formação de grupos com tamanhos semelhantes. Ele assegura que as distâncias calculadas, dentre todos os componentes do grupo, estarão inseridas na distância utilizada em sua formação (JOHNSON e WICHERN, 1998).

Esse método forma grupos mais homogêneos que os formados por meio do Método das Médias das Distâncias e do Método da Ligação Simples. Além disso, como ressalta (JOHNSON e WICHERN, 1998), é um método que produz grupos que não se modificam mesmo quando outro coeficiente é adotado para o cálculo das distâncias, ou seja, ele mantém a ordenação das distâncias. O Método da Ligação Simples também possui essa característica.

\subsubsection{Método do Centroide}

Esse método é o mais direto no cálculo da distância entre um elemento de um grupo ou entre dois grupos. Para cada novo grupo formado uma nova distância é calculada e representa o centro médio dos elementos do grupo. Em outras palavras, em cada etapa procura-se criar grupos que tenham a menor distância entre si, sendo essa distância definida entre os centros de cada grupo. A FIGURA 6-5 apresenta isso. 
Figura 6-5. Método do Centroide

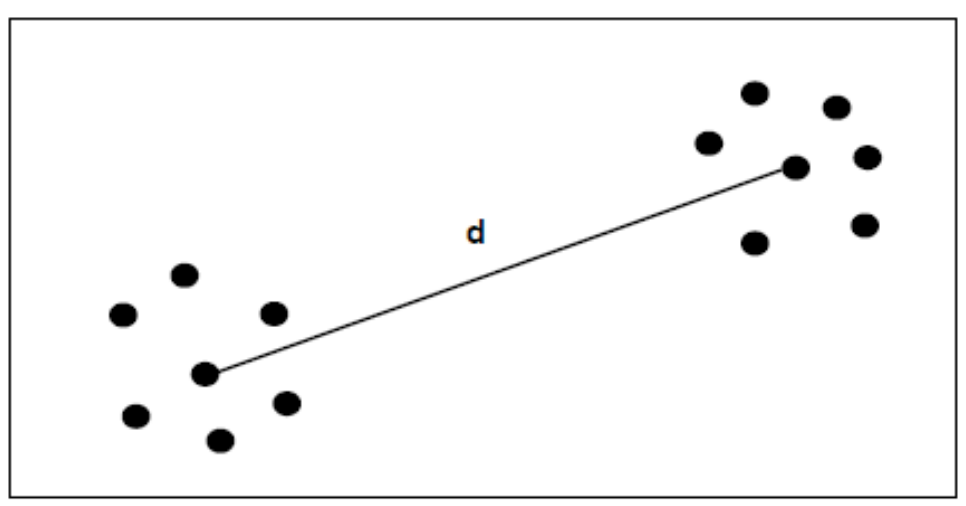

Fonte: (BASSAB et al. 1990).

Esse método é similar ao Método das Médias das Distâncias. Seus resultados, em virtude disso, também são similares. A maior dificuldade do método, no entanto, como ressalta (BASSAB et al. 1990), é a necessidade de se recuperar os dados originais, a cada grupo criado, para que seja possível recalcular o valor das distâncias. Quando muitas variáveis e objetos estão presentes o processo pode se tornar muito demorado.

Outro problema, em nível computacional, também merece atenção. Os cálculos feitos a cada iteração podem trazer junções no Dendograma com valores inferiores ao de alguma junção calculada em outra iteração anterior. A junção, que deveria ser simultânea, não ocorre e o algoritmo precisa supor o mesmo nível da junção anterior. Na prática, principalmente na presença de muitas variáveis, isso não é muito comum.

\subsubsection{Método K-Médias}

As Técnicas de Partição, como o próprio nome diz, buscam produzir agrupamentos através de partições do conjunto original de elementos de análise. A FIGURA 6-6 a seguir, já utilizada quando se mostrou as técnicas de agrupamento, possui uma seta vertical em sentido contrário, mostrando a direção de formação de subconjuntos, ou partições, a partir de um conjunto de dados. 
Figura 6-6. Processo de Divisão de um Conjunto através das Técnicas de Partição

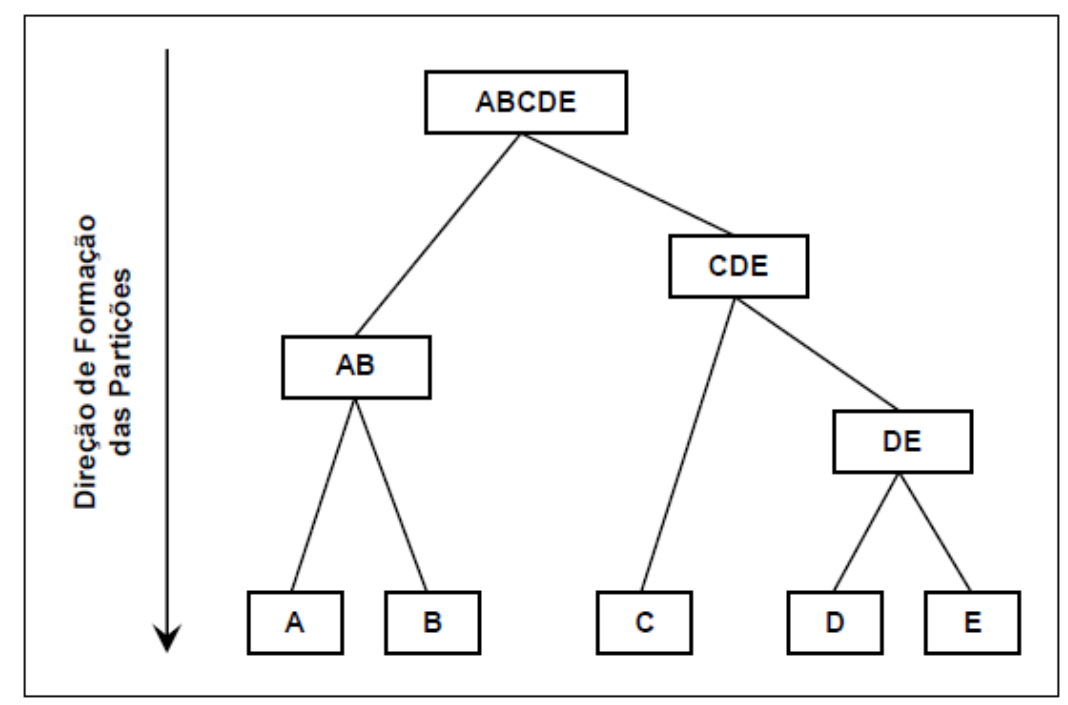

Fonte: (BASSAB et al. 1990).

Cada partição deve mostrar coesão interna dentro de um mesmo grupo e isolamento entre os demais grupos. Além disso, as técnicas de partição já precisam definir o número total de grupos que serão criados antes de sua aplicação.

Um método de partição bastante conhecido e talvez o mais usado em Análise de Agrupamentos quando se tem muitos objetos (BASSAB et al., 1990) é o K-Médias. O K-Médias é uma técnica de partição que procura alocar os elementos de dados em $\mathrm{K}$ grupos previamente definidos. É um método que minimiza a soma dos quadrados residuais dentro de cada grupo formado, aumentando a homogeneidade dentro dele ao mesmo tempo em que aumenta a diferença entre eles. Segundo (JOHNSON e WICHERN, 1998), esse método foi introduzido por ( MACQUEEN, 1967).

O processo algorítmico do método é relativamente simples. Inicialmente é distribuído um elemento do conjunto de dados para cada grupo definido. Essa distribuição pode ser feita aleatoriamente ou através dos elementos que apresentem valores mais distantes de uma variável escolhida (como a média, por exemplo). Essa última opção é a mais utilizada e mais adequada. 
Cada um desses $\mathrm{K}$ elementos se torna, então, o elemento central do grupo a que pertence e representam as sementes dos agrupamentos no momento inicial do processo. Quando, no decorrer do processo, novos elementos entrarem no grupo, o elemento central passa a ser a média entre eles. O processo segue designando cada novo elemento para um determinado grupo, especificamente aquele que apresente o elemento central mais próximo deste. Ao final da distribuição de todos os elementos do conjunto de dados nos $\mathrm{K}$ grupos a soma dos quadrados residuais de cada grupo é calculada.

Isso pode ser feito por meio da equação:

$\operatorname{SQRes}(k)=\sum_{i=1}^{n}\left(x_{i}-m X\right)^{2}$

$\boldsymbol{k}$ é a quantidade de grupos previamente definida

$S Q \boldsymbol{R} \boldsymbol{s}(\boldsymbol{k})$ é a soma dos quadrados residuais de cada grupo $k$

$n$ é a quantidade de elementos de cada grupo $k$

$\boldsymbol{x}_{i}$ é o i-ésimo elemento de cada grupo $k$

$\boldsymbol{m} \boldsymbol{X}$ é a média dos elementos de cada grupo $k$

Depois que todos os cálculos forem feitos para cada grupo, calcula-se:

SQRes $=\sum_{i=1}^{k} \operatorname{SQRes}(k)$

$\boldsymbol{k}$ é a quantidade de grupos

$S Q$ Res é a soma dos quadrados residuais

$S Q \operatorname{Res}(k)$ é a soma dos quadrados residuais de cada grupo $k$. 
Quanto menor o valor de $S Q R e s$ mais homogêneo são os grupos formados. Nesse momento do processo os elementos de um grupo serão movidos para outros grupos buscando a formação de grupos os mais homogêneos possíveis. Cada movimentação implica no recalculo da média do grupo, da soma dos quadrados residuais de cada grupo, $S Q \operatorname{Re} s(k)$, e a soma dos quadrados gerais para todos os grupos, $S Q$ Re $s$.

Se $S Q$ Re $S$ diminui, indicando aumento da homogeneidade, a movimentação é mantida e caso contrário ela é desfeita e o objeto movido retorna ao seu grupo original ou é movido para algum outro grupo, quando o ciclo se inicia novamente. Quando $S Q$ Re $s$ não diminui mais ao longo das iterações (que podem, inclusive, ter um número determinado), o processo termina. Os grupos são apresentados na FIGURA 6-7.

Figura 6-7. llustração do Método K-Médias. Agrupamento de cores padrão RGB

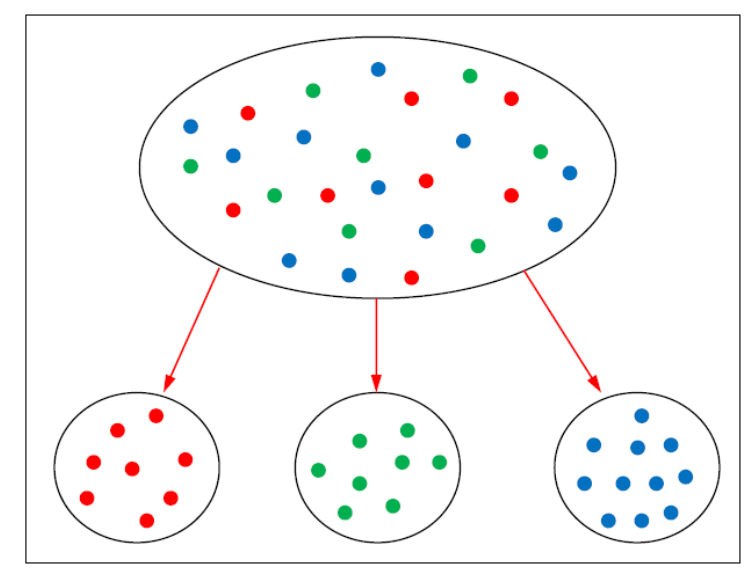

Fonte: (JOHNSON e WICHERN, 1998).

Algumas comparações entre os Métodos de Agrupamento podem ser feitas. Os métodos hierárquicos não mudam elementos de um grupo para outro. Quando um elemento entra em um grupo ele permanece nele até a finalização do processo quando então todo o agrupamento feito poderá ser avaliado.

(JOHNSON e WICHERN, 1998), afirmam que quando a quantidade de observações em análise é grande, o uso do K-Médias pode ser melhor que o uso 
das outras técnicas hierárquicas. Os resultados representados na forma de árvores, binárias ou n-áreas, são difíceis de análise quando se tem muitos objetos.

No K-Médias os agrupamentos são feitos em domínios numéricos através de partições realizadas em grupos disjuntos. Como o número de agrupamentos é definido antecipadamente, esse método deve ser direcionado para se criar poucos agrupamentos.

É importante que se diga, também, que os processos de partições como ○ KMédias, podem não revelar similaridades entre objetos individuais e isso precisa ser considerado.

O que se conclui é que a escolha de um tipo particular de algoritmo para se realizar a Análise de Agrupamentos, deve ser função dos objetivos de um pesquisador frente aos dados de trabalho que ele possui. A utilização de computadores para tornar mais ágil os processos de cálculo envolvidos podem ser muito úteis para o teste de diferentes métodos. 


\section{Capítulo 7 - As técnicas estatísticas de análise multivariada}

\subsection{Introdução}

O desenvolvimento da estatística clássica baseou-se em uma única variável, conhecida como análise univariada. Não obstante, é fato que, na prática da pesquisa quantitativa, por vezes o conjunto de elementos estudados envolve muitas outras variáveis.

O olhar sobre uma única variável parece ter muitas vantagens. Quando o fenômeno observador é medido a partir de muitas variáveis, esse tipo de análise pode ser insuficiente, haja vista que desconsidera os efeitos ou relações sinergéticas ou até inconsistentes entre as variáveis. Além disso, a análise multivariada pode levar, com alguma segurança, à interpretação de problemas com comportamentos complexos, usando as informações disponibilizadas por poucas variáveis.

Dessa forma, a análise multivariada permite estudar e evidenciar as ligações, as semelhanças e diferenças existentes entre todas as variáveis envolvidas no processo.

Segundo (STEINER, 1995), é a necessidade de entender o relacionamento entre as diversas variáveis aleatórias o que faz da análise multivariada uma metodologia com grande potencial de aplicação.

Para (LOURENÇO; MATIAS, 2001), as técnicas estatísticas multivariadas são mais complexas do que aquelas da estatística univariada. Por outro lado, apesar de uma razoável complexidade teórica fundamentada na matemática, as técnicas multivariadas, por permitirem o tratamento de diversas variáveis ao mesmo tempo, podem oferecer ao pesquisador um material bastante robusto para a análise dos dados da pesquisa.

Conforme (HAIR et al., 2005), a análise multivariada auxilia na formulação de questões relativamente complexas de forma específica e precisa, possibilitando a condução de pesquisas teoricamente significativas. 


\subsection{Objetivos de aplicação das técnicas estatísticas de análise multivariada}

Para (JOHNSON; WICHERN, 1998), é uma tarefa um tanto complicada estabelecer um esquema de objetivos singulares para cada técnica de análise multivariada, ou seja, esse autor sugere existir alto grau de nuances entre as muitas técnicas disponíveis, além de as mesmas apresentarem, por vezes, inúmeros outros objetivos de aplicação que não aqueles para os quais foram construídas.

Assim, por exemplo, uma técnica de Análise Fatorial, que inicialmente objetiva a redução do número de variáveis presentes na análise, pode ser aplicada com o único objetivo de preparar os dados para "input" da Análise de Regressão, como tratamento do problema de multicolinearidade.

Entretanto, a escolha dos métodos e dos tipos de análises empregadas nos trabalhos científicos deve ser totalmente determinada pelo problema de pesquisa. Nesse sentido, (JOHNSON; WICHERN, 1998) propõem uma classificação dos objetivos para atendimento do problema em cinco categorias, conforme FIGURA 7-1.

Figura 7-1. Categorias dos objetivos das técnicas de análise multivariada

\begin{tabular}{|c|c|}
\hline Classificação & Técnicas relacionadas \\
\hline $\begin{array}{l}\text { - Investigação da dependência entre as variáveis. } \\
\text { - Todas as variáveis são mutuamente independentes ou uma ou mais } \\
\text { variáveis são dependentes de outras Predição. }\end{array}$ & $\begin{array}{l}\text { - Análise Discriminante } \\
\text { - Análise de Regressão } \\
\text { - Correlação Canônica } \\
\text { - Regressão Logística } \\
\text { - Análise Conjunta } \\
\text { - MANOVA }\end{array}$ \\
\hline $\begin{array}{l}\text { - As relações entre as variáveis devem ser determinadas com o objetivo } \\
\text { de predizer o valor de uma ou mais variáveis com base nas } \\
\text { observações de outras variáveis. }\end{array}$ & $\begin{array}{l}\text { - Análise Discriminante } \\
\text { - Análise de Regressão } \\
\text { - Análise de Regressão Logística }\end{array}$ \\
\hline 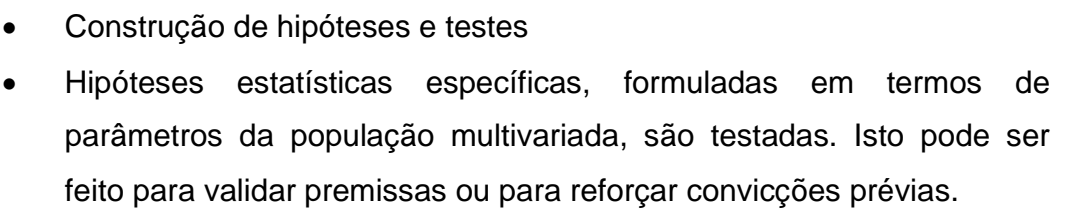 & $\begin{array}{l}\text { - Modelagem de Equações } \\
\text { Estruturais } \\
\text { - Análise Fatorial Confirmatória }\end{array}$ \\
\hline $\begin{array}{l}\text { - Redução dos dados ou simplificação estrutural. } \\
\text { - O fenômeno em estudo é representado de um modo tão simples } \\
\text { quanto possível sem sacrificar informações importantes. }\end{array}$ & - Análise Fatorial Exploratória \\
\hline
\end{tabular}


- Agrupamento de objetos ou variáveis.

- Grupos de objetivos ou variáveis "similares" são criadas com base nas medidas características.
- Análise de Conglomerados

- Análise de Correspondências

- Escalonamento

Multidimensional

Fonte: (JOHNSON; WICHERN, 1998).

\subsection{Análise Multivariada da Variância (MANOVA)}

Quando há o interesse em verificar se variáveis categóricas independentes afetam as variáveis dependentes métricas, a Análise Multivariada da Variância (MANOVA) é a técnica estatísticas de análise multivariada mais adequada.

Segundo (SHARMA, 1996), a MANOVA é uma extensão da ANOVA, extensão do "teste-t", que permite verificar qual o efeito sobre uma variável dependente categórica (PESTANA; GAGEIRO, 2000), com a única diferença que a primeira envolve um conjunto de variáveis dependentes, conforme FIGURA 7-2.

Figura 7-2. Objetivos da técnica de Análise Multivariada da Variância (MANOVA)

\begin{tabular}{c|l|l}
\hline \multicolumn{1}{c|}{ Categoria } & \multicolumn{1}{|c}{ Principal objetivo indicado no estudo } & \multicolumn{1}{c}{ Fontes } \\
\hline \multirow{4}{*}{$\begin{array}{c}\text { Investigação da } \\
\text { dependência entre } \\
\text { as variáveis }\end{array}$} & $\begin{array}{l}\text { Verificar se uma ou mais variáveis independentes têm } \\
\text { influência sobre um conjunto de variáveis dependentes. }\end{array}$ & $\begin{array}{l}\text { HAIR et al } \\
(2005)\end{array}$ \\
\cline { 2 - 4 } & $\begin{array}{l}\text { Examinar o efeito das variáveis independentes em um } \\
\text { conjunto de variáveis dependentes de natureza quantitativa. }\end{array}$ & $\begin{array}{l}\text { PESTANA e } \\
\text { GAGEIRO } \\
(2000)\end{array}$ \\
\cline { 2 - 4 } & $\begin{array}{l}\text { Examinar as diferenças entre grupos simultaneamente ao } \\
\text { longo de múltiplas variáveis dependentes. }\end{array}$ & $\begin{array}{l}\text { MALHOTRA } \\
(2001)\end{array}$ \\
\cline { 2 - 4 } & $\begin{array}{l}\text { Verificar a principal interação das variáveis categóricas em } \\
\text { variáveis métricas dependentes múltiplas. } \\
\text { Identificar as variáveis independentes que diferenciem um } \\
\text { grupo de variáveis dependentes. }\end{array}$ & $\begin{array}{l}\text { GARSON } \\
(2007)\end{array}$ \\
\hline
\end{tabular}

Fonte: (Adaptado de Johnson e WICHERN, 1998, p.2). 
Ainda que a técnica de Análise Multivariada da Variância exija o atendimento a um grande número de premissas subjacentes ao uso, segundo (LEWIS, 1995), muitos estudos empíricos têm demonstrado que os efeitos negativos do não atendimento a essas premissas parecem não ser tão comprometedores. Ainda assim, na falta de uma conclusão científica que desconstrua a teorização em cima dessa técnica, devem-se considerar o conjunto de premissas referenciado pela maior parte dos autores da área.

\subsection{Análise de Regressão}

A terminologia "regressão" foi proposta pela primeira vez por Francis Galton, 1885, em estudo onde demonstrou que a altura dos filhos não tende a refletir a altura dos pais, mas tende a regredir para a média da população (MAROCO, 2003).

O modelo clássico de regressão linear baseia-se na associação entre uma variável dependente $\mathrm{Y}$ e uma coleção de variáveis preditoras $\mathrm{x}_{1}, \mathrm{x}_{2}, \ldots, \mathrm{x}_{\mathrm{r}}$.

Conforme FIGURA 7-3 o objetivo de aplicação da técnica de análise de regressão, em função de inúmeros objetivos "secundários possíveis, faz-se necessário sublinhar que o objetivo mais dessa técnica é a avaliação do relacionamento entre variáveis.

Figura 7-3. Objetivos da aplicação da técnica de Análise de Regressão

\begin{tabular}{l|c|c}
\hline \multicolumn{1}{c|}{ Categoria } & \multicolumn{1}{c|}{ Principal objetivo indicado no estudo } & Fontes \\
\hline $\begin{array}{l}\text { Investigação da } \\
\text { dependência entre as } \\
\text { variáveis }\end{array}$ & $\begin{array}{l}\text { - Avaliação do relacionamento de uma variável dependente } \\
\text { com diversas variáveis independentes }\end{array}$ & Tabachnick e Fidell \\
\cline { 2 - 3 } & $\begin{array}{l}\text { Predição de valores de uma variável dependente a partir } \\
\text { de uma coleção de variáveis independentes }\end{array}$ & $\begin{array}{c}\text { Johnson e Wichern } \\
\text { (1998) }\end{array}$ \\
\hline
\end{tabular}




\begin{tabular}{|c|c|c|}
\hline \multirow[t]{2}{*}{ Predição } & $\begin{array}{l}\text { - Identificar se as variáveis independentes explicam uma } \\
\text { variação significativa da variável dependente. } \\
\text { - Determinar a estrutura da relação a partida equação } \\
\text { matemática que relaciona as variáveis independentes e } \\
\text { dependente. } \\
\text { - Identificar quanto da variação na variável dependente } \\
\text { pode ser explicada pelas variáveis independentes: } \\
\text { intensidade da relação. }\end{array}$ & Malhotra (2001) \\
\hline & $\begin{array}{l}\text { - Estabelecer que um grupo de variáveis independentes } \\
\text { explica uma proporção da variação de uma variável } \\
\text { dependente, a um nível de significância. } \\
\text { - Estabelecer a importância de predição relativa das } \\
\text { variáveis independentes (comparando os coeficientes } \\
\text { padronizados). }\end{array}$ & Garson (2007) \\
\hline
\end{tabular}

Fonte: (JOHNSON; WICHERN, 1998).

\subsection{Modelo de regressão linear múltipla}

$\mathrm{Na}$ regressão linear múltipla assume-se que existe uma relação linear entre uma variável $Y$ (a variável dependente) e $k$ variáveis independentes, $x_{j}(j=1, \ldots, k)$. As variáveis independentes são também chamadas variáveis explicatórias ou regressores, uma vez que são utilizadas para explicarem a variação de $Y$. Muitas vezes são também chamadas variáveis de predição, devido à sua utilização para se predizer $Y$.

As condições subjacentes à regressão linear múltipla são análogas à da regressão linear simples, resumidamente:

1. As variáveis independentes $x_{j}$ são não aleatórias (fixas);

2. Para cada conjunto de valores de $x_{j}$ há uma subpopulação de valores de $Y$. Para a construção dos intervalos de confiança e dos testes de hipóteses deve poder-se assumir que estas subpopulações seguem a distribuição normal;

3. As variâncias das subpopulações de $Y$ são iguais; 
4. Os valores de $Y$ são estatisticamente independentes. Por outras palavras, quando se extrai a amostra, assume-se que os valores de $Y$ obtidos para um determinado conjunto de valores de $x_{j}$ são independentes dos valores de $Y$ obtidos para outro qualquer conjunto de valores de $x_{j}$.

Os dados podem ser organizados conforme TABELA 7-1.

Tabela 7- 1. Matriz utilizada para regressão linear múltipla

\begin{tabular}{c|c|c|c|c}
\hline $\mathbf{y}$ & $\mathbf{x}_{\mathbf{1}}$ & $\mathbf{x}_{2}$ & $\ldots$ & $\mathbf{x}_{\mathbf{k}}$ \\
\hline $\mathbf{y}_{\mathbf{1}}$ & $\mathrm{x}_{11}$ & $\mathrm{x}_{12}$ & $\ldots$ & $\mathrm{x}_{1 \mathrm{k}}$ \\
\hline $\mathbf{y}_{\mathbf{2}}$ & $\mathrm{x}_{21}$ & $\mathrm{x}_{12}$ & $\cdots$ & $\mathrm{x}_{2 \mathrm{k}}$ \\
\hline$\vdots$ & $\vdots$ & $\vdots$ & $\vdots$ & $\vdots$ \\
\hline $\mathbf{y}_{\mathbf{n}}$ & $\mathrm{x}_{\mathrm{n} 1}$ & $\mathrm{x}_{\mathrm{n} 2}$ & $\ldots$ & $\mathrm{x}_{\mathrm{nk}}$ \\
\hline
\end{tabular}

Fonte:(MAROCO, 2003).

Na TABELA 7-1 estão representados os valores de $k$ variáveis independentes (não aleatórias) e os valores da variável resposta (aleatória) depois de efetuada uma determinada experiência para uma amostra de tamanho $n$.

Um modelo de regressão linear múltiplo descreve uma relação entre as k variáveis independentes, $x_{j}$, e a variável dependente, $\mathrm{Y}$, da seguinte maneira:

$Y=\beta+\beta_{1} x_{1}+\beta_{2} x_{2}+\cdots+\beta_{k} x_{k}+\varepsilon$

Designado por modelo de regressão múltipla (convencional) com k regressores. Os, $\mathrm{p}=\mathrm{k}+1$, parâmetros $\beta_{\mathrm{j}}, \mathrm{j}=0,1 \ldots, \mathrm{k}$, são os coeficientes de regressão (parciais) e $\varepsilon$ é o erro aleatório. Este modelo descreve um hiperplano no espaço kdimensional dos regressores $\left\{\mathrm{Xj}_{\mathrm{j}}\right\}$. Em tudo o que se segue iremos supor a presença de $\beta_{0}$ no modelo. Os parâmetros $\beta_{\mathrm{j}}, \mathrm{j}=1, \ldots, \mathrm{k}$ representam a variação 146 
esperada na resposta $Y$ para cada unidade de variação em $\mathrm{xj}$ quando todos os restantes regressores $\mathrm{xi}(i \neq j)$ são considerados constantes em termos experimentais. Assume-se, assim, que o modelo que nos permite descrever a iésima resposta yi é

$y_{i}=\beta_{0}+\beta_{1} x_{i 1}+\beta_{2} x_{i 2}+\cdots+\beta_{k} x_{i k}+\varepsilon_{i}=\beta_{0}+\sum_{j=1}^{k} \beta_{j} x_{i j}+\varepsilon_{i}, i=1, \cdots, n$

Isto é, cada observação $\left(x_{i 1}, x_{i 2}, \cdots, x_{i k}, y_{i}\right), i=1, \cdots, n(n>k)$ satisfaz esta equação. Supõe-se, portanto, que a variável $y$ é função linear de $k$ regressores, do termo independente $(p=k+1$ parâmetros) e do erro aleatório.

Para se proceder ao ajustamento deste modelo de regressão, devido às dificuldades de cálculo no manuseamento do elevado números de parâmetros, é conveniente expressar as operações matemáticas utilizando notação matricial.

O modelo apresentado na equação (2.2) é um sistema de $n$ equações que pode ser representado matricialmente por

$Y=X \beta+\varepsilon$

onde,

$Y=\left[\begin{array}{c}y_{1} \\ y_{2} \\ \vdots \\ y_{n}\end{array}\right], X=\left[\begin{array}{ccccc}1 & x_{11} & x_{12} & \ldots & x_{1 k} \\ 1 & x_{21} & x_{22} & & x_{2 k} \\ & \vdots & & & \vdots \\ 1 & x_{n 1} & x_{n 2} & \cdots & x_{n k}\end{array}\right], \beta=\left[\begin{array}{c}\beta_{0} \\ \beta_{1} \\ \vdots \\ \beta_{k}\end{array}\right]$ e $\varepsilon=\left[\begin{array}{c}\varepsilon_{1} \\ \varepsilon_{2} \\ \vdots \\ \varepsilon_{n}\end{array}\right]$ 


\subsection{Significância do modelo de regressão múltipla}

Até agora assumiu-se um modelo linear da forma $Y=\beta_{0}+\beta_{1} x_{1}+\beta_{2} x_{2}+\cdots+$ $\beta_{k} x_{k}+\varepsilon$ e obtivemos estimadores para os coeficientes de regressão. Queremos verificar se as variáveis independentes, $x_{1}, x_{2}, \cdots, x_{k}$ contribuem significativamente com informação para explicar linearmente a variação da variável resposta (variável dependente) $Y$. Pois quanto maior for esta contribuição melhores serão os resultados da estimação e da predição.

O teste de significância para a regressão é um teste para se determinar se há uma relação linear entre a função resposta $y$ e os regressores $x$, para este efeito podese utilizar um teste de hipótese. Estes testes hipóteses acerca dos parâmetros do modelo de regressão, requerem que os termos do erro $\varepsilon_{t}$ no modelo de regressão sejam normais e independentemente distribuídos com média zero e variância $\sigma^{2}$.

As hipóteses a testar são:

$H_{0}: \beta_{1}=\beta_{2}=\cdots=\beta_{k}$ (Hipótese nula)

$H_{1}: \beta_{j} \neq 0$ para algum $\mathrm{j}, \mathrm{j}=1, \ldots, \mathrm{k}$ (Hipótese alternativa)

Temos, portanto, um teste bilateral face a $n$ observações (a amostra). A hipótese nula que se pretende testar é a não existência de regressão. A rejeição de $H_{0}$ significa que pelo menos umas das variáveis independentes $x_{1}, x_{2}, \cdots, x_{k}$, (regressores) contribui significativamente para explicar a variação da variável dependente $Y$, e esta explicação pode ser representada por um modelo de regressão linear (o modelo diz-se significativo).

Caso não se rejeite $H_{0}$, ter-se-á o modelo $Y=\beta_{0}+\varepsilon$, ou seja, $E[Y]=E\left[\beta_{0}+\varepsilon\right]=$ $\beta_{0}$ (constante), concluindo-se que os $x_{1}, x_{2}, \cdots, x_{k}$ não contribuem para explicar a 148 
variação de $Y$. O que leva à conclusão de que não há relação linear entre as variáveis (mau ajustamento do modelo linear em relação aos dados). O modelo é não significativo e não deve ser utilizado.

Quando se pretende realizar um teste bilateral a análise de variância (Anova) pode ser utilizada para se analisar a significância do modelo de regressão. Para isso, utiliza-se a partição da soma de quadrados, a identidade da análise de variância, $S Q_{T}=S Q_{R}+S Q_{E}$. Em notação matricial temos:

$S Q_{T}=Y^{T} Y-\frac{\left(\sum_{i=1}^{n} y_{i}\right)^{2}}{n}=Y^{T} Y-n \bar{y}^{2}$

$S Q_{T}$, a soma de quadrados total, mede a variação total das observações em torno da sua média.

$S Q_{R}=\hat{\beta}^{T} X^{T} Y-\frac{\left(\sum_{i=1}^{n} y_{i}\right)^{2}}{n}=\hat{\beta}^{T} X^{T} Y-n \bar{y}^{2}$

$S Q_{R}$, a soma de quadrados da regressão, mede a quantidade de variação da variável dependente explicada pela equação de regressão (o modelo).

$S Q_{E}=Y^{T} Y-\hat{\beta}^{T} X^{T} Y$

$S Q_{E}$, a soma de quadrados do erro (residual), é a variação devida ao erro, ou seja, mede a variação não explicada pela regressão (pelo modelo).

O procedimento da análise de variância para a regressão linear múltipla tem a seguinte estrutura: 
Hipótese nula: $H_{0}: \beta_{1}=\beta_{1}=\cdots=\beta_{2}=0$

Hipóteses alternativa: $H_{1}: \beta_{1} \neq 0$ para algum $\mathrm{j}, \mathrm{j}=1, \ldots, \mathrm{k}$;

Estatística de teste: $F_{0}=\frac{M Q_{R}}{M Q_{E}}$, onde $M Q_{R}=\frac{s Q_{R}}{g l_{R}}$ e $M Q_{E}=\frac{s Q_{E}}{g l_{E}}$

Critério de rejeição: $f_{0}>f_{t}=f_{\alpha}[k, n-p]$

Que pode ser sumariado na seguinte TABELA 7-2.

Tabela 7- 2. Anova para regressão linear múltipla

\begin{tabular}{ccccc}
\hline $\begin{array}{c}\text { Fonte de } \\
\text { variação }\end{array}$ & $\begin{array}{c}\text { Graus de } \\
\text { liberdade }\end{array}$ & $\begin{array}{c}\text { Soma de } \\
\text { quadrados }\end{array}$ & $\begin{array}{c}\text { Média } \\
\text { quadrática }\end{array}$ & $\mathrm{F}_{\mathrm{o}}$ \\
\hline $\begin{array}{c}\text { Regressão } \\
\text { (modelo) }\end{array}$ & $\mathrm{K}$ & $\mathrm{SQ}_{\mathrm{R}}$ & $\mathrm{MQ}_{\mathrm{R}}$ & $\frac{M Q_{R}}{M Q_{E}}$ \\
\hline Erro (residual) & $\mathrm{n}-\mathrm{p}$ & $\mathrm{SQ}_{\mathrm{E}}$ & $\mathrm{MQ}_{\mathrm{E}}$ & - \\
\hline Total & $\mathrm{n}-1$ & $\mathrm{SQ}$ & - & - \\
\hline
\end{tabular}

Fonte: (MAROCO, 2003).

Assim, relativamente à hipótese $\mathrm{H}_{0}: \beta_{1}=\beta_{2}=\ldots=\beta_{\mathrm{k}}=0$, rejeita-se a hipótese nula, com um grau de significância $\alpha$, se o valor da estatística de teste, $F_{0}$ (valor de $F$ observado a partir da regressão), for maior do que o valor de $F_{t}$ (valor Tabelado para a distribuição $F)\left.\operatorname{com} g\right|_{R}=k$ e $\left.g\right|_{E}=n-k$ graus de liberdade. Resumindo:

i) $\quad \mathrm{Se}_{0} \leq \mathrm{f}_{\alpha}[k, n-p]=>$ não se rejeita $\mathrm{H}_{0}$

ii) $\quad$ Se $f_{0}>f_{\alpha}[k, n-p]=>$ rejeição de $H_{0}$, ou seja, não rejeitar $H_{1}$.

Caso se verifique ii) conclui-se, com (1- $\alpha) \times 100 \%$ de confiança, que o modelo é significativo, isto é, que pelo menos um $x_{j}, j=1, \ldots, k$, contribui significativamente para explicar a variação de $Y$. 


\subsection{Coeficiente de determinação}

Tal como no modelo de regressão simples o coeficiente de determinação é dado por:

$R^{2}=\frac{S Q_{R}}{S Q_{T}}=1-\frac{S Q_{E}}{S Q_{T}}$

Este coeficiente é uma medida da proporção da variação da variável resposta $Y$ que é explicada pela equação de regressão quando estão envolvidas as variáveis independentes $\mathrm{x}_{1}, \mathrm{x}_{2}, \ldots, \mathrm{x}_{\mathrm{k}}$. Devido à identidade da análise de variância $0 \leq R^{2} \leq 1$. Contudo, um grande valor de $\mathrm{R}^{2}$ não implica necessariamente que o modelo de regressão seja um bom ajustamento, uma vez que a adição de uma variável aumenta sempre o valor deste coeficiente (a adição de uma variável ao modelo faz sempre com que a soma de quadrados da regressão aumente), sem ter em conta se a variável que se adiciona é ou não estatisticamente significativa. Assim, modelos com um elevado valor de $\mathrm{R}^{2}$ podem produzir predições pouco confiáveis de novas observações ou estimativas pouco confiáveis do valor esperado de $Y$. Por este motivo $R^{2}$ não será um bom indicador do grau de ajustamento do modelo. Por este fato, alguns investigadores preferem utilizar o coeficiente de determinação ajustado.

$R_{\text {ajust. }}^{2}=1-\frac{\frac{S Q_{E}}{n-p}}{\frac{S Q_{T}}{n-1}}=1-\left(\frac{n-1}{n-p}\right)\left(1-R^{2}\right)$

Este coeficiente dá uma melhor idéia da proporção de variação de $Y$ explicada pelo modelo de regressão, uma vez que leva em conta o número de regressores. Ao 
contrário do que acontecia com o coeficiente de determinação múltiplo, $R_{\text {ajust. não }}^{2}$ aumenta sempre, quando uma nova variável é adicionada ao modelo. Este só aumenta se de alguma maneira, quando houver vantagem na adição de uma nova variável. De facto, se forem adicionados termos desnecessários, o valor de $R_{\text {ajust. }}^{2}$, na maior parte dos casos decresce. Quando a diferença entre $R^{2}$ e $R_{\text {ajust. é }}^{2}$ acentuada, há uma boa hipótese de que tenham sido incluídos no modelo termos estatisticamente não significativos.

\subsection{Testes de significância para os coeficientes de regressão}

Na regressão múltipla, temos muitas vezes o interesse de testar hipóteses sobre os coeficientes de regressão. Estas constituem outra maneira de se determinar o potencial de cada regressor no modelo de regressão. Por exemplo, o modelo pode tornar-se mais eficaz com a inclusão de novas variáveis ou com a exclusão de uma ou mais variáveis existentes no modelo. A inclusão de uma variável ao modelo faz, sempre, aumentar a soma de quadrados da regressão e diminuir a soma de quadrados do erro. Deve-se decidir se o aumento na soma de quadrados do erro justifica a inclusão da nova variável. Para além disso, a inclusão de uma variável pouco importante ao modelo pode fazer com que a média quadrática do erro aumente, fazendo decrescer a utilidade do modelo (isto é, indicando que esta inclusão não faz sentido, uma vez que "empobrece" o grau de ajustamento do modelo aos dados).

Um teste de significância para os coeficientes de regressão, os $\beta_{j}$ 's, é elaborado de modo seguinte:

Hipótese nula $\mathrm{H}_{0}: \beta_{j}=0$;

Hipótese alternativa: $\mathrm{H}_{1}: \beta_{j} \neq 0$;

Estatística de teste: $T_{0}=\frac{\beta_{j}}{s e\left(\beta_{j}\right)}$, onde se $\beta_{j}$ é dado por (2.15)

Região de rejeição: $\left|t_{0}\right|>t_{1}=t_{\alpha / 2}[n-p]$. 
Se $H_{0}$ não for rejeitada, isto indica que o regressor $x_{j}$ pode ser "eliminado" do modelo. Este teste é considerado parcial uma vez que o coeficiente de regressão $\beta_{j}$ depende de todos os outros regressores $x_{i}(i \neq j)$ existentes no modelo. 


\section{Capítulo 8 - Metodologia}

\subsection{Plano de amostragem}

O estudo iniciou com a proposta de avaliar e comparar a performance dos cilindros não revestidos e revestidos em diferentes tipos de materiais de chapa laminada não revestida. Portanto, um estudo em diferentes empresas de laminação de planos, de materiais ferrosos (aço) e não ferrosos (alumínio e cobre).

Um dos objetivos dos cilindros utilizados no processo de laminação a frio, é a transferência de rugosidade para a chapa laminada. $O$ valor da rugosidade e o método utilizado para obtê-la, conforme estratégia de cada empresa na garantia do atendimento às necessidades do cliente. Para tal, os métodos convencionais e disponíveis nas empresas que realizada as amostragens, conforme FIGURA 8-1.

Figura 8- 1. Plano de amostragem - Etapa 1

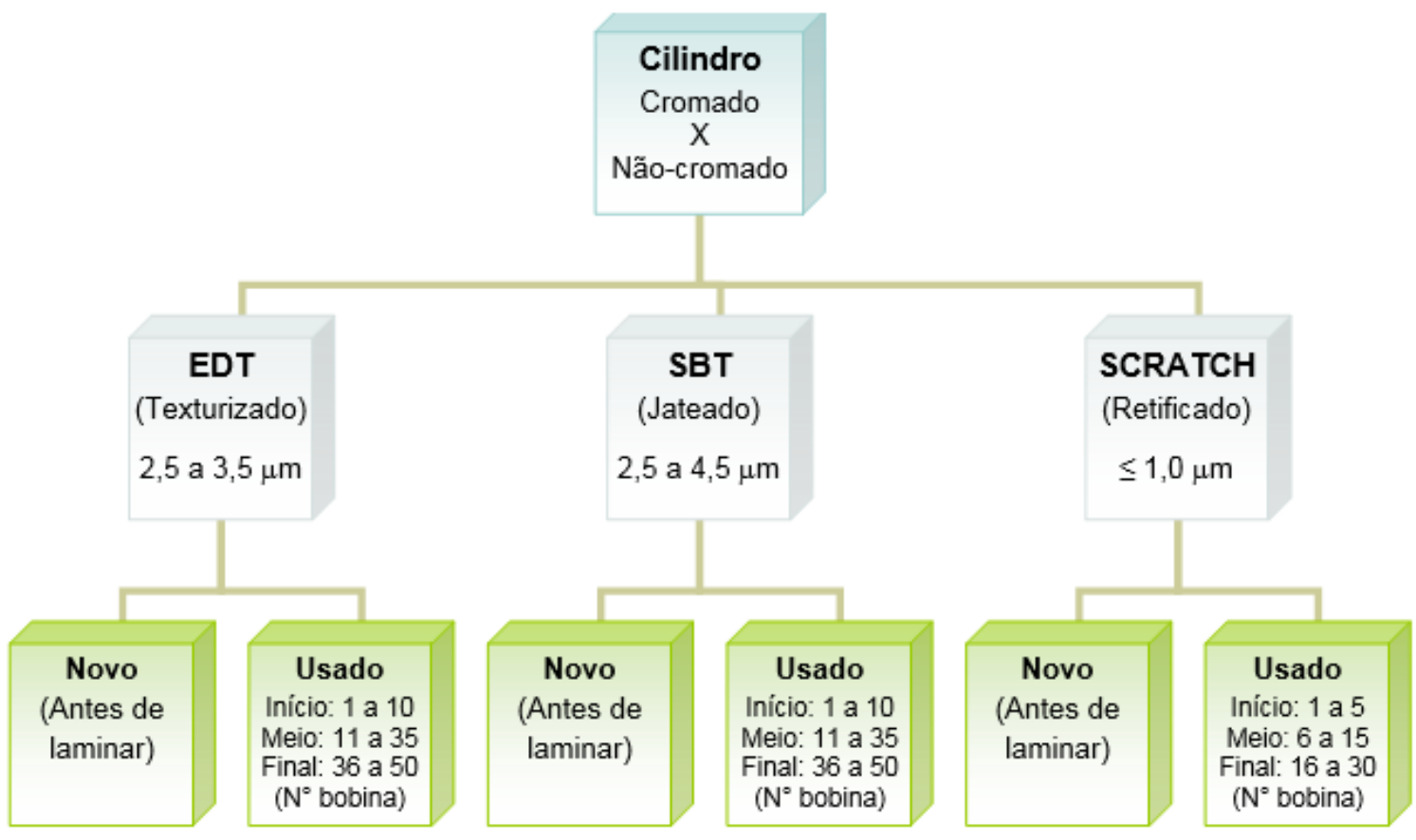

Fonte: (Autor). 
Conceituando a condição da topografia de superfície do cilindro, temos:

I. Cilindro novo: é o cilindro de trabalho usinado na oficina de cilindros, pronto para retornar ao laminador. Podendo este, ter sido aplicado o revestimento ou não de cromo duro.

II. Cilindro usado: é o cilindro em processo de laminação, com a superfície da mesa desgastada. Sendo que este desgaste, aumenta com número de bobinas laminadas. Podendo este, ter sido aplicado o revestimento ou não de cromo duro.

A utilização da réplica de resina epóxi durante o processo de amostragem, se justifica, devido a impossibilidade de realizar amostra da condição real do cilindro durante o processo de laminação. A aplicação da resina nos cilindros de laminação realizado conforme FIGURA 8-2.

Figura 8-2. Amostragem da aplicação de resina na mesa do cilindro

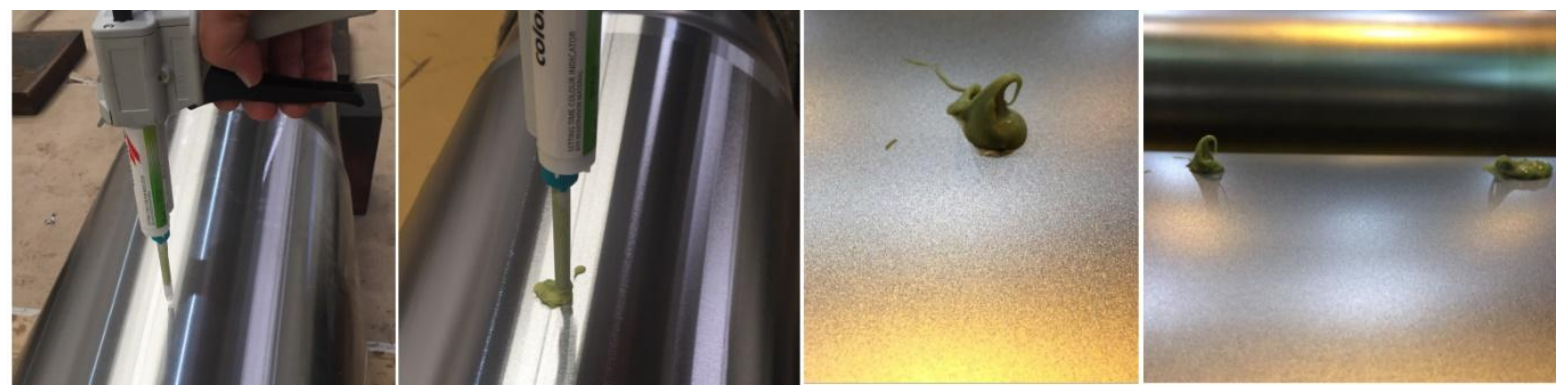

Fonte: (Autor - aplicador e resina epóxi).

Tivemos certa dificuldade para encontrar a melhor réplica, ou seja, aquela que permitisse extrair da superfície do cilindro o maior número de informações em um curto período de tempo, em torno de 2 minutos, devido principalmente ao custo da parada do laminador.

As réplicas utilizadas no processo de amostragem, são de resinas epóxi, constituída de duas cápsulas, sendo uma contendo a resina e a outra, o catalizador. Na ponta final do aplicador, é utilizado um misturador que garante à resina final, um material altamente viscoso, permitindo uma eficiente penetração e 
contorno de todos os orifícios (picos e vales) do cilindro amostrado e ainda, rápida secagem da resina aplicada na superfície do cilindro, devido ação do catalizador misturado previamente, altamente necessária para fixação da imagem da superfície e otimização no processo de amostragem.

Estabelecido os locais de amostragem na superficie do cilindro para a coleta de dados, conforme FIGURA 8-3.

Figura 8-3. Região de amostragem da resina na mesa do cilindro de laminação.

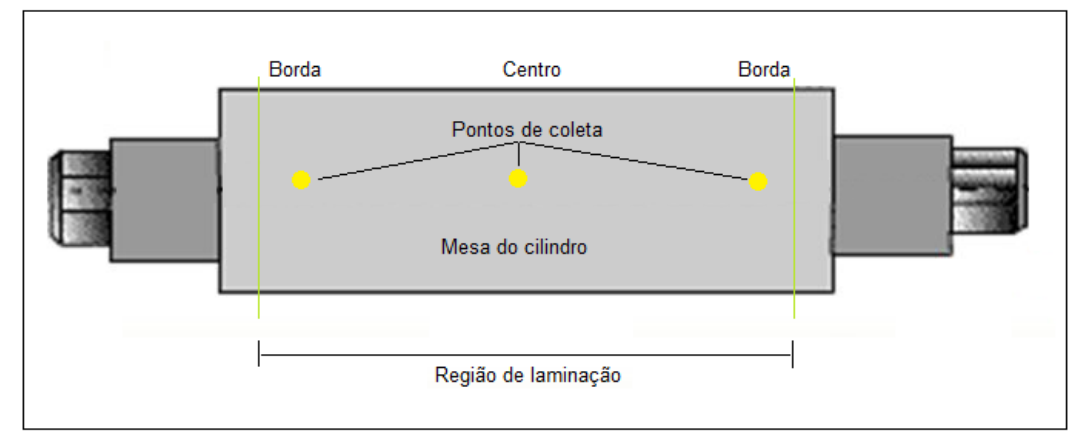

Fonte: (Autor - desenho esquemático cilindro).

As réplicas foram aplicadas nos cilindros de trabalho, em 3 posições estratégicas na mesa do cilindro de laminação garantindo assim, a amostragem nas regiões críticas do cilindro, ou seja, regiões onde são aplicadas cargas para correção do aplainamento da chapa durante a laminação. A amostragem nestes locais tem o objetivo de minimizar o efeito desta variação ao longo da seção transversal. Ressaltando que os pontos de amostragem localizados na borda do cilindro, foram previamente estabelecidos em função das dimensões das chapas nas respectivas empresas e laminadores.

Outro fator crítico da amostragem e fundamental na busca da melhor representabilidade do processo de laminação, foi a dificuldade de interromper o processo de laminação para realizar a amostragem no cilindro, devido principalmente ao custo elevado da parada do laminador. Para tal, foi realizado várias reuniões com as respectivas empresas e uma agenda de amostragem, 156 
estabelecendo parada para amostragem, estabelecendo: quantidade de amostras ao longo do cone de laminação e principalmente, tempo parada para coleta, inferior a 5 minutos. A boa qualidade da resina e sua capacidade de secagem, após aplicação na superficie do cilindro, em torno de 1 minuto, foi determinante para atendermos os requisitos solicitados na amostragem e, na obtenção de excelentes resultados de reprodutibilidade da imagem da superfície do cilindro.

Outra dificuldade identificada, foi a dinâmica dos cones de laminação, ou seja, alteração do programa de produção, é uma rotina para os laminadores. Esta condição, torna complexa e longa a execução do planejamento de amostragem. Impactando na necessidade de reamostragem.

O cone de laminação, define-se como "a quantidade de bobinas produzidas com o mesmo conjunto de cilindros", conforme FIGURA 8-4. Sendo portanto, de certa importância, a busca do aumento do cone de laminação e consequente, aumento de produtividade do laminador e menor custo de processo e produto laminado, a utilização do revestimento de cromo na superfície do cilindro.

O critério de amostragem, em função do cone de laminação, realizado conforme critério abaixo:

- Amostra I: retirar amostra do cilindro, após processamento da segunda bobina do cone de laminação.

- Amostra II: retirar amostra do cilindro, após processamento da(s) bobina(s) que estiverem na metade do cone de laminação.

- Amostra III: retirar amostra do cilindro, após processamento da penúltima bobina do cone de laminação. 
Figura 8-4. Desenho esquemático do cone de laminação e campanha do cilindro

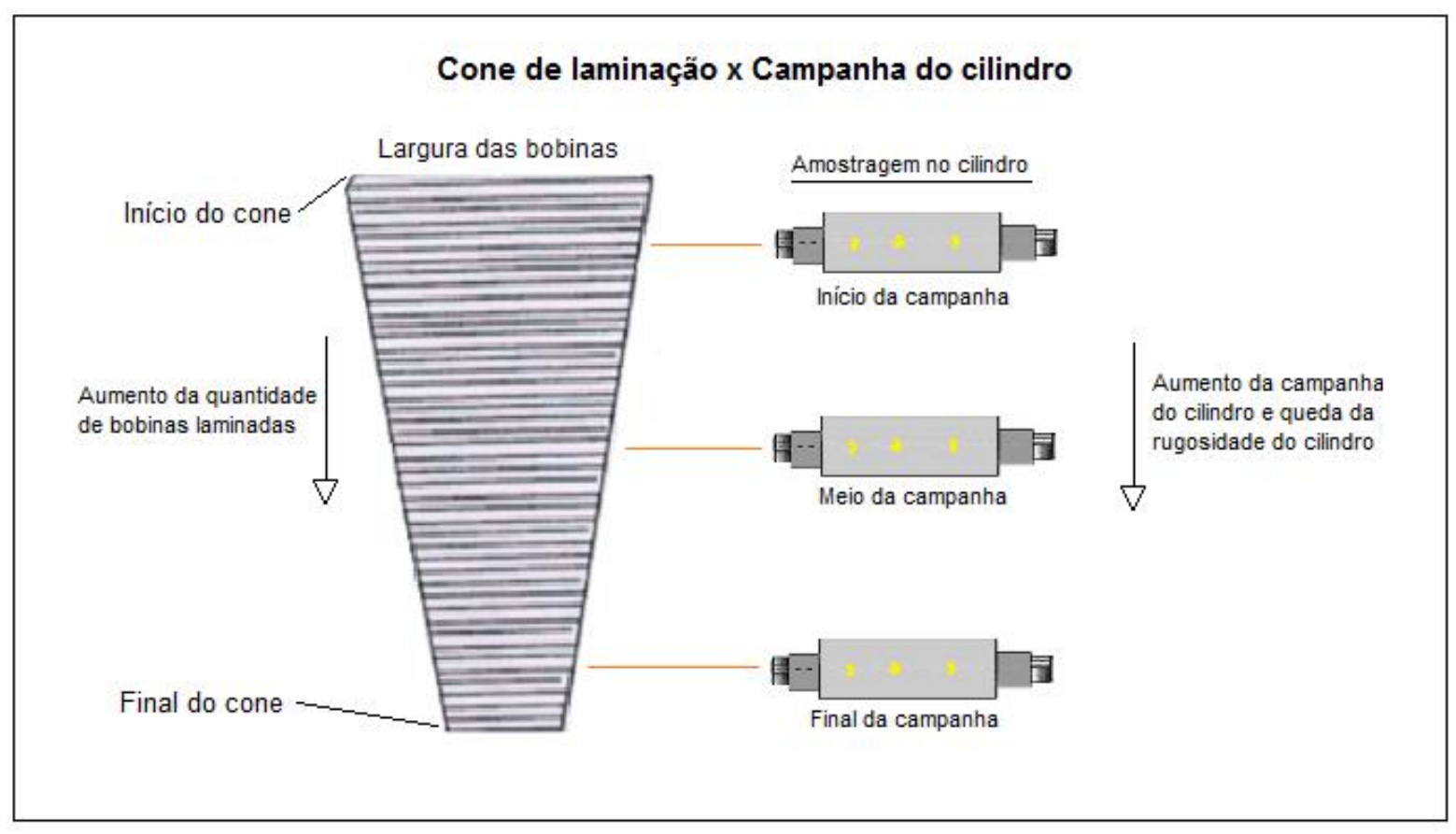

Fonte: (Autor).

O plano de amostragem foi dividido em duas etapas:

Etapa 1: coleta de dados nos diferentes cilindros, nas respectivas empresas de laminação.

Etapa 2: leitura e análise das réplicas aplicadas nas superfícies dos cilindros.

$\mathrm{Na}$ Etapa 1, consistiu em definir o tipo de textura do cilindro (EDT, SBT, SCRATCH), o laminador a ser processado de cada empresa, o tipo de cilindro (Forjado, Fundido), o tipo de material da chapa laminada (aço, cobre e alumínio), conforme FIGURA 8-5.

Os processos de laminação apresentam as seguintes características:

Laminação de aço: cilindro do laminador de tiras a frio das empresas $A$ e $B$ Laminação de cobre: cilindro do laminador a frio da empresa $C$ 
Laminação de alumínio: cilindro do laminador a frio da empresa D

Figura 8- 5. Plano de amostragem - Etapa 1

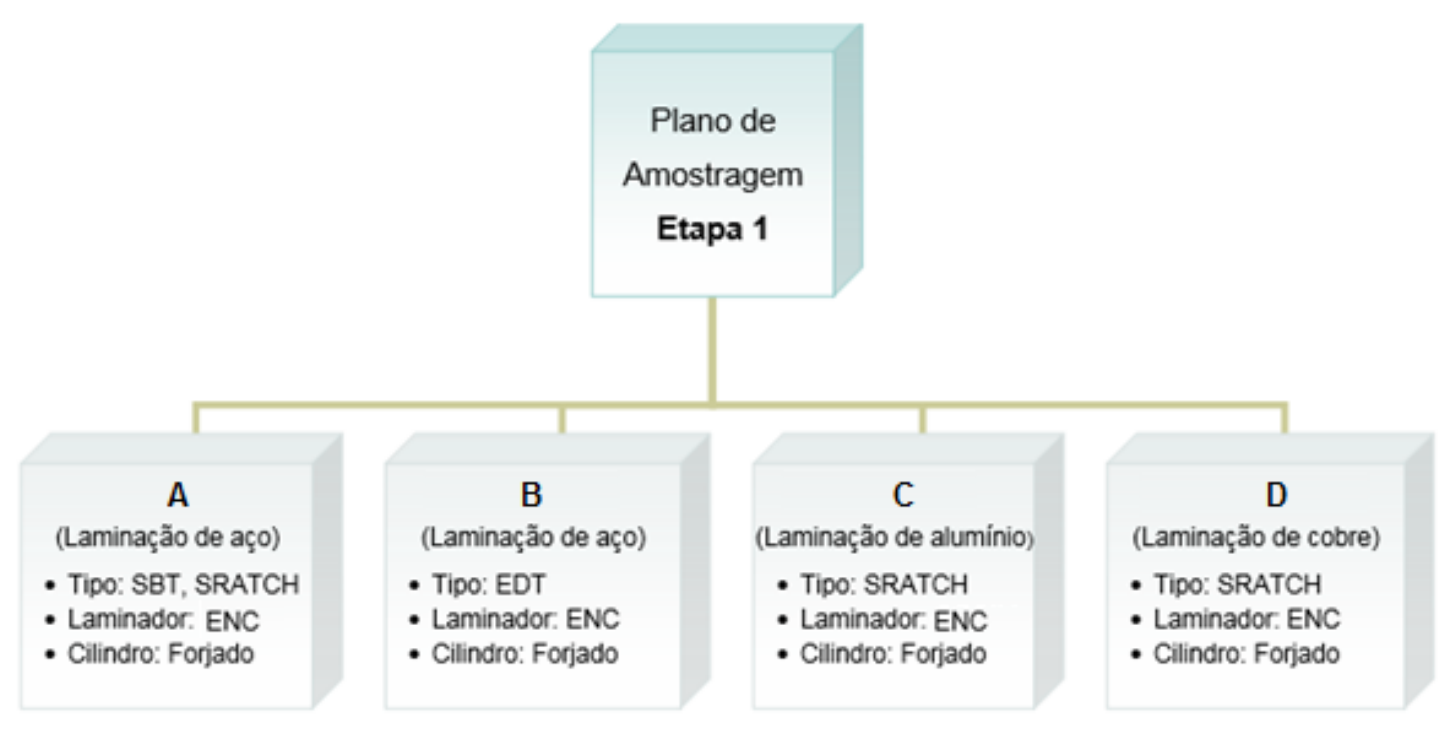

Fonte: (Autor).

A Etapa 2 do plano de amostragem, consistiu em analisar as 162 réplicas de resina epóxi, retiradas da superfície dos cilindros, conforme FIGURA 8-1, que foram submetidos à diversas condições de desgastes superficiais.

$\mathrm{Na}$ etapa 2, conforme FIGURA 8-6, realizada no Laboratório de Fenômenos de Superfície (LFS), do Departamento de Mecânica da USP, a leitura da topografia de superfície das réplicas, utilizando o equipamento interferômetro. Tanto os mecanismos de funcionamento do interferômetro, como os procedimentos de preparação e especificação do equipamento, estão descritos no CAPÍTULO 8.3.

Em seguida utilizamos três softwares para realizar a interpretação e análise dos dados gerados pelo interferômetro, sendo:
I. SOM - Self-organising Maps
II. SPSS - Statistical Package for the Social Sciences
III. Excel - planilha de dados do pacote Windows 


\section{Action - software estatístico}

Figura 8- 6. Plano de amostragem - Etapa 2

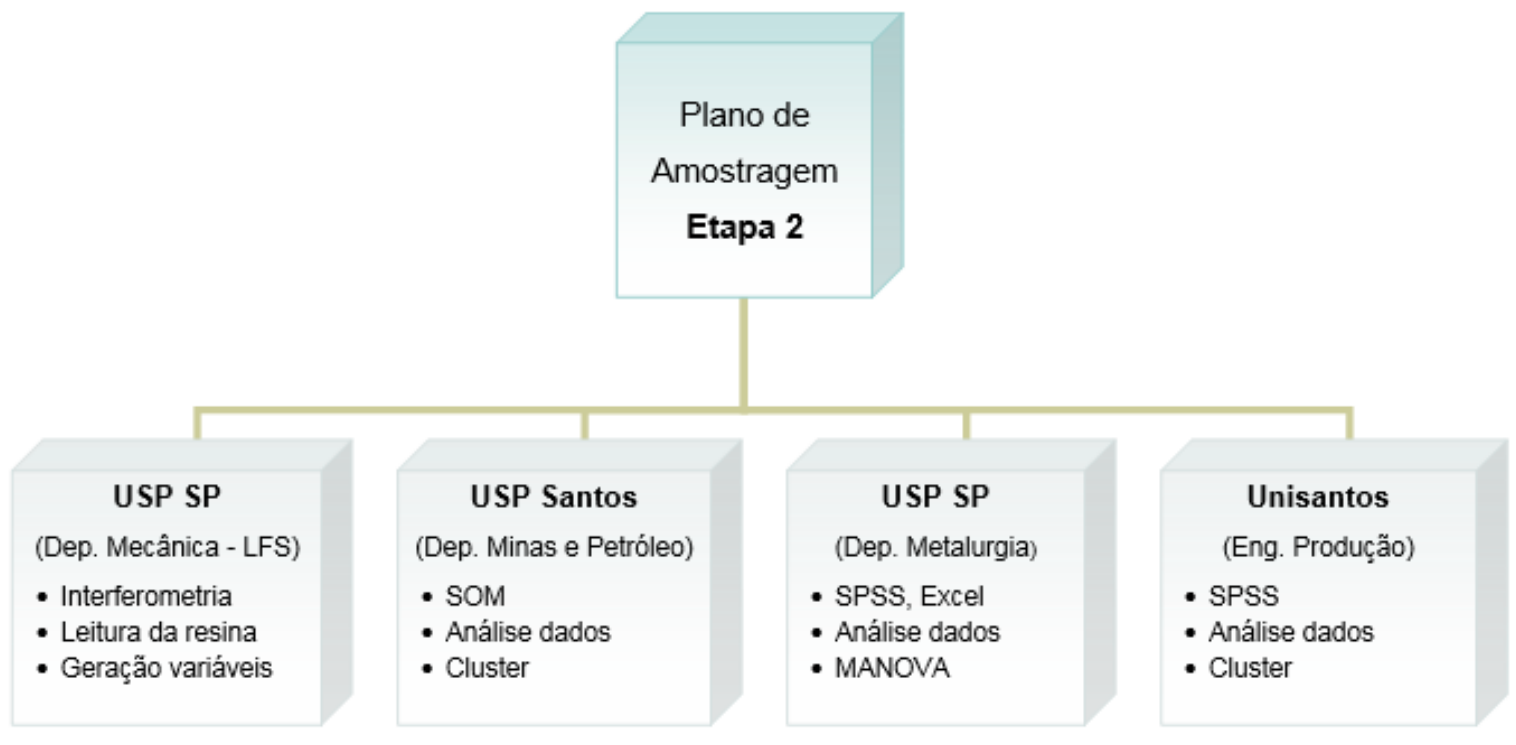

Fonte: (Autor).

Estes métodos foram escolhidos em função da interatividade entre os mesmos, gerando resultados mais consistentes e devido a particularidade de cada método, sendo:

SOM - devido sua capacidade de utilizar aproximação dos pontos similares onde os mesmos são processados separadamente e permite ao mapa obter centros em um plano bidimensional disponibilizando uma visualização facilmente compreensível.

SPSS - por possuir um pacote de apoio à tomada de decisão que inclui: aplicação analítica, mineração de dados, mineração de texto e estatística que transformam os dados em informações importantes.

ACTION - Permite que você trabalhe junto com o Excel, de forma integrada. Utiliza ainda, a seleção de variáveis para se chegar a um modelo, com objetivo de construir um modelo que seja bom para obter predições ou que explique bem o relacionamento entre os dados. 


\subsubsection{Validação da réplica através de método comparativo}

A utilização de réplicas (resina epóxi) para coletar as informações de desgaste da superfície dos cilindros de laminação, tem se tornado uma prática cada vez mais comum quando se quer avaliar a topografia de superfície em grandes peças, principalmente pela qualidade das informações transferidas da peça para a réplica.

Para validação da qualidade da réplica, realizamos uma análise estatística comparativa, especificamente o coeficiente de correlação, utilizando o padrão de aferição do rugosimetro em comparação com a réplica aplicada sobre o mesmo.

Realizado a leitura no interferômetro diretamente no padrão de aferição e, posteriormente, na réplica utilizada para amostrar o padrão de aferição.

Foram utilizados um padrão de aferição, com diferentes rugosidades, conforme apresentado na TABELA 8-1. Os parâmetros de rugosidade obtidos das duas situações, apresentaram um alto coeficiente de correlação dos principais parâmetros de rugosidade 3D gerados pelo interferômetro. Validando, portanto, a qualidade e capacidade da resina representar as características topográficas da superfície do cilindro. Estudo similar com réplicas, que foram adquiridas e validado por LEITE et al. (2011), para amostragem da superfície do cilindro.

Tabela 8-1. Coeficiente de correlação da réplica.

\begin{tabular}{|c|c|c|c|c|c|c|}
\hline \multirow{2}{*}{ Parâmetro } & \multicolumn{4}{|c|}{ Avaliação comparativa do padrão de aferição versus réplica } \\
\cline { 2 - 7 } & \multicolumn{3}{|c|}{ Ra (bloco padrão) } & \multicolumn{3}{c|}{ Ra (réplica epóxi) } \\
\hline & Medição 1 & Medição 2 & Medição 3 & Medição 1 & Medição 2 & Medição 3 \\
\hline Sq & 0,885 & 0,881 & 0,879 & 0,886 & 0,879 & 0,882 \\
\hline Ssk & 0,133 & 0,135 & 0,131 & 0,130 & 0,115 & 0,127 \\
\hline Sku & 1,558 & 1,562 & 1,551 & 1,560 & 1,542 & 1,555 \\
\hline Sp & 1,571 & 1,578 & 1,569 & 1,528 & 1,571 & 1,543 \\
\hline Sv & 1,437 & 1,435 & 1,432 & 1,450 & 1,457 & 1,462 \\
\hline Sz & 3,009 & 3,019 & 3,031 & 2,979 & 2,983 & 2,991 \\
\hline Sa & 0,790 & 0,718 & 0,732 & 0,791 & 0,795 & 0,798 \\
\hline
\end{tabular}

\begin{tabular}{|l|l|l|l|}
\hline $\begin{array}{l}\text { Coeficiente } \\
\text { correlação }\end{array}$ & 0,999812 & 0,999272 & 0,9994628 \\
\hline
\end{tabular}


Fonte: (Autor - Excel).

A FIGURA 8-7 apresenta o interferômetro 3D - Talysurf $\mathrm{CCl}$ analisando uma réplica de resina epóxi amostrada do cilindro de laminação.

Figura 8- 7. Análise de réplica através do Interferômetro CCI

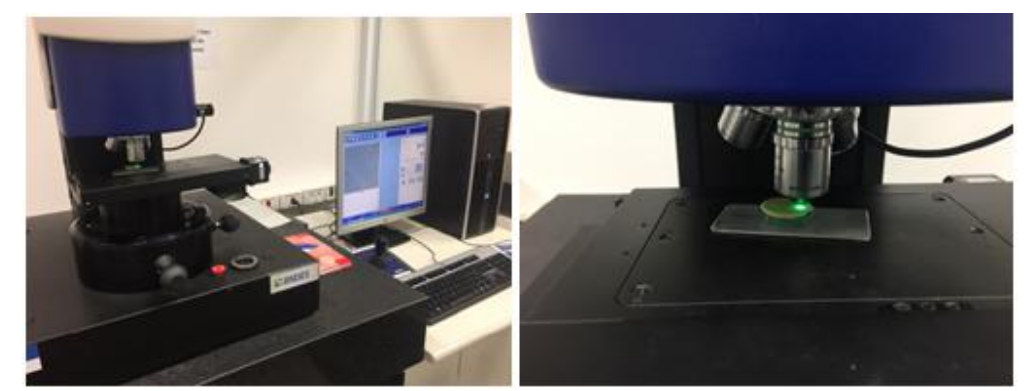

Fonte: (Autor - CCl Taylor Robson)

\subsection{Interferometria 3D}

Para iniciar as medições via interferometria 3D, primeiramente foram selecionados os parâmetros de medição (área de medição, densidade de pontos na direção x, densidade de pontos da direção y, taxa de medição e modo de medição). Usou-se uma densidade de pontos de 1000×100 pontos nas direções de movimentação do sensor $(x)$ e perpendicular $(y)$, respectivamente. A taxa de medição foi de 300 pontos/s e o modo de medição foi contínuo. Para a avaliação dos mecanismos de desgaste ocorridos no cilindro de laminação, bem como para a avaliação das modificações superficiais, as medições foram realizadas em áreas de $5 \times 5 \mathrm{~mm}$.

Após a realização das medições, foram realizadas análises das imagens utilizando o software Digital Surf Mountains Map Universal, versão 3.0. Importante ressaltar que os materiais de réplicas invertem a topografia original do cilindro, de forma que se obtém uma imagem negativa da topografia superficial real do cilindro. Após a caracterização topográfica das réplicas via interferometria a laser, foi utilizada uma função do software que promove o espelhamento em relação ao eixo $z$, de forma a obter-se uma imagem que correspondesse à superfície real do cilindro.

Para a quantificação da topografia das superfícies, o presente trabalho utilizou parâmetros topográficos tridimensionais. Os parâmetros tridimensionais, são bem 
conhecidos da literatura e definidos pela Comissão da Comunidade Europeia (STOUT et al., 1993; STOUT, 2000). Os parâmetros tridimensionais são extrapolações dos parâmetros bidimensionais definidos pela norma ISO 4287 (1997). Enquanto os parâmetros bidimensionais são quantificações do perfil de rugosidade, os parâmetros tridimensionais são definidos em comparação ao plano médio da superfície e calculado através do nivelamento usando o método dos mínimos quadrados aplicado à superfície de medida.

\subsection{Texturização do cilindro}

O tipo de texturização do cilindro é uma variável importante na relação de desgaste chapa/cilindro durante o processo de laminação. No entanto, para o nosso estudo, o aspecto de rugosidade ou acabamento, é uma das principais variáveis de análise deste trabalho.

As amostras em estudo foram obtidas em diferentes tipos de processos de laminação, já discutido anteriormente, com diferentes processos de acabamento, sendo:

- Texturização por descarga elétrica (EDT): chapas de aço;

- Texturização por jateamento abrasivo (SBT): chapas de aço;

- Texturização com rebolo na retífica: chapas de aço, cobre e alumínio.

As amostras utilizadas neste trabalho a partir do processo de texturização por descarga elétrica e jateamento abrasivo, são específicos aos cilindros que laminam chapas de aço. E as amostras referente ao processo de texturização com rebolo, tem aplicação em todos os tipos de laminação de aço, cobre e alumínio.

\subsection{Revestimento de cromo duro}


As etapas de revestimentos de cromo foram realizadas para os 3 tipos de laminação: aço, cobre e alumínio. No entanto, para as laminações de cobre e alumínio, devido a baixa carga de laminação e aplicações das chapas laminadas, convencionalmente não se utiliza altos valores do parâmetro de rugosidade, utilizando para tal a retífica para se obter a rugosidade na superfície do cilindro.

As amostras coletadas apresentam diferentes grupos, conforme o tipo de chapa laminada e texturização, com os seguintes padrões de revestimento e acabamento:

- Cilindro cromado e jateado: chapa de aço;

- Cilindro não-cromado e jateado: chapa de aço;

- Cilindro cromado e EDT: chapa de aço;

- Cilindro não-cromado e EDT: chapa de aço;

- Cilindro cromado e retificado: chapa de aço, cobre e alumínio;

- Cilindro não-cromado e retificado: chapa de aço, cobre e alumínio.

\subsection{Parâmetros processo de cromagem}

Para esta etapa de revestimento de cromo duro, todos os cilindros após estabelecidas suas rugosidades seja, por EDT, SBT ou SCRATCH, os mesmos são enviados para a CRC do Sul para aplicação da camada de cromo, localizada na cidade de Mauá - SP. A deposição do revestimento nas amostras foi feita em banho sem aditivos, em uma temperatura entre 55 e $60^{\circ} \mathrm{C}$ e corrente entre 30 e 35 $\mathrm{A} / \mathrm{dm}^{2}$, conforme FIGURAS 8-8 e 8-9 
Figura 8-8. Processo de cromagem de cilindros

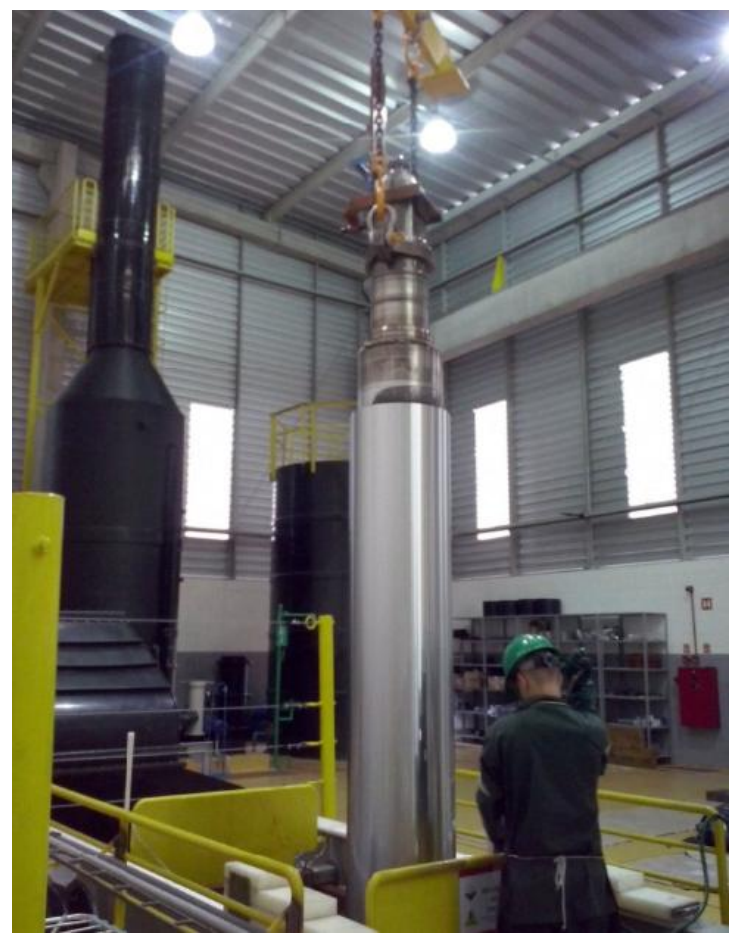

Fonte: (Autor - Tanque de cromagem CRC Mauá)

Figura 8- 9. Unidade de cromagem da CRC Mauá

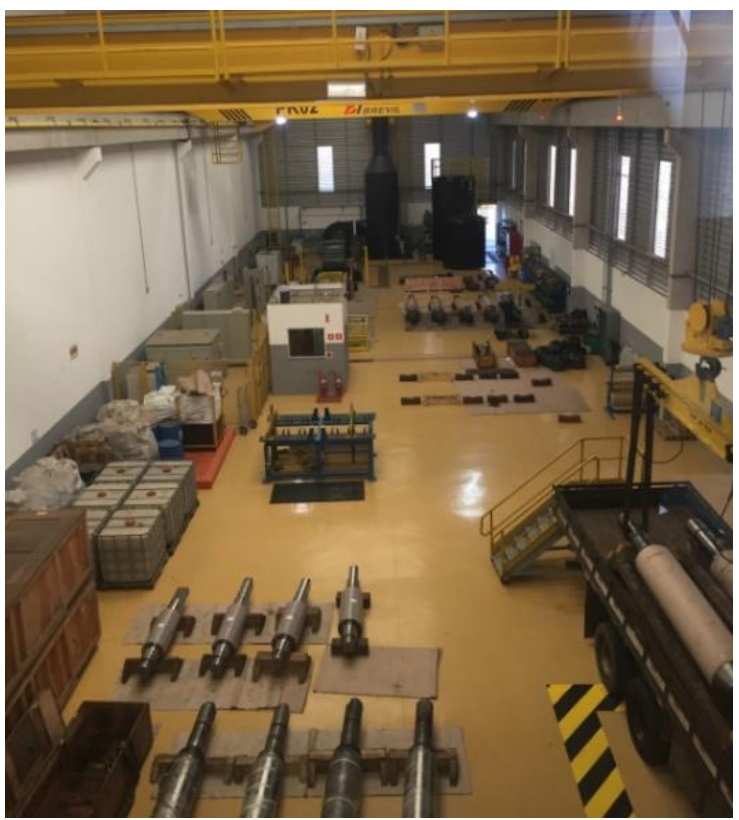

Fonte: (Autor - Unidade de produção CRC Mauá) 
Este processo de cromagem superficial dos cilindros de trabalho nos laminadores a frio, busca o aumento da resistência ao desgaste através do depósito de uma camada de cromo entre 3 a 8 mícrons, com dureza superficial elevada, conforme FIGURA 8-10. Esta nova condição de revestimento de cromo no cilindro, permite a formação de cones dinâmicos de laminação e menores taxas de desgaste, com aumento da quilometragem laminada.

Os tipos de materiais utilizados neste estudo foram:

1-) Aço

- Aço baixa liga - a soma dos teores de todos os elementos liga adicionados não ultrapassa $5 \%$ de todo o material;

- Aço média liga - a soma dos teores de todos os elementos liga fica entre $5 \%$ e $12 \%$ de todo o material;

2-) Alumínio

Liga 5005 - utilizada em coberturas para construção civil (telhas); calhas e forros; carrocerias de ônibus e furgões; utensílios domésticos; equipamentos para indústria química e alimentícia.

São ligas do grupo alumínio-magnésio, nas quais o magnésio é o principal elemento de liga.

São dúcteis no estado recozido, mas endurecem rapidamente sob trabalho a frio; possuem excelente soldabilidade e alta resistência à corrosão em ambientes marítimos. Em geral a resistência mecânica aumenta com os teores crescentes de magnésio.

3-) Cobre

- Ligas: C10200, C10400, C11000 - ligas com propriedades mecânicas variadas em função do teor de estanho, que tem como principal função o aumento da resistência à corrosão, elevando significativamente a resistência mecânica. 
Figura 8- 10. Processo de limpeza e cromagem do cilindro de laminação a frio
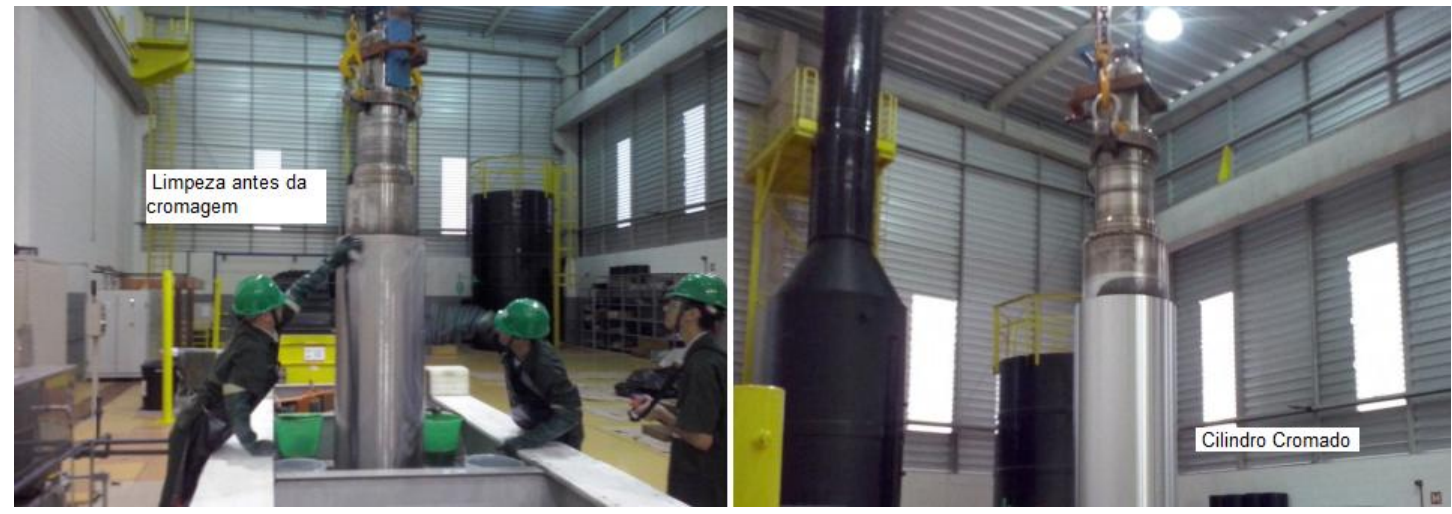

Fonte: (Autor - Unidade de limpeza CRC Mauá)

\subsection{Parâmetros funcionais}

Os parâmetros de rugosidade analisados para a caracterização das réplicas foram escolhidos por já terem sidos usados na literatura e foram Sa, Sz, Sq, Ssk, Sku, Sp, Sv, Vm, Vmc, Vvc e Vvv.

\subsubsection{Parâmetro de amplitude Sa}

O parâmetro Sa (altura média aritmética), é a extensão de Ra (altura de uma linha média aritmética) para uma superfície. Expressa, como um valor absoluto, a diferença na altura de cada ponto comparado com a média aritmética da superfície. Este parâmetro é usado geralmente para avaliar a rugosidade superficial.

$S_{a}=\frac{1}{A} \iint_{A}|Z(x, y)| d x d y$ 
Figura 8- 11. Altura média aritmética da superfície

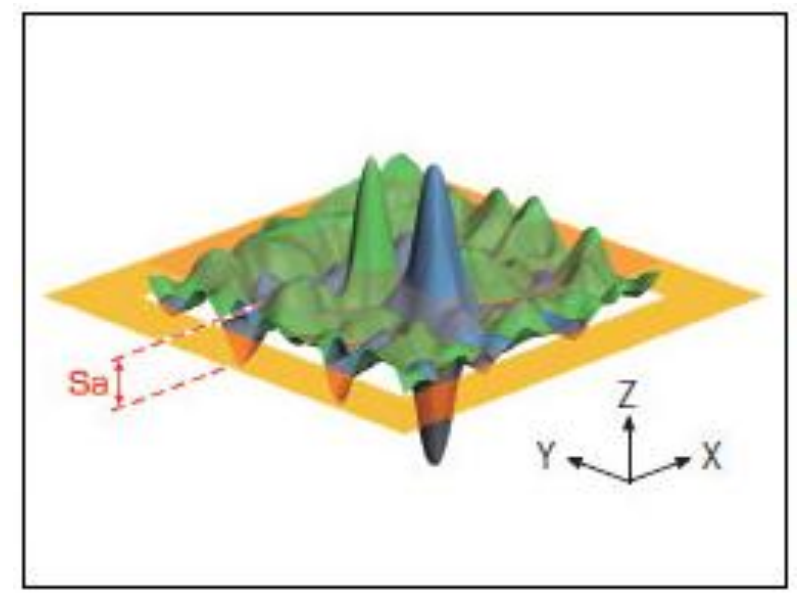

Fonte: STOUT, K. J. (2000).

\subsubsection{Parâmetro de amplitude Sz}

O parâmetro Sz (altura máxima), é definida como a soma do valor da altura do maior pico e o valor da profundidade do maior vale dentro da área definida.

$S_{z}=S_{p}+S_{v}$

Onde:

$S_{p}=$ pico maior

$\mathrm{S}_{\mathrm{v}}=$ vale maior 
Figura 8- 12. Altura máxima entre o maior pico e o maior vale

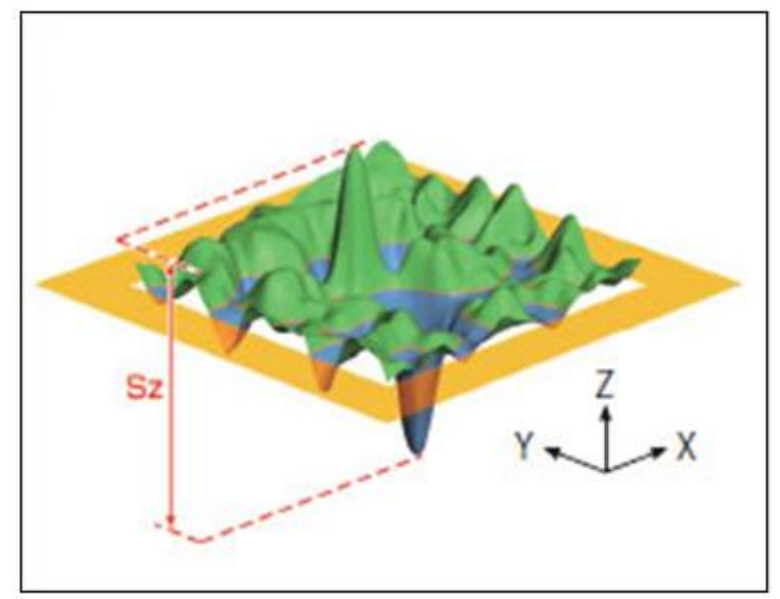

Fonte: STOUT, K. J. (2000)

\subsubsection{Parâmetro de amplitude Sq}

O parâmetro de amplitude $\mathrm{Sq}$ representa a rugosidade superficial quadrática média, e é o valor RMS das alturas em relação ao plano médio da superfície, calculado por meio da Equação 3.1 (DONG; SULLIVAN; STOUT, 1994).

$S_{q}=\sqrt{\frac{1}{A} \iint_{A} Z^{2}(x, y) d x d y}$

Onde:

$M=$ número de pontos na direção $x$

$\mathrm{N}$ = número de pontos na direção $\mathrm{y}$

$\mathrm{Z}=$ altura relativa ao ponto de coordenadas $(\mathrm{k}, \mathrm{i})$ 
Figura 8- 13. Rugosidade média quadrática

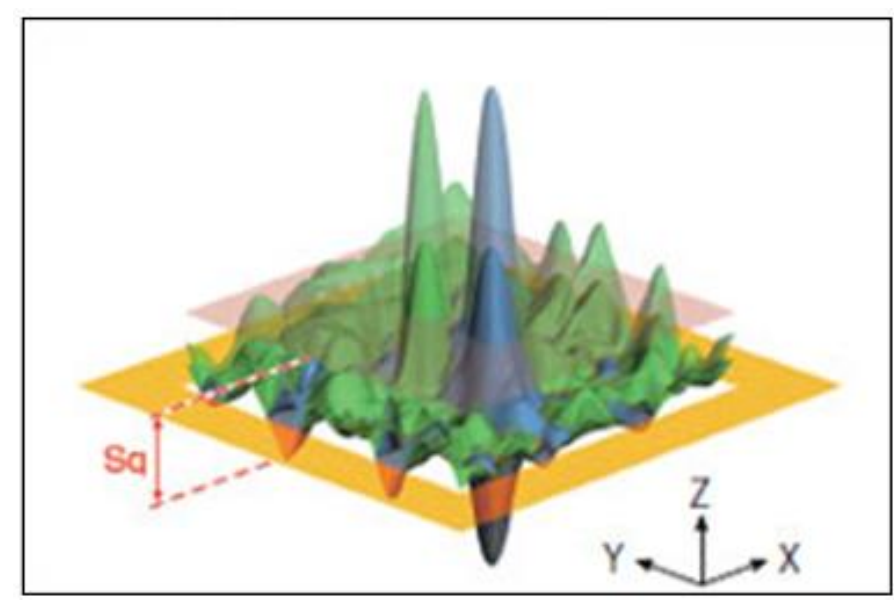

Fonte: STOUT, K. J. (2000)

\subsubsection{Parâmetro de amplitude Ssk}

Ssk (Skewness), representa o grau de bias da forma da rugosidade (aspereza). O grau bias corresponde ao erro, incerteza ou desvio sistemático ou tendenciosidade. Com isto, temos:

- Ssk < 0 A distribuição da altura é assimétrica, acima do plano médio

- Ssk = 0 A distribuição da altura (picos e vales) é simétrica, em torno do plano médio

- Ssk >0 A distribuição da altura é assimétrica, em abaixo do plano médio

$S_{S k}=\frac{1}{S_{q}^{3}}\left[\frac{1}{A} \iint_{A} Z^{3}(x, y) d x d y\right]$ 
Figura 8-14. Curvas de distribuição Skewness

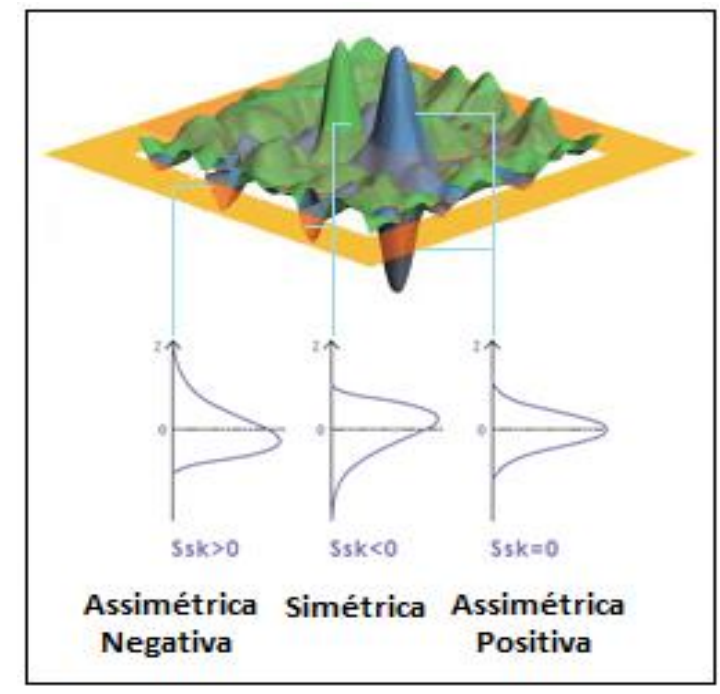

Fonte: STOUT, K. J. (2000)

\subsubsection{Parâmetro de amplitude Sku}

Sku (curtose), representa a medida da agudez do perfil de rugosidade, sendo assim:

- Sku $<3$ Distribuição da altura não é aguda.

- $\quad$ Sku $=3$ Distribuição da altura é normal.

- Sku > 3 Distribuição da altura é aguda 
Figura 8-15. Curvas de distribuição Curtose

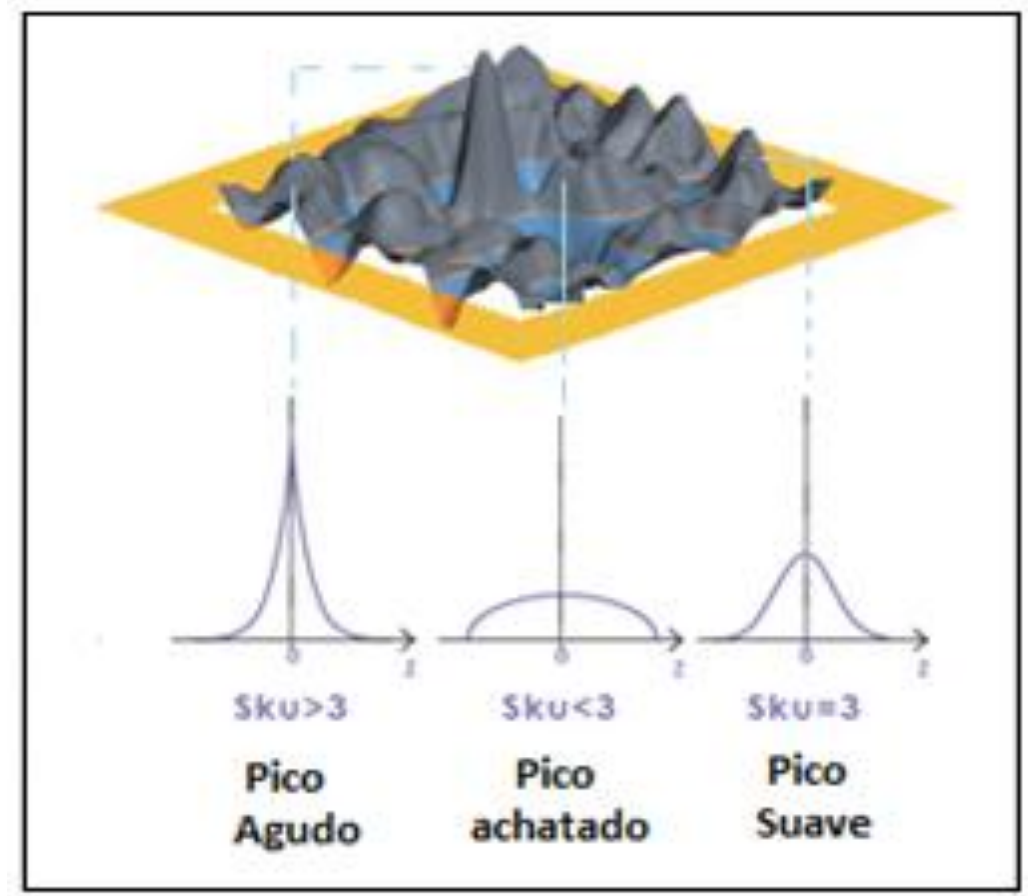

Fonte: STOUT, K. J. (2000)

\subsubsection{Parâmetro de amplitude Sp}

Sp (altura máxima do pico), representa a altura do pico mais alto, dentro da área definida.

Figura 8-16. Altura máxima do pico

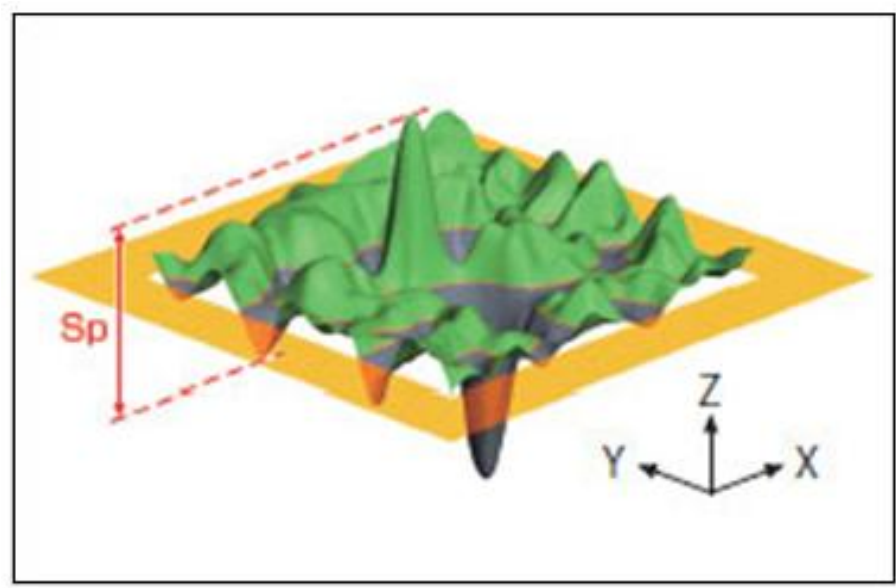

Fonte: STOUT, K. J. (2000). 


\subsubsection{Parâmetro de amplitude Sv}

Sv (altura máxima do vale), representa a altura do mais baixo vale dentro da área definida.

$S_{V}=\left|\min _{A} z(x, y)\right|$

Figura 8-17. Altura máxima do vale

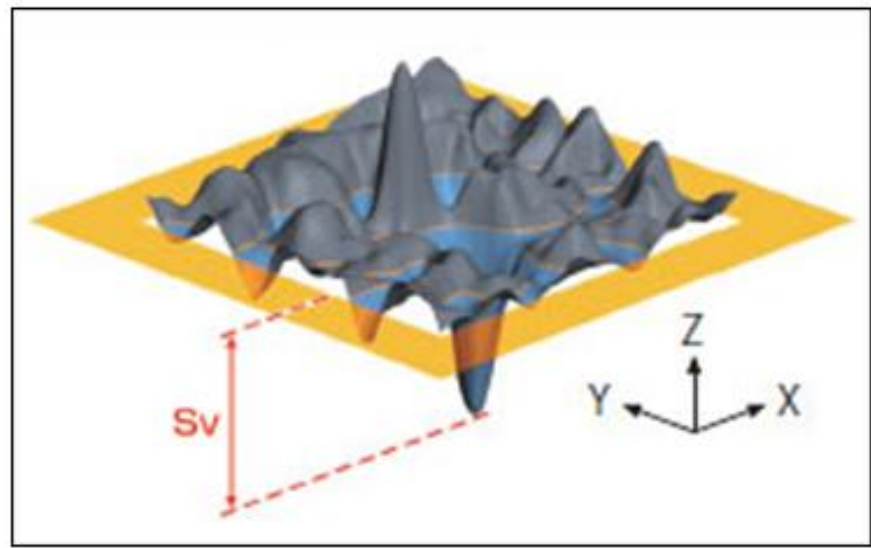

Fonte: STOUT, K. J. (2000)

\subsection{7 Índice de volume de material e do volume vazio}

Para usar parâmetros de volume, os valores da razão do material de área que dividem os picos reduzidos e os vales reduzidos da superfície do núcleo devem ser especificados. Por padrão, $10 \%$ e $80 \%$ são usados, conforme mostrado FIGURA 8.17.

Vmp (volume de material de pico) representa o volume de material na razão entre material e $\mathrm{p} \%$.

Vmc (volume do material do núcleo) representa a diferença entre o volume do material na relação de material real $q \%$ e o volume do material na razão entre material e $\mathrm{p} \%$. 
Vvc (volume de núcleo vazio) representa a diferença entre o volume de vazios na relação entre o material de área p\% e o volume de vazios na relação do material $\mathrm{q} \%$.

Vvv (volume nulo baixo) representa o volume vazio do vale na área entre o material e o $\mathrm{p} \%$.

Vmp, Vmc, Vvc e Vvv representam os volumes dos picos reduzidos, material do núcleo, vazio do núcleo e vazio do vale, respectivamente. Também podem ser usados para quantificar a magnitude da superfície do núcleo, picos reduzidos e vales reduzidos com base nos parâmetros de volume.

Figura 8-18. Diagrama esquemática do volume de material e do volume vazio de uma superfície

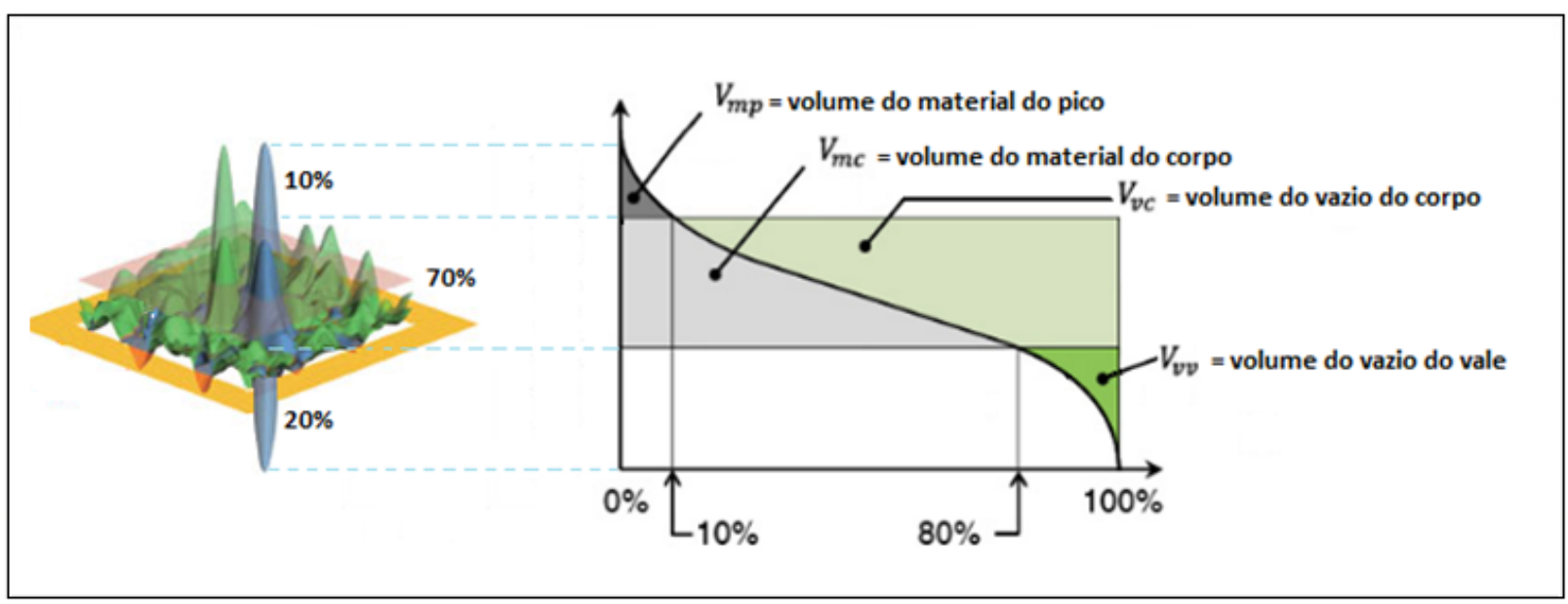

Fonte: STOUT, K. J. (2000)

Suh, Polycarpou e Conry (2003) mostram através de um teste tribológico controlado, de uma típica superfície de engenharia, a evolução da rugosidade através destes parâmetros. Neste experimento é mostrada a capacidade dos parâmetros funcionais em traduzir o efeito progressivo do desgaste através da redução da capacidade de retenção de fluido e um aumento no índice de apoio da superfície, onde ambos indicam que o lubrificante não pode ser mais retido suficientemente. A perda da capacidade de retenção do lubrificante significa um 174 
aumento da área real de contato, levando a um eventual contato metal-metal sem qualquer filme no processo de desgaste. Desta forma os autores mostram que os parâmetros funcionais podem ser usados para correlacionar as mudanças topográficas com as mudanças físicas que ocorrem durante o desgaste progressivo da superfície.

A avaliação da performance da topografia em função do desgaste durante o processo de laminação foi feita utilizando os parâmetros tridimensionais $S a, S z, S q$, Ssk, Sku, Sp, Sv, Vm, Vmc, Vvc e Vvv. 


\section{Capítulo 9 - Resultados}

Esse capítulo apresenta a análise dos resultados segundo os objetivos delineados nesse estudo. Para isso, esse capítulo foi estruturado em três partes.

A primeira parte, tratou essencialmente de apresentar os resultados encontradas a partir da utilização de ferramenta estatística do software Portal Action, com análise de regressão linear múltipla e suas derivações.

A segunda parte, tratou de evidenciar a influência das variáveis em análise, através do uso do aplicativo SPSS.

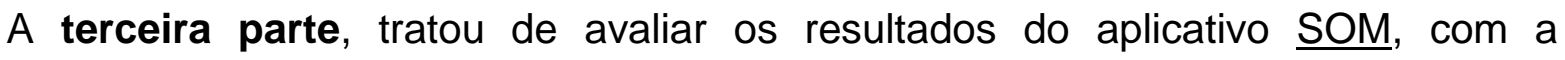
utilização da técnica disponível para este tipo de análise.

A quarta e última parte, tratou de avaliar as figuras geradas pelo interferômetro nas diversas condições de amostragem realizadas em campo.

\subsection{Análise multivariada de dados}

$\mathrm{Na}$ análise multivariada, utilizamos equações de regressão múltipla, conforme a seguir:

\subsubsection{Equação de regressão múltipla}

A partir dos resultados extraídos do interferômetro $(\mathrm{CCl})$, foram desenvolvidas equações regressão linear múltipla, através da ferramenta estatística do software Excel.

- Equação I - variáveis (chapa: aço; cilindro: jateado, cromado)

a) resultado da análise de regressão multivariada 
Tabela 9- 1. Análise regressão multivariada para equação 9.1

\begin{tabular}{|c|c|c|c|c|c|c|c|c|}
\hline RESUMO DOS RESULTADOS & & & & & & & & \\
\hline \multicolumn{9}{|l|}{ Estatistica de regressão } \\
\hline R múltiplo & 0,96 & & & & & & & \\
\hline R-Quadrado & 0,92 & & & & & & & \\
\hline R-quadrado ajustado & 0,88 & & & & & & & \\
\hline Erro padrão & 598,47 & & & & & & & \\
\hline Observações & 30 & & & & & & & \\
\hline \multicolumn{9}{|l|}{ ANOVA } \\
\hline & $g l$ & $S Q$ & $M Q$ & $F$ & Fde significação & & & \\
\hline Regressão & 10 & 76810941 & 7681094 & 21 & 0,000000028 & & & \\
\hline Resíduo & 19 & 6805068 & 358161 & & & & & \\
\hline \multirow[t]{2}{*}{ Total } & 29 & 83616009 & & & & & & \\
\hline & Coeficientes & Erro padrão & Stat $t$ & valor-P & $95 \%$ inferiores & 95\% superiores & Inferior $95,0 \%$ & Superior $95,0 \%$ \\
\hline Interseção & 6051,61 & 842,14 & 7,19 & 0,00 & 4288,99 & 7814,24 & 4288,99 & 7814,24 \\
\hline Sa & 138,79 & 1297,28 & 0,11 & 0,92 & $-2576,45$ & 2854,03 & $-2576,45$ & 2854,03 \\
\hline $\mathrm{Sq}$ & $-692,31$ & 1266,76 & $-0,55$ & 0,59 & $-3343,66$ & 1959,05 & $-3343,66$ & 1959,05 \\
\hline Ssk & 278,93 & 436,26 & 0,64 & 0,53 & $-634,18$ & 1192,04 & $-634,18$ & 1192,04 \\
\hline Sku & $-93,06$ & 81,88 & $-1,14$ & 0,27 & $-264,43$ & 78,31 & $-264,43$ & 78,31 \\
\hline $\mathrm{Sp}$ & $-250,34$ & 47,46 & $-5,27$ & 0,00 & $-349,67$ & $-151,01$ & $-349,67$ & $-151,01$ \\
\hline Sv & $-126,18$ & 46,68 & $-2,70$ & 0,01 & $-223,89$ & $-28,48$ & $-223,89$ & $-28,48$ \\
\hline $\mathrm{Vmp}$ & $-1041,62$ & 1589,42 & $-0,66$ & 0,52 & $-4368,32$ & 2285,08 & $-4368,32$ & 2285,08 \\
\hline $\mathrm{Vmc}$ & 416,96 & 1167,43 & 0,36 & 0,72 & $-2026,50$ & 2860,41 & $-2026,50$ & 2860,41 \\
\hline Vvc & $-205,24$ & 592,86 & $-0,35$ & 0,73 & $-1446,12$ & 1035,64 & $-1446,12$ & 1035,64 \\
\hline Vvv & 2979,85 & 4622,89 & 0,64 & 0,53 & $-6695,98$ & 12655,67 & $-6695,98$ & 12655,67 \\
\hline
\end{tabular}

Fonte: (Autor - software portal Action)

b) equação da chapa de aço laminada com cilindro jateado e cromado

\section{Equação 9.1}

$\mathrm{Y}=6051,61+138,79 \mathrm{Sa}-692,31 \mathrm{Sq}+278,93 \mathrm{Ssk}-93,06 \mathrm{Sku}-250,34 \mathrm{Sp}-126,28 \mathrm{~Sv}-$ $1041,62 \mathrm{Vmp}+416,96 \mathrm{Vmc}-205,24 \mathrm{Vvc}+2979,86 \mathrm{Vvv}$

c) simulação da equação com valores específicos

Tabela 9- 2. Simulação valores da Equação 9.1

\begin{tabular}{|c|c|c|c|c|c|c|c|c|c|c|c|}
\hline Parâmetros & Campanha & Sa & Sq & Ssk & Sku & Sp & Sv & Vmp & Vmc & Vvc & Vvv \\
\hline média & 2369 & 1,68 & 2,23 & 0,71 & 5,33 & 6,66 & 8,10 & 0,18 & 1,92 & 3,11 & 0,21 \\
\hline máximo & 4403 & 0,80 & 1,09 & $-1,49$ & 2,55 & 1,25 & 2,16 & 0,01 & 0,77 & 1,30 & 0,06 \\
\hline mínimo & -2831 & 2,92 & 3,34 & 3,20 & 16,81 & 12,62 & 18,86 & 2,13 & 3,31 & 7,74 & 0,56 \\
\hline
\end{tabular}

Fonte: (Autor - software portal Action)

- Equação II - variáveis (chapa: aço; cilindro: jateado, não-cromado)

a) resultado da análise de regressão multivariada 
Tabela 9- 3. Análise regressão multivariada para equação 9.2

\begin{tabular}{|c|c|c|c|c|c|c|c|c|}
\hline RESUMO DOS RESULTADOS & & & & & & & & \\
\hline \multicolumn{9}{|l|}{ Estatística de regressão } \\
\hline R múltiplo & 0,99 & & & & & & & \\
\hline R-Quadrado & 0,98 & & & & & & & \\
\hline R-quadrado ajustado & 0,89 & & & & & & & \\
\hline Erro padrão & 131,73 & & & & & & & \\
\hline Observações & 13 & & & & & & & \\
\hline \multicolumn{9}{|l|}{ ANOVA } \\
\hline & $g l$ & $S Q$ & $M Q$ & $F$ & Fde significação & & & \\
\hline Regressão & 10 & 1925451 & 192545 & 11 & 0,09 & & & \\
\hline Resíduo & 2 & 34706 & 17353 & & & & & \\
\hline Total & 12 & 1960157 & & & & & & \\
\hline & Coeficientes & Erro padrão & Stat $t$ & valor- $P$ & 95\% inferiores & 95\% superiores & Inferior $95,0 \%$ & Superior $95,0 \%$ \\
\hline Interseção & 1302,93 & 250,08 & 5,21 & 0,03 & 226,91 & 2378,95 & 226,91 & 2378,95 \\
\hline Sa & 386,43 & 578,14 & 0,67 & 0,57 & $-2101,12$ & 2873,99 & $-2101,12$ & 2873,99 \\
\hline $\mathrm{Sq}$ & $-277,31$ & 292,02 & $-0,95$ & 0,44 & $-1533,79$ & 979,17 & $-1533,79$ & 979,17 \\
\hline Ssk & $-267,68$ & 192,36 & $-1,39$ & 0,30 & $-1095,34$ & 559,99 & $-1095,34$ & 559,99 \\
\hline Sku & 28,92 & 31,23 & 0,93 & 0,45 & $-105,45$ & 163,30 & $-105,45$ & 163,30 \\
\hline $\mathrm{Sp}$ & $-25,55$ & 61,90 & $-0,41$ & 0,72 & $-291,89$ & 240,80 & $-291,89$ & 240,80 \\
\hline Sv & $-69,19$ & 71,86 & $-0,96$ & 0,44 & $-378,38$ & 240,01 & $-378,38$ & 240,01 \\
\hline Vmp & $-1827,29$ & 2408,98 & $-0,76$ & 0,53 & $-12192,29$ & 8537,71 & $-12192,29$ & 8537,71 \\
\hline Vmc & $-61,44$ & 95,43 & $-0,64$ & 0,59 & $-472,03$ & 349,15 & $-472,03$ & 349,15 \\
\hline Vvc & 7,88 & 98,47 & 0,08 & 0,94 & $-415,81$ & 431,57 & $-415,81$ & 431,57 \\
\hline Vvv & 3222,48 & 2734,83 & 1,18 & 0,36 & $-8544,55$ & 14989,52 & $-8544,55$ & 14989,52 \\
\hline
\end{tabular}

Fonte: (Autor - software portal Action)

b) equação da chapa de aço laminada com cilindro jateado e não-cromado

\section{Equação 9.2}

$\mathrm{Y}=1302,93+386,43 \mathrm{Sa}-277,31$ Sq $-267,68 \mathrm{Ssk}+28,92 \mathrm{Sku}-25,55 \mathrm{Sp}-69,19 \mathrm{~Sv}-$ $1827,29 \mathrm{Vmp}-61,44 \mathrm{Vmc}+7,88 \mathrm{Vvc}+3222,48 \mathrm{Vvv}$

c) simulação da equação com valores específicos

Tabela 9- 4. Simulação valores da Equação 9.2

\begin{tabular}{|c|c|c|c|c|c|c|c|c|c|c|c|}
\hline Parâmetros & Campanha & Sa & Sq & Ssk & Sku & Sp & Sv & Vmp & Vmc & Vvc & Vvv \\
\hline média & 693 & 1,30 & 1,75 & 1,21 & 6,76 & 9,62 & 5,50 & 0,14 & 1,41 & 2,35 & 0,14 \\
\hline máximo & 1419 & 0,58 & 0,73 & $-0,32$ & 3,20 & 2,84 & 1,73 & 0,01 & 0,65 & 0,97 & 0,05 \\
\hline mínimo & 312 & 2,12 & 2,74 & 3,12 & 18,30 & 13,73 & 12,04 & 0,21 & 2,16 & 4,03 & 0,29 \\
\hline
\end{tabular}

Fonte: (Autor - software portal Action)

- Equação III - variáveis (chapa: aço; cilindro: retificado, cromado)

a) resultado da análise de regressão multivariada 
Tabela 9- 5. Análise regressão multivariada para equação 9.3

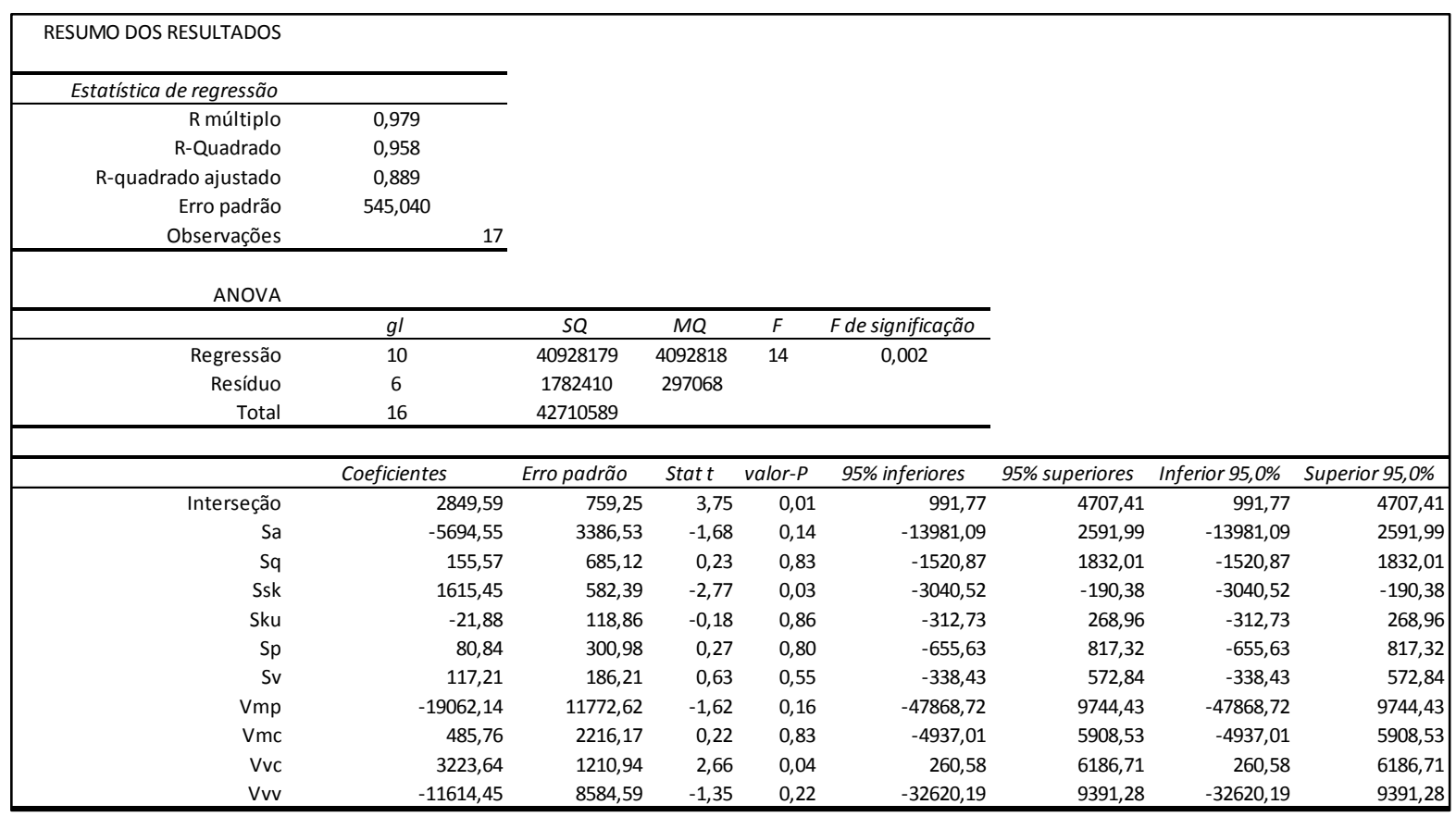

Fonte: (Autor - software portal Action)

b) equação da chapa de aço laminada com cilindro retificado e cromado

\section{Equação 9.3}

$\mathrm{Y}=2849,59-5694,55 \mathrm{Sa}+155,57 \mathrm{Sq}+1615,45$ Ssk $-21,88 \mathrm{Sku}+80,84 \mathrm{Sp}+117,21 \mathrm{~Sv}-$ $19062,14 \mathrm{Vmp}+485,76 \mathrm{Vmc}+3223,64 \mathrm{Vvc}-11614,45 \mathrm{Vvv}$

c) simulação da equação com valores específicos

Tabela 9- 6. Simulação valores da Equação 9.3

\begin{tabular}{|c|c|c|c|c|c|c|c|c|c|c|c|}
\hline Parâmetros & Campanha & Sa & Sq & Ssk & Sku & Sp & Sv & Vmp & Vmc & Vvc & Vvv \\
\hline média & 1667 & 0,75 & 1,47 & $-0,05$ & 4,21 & 4,42 & 5,70 & 0,08 & 0,84 & 1,38 & 0,12 \\
\hline máximo & 2873 & 0,24 & 0,44 & $-0,98$ & 1,15 & 1,36 & 2,11 & 0,00 & 0,22 & 0,90 & 0,03 \\
\hline mínimo & 691 & 1,61 & 2,85 & 0,78 & 10,83 & 9,97 & 10,52 & 0,17 & 1,65 & 2,91 & 0,30 \\
\hline
\end{tabular}

Fonte: (Autor - software portal Action) 
- Equação IV - variáveis (chapa: aço; cilindro: retificado, não-cromado)

a) resultado da análise de regressão multivariada

Tabela 9- 7. Análise regressão multivariada para equação 9.4

\begin{tabular}{|c|c|c|c|c|c|c|c|c|}
\hline RESUMO DOS RESULTADOS & & & & & & & & \\
\hline \multicolumn{9}{|l|}{ Estatística de regressão } \\
\hline R múltiplo & 0,98 & & & & & & & \\
\hline R-Quadrado & 0,96 & & & & & & & \\
\hline R-quadrado ajustado & 0,87 & & & & & & & \\
\hline Erro padrão & 182,35 & & & & & & & \\
\hline Observações & 15 & & & & & & & \\
\hline \multicolumn{9}{|l|}{ ANOVA } \\
\hline & $g l$ & $S Q$ & $M Q$ & $F$ & Fde significação & & & \\
\hline Regressão & 10 & 3523462 & 352346 & 11 & 0,018 & & & \\
\hline Resíduo & 4 & 133008 & 33252 & & & & & \\
\hline Total & 14 & 3656470 & & & & & & \\
\hline & Coeficientes & Erro padrão & Stat $t$ & valor-P & $95 \%$ inferiores & $95 \%$ superiores & Inferior $95,0 \%$ & Superior $95,0 \%$ \\
\hline Interseção & 847,75 & 306,60 & 2,76 & 0,05 & $-3,52$ & 1699,02 & $-3,52$ & 1699,02 \\
\hline $\mathrm{Sa}$ & 444,78 & 330,44 & 1,35 & 0,25 & $-472,68$ & 1362,24 & $-472,68$ & 1362,24 \\
\hline $\mathrm{Sq}$ & 244,16 & 264,09 & 0,92 & 0,41 & $-489,08$ & 977,40 & $-489,08$ & 977,40 \\
\hline Ssk & 156,74 & 166,99 & 0,94 & 0,40 & $-306,90$ & 620,38 & $-306,90$ & 620,38 \\
\hline Sku & 29,27 & 56,80 & 0,52 & 0,63 & $-128,44$ & 186,98 & $-128,44$ & 186,98 \\
\hline $\mathrm{Sp}$ & $-109,26$ & 128,10 & $-0,85$ & 0,44 & $-464,94$ & 246,41 & $-464,94$ & 246,41 \\
\hline Sv & $-45,24$ & 33,37 & $-1,36$ & 0,25 & $-137,88$ & 47,41 & $-137,88$ & 47,41 \\
\hline Vmp & $-13439,30$ & 11433,58 & $-1,18$ & 0,31 & $-45183,99$ & 18305,40 & $-45183,99$ & 18305,40 \\
\hline $\mathrm{Vmc}$ & $-340,92$ & 323,40 & $-1,05$ & 0,35 & $-1238,81$ & 556,97 & $-1238,81$ & 556,97 \\
\hline Vvc & 335,32 & 280,95 & 1,19 & 0,30 & $-444,72$ & 1115,35 & $-444,72$ & 1115,35 \\
\hline Vvv & 6513,73 & 4666,71 & 1,40 & 0,24 & $-6443,14$ & 19470,61 & $-6443,14$ & 19470,61 \\
\hline
\end{tabular}

Fonte: (Autor - software portal Action)

b) equação da chapa de aço laminada com cilindro retificado e não-cromado

Equação 9.4

$\mathrm{Y}=847,75+444,78 \mathrm{Sa}+244,16 \mathrm{Sq}+156,74$ Ssk $+29,27$ Sku $-109,26 \mathrm{Sp}-45,24$ Sv $13439,30 \mathrm{Vmp}-340,92 \mathrm{Vmc}+335,32 \mathrm{Vvc}+6513,73 \mathrm{Vvv}$

c) simulação da equação com valores específicos

Tabela 9- 8. Simulação valores da Equação 9.4

\begin{tabular}{|c|c|c|c|c|c|c|c|c|c|c|c|}
\hline Parâmetros & Campanha & Sa & Sq & Ssk & Sku & Sp & Sv & Vmp & Vmc & Vvc & Vvv \\
\hline média & 717 & 0,58 & 1,26 & $-0,10$ & 5,05 & 4,29 & 5,48 & 0,06 & 0,58 & 1,05 & 0,08 \\
\hline máximo & 758 & 0,12 & 0,42 & $-1,27$ & 1,02 & 1,01 & 1,29 & 0,01 & 0,16 & 0,69 & 0,01 \\
\hline mínimo & 664 & 1,86 & 2,20 & 1,42 & 13,33 & 9,22 & 17,79 & 0,16 & 0,99 & 1,58 & 0,24 \\
\hline
\end{tabular}

Fonte: (Autor - software portal Action) 
- Equação V - variáveis (chapa: aço; cilindro: texturizado, cromado)

a) resultado da análise de regressão multivariada

Tabela 9- 9. Análise regressão multivariada para equação 9.5

\begin{tabular}{|c|c|c|c|c|c|c|c|c|}
\hline RESUMO DOS RESULTADOS & & & & & & & & \\
\hline \multicolumn{9}{|l|}{ Estatística de regressão } \\
\hline R múltiplo & 1,00 & & & & & & & \\
\hline R-Quadrado & 1,00 & & & & & & & \\
\hline R-quadrado ajustado & 0,99 & & & & & & & \\
\hline Erro padrão & 204,77 & & & & & & & \\
\hline Observações & 15 & & & & & & & \\
\hline \multicolumn{9}{|l|}{ ANOVA } \\
\hline & $g l$ & $S Q$ & $M Q$ & $F$ & F de significação & & & \\
\hline Regressão & 10 & 54535393 & 5453539 & 130 & 0,0001 & & & \\
\hline Resíduo & 4 & 167731 & 41933 & & & & & \\
\hline \multirow[t]{2}{*}{ Total } & 14 & 54703123 & & & & & & \\
\hline & Coeficientes & Erro padrão & Stat $t$ & valor- $P$ & 95\% inferiores & 95\% superiores & Inferior $95,0 \%$ & Superior $95,0 \%$ \\
\hline Interseção & 4583,20 & 2832,38 & 1,62 & 0,18 & $-3280,76$ & 12447,16 & $-3280,76$ & 12447,16 \\
\hline Sa & $-529,38$ & 301,02 & $-1,76$ & 0,15 & $-1365,14$ & 306,37 & $-1365,14$ & 306,37 \\
\hline $\mathrm{Sq}$ & 1394,70 & 550,95 & 2,53 & 0,06 & $-134,97$ & 2924,38 & $-134,97$ & 2924,38 \\
\hline Ssk & 2766,42 & 624,26 & 4,43 & 0,01 & 1033,20 & 4499,65 & 1033,20 & 4499,65 \\
\hline Sku & $-217,84$ & 306,03 & $-0,71$ & 0,52 & $-1067,51$ & 631,84 & $-1067,51$ & 631,84 \\
\hline Sp & $-321,10$ & 68,22 & $-4,71$ & 0,01 & $-510,50$ & $-131,70$ & $-510,50$ & $-131,70$ \\
\hline Sv & 189,30 & 182,45 & 1,04 & 0,36 & $-317,27$ & 695,88 & $-317,27$ & 695,88 \\
\hline Vmp & $-4640,84$ & 9842,85 & $-0,47$ & 0,66 & $-31968,97$ & 22687,29 & $-31968,97$ & 22687,29 \\
\hline Vmc & $-1093,98$ & 375,92 & $-2,91$ & 0,04 & $-2137,71$ & $-50,25$ & $-2137,71$ & $-50,25$ \\
\hline Vvc & $-328,12$ & 314,06 & $-1,04$ & 0,36 & $-1200,09$ & 543,84 & $-1200,09$ & 543,84 \\
\hline Vvv & 4320,78 & 3696,32 & 1,17 & 0,31 & $-5941,83$ & 14583,40 & $-5941,83$ & 14583,40 \\
\hline
\end{tabular}

Fonte: (Autor - software portal Action)

b) equação da chapa de aço laminada com cilindro retificado e não-cromado

\section{Equação 9.5}

$\mathrm{Y}=4583,20-529,38 \mathrm{Sa}+1394,70 \mathrm{Sq}+2766,42 \mathrm{Ssk}-217,84$ Sku $-321,10 \mathrm{Sp}+189,30 \mathrm{~Sv}$ - 4640,84Vmp - 1093,98Vmc - 328,12Vvc + 4320,78Vvv

c) simulação da equação com valores específicos

Tabela 9- 10. Simulação valores da Equação 9.5

\begin{tabular}{|c|c|c|c|c|c|c|c|c|c|c|c|}
\hline Parâmetros & Campanha & Sa & Sq & Ssk & Sku & Sp & Sv & Vmp & Vmc & Vvc & Vvv \\
\hline média & 2557 & 2,35 & 3,17 & $-0,15$ & 1,83 & 11,50 & 11,43 & 0,09 & 1,92 & 4,59 & 0,27 \\
\hline máximo & 2915 & 1,16 & 1,93 & $-0,57$ & 0,19 & 5,66 & 4,45 & 0,01 & 0,10 & 3,89 & 0,06 \\
\hline mínimo & 3496 & 3,99 & 5,79 & 0,38 & 3,85 & 19,60 & 19,32 & 0,17 & 3,60 & 6,89 & 0,55 \\
\hline
\end{tabular}

Fonte: (Autor - software portal Action) 
- Equação VI - variáveis (chapa: aço; cilindro: texturizado, não-cromado)

a) resultado da análise de regressão multivariada

Tabela 9- 11. Análise regressão multivariada para equação 9.6

\begin{tabular}{|c|c|c|c|c|c|c|c|c|}
\hline RESUMO DOS RESULTADOS & & & & & & & & \\
\hline \multicolumn{9}{|l|}{ Estatística de regressão } \\
\hline R múltiplo & 1,00 & & & & & & & \\
\hline R-Quadrado & 1,00 & & & & & & & \\
\hline R-quadrado ajustado & 1,00 & & & & & & & \\
\hline Erro padrão & 19,42 & & & & & & & \\
\hline Observações & 13 & & & & & & & \\
\hline \multicolumn{9}{|l|}{ ANOVA } \\
\hline & $g l$ & $S Q$ & $M Q$ & $F$ & Fde significação & & & \\
\hline Regressão & 10 & 2411936 & 241194 & 640 & 0,002 & & & \\
\hline Resíduo & 2 & 754 & 377 & & & & & \\
\hline Total & 12 & 2412690 & & & & & & \\
\hline & Coeficientes & Erro padrão & Stat $t$ & valor- $P$ & 95\% inferiores & 95\% superiores & Inferior $95,0 \%$ & Superior $95,0 \%$ \\
\hline Interseção & 3725,10 & 219,95 & 16,94 & 0,00 & 2778,72 & 4671,48 & 2778,72 & 4671,48 \\
\hline Sa & 1635,33 & 167,37 & 9,77 & 0,01 & 915,21 & 2355,44 & 915,21 & 2355,44 \\
\hline $\mathrm{Sq}$ & $-892,38$ & 111,46 & $-8,01$ & 0,02 & $-1371,94$ & $-412,82$ & $-1371,94$ & $-412,82$ \\
\hline Ssk & 34,83 & 36,60 & 0,95 & 0,44 & $-122,64$ & 192,31 & $-122,64$ & 192,31 \\
\hline Sku & 121,66 & 15,04 & 8,09 & 0,01 & 56,93 & 186,39 & 56,93 & 186,39 \\
\hline Sp & $-241,05$ & 19,04 & $-12,66$ & 0,01 & $-322,97$ & $-159,12$ & $-322,97$ & $-159,12$ \\
\hline Sv & $-3,29$ & 5,54 & $-0,59$ & 0,61 & $-27,12$ & 20,53 & $-27,12$ & 20,53 \\
\hline Vmp & 2717,37 & 1748,22 & 1,55 & 0,26 & $-4804,61$ & 10239,35 & $-4804,61$ & 10239,35 \\
\hline Vmc & $-58,63$ & 47,00 & $-1,25$ & 0,34 & $-260,84$ & 143,59 & $-260,84$ & 143,59 \\
\hline Vvc & $-365,56$ & 30,93 & $-11,82$ & 0,01 & $-498,65$ & $-232,48$ & $-498,65$ & $-232,48$ \\
\hline Vvv & $-516,62$ & 224,90 & $-2,30$ & 0,15 & $-1484,30$ & 451,06 & $-1484,30$ & 451,06 \\
\hline
\end{tabular}

Fonte: (Autor - software portal Action)

b) equação chapa de aço laminada com cilindro texturizado e não-cromado

\section{Equação 9.6}

$\mathrm{Y}=3725,10+1635,33 \mathrm{Sa}-892,38 \mathrm{Sq}+34,83$ Ssk $+121,66 \mathrm{Sku}-241,05 \mathrm{Sp}-3,29 \mathrm{~Sv}+$ $2717,37 \mathrm{Vmp}-58,63 \mathrm{Vmc}-365,56 \mathrm{Vvc}-516,62 \mathrm{Vvv}$

c) simulação da equação com valores específicos

Tabela 9- 12. Simulação valores da Equação 9.6

\begin{tabular}{|c|c|c|c|c|c|c|c|c|c|c|c|}
\hline Parâmetros & Campanha & Sa & Sq & Ssk & Sku & Sp & Sv & Vmp & Vmc & Vvc & Vvv \\
\hline média & 655 & 1,35 & 2,10 & $-0,14$ & 2,20 & 8,05 & 9,10 & 0,09 & 1,55 & 4,67 & 0,27 \\
\hline máximo & 2073 & 0,52 & 0,81 & $-1,93$ & 0,19 & 1,55 & 1,86 & 0,01 & 0,10 & 3,69 & 0,06 \\
\hline mínimo & -1644 & 3,41 & 5,06 & 1,38 & 5,62 & 16,85 & 18,35 & 0,17 & 3,26 & 7,89 & 0,82 \\
\hline
\end{tabular}

Fonte: (Autor - software portal Action) 
- Equação VII - variáveis (chapa: cobre; cilindro: retificado, cromado)

a) resultado da análise de regressão multivariada

Tabela 9- 13. Análise regressão multivariada para equação 9.7

\begin{tabular}{|c|c|c|c|c|c|c|c|c|}
\hline RESUMO DOS RESULTADOS & & & & & & & & \\
\hline \multicolumn{9}{|l|}{ Estatística de regressão } \\
\hline R múltiplo & 0,96 & & & & & & & \\
\hline R-Quadrado & 0,91 & & & & & & & \\
\hline R-quadrado ajustado & 0,79 & & & & & & & \\
\hline Erro padrão & 303,49 & & & & & & & \\
\hline Observações & 18 & & & & & & & \\
\hline \multicolumn{9}{|l|}{ ANOVA } \\
\hline & $g l$ & $S Q$ & $M Q$ & $F$ & Fde significação & & & \\
\hline Regressão & 10 & 6817912 & 681791 & 7 & 0,007 & & & \\
\hline Resíduo & 7 & 644752 & 92107 & & & & & \\
\hline Total & 17 & 7462665 & & & & & & \\
\hline & Coeficientes & Erro padrão & Stat $t$ & valor- $P$ & 95\% inferiores & 95\% superiores & Inferior 95,0\% & Superior $95,0 \%$ \\
\hline Interseção & 2086,47 & 774,90 & 2,69 & 0,03 & 254,12 & 3918,83 & 254,12 & 3918,83 \\
\hline Sa & $-648,37$ & 958,45 & $-0,68$ & 0,52 & $-2914,75$ & 1618,01 & $-2914,75$ & 1618,01 \\
\hline $\mathrm{Sq}$ & $-641,65$ & 347,56 & $-1,85$ & 0,11 & $-1463,49$ & 180,20 & $-1463,49$ & 180,20 \\
\hline Ssk & 372,82 & 313,80 & 1,19 & 0,27 & $-369,20$ & 1114,85 & $-369,20$ & 1114,85 \\
\hline Sku & 181,75 & 106,19 & 1,71 & 0,13 & $-69,35$ & 432,85 & $-69,35$ & 432,85 \\
\hline $\mathrm{Sp}$ & $-60,00$ & 83,01 & $-0,72$ & 0,49 & $-256,28$ & 136,27 & $-256,28$ & 136,27 \\
\hline Sv & $-18,75$ & 28,64 & $-0,65$ & 0,53 & $-86,48$ & 48,98 & $-86,48$ & 48,98 \\
\hline Vmp & $-8036,99$ & 7932,83 & $-1,01$ & 0,34 & $-26795,15$ & 10721,16 & $-26795,15$ & 10721,16 \\
\hline Vmc & $-1708,09$ & 916,49 & $-1,86$ & 0,10 & $-3875,25$ & 459,06 & $-3875,25$ & 459,06 \\
\hline Vvc & 82,13 & 350,72 & 0,23 & 0,82 & $-747,20$ & 911,45 & $-747,20$ & 911,45 \\
\hline Vvv & 5716,73 & 3887,32 & 1,47 & 0,18 & $-3475,31$ & 14908,77 & $-3475,31$ & 14908,77 \\
\hline
\end{tabular}

Fonte: (Autor - software portal Action)

b) equação da chapa de cobre laminada com cilindro retificado e cromado

\section{Equação 9.7}

$\mathrm{Y}=2086,47-648,37 \mathrm{Sa}-641,65 \mathrm{Sq}+372,82 \mathrm{Ssk}+181,75 \mathrm{Sku}-60 \mathrm{Sp}-18,75 \mathrm{~Sv}-$ $8036,99 \mathrm{Vmp}-1708,09 \mathrm{Vmc}+82,13 \mathrm{Vvc}+5716,73 \mathrm{Vvv}$

c) simulação da equação com valores específicos

Tabela 9- 14. Simulação valores da Equação 9.7

\begin{tabular}{|c|c|c|c|c|c|c|c|c|c|c|c|}
\hline Parâmetros & Campanha & Sa & Sq & Ssk & Sku & Sp & Sv & Vmp & Vmc & Vvc & Vvv \\
\hline média & 445 & 0,75 & 1,36 & 1,15 & 3,73 & 4,86 & 6,54 & 0,06 & 0,63 & 1,34 & 0,08 \\
\hline mínimo & 1716 & 0,37 & 0,63 & 0,50 & 1,09 & 1,24 & 1,76 & 0,01 & 0,06 & 0,88 & 0,02 \\
\hline máximo & -822 & 1,27 & 2,94 & 1,74 & 6,45 & 9,10 & 21,34 & 0,15 & 1,10 & 1,89 & 0,33 \\
\hline
\end{tabular}

Fonte: (Autor - software portal Action) 
- Equação VIII - variáveis (chapa: cobre; cilindro: retificado, não-cromado)

a) resultado da análise de regressão multivariada

Tabela 9- 15. Análise regressão multivariada para equação 9.8

\begin{tabular}{|c|c|c|c|c|c|c|c|c|}
\hline RESUMO DOS RESULTADOS & & & & & & & & \\
\hline Estatística de regressão & & & & & & & & \\
\hline R múltiplo & 0,999879057 & & & & & & & \\
\hline R-Quadrado & 0,99975813 & & & & & & & \\
\hline R-quadrado ajustado & 0,997339425 & & & & & & & \\
\hline Erro padrão & 1,905311806 & & & & & & & \\
\hline Observações & 12 & & & & & & & \\
\hline \multicolumn{9}{|l|}{ ANOVA } \\
\hline & $g l$ & $S Q$ & $M Q$ & $F$ & Fde significação & & & \\
\hline Regressão & 10 & 15005 & 1501 & 413 & 0,038 & & & \\
\hline Resíduo & 1 & 4 & 4 & & & & & \\
\hline Total & 11 & 15009 & & & & & & \\
\hline & Coeficientes & Erro padrão & Stat $t$ & valor- $P$ & 95\% inferiores & 95\% superiores & Inferior $95,0 \%$ & Superior $95,0 \%$ \\
\hline Interseção & 133,32 & 12,83 & 10,39 & 0,06 & $-29,72$ & 296,37 & $-29,72$ & 296,37 \\
\hline Sa & 22,28 & 8,48 & $-2,63$ & 0,23 & $-130,02$ & 85,47 & $-130,02$ & 85,47 \\
\hline $\mathrm{Sq}$ & $-17,73$ & 15,02 & $-1,18$ & 0,45 & $-208,59$ & 173,13 & $-208,59$ & 173,13 \\
\hline Ssk & $-6,71$ & 3,43 & $-1,96$ & 0,30 & $-50,28$ & 36,87 & $-50,28$ & 36,87 \\
\hline Sku & $-3,67$ & 0,97 & $-3,80$ & 0,16 & $-15,94$ & 8,59 & $-15,94$ & 8,59 \\
\hline Sp & $-2,35$ & 0,69 & $-3,39$ & 0,18 & $-11,17$ & 6,47 & $-11,17$ & 6,47 \\
\hline Sv & $-1,34$ & 0,64 & $-2,10$ & 0,28 & $-9,41$ & 6,74 & $-9,41$ & 6,74 \\
\hline Vmp & $-396,59$ & 116,14 & $-3,41$ & 0,18 & $-1872,27$ & 1079,09 & $-1872,27$ & 1079,09 \\
\hline Vmc & $-31,75$ & 8,19 & $-3,88$ & 0,16 & $-135,79$ & 72,30 & $-135,79$ & 72,30 \\
\hline Vvc & 8,55 & 2,85 & 3,01 & 0,20 & $-27,60$ & 44,71 & $-27,60$ & 44,71 \\
\hline Vvv & 209,15 & 71,52 & 2,92 & 0,21 & $-699,55$ & 1117,85 & $-699,55$ & 1117,85 \\
\hline
\end{tabular}

Fonte: (Autor - software portal Action)

b) equação da chapa de cobre laminada com cilindro retificado e não-cromado

\section{Equação 9.8}

$\mathrm{Y}=133,32+22,28 \mathrm{Sa}-17,73 \mathrm{Sq}-6,71$ Ssk $-3,67 \mathrm{Sku}-2,35 \mathrm{Sp}-1,34 \mathrm{~Sv}-396,59 \mathrm{Vmp}-$ $31,75 \mathrm{Vmc}+8,55 \mathrm{Vvc}+209,15 \mathrm{Vvv}$

c) simulação da equação com valores específicos

Tabela 9- 16. Simulação valores da Equação 9.8

\begin{tabular}{|c|c|c|c|c|c|c|c|c|c|c|c|}
\hline Parâmetros & Campanha & Sa & Sq & Ssk & Sku & Sp & Sv & Vmp & Vmc & Vvc & Vvv \\
\hline média & 76 & 0,79 & 1,68 & 0,70 & 3,10 & 4,23 & 4,77 & 0,05 & 0,55 & 1,45 & 0,06 \\
\hline máximo & 130 & 0,37 & 0,63 & $-0,85$ & 1,29 & 1,24 & 1,72 & 0,01 & 0,06 & 0,94 & 0,02 \\
\hline mínimo & 1 & 1,92 & 3,80 & 1,45 & 5,70 & 9,36 & 10,00 & 0,15 & 0,98 & 1,89 & 0,15 \\
\hline
\end{tabular}

Fonte: (Autor - software portal Action) 
- Equação IX - variáveis (chapa: alumínio; cilindro: retificado, cromado)

a) resultado da análise de regressão linear múltipla

Tabela 9- 17. Análise regressão multivariada para equação 9.9

\begin{tabular}{|c|c|c|c|c|c|c|c|c|}
\hline RESUMO DOS RESULTADOS & & & & & & & & \\
\hline \multicolumn{9}{|l|}{ Estatística de regressão } \\
\hline R múltiplo & 0,99 & & & & & & & \\
\hline R-Quadrado & 0,99 & & & & & & & \\
\hline R-quadrado ajustado & 0,94 & & & & & & & \\
\hline Erro padrão & 309,22 & & & & & & & \\
\hline Observações & 13 & & & & & & & \\
\hline \multicolumn{9}{|l|}{ ANOVA } \\
\hline & $g l$ & $S Q$ & $M Q$ & $F$ & F de significação & & & \\
\hline Regressão & 10 & 18286345 & 1828635 & 19 & 0,051 & & & \\
\hline Resíduo & 2 & 191230 & 95615 & & & & & \\
\hline Total & 12 & 18477575 & & & & & & \\
\hline & Coeficientes & Erro padrão & Stat $t$ & valor- $P$ & 95\% inferiores & 95\% superiores & Inferior $95,0 \%$ & Superior $95,0 \%$ \\
\hline Interseção & 2462,73 & 2074,36 & 1,19 & 0,36 & $-6462,54$ & 11388,00 & $-6462,54$ & 11388,00 \\
\hline $\mathrm{Sa}$ & $-3786,48$ & 1074,36 & $-3,52$ & 0,07 & $-8409,08$ & 836,13 & $-8409,08$ & 836,13 \\
\hline $\mathrm{Sq}$ & 2327,51 & 938,58 & 2,48 & 0,13 & $-1710,89$ & 6365,91 & $-1710,89$ & 6365,91 \\
\hline Ssk & $-381,08$ & 593,26 & $-0,64$ & 0,59 & $-2933,66$ & 2171,50 & $-2933,66$ & 2171,50 \\
\hline Sku & 375,05 & 274,86 & 1,36 & 0,31 & $-807,58$ & 1557,68 & $-807,58$ & 1557,68 \\
\hline $\mathrm{Sp}$ & 204,35 & 171,84 & 1,19 & 0,36 & $-535,03$ & 943,74 & $-535,03$ & 943,74 \\
\hline Sv & $-334,23$ & 173,58 & $-1,93$ & 0,19 & $-1081,10$ & 412,64 & $-1081,10$ & 412,64 \\
\hline Vmp & $-7523,12$ & 2807,00 & $-2,68$ & 0,12 & $-19600,67$ & 4554,43 & $-19600,67$ & 4554,43 \\
\hline Vmc & 523,03 & 801,75 & 0,65 & 0,58 & $-2926,62$ & 3972,67 & $-2926,62$ & 3972,67 \\
\hline Vvc & $-249,01$ & 458,73 & $-0,54$ & 0,64 & $-2222,75$ & 1724,73 & $-2222,75$ & 1724,73 \\
\hline Vvv & 5269,73 & 2279,43 & 2,31 & 0,15 & $-4537,85$ & 15077,31 & $-4537,85$ & 15077,31 \\
\hline
\end{tabular}

Fonte: (Autor - software portal Action)

b) equação da chapa de alumínio laminada com cilindro retificado e cromado

\section{Equação 9.9}

$\mathrm{Y}=2462,72-3786,48 \mathrm{Sa}+2327,51 \mathrm{Sq}-381,08 \mathrm{Ssk}+375,05 \mathrm{Sku}+204,35 \mathrm{Sp}-334,23 \mathrm{~Sv}$ $-7523,12 \mathrm{Vmp}+523,03 \mathrm{Vmc}-249,01 \mathrm{Vvc}+5269,73 \mathrm{Vvv}$

c) simulação da equação com valores específicos

Tabela 9- 18. Simulação valores da Equação 9.9

\begin{tabular}{|c|c|c|c|c|c|c|c|c|c|c|c|}
\hline Parâmetros & Campanha & Sa & Sq & Ssk & Sku & Sp & Sv & Vmp & Vmc & Vvc & Vvv \\
\hline média & 1483 & 1,58 & 2,40 & 0,07 & 3,11 & 8,39 & 8,51 & 0,19 & 1,29 & 2,63 & 0,16 \\
\hline máximo & 3420 & 0,93 & 1,64 & $-1,49$ & 1,15 & 5,92 & 4,80 & 0,01 & 0,91 & 1,46 & 0,01 \\
\hline máximo & -4127 & 2,83 & 4,20 & 1,88 & 4,93 & 13,28 & 15,93 & 0,87 & 2,10 & 3,89 & 0,42 \\
\hline
\end{tabular}

Fonte: (Autor - software portal Action) 
- Equação X - variáveis (chapa: alumínio; cilindro: retificado, não-cromado)

a) resultado da análise de regressão multivariada

Tabela 9- 19. Análise regressão multivariada para equação 9.10

\begin{tabular}{|c|c|c|c|c|c|c|c|c|}
\hline RESUMO DOS RESULTADOS & & & & & & & & \\
\hline \multicolumn{9}{|l|}{ Estatística de regressão } \\
\hline R múltiplo & 0,90 & & & & & & & \\
\hline R-Quadrado & 0,81 & & & & & & & \\
\hline R-quadrado ajustado & 0,62 & & & & & & & \\
\hline Erro padrão & 59,65 & & & & & & & \\
\hline Observações & 21 & & & & & & & \\
\hline \multicolumn{9}{|l|}{ ANOVA } \\
\hline & $g l$ & $S Q$ & $M Q$ & $F$ & F de significação & & & \\
\hline Regressão & 10 & 151358 & 15136 & 4 & 0,016 & & & \\
\hline Resíduo & 10 & 35577 & 3558 & & & & & \\
\hline \multirow[t]{2}{*}{ Total } & 20 & 186935 & & & & & & \\
\hline & Coeficientes & Erro padrão & Stat $t$ & valor- $P$ & 95\% inferiores & 95\% superiores & Inferior 95,0\% & Superior $95,0 \%$ \\
\hline Interseção & 140,71 & 47,36 & 2,97 & 0,01 & 35,18 & 246,24 & 35,18 & 246,24 \\
\hline Sa & 1048,38 & 796,56 & 1,32 & 0,22 & $-726,47$ & 2823,22 & $-726,47$ & 2823,22 \\
\hline $\mathrm{Sq}$ & 75,29 & 33,38 & 2,26 & 0,05 & 0,91 & 149,68 & 0,91 & 149,68 \\
\hline Ssk & $-104,10$ & 45,97 & $-2,26$ & 0,05 & $-206,53$ & $-1,67$ & $-206,53$ & $-1,67$ \\
\hline Sku & 8,25 & 5,61 & 1,47 & 0,17 & $-4,26$ & 20,76 & $-4,26$ & 20,76 \\
\hline $\mathrm{Sp}$ & 1,09 & 8,09 & 0,13 & 0,90 & $-16,94$ & 19,12 & $-16,94$ & 19,12 \\
\hline Sv & 22,10 & 19,17 & 1,15 & 0,28 & $-20,62$ & 64,82 & $-20,62$ & 64,82 \\
\hline Vmp & $-670,07$ & 343,56 & $-1,95$ & 0,08 & $-1435,58$ & 95,44 & $-1435,58$ & 95,44 \\
\hline Vmc & $-975,54$ & 436,25 & $-2,24$ & 0,05 & $-1947,56$ & $-3,51$ & $-1947,56$ & $-3,51$ \\
\hline Vvc & $-78,24$ & 250,16 & $-0,31$ & 0,76 & $-635,64$ & 479,16 & $-635,64$ & 479,16 \\
\hline Vvv & $-1062,05$ & 601,66 & $-1,77$ & 0,11 & $-2402,63$ & 278,54 & $-2402,63$ & 278,54 \\
\hline
\end{tabular}

Fonte: (Autor - software portal Action)

b) equação da chapa de alumínio laminada com cilindro retificado e não-cromado

\section{Equação 9.10}

$$
\begin{aligned}
& \mathrm{Y}=140,71+1048,38 \mathrm{Sa}+75,29 \mathrm{Sq}-104,10 \mathrm{Ssk}+8,25 \mathrm{Sku}+1,09 \mathrm{Sp}+ \\
& 22,10 \mathrm{~Sv}-670,07 \mathrm{Vmp}-975,54 \mathrm{Vmc}-78,24 \mathrm{Vvc}-1062,05 \mathrm{Vvv}
\end{aligned}
$$

c) simulação da equação com valores específicos

Tabela 9- 20. Simulação valores da Equação 9.10

\begin{tabular}{|c|c|c|c|c|c|c|c|c|c|c|c|}
\hline Parâmetros & Campanha & Sa & Sq & Ssk & Sku & Sp & Sv & Vmp & Vmc & Vvc & Vvv \\
\hline média & 119 & 0,57 & 1,44 & 0,86 & 6,36 & 5,82 & 2,61 & 0,05 & 0,60 & 0,97 & 0,06 \\
\hline máximo & 268 & 0,14 & 0,53 & $-0,37$ & 1,23 & 1,90 & 0,41 & 0,00 & 0,10 & 0,17 & 0,01 \\
\hline mínimo & 100 & 2,07 & 3,73 & 2,46 & 29,23 & 12,80 & 10,33 & 0,23 & 2,10 & 3,73 & 0,21 \\
\hline
\end{tabular}

Fonte: (Autor - software portal Action) 
A TABELA 9-21 apresenta o resumo das equações ( $\mathrm{I}$ a $X$ ) de regressão linear multivariada, que representa as diversas condições de laminação realizadas neste estudo. 
Tabela 9- 21. Resumo das equações de regressão linear multivariada

\begin{tabular}{|c|c|}
\hline Descrição & Equação \\
\hline $\begin{array}{l}\text { Cilindro Jateado Cromado (Chapa } \\
\text { de aço) }\end{array}$ & $\begin{array}{l}Y=6051,61+138,79 \mathrm{Sa}-692,31 \mathrm{Sq}+278,93 \mathrm{Ssk}-93,06 \mathrm{Sku}-250,34 \mathrm{Sp}-126,28 \mathrm{~Sv}-1041,62 \mathrm{Vmp}+416,96 \mathrm{Vmc}-205,24 \mathrm{Vvc} \\
+2979,86 \mathrm{Vvv}\end{array}$ \\
\hline $\begin{array}{l}\text { Cilindro Jateado Não Cromado } \\
\text { (Chapa de aço) }\end{array}$ & $\begin{array}{l}\mathrm{Y}=1302,93+386,43 \mathrm{Sa}-277,31 \mathrm{Sq}-267,68 \mathrm{Ssk}+28,92 \mathrm{Sku}-25,55 \mathrm{Sp}-69,19 \mathrm{~Sv}-1827,29 \mathrm{Vmp}-61,44 \mathrm{Vmc}+7,88 \mathrm{Vvc}+ \\
3222,48 \mathrm{Vvv}\end{array}$ \\
\hline $\begin{array}{l}\text { Cilindro Retificado Cromado } \\
\text { (Chapa de aço) }\end{array}$ & $\begin{array}{l}Y=2849,59-5694,55 \mathrm{Sa}+155,57 \mathrm{Sq}+1615,45 \mathrm{Ssk}-21,88 \mathrm{Sku}+80,84 \mathrm{Sp}+117,21 \mathrm{~Sv}-19062,14 \mathrm{Vmp}+485,76 \mathrm{Vmc}+ \\
3223,64 \mathrm{vvc}-11614,45 \mathrm{Vvv}\end{array}$ \\
\hline $\begin{array}{l}\text { Cilindro Retificado Não Cromado } \\
\text { (Chapa de aço) }\end{array}$ & $\begin{array}{l}Y=847,75+444,78 \mathrm{Sa}+244,16 \mathrm{Sq}+156,74 \mathrm{Ssk}+29,27 \mathrm{Sku}-109,26 \mathrm{Sp}-45,24 \mathrm{~Sv}-13439,30 \mathrm{Vmp}-340,92 \mathrm{vmc}+335,32 \mathrm{Vvc} \\
+6513,73 \mathrm{Vvv}\end{array}$ \\
\hline $\begin{array}{l}\text { Cilindro Texturizado Cromado } \\
\text { (Chapa de aço) }\end{array}$ & $\begin{array}{l}Y=4583,20-529,38 \mathrm{Sa}+1394,70 \mathrm{Sq}+2766,42 \mathrm{Ssk}-217,84 \mathrm{Sku}-321,10 \mathrm{Sp}+189,30 \mathrm{~Sv}-4640,84 \mathrm{Vmp}-1093,98 \mathrm{Vmc}- \\
328,12 \mathrm{Vvc}+4320,78 \mathrm{Vvv}\end{array}$ \\
\hline $\begin{array}{l}\text { Cilindro Texturizado Não } \\
\text { Cromado (Chapa de aço) }\end{array}$ & $\begin{array}{l}Y=3725,10+1635,33 \mathrm{Sa}-892,38 \mathrm{Sq}+34,83 \mathrm{Ssk}+121,66 \mathrm{Sku}-241,05 \mathrm{Sp}-3,29 \mathrm{~Sv}+2717,37 \mathrm{Vmp}-58,63 \mathrm{Vmc}-365,56 \mathrm{Vvc}- \\
516,62 \mathrm{Vvv}\end{array}$ \\
\hline $\begin{array}{l}\text { Cilindro Retificado Cromado } \\
\text { (Chapa de cobre) }\end{array}$ & $\begin{array}{l}Y=2086,47-648,37 \mathrm{Sa}-641,65 \mathrm{Sq}+372,82 \mathrm{Ssk}+181,75 \mathrm{Sku}-60 \mathrm{Sp}-18,75 \mathrm{~Sv}-8036,99 \mathrm{Vmp}-1708,09 \mathrm{Vmc}+82,13 \mathrm{Vvc}+ \\
5716,73 \mathrm{Vvv}\end{array}$ \\
\hline $\begin{array}{l}\text { Cilindro Retificado Não Cromado } \\
\text { (Chapa de cobre) }\end{array}$ & $\mathrm{Y}=133,32+22,28 \mathrm{Sa}-17,73 \mathrm{Sq}-6,71 \mathrm{Ssk}-3,67 \mathrm{Sku}-2,35 \mathrm{Sp}-1,34 \mathrm{~Sv}-396,59 \mathrm{Vmp}-31,75 \mathrm{Vmc}+8,55 \mathrm{Vvc}+209,15 \mathrm{Vvv}$ \\
\hline $\begin{array}{l}\text { Cilindro Retificado Cromado } \\
\text { (Chapa de alumínio) }\end{array}$ & $\begin{array}{l}Y=2462,72-3786,48+2327,51-381,08 S s k+375,05 S k u+204,35 S p-334,23 S v-7523,12 \mathrm{Vmp}+523,03 \mathrm{Vmc}-249,01 \mathrm{Vvc} \\
+5269,73 \mathrm{Vvv}\end{array}$ \\
\hline $\begin{array}{l}\text { Cilindro Retificado Não Cromado } \\
\text { (Chapa de alumínio) }\end{array}$ & $\begin{array}{l}Y=140,71+1048,38 S a+75,29 S q-104,10 S s k+8,25 S k u+1,09 S p+22,10 S v-670,07 V m p-975,54 V m c-78,24 V v c- \\
1062,05 V v v\end{array}$ \\
\hline
\end{tabular}




\subsection{Análise de cluster por SPSS}

Com a utilização do software IBM SPSS statistics versão 22, permitiu-se realizar algumas análises quantitativas. O Statistical Package for Social Science for Windows (SPSS) é um software para análise estatística de dados, em um ambiente amigável, utilizando-se de menus e janelas de diálogo, que permite realizar cálculos complexos e visualizar seus resultados de forma simples e autoexplicativas.

\subsubsection{Análise de frequências das componentes}

Em análise das variáveis de processo em relação algumas propriedades estatísticas, identificamos que havia uma assimetria considerável nos dados originais. Assimetria é a propriedade que indica a tendência de maior concentração dos dados em relação ao ponto central, conforme FIGURA 9-1.

Figura 9- 1. Distribuição simétrica e assimétrica

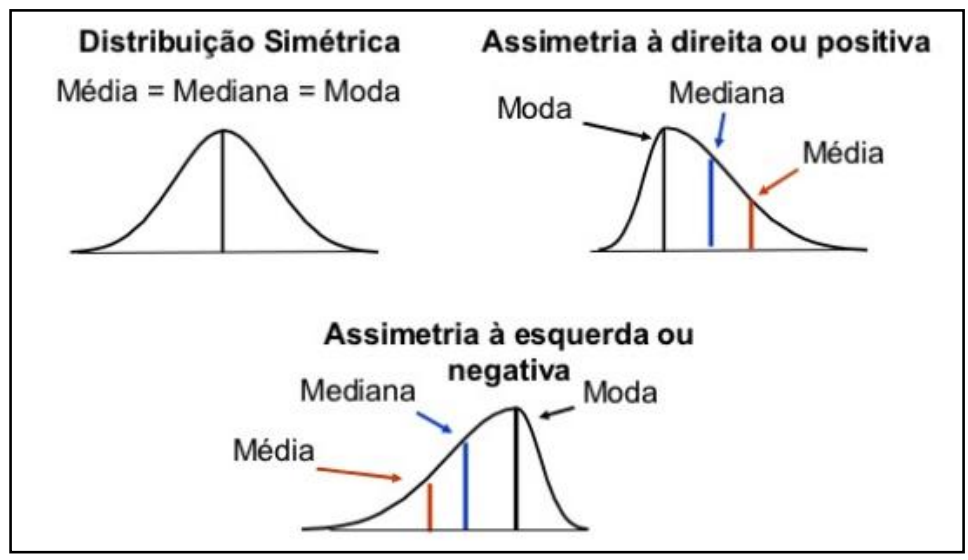

Fonte: (Autor)

Através da Tabela de frequência definiu-se a assimetria das varáveis de processo, conforme TABELA 9-22. 
Tabela 9- 22. Tabela de frequências das variáveis

\begin{tabular}{|c|c|c|c|c|c|c|c|c|c|c|c|c|c|}
\hline & & $\mathrm{Sq}$ & Sa & Ssk & Sku & Sp & Sv & $\mathrm{Sz}$ & Vmp & Vmc & $\mathrm{W}$ & Wu & $\mathrm{Vw}$ \\
\hline \multirow[t]{2}{*}{$\mathrm{N}$} & Válido & 162 & 162 & 162 & 162 & 162 & 162 & 162 & 162 & 162 & 162 & 162 & 162 \\
\hline & Ausente & 0 & 0 & 0 & 0 & 0 & 0 & 0 & 0 & 0 & 0 & 0 & 0 \\
\hline \multicolumn{2}{|c|}{ Média } & 1,6134 & 1,2678 & .3109 & 4,8558 & 8,5341 & 7,3636 & 15,2501 & .1105 & 1,3439 & 2,0802 & 1,9141 & .1654 \\
\hline \multicolumn{2}{|c|}{ Mediana } & 1,3600 & 1,0350 & .3750 & 3,9100 & 7,8850 & 5,8600 & 13,9600 & .0700 & 1,1300 & 1,6800 & 1,5050 &, 1400 \\
\hline \multicolumn{2}{|c|}{ Desvio Padrăo } & 1,19318 & 98085 & 88533 & 3,11173 & 6,88251 & 6,79239 & 7,90948 & .18859 & 1,05236 & 1,34562 & 1,23682 & .12721 \\
\hline \multicolumn{2}{|c|}{ Assimetria } & 3,435 & 3,031 & .310 & 1,945 & 7,939 & 4,423 & 1,369 & 8,648 & 3,323 & 1,052 & 1,097 & 1,323 \\
\hline \multicolumn{2}{|c|}{ Erro de assimetria padrão } &, 191 &, 191 &, 191 & .191 & .191 &, 191 &, 191 & , 191 & .191 &, 191 &, 191 & ,191 \\
\hline \multicolumn{2}{|c|}{ Curtose } & 24,006 & 16,571 &, 316 & 4,091 & 84,171 & 33,219 & 2,526 & 86,824 & 21,776 & 1,636 & 1,821 & 1,286 \\
\hline \multicolumn{2}{|c|}{ Erro de Curtose padrão } &, 379 &, 379 & 379 & .379 &, 379 & .379 & .379 & 379 &, 379 & 379 & .379 &, 379 \\
\hline
\end{tabular}

Fonte: (Autor - software SPSS)

Aplicamos o logaritmo neperiano, corrigindo o erro assimétrico da distribuição da população, tornando os parâmetros ortogonais e com maior grau de simetria conforme TABELA 9-23.

Tabela 9- 23. Tabela de frequências com correção assimetria

\begin{tabular}{|c|c|c|c|c|c|c|c|c|c|c|c|c|c|}
\hline & & LnSq & LnSa & LnSku & LnSp & LnSV & LnSz & LnVmp & LnVme & LnW & LnWc & LnWw & Campanha \\
\hline \multirow[t]{2}{*}{$\mathrm{N}$} & Válido & 162 & 162 & 162 & 162 & 162 & 162 & 162 & 162 & 162 & 162 & 162 & 162 \\
\hline & Ausente & 0 & 0 & 0 & 0 & 0 & 0 & 0 & 0 & 0 & 0 & 0 & 0 \\
\hline \multicolumn{2}{|c|}{ Média } &, 2530 &,- 0052 & 1,4132 & 1,9974 & 1,6998 & 2,6001 & $-2,6143$ & .0401 & ,4991 & .4290 & $-2,1032$ & 46,3765 \\
\hline \multicolumn{2}{|c|}{ Desvio Padrão } & .69374 & .71438 & .58266 & .51814 & .78786 &, 50593 & 84665 &, 75000 & ,74215 & .69675 & .83031 & 32,08258 \\
\hline \multicolumn{2}{|c|}{ Assimetria } &,- 261 & -185 &,- 213 & 092 & -185 & -123 & .164 &,- 455 &,- 756 & -299 &,- 407 & .181 \\
\hline \multicolumn{2}{|c|}{ Erro de Curtose padräo } & .379 & .379 & .379 & .379 & .379 & .379 & .379 & .379 & .379 & 379 & 379 & .379 \\
\hline
\end{tabular}

Fonte: (Autor - software SPSS)

$\mathrm{Na}$ TABELA 9-24, mostra o resultado da análise de estatística descritiva, determinando a média e o desvio padrão das amostras em relação ao centroide dos elementos. 
Tabela 9- 24. Média e desvio padrão das variáveis

\begin{tabular}{|l|r|r|r|}
\hline & \multicolumn{3}{|c|}{ Estatísticas descritivas } \\
\hline Ssk & \multicolumn{1}{|c|}{ Média } & \multicolumn{1}{c|}{$\begin{array}{l}\text { Desvio } \\
\text { Padrão }\end{array}$} & Análise N \\
LnSq &, 2530 &, 88533 & 162 \\
LnSa &,- 0052 &, 69374 & 162 \\
LnSku & 1,4132 &, 71438 & 162 \\
LnSp & 1,9974 &, 58266 & 162 \\
LnSv & 1,6998 &, 51814 & 162 \\
LnSz & 2,6001 &, 78786 & 162 \\
LnVmp & $-2,6143$ &, 50593 & 162 \\
LnVmc &, 0401 &, 84665 & 162 \\
LnV &, 4991 &, 75000 & 162 \\
LnVc &, 4290 &, 74215 & 162 \\
LnVw & $-2,1032$ &, 69675 & 162 \\
\end{tabular}

Fonte: (Autor - software SPSS)

Conforme TABELA 9-25 - matriz de correlação, foi aplicado o logaritmo neperiano, para garantir que cada parâmetro esteja ortogonal às variáveis de processo.

Tabela 9- 25. Matriz de correlação

\begin{tabular}{|c|c|c|c|c|c|c|c|c|c|c|c|c|c|}
\hline \multicolumn{14}{|c|}{ Matriz de correlaçöes } \\
\hline & & Ssk & LnSq & LnSa & LnSku & LnSp & LnSv & LnSz & LnVmp & LnVmc & LnW & LnVwc & LnVW \\
\hline \multirow{8}{*}{ Correlação } & LnSq & ,071 & 1,000 & ,954 & ,098 &, 580 &, 672 & ,709 & ,779 & ,900 &, 944 & ,980 & 875 \\
\hline & LnSku &, 350 &, 098 &, 062 & 1,000 &, 351 & 211 &, 338 & .099 &, 052 &, 052 &, 045 &, 079 \\
\hline & LnSp &, 416 &, 580 & .510 &, 351 & 1,000 & .497 & .834 & .578 & .524 & .575 &, 581 &, 366 \\
\hline & LnSv &, 033 & .672 & .646 &, 211 &, 497 & 1,000 &, 857 & ,407 & .606 &, 596 &, 608 &, 728 \\
\hline & LnVmc &,- 015 & 900 & 801 & .052 & .524 & .606 & .652 &, 564 & 1,000 &, 929 & 878 & 847 \\
\hline & LnW &, 117 &, 944 & .821 & .052 &, 575 &, 596 & .670 &, 675 &, 929 & 1,000 &, 947 &, 804 \\
\hline & LnWve &, 126 &, 980 &, 946 & .045 & .581 &, 608 &, 678 &, 822 &, 878 &, 947 & 1,000 &, 796 \\
\hline & LnVw &,- 203 & 875 & .834 &, 079 & 366 &, 728 & .626 &, 482 & 847 & .804 &, 796 & 1,000 \\
\hline
\end{tabular}

Fonte: (Autor - software SPSS)

Na TABELA 9-26, com os vetores ortogonais, é possível afirmar que estes estão no mesmo plano cartesiano do centroide dos elementos. 
Tabela 9- 26. Variância total explicada

\begin{tabular}{|c|c|c|c|c|c|c|c|c|c|}
\hline \multirow[b]{3}{*}{ Componente } & \multicolumn{9}{|c|}{ Variância total explicada } \\
\hline & \multicolumn{3}{|c|}{ Valores próprios iniciais } & \multicolumn{3}{|c|}{$\begin{array}{c}\text { Somas de extração de carregamentos ao } \\
\text { quadrado }\end{array}$} & \multicolumn{3}{|c|}{ Somas rotativas de carregamentos ao quadrado } \\
\hline & Total & $\begin{array}{c}\text { \% de } \\
\text { variância }\end{array}$ & $\%$ cumulativa & Total & $\begin{array}{c}\text { \% de } \\
\text { variância }\end{array}$ & $\%$ cumulativa & Total & $\begin{array}{c}\% \text { de } \\
\text { variância }\end{array}$ & $\%$ cumulativa \\
\hline 1 & 7,541 & 62,844 & 62,844 & 7,541 & 62,844 & 62,844 & 4,995 & 41,622 & 41,622 \\
\hline 2 & 1,758 & 14,648 & 77,492 & 1,758 & 14,648 & 77,492 & 1,718 & 14,313 & 55,935 \\
\hline 3 & 1,008 & 8,396 & 85,887 & 1,008 & 8,396 & 85,887 & 1,402 & 11,680 & 67,615 \\
\hline 6 & ,384 & 3,200 & 97,764 &, 384 & 3,200 & 97,764 & 1,052 & 8,768 & 97,182 \\
\hline 7 & ,115 &, 958 & 98,721 &, 115 & 958 & 98,721 &, 121 & 1,012 & 98,194 \\
\hline 8 &, 063 &, 527 & 99,249 &, 063 &, 527 & 99,249 & 108 & ,903 & 99,097 \\
\hline 9 & ,058 & .482 & 99,731 &, 058 &, 482 & 99,731 & 070 & .581 & 99,678 \\
\hline 10 & .024 &, 204 & 99,935 &, 024 & 204 & 99,935 &, 030 & 247 & 99,925 \\
\hline
\end{tabular}

Fonte: (Autor - software SPSS)

A TABELA 9-27 apresenta a correlação dos principais componentes e suas respectivas variáveis associadas.

Tabela 9- 27. Matriz de componente

Matriz de componente ${ }^{a}$

\begin{tabular}{|c|c|c|c|c|c|c|c|c|c|c|c|c|}
\hline & \multicolumn{12}{|c|}{ Componente } \\
\hline & 1 & 2 & 3 & 4 & 5 & 6 & 7 & 8 & 9 & 10 & 11 & 12 \\
\hline LnSq & ,977 &,- 136 &,- 089 & ,096 &, 017 & ,021 & ,026 &,- 049 &,- 017 &, 025 &,- 066 &,- 012 \\
\hline LnW & ,928 & -125 & -123 & ,038 &, 260 &,- 062 &,- 130 & - 129 &, 023 &,- 008 &, 003 &, 018 \\
\hline LnSa & ,928 &,- 174 & -117 & ,112 &,- 194 &, 091 & ,134 &, 039 & -126 &, 014 & ,003 &, 017 \\
\hline LnVmc & ,897 &,- 212 &, 022 & ,056 & ,303 & -,124 &,- 066 & , 190 &, 003 &, 008 &, 000 &,- 001 \\
\hline LnVmp & ,775 & , 106 &,- 457 &, 093 &,- 382 &, 019 &,- 095 &, 046 & ,115 &,- 021 & ,001 &, 001 \\
\hline LnSv &, 761 &, 050 & ,483 &,- 253 &,- 105 & ,308 &,- 100 &, 007 & ,021 & ,072 &, 006 & ,001 \\
\hline LnSp & ,697 &, 526 &,- 012 &,- 264 &,- 046 &,- 391 & ,095 &,- 018 &, 027 &, 062 & ,007 &, 000 \\
\hline Ssk & 142 & 800 &,- 404 &,- 072 &, 263 & ,311 &, 072 &, 018 &, 012 &,- 002 &, 000 &, 000 \\
\hline LnSku & .179 & 692 & 397 & .570 & -.036 &,- 051 & -.040 &,- 005 & -.012 & .004 &, 002 & .000 \\
\hline
\end{tabular}

Método de Extração: Análise de Componente Principal.

a. 12 componentes extraídos.

Fonte: (Autor - software SPSS)

\subsubsection{Análise dos clusters K-means}

A TABELA 9-28, apresenta os parâmetros iniciais selecionadas pelo software para iniciar a análise. O cluster 1 possui o centro igual a -2,77612, o cluster 2 possui centro igual a 2,10234 para a variável "volume do material". As demais variáveis, aplica-se a mesma consideração. 
Tabela 9- 28. Centro de cluster inicial

\begin{tabular}{|l|r|r|}
\hline \multirow{2}{*}{} & \multicolumn{2}{|c|}{ Cluster } \\
\cline { 2 - 3 } & \multicolumn{1}{|c|}{1} & \multicolumn{1}{c|}{2} \\
\hline Volume do material & $-2,77612$ & 2,10234 \\
Altura do pico & 2,08704 & $-1,78919$ \\
Altura do vale & 1,62324 & $-1,43432$ \\
\hline
\end{tabular}

Fonte: (Autor - software SPSS)

A TABELA 9-29, apresenta o centro final dos clusters para cada variável. Estes valores correspondem à média dos valores do objeto ao qual pertencem ao cluster.

Tabela 9- 29. Distância entre os centróides dos clusters

\begin{tabular}{|l|r|r|}
\hline \multirow{2}{*}{ Componente } & \multicolumn{2}{|c|}{ Cluster } \\
\cline { 2 - 3 } & \multicolumn{1}{|c|}{1} & \multicolumn{1}{c|}{2} \\
\hline Volume do material &, 52985 & $-1,08970$ \\
Altura máxima do pico &,- 12380 &, 25460 \\
Altura máxima do vale &, 20526 &,- 42213 \\
\hline
\end{tabular}

Fonte: (Autor - software SPSS)

A TABELA 9-30, apresenta o número de casos nos clusters. Sendo, 109 casos no cluster 1 e 53 casos no cluster 2 .

Tabela 9- 30. Número de casos em cada cluster

\begin{tabular}{|ll|r|}
\hline Cluster & 2 & 109,000 \\
& 1 & 53,000 \\
Válido & & 162,000 \\
Ausente & &, 000 \\
\hline
\end{tabular}

Fonte: (Autor - software SPSS) 


\subsubsection{Análise dos gráficos scatters 3D}

Os resultados da análise evidenciaram os agrupamentos realizados e em quais clusters está cada componente. Sendo, $67 \%$ dos casos no cluster $1 ; 2$ e $33 \%$ no cluster 2, conforme FIGURAS 9.5 a 9.9 do tipo "Scatters 3D" no ANEXO I.

Nestas FIGURAS foram realizadas análises de dispersão para os seguintes agrupamentos com clusters: 2, 3, 5, 10 e 15 níveis. O objetivo destes diferentes valores de agrupamentos, é evidenciar as similaridades e dissimilaridades que 0 método utiliza na organização das variáveis.

No próximo item, analisaremos pelo método SOM, o critério de agrupamento, similaridades e dissimilaridades, utilizando a mesma quantidade de clusters aplicado no SPSS.

Figura 9- 2. Gráfico de dispersão para 2 clusters

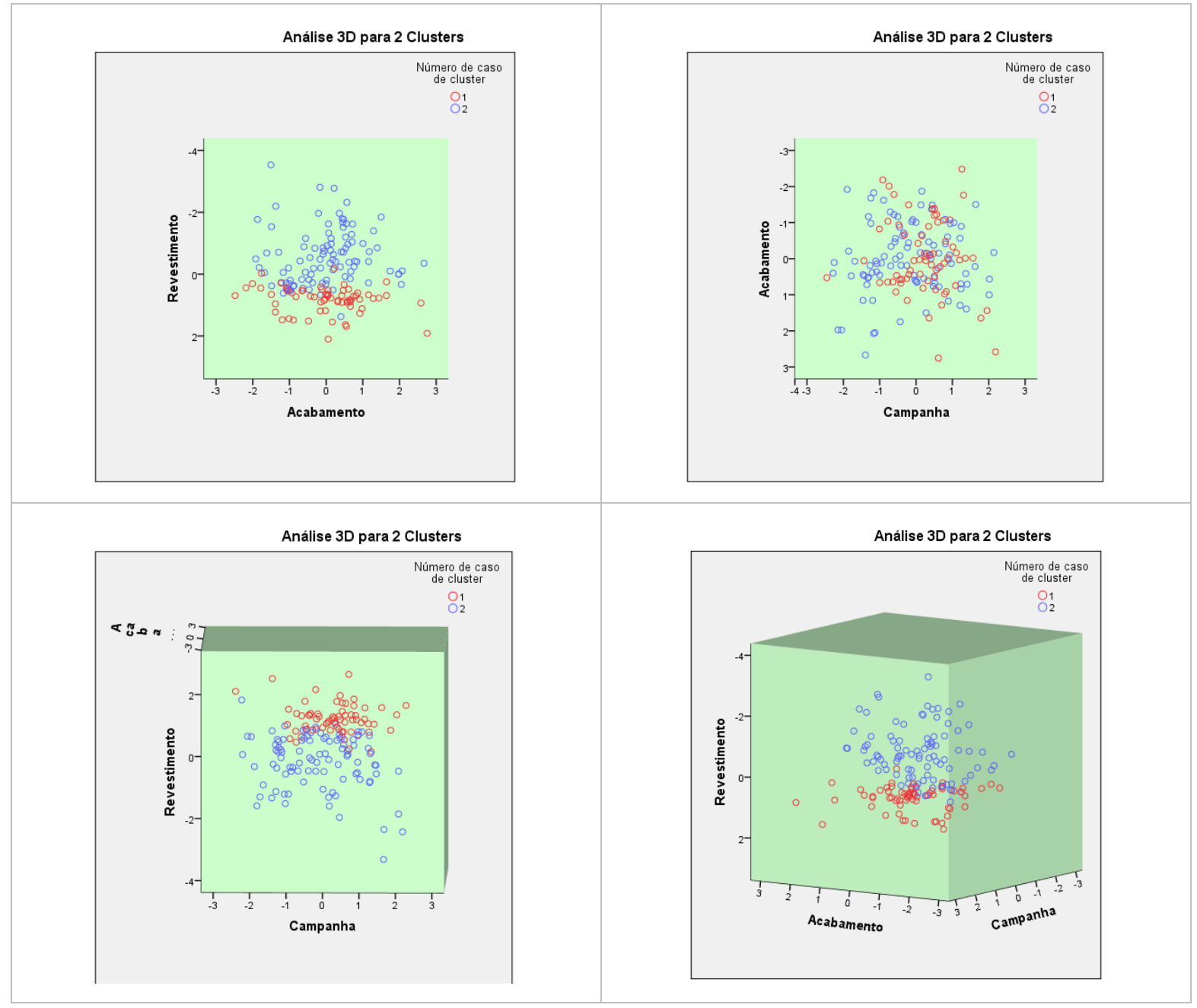



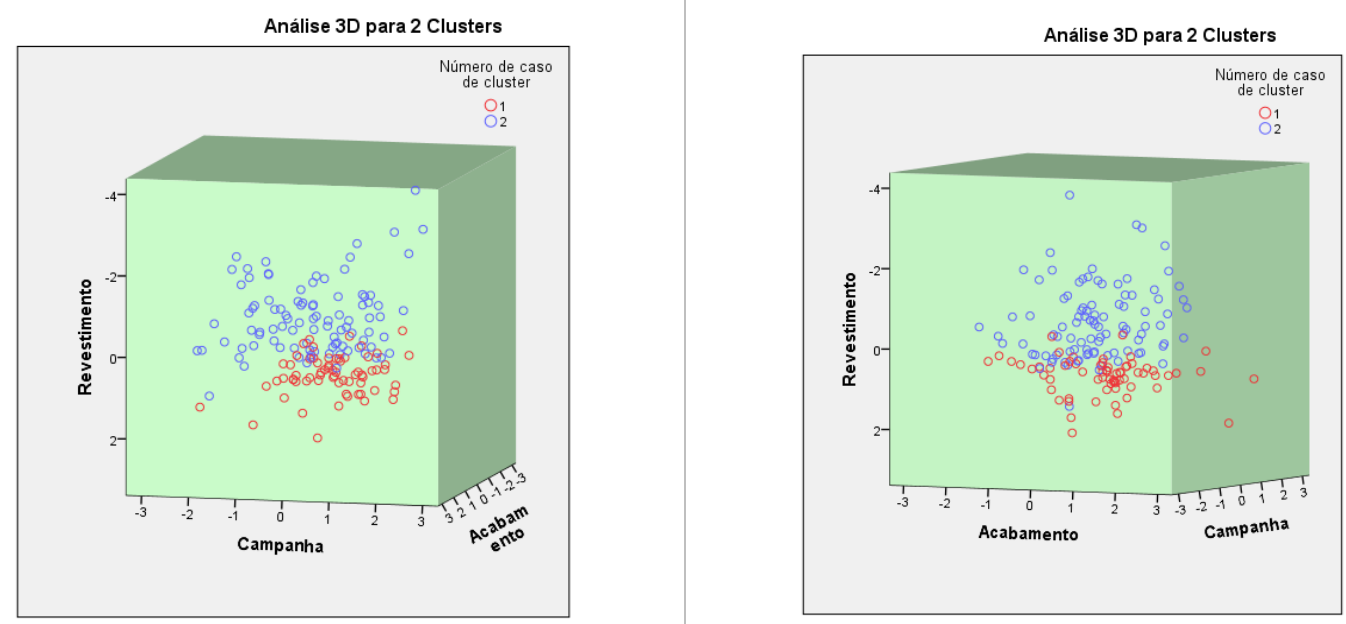

Fonte: (Autor - software SPSS)

Figura 9- 3. Gráfico de dispersão para 3 Clusters.

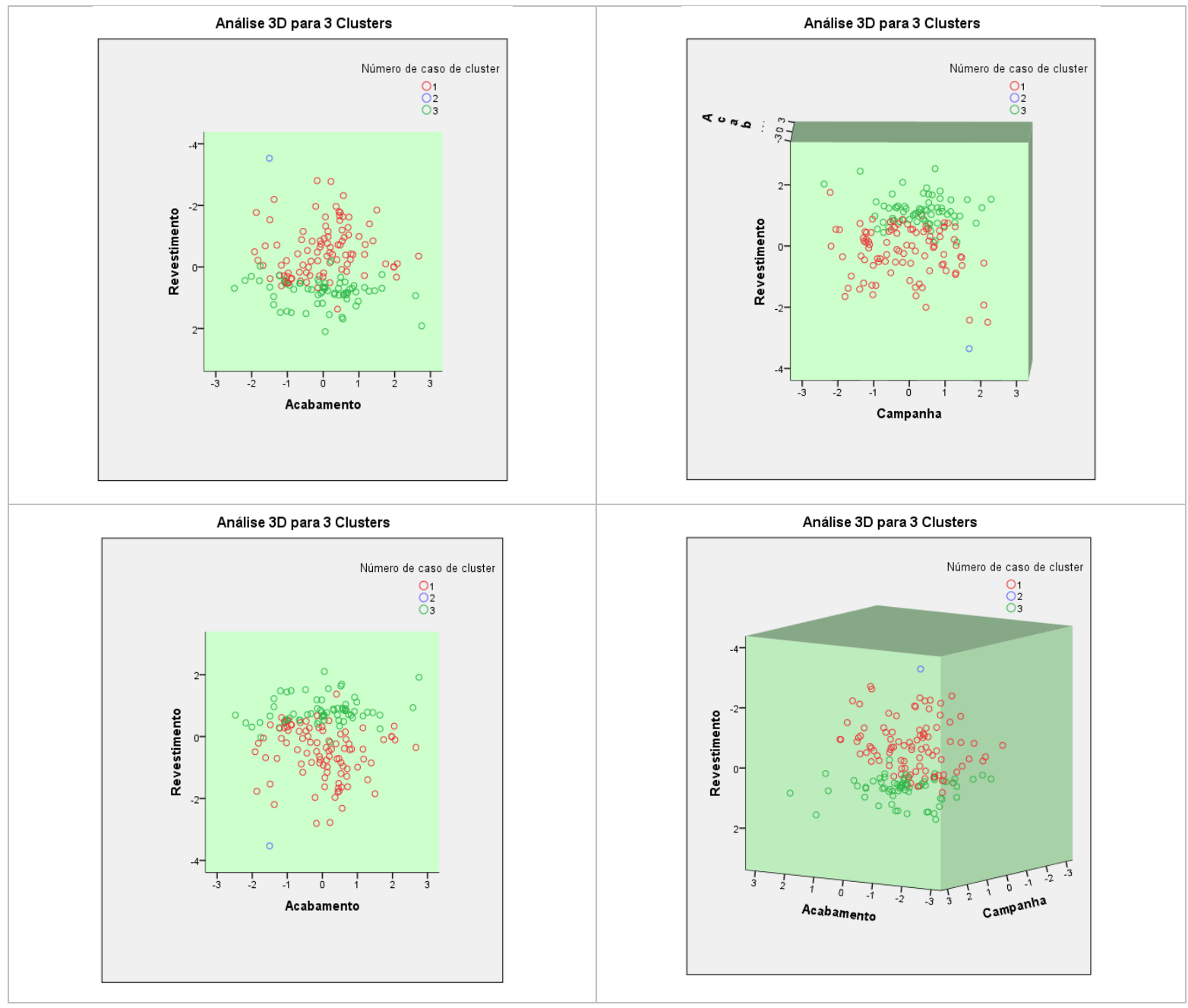




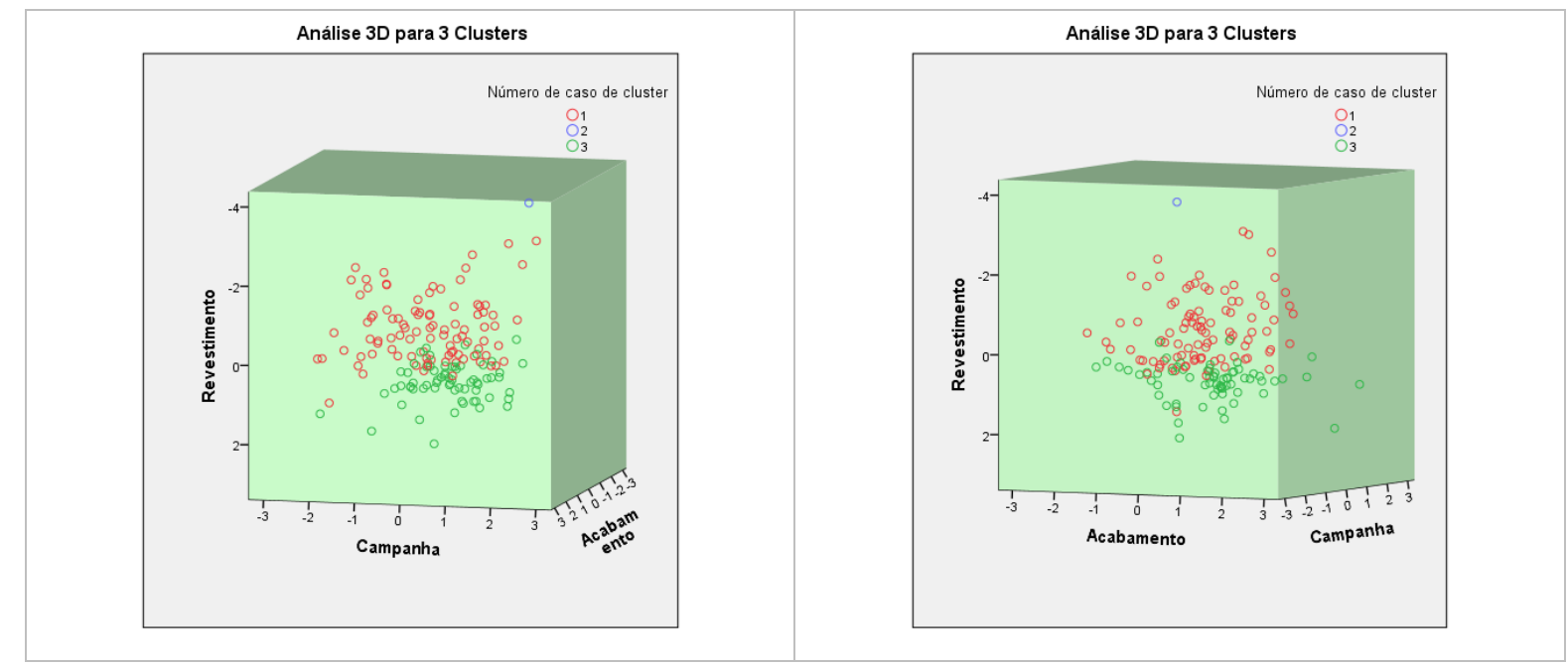

Fonte: (Autor - software SPSS)

Figura 9- 4. Gráfico de dispersão para 5 Clusters.

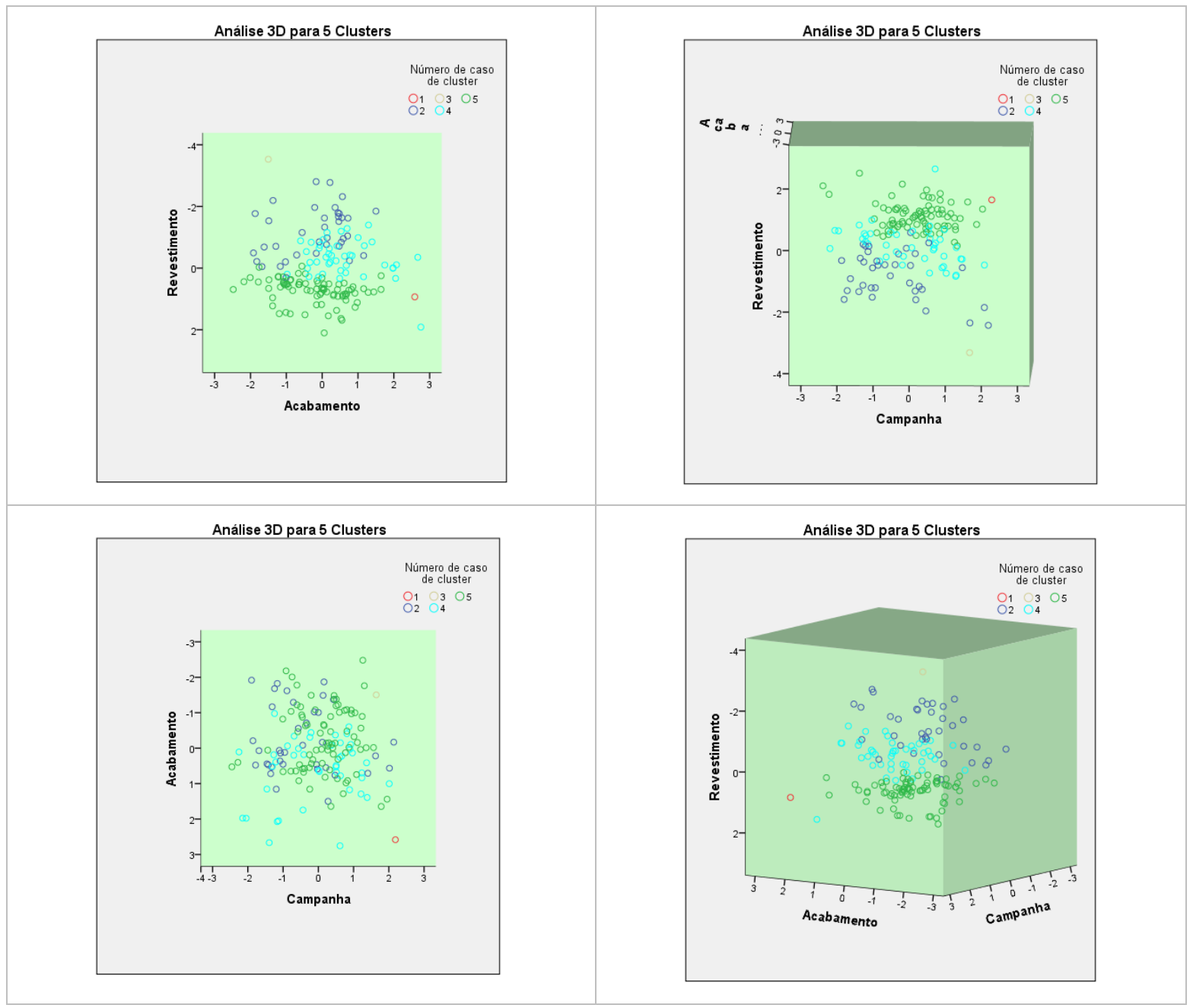



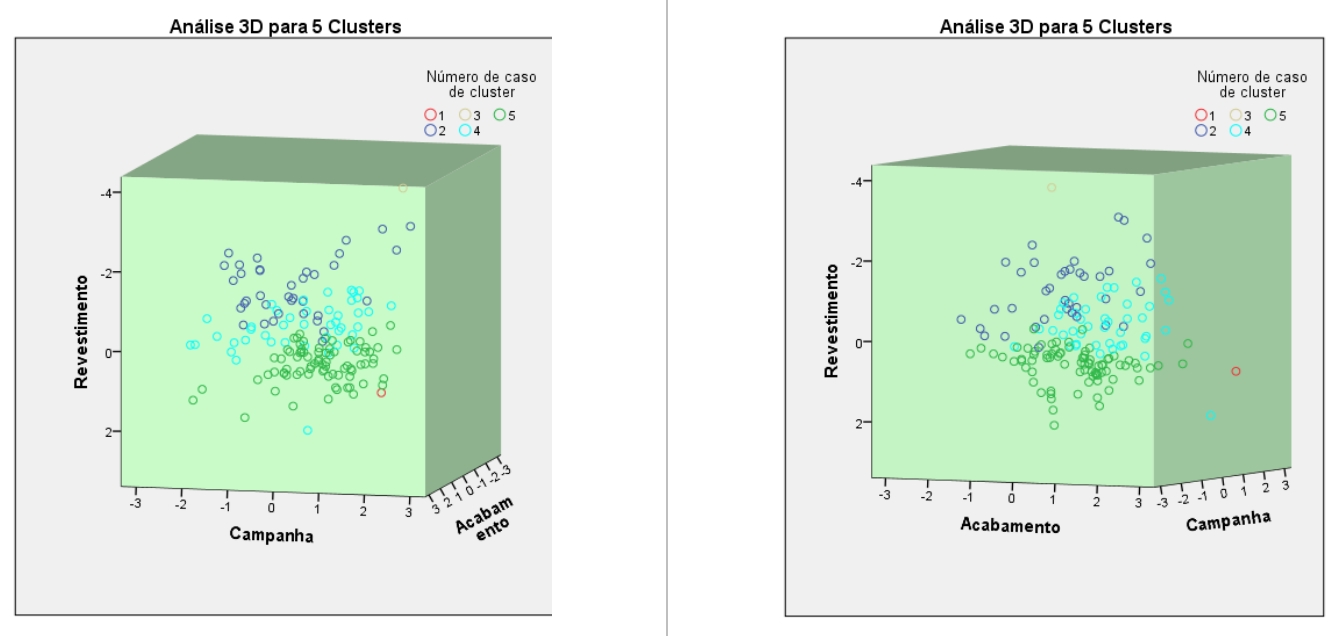

Fonte: (Autor - software SPSS)

Figura 9- 5. Gráfico de dispersão para 10 Clusters.

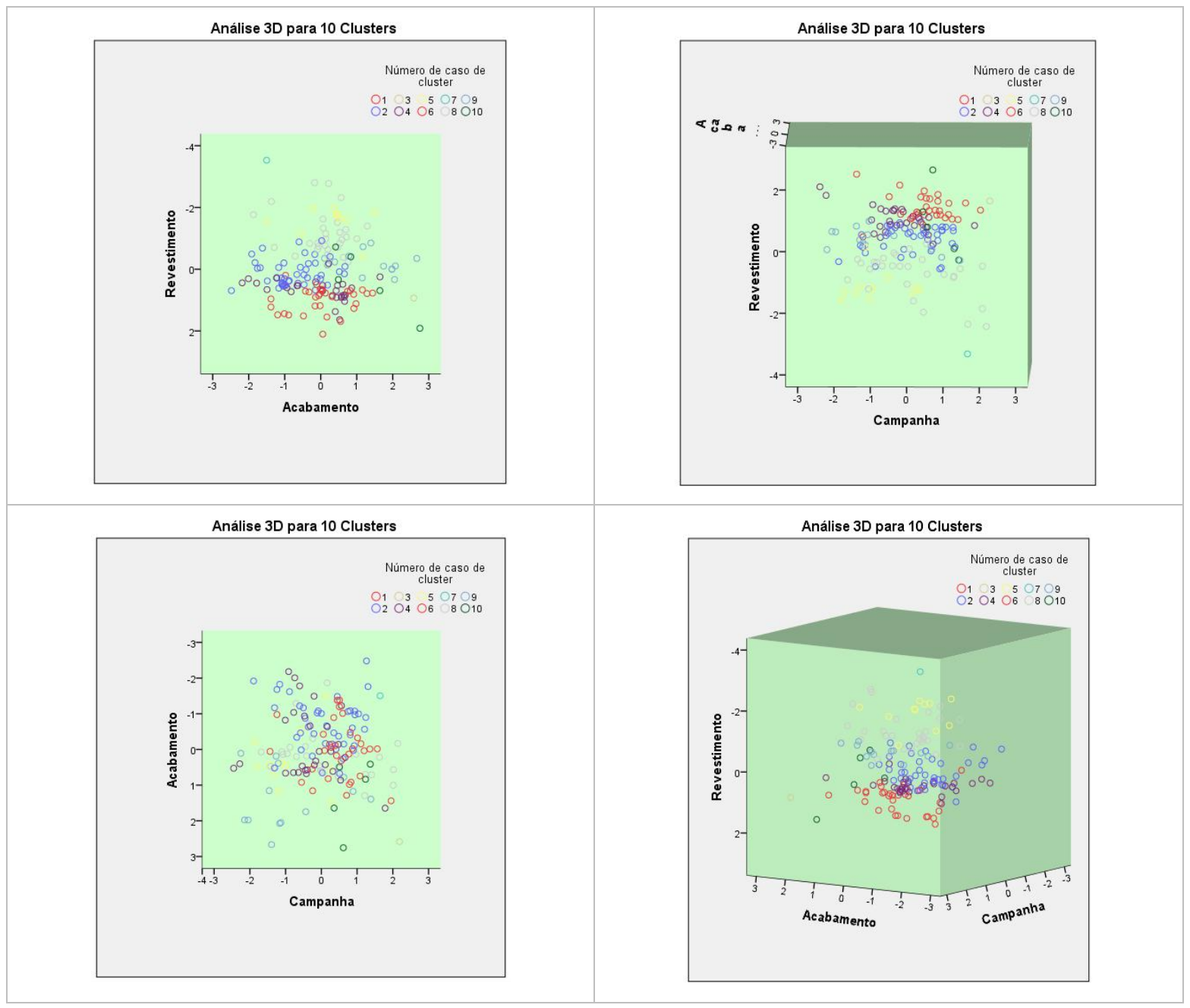



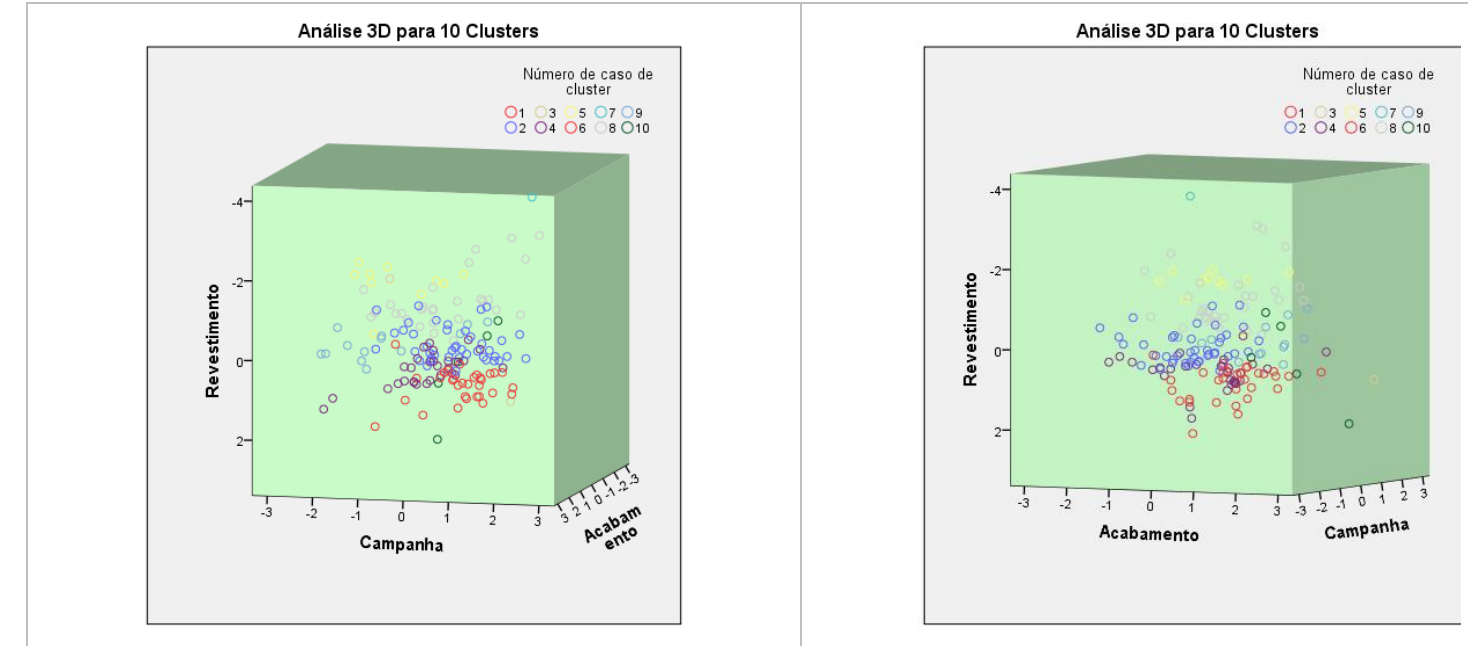

Fonte: (Autor - software SPSS)

Figura 9- 6. Gráfico de dispersão para 15 Clusters.

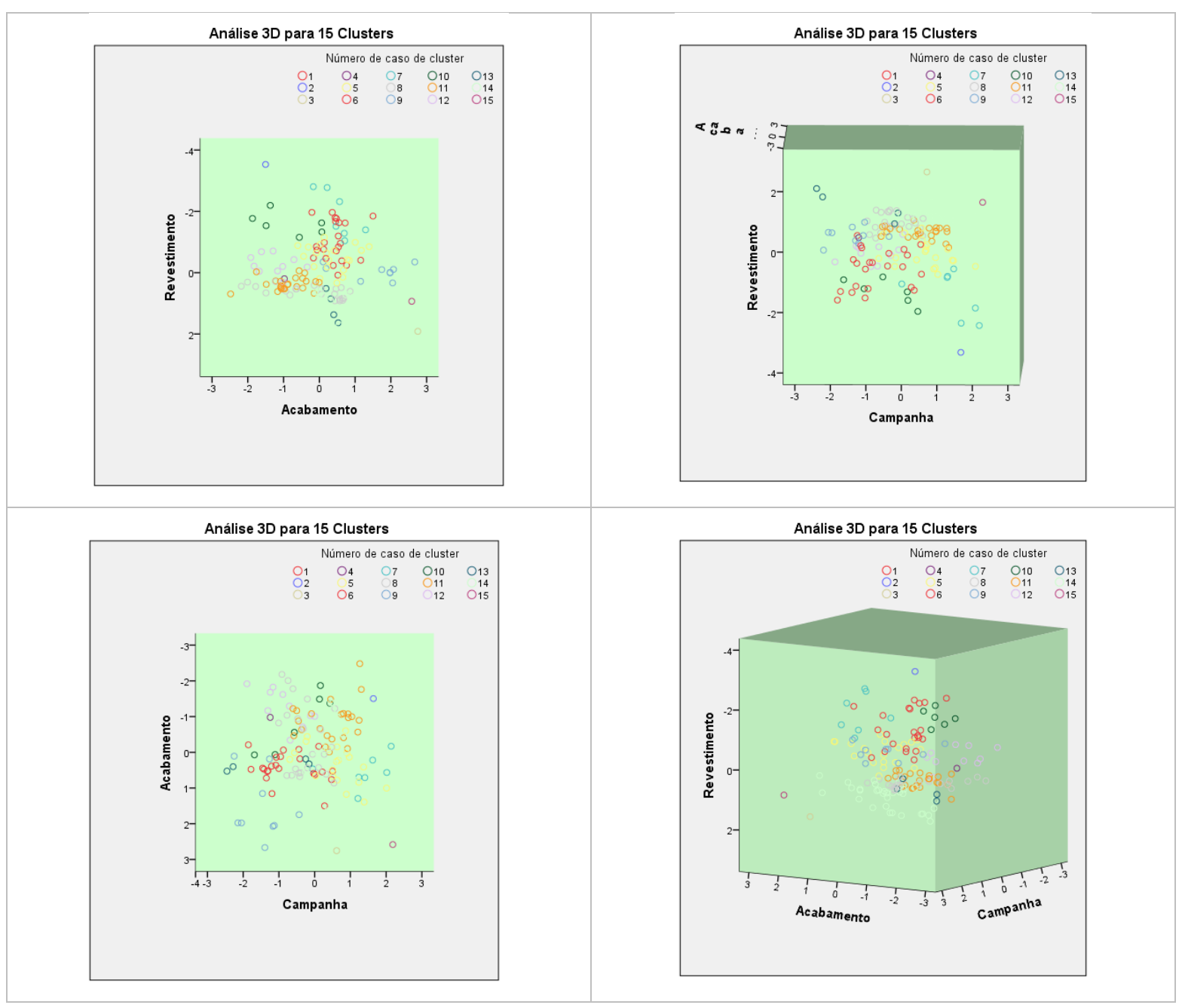




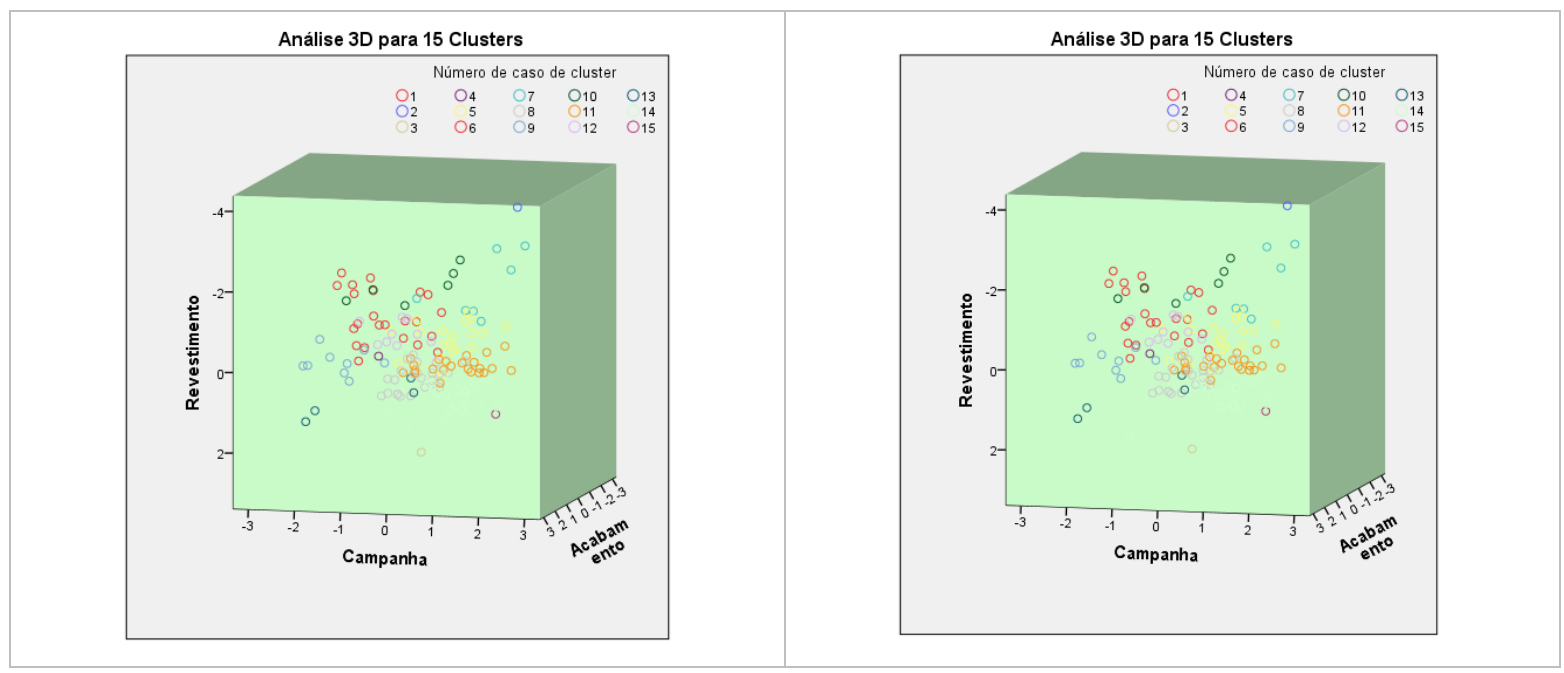

Fonte: (Autor - software SPSS)

\subsection{Resultados do SOM}

A rede SOM pode ser encarada como uma técnica de redução da dimensionalidade ao mapear os neurônios do espaço de entrada para a grade fixa do espaço de saída. Nesse sentido a rede SOM é uma generalização não linear da análise de componentes principais (Ritter, 1998).

Os seguintes parâmetros de configuração do SOM foram escolhidos para este estudo: o espaço de dados foi iniciado de forma aleatória; uma grade hexagonal foi escolhida como formato de visualização; a superfície de um hipervolume toroidal foi utilizado para a projeção dos neurônios ou BMU's.

A análise Davies-Bouldin (Davies e Bouldin, 1979) foi executada para definir o número ideal de clusters para os neurônicos provenientes das análises SOM. Assim, depois de algumas tentativas, um tamanho de mapa de 8 linhas $\times 8$ colunas foi escolhido como adequado para este estudo exploratório para representar os agrupamentos de node-vectors em uma classificação baseada em médias-K, conforme FIGURA 9.7. Após a geração do mapa-auto organizado, foram geradas as imagens da Matriz- $U$ e parcelas componentes. 
Figura 9- 7. Cálculo para definição do índice de David-Bouldin

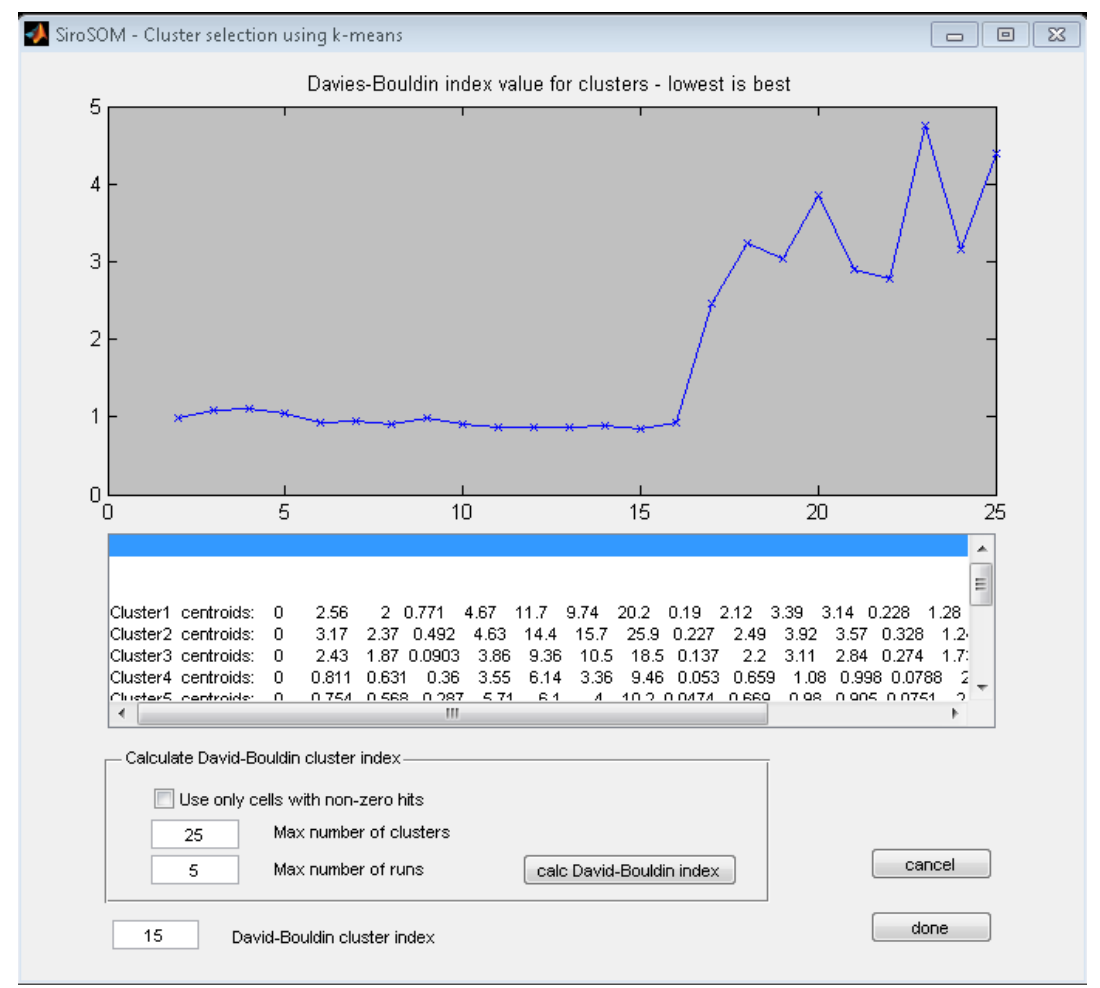

Fonte: (Autor - software SPSS)

Cada neurônio ou BMU no mapa auto-organizado representa, de fato, um "minicluster" das variáveis de entrada. No entanto, para entender o comportamento destes neurônios em agrupamentos maiores, é indicado a classificação do mapaauto organizável. Neste trabalho, os neurônios resultantes foram classificados a partir da média-K, baseado no número de classes determinadas pelas análises de Davies e Boldin (1979).

Para visualizar a distribuição espacial dos resultados dessa classificação, os pontos resultantes foram interpolados a partir do método dos principais componentes, para os dados discretos.

\subsubsection{Matriz da Distância Unificada (Matriz-U)}

A representação do mapa auto organizável na forma da Matriz-U evidencia as proximidades entre neurônios adjacentes neste mapa, em termos da distância euclidiana. Uma escala temperatura-cor é usada, sendo que cores frias (azuis) representam neurônios adjacentes com maior similaridade, enquanto as cores 
quentes (vermelhas) indicam maior distância ou separação euclidiana, ou ainda, neurônios com maior dissimilaridade. Para auxiliar a representação gráfica, neurônios simulados alternados são adicionados à Matriz-U, e estes são coloridos conforme a distância dos neurônios adjacentes. Desse modo, neurônios com maior similaridade (tons azuis) separados por neurônios mais dissimilares (tons vermelhos) representam amostras pertencentes a grupos diferentes, conforme FIGURA 9-8.

Figura 9- 8. Matrix U (matriz da distância unificada)

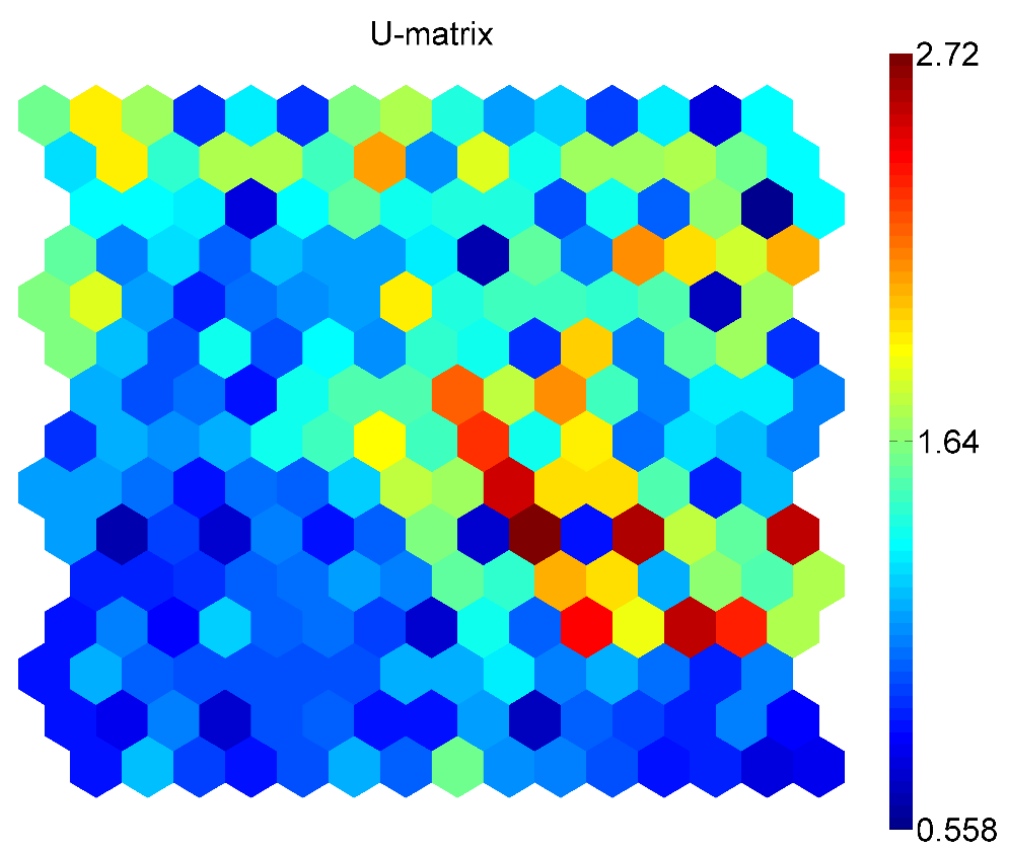

Fonte: (Autor - software SOM)

Os Best Matching Units (BMU's), são vetores resultantes, treinados para representar a distribuição original das amostras envolvidas no processo, todas as amostras próximas a estes são representadas em um mapa 2D. Uma regressão é usada para transformar a representação dos dados do espaço $\mathrm{Nd}$ para o espaço 2D. Uma das características chave desta transformação é que as relações topológicas entre os BMU's são preservadas. Ou seja, BMU's que são próximos no espaço $\mathrm{Nd}$ permanecem próximos no espaço 2D. As amostras originais são representadas nesta fase por neurônios particulares no mapa auto organizável, e estes neurônios podem vir a formar clusters ou agrupamentos. O mapa auto 
organizável é, portanto, um produto ordenado, representação 2D de um conjunto de múltiplos parâmetros.

Desse modo, é um produto ideal para visualização e interpretações posteriores. A "matriz da distância unificada" também chamada de Matriz-U ou U-Matrix e as "parcelas componentes" ou component plots, são dois exemplos dessas visualizações.

\subsubsection{Matriz-U Hits}

A matriz-U de hits consiste numa matriz de acumulação de mesmo tamanho do mapa, em que cada posição da matriz está associada com a posição do respectivo neurônio na grade da rede SOM. O histograma de hits representa número de padrões em que cada neurônio é o BMU. Nas posições da matriz de acumulação são mostradas o número de padrões para os quais aquele neurônio é o vencedor. Em outras palavras, trata-se de um histograma 2D onde cada intervalo de bloco (bin) é a posição do neurônio e soma-se uma unidade para cada padrão onde aquele neurônio é o vencedor (BMU). Dessa forma, tem-se uma maneira de observar a densidade de padrões no mapa em função dos hits associados a cada neurônio. $\mathrm{O}$ histograma de hits exibe comportamento inverso da matriz $\mathrm{U}$ em se tratando de dependência do tamanho do mapa: há o fenômeno da dissolução dos hits conforme apresentado na FIGURA 9-9. Quanto maior o mapa, menor o PNR (número de padrões por neurônios), de forma que a matriz (histograma 2D) começa a ficar esparsa. 
Figura 9- 9. Matrix U Hits

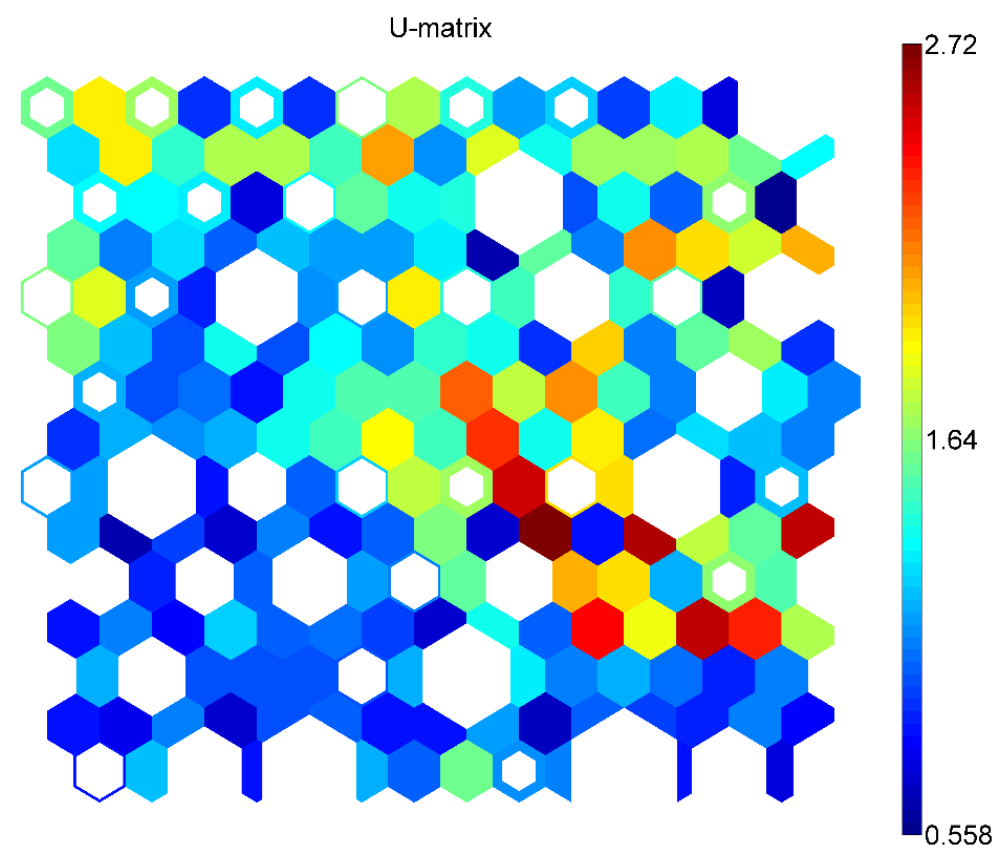

Fonte: (Autor - software SOM)

A FIGURA 9-10 representa a Matriz-U hits, gerada com 15 clusters a partir dos componentes analisados da Matriz-U.

Figura 9- 10. Matrix U Hits para 15 clusters

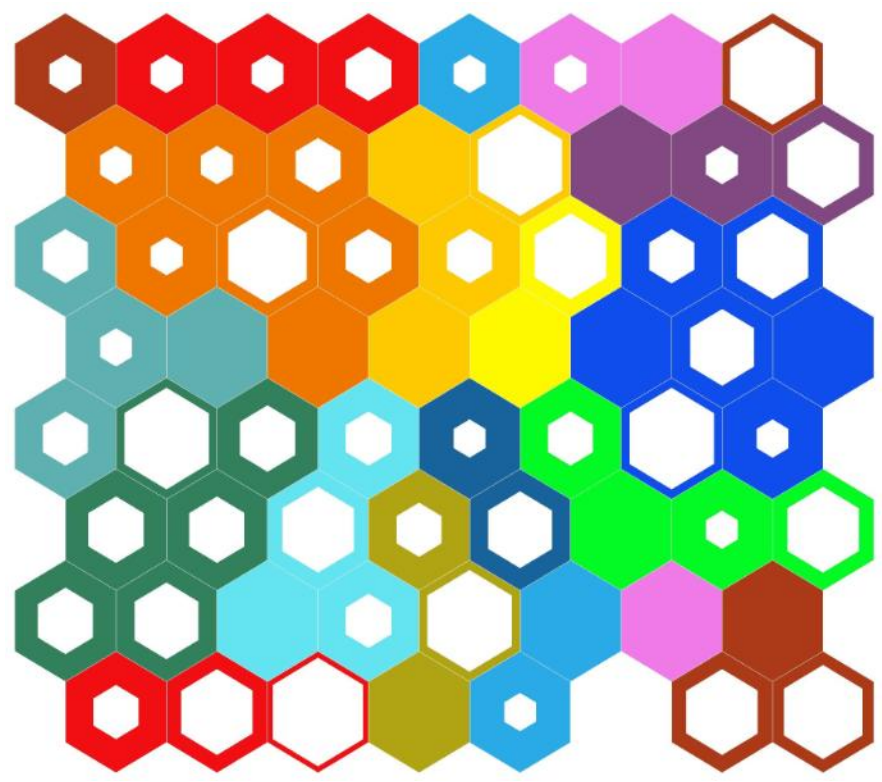

Fonte: (Autor - software SOM) 


\subsubsection{Componentes Plots}

A FIGURA 9.5 apresenta várias matrizes-U, uma para cada atributo do conjunto, onde pode-se observar as tendências de agrupamento de cada atributo em particular e, portanto, sua contribuição para o resultado geral.

Esta possibilidade de uso da ferramenta SOM permite descobrir possíveis correlações entre atributos observando as matrizes-U individuais de cada atributo: figuras semelhantes indicam correlação positiva (similaridade), enquanto figuras com padrão de cor invertido indicam correlação negativa (dissimilaridade). A análise visual de correlação é discutida em Vesanto \& Ahola (1999). Com essa inspeção visual, é possível identificar atributos que podem ser removidos, reduzindo assim, a dimensão dos vetores de dados, ou atributos que apresentam grande influência no resultado final.

Figura 9- 11. Componentes Plots
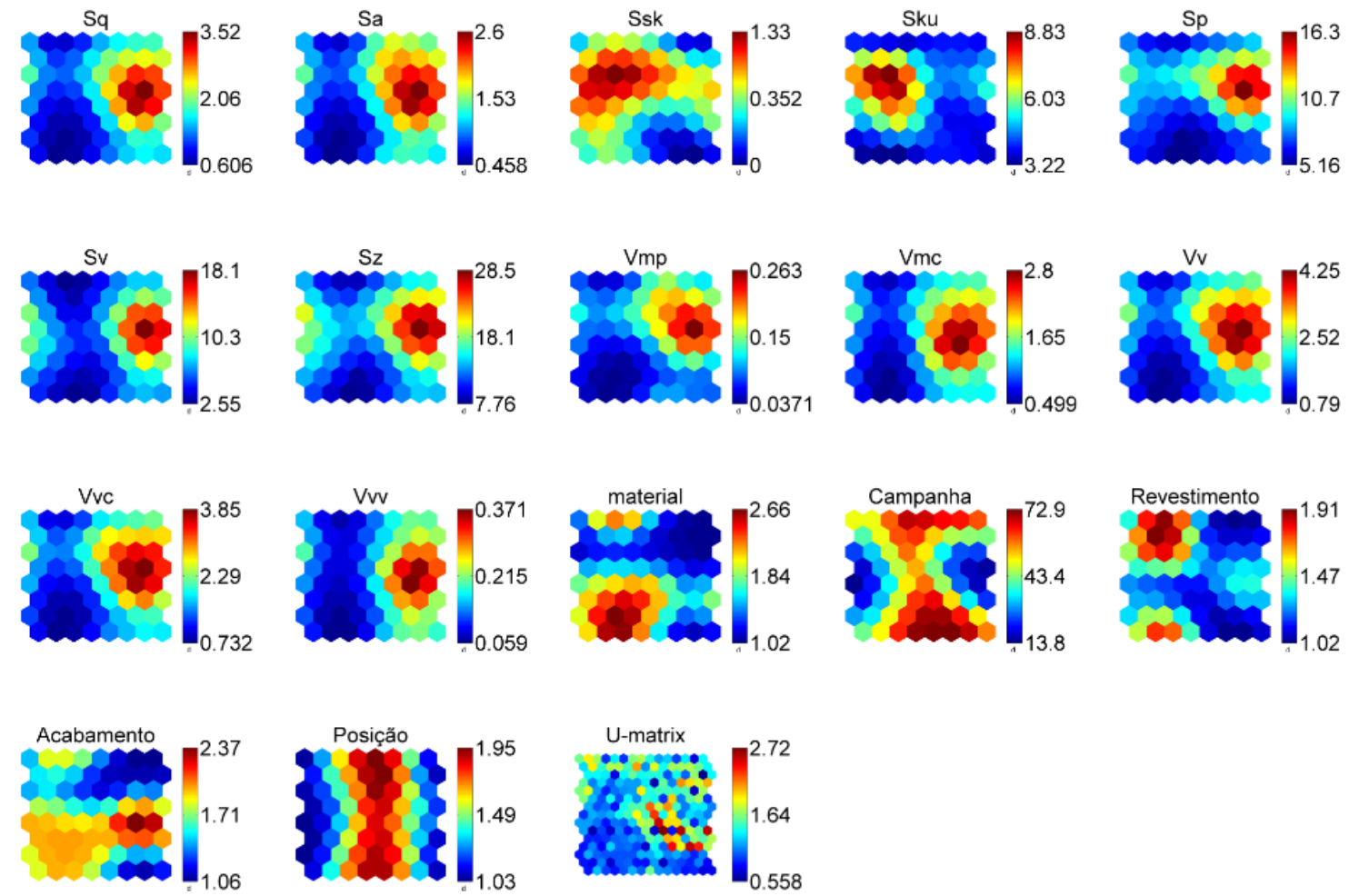

Fonte: (Autor - software SOM) 


\subsubsection{Resultados do revestimento de cromo}

O resumo dos resultados destas figuras conforme TABELA 9-31.

Tabela 9- 31. Resultado das equações de regressão linear múltipla

\begin{tabular}{|c|c|c|c|c|c|c|c|c|c|c|}
\hline \multirow{2}{*}{$\begin{array}{c}\text { Resultados "y" } \\
\text { do modelo de } \\
\text { regressão }\end{array}$} & \multicolumn{4}{|c|}{ Aço } & \multicolumn{2}{c|}{ Cobre } & \multicolumn{2}{c|}{ Alumínio } \\
\cline { 2 - 12 } & Retificado & \multicolumn{2}{|c|}{ Jateado } & Texturizado & \multicolumn{2}{c|}{ Retificado } & \multicolumn{2}{c|}{ Retificado } \\
\cline { 2 - 12 } & Crom & Ncrom & Crom & Ncrom & Crom & Ncrom & Crom & Ncrom & Crom & Ncrom \\
\hline Média & 1667 & 717 & 2369 & 693 & 2557 & 655 & 445 & 76 & 1483 & 119 \\
\hline Máximo & 691 & 664 & - & 312 & 3496 & -1644 & -822 & 1 & - & 100 \\
\hline Mínimo & 2873 & 758 & 4403 & 1419 & 2915 & 2073 & 1716 & 130 & 3420 & 268 \\
\hline
\end{tabular}

Fonte: (Autor - software SOM)

\subsubsection{Resultados de Cluster}

Os resultados dos clusters em função da quantidade:

\section{I- Cluster 2}

Tabela 9- 32. Cluster com 2 componentes

\begin{tabular}{l|cc}
\hline Variáveis/Cluster & $\mathbf{1}$ & $\mathbf{2}$ \\
\hline Amostras & 49,00 & 113,00 \\
\hline Erro quadrático & 2,37 & 1,78 \\
\hline Sq & 2,63 & 1,15 \\
\hline Sa & 2,04 & 0,92 \\
\hline Ssk & 0,46 & 0,21 \\
\hline Sku & 4,55 & 4,92 \\
\hline Sp & 12,03 & 7,00 \\
\hline Sv & 11,75 & 5,42 \\
\hline Vmp & 0,19 & 0,08 \\
\hline Vmc & 2,12 & 0,99 \\
\hline Vvc & 3,10 & 1,38 \\
\hline Vvv & 0,26 & 0,12 \\
\hline Material & 1,29 & 1,81 \\
\hline Campanha & 26,18 & 55,13 \\
\hline Revestimento & 1,27 & 1,33 \\
\hline Acabamento & 1,61 & 1,65 \\
\hline
\end{tabular}

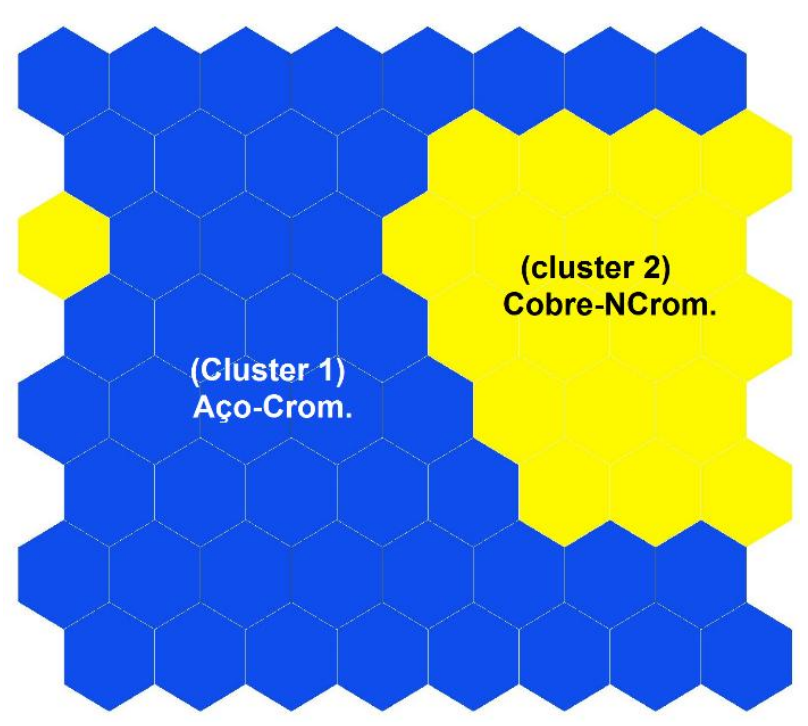

Fonte: (Autor - software SOM) 


\section{II - Cluster 3}

Tabela 9- 33. Cluster com 3 componentes

\begin{tabular}{l|ccc}
\hline Variáveis/Cluster & $\mathbf{1}$ & $\mathbf{2}$ & $\mathbf{3}$ \\
\hline Amostras & 27,00 & 59,00 & 76,00 \\
\hline Erro quadrático & 3,04 & 1,75 & 1,73 \\
\hline Sq & 3,06 & 1,80 & 0,93 \\
\hline Sa & 2,32 & 1,48 & 0,71 \\
\hline Ssk & 0,45 & $-0,08$ & 0,52 \\
\hline Sku & 4,44 & 4,22 & 5,39 \\
\hline Sp & 13,51 & 8,34 & 6,89 \\
\hline Sv & 14,15 & 7,42 & 4,85 \\
\hline Vmp & 0,21 & 0,12 & 0,06 \\
\hline Vmc & 2,47 & 1,53 & 0,78 \\
\hline Vvc & 3,50 & 2,15 & 1,13 \\
\hline Vvv & 0,31 & 0,19 & 0,09 \\
\hline Material & 1,22 & 1,29 & 2,09 \\
\hline Campanha & 18,04 & 60,29 & 45,64 \\
\hline Revestimento & 1,30 & 1,10 & 1,47 \\
\hline Acabamento & 1,93 & 1,20 & 1,88 \\
\hline
\end{tabular}

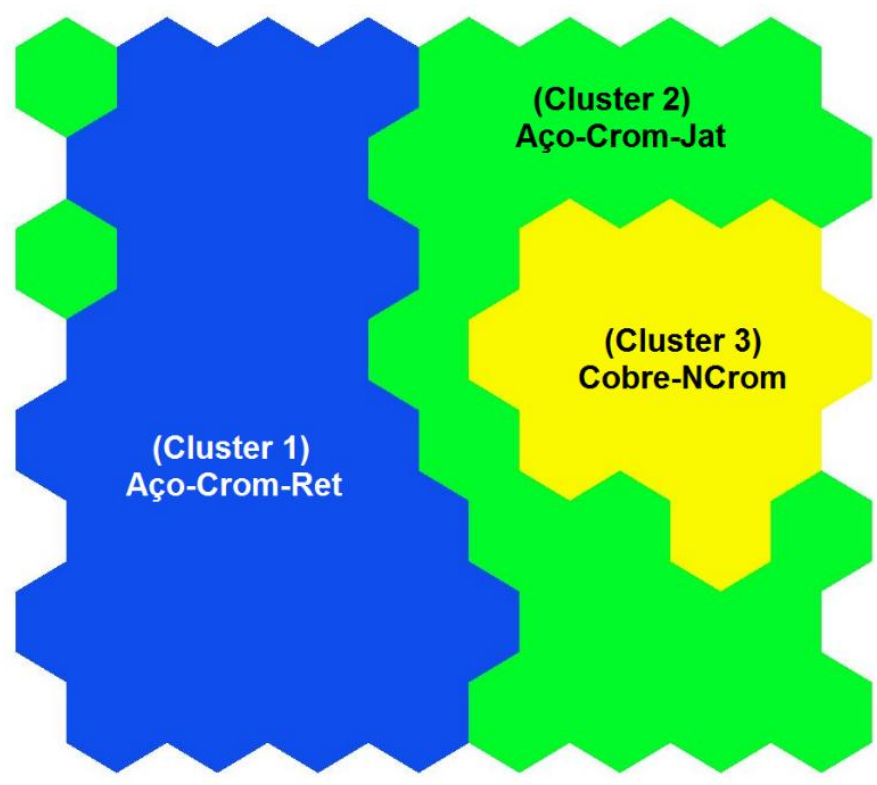

Fonte: (Autor - software SOM)

\section{III - Cluster 5}

Tabela 9- 34. Cluster com 5 componentes

\begin{tabular}{l|ccccc}
\hline Variáveis/Cluster & $\mathbf{1}$ & $\mathbf{2}$ & $\mathbf{3}$ & $\mathbf{4}$ & $\mathbf{5}$ \\
\hline Amostras & 37,00 & 19,00 & 44,00 & 28,00 & 34,00 \\
\hline Erro quadrático & 1,88 & 3,47 & 1,69 & 1,56 & 1,86 \\
\hline Sq & 1,62 & 3,24 & 0,80 & 2,27 & 1,16 \\
\hline Sa & 1,35 & 2,42 & 0,62 & 1,83 & 0,87 \\
\hline Ssk & $-0,41$ & 0,40 & 0,22 & 0,47 & 0,92 \\
\hline Sku & 3,94 & 4,48 & 4,45 & 4,41 & 6,72 \\
\hline Sp & 7,22 & 14,36 & 5,98 & 10,58 & 8,26 \\
\hline Sv & 6,59 & 15,68 & 3,84 & 9,20 & 6,47 \\
\hline Vmp & 0,10 & 0,23 & 0,05 & 0,17 & 0,08 \\
\hline Vmc & 1,43 & 2,57 & 0,72 & 1,86 & 0,89 \\
\hline Vvc & 1,88 & 3,63 & 0,96 & 2,79 & 1,41 \\
\hline Vvv & 0,19 & 0,34 & 0,08 & 0,21 & 0,10 \\
\hline Material & 1,24 & 1,00 & 2,57 & 1,50 & 1,41 \\
\hline Campanha & 74,62 & 12,95 & 57,34 & 36,54 & 28,24 \\
\hline Revestimento & 1,03 & 1,37 & 1,48 & 1,14 & 1,50 \\
\hline Acabamento & 1,19 & 2,16 & 2,00 & 1,29 & 1,68 \\
\hline & & & & &
\end{tabular}

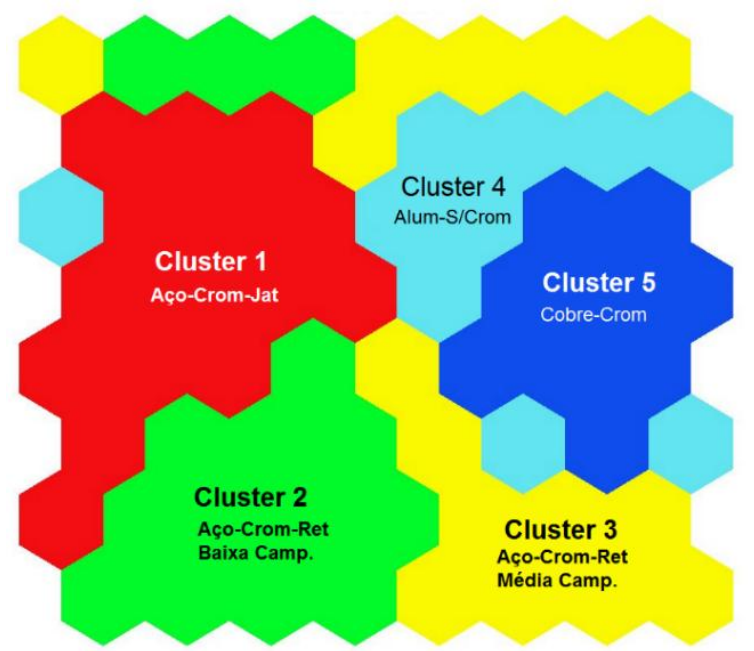




\section{IV - Cluster 10}

Tabela 9- 35. Cluster com 10 componentes

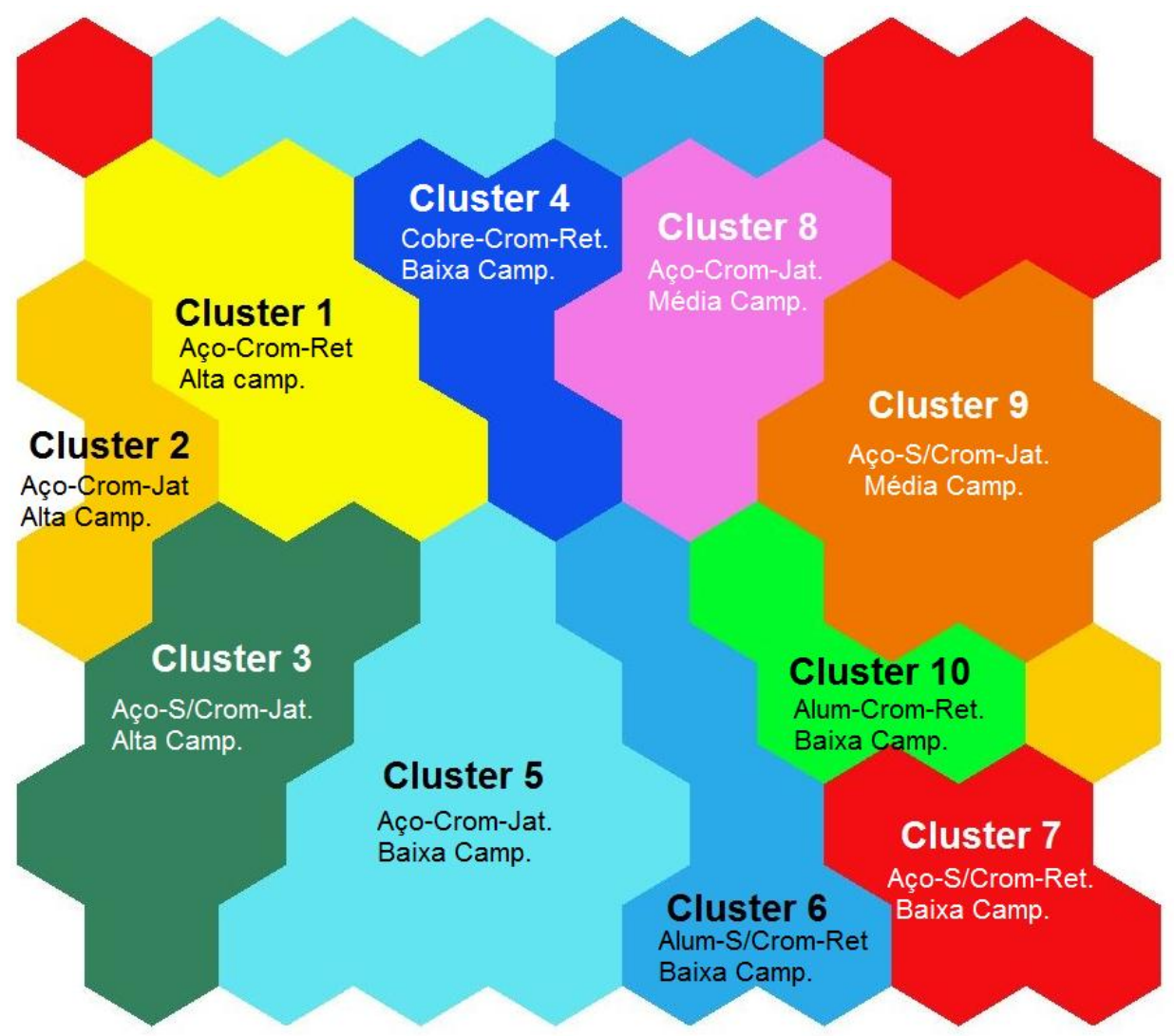

\begin{tabular}{l|cccccccccc}
\hline Variáveis/Cluster & $\mathbf{1}$ & $\mathbf{2}$ & $\mathbf{3}$ & $\mathbf{4}$ & $\mathbf{5}$ & $\mathbf{6}$ & $\mathbf{7}$ & $\mathbf{8}$ & $\mathbf{9}$ & $\mathbf{1 0}$ \\
\hline Amostras & 24,00 & 26,00 & 12,00 & 25,00 & 12,00 & 28,00 & 5,00 & 9,00 & 13,00 & 8,00 \\
\hline Erro quadrático & 1,79 & 1,68 & 4,23 & 1,60 & 1,92 & 1,76 & 2,25 & 1,18 & 2,06 & 2,36 \\
\hline Sq & 1,38 & 1,83 & 3,39 & 0,87 & 2,83 & 0,75 & 1,57 & 2,07 & 1,27 & 2,27 \\
\hline Sa & 1,19 & 1,45 & 2,53 & 0,66 & 2,17 & 0,58 & 1,18 & 1,81 & 0,94 & 1,74 \\
\hline Ssk & $-0,36$ & $-0,33$ & 0,33 & 0,62 & 0,64 & 0,29 & 0,93 & 0,74 & 1,17 & 0,25 \\
\hline Sku & 4,18 & 3,99 & 4,23 & 5,36 & 4,78 & 4,44 & 6,60 & 4,64 & 7,86 & 3,92 \\
\hline Sp & 6,19 & 8,60 & 14,09 & 7,24 & 13,82 & 5,86 & 9,28 & 10,15 & 8,87 & 9,38 \\
\hline Sv & 5,31 & 7,74 & 16,13 & 6,51 & 13,04 & 3,38 & 9,83 & 6,77 & 4,34 & 10,73 \\
\hline Vmp & 0,09 & 0,11 & 0,23 & 0,06 & 0,22 & 0,05 & 0,10 & 0,18 & 0,11 & 0,13 \\
\hline Vmc & 1,36 & 1,51 & 2,73 & 0,70 & 2,20 & 0,65 & 1,24 & 1,65 & 0,94 & 1,97 \\
\hline Vvc & 1,60 & 2,16 & 3,76 & 1,05 & 3,33 & 0,92 & 1,87 & 2,68 & 1,58 & 2,68 \\
\hline Vvv & 0,17 & 0,20 & 0,37 & 0,09 & 0,27 & 0,07 & 0,16 & 0,16 & 0,10 & 0,25 \\
\hline Material & 1,63 & 1,04 & 1,00 & 2,12 & 1,00 & 2,71 & 1,00 & 1,00 & 1,00 & 2,75 \\
\hline Campanha & 75,92 & 64,88 & 14,58 & 22,48 & 12,25 & 60,39 & 2,80 & 55,89 & 52,23 & 27,50 \\
\hline Revestimento & 1,00 & 1,04 & 1,50 & 1,20 & 1,08 & 1,61 & 1,60 & 1,11 & 2,00 & 1,38 \\
\hline Acabamento & 1,50 & 1,08 & 2,83 & 2,00 & 1,00 & 2,00 & 1,60 & 1,00 & 1,00 & 2,00 \\
\hline
\end{tabular}

Fonte: (Autor - software SOM) 
Tabela 9- 36. Cluster com 15 componentes

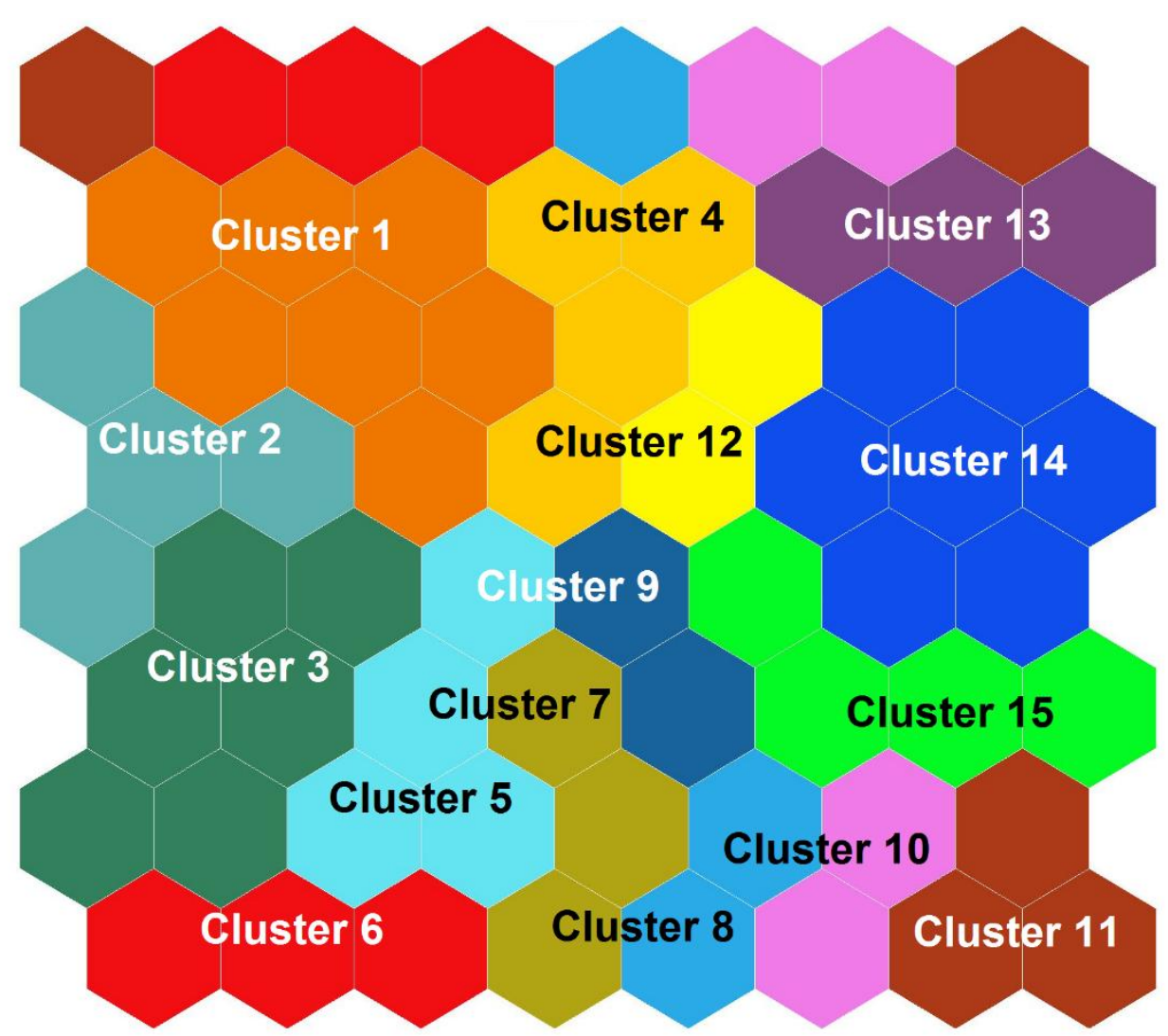

\begin{tabular}{|c|c|c|c|c|c|c|c|c|c|c|c|c|c|c|c|}
\hline Variáveis/Cluster & 1 & 2 & 3 & 4 & 5 & 6 & 7 & 8 & 9 & 10 & 11 & 12 & 13 & 14 & 15 \\
\hline Amostras & 5,00 & 19,00 & 8,00 & 19,00 & 9,00 & 9,00 & 11,00 & 23,00 & 2,00 & 13,00 & 5,00 & 6,00 & 9,00 & 19,00 & 5,00 \\
\hline Erro quadrático & 1,56 & 3,47 & 2,36 & 1,59 & 2,18 & 1,18 & 2,09 & 1,59 & 1,99 & 2,06 & 2,25 & 1,04 & 1,48 & 1,49 & 2,89 \\
\hline $\mathrm{Sq}$ & 2,62 & 3,24 & 2,27 & 0,73 & 0,77 & 2,07 & 1,54 & 0,87 & 1,36 & 1,27 & 1,57 & 2,28 & 1,02 & 1,70 & 1,59 \\
\hline $\mathrm{Sa}$ & 2,09 & 2,42 & 1,74 & 0,57 & 0,58 & 1,81 & 1,42 & 0,66 & 1,31 & 0,94 & 1,18 & 1,75 & 0,82 & 1,34 & 1,23 \\
\hline Ssk & 0,82 & 0,40 & 0,25 & 0,32 & 0,28 & 0,74 & $-0,54$ & 0,65 & $-0,07$ & 1,17 & 0,93 & 0,05 & $-0,26$ & $-0,46$ & $-0,09$ \\
\hline Sku & 4,62 & 4,48 & 3,92 & 3,37 & 6,23 & 4,64 & 3,94 & 5,53 & 3,91 & 7,86 & 6,60 & 4,56 & 4,65 & 3,81 & 4,49 \\
\hline$S p$ & 12,42 & 14,36 & 9,38 & 5,80 & 6,17 & 10,15 & 6,52 & 7,29 & 6,46 & 8,87 & 9,28 & 11,29 & 5,46 & 7,81 & 6,83 \\
\hline Sv & 10,40 & 15,68 & 10,73 & 3,10 & 4,18 & 6,77 & 6,48 & 6,66 & 4,62 & 4,34 & 9,83 & 9,84 & 3,78 & 7,17 & 5,44 \\
\hline Vmp & 0,20 & 0,23 & 0,13 & 0,05 & 0,05 & 0,18 & 0,10 & 0,06 & 0,12 & 0,11 & 0,10 & 0,16 & 0,06 & 0,10 & 0,09 \\
\hline Vmc & 2,09 & 2,57 & 1,97 & 0,60 & 0,69 & 1,65 & 1,34 & 0,70 & 1,17 & 0,94 & 1,24 & 1,82 & 1,11 & 1,41 & 1,81 \\
\hline Vvc & 3,23 & 3,63 & 2,68 & 0,90 & 0,92 & 2,68 & 1,73 & 1,05 & 1,66 & 1,58 & 1,87 & 2,75 & 1,22 & 1,99 & 1,90 \\
\hline Vwv & 0,23 & 0,34 & 0,25 & 0,07 & 0,08 & 0,16 & 0,20 & 0,09 & 0,14 & 0,10 & 0,16 & 0,23 & 0,12 & 0,20 & 0,18 \\
\hline Material & 1,00 & 1,00 & 2,75 & 2,68 & 2,67 & 1,00 & 1,09 & 2,13 & 1,00 & 1,00 & 1,00 & 1,00 & 2,11 & 1,00 & 2,60 \\
\hline Campanha & 15,20 & 12,95 & 27,50 & 66,42 & 48,33 & 55,89 & 71,82 & 19,22 & 95,00 & 53,23 & 2,80 & 34,80 & 70,89 & 72,21 & 81,80 \\
\hline Revestimento & 1,00 & 1,37 & 1,38 & 1,89 & 1,00 & 1,11 & 1,00 & 1,22 & 1,00 & 2,00 & 1,60 & 1,00 & 1,00 & 1,05 & 1,00 \\
\hline Acabamento & 1,00 & 2,16 & 2,00 & 2,00 & 2,00 & 1,00 & 1,09 & 2,00 & 1,00 & 1,31 & 1,60 & 1,00 & 2,00 & 1,05 & 2,00 \\
\hline
\end{tabular}

Fonte: (Autor - software SOM) 


\subsubsection{Resultados de Cluster}

Os resultados dos clusters em função da quantidade:

Estabelecidos os critérios para avaliação dos resultados encontrados, sendo:

Tabela 9- 37. Parametrização das variáveis processo I

\begin{tabular}{|c|c|c|c|c|c|c|c|}
\hline Campanha & Valor & Material & Valor & Revestimento & Valor & Acabamento & Valor \\
\hline Alta & $>70$ & Aço & 1 & Cromo & 1 & Jateado & 1 \\
\hline Média & $\begin{array}{l}>50 \\
<70\end{array}$ & Cobre & 2 & & 2 & Retificado & 2 \\
\hline Baixa & $<50$ & Alumínio & 3 & & & Texturizado & 3 \\
\hline
\end{tabular}

Fonte: (Autor - software Excel)

E as avaliações para as variáveis foram estabelecidas conforme abaixo:

Tabela 9- 38. Parametrização das variáveis processo II

\begin{tabular}{|c|c|c|c|}
\hline Variáveis & Alto & Médio & Baixo \\
\hline $\mathrm{Sq}$ & 3 & 2 & 1 \\
$\mathrm{Sa}$ & 3 & 2 & 1 \\
$\mathrm{Ssk}$ & $>0$ & $=0$ & $<0$ \\
$\mathrm{Sku}$ & $>3$ & $=3$ & $<3$ \\
$\mathrm{Sp}$ & 13 & 10 & 7 \\
$\mathrm{~Sv}$ & 13 & 10 & 7 \\
$\mathrm{Vmp}$ & 0,20 & 0,15 & 0,10 \\
$\mathrm{Vmc}$ & 2,0 & 1,5 & 1,0 \\
$\mathrm{Vvc}$ & 3 & 2 & 1 \\
$\mathrm{Vvv}$ & 0,3 & 0,2 & 0,1 \\
\hline
\end{tabular}

Fonte: (Autor - software Excel)

Os resultados das classificações nos respectivos clusters:

Para 2 clusters: 
Tabela 9- 39. Resultados parametrização para 2 clusters

\begin{tabular}{|l|c|c|}
\hline \multicolumn{1}{|c|}{ Variável } & Cluster $\mathbf{1}$ & Cluster 2 \\
\hline Sq & Alto & Baixo \\
Sa & Alto & Baixo \\
Ssk & Alto & Baixo \\
Sku & Médio & Alto \\
$\mathrm{Sp}$ & Alto & Baixo \\
$\mathrm{Sv}$ & Alto & Baixo \\
Vmp & Alto & Baixo \\
Vmc & Alto & Baixo \\
Vvc & Alto & Baixo \\
Vvv & Alto & Baixo \\
Material & Aço & Cobre \\
Campanha & Baixa & Média \\
Revestimento & Cromo & Cromo \\
Acabamento & Jateado + retificado & Jateado + retificado \\
\hline
\end{tabular}

Fonte: (Autor - software Excel)

Para 3 clusters:

Tabela 9- 40. Resultados parametrização para 3 clusters

\begin{tabular}{|l|c|c|l|}
\hline \multicolumn{1}{|c|}{ Variável } & Cluster 1 & Cluster 2 & \multicolumn{1}{c|}{ Cluster 3} \\
\hline $\mathrm{Sq}$ & Alto & Médio & Baixo \\
$\mathrm{Sa}$ & Médio & Médio & Baixo \\
$\mathrm{Ssk}$ & Alto & Baixo & Alto \\
$\mathrm{Sku}$ & Alto & Alto & Alto \\
$\mathrm{Sp}$ & Alto & Médio & Baixo \\
$\mathrm{Sv}$ & Alto & Baixo & Baixo \\
Vmp & Alto & Médio & Baixo \\
Vmc & Alto & Médio & Baixo \\
Vvc & Alto & Médio & Médio \\
Vvv & Alto & Médio & Baixo \\
Material & Aço & Aço & Cobre \\
Campanha & Baixa & Média & Baixa \\
Revestimento & Cromo & Cromo & Sem Cromo \\
Acabamento & Retificado & Jateado & Retificado \\
\hline
\end{tabular}

Fonte: (Autor - software Excel) 
Para 5 clusters:

Tabela 9- 41. Resultados parametrização para 5 clusters

\begin{tabular}{|l|c|c|c|c|c|}
\hline \multicolumn{1}{|c|}{ Variável } & Cluster 1 & Cluster $\mathbf{2}$ & Cluster $\mathbf{3}$ & Cluster 4 & Cluster 5 \\
\hline $\mathrm{Sq}$ & Médio & Alto & Baixo & Médio & Baixo \\
$\mathrm{Sa}$ & Baixo & Médio & Baixo & Médio & Baixo \\
$\mathrm{Ssk}$ & Baixo & Alto & Médio & Alto & Alto \\
$\mathrm{Sku}$ & Alto & Alto & Alto & Alto & Alto \\
$\mathrm{Sp}$ & Baixo & Alto & Baixo & Médio & Baixo \\
$\mathrm{Sv}$ & Baixo & Alto & Baixo & Médio & Baixo \\
Vmp & Baixo & Alto & Baixo & Médio & Baixo \\
Vmc & Médio & Alto & Baixo & Alto & Baixo \\
Vvc & Médio & Alto & Baixo & Alto & Baixo \\
Vvv & Médio & Alto & Baixo & Médio & Baixo \\
Material & Aço & Aço & Aço & Cobre & Alumínio \\
Campanha & Alto & Baixo & Médio & Baixo & Baixo \\
Revestimento & Cromo & Cromo & Cromo & Cromo & Sem Cromo \\
Acabamento & Jateado & Retificado & Retificado & Jateado & Retificado \\
\hline
\end{tabular}

Fonte: (Autor - software Excel) 
Para 10 clusters:

Tabela 9- 42. Resultados parametrização para 10 clusters

\begin{tabular}{|c|c|c|c|c|c|c|c|c|c|c|}
\hline Variável & Cluster 1 & Cluster 2 & Cluster 3 & Cluster 4 & Cluster 5 & Cluster 6 & Cluster 7 & Cluster 8 & Cluster 9 & Cluster 10 \\
\hline $\mathrm{Sq}$ & Baixo & Médio & Alto & Baixo & Alto & Baixo & Médio & Médio & Baixo & Médio \\
\hline Sa & Baixo & Baixo & Médio & Baixo & Médio & Baixo & Baixo & Médio & Baixo & Médio \\
\hline Ssk & Baixo & Baixo & Médio & Alto & Alto & Médio & Alto & Alto & Alto & Médio \\
\hline Sku & Alto & Médio & Alto & Alto & Alto & Alto & Alto & Alto & Alto & Médio \\
\hline Sp & Baixo & Médio & Alto & Baixo & Alto & Baixo & Médio & Médio & Médio & Médio \\
\hline Sv & Baixo & Baixo & Alto & Baixo & Alto & Baixo & Médio & Baixo & Médio & Médio \\
\hline Vmp & Baixo & Baixo & Alto & Baixo & Alto & Baixo & Baixo & Alto & Baixo & Médio \\
\hline Vmc & Médio & Médio & Alto & Baixo & Alto & Baixo & Médio & Médio & Baixo & Alto \\
\hline Vvc & Médio & Médio & Alto & Baixo & Alto & Baixo & Médio & Alto & Médio & Alto \\
\hline Vvv & Médio & Médio & Alto & Baixo & Alto & Baixo & Médio & Médio & Baixo & Alto \\
\hline Material & Cobre & Aço & Aço & Cobre & Aço & Alumínio & Aço & Aço & Aço & Alumínio \\
\hline Campanha & Alta & Alto & Baixa & Baixa & Baixa & Média & Baixa & Média & Média & Baixa \\
\hline Revestimento & Cromo & Cromo & Sem Cromo & Cromo & Cromo & Sem Cromo & Sem Cromo & Cromo & Sem Cromo & Cromo \\
\hline Acabamento & Jateado & Jateado & Texturizado & Retificado & Jateado & Retificado & Retificado & Jateado & Jateado & Retificado \\
\hline
\end{tabular}

Fonte: (Autor - software Excel) 
Para 15 clusters:

Tabela 9- 43. Resultados parametrização para 15 clusters

\begin{tabular}{|c|c|c|c|c|c|c|c|c|c|c|c|c|c|c|c|}
\hline Variável & Cluster 1 & Cluster 2 & Cluster 3 & Cluster 4 & Cluster 5 & $\begin{array}{c}\text { Cluster } \\
6 \\
\end{array}$ & $\begin{array}{c}\text { Cluster } \\
7 \\
\end{array}$ & Cluster 8 & $\begin{array}{c}\text { Cluster } \\
9 \\
\end{array}$ & $\begin{array}{c}\text { Cluster } \\
10 \\
\end{array}$ & $\begin{array}{c}\text { Cluster } \\
11 \\
\end{array}$ & $\begin{array}{c}\text { Cluster } \\
12 \\
\end{array}$ & $\begin{array}{c}\text { Cluster } \\
13 \\
\end{array}$ & $\begin{array}{c}\text { Cluster } \\
14 \\
\end{array}$ & $\begin{array}{c}\text { Cluster } \\
15 \\
\end{array}$ \\
\hline $\mathrm{Sq}$ & Alto & Alto & Médio & Baixo & Baixo & Médio & Médio & Baixo & Baixo & Baixo & Médio & Médio & Baixo & Médio & Médio \\
\hline Sa & Médio & Médio & Médio & Baixo & Baixo & Médio & Baixo & Baixo & Baixo & Baixo & Baixo & Médio & Baixo & Baixo & Baixo \\
\hline Ssk & Alto & Alto & Médio & Alto & Alto & Alto & Baixo & Alto & Baixo & Alto & Alto & Médio & Baixo & Baixo & Baixo \\
\hline Sku & Alto & Alto & Médio & Médio & Alto & Alto & Médio & Alto & Médio & Alto & Alto & Alto & Alto & Médio & Alto \\
\hline $\mathrm{Sp}$ & Alto & Alto & Médio & Baixo & Baixo & Médio & Baixo & Baixo & Baixo & Médio & Médio & Médio & Baixo & Baixo & Baixo \\
\hline Sv & Médio & Alto & Médio & Baixo & Baixo & Baixo & Baixo & Baixo & Baixo & Baixo & Médio & Médio & Baixo & Baixo & Baixo \\
\hline Vmp & Alto & Alto & Médio & Baixo & Baixo & Alto & Baixo & Baixo & Baixo & Baixo & Baixo & Médio & Baixo & Baixo & Baixo \\
\hline Vmc & Alto & Alto & Médio & Baixo & Baixo & Médio & Médio & Baixo & Baixo & Baixo & Baixo & Alto & Baixo & Médio & Alto \\
\hline Vvc & Alto & Alto & Alto & Baixo & Baixo & Alto & Médio & Baixo & Médio & Médio & Médio & Alto & Baixo & Alto & Médio \\
\hline Vvv & Médio & Alto & Médio & Baixo & Baixo & Médio & Médio & Baixo & Baixo & Baixo & Médio & Médio & Baixo & Médio & Médio \\
\hline Material & Aço & Aço & Alumínio & Alumínio & Alumínio & Aço & Aço & Cobre & Aço & Aço & Aço & Aço & Cobre & Aço & Alumínio \\
\hline Campanha & Baixa & Baixo & Baixo & Alto & Baixo & Médio & Alto & Baixo & Alto & Médio & Baixo & Baixo & Baixo & Alto & Alto \\
\hline Revestimento & Cromo & Cromo & Cromo & $\mathrm{N}$-cromo & Cromo & Cromo & Cromo & Cromo & Cromo & $\mathrm{N}$-cromo & $\mathrm{N}$-cromo & Cromo & Cromo & Cromo & Cromo \\
\hline Acabamento & Retificado & Retificado & Retificado & Retificado & Retificado & Jateado & Jateado & Retificado & Jateado & Jateado & Retificado & Jateado & Retificado & Jateado & Retificado \\
\hline
\end{tabular}

Fonte: (Autor - software Excel) 


\subsection{Resultados do Interferômetro}

Os resultados de desgaste obtidas nos ensaios dos cilindros de laminação foram observadas no interferômetro do laboratório de Fenômenos de Superfície do departamento de Mecânica da USP. Os ensaios em campo, ocorreram no início, meio e final das campanhas de laminação.

\section{Chapa de aço com cilindro jateado e cromado}

IA) Início da campanha

Tabela 9- 44. Superfície do cilindro jateado e cromado - chapa aço (início)

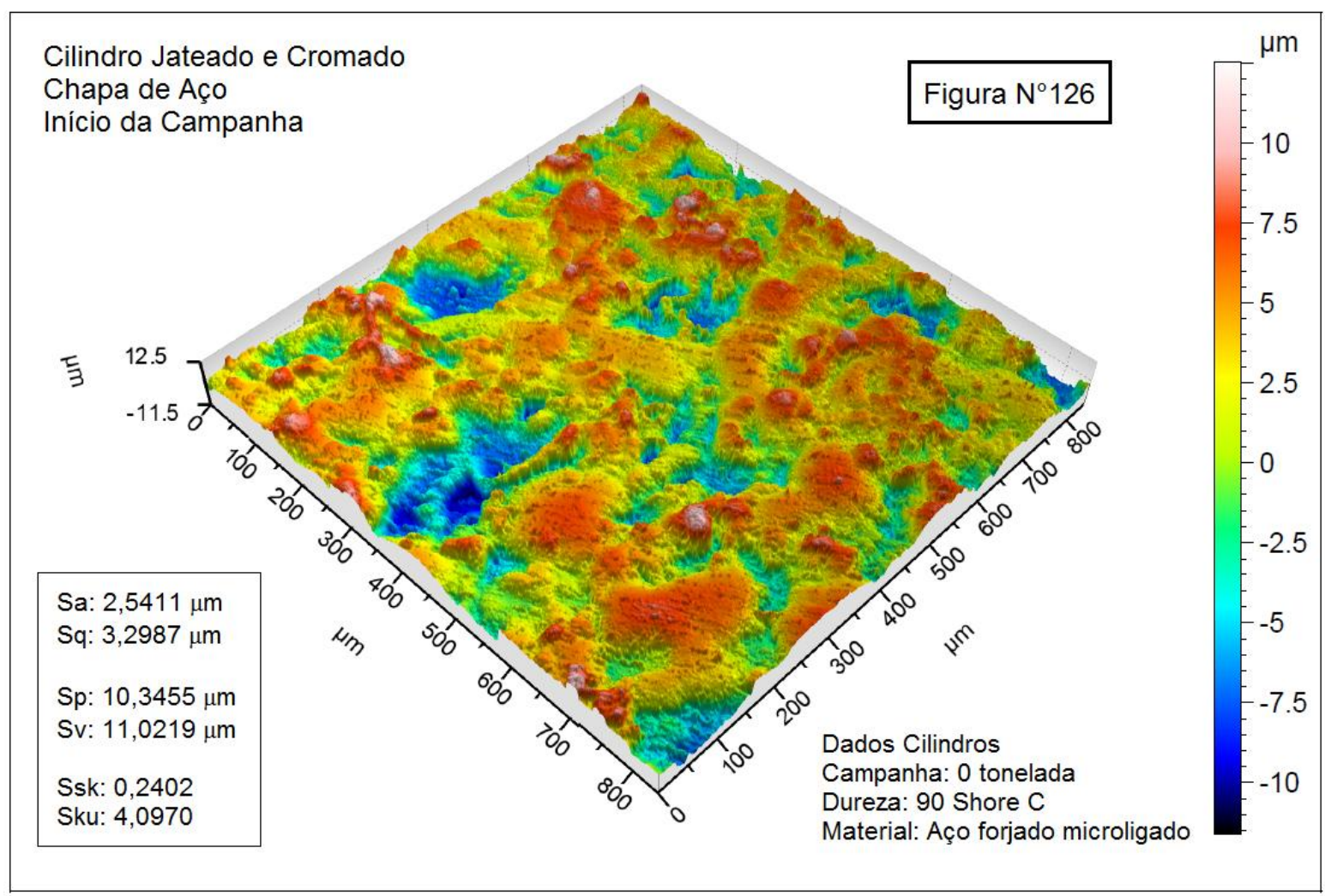

Fonte: (Autor - software CCl) 
Tabela 9- 45. Curva Abbott - cilindro jateado e cromado - chapa aço (início)

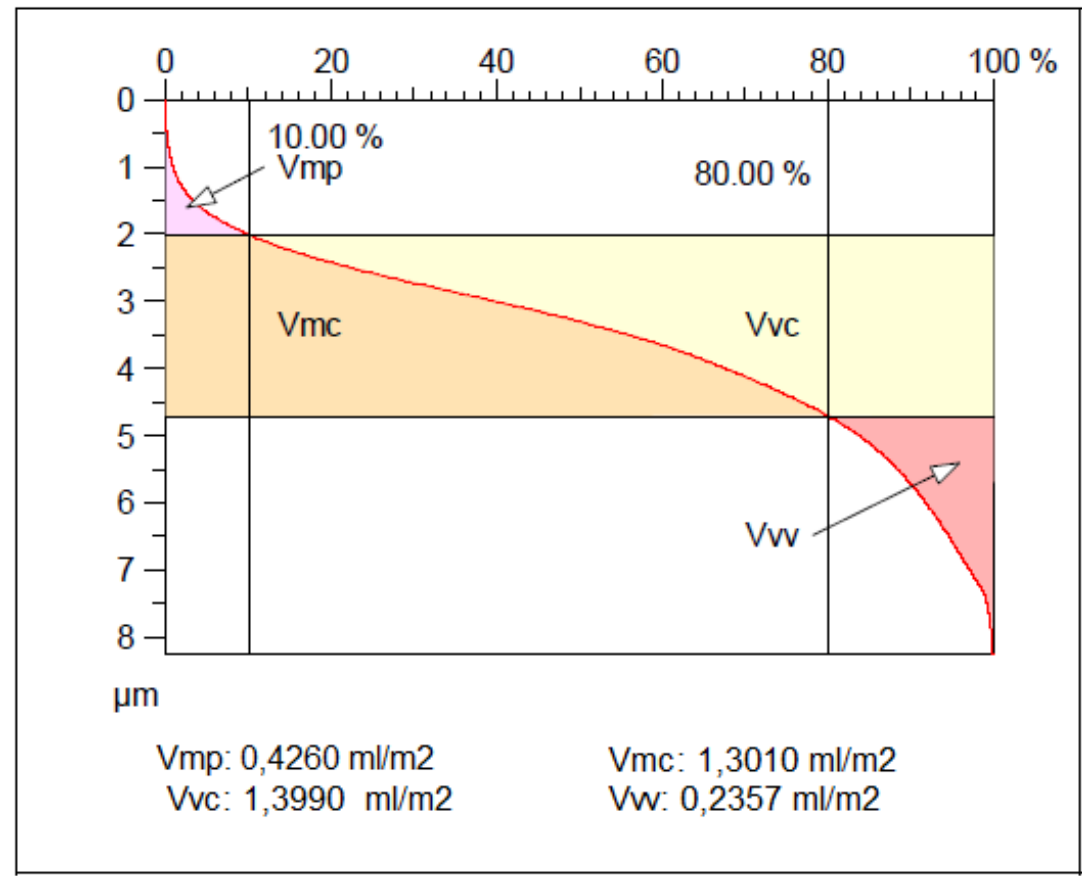

Fonte: (Autor - software CCl)

IB) Meio da campanha

Tabela 9- 46. Superfície do cilindro jateado e cromado - chapa aço (meio)

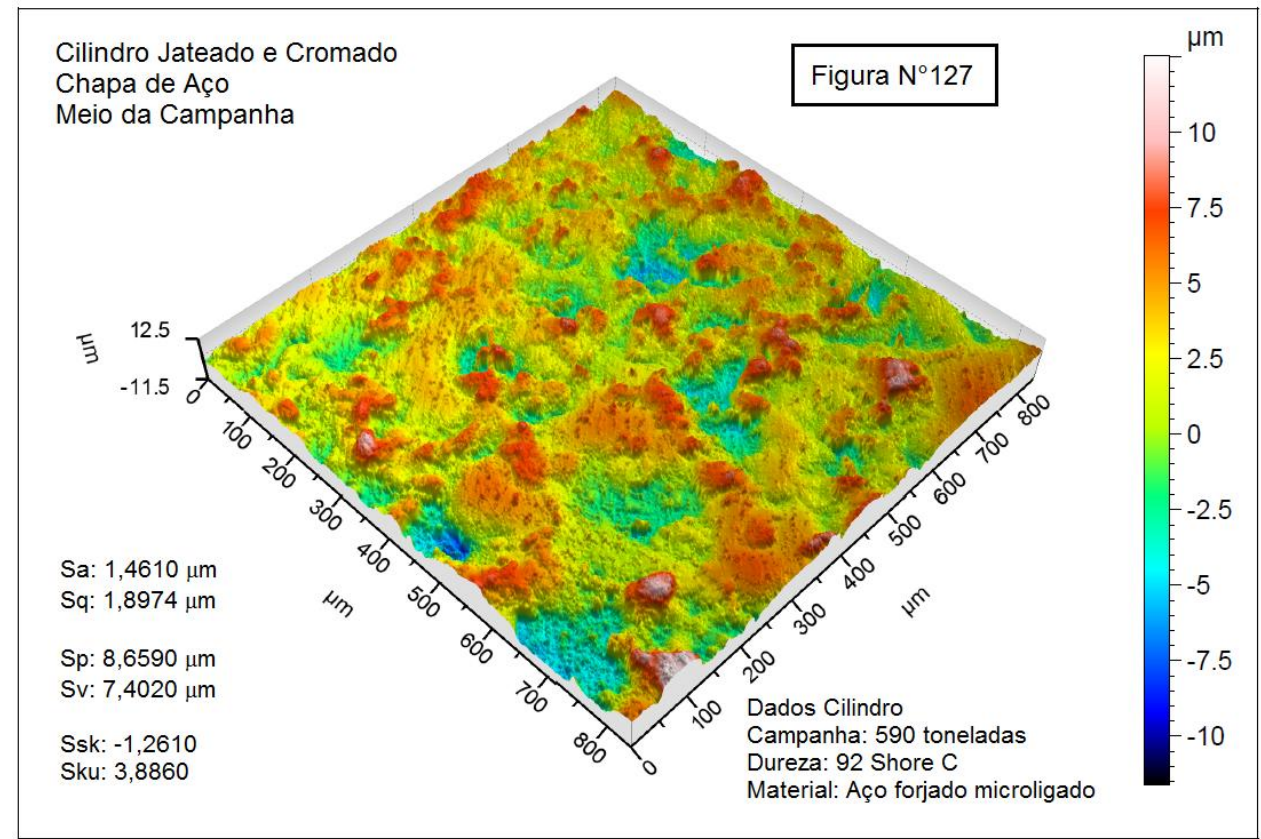

Fonte: (Autor - software CCl) 
Tabela 9- 47. Curva Abbott - cilindro jateado e cromado - chapa aço (meio)

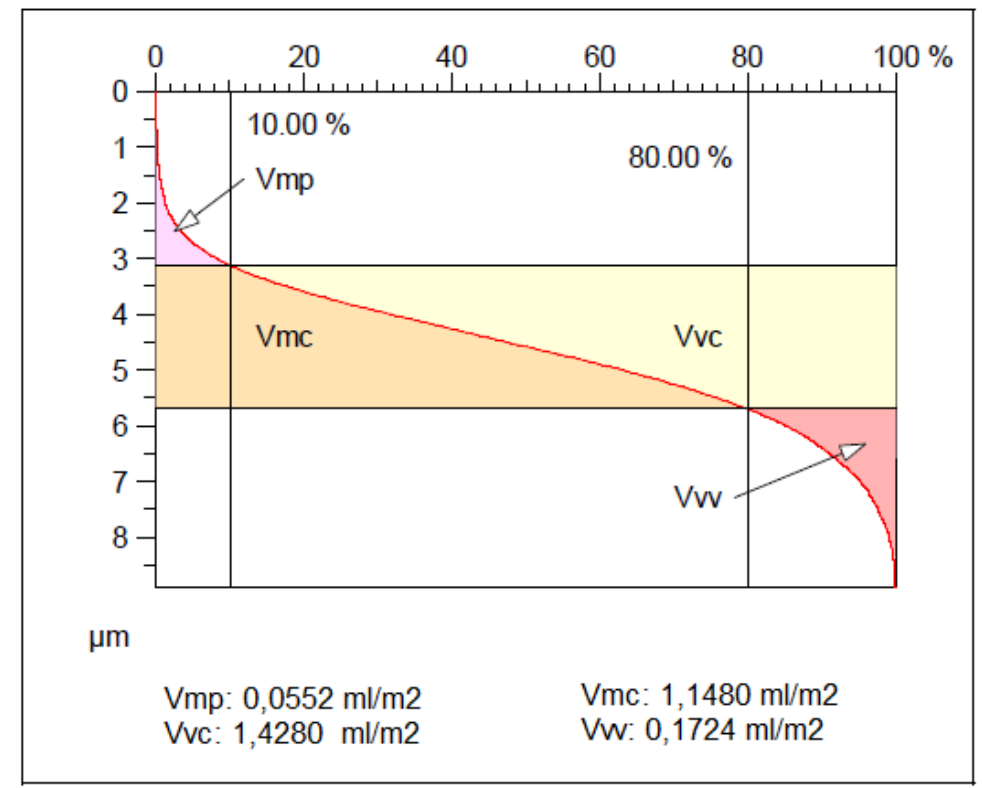

Fonte: (Autor - software CCl)

IC) Final da campanha

Tabela 9- 48. Superfície do cilindro jateado e cromado - chapa aço (final)

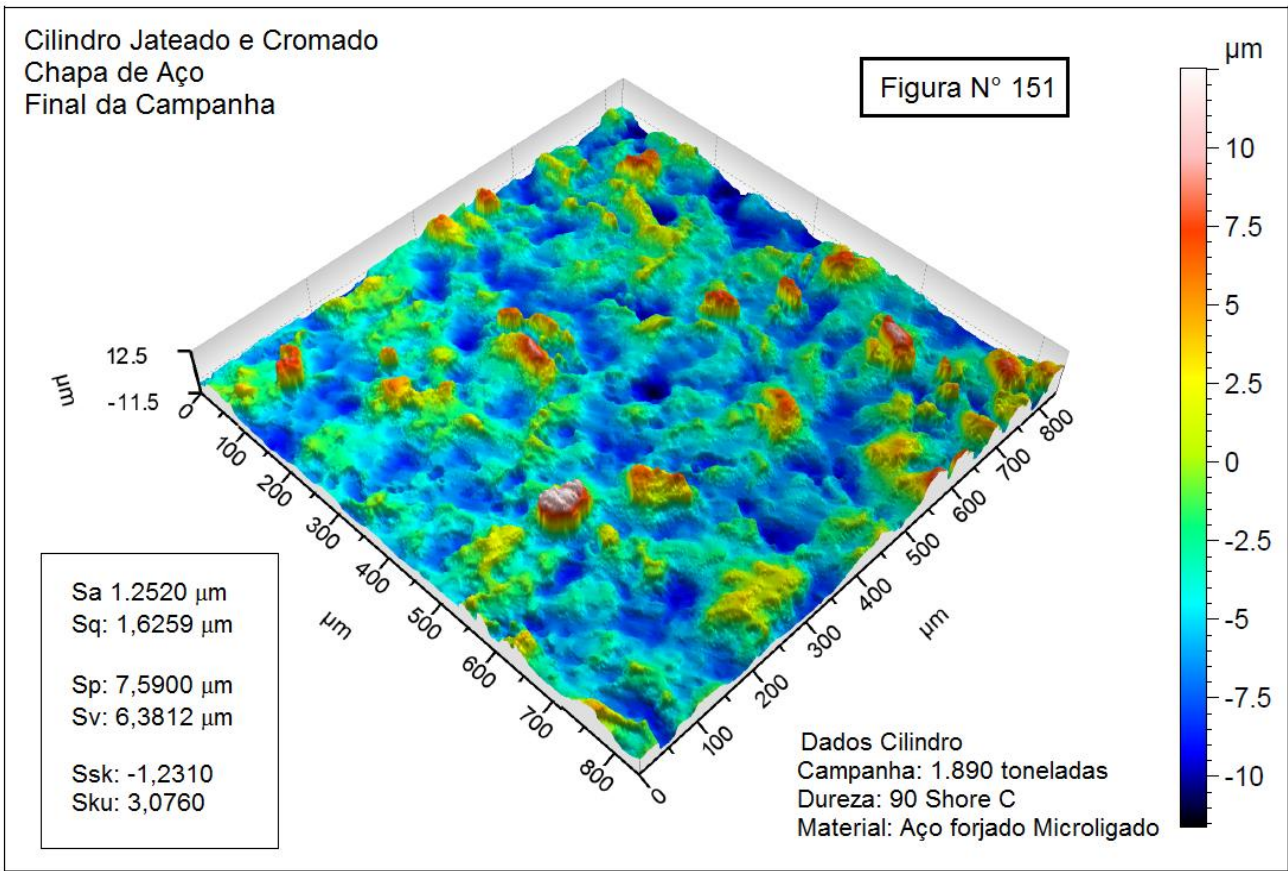

Fonte: (Autor - software CCl) 
Tabela 9- 49. Curva Abbott - cilindro jateado e cromado - chapa aço (final)

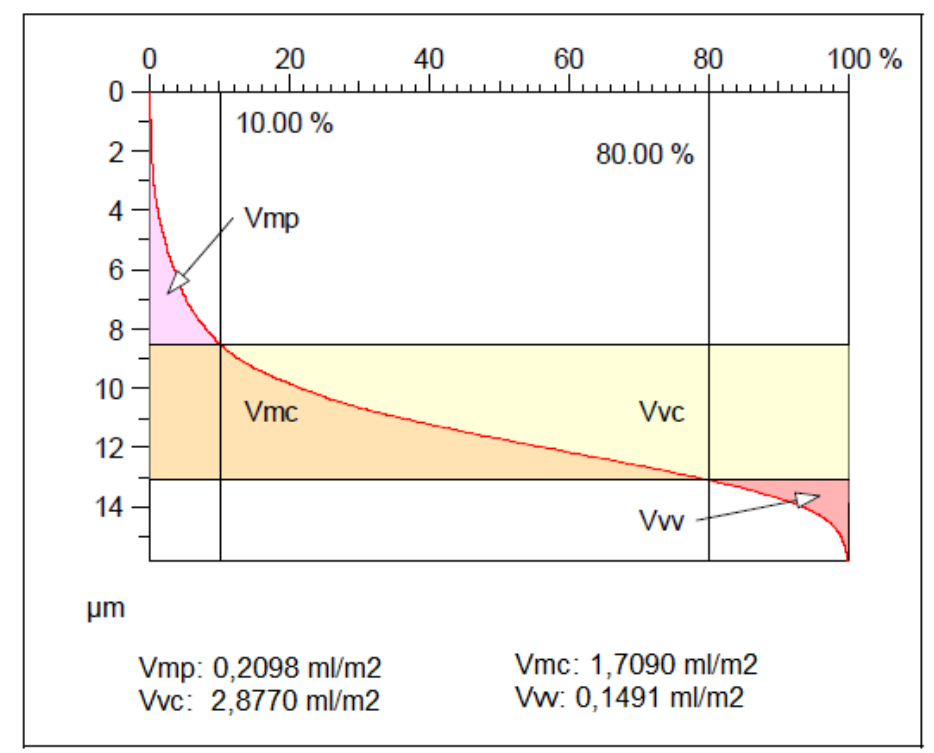

Fonte: (Autor - software CCl)

\section{Chapa de aço com cilindro jateado e não-cromado}

IIA) Início da campanha

Tabela 9- 50. Superfície do cilindro jateado e não cromado - chapa aço (início)

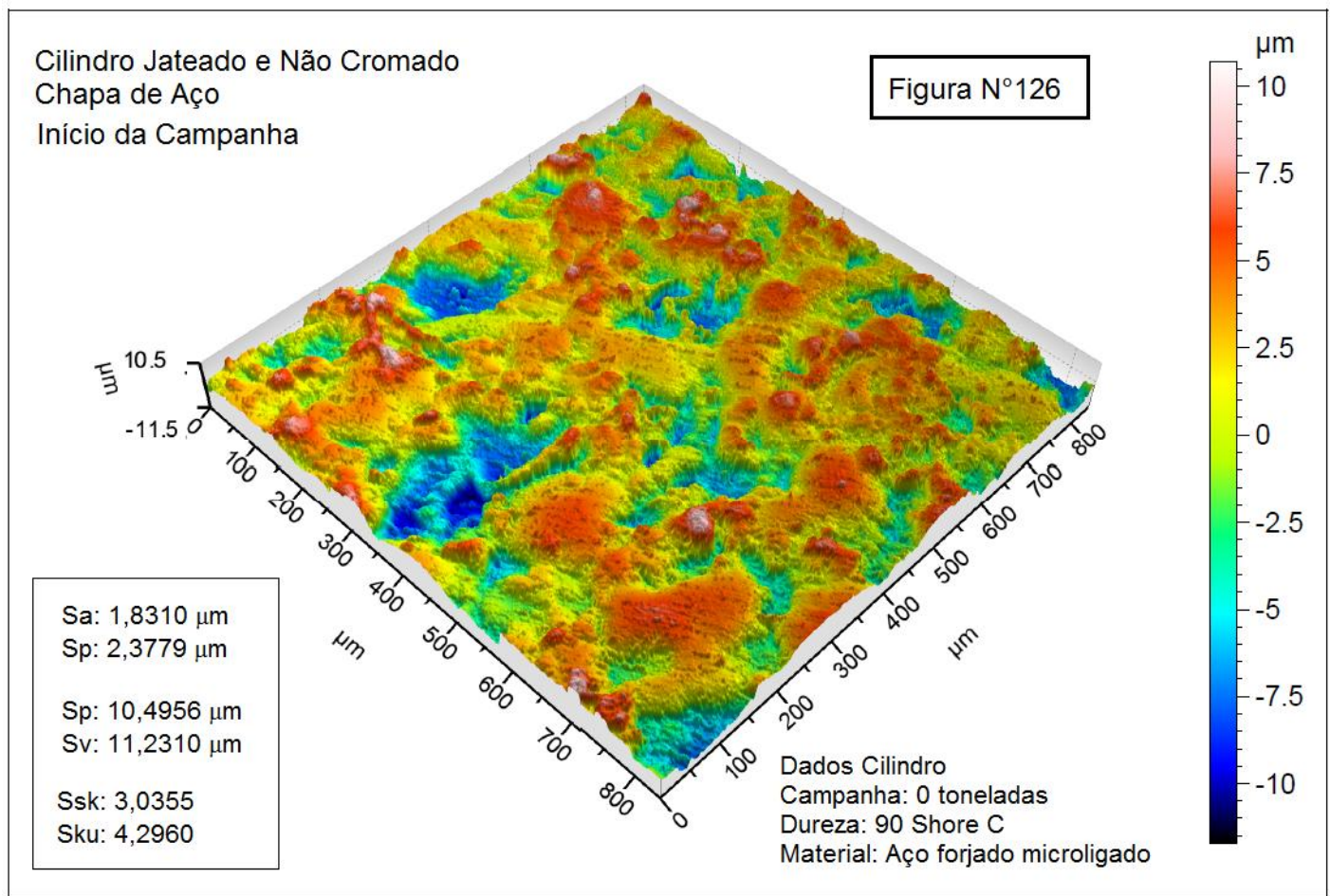

Fonte: (Autor - software CCl) 
Tabela 9- 51. Curva Abbott - cilindro jateado e não cromado - chapa aço (início)

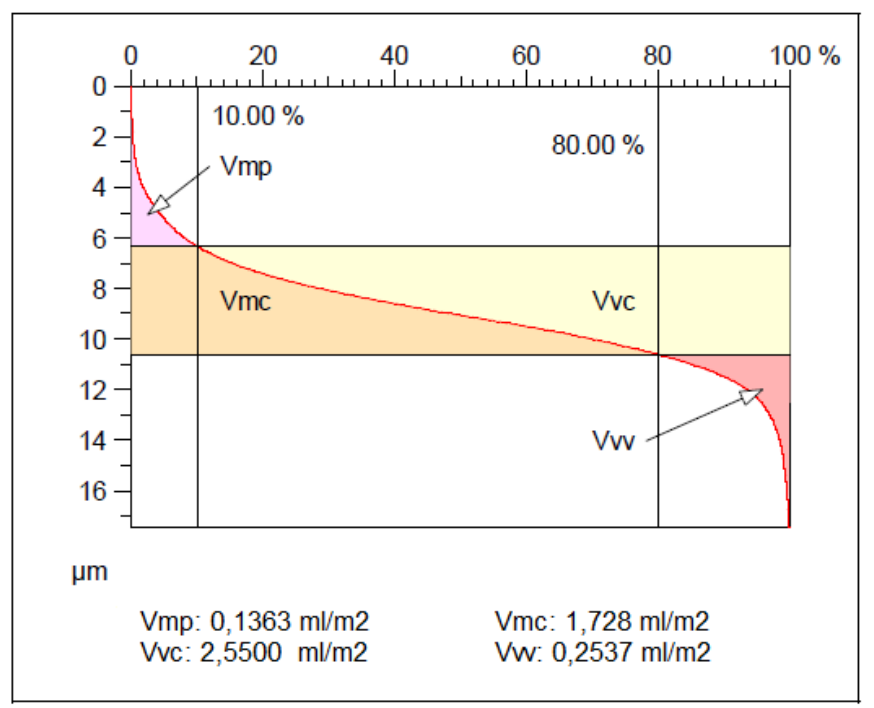

Fonte: (Autor - software CCl)

IIB) Meio da campanha

Tabela 9- 52. Superfície do cilindro jateado e não cromado - chapa aço (meio)

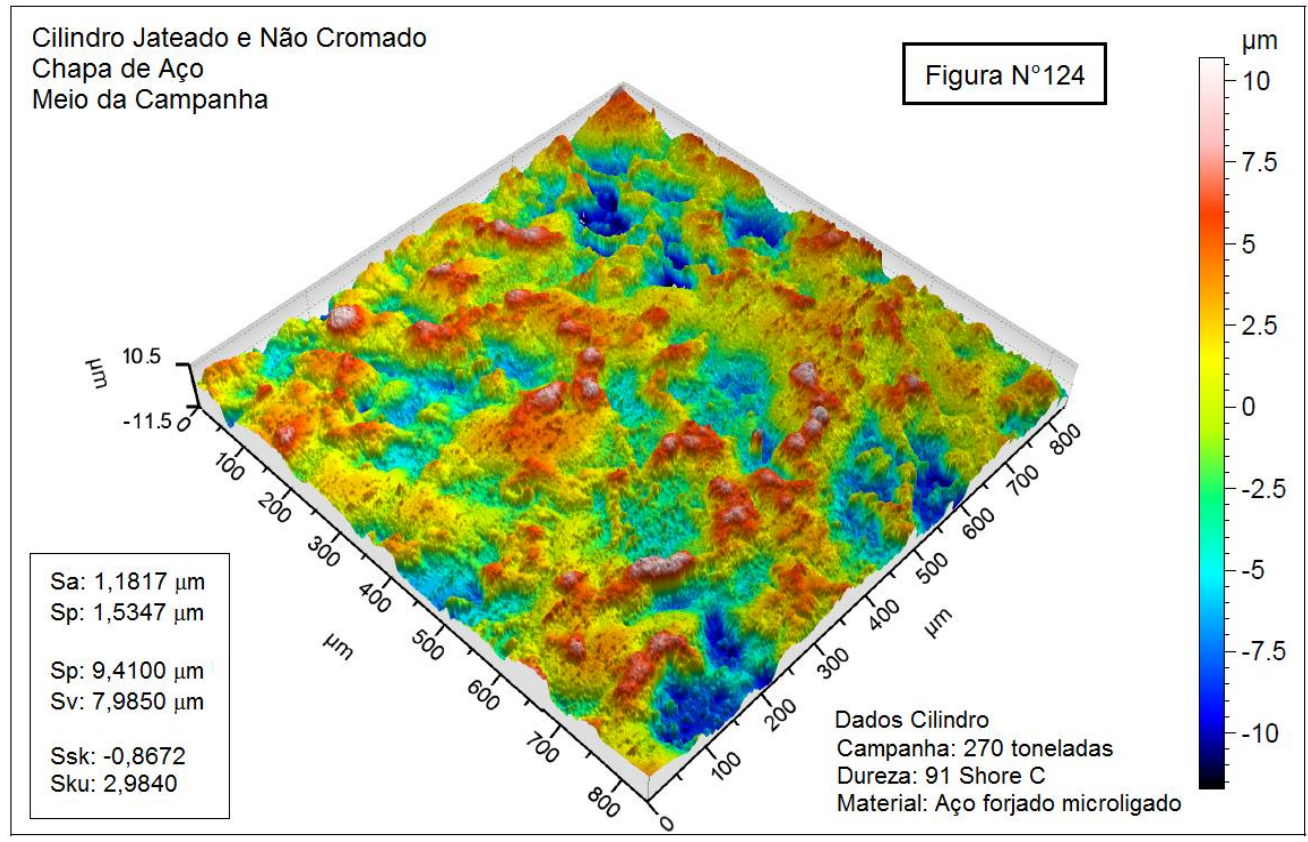

Fonte: (Autor - software CCl) 
Tabela 9- 53. Curva Abbott - cilindro jateado e não cromado - chapa aço (meio)

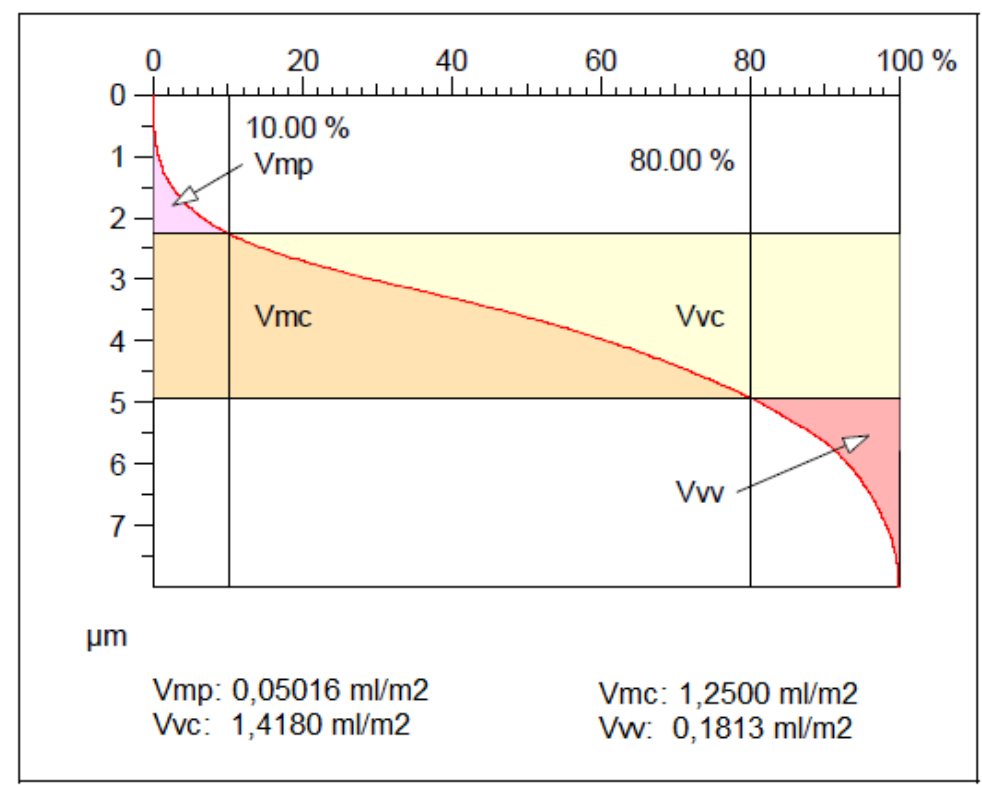

Fonte: (Autor - software CCl)

IIC) Final da campanha

Tabela 9- 54. Superfície do cilindro jateado e não cromado - chapa aço (final)

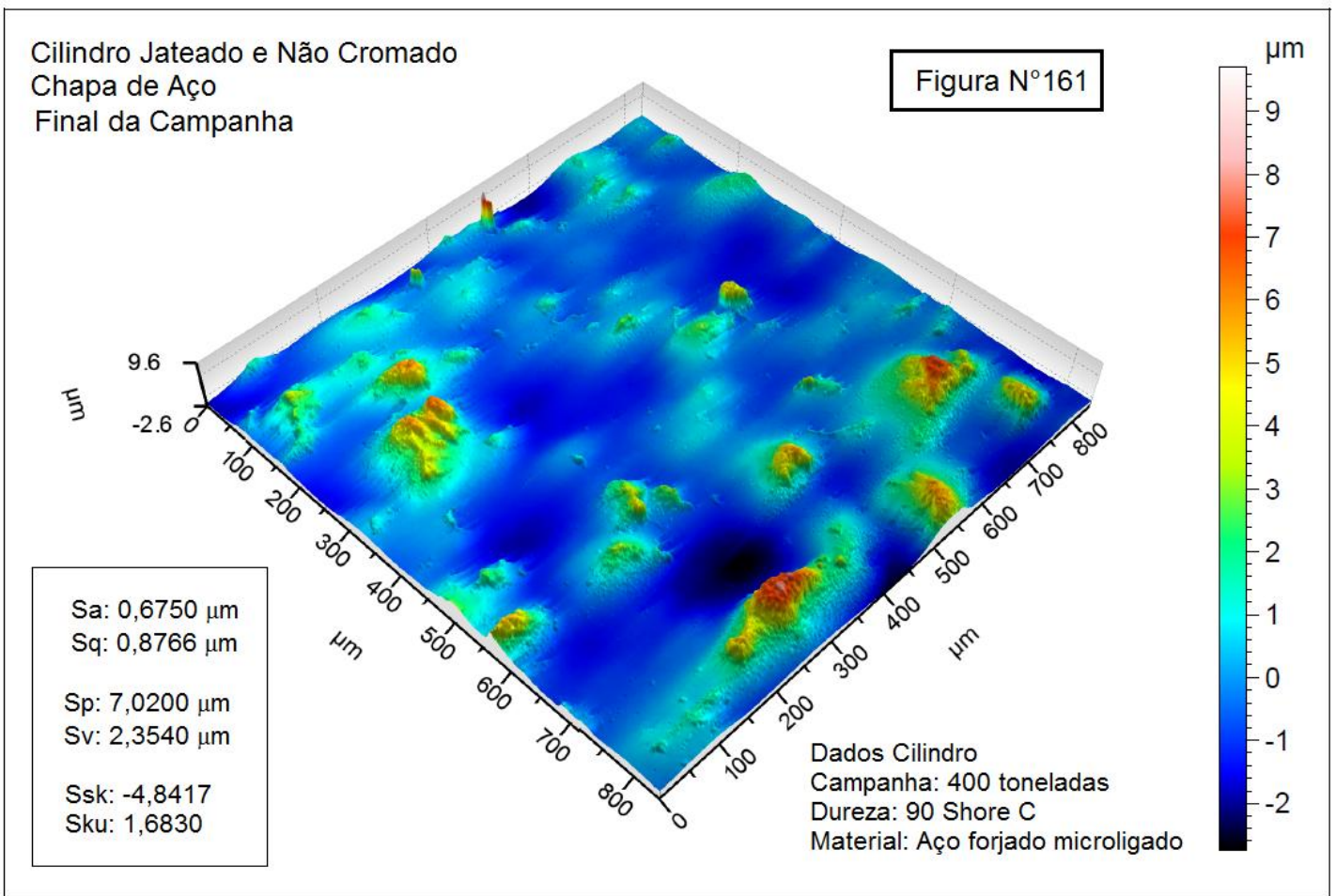

Fonte: (Autor - software $\mathrm{CCl})$ 
Tabela 9- 55. Curva Abbott - cilindro jateado e não cromado - chapa aço (final)

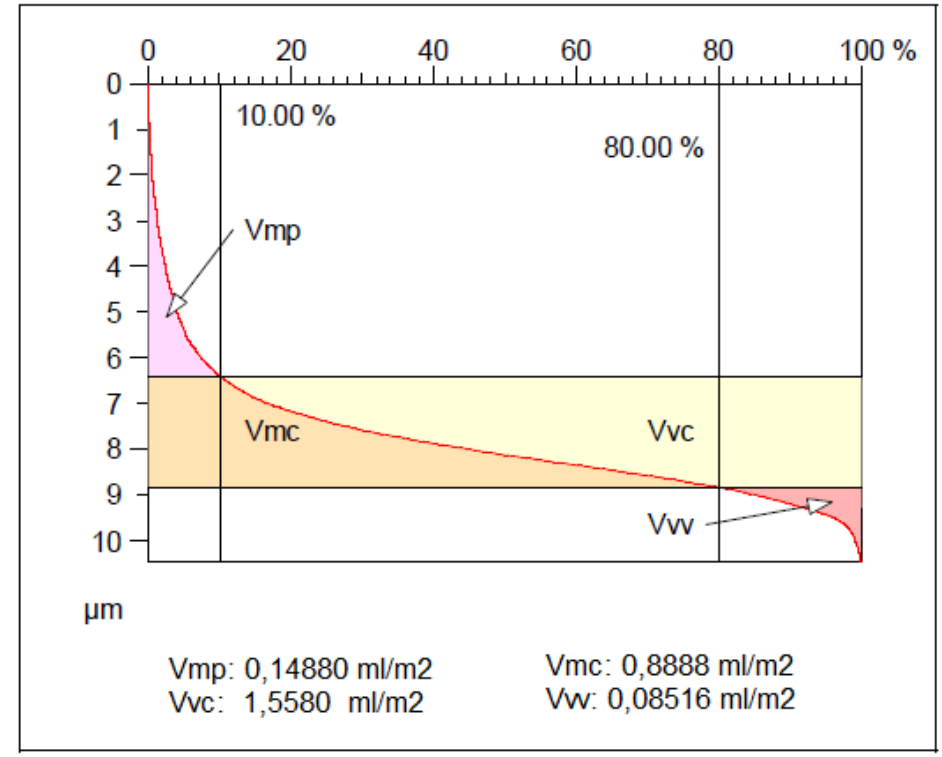

Fonte: (Autor - software CCl)

\section{Chapa de aço com cilindro retificado e cromado}

IIIA) Início da campanha

Tabela 9- 56. Superfície do cilindro retificado e cromado - chapa aço (início)

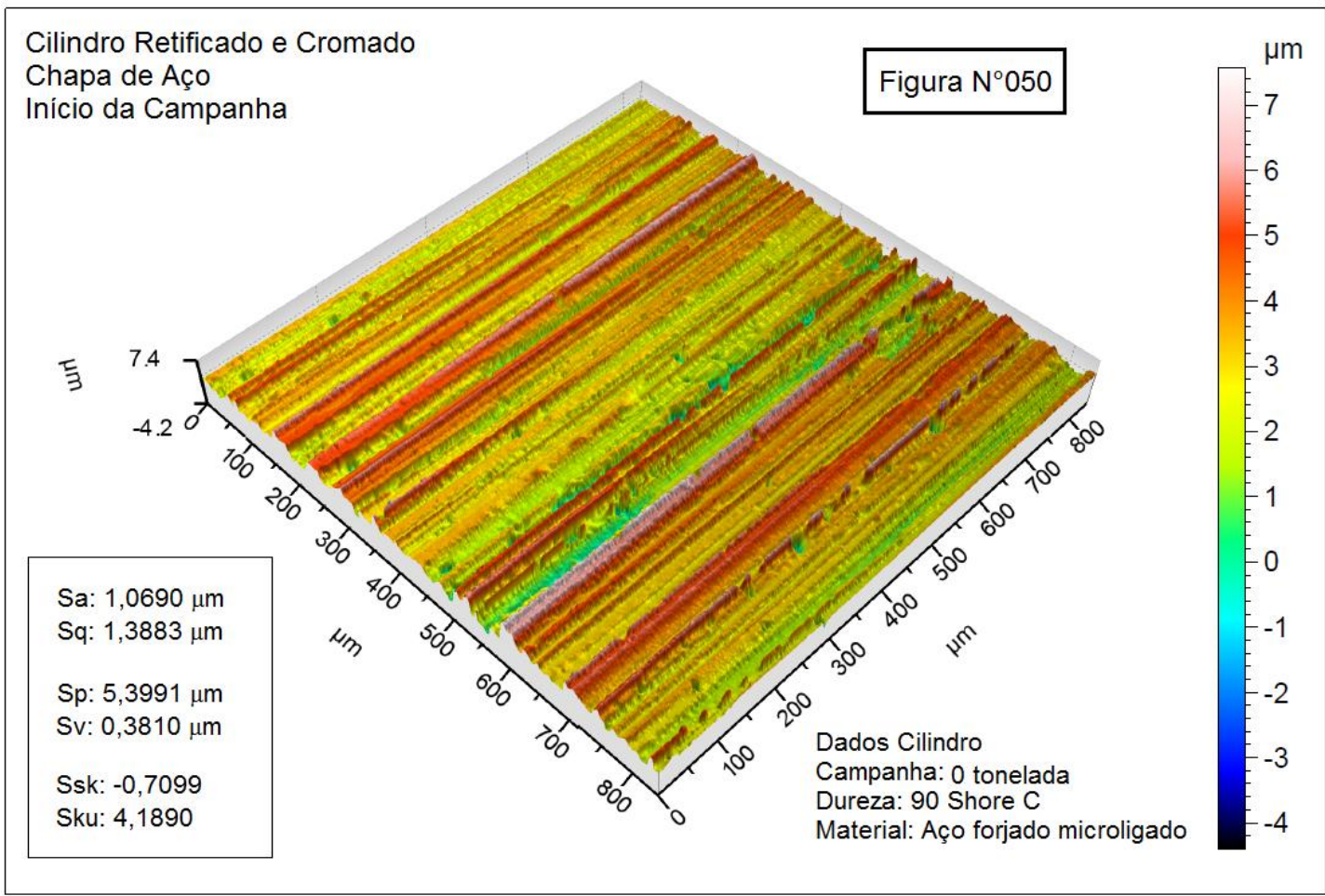

Fonte: (Autor - software CCl) 
Tabela 9- 57. Curva Abbott - cilindro retificado e cromado - chapa aço (início)

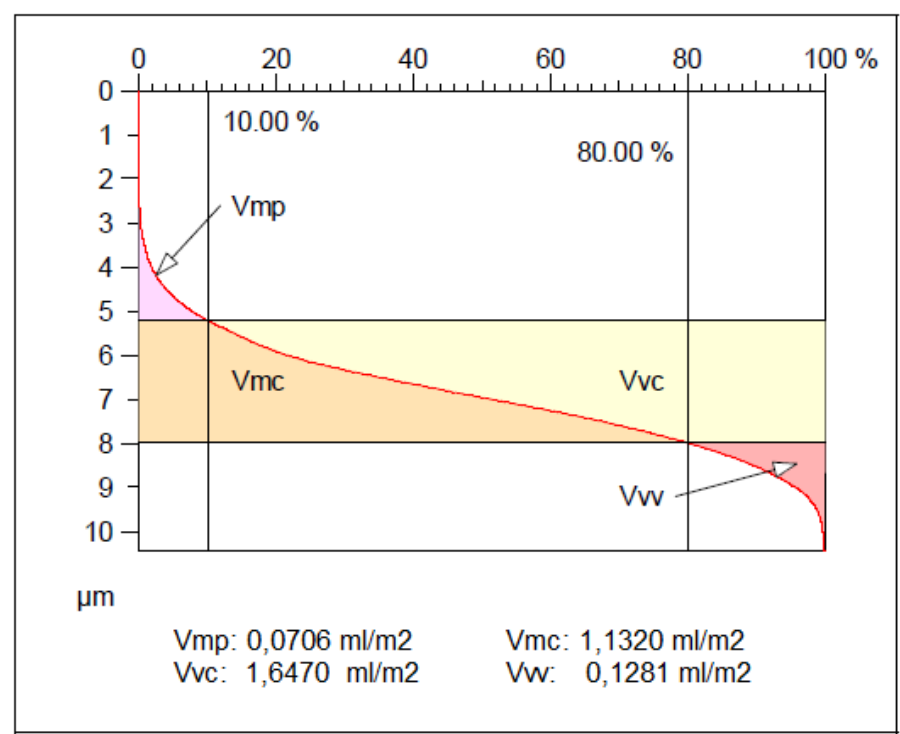

Fonte: (Autor - software CCl)

IIIB) Meio da campanha

Tabela 9- 58. Superfície do cilindro retificado e cromado - chapa aço (meio)

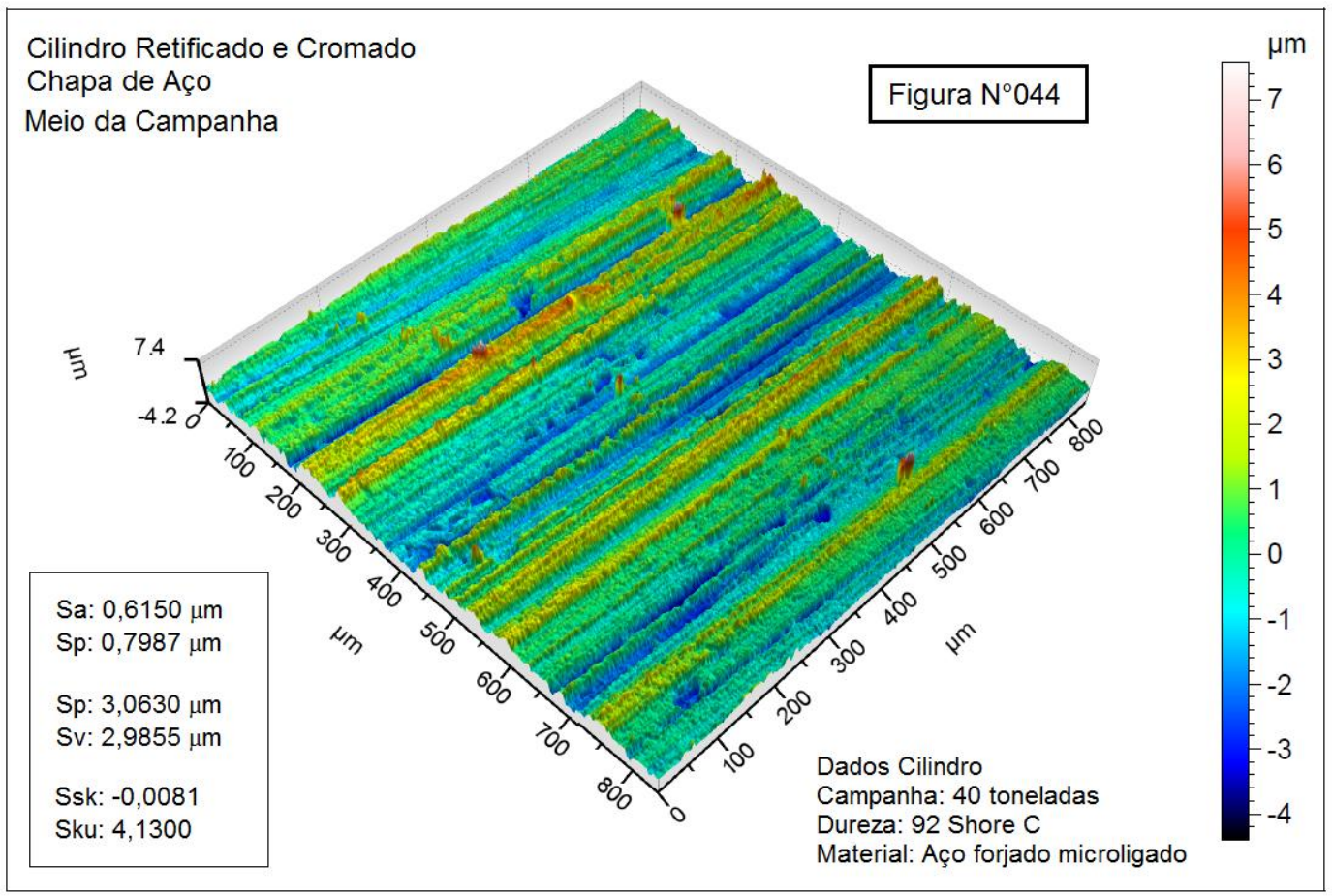

Fonte: (Autor - software CCl) 
Tabela 9- 59. Curva Abbott - cilindro retificado e cromado - chapa aço (meio)

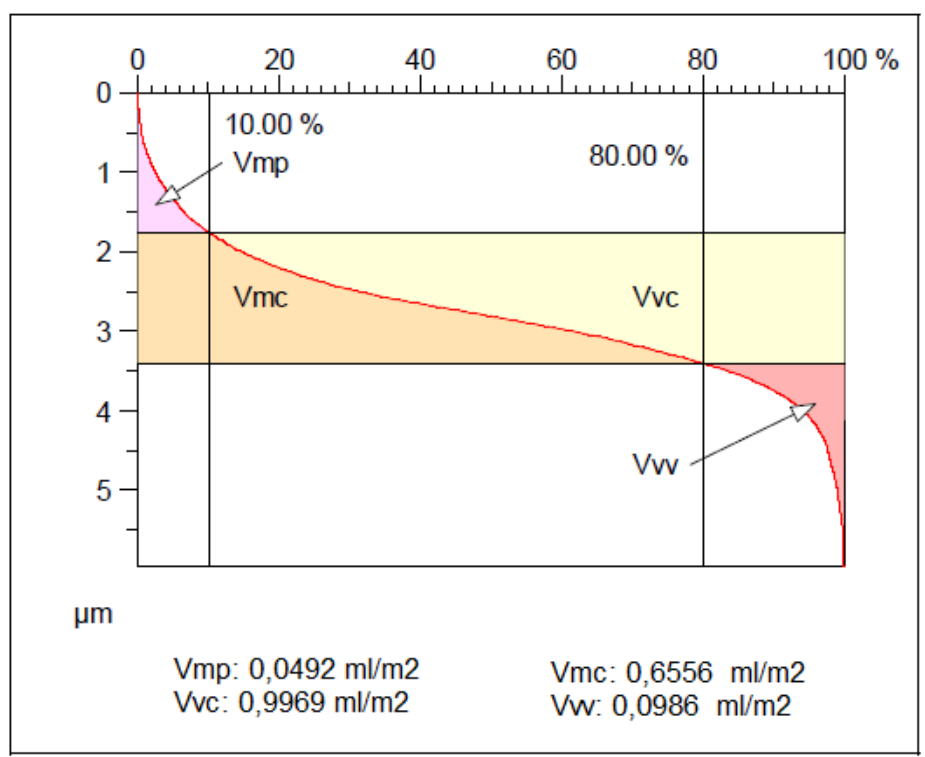

Fonte: (Autor - software CCl)

IIIC) Final da campanha

Tabela 9- 60. Superfície do cilindro retificado e cromado - chapa aço (final)

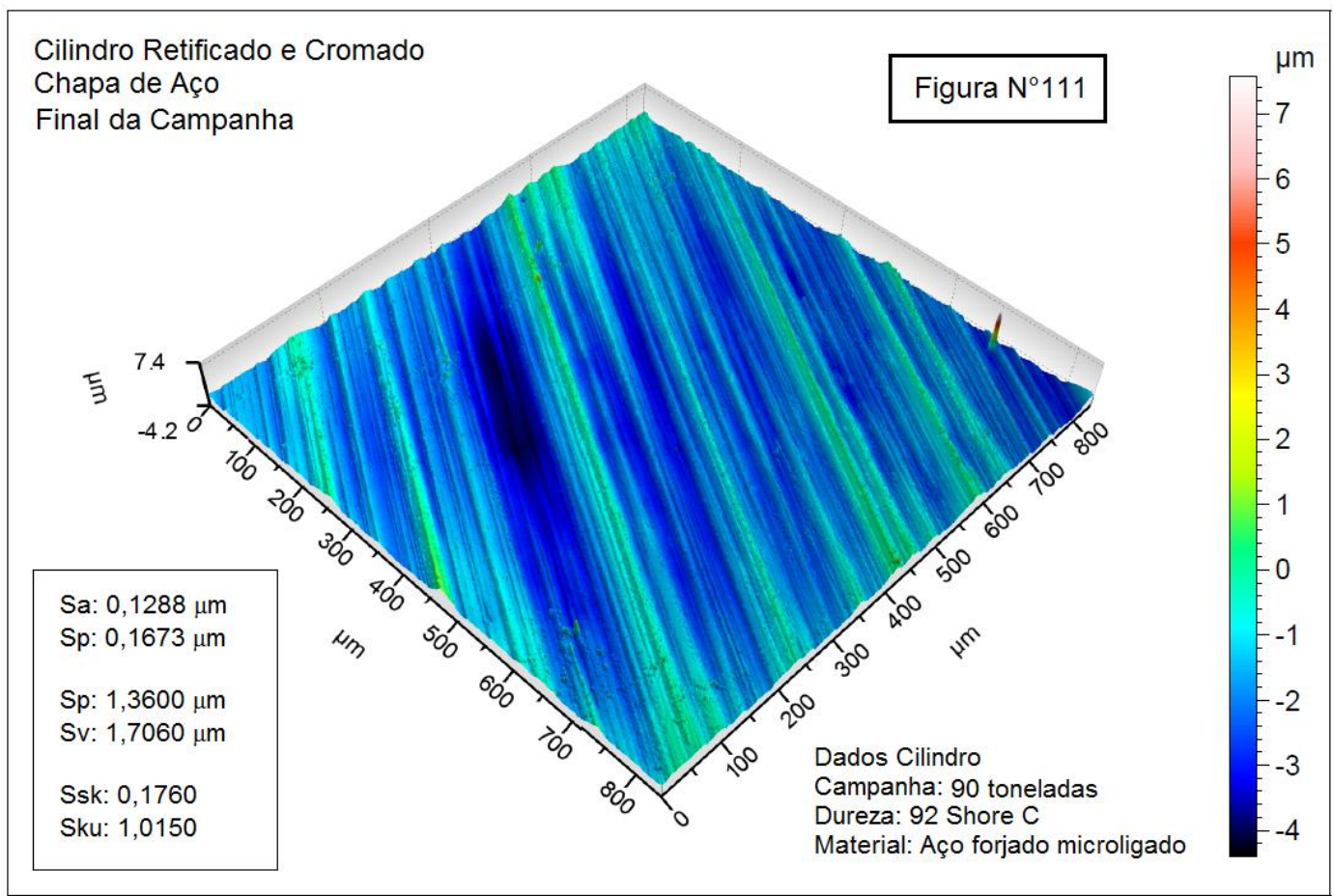

Fonte: (Autor - software CCl) 
Tabela 9- 61. Curva Abbott - cilindro retificado e cromado - chapa aço (final)

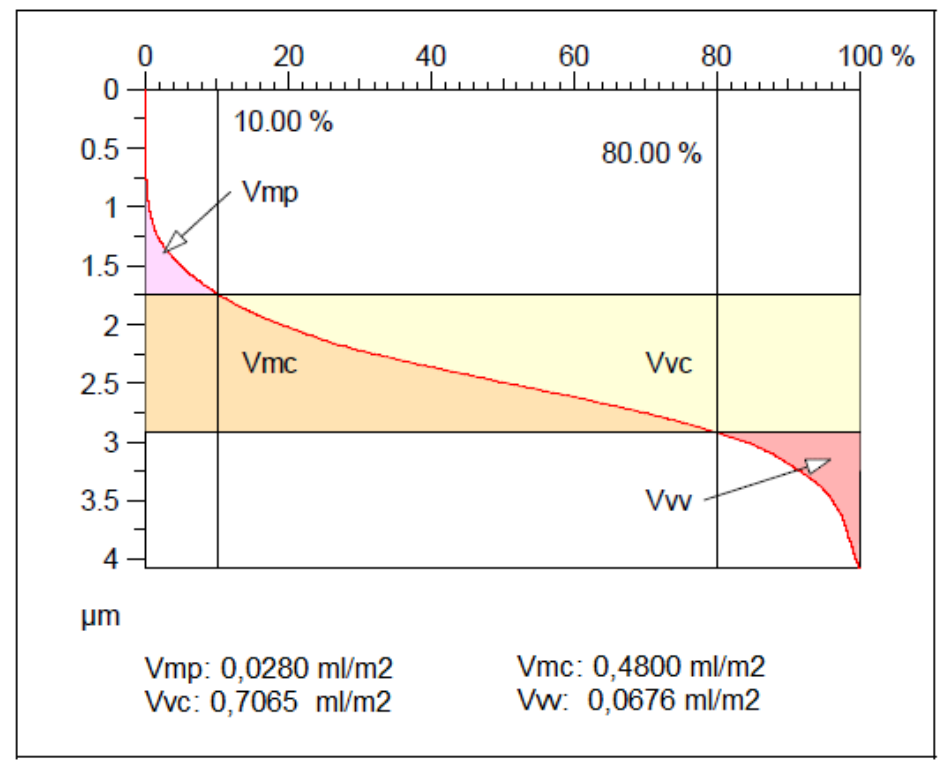

Fonte: (Autor - software CCl)

\section{Chapa de aço com cilindro retificado e não-cromado}

IVA) Início da campanha

Tabela 9- 62. Superfície do cilindro retificado e não-cromado - chapa aço (início)

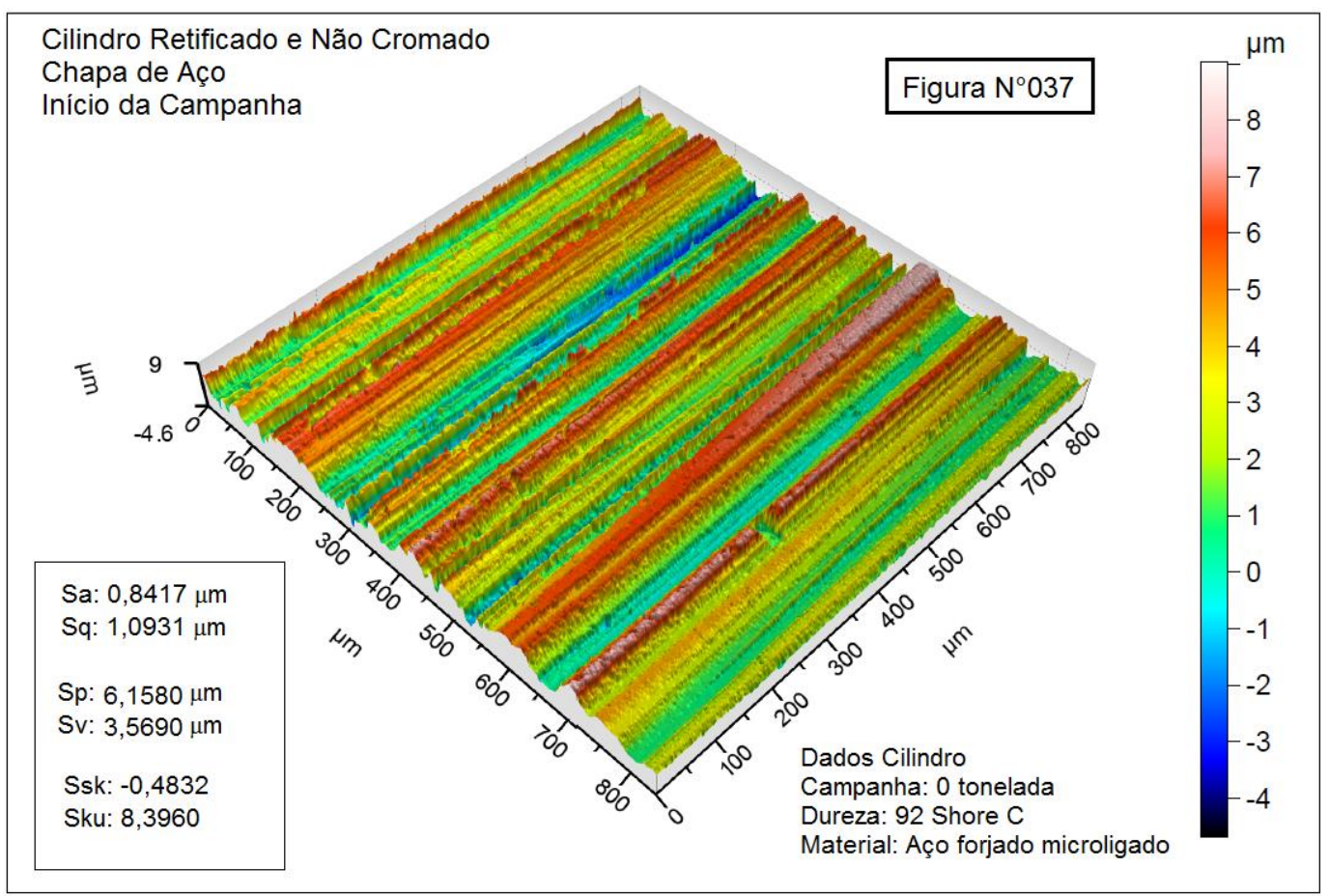


Tabela 9- 63. Curva Abbott - cilindro retificado e não-cromado - chapa aço (início)

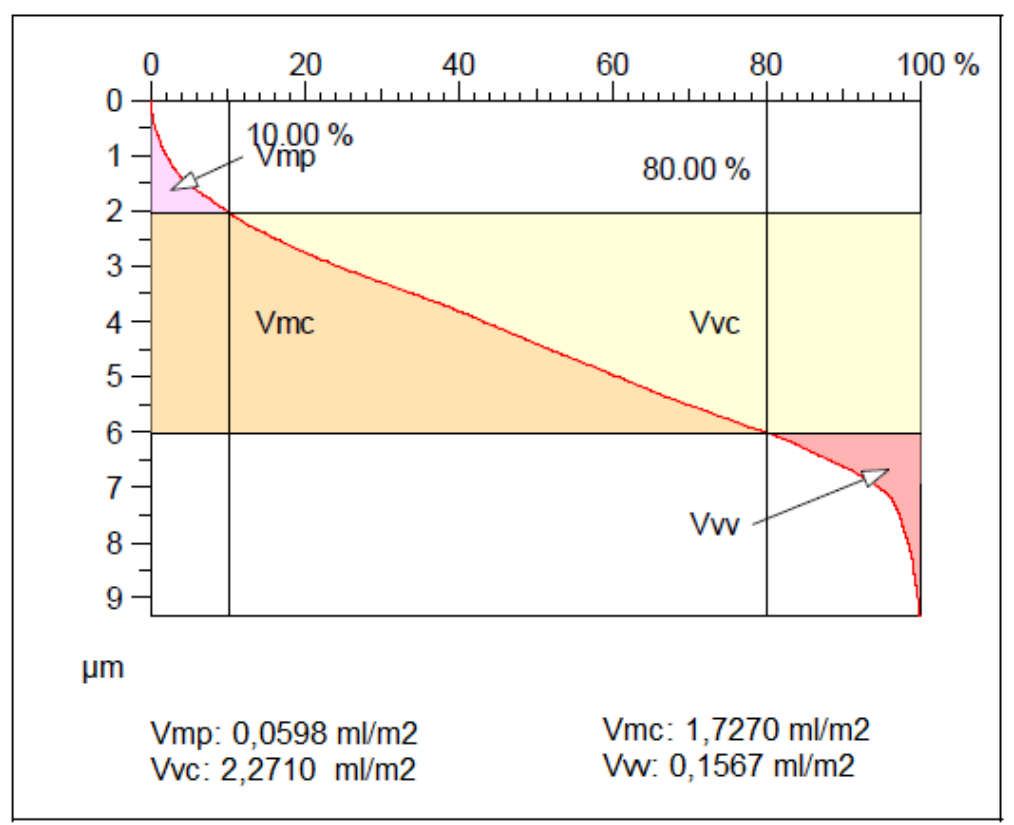

Fonte: (Autor - software CCl)

IVB) Meio da campanha

Tabela 9- 64. Superfície do cilindro retificado e não-cromado - chapa aço (meio)

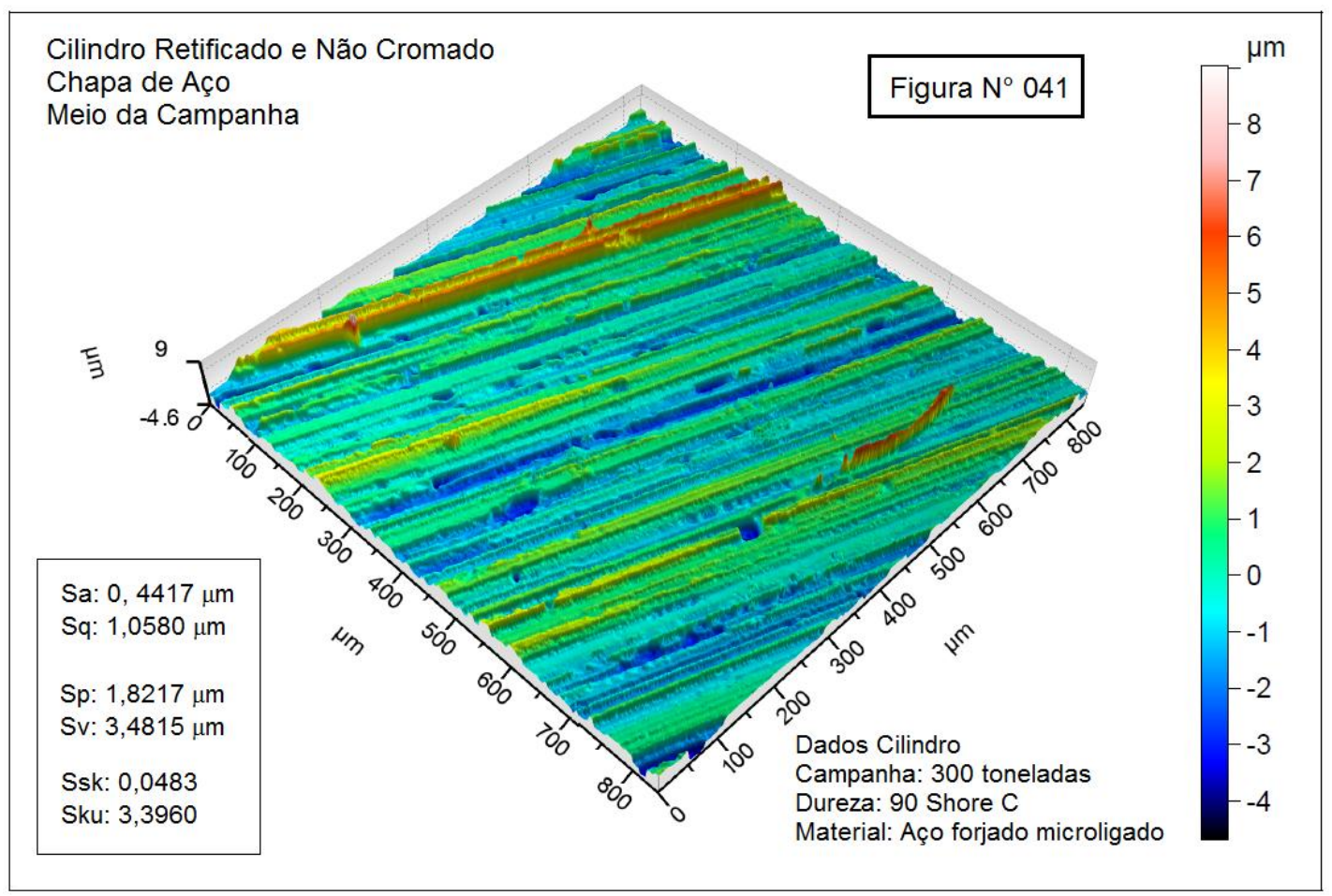

Fonte: (Autor - software CCl) 
Tabela 9- 65. Curva Abbott - cilindro retificado e não-cromado - chapa aço (meio)

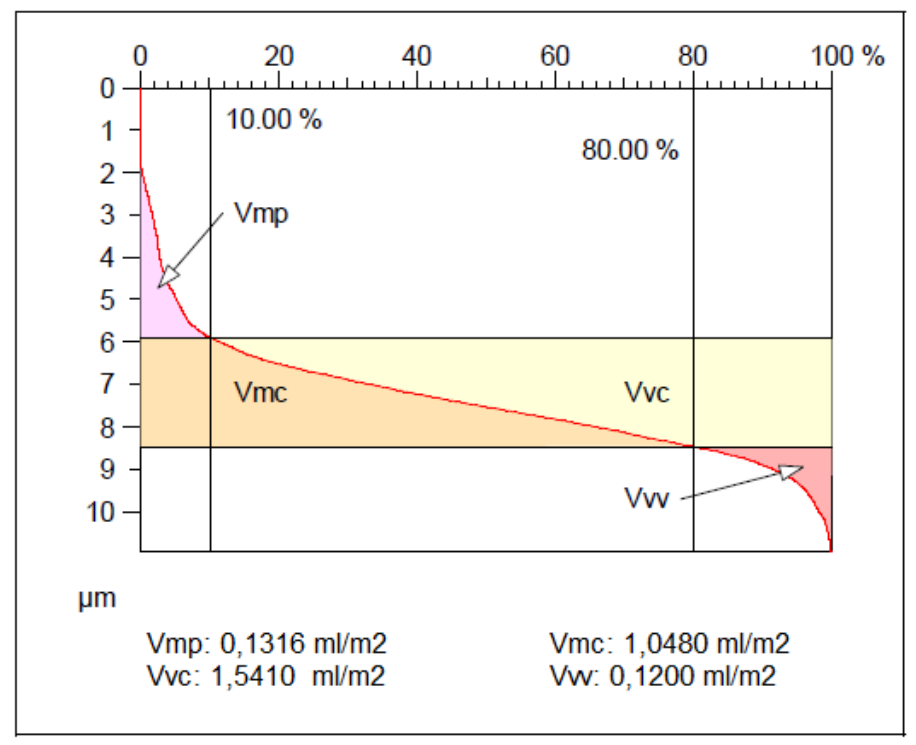

Fonte: (Autor - software CCI)

IVC) Final da campanha

Tabela 9- 66. Superfície do cilindro retificado e não-cromado - chapa aço (final)

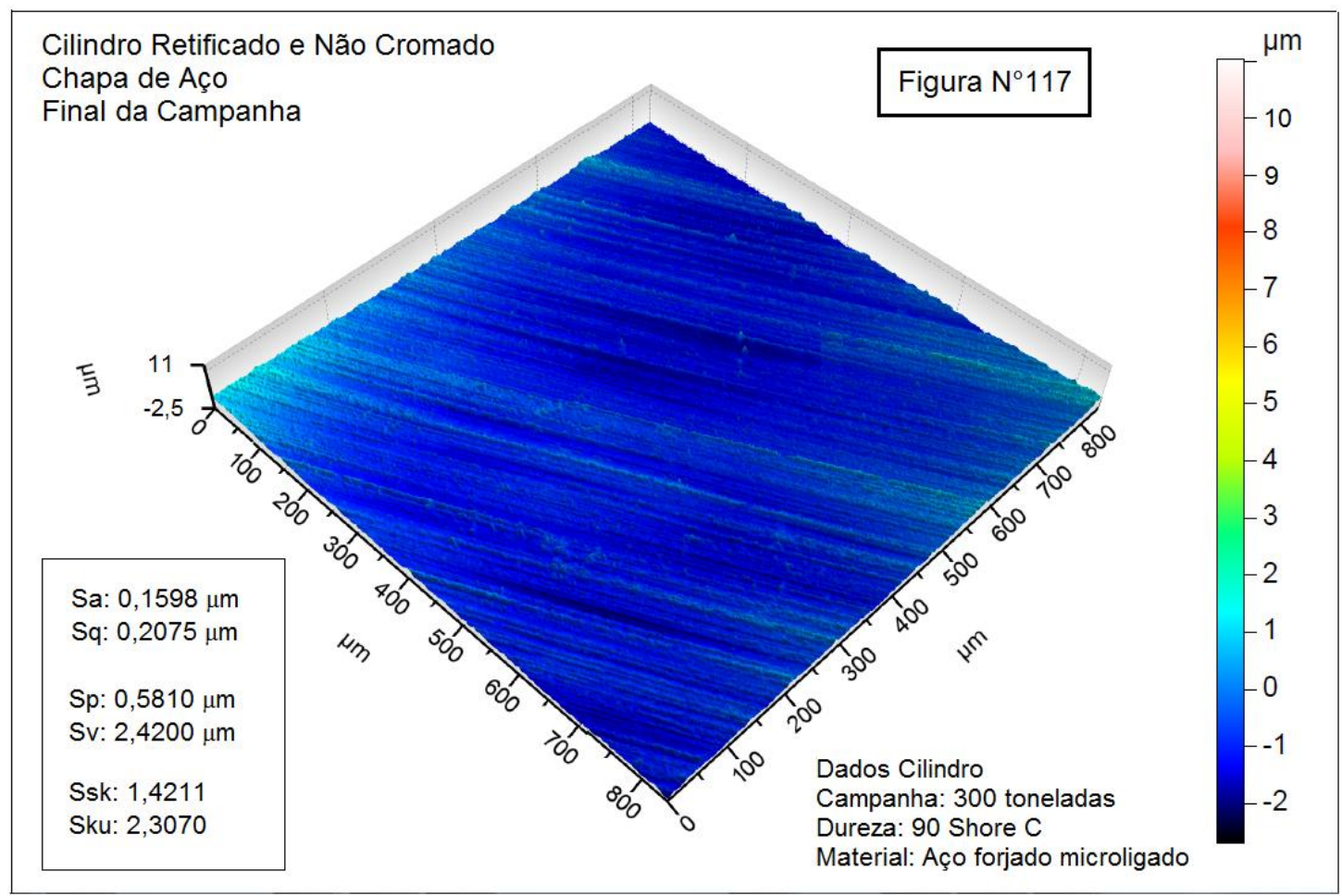

Fonte: (Autor - software CCl) 
Tabela 9- 67. Curva Abbott - cilindro retificado e não-cromado - chapa aço (final)

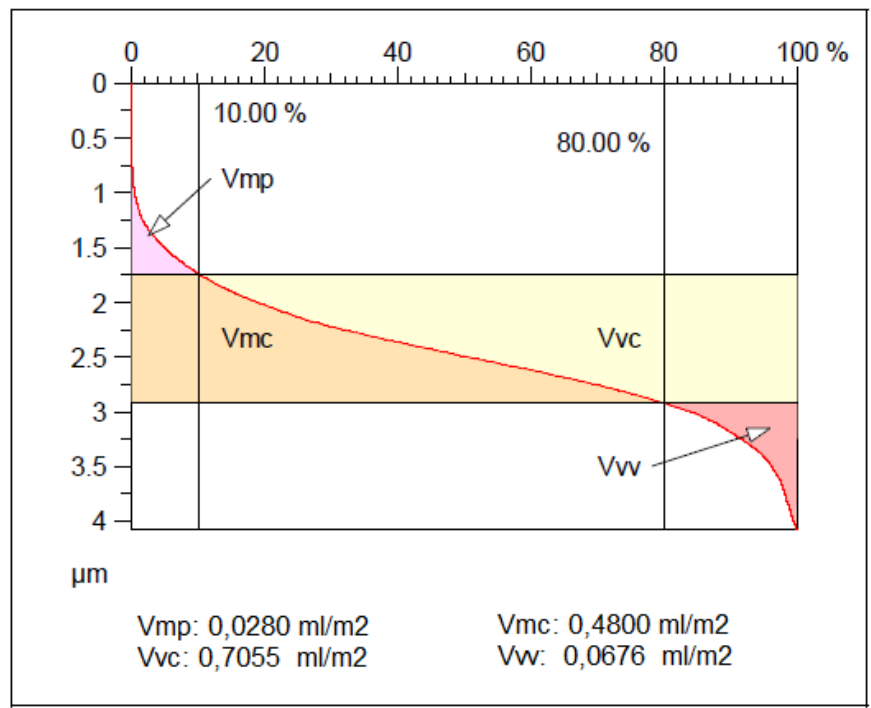

Fonte: (Autor - software CCl)

\section{Chapa de aço com cilindro texturizado e cromado}

VA) Início da campanha

Tabela 9- 68. Superfície do cilindro texturizado e cromado - chapa aço (início)

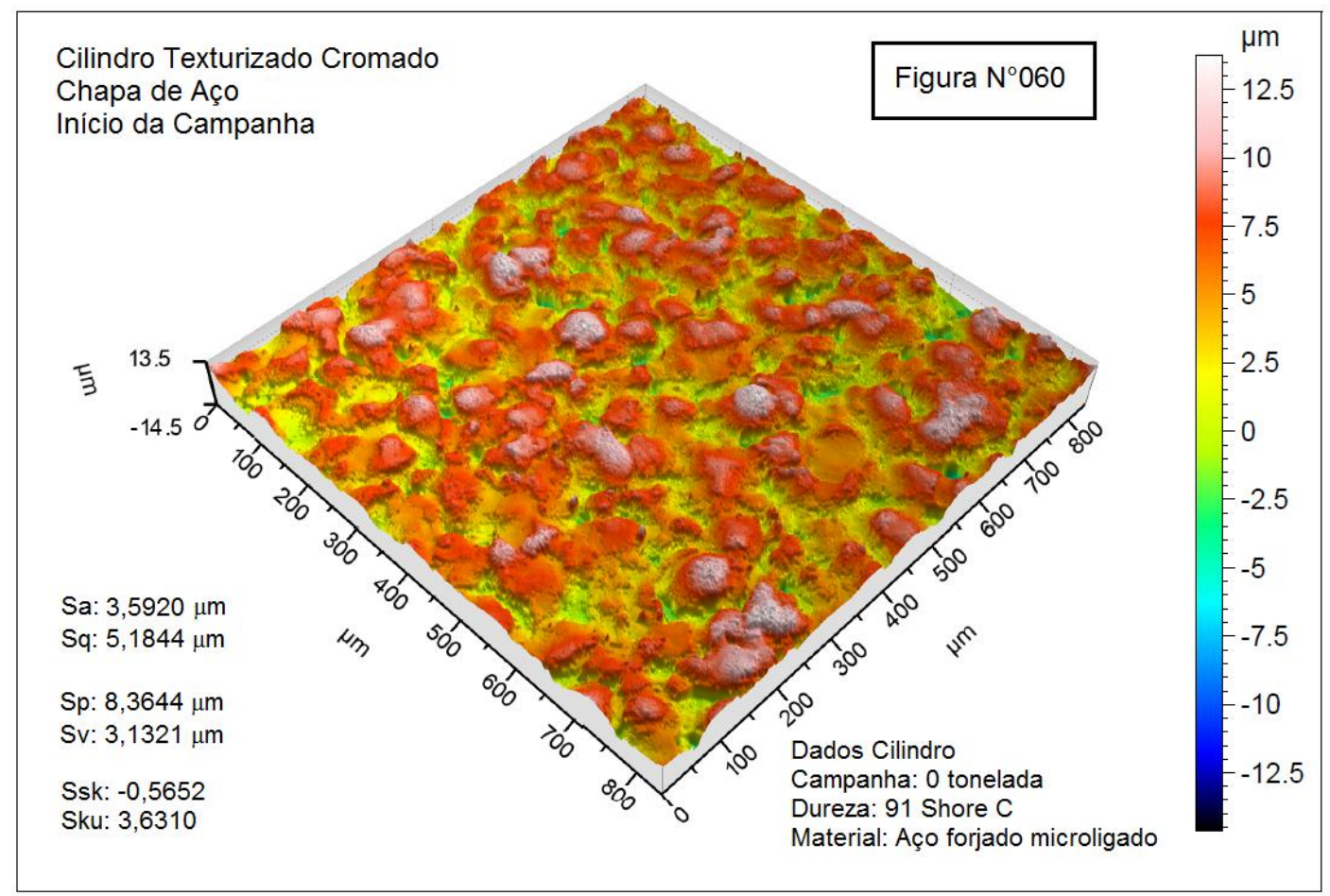

Fonte: (Autor - software CCl) 
Tabela 9- 69. Curva Abbott - cilindro texturizado e cromado - chapa aço (início)

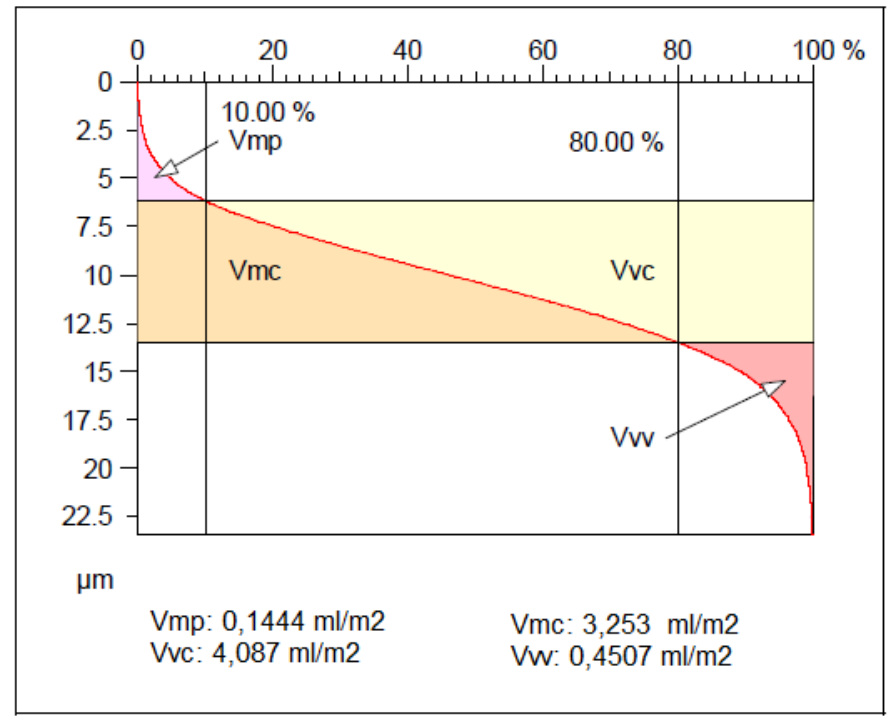

Fonte: (Autor - software CCl)

VB) Meio da campanha

Tabela 9- 70. Superfície do cilindro texturizado e cromado - chapa aço (meio)

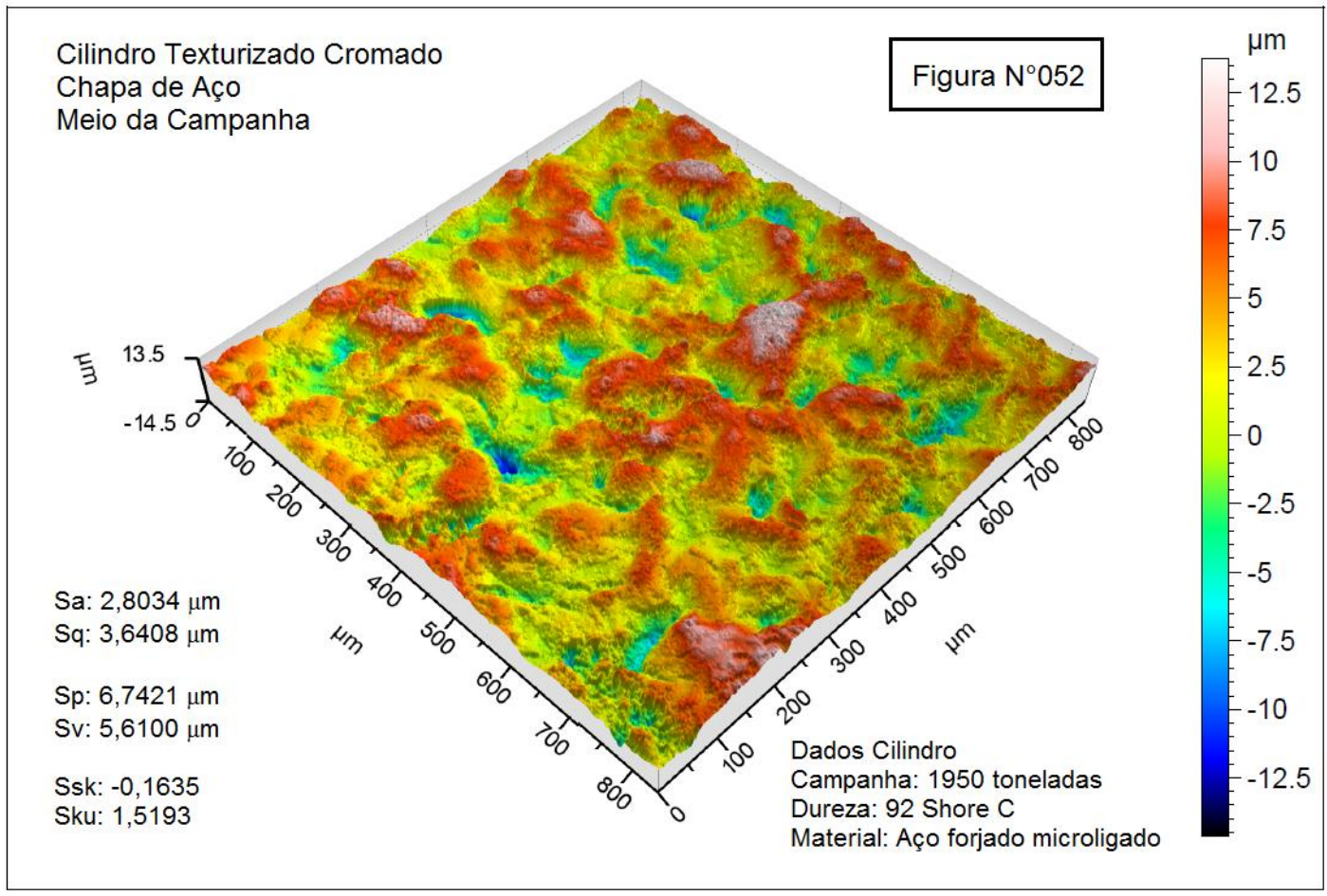

Fonte: (Autor - software CCl) 
Tabela 9- 71. Curva Abbott - cilindro texturizado e cromado - chapa aço (meio)

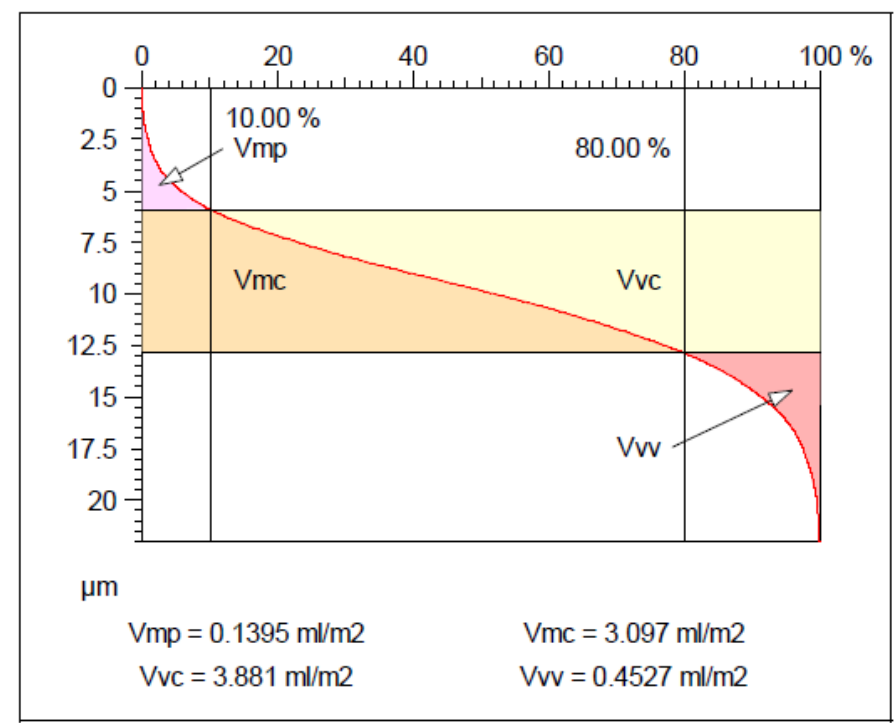

Fonte: (Autor - software CCl)

VC) Final da campanha

Tabela 9- 72. Superfície do cilindro texturizado e cromado - chapa aço (final)

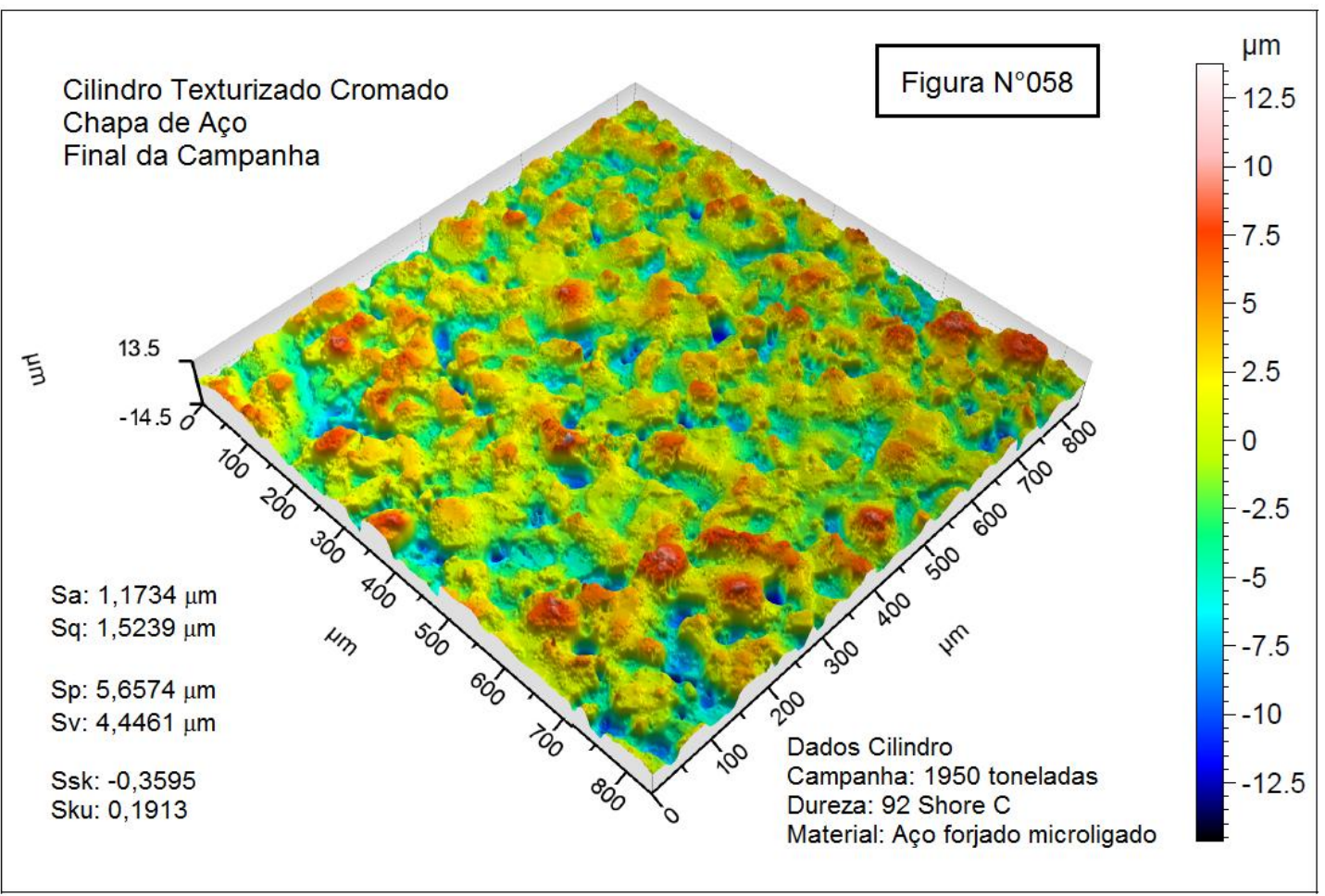

Fonte: (Autor - software CCl) 
Tabela 9- 73. Curva Abbott - cilindro texturizado e cromado - chapa aço (final)

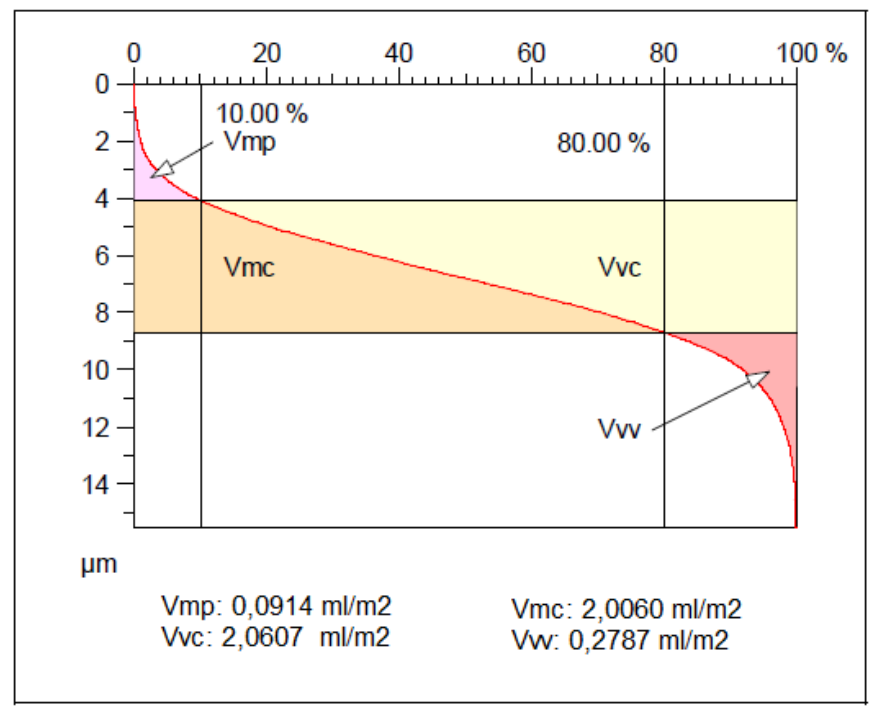

Fonte: (Autor - software CCl)

\section{Chapa de aço com cilindro texturizado e não-cromado}

VIA) Início da campanha

Tabela 9- 74. Superfície do cilindro texturizado e não-cromado - chapa aço (início)

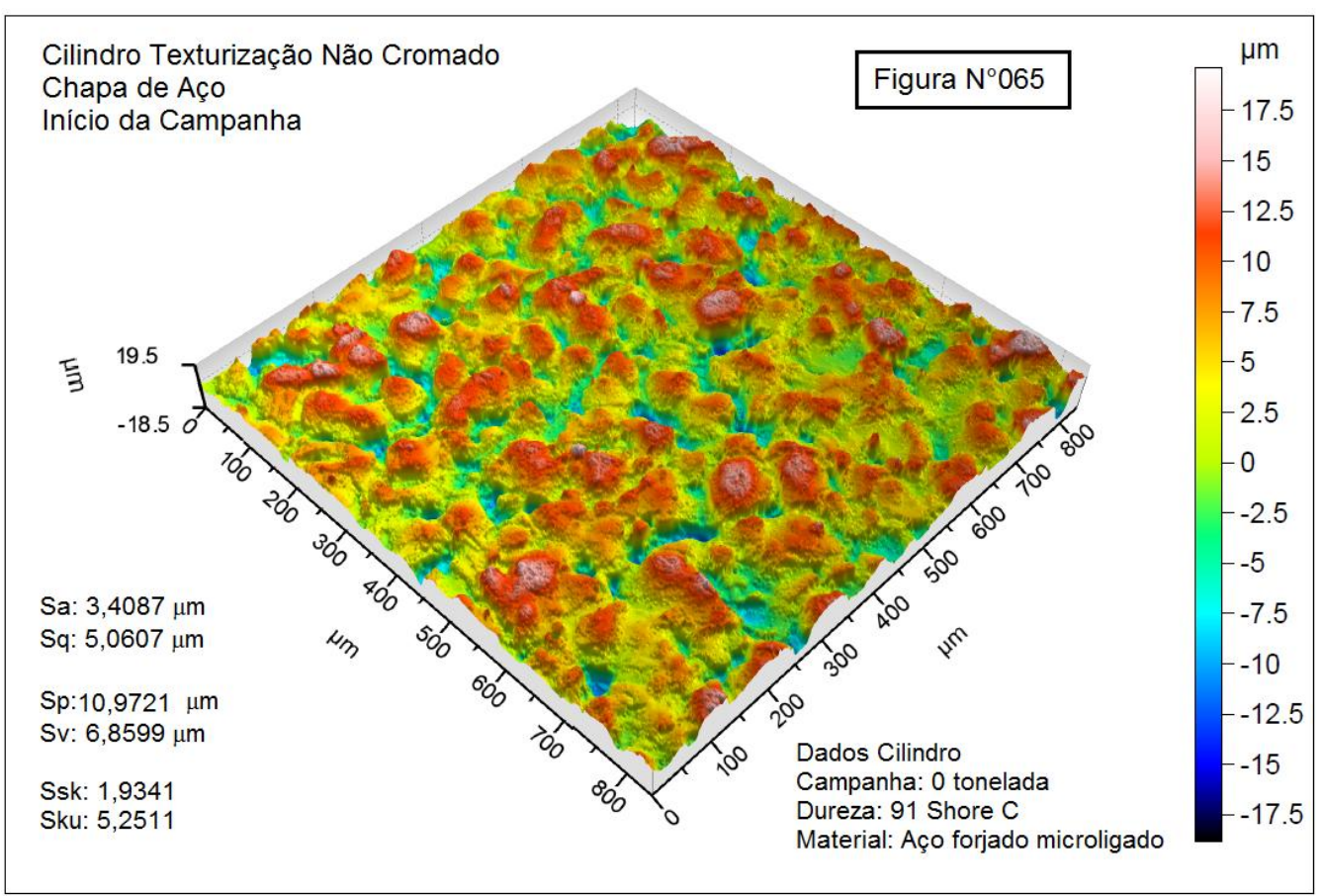

Fonte: (Autor - software CCI) 
Tabela 9- 75. Curva Abbott - cilindro texturizado e não-cromado - chapa aço (início)

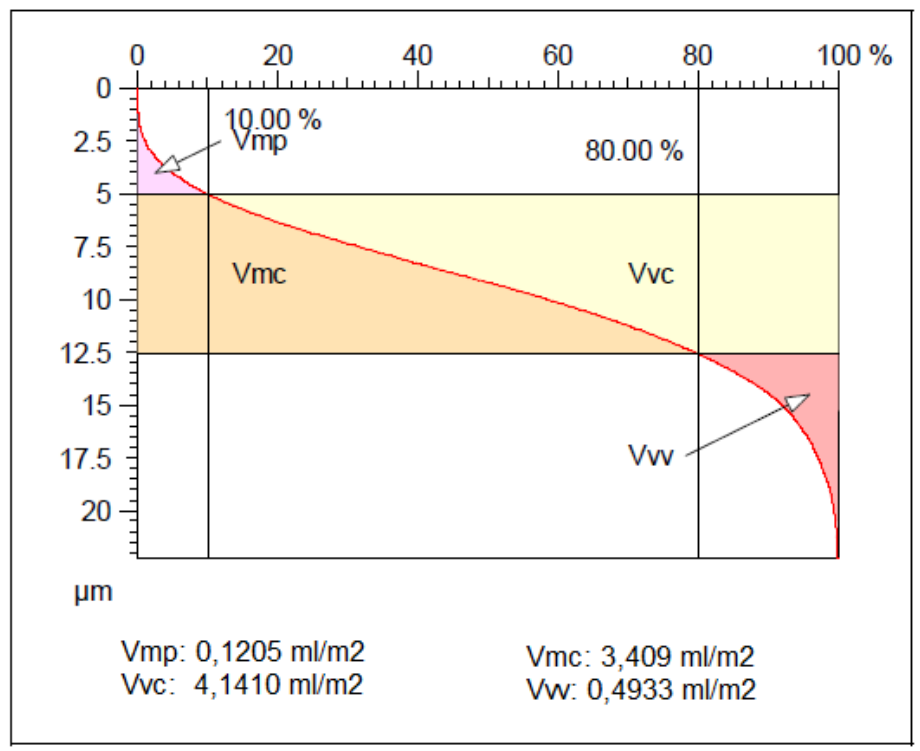

Fonte: (Autor - software CCI)

VIB) Meio da campanha

Tabela 9- 76. Superfície do cilindro texturizado e não-cromado - chapa aço (meio)

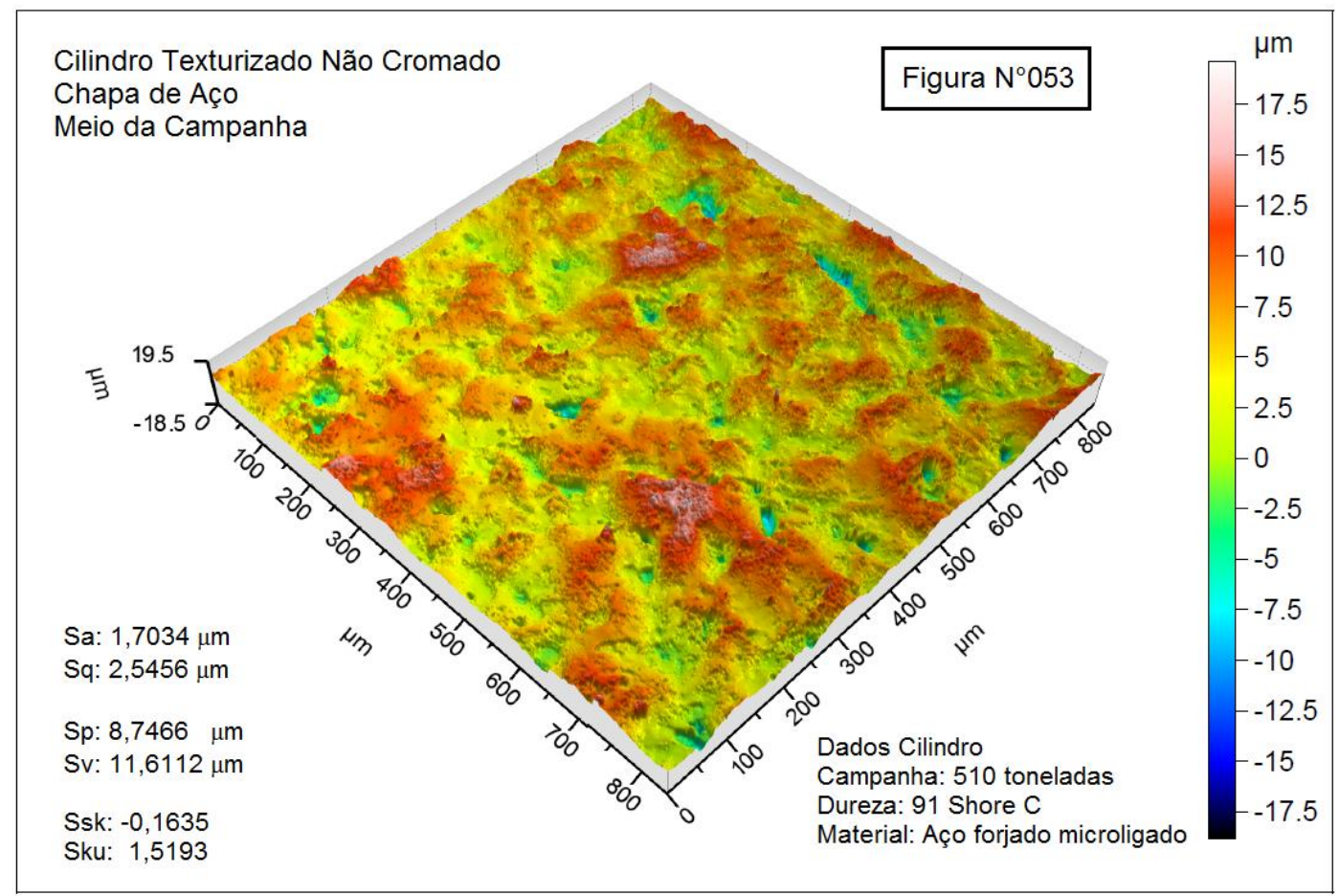

Fonte: (Autor - software CCl) 
Tabela 9- 77. Curva Abbott - cilindro texturizado e não-cromado - chapa aço (meio)

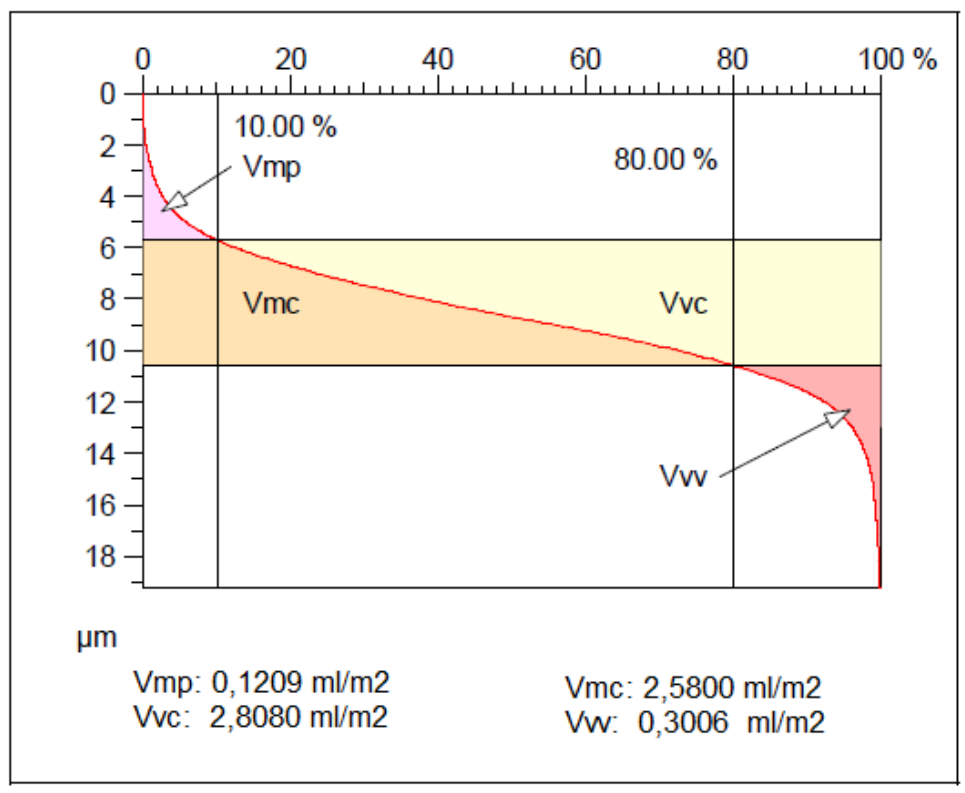

Fonte: (Autor - software CCl)

VIC) Final da campanha

Tabela 9- 78. Superfície do cilindro texturizado e não-cromado - chapa aço (final)

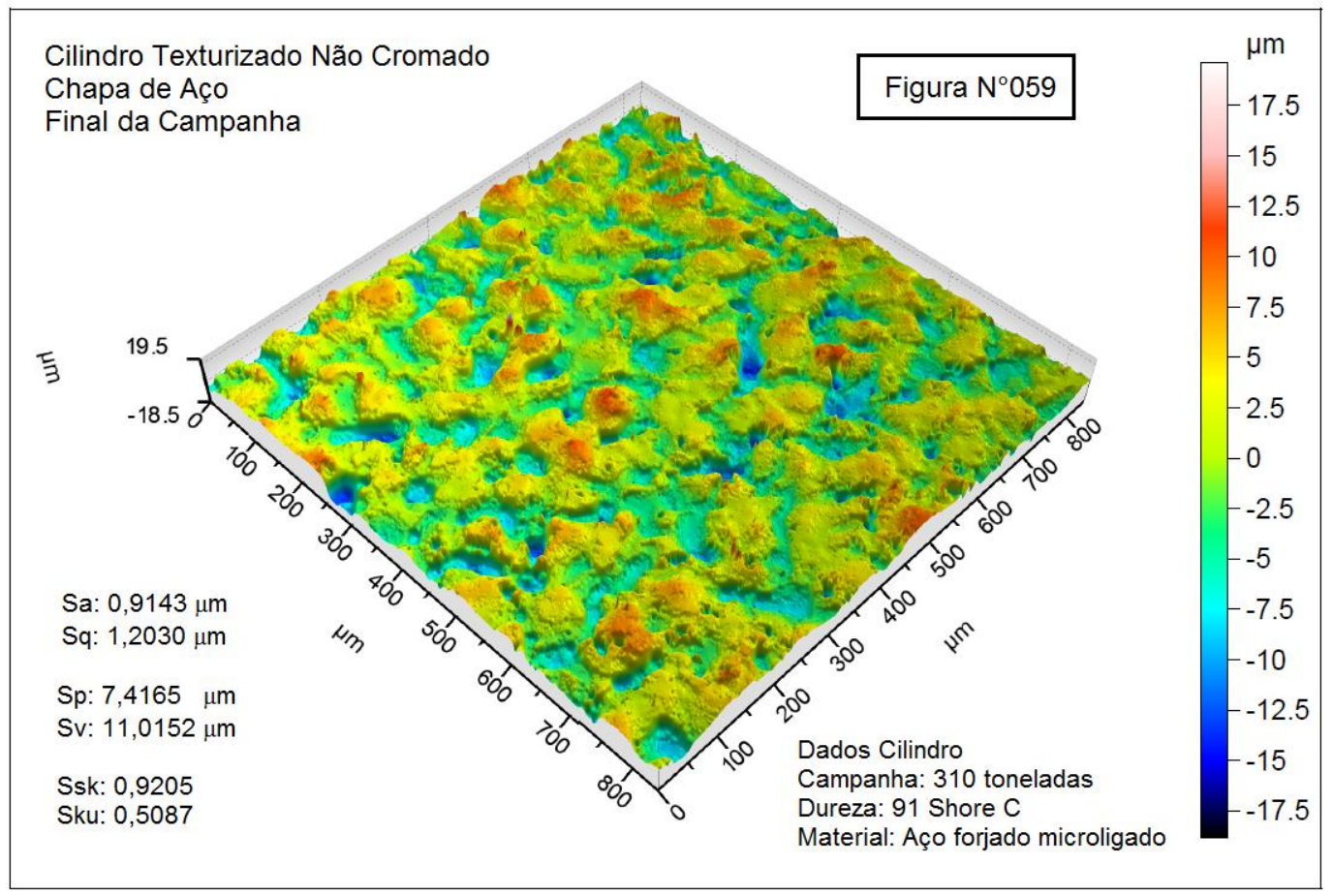

Fonte: (Autor - software CCl) 
Tabela 9- 79. Curva Abbott - cilindro texturizado e não-cromado - chapa aço (final)

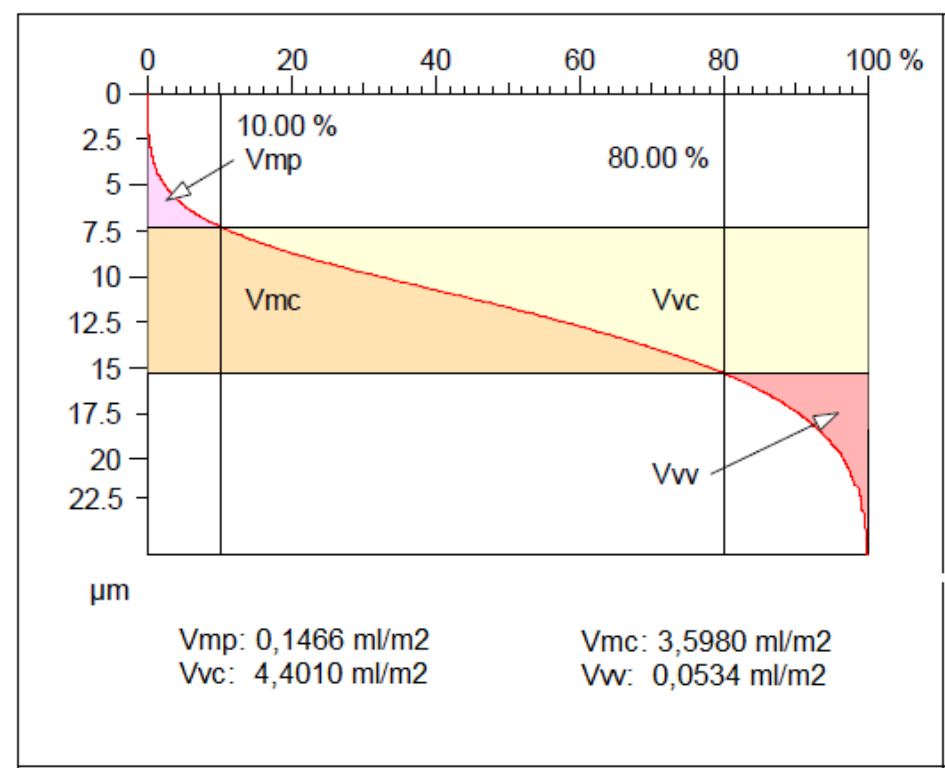

Fonte: (Autor - software CCI)

\section{Chapa de cobre com cilindro retificado e cromado}

VIIA) Início da campanha

Tabela 9- 80. Superfície do cilindro retificado e cromado - chapa cobre (início)

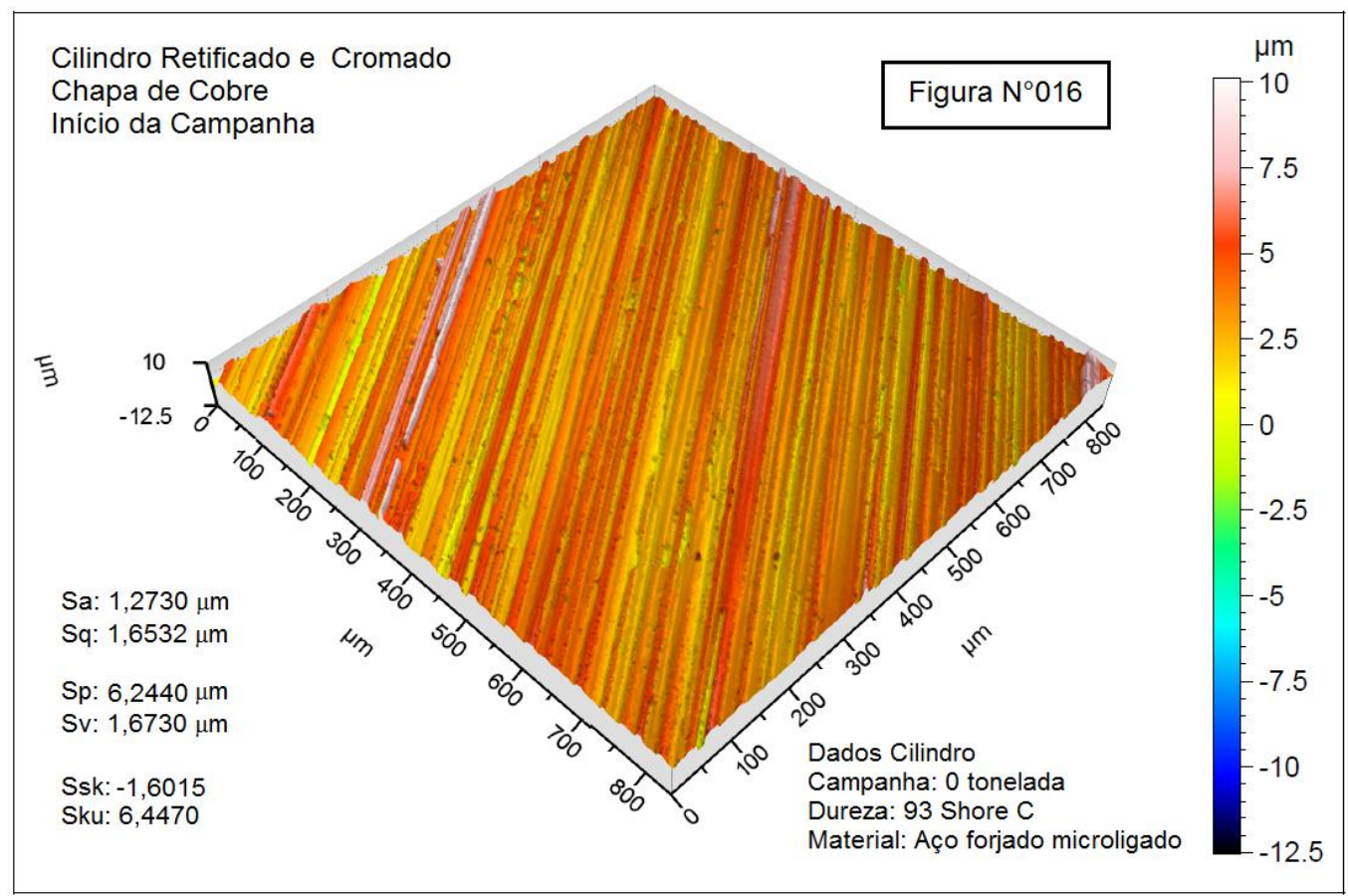

Fonte: (Autor - software CCl) 
Tabela 9- 81. Curva Abbott - cilindro retificado e cromado - chapa cobre (início)

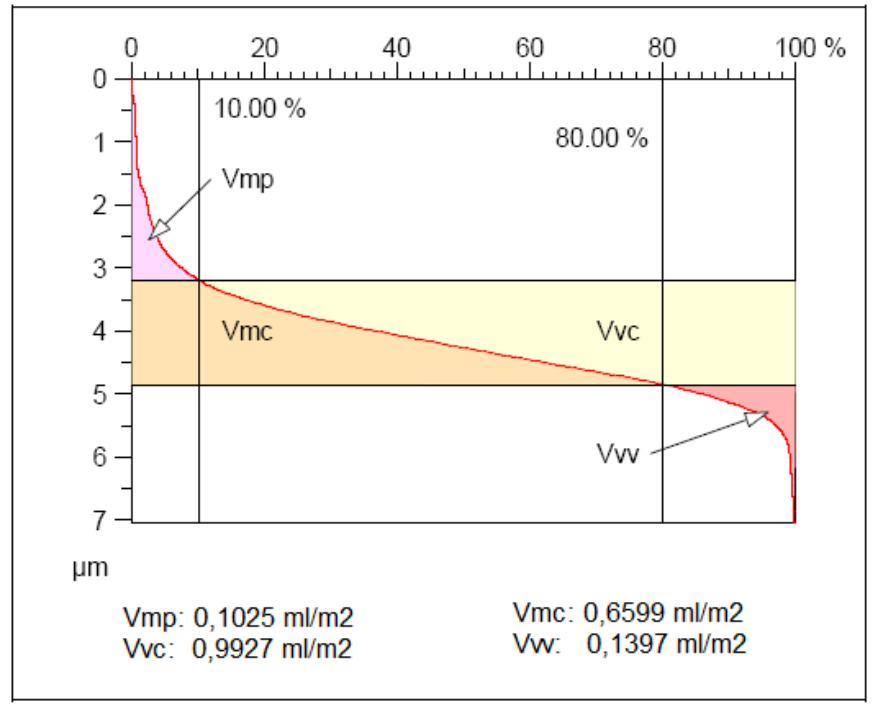

Fonte: (Autor - software CCl)

VIIB) Meio da campanha

Tabela 9- 82. Superfície do cilindro retificado e cromado - chapa cobre (meio)

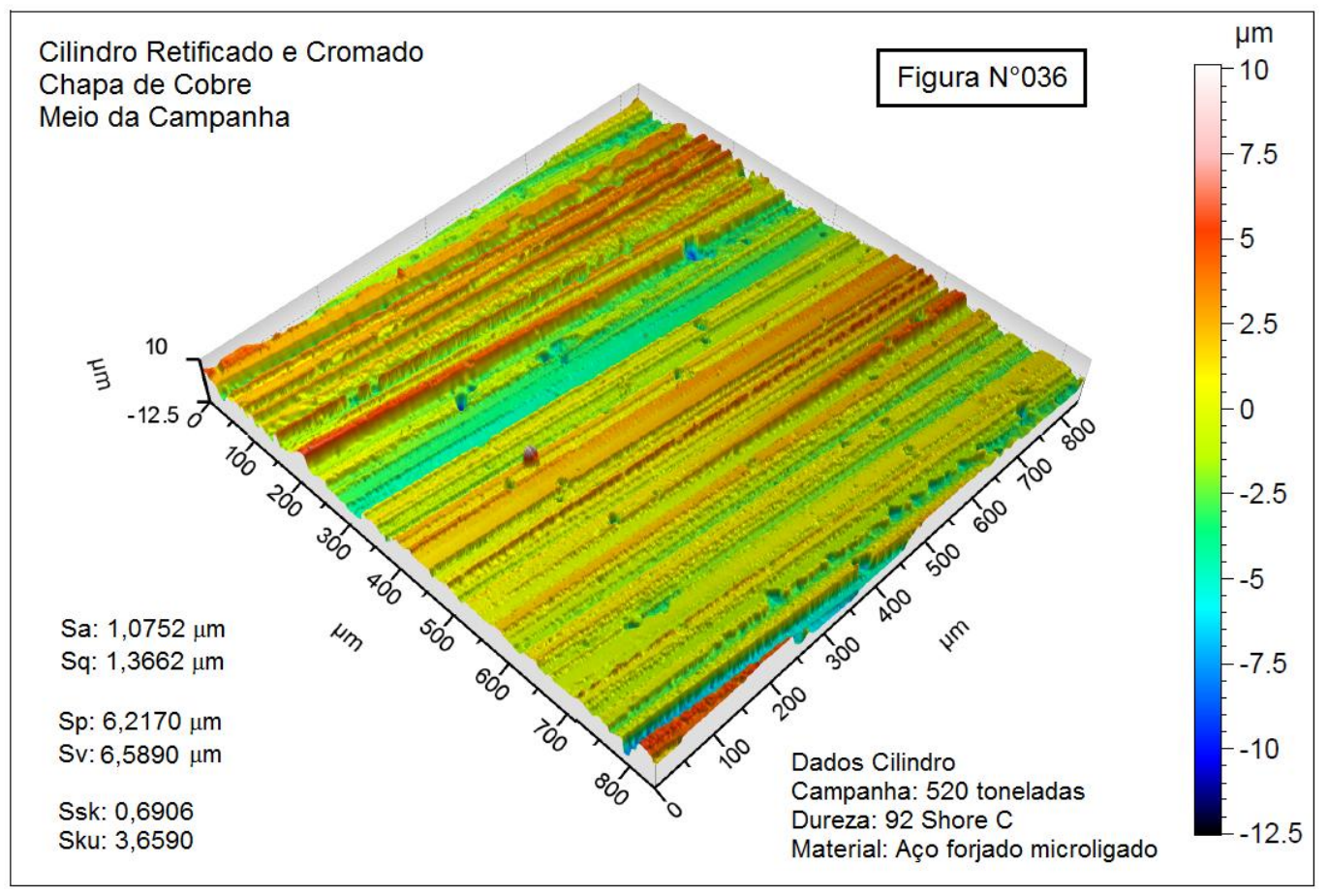

Fonte: (Autor - software CCl) 
Tabela 9- 83. Curva Abbott - cilindro retificado e cromado - chapa cobre (meio)

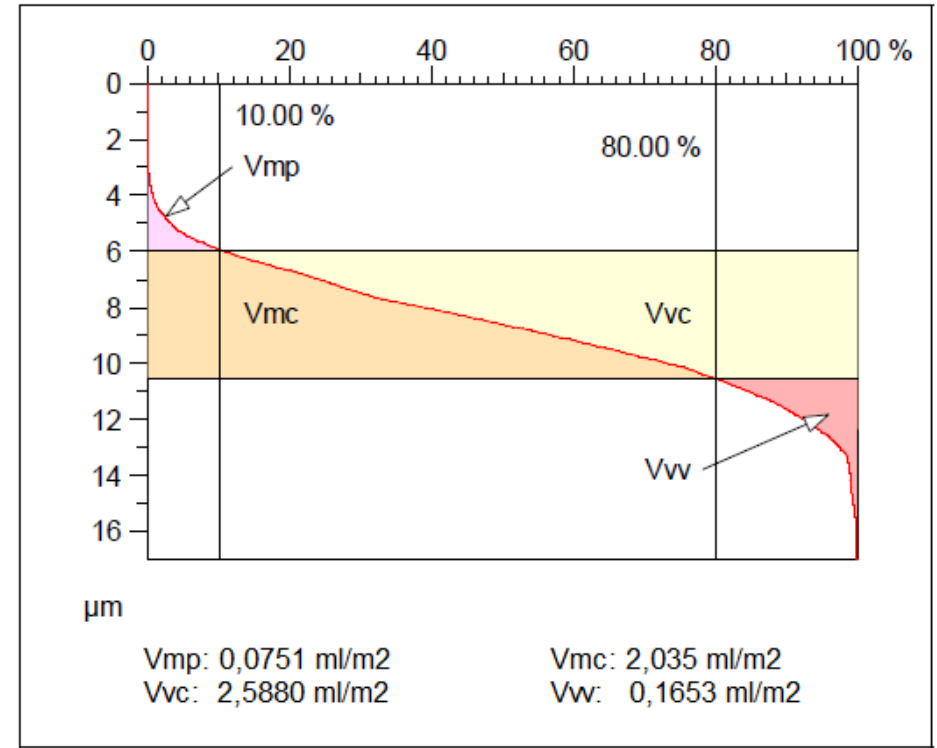

Fonte: (Autor - software CCl)

VIIC) Final da campanha

Tabela 9- 84. Superfície do cilindro retificado e cromado - chapa cobre (final)

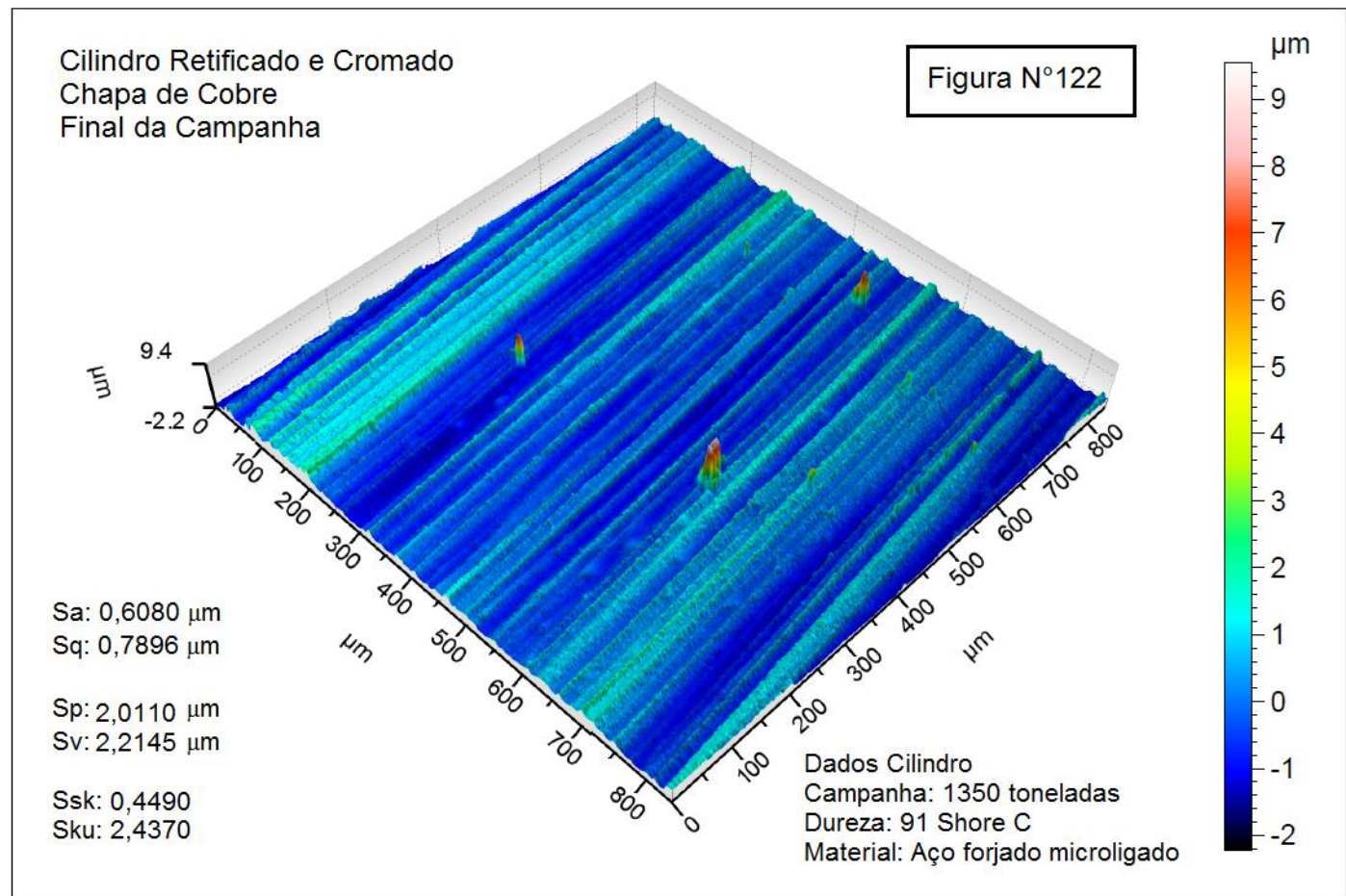

Fonte: (Autor - software $\mathrm{CCl}$ ) 
Tabela 9- 85. Curva Abbott - cilindro retificado e cromado - chapa cobre (final)

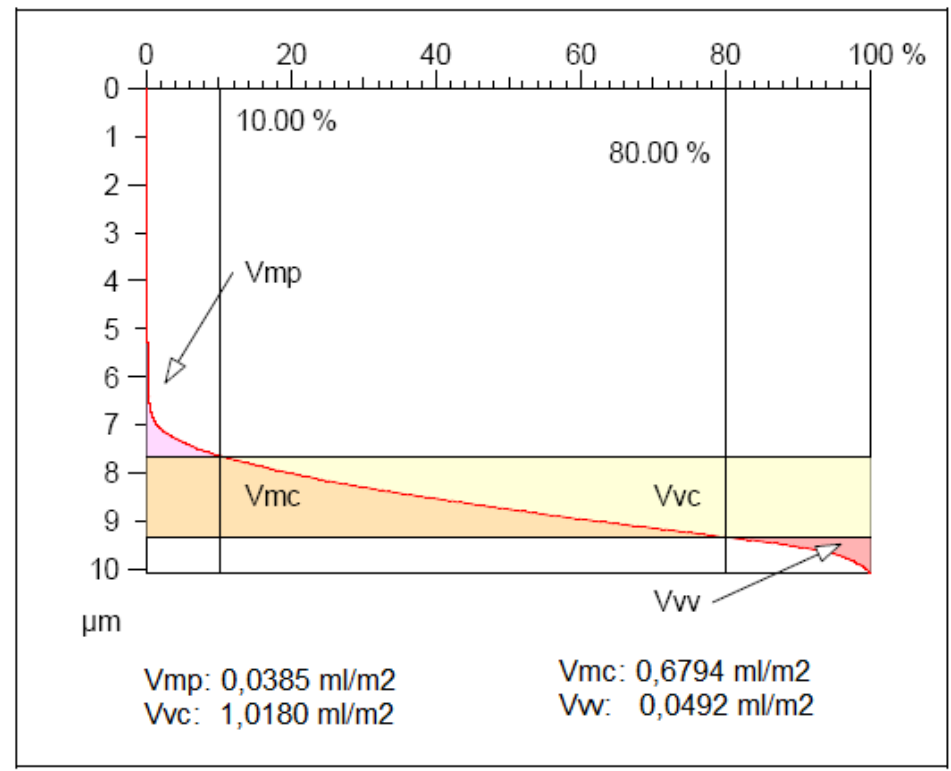

Fonte: (Autor - software CCI)

\section{Chapa de cobre com cilindro retificado e não-cromado}

VIIIA) Início da campanha

Tabela 9- 86. Superfície do cilindro retificado e não-cromado - chapa cobre (início)

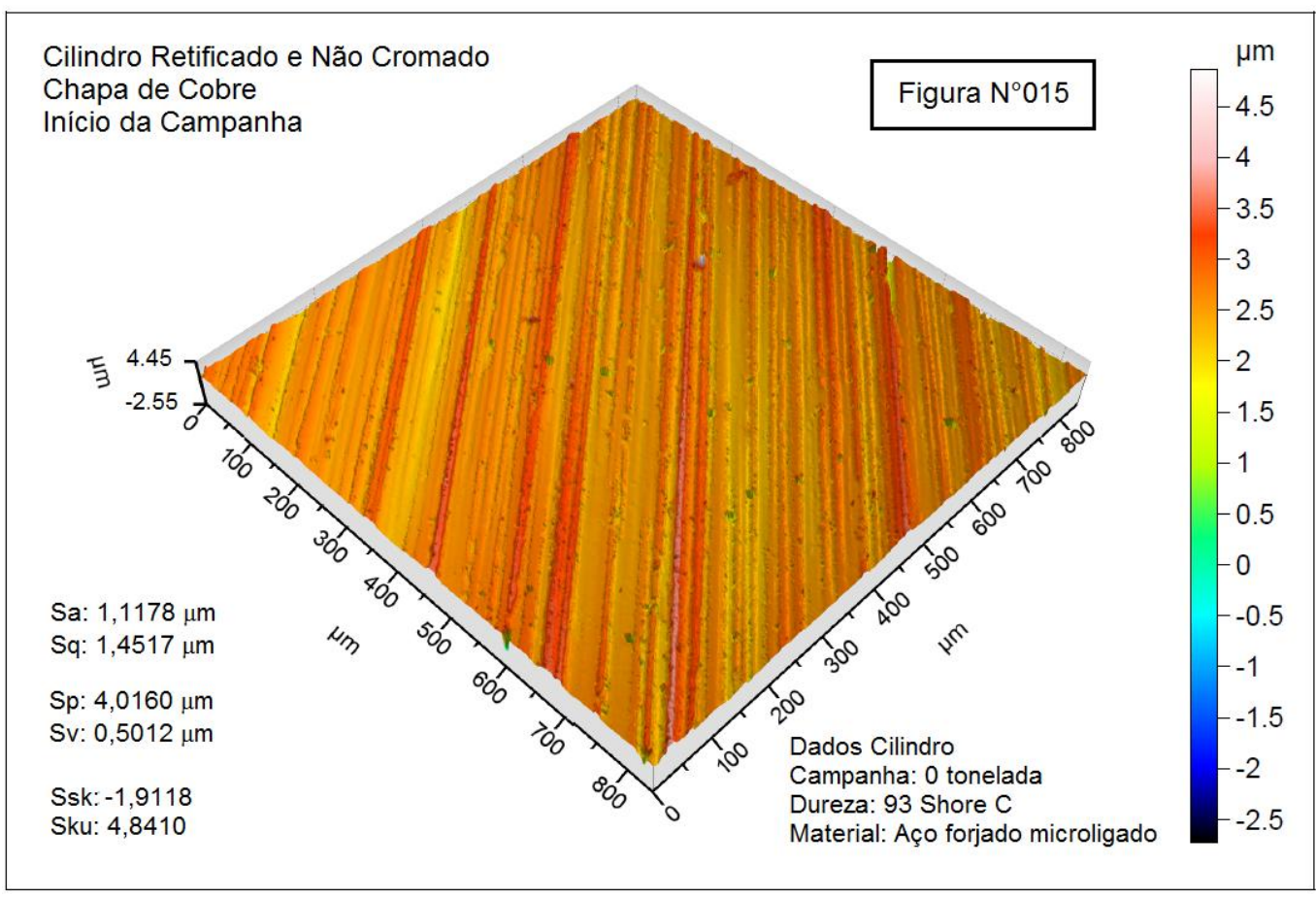

Fonte: (Autor - software CCl) 
Tabela 9- 87. Curva Abbott - cilindro retificado e não-cromado - chapa cobre (início)

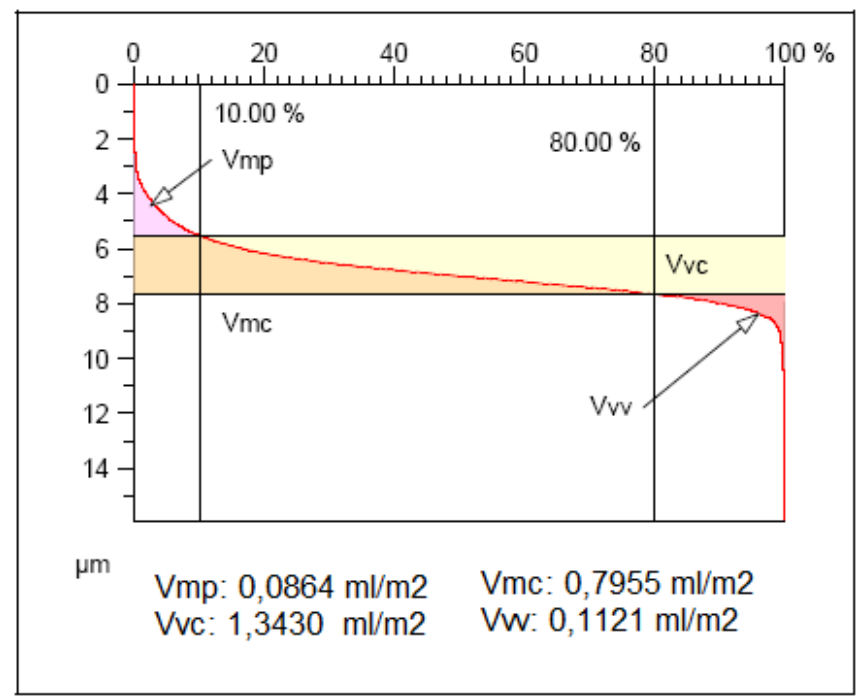

Fonte: (Autor - software CCl)

VIIIB) Meio da campanha

Tabela 9- 88. Superfície do cilindro retificado e não-cromado - chapa cobre (meio)

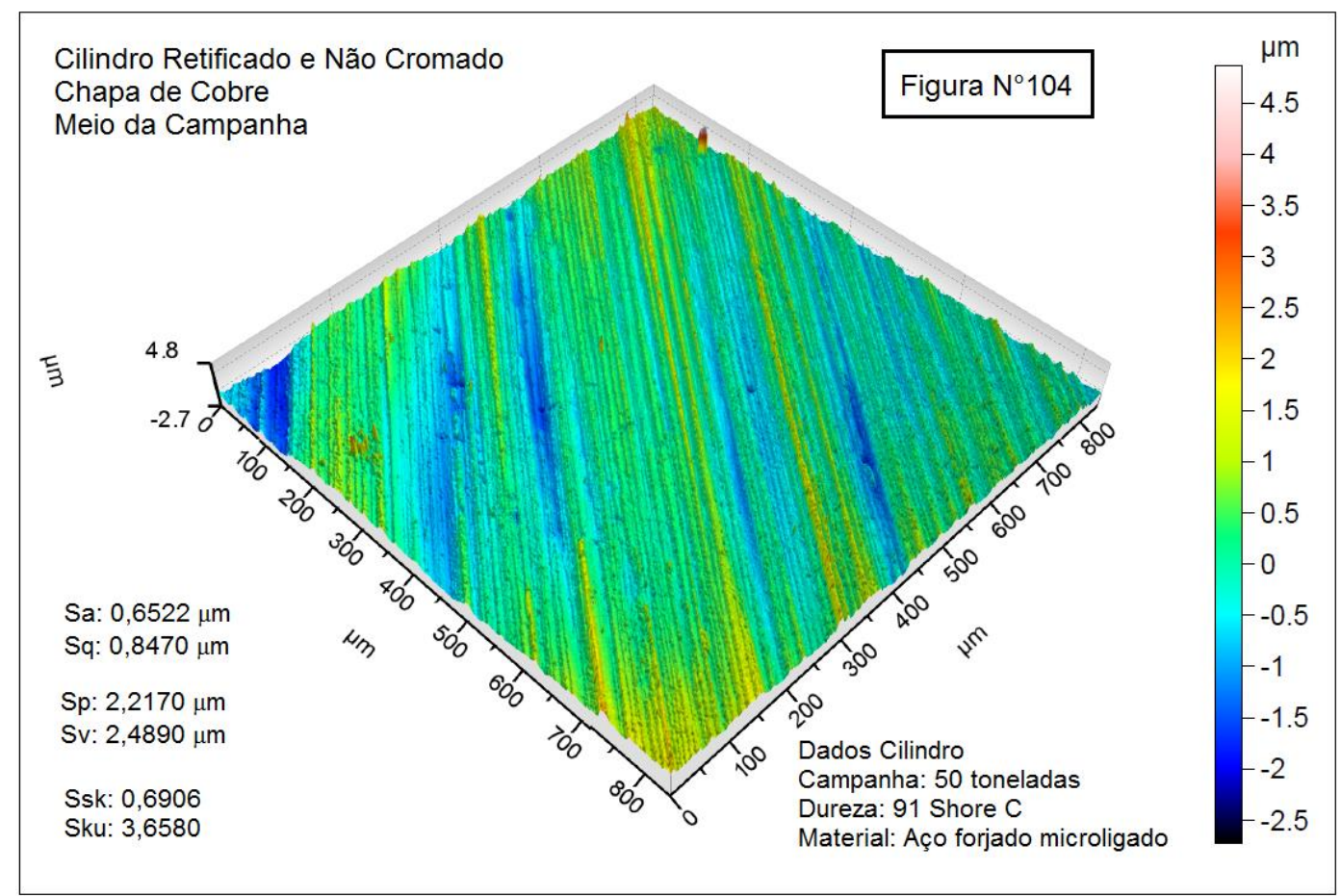

Fonte: (Autor - software CCl) 
Tabela 9- 89. Curva Abbott - cilindro retificado e não-cromado - chapa cobre (meio)

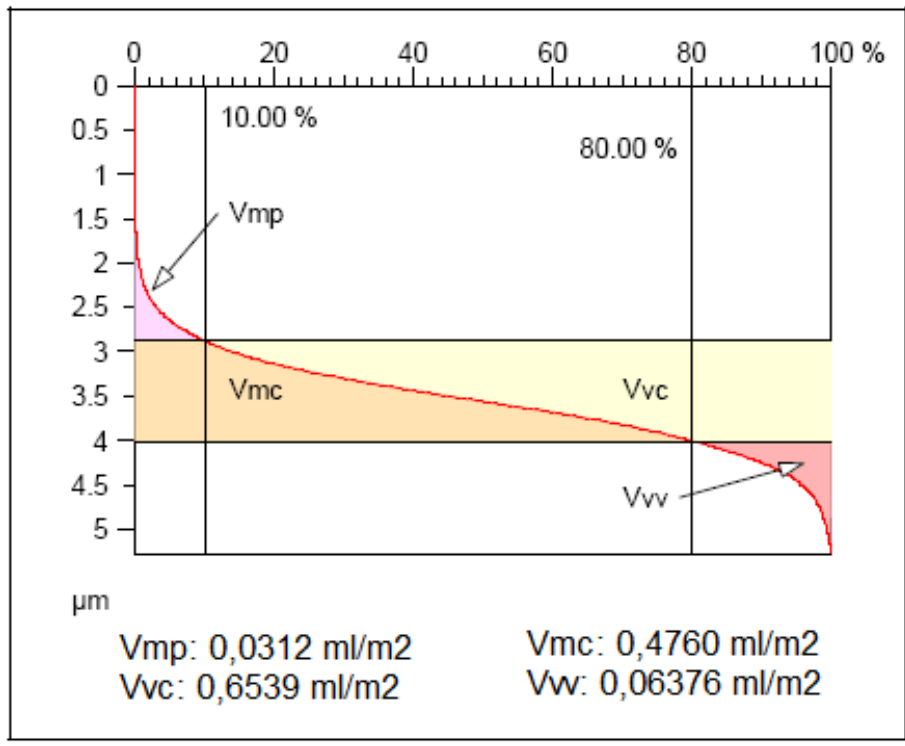

Fonte: (Autor - software $\mathrm{CCl}$ )

VIIIC) Final da campanha

Tabela 9- 90. Superfície do cilindro retificado e não-cromado - chapa cobre (final)

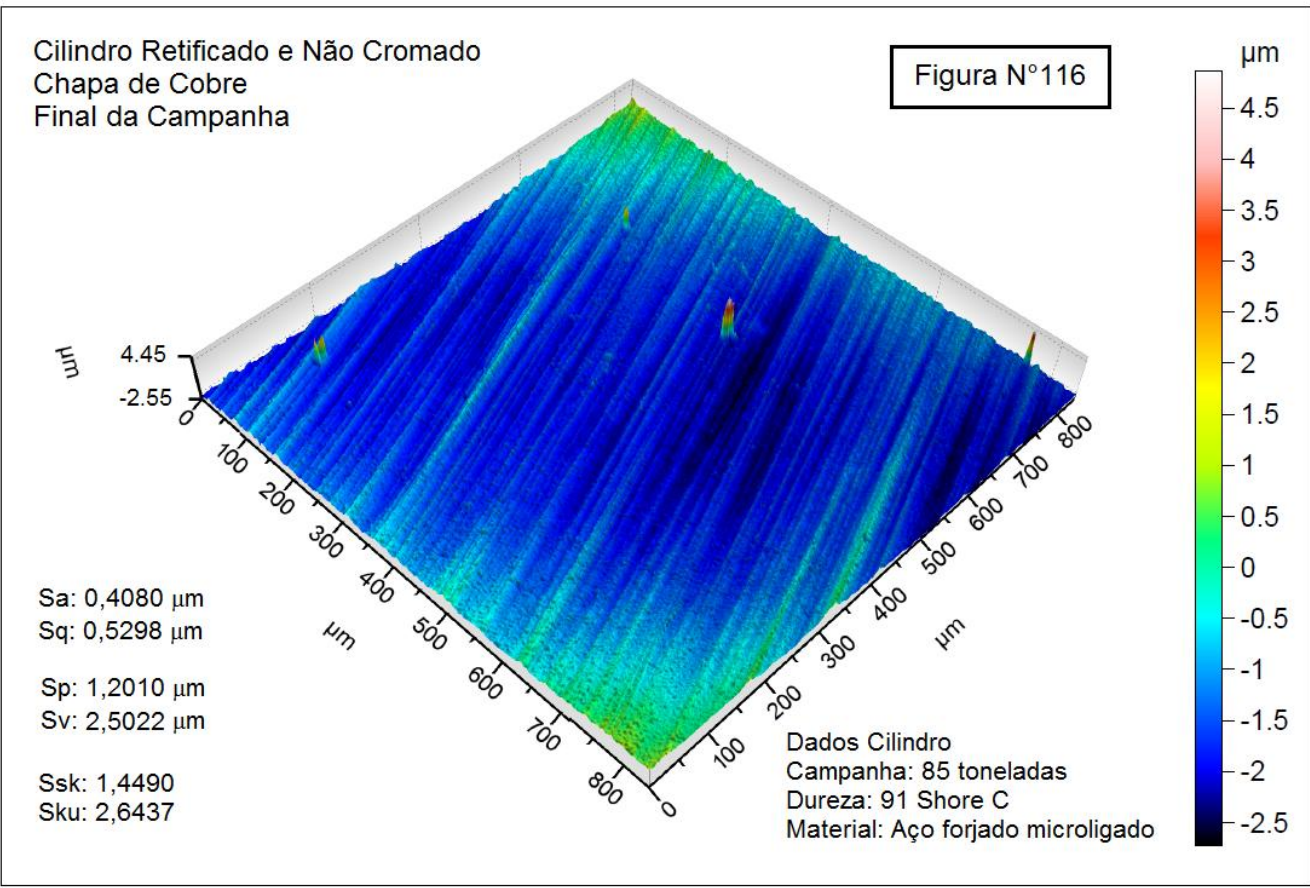

Fonte: (Autor - software CCl) 
Tabela 9- 91. Curva Abbott - cilindro retificado e não-cromado - chapa cobre (final)

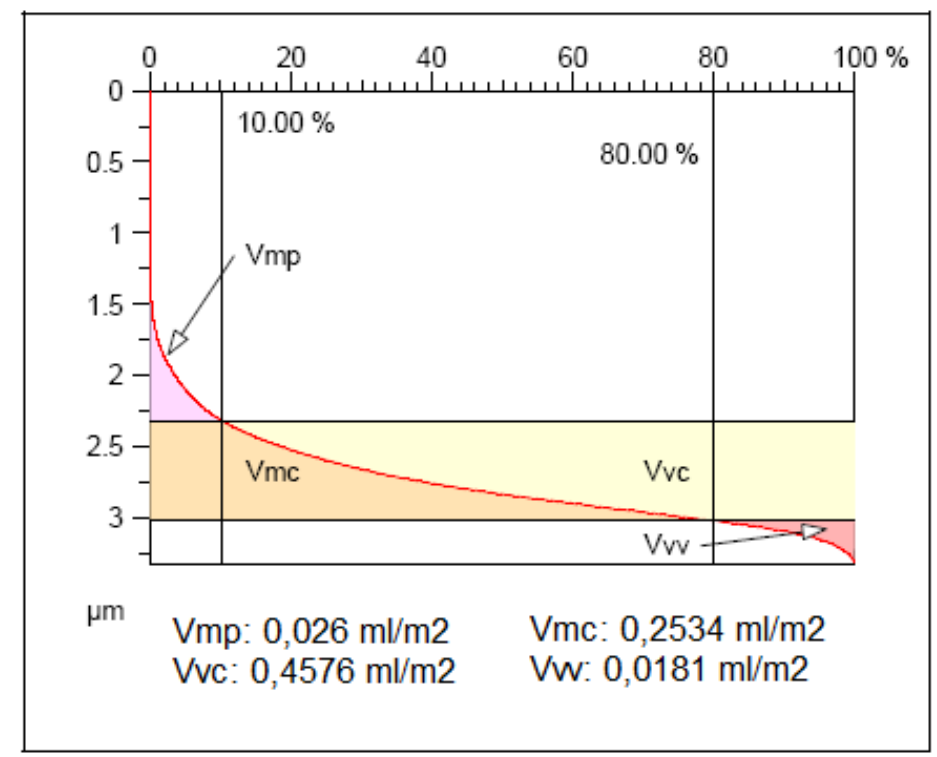

Fonte: (Autor - software CCl)

\section{Chapa de alumínio com cilindro retificado e cromado}

IXA) Início da campanha

Tabela 9- 92. Superfície do cilindro retificado e cromado - chapa alumínio (início)

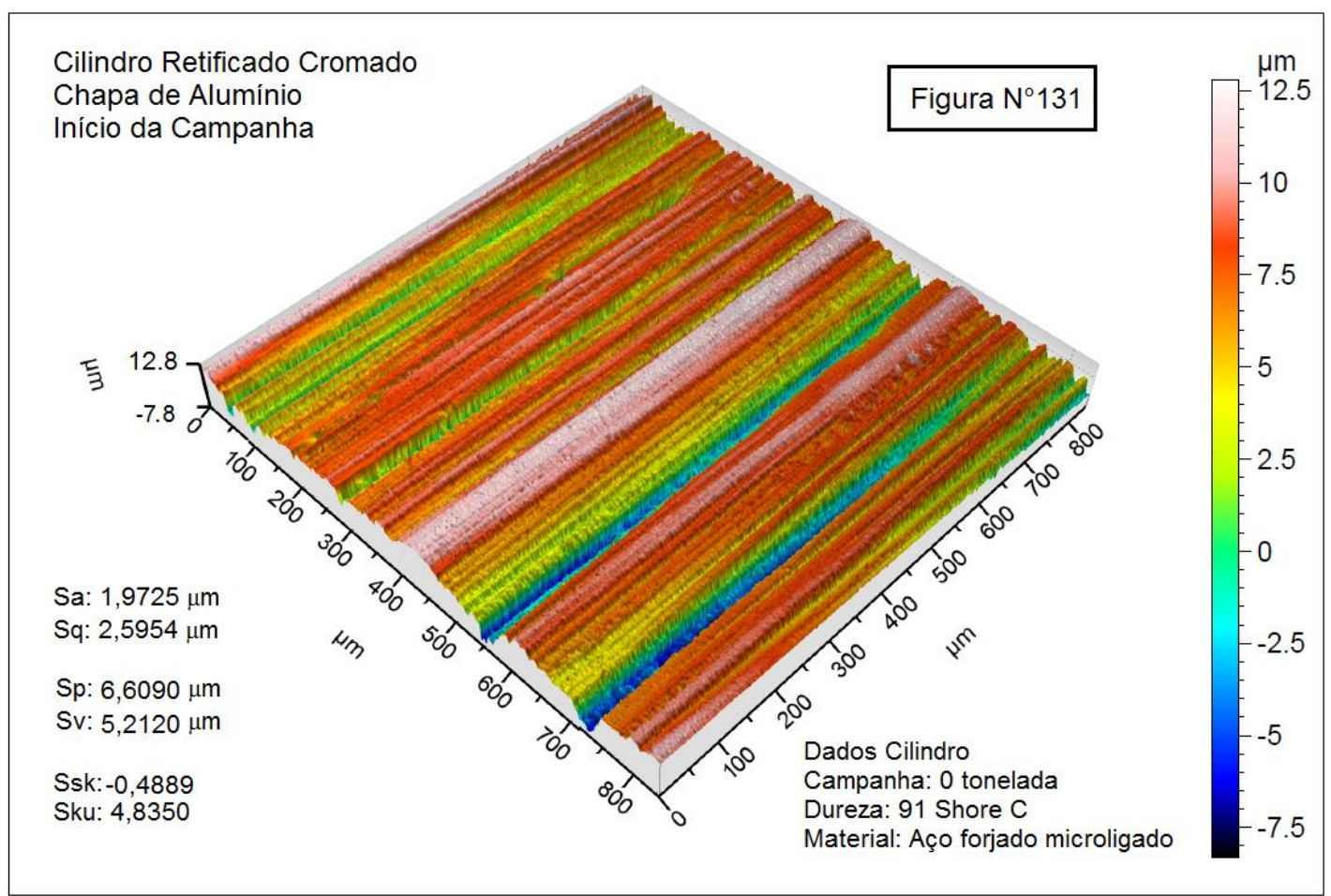

Fonte: (Autor - software CCl) 
Tabela 9- 93. Curva Abbott - cilindro retificado e cromado - chapa alumínio (início)

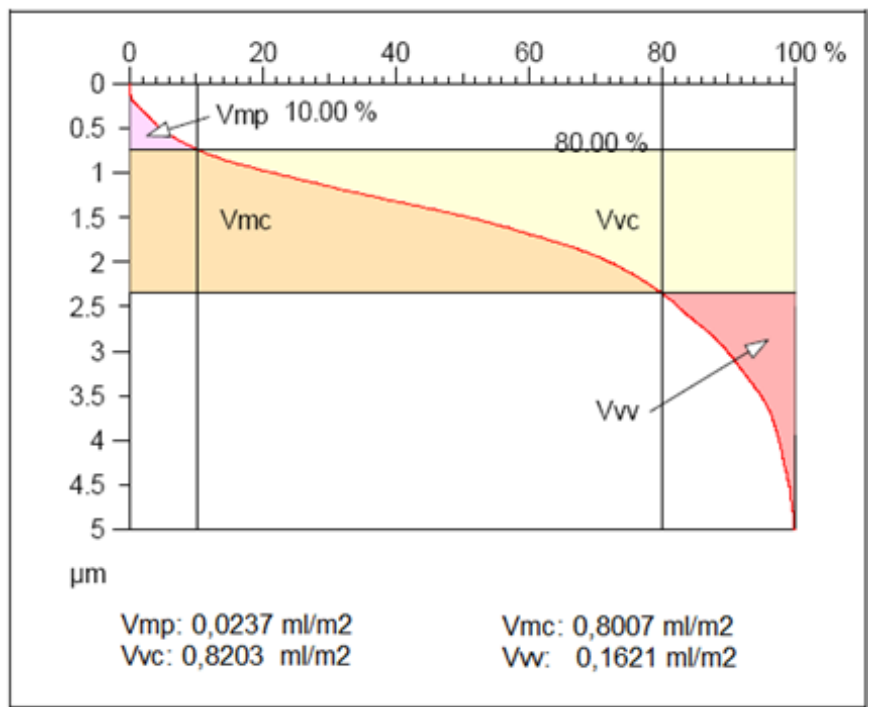

Fonte: (Autor - software CCl)

IXB) Meio da campanha

Tabela 9- 94. Superfície do cilindro retificado e cromado - chapa alumínio (meio)

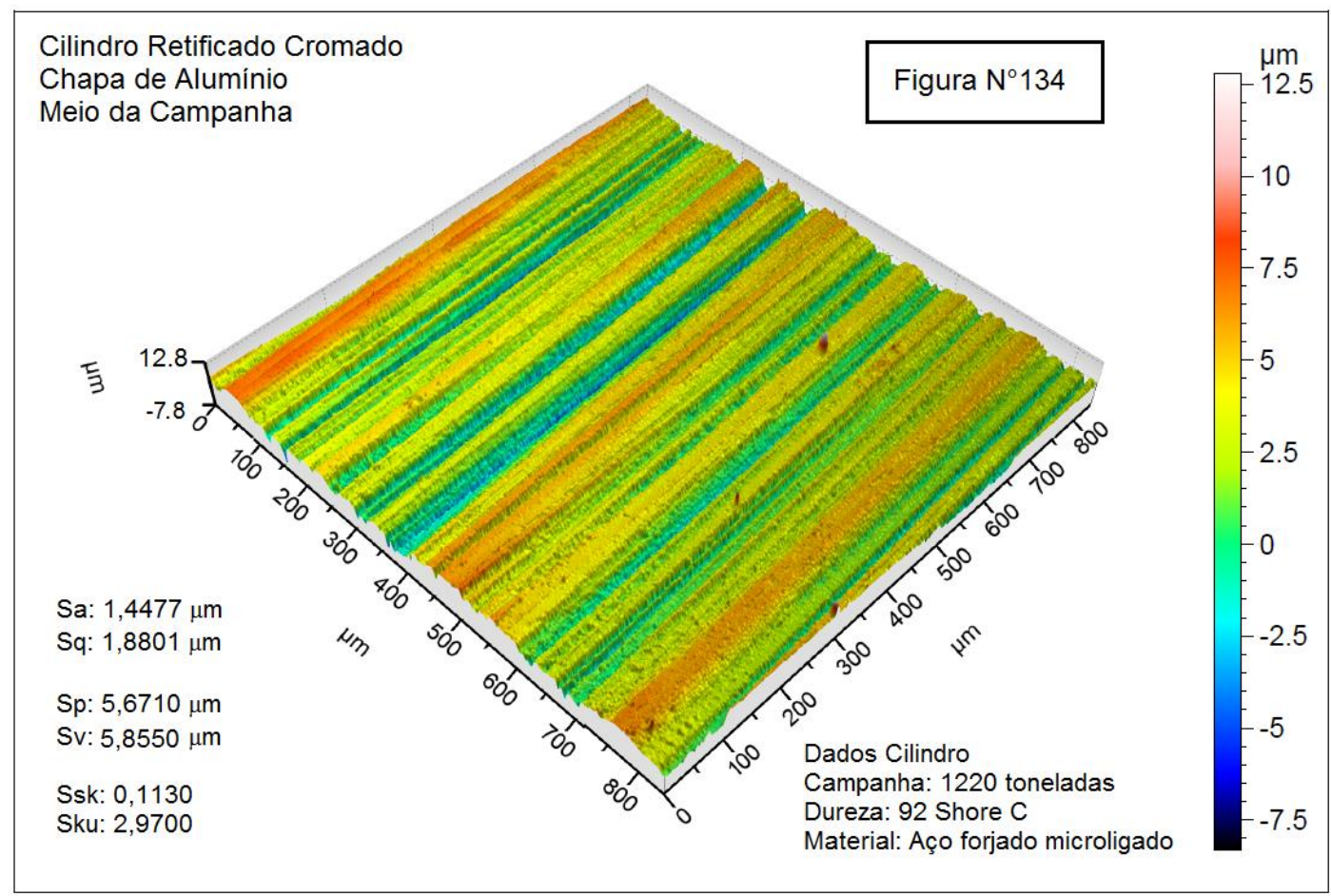

Fonte: (Autor - software CCl) 
Tabela 9- 95. Curva Abbott - cilindro retificado e cromado - chapa alumínio (meio)

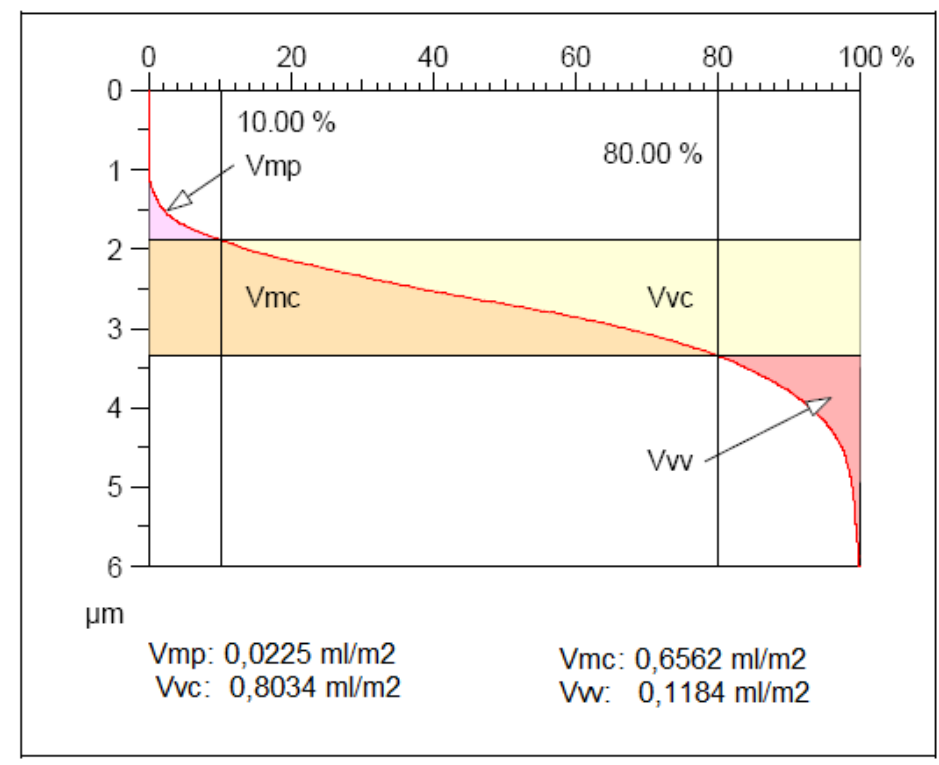

Fonte: (Autor - software CCl)

IXC) Final da campanha

Tabela 9- 96. Superfície do cilindro retificado e cromado - chapa alumínio (final)

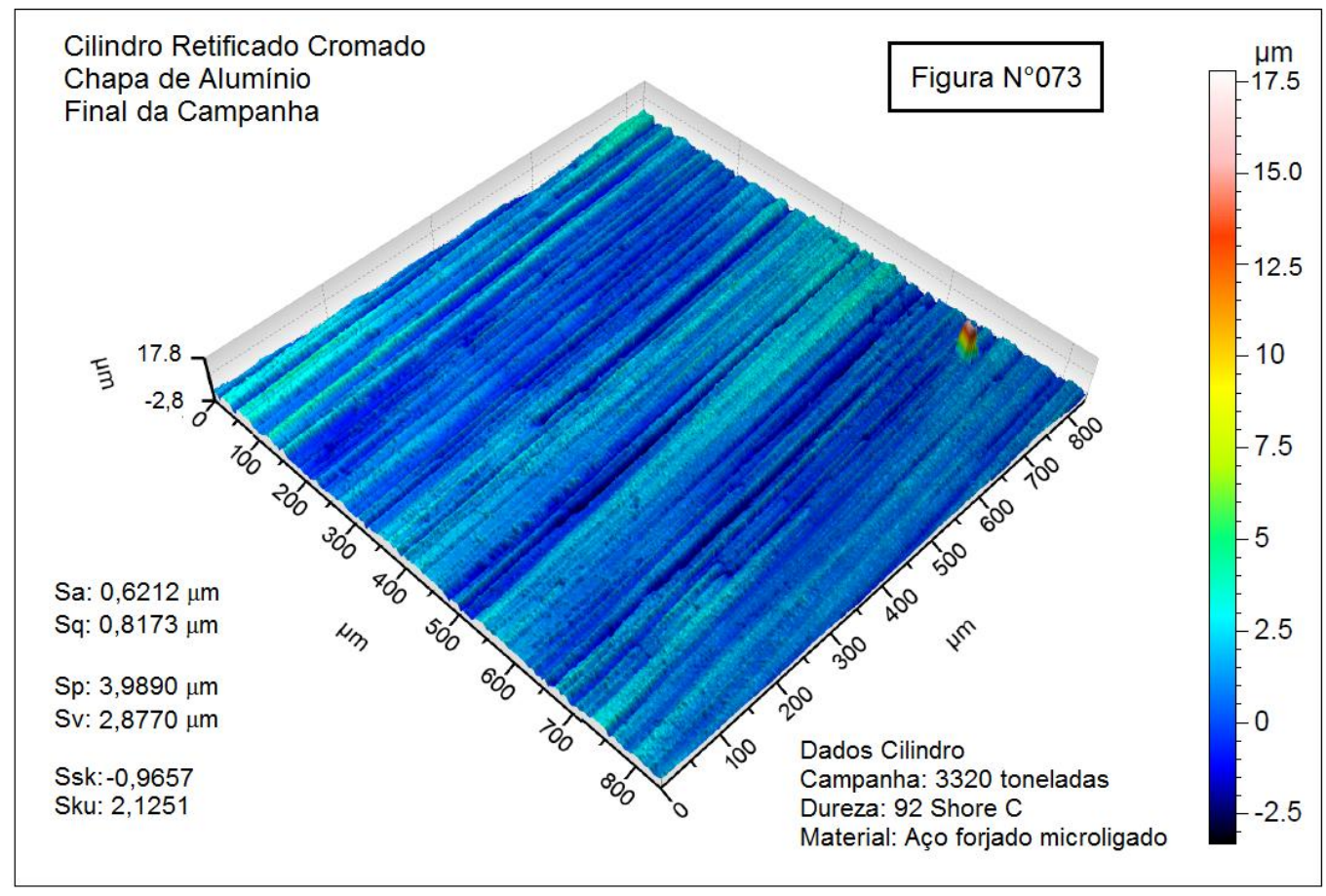

Fonte: (Autor - software CCl) 
Tabela 9- 97. Curva Abbott - cilindro retificado e cromado - chapa alumínio (final)

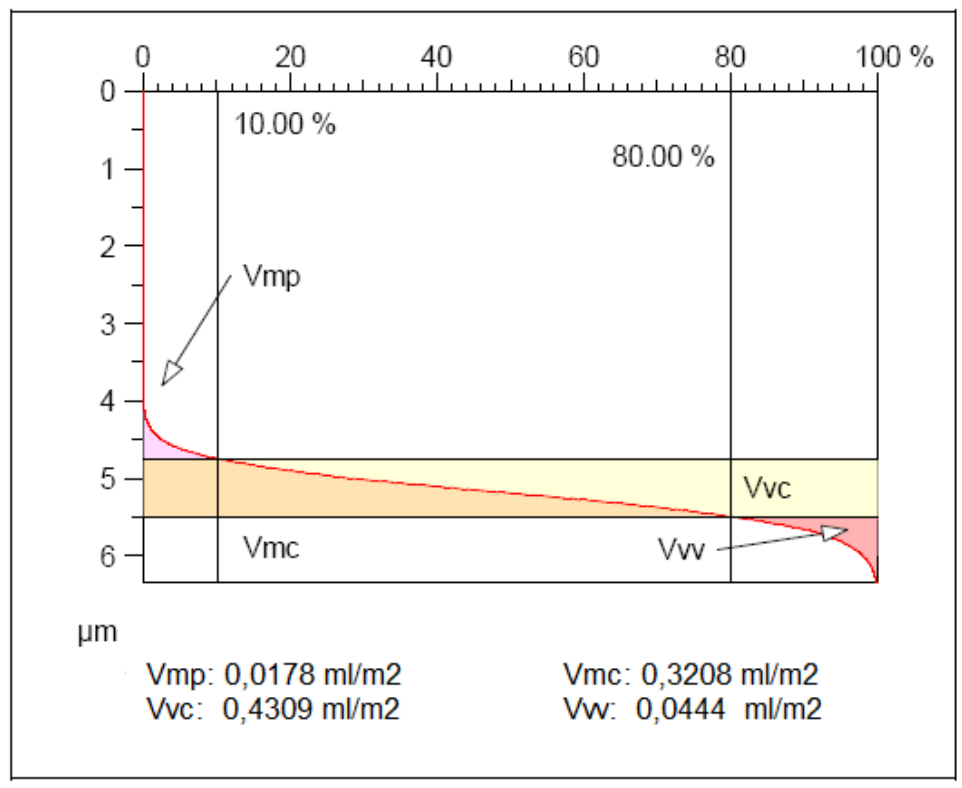

Fonte: (Autor - software CCl)

\section{Chapa de alumínio e cilindro retificado e não-cromado}

XA) Início da campanha

Tabela 9- 98. Superfície do cilindro retificado e não-cromado chapa alumínio (início)

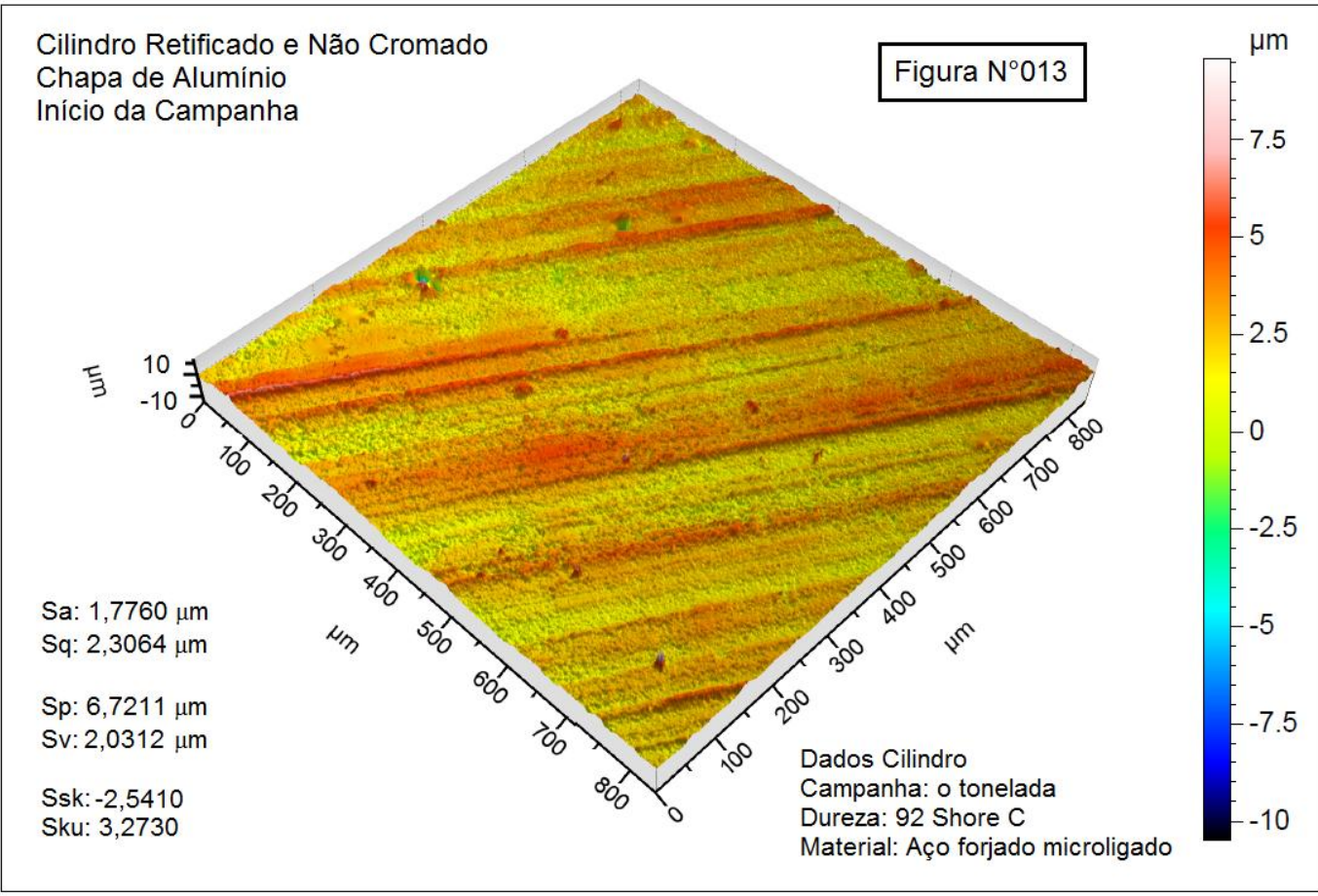


Fonte: (Autor - software CCl)

Tabela 9- 99. Curva Abbott cilindro retificado não-cromado-chapa alumínio (início)

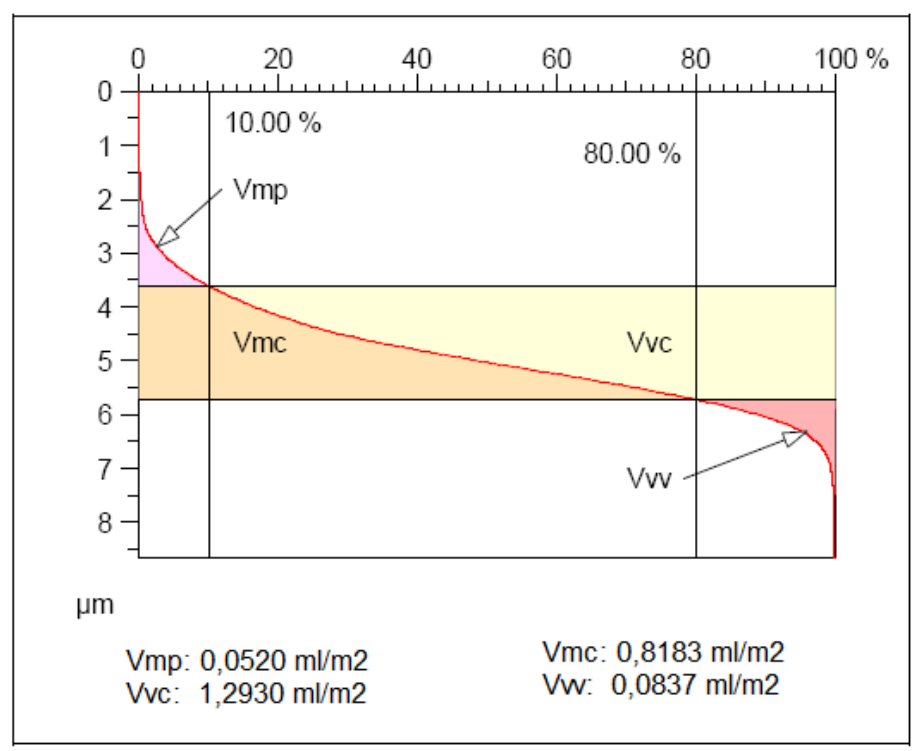

Fonte: (Autor - software CCl)

XB) Meio da campanha

Tabela 9- 100. Superfície do cilindro retificado e não-cromado chapa alumínio (meio)

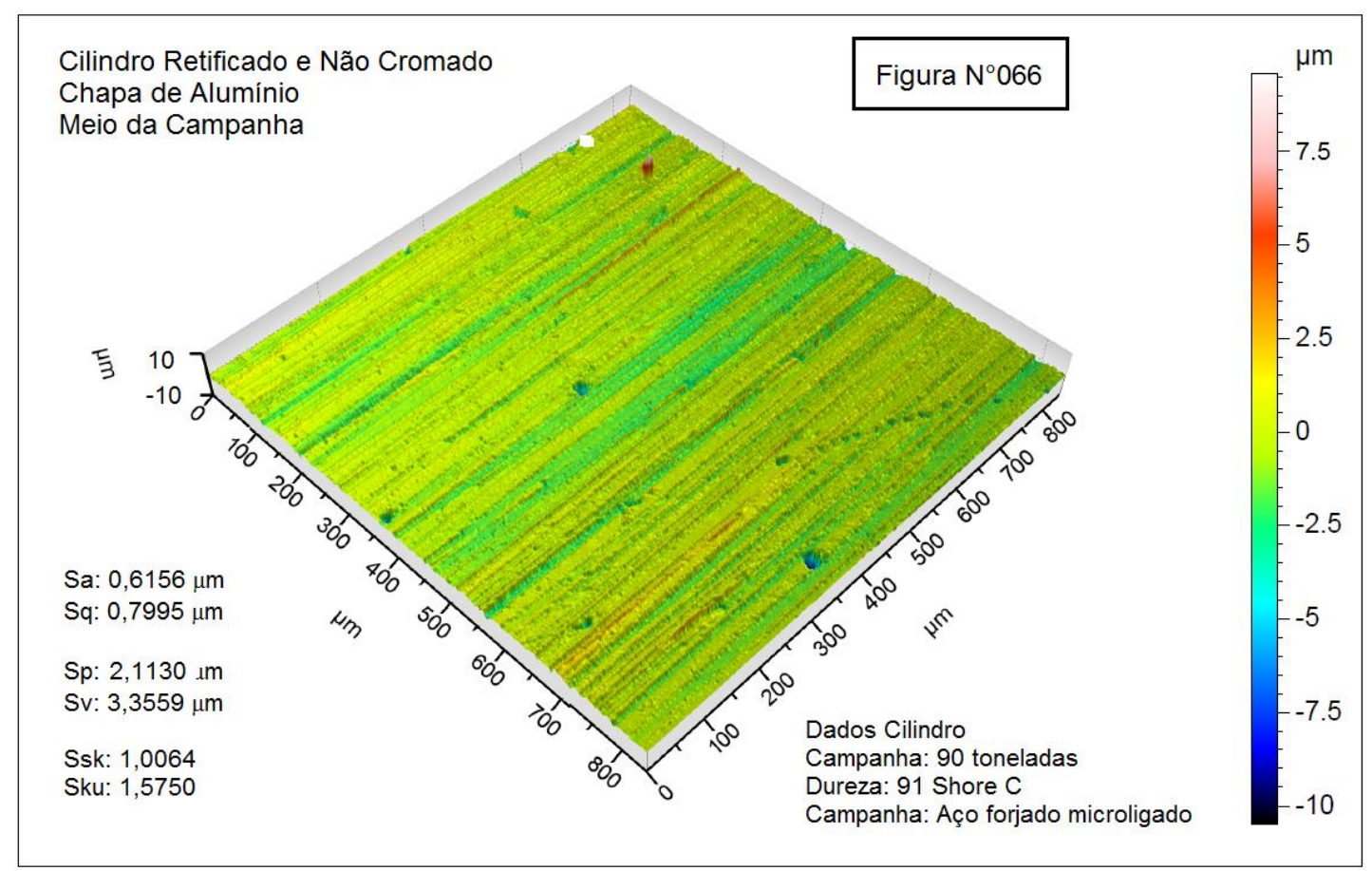

Fonte: (Autor - software CCl) 
Tabela 9- 101. Curva Abbott-cilindro retificado não-cromado-chapa alumínio (meio)

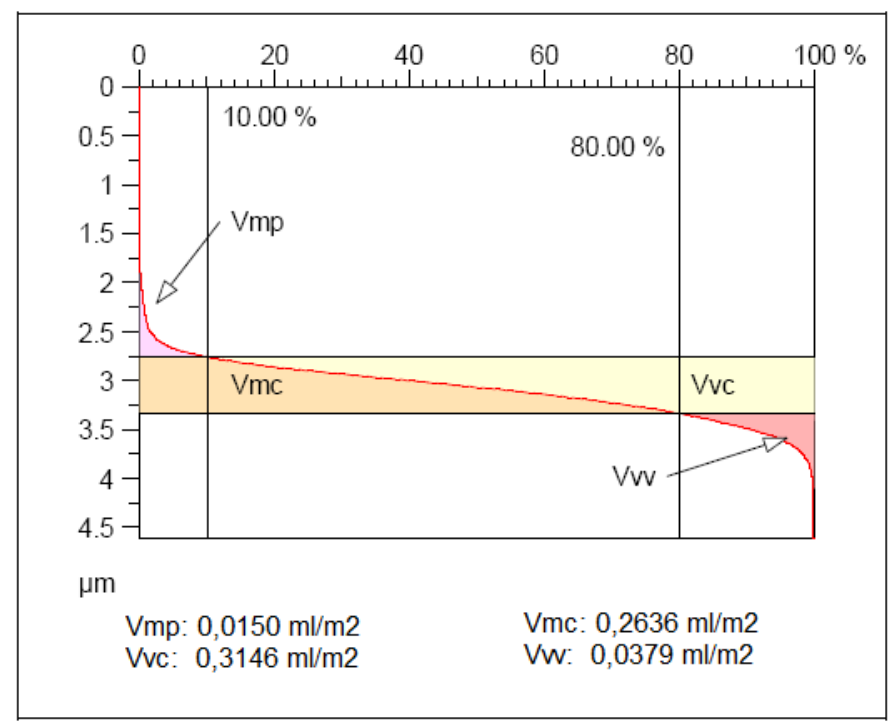

Fonte: (Autor - software CCI)

XC) Final da campanha

Tabela 9- 102. Superfície do cilindro retificado não-cromado chapa alumínio (final) 


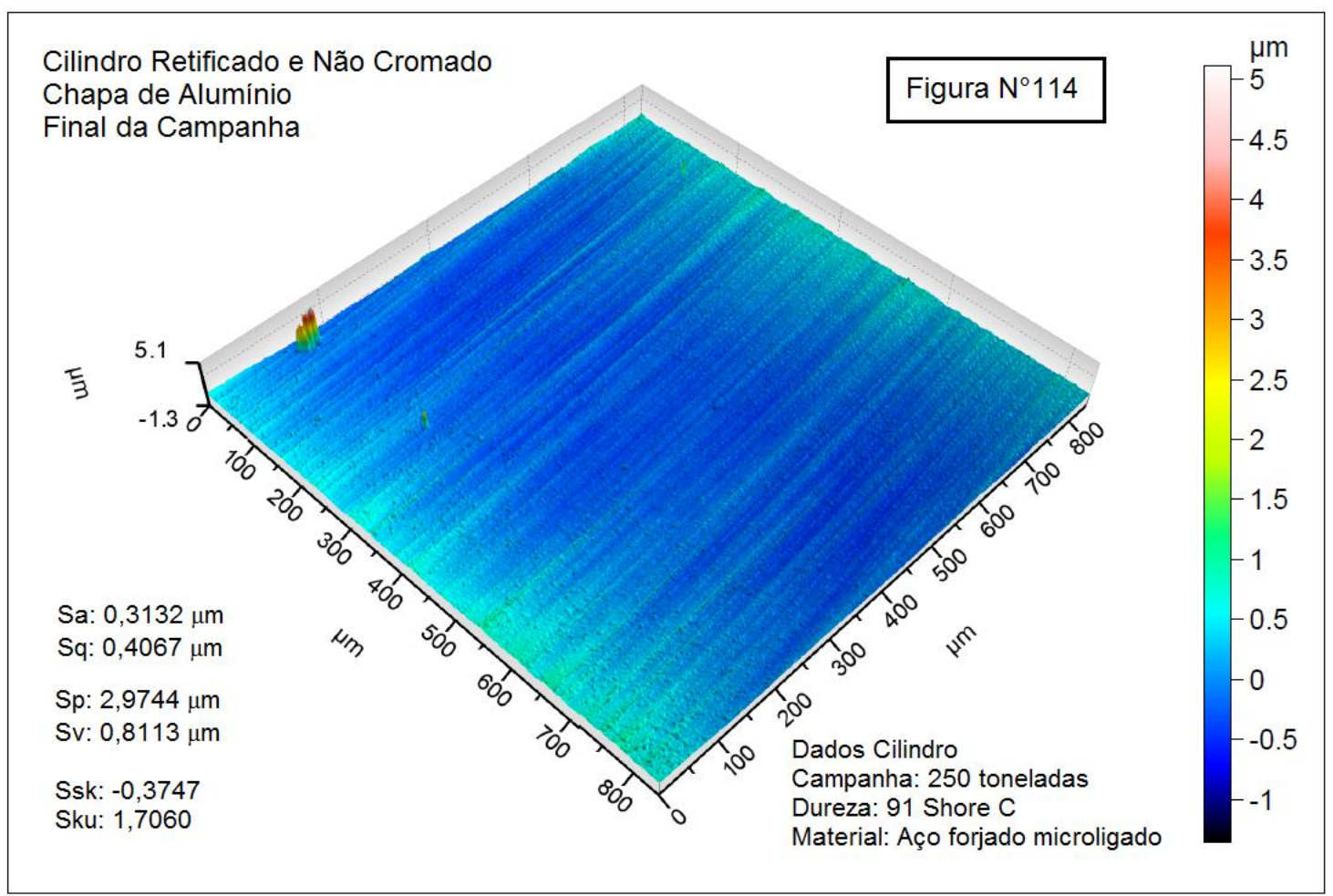

Fonte: (Autor - software CCl)

Tabela 9- 103. Curva Abbott-cilindro retificado não-cromado-chapa alumínio (final)

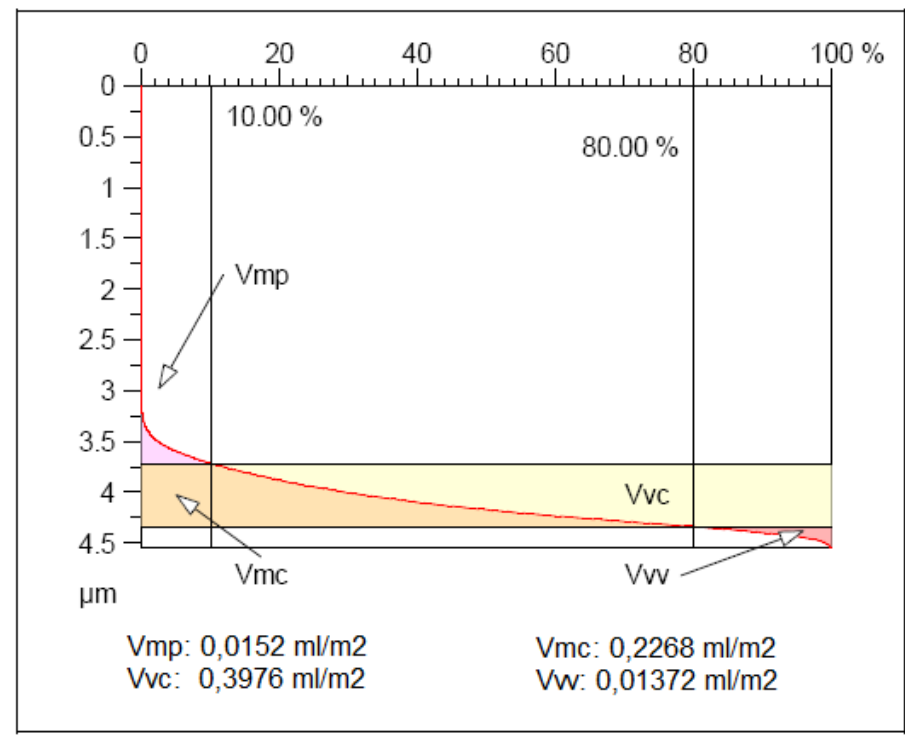

Fonte: (Autor - software CCl)

O resultado das variações dos parâmetros obtidos do interferômetro pode ser verificado na TABELA 9.104, representando a influência positiva do revestimento de cromo (no sentido de aumentar a campanha do cilindro e/ou diminuir o desgaste) aplicado nos cilindros de laminação nos parâmetros de processo. 
Tabela 9- 104. Resultado dos parâmetros de processo - interferômetro

\begin{tabular}{|c|c|c|c|c|c|c|c|c|c|c|}
\hline Jateado e Cromado (aço) & Sa & Sq & Ssk & Sku & Sp & Sv & Vmp & Vmc & Vvc & Vvv \\
\hline Início campanha & 2,14 & 2,74 & 0,15 & 6,84 & 11,04 & 14,86 & 0,39 & 2,27 & 3,69 & 0,36 \\
\hline Final campanha & 1,41 & 1,96 & 0,88 & 4,54 & 3,26 & 4,75 & 0,08 & 1,74 & 2,90 & 0,16 \\
\hline Diferença & 0,34 & 0,28 & $-4,88$ & 0,34 & 0,70 & 0,68 & 0,81 & 0,23 & 0,21 & 0,57 \\
\hline Jateado e Não Cromado (aço) & Sa & Sq & Ssk & Sku & Sp & Sv & Vmp & Vmc & Vvc & Vvv \\
\hline Início campanha & 1,90 & 3,00 & 2,39 & 9,16 & 11,21 & 12,09 & 0,15 & 1,99 & 3,63 & 0,21 \\
\hline Final campanha & 0,65 & 1,47 & 0,47 & 3,36 & 5,55 & 4,03 & 0,05 & 1,19 & 2,41 & 0,12 \\
\hline Diferença & 0,66 & 0,51 & 0,80 & 0,63 & 0,51 & 0,67 & 0,68 & 0,40 & 0,34 & 0,43 \\
\hline Retificado e cromado (aço) & Sa & Sq & Ssk & Sku & Sp & Sv & Vmp & Vmc & Vvc & Vvv \\
\hline Início campanha & 1,39 & 2,59 & $-0,52$ & 6,20 & 7,58 & 9,11 & 0,16 & 1,47 & 2,31 & 0,23 \\
\hline Final campanha & 0,31 & 0,57 & 0,14 & 2,00 & 2,07 & 2,95 & 0,02 & 0,34 & 0,85 & 0,05 \\
\hline Diferença & 0,78 & 0,78 & 1,27 & 0,68 & 0,73 & 0,68 & 0,90 & 0,77 & 0,63 & 0,78 \\
\hline Retificado e Não Cromado (aço) & Sa & Sq & Ssk & Sku & Sp & Sv & Vmp & Vmc & Vvc & Vvv \\
\hline Início campanha & 1,22 & 2,19 & $-0,77$ & 9,86 & 7,44 & 9,66 & 0,12 & 0,84 & 1,27 & 0,15 \\
\hline Final campanha & 0,20 & 0,68 & 0,32 & 2,05 & 2,18 & 2,30 & 0,02 & 0,28 & 0,89 & 0,04 \\
\hline Diferença & 0,84 & 0,69 & 1,42 & 0,79 & 0,71 & 0,76 & 0,85 & 0,67 & 0,30 & 0,76 \\
\hline Texturizado e Cromado (aço) & Sa & Sq & Ssk & Sku & Sp & Sv & Vmp & Vmc & Vvc & Vvv \\
\hline Início campanha & 3,54 & 4,12 & $-0,49$ & 3,41 & 17,50 & 17,59 & 0,14 & 3,35 & 4,15 & 0,50 \\
\hline Final campanha & 1,35 & 2,41 & 0,25 & 0,61 & 6,57 & 6,05 & 0,05 & 0,45 & 5,40 & 0,11 \\
\hline Diferença & 0,62 & 0,41 & 1,51 & 0,82 & 0,62 & 0,66 & 0,68 & 0,86 & $-0,30$ & 0,78 \\
\hline Texturizado e Não Cromado (aço) & Sa & Sq & Ssk & Sku & Sp & Sv & Vmp & Vmc & Vvc & Vvv \\
\hline Início campanha & 2,73 & 3,90 & $-1,56$ & 5,08 & 15,33 & 16,78 & 0,15 & 2,82 & 3,88 & 0,67 \\
\hline Final campanha & 0,67 & 1,05 & 0,76 & 0,61 & 3,53 & 3,35 & 0,05 & 0,38 & 5,59 & 0,10 \\
\hline Diferença & 0,76 & 0,73 & 1,49 & 0,88 & 0,77 & 0,80 & 0,70 & 0,87 & $-0,44$ & 0,85 \\
\hline Retificado e cromado (cobre) & Sa & Sq & Ssk & Sku & Sp & Sv & Vmp & Vmc & Vvc & Vvv \\
\hline Início campanha & 0,92 & 1,78 & 1,34 & 4,54 & 6,02 & 9,59 & 0,08 & 0,76 & 1,27 & 0,11 \\
\hline Final campanha & 0,50 & 0,78 & 1,09 & 2,61 & 2,85 & 2,20 & 0,04 & 0,41 & 1,43 & 0,04 \\
\hline Diferença & 0,46 & 0,56 & 0,19 & 0,43 & 0,53 & 0,77 & 0,53 & 0,46 & $-0,13$ & 0,65 \\
\hline Retificado e não cromado (cobre) & Sa & Sq & Ssk & Sku & Sp & Sv & Vmp & Vmc & Vvc & Vvv \\
\hline Início campanha & 1,58 & 3,20 & $-0,33$ & 4,79 & 8,52 & 8,65 & 0,12 & 0,85 & 1,27 & 0,12 \\
\hline Final campanha & 0,45 & 1,05 & 1,19 & 2,03 & 2,01 & 2,18 & 0,02 & 0,41 & 1,59 & 0,04 \\
\hline Diferença & 0,72 & 0,67 & 4,56 & 0,58 & 0,76 & 0,75 & 0,83 & 0,51 & $-0,25$ & 0,70 \\
\hline Alumínio retificado e cromado & Sa & Sq & Ssk & Sku & Sp & Sv & Vmp & Vmc & Vvc & Vvv \\
\hline Início campanha & 1,15 & 3,43 & $-1,31$ & 4,44 & 10,26 & 13,03 & 0,52 & 1,59 & 2,21 & 0,30 \\
\hline Final campanha & 0,88 & 1,72 & 1,04 & 2,04 & 5,82 & 5,19 & 0,03 & 1,07 & 2,89 & 0,06 \\
\hline Diferença & 0,28 & 0,50 & 1,79 & 0,54 & 0,43 & 0,60 & 0,95 & 0,32 & $-0,31$ & 0,78 \\
\hline Alumínio retificado e não cromado & Sa & Sq & Ssk & Sku & Sp & Sv & Vmp & Vmc & Vvc & Vvv \\
\hline Início campanha & 0,83 & 1,72 & 1,02 & 8,12 & 6,24 & 3,28 & 0,12 & 0,78 & 1,26 & 0,13 \\
\hline Final campanha & 0,40 & 0,70 & $-0,13$ & 1,82 & 2,92 & 0,61 & 0,02 & 0,11 & 0,18 & 0,03 \\
\hline Diferença & 0,51 & 0,59 & 1,13 & 0,78 & 0,53 & 0,81 & 0,80 & 0,86 & 0,86 & 0,74 \\
\hline
\end{tabular}

Fonte: (Autor - software Excel) 


\subsection{Resultados do software estatístico Portal Action}

Resultados obtidos das curvas de regressão linear múltipla, aplicadas nas equações (modelos) das diversas condições de laminação simuladas no processo de laminação.

\subsubsection{Análise de Plot 3D}

A Figura 9.105 abaixo apresenta o mapeamento da posição de cada critério de laminação, a partir das equações de regressão múltipla.

Tabela 9- 105. Posição da campanha de cada critério de laminação

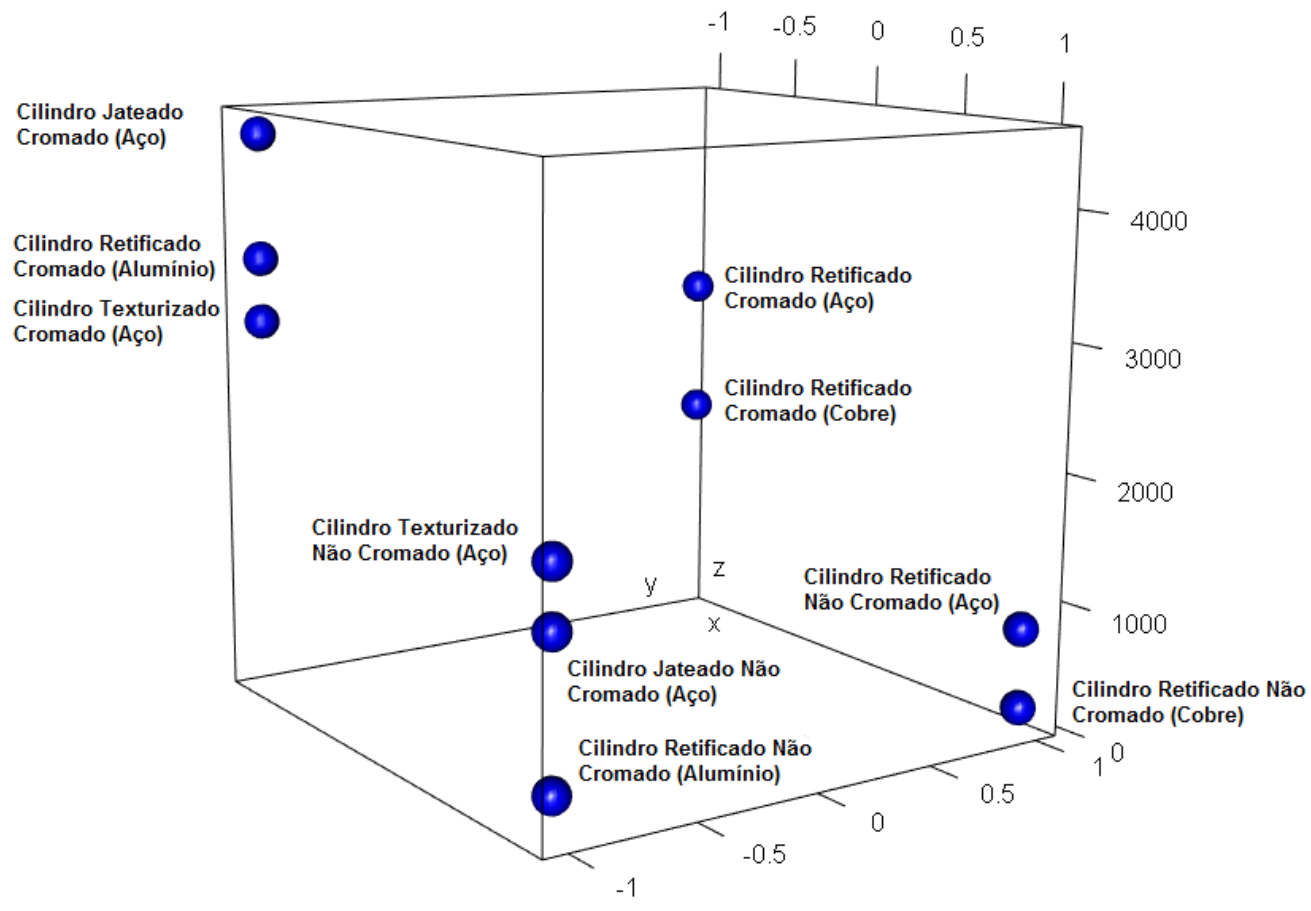

Fonte: (Autor - software portal Action)

\subsubsection{Análise das componentes principais}


Análise das componentes principais para determinação das variáveis significativas.

Tabela 9- 106. Tabela de avaliação dos principais componentes

\begin{tabular}{|ccccccccccc|}
\hline & \multicolumn{10}{c|}{ Importância dos componentes } \\
Informação & Comp.1 & Comp.2 & Comp.3 & Comp.4 & Comp.5 & Comp.6 & Comp.7 & Comp.8 & Comp.9 & Comp.10 \\
\hline Desvio Padrão & 1,99 & 1,53 & 1,26 & 1,04 & 0,85 & 0,48 & 0,29 & 0,10 & 0,06 & 0,00 \\
Proporção da variância & 0,40 & 0,24 & 0,16 & 0,11 & 0,07 & 0,02 & 0,01 & 0,00 & 0,00 & 0,00 \\
Proporção Acumulada & 0,40 & 0,63 & 0,79 & 0,90 & 0,97 & 0,99 & 1,00 & 1,00 & 1,00 & 1,00 \\
\hline
\end{tabular}

Fonte: (Autor - software portal Action)

No Gráfico 9.3 apresenta as principais componentes em função da variância.

Gráfico 9- 1. Análise das principais componentes pela variância

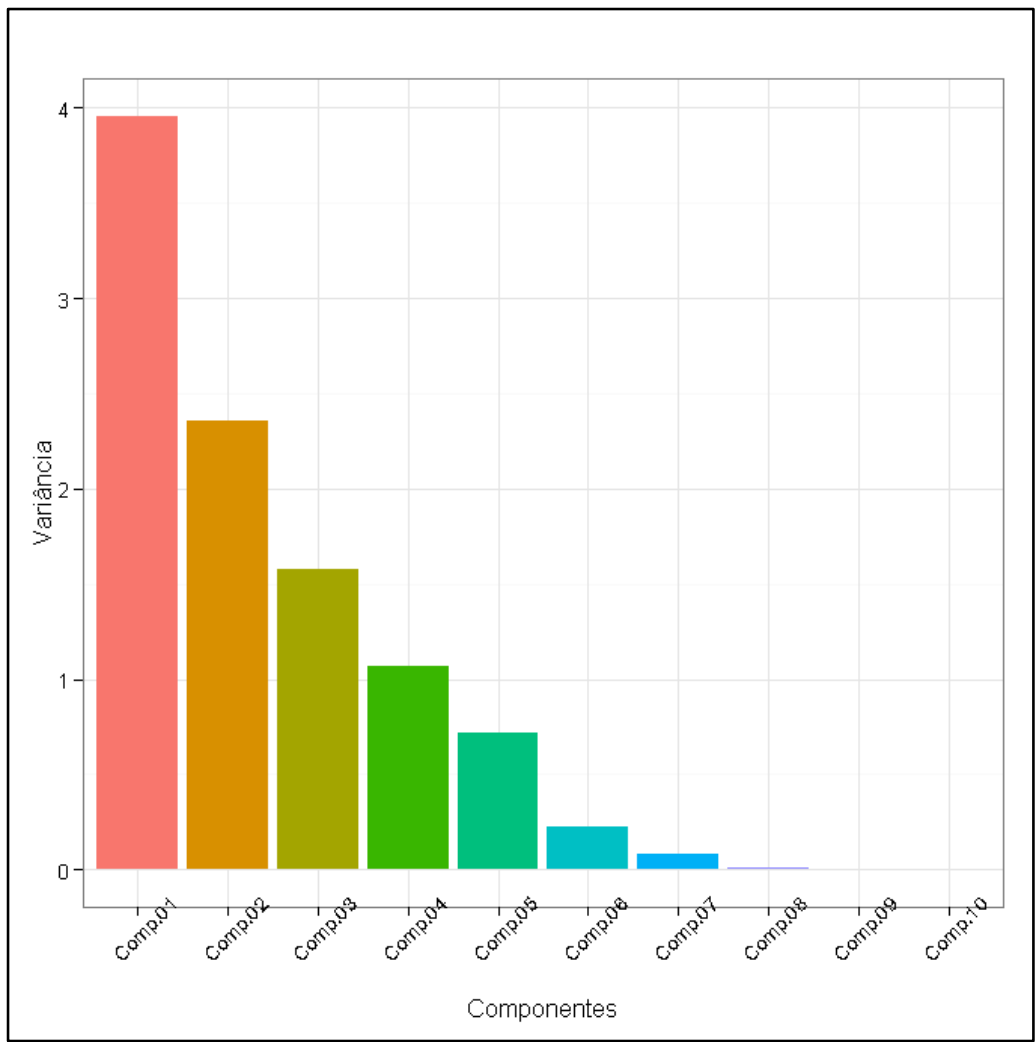

Fonte: (Autor - software portal Action) 
Tabela 9- 107. Matriz de autovetores

\begin{tabular}{|c|c|c|c|c|c|c|c|c|c|c|}
\hline \multicolumn{11}{|c|}{ Autovetores } \\
\hline & Comp.1 & Comp. 2 & Comp.3 & Comp.4 & Comp.5 & Comp. 6 & Comp.7 & Comp.8 & Comp.9 & Comp.10 \\
\hline Sa & 0,43 & $-0,04$ & 0,39 & $-0,05$ & 0,07 & $-0,09$ & $-0,06$ & 0,42 & 0,56 & 0,38 \\
\hline $\mathrm{Sq}$ & $-0,35$ & $-0,33$ & $-0,37$ & $-0,06$ & 0,14 & 0,38 & $-0,27$ & $-0,05$ & 0,13 & 0,61 \\
\hline Ssk & 0,42 & $-0,14$ & $-0,30$ & 0,17 & 0,00 & $-0,42$ & $-0,68$ & $-0,16$ & $-0,11$ & $-0,04$ \\
\hline Sku & $-0,17$ & 0,40 & 0,19 & 0,57 & $-0,37$ & 0,10 & $-0,23$ & 0,28 & $-0,30$ & 0,29 \\
\hline $\mathrm{Sp}$ & 0,33 & $-0,26$ & $-0,05$ & 0,02 & $-0,69$ & 0,51 & 0,00 & $-0,16$ & 0,16 & $-0,18$ \\
\hline Sv & $-0,26$ & $-0,25$ & 0,16 & $-0,53$ & $-0,51$ & $-0,42$ & $-0,07$ & 0,17 & $-0,23$ & 0,18 \\
\hline Vmp & $-0,04$ & 0,52 & $-0,20$ & $-0,50$ & 0,01 & 0,28 & $-0,42$ & 0,33 & 0,09 & $-0,26$ \\
\hline Vmc & 0,06 & 0,49 & $-0,45$ & $-0,03$ & $-0,30$ & $-0,30$ & 0,31 & $-0,28$ & 0,32 & 0,31 \\
\hline Vvc & $-0,40$ & 0,12 & 0,46 & 0,03 & $-0,06$ & $-0,06$ & $-0,36$ & $-0,53$ & 0,44 & $-0,12$ \\
\hline Vvv & $-0,38$ & $-0,24$ & $-0,31$ & 0,33 & $-0,12$ & $-0,22$ & 0,03 & 0,44 & 0,43 & $-0,38$ \\
\hline
\end{tabular}

Tabela 9- 108. Matriz de scores dos critérios de laminação

\begin{tabular}{|c|c|c|c|c|c|c|c|c|c|c|}
\hline \multicolumn{11}{|c|}{ Scores } \\
\hline & Comp.1 & Comp.2 & Comp.3 & Comp.4 & Comp.5 & Comp. 6 & Comp.7 & Comp.8 & Comp.9 & Comp.10 \\
\hline Aço Jateado Cromado & $-0,43$ & 0,96 & 0,88 & $-0,79$ & 0,70 & 0,67 & 0,35 & $-0,15$ & $-0,06$ & 0,00 \\
\hline Aço Jateado Não Cromado & 0,18 & $-0,32$ & 0,15 & 0,07 & 0,67 & $-1,18$ & $-0,12$ & $-0,08$ & $-0,07$ & 0,00 \\
\hline Aço Retificado Cromado & $-1,03$ & $-2,45$ & 1,07 & $-1,26$ & 0,84 & 0,29 & $-0,37$ & 0,09 & 0,02 & 0,00 \\
\hline Aço Retificado Não Cromado & 0,47 & 0,30 & 0,51 & 1,74 & $-0,55$ & 0,38 & $-0,53$ & $-0,11$ & 0,02 & 0,00 \\
\hline Aço Texturizado Cromado & $-0,13$ & 0,86 & 0,92 & 1,65 & 0,30 & 0,11 & 0,21 & 0,19 & $-0,06$ & 0,00 \\
\hline Aço Texturizado Não Cromado & $-0,29$ & 0,06 & 0,70 & 0,43 & 0,44 & $-0,33$ & 0,35 & $-0,02$ & 0,15 & 0,00 \\
\hline Cobre Retificado Cromado & 0,87 & 3,50 & $-0,54$ & $-1,41$ & $-0,21$ & $-0,09$ & $-0,26$ & 0,07 & 0,02 & 0,00 \\
\hline Cobre Retificado Não Cromado & $-0,16$ & $-1,08$ & 0,95 & $-0,72$ & $-2,21$ & $-0,16$ & 0,19 & 0,01 & $-0,02$ & 0,00 \\
\hline Alumínio Retificado Cromado & 4,56 & $-1,47$ & $-1,93$ & 0,01 & 0,16 & 0,22 & 0,13 & 0,01 & 0,00 & 0,00 \\
\hline Alumínio Retificado Não Cromado & $-4,04$ & $-0,35$ & $-2,71$ & 0,27 & $-0,14$ & 0,10 & 0,05 & 0,00 & 0,00 & 0,00 \\
\hline
\end{tabular}


Figura 9- 12. Resultado das componentes principais

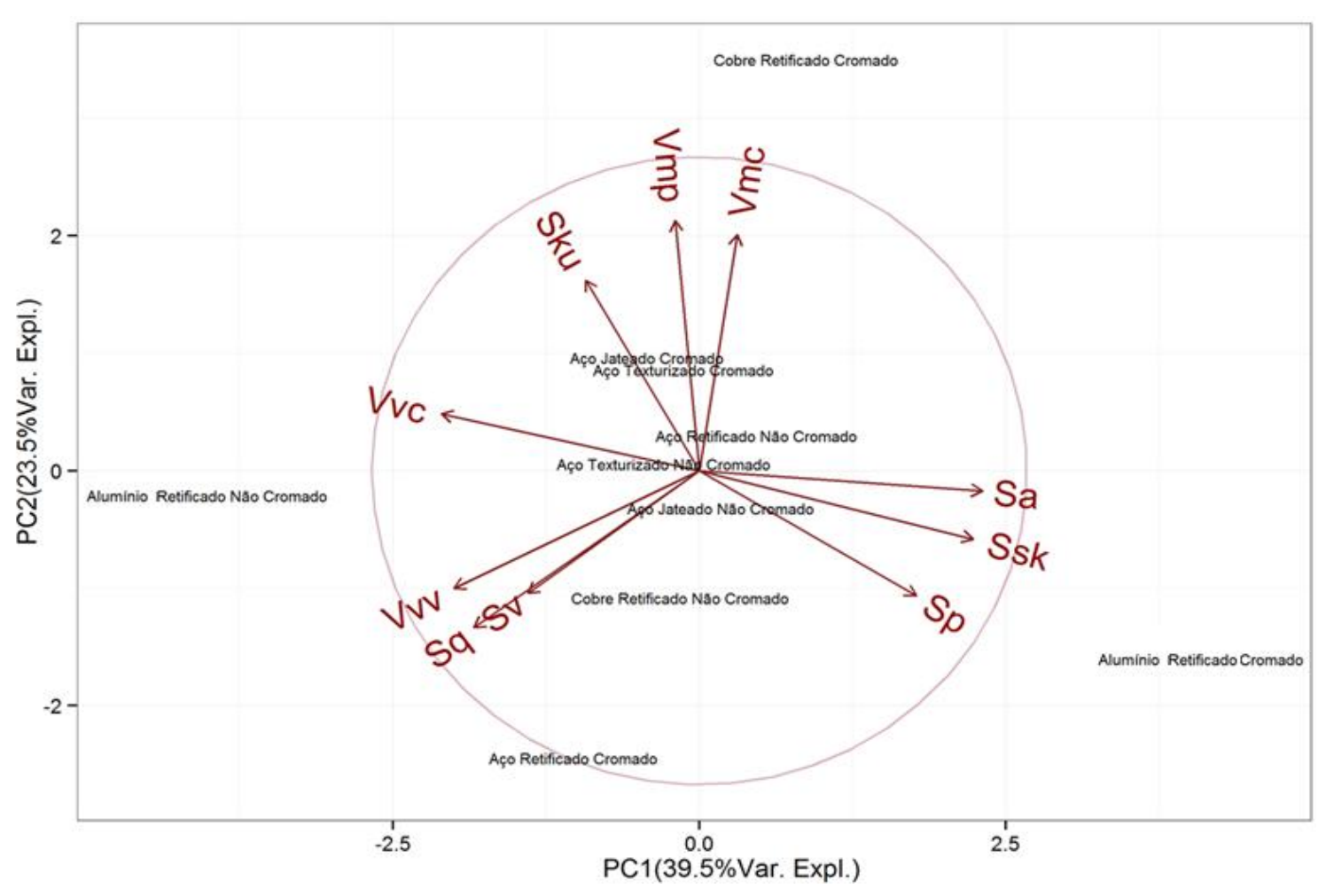

Fonte: (Autor - software portal Action)

A primeira componente principal explica $39,5 \%$ da variação total. As variáveis Sa e Ssk têm pesos positivamente altos na primeira componente principal,0,43 e 0,42 respectivamente; a variável $\mathrm{Sp}$ afeta essa componente com menor intensidade, pois o seu peso é mais baixo, 0,33.

Assim, a primeira componente pode ser interpretada como um índice de desempenho global da campanha do cilindro. Como os pesos são positivos, quanto maior for o Sa e Ssk, maior é o valor dessa componente e melhor é a campanha do cilindro. As campanhas "Alumínio Retificado Cromado", teve o melhor índice de desempenho de campanha, enquanto a pior campanha, que ficou com o pior índice foi o "Alumínio Retificado Não Cromado". 


\subsubsection{Análise de agrupamento - método hierárquico}

Análise de agrupamento utilizando o método hierárquico, variando o número de clusters: 2, 3, 5 e 9, conforme os Dendogramas abaixo:

- Análise com 2 clusters:

\begin{tabular}{|cc|}
\hline \multicolumn{2}{|c|}{ Agrupamento: Método Hierárquico } \\
Grupo 1 & Grupo 2 \\
\hline AC_JCR & CO_RCR \\
AC_JNCR & AL_RCR \\
AC_RCR & \\
AC_RNCR & \\
AC_TCR & \\
AC_TNCR & \\
CO_RNCR & \\
AL_RNCR & \\
\hline
\end{tabular}

Figura 9- 13. Dendograma com 2 clusters

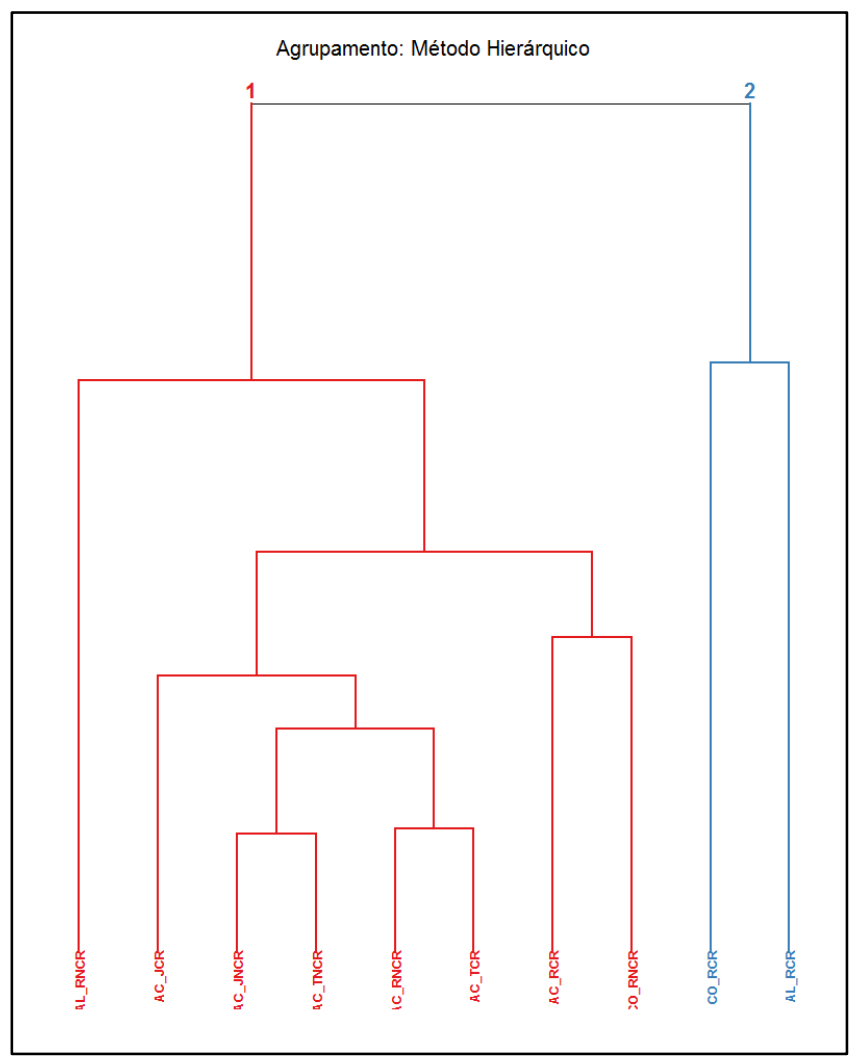

Fonte: (Autor - software portal Action) 
- Análise com 3 clusters:

\begin{tabular}{|cll|}
\hline \multicolumn{3}{|c|}{ Agrupamento: Método Hierárquico } \\
Grupo 1 & Grupo 2 & Grupo 3 \\
\hline AC_JCR & CO_RCR & AL_RCR \\
\hline AC_JNCR & & \\
AC_RCR & \\
AC_RNCR & \\
AC_TCR & \\
AC_TNCR & \\
CO_RNCR & \\
AL_RNCR & \\
\hline
\end{tabular}

Figura 9- 14. Dendograma com 3 clusters

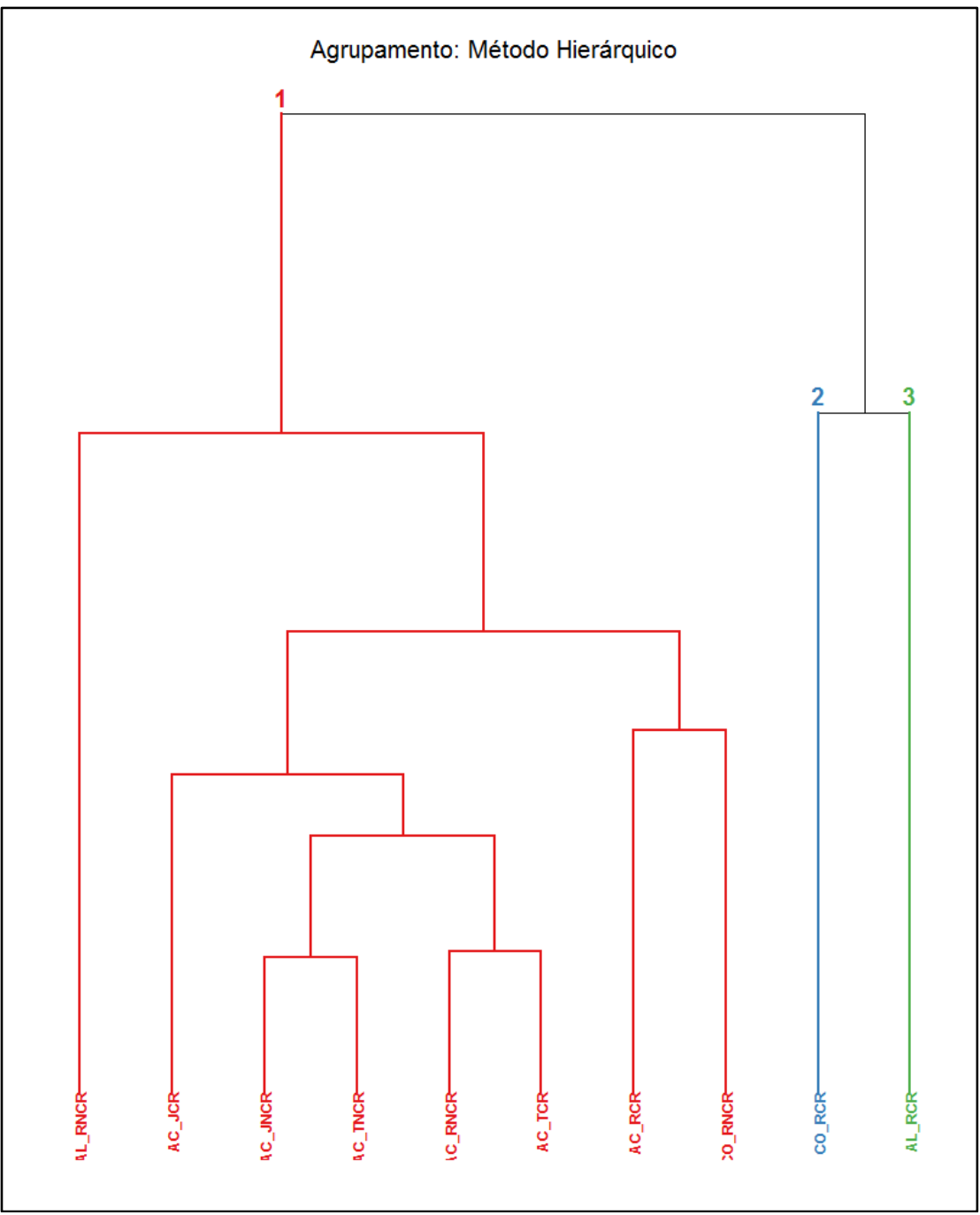

Fonte: (Autor - software portal Action) 
- Análise com 5 clusters:

\begin{tabular}{|ccccc|}
\hline \multicolumn{5}{|c|}{ Agrupamento: Método Hierárquico } \\
Grupo 1 & Grupo 2 & Grupo 3 & Grupo 4 & Grupo 5 \\
\hline AC_JCR & AC_RCR & CO_RCR & AL_RCR & AL_RNCR \\
\hline AC_JNCR & CO_RNCR & & & \\
AC_RNCR & & & & \\
AC_TCR & & & & \\
AC_TNCR & & & & \\
\hline
\end{tabular}

Figura 9- 15. Dendograma com 5 clusters

Agrupamento: Método Hierárquico

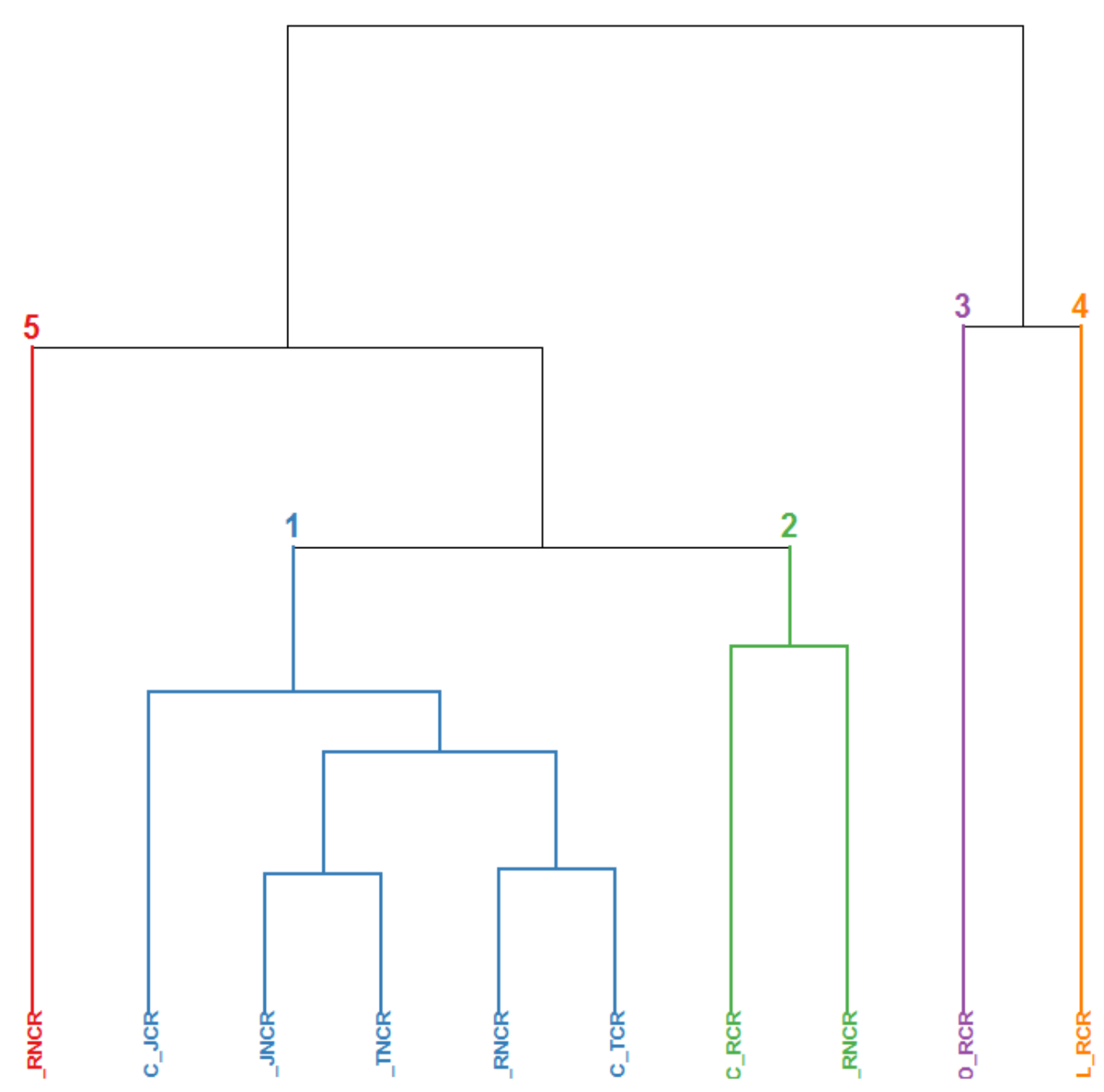

Fonte: (Autor - software portal Action) 
- Análise com 9 clusters:

Agrupamento: Método Hierárquico

\begin{tabular}{|ccccccccc|} 
Grupo 1 & Grupo 2 & Grupo 3 & Grupo 4 & Grupo 5 & Grupo 6 & Grupo 7 & Grupo 8 & Grupo 9 \\
\hline AC_JCR & AC_JNCR & AC_RCR & AC_RNCR & AC_TCR & CO_RCR & CO_RNCR & AL_RCR & AL_RNCR \\
\hline & AC_TNCR & & & & & & & \\
\hline
\end{tabular}

Figura 9- 16. Dendograma com 9 clusters

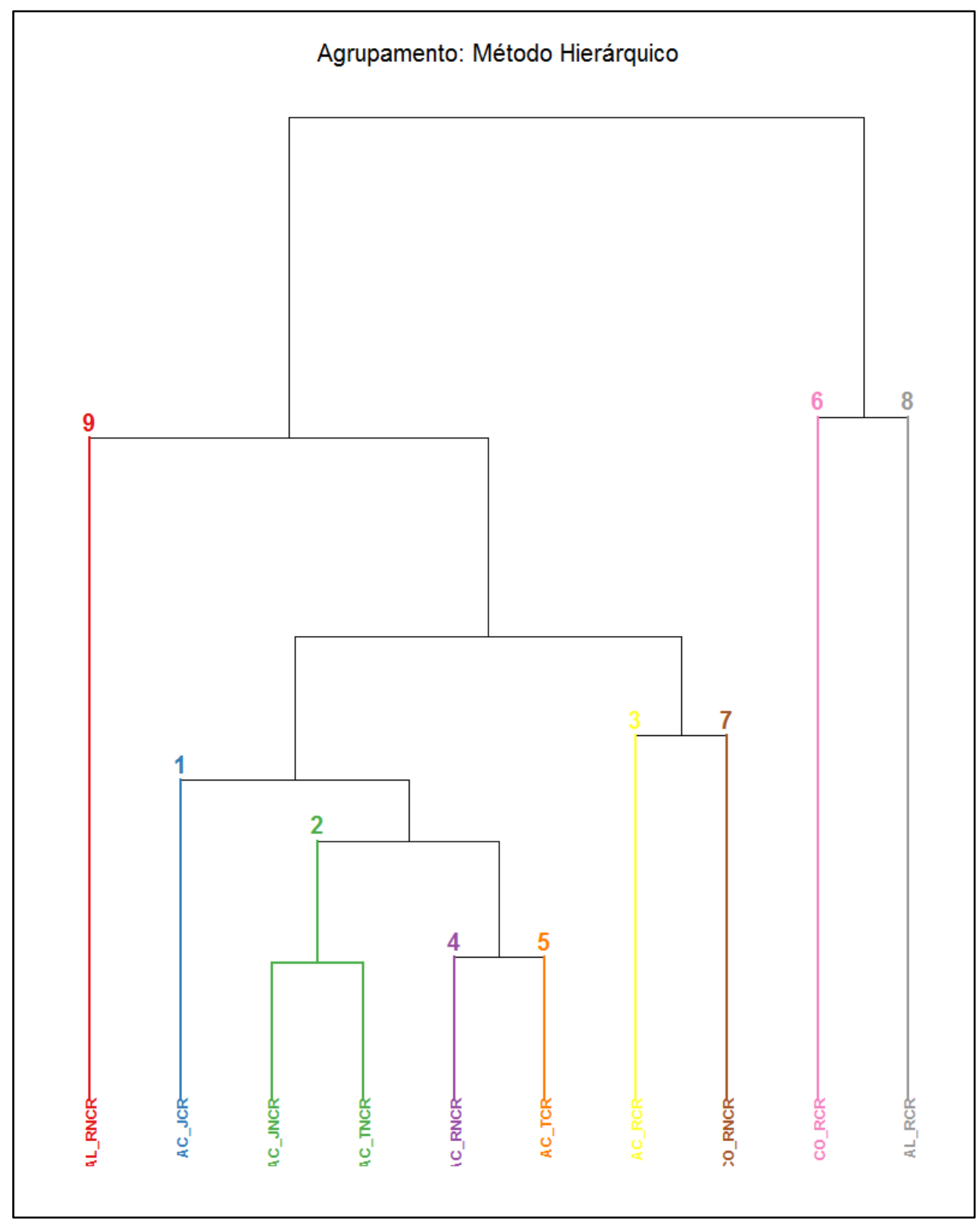

Fonte: (Autor - software portal Action) 


\subsubsection{Análise das interações}

Análise das interações irá determinar o gráfico de interações, que pode ser utilizado quando temos ao menos dois fatores em análise. Estas interações têm como principal função identificar visualmente se os fatores apresentam efeito conjunto ou se são independentes.

Tabela 9- 109. Critérios de seleção das interações

\begin{tabular}{l|c|c|c}
\hline \multicolumn{1}{c|}{ Critérios } & Material & Acabamento & Revestimento \\
\hline Aço Jateado Cromado & AÇO & JAT & CRO \\
\hline Aço Jateado Não Cromado & AÇO & JAT & NCR \\
\hline Aço Retificado Cromado & AÇO & RET & CRO \\
\hline Aço Retificado Não Cromado & AÇO & RET & NCR \\
\hline Aço Texturizado Cromado & AÇO & TEX & CRO \\
\hline Aço Texturizado Não Cromado & AÇO & TEX & NCR \\
\hline Cobre Retificado Cromado & COB & RET & CRO \\
\hline Cobre Retificado Não Cromado & COB & RET & NCR \\
\hline Alumínio Retificado Cromado & ALU & RET & CRO \\
\hline Alumínio Retificado Não Cromado & ALU & RET & NCR \\
\hline
\end{tabular}

Fonte: (Autor - software Excel)

A partir dos critérios estabelecidos para realizar as interações, aplicamos os resultados das equações:

Tabela 9- 110. Resultados das equações de regressão

\begin{tabular}{l|c|c|c|ccc}
\hline \multicolumn{1}{c|}{ Critérios } & Material & Acabamento & Revestimento & Média & Máx. & Mín. \\
\hline Aço Jateado Cromado & AÇO & JAT & CRO & 2369 & 4403 & -2831 \\
\hline Aço Jateado Não Cromado & AÇO & JAT & NCR & 693 & 1419 & 312 \\
\hline Aço Retificado Cromado & AÇO & RET & CRO & 1667 & 2873 & 691 \\
\hline Aço Retificado Não Cromado & AÇO & RET & NCR & 717 & 758 & 664 \\
\hline Aço Texturizado Cromado & AÇO & TEX & CRO & 2557 & 2915 & 3496 \\
\hline Aço Texturizado Não Cromado & AÇO & TEX & NCR & 655 & 2073 & -1644 \\
\hline Cobre Retificado Cromado & COB & RET & CRO & 445 & 1716 & -822 \\
\hline Cobre Retificado Não Cromado & COB & RET & NCR & 76 & 130 & 1 \\
\hline Alumínio Retificado Cromado & ALU & RET & CRO & 1483 & 3420 & -4127 \\
\hline Alumínio Retificado Não Cromado & ALU & RET & NCR & 119 & 268 & 100 \\
\hline
\end{tabular}

Fonte: (Autor - software Excel 
Os Gráficos 9.2 a 9.4 apresentam os resultados das interações dos critérios de laminação em função da campanha de laminação.

Gráfico 9- 2. Interações para máxima campanha dos cilindros

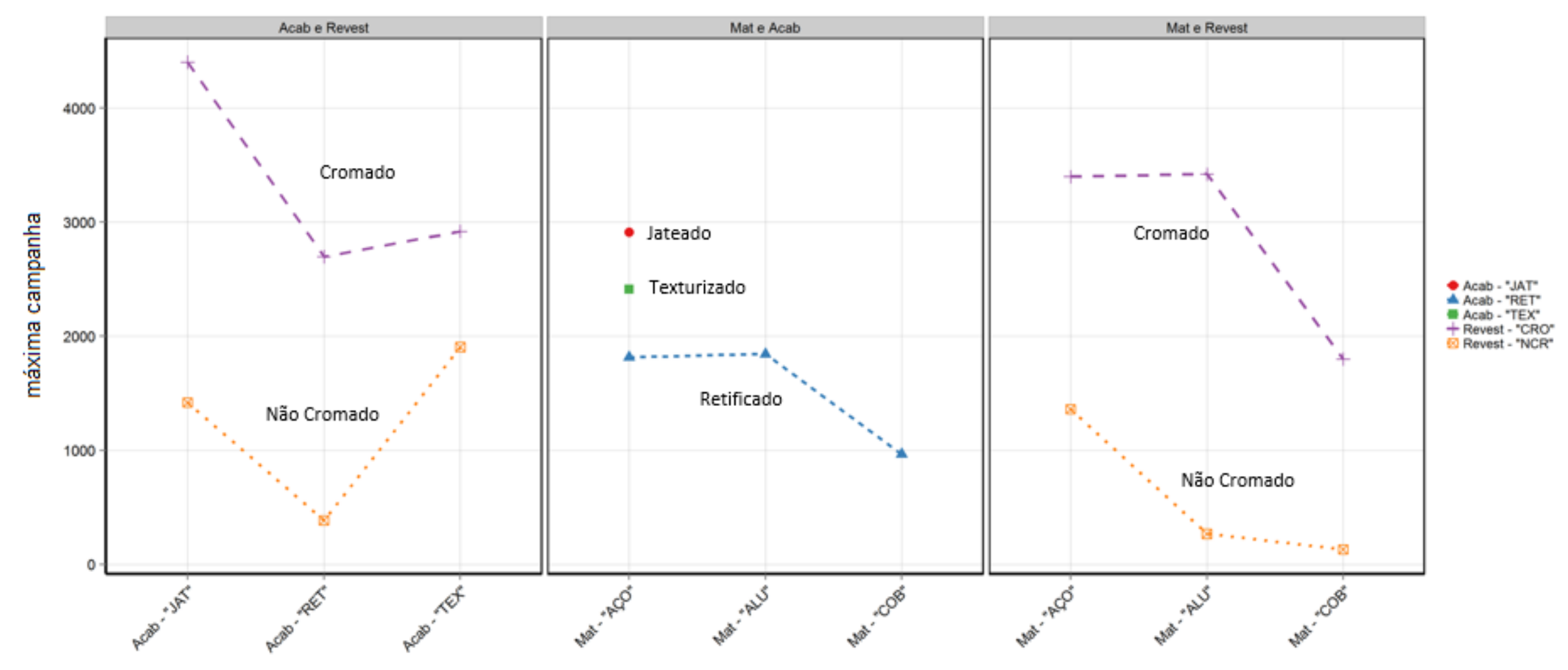

Fonte: (Autor - software portal Action) 
Gráfico 9- 3. Interações para mínima campanha dos cilindros

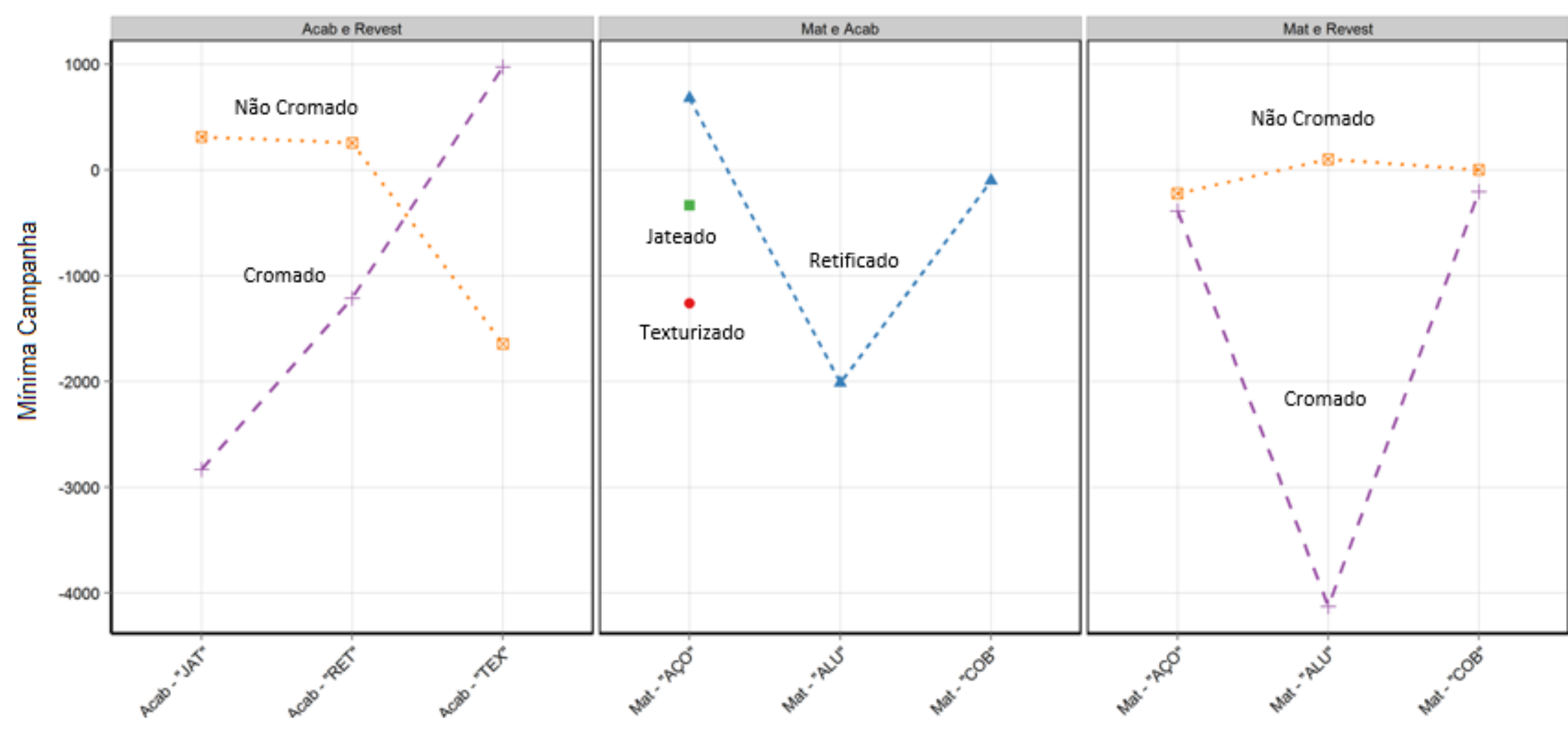

Fonte: (Autor - software portal Action) 
Gráfico 9- 4. Interação para média campanha dos cilindros

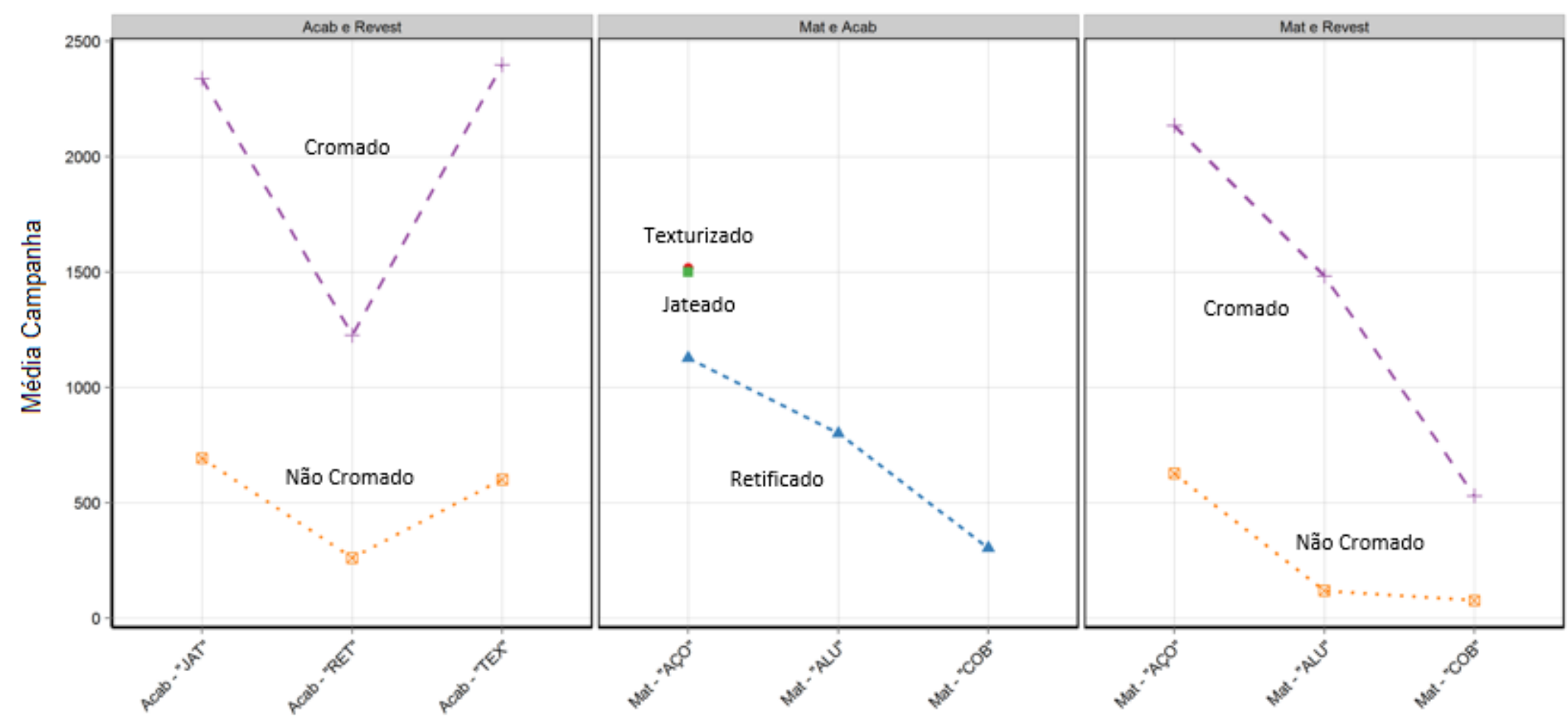

Fonte: (Autor - software portal Action) 


\subsubsection{Análise do gráfico de cubo}

A análise de cubo utiliza o método de um experimento fatorial em que temos a influência de 3 fatores numa determinada variável resposta, e cada fator assume dois níveis. Neste caso, o número de tratamentos que teremos:

- Número de tratamentos: $8\left(2^{3}\right)$

- Variável resposta: Campanha "Máxima" e Campanha "Real"

Tabela 9- 111. Experimento fatorial para máxima campanha do cilindro

\begin{tabular}{l|c|c|c|c}
\hline \multicolumn{1}{c|}{ Critérios } & Material & Acabamento & Revestimento & Máxima \\
\hline Aço Jateado Cromado & AÇO & JAT & CRO & 4403 \\
\hline Aço Jateado Não Cromado & AÇO & JAT & NCR & 1419 \\
\hline Aço Retificado Cromado & AÇO & RET & CRO & 2873 \\
\hline Aço Retificado Não Cromado & AÇO & RET & NCR & 758 \\
\hline Aço Texturizado Cromado & AÇO & TEX & CRO & 2915 \\
\hline Aço Texturizado Não Cromado & AÇO & TEX & NCR & 2073 \\
\hline Cobre Retificado Cromado & COB & RET & CRO & 1716 \\
\hline Cobre Retificado Não Cromado & COB & RET & NCR & 130 \\
\hline Alumínio Retificado Cromado & ALU & RET & CRO & 3420 \\
\hline Alumínio Retificado Não Cromado & ALU & RET & NCR & 268 \\
\hline
\end{tabular}

- Fatores:

Fonte: (Autor - software portal Action)
- A: Tipo Material Chapa (Aço:-1; Cobre: +1)
- B: Tipo Acabamento (Jato: B-1; Ret: B+1)
○ C: Tipo Revestimento (Cromo: C-1; Não Cromo: C+1)

- Tratamentos:

Tabela 9- 112. Análise dos tratamentos

\begin{tabular}{c|c|c|c|c|l}
\hline Tratamento & A & B & C & Y & \multicolumn{1}{|c}{ Rótulo (MÁX) } \\
\hline O & -1 & -1 & -1 & 4403 & Aço jateado cromado \\
\hline A & 1 & -1 & -1 & 4200 & Cobre jateado cromado \\
\hline B & -1 & 1 & -1 & 2873 & Aço retificado cromado \\
\hline AB & 1 & 1 & -1 & 1800 & Cobre retificado cromado \\
\hline C & -1 & -1 & 1 & 1419 & Aço jateado não-cromado \\
\hline AC & 1 & -1 & 1 & 1200 & Cobre jateado não-cromado \\
\hline BC & -1 & 1 & 1 & 758 & Aço retificado não-cromado \\
\hline ABC & 1 & 1 & 1 & 130 & Cobre retificado não-cromado \\
\hline 0 & -1 & -1 & -1 & 4403 & Aço jateado cromado \\
\hline A & 1 & -1 & -1 & 4200 & Cobre jateado cromado \\
\hline B & -1 & 1 & -1 & 2873 & Aço retificado cromado \\
\hline
\end{tabular}




\begin{tabular}{c|c|c|c|c|l}
\hline$A B$ & 1 & 1 & -1 & 1800 & Cobre retificado cromado \\
\hline$C$ & -1 & -1 & 1 & 1419 & Aço jateado não-cromado \\
\hline$A C$ & 1 & -1 & 1 & 1200 & Cobre jateado não-cromado \\
\hline$B C$ & -1 & 1 & 1 & 758 & Aço retificado não-cromado \\
\hline$A B C$ & 1 & 1 & 1 & 130 & Cobre retificado não-cromado \\
\hline
\end{tabular}

Fonte: (Autor - software portal Action)

Figura 9-17. Gráfico de cubo dos materiais aço x cobre (modelo)

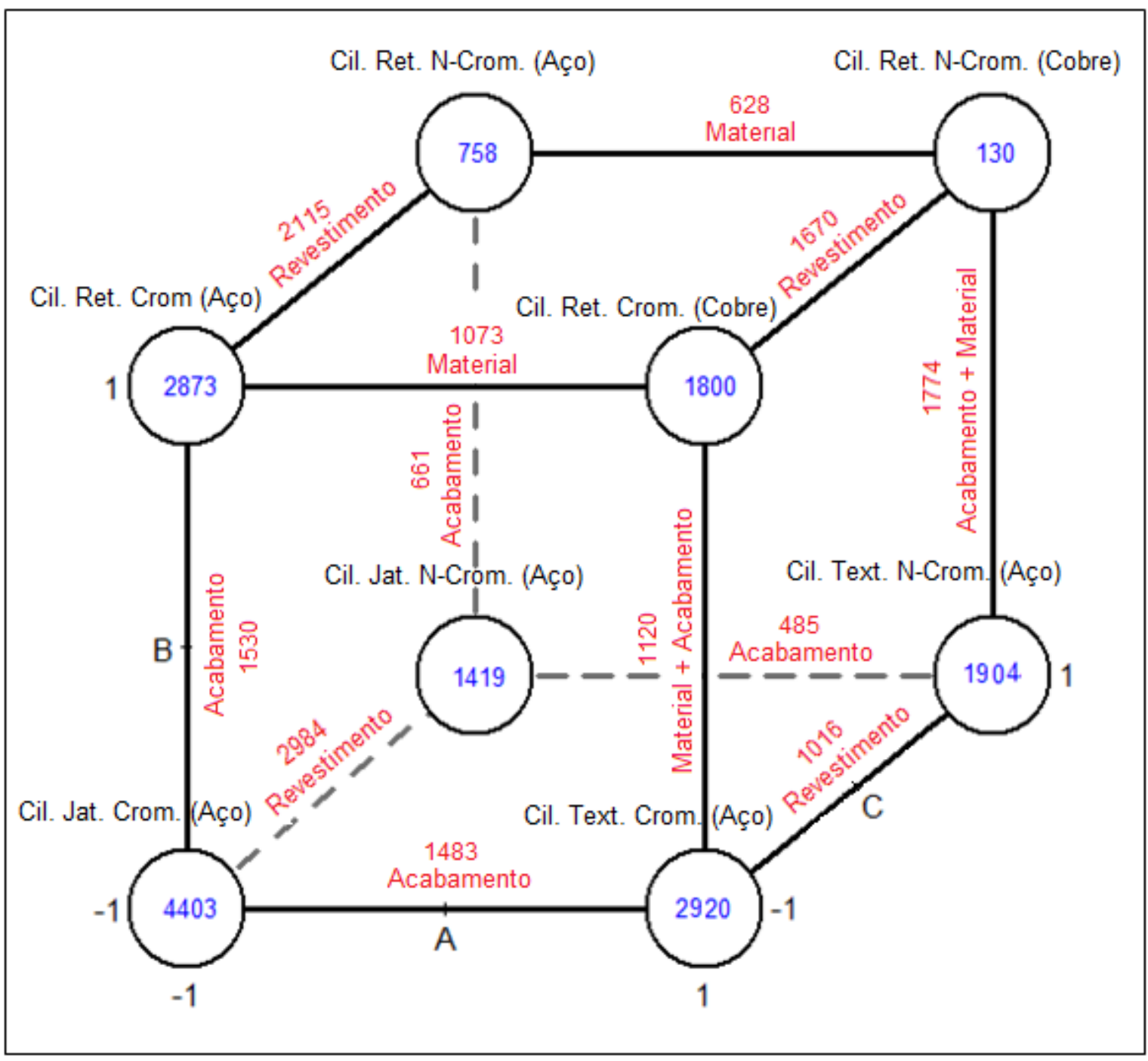

Fonte: (Autor - software portal Action) 
Figura 9- 18. Gráfico de cubo dos materiais aço x cobre (real)

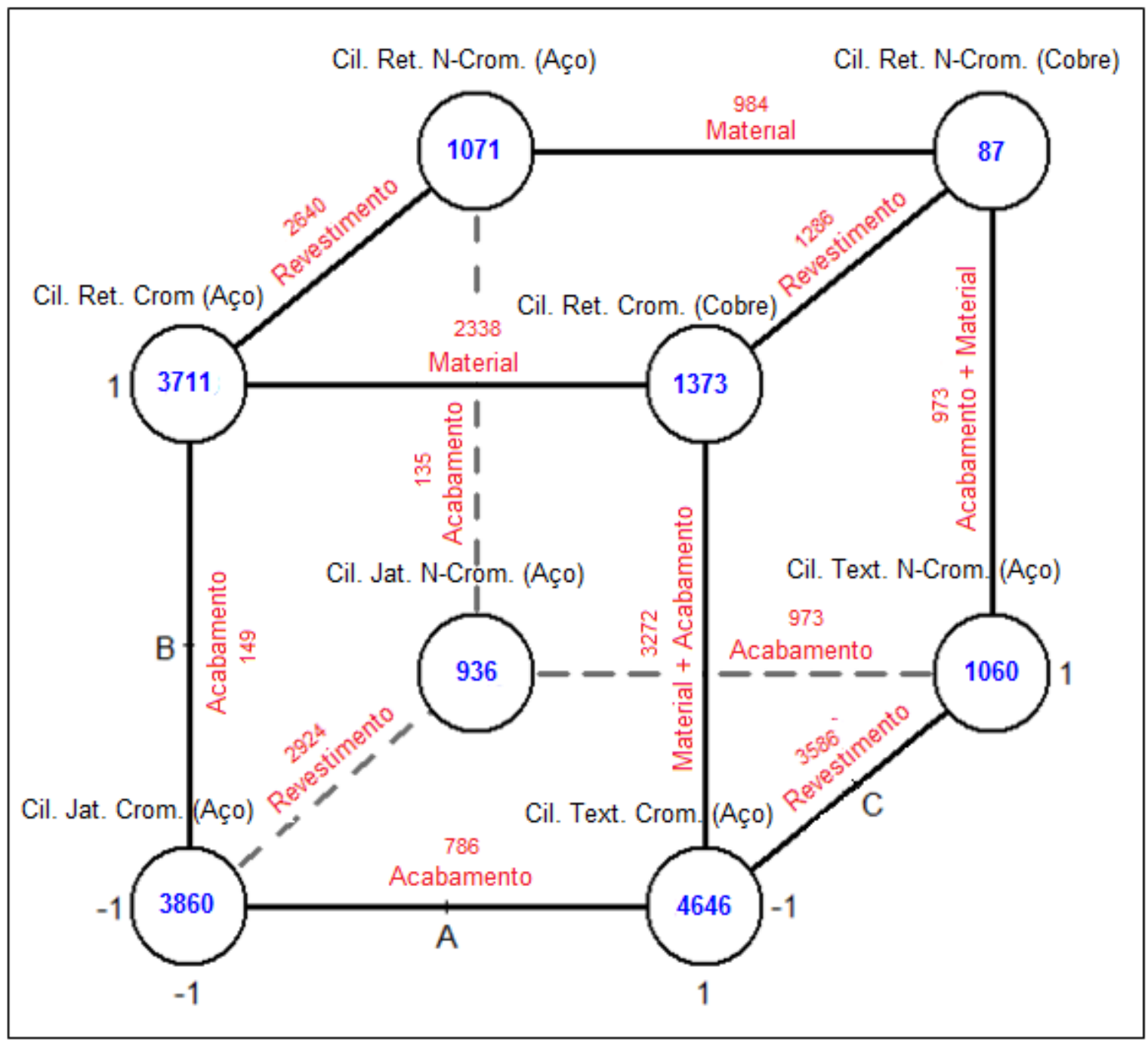

Fonte: (Autor - software portal Action) 
Figura 9- 19. Gráfico de cubo dos materiais aço x alumínio (modelo)

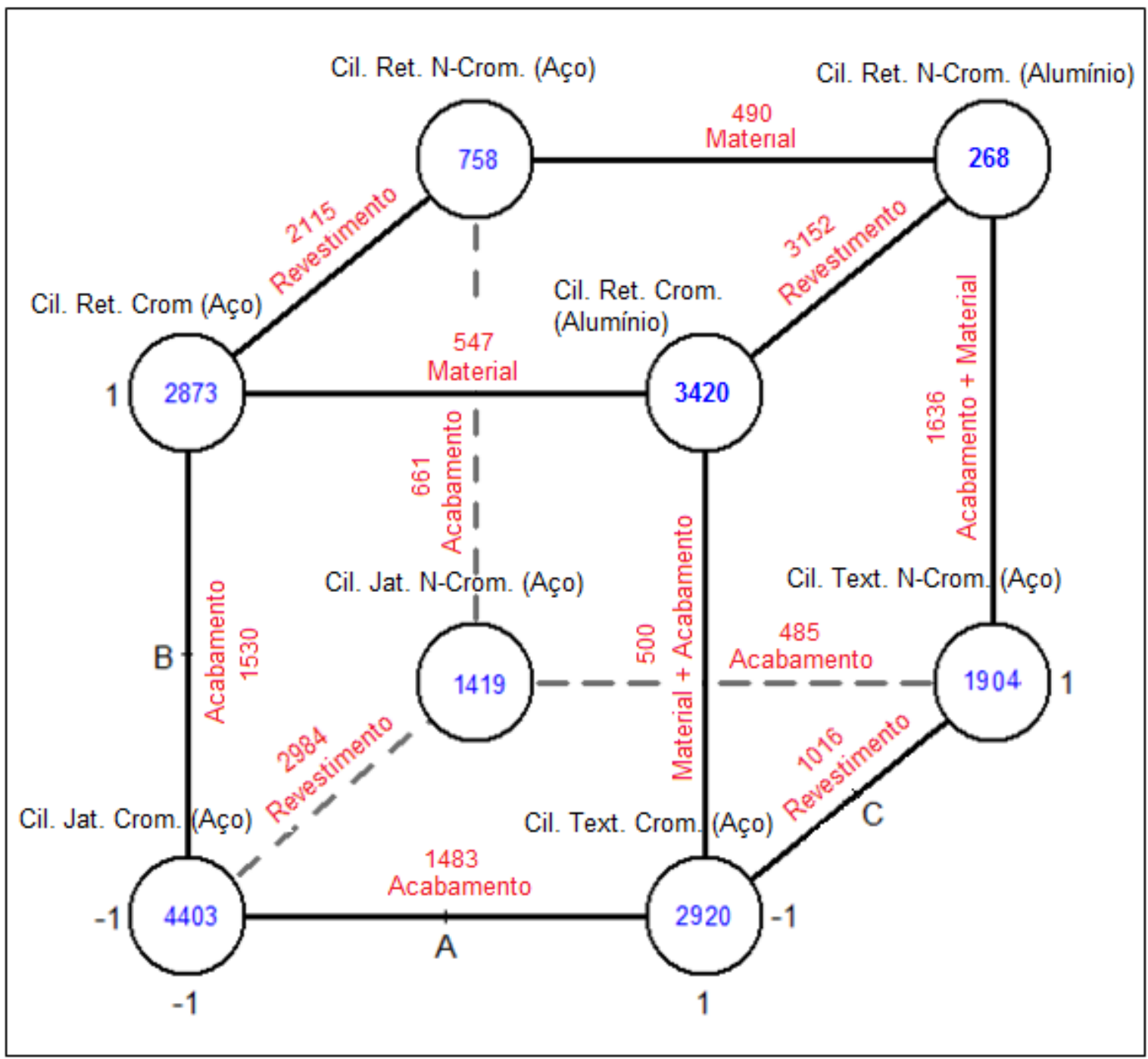

Fonte: (Autor - software portal Action) 
Figura 9- 20. Gráfico de cubo dos materiais aço x alumínio (real)

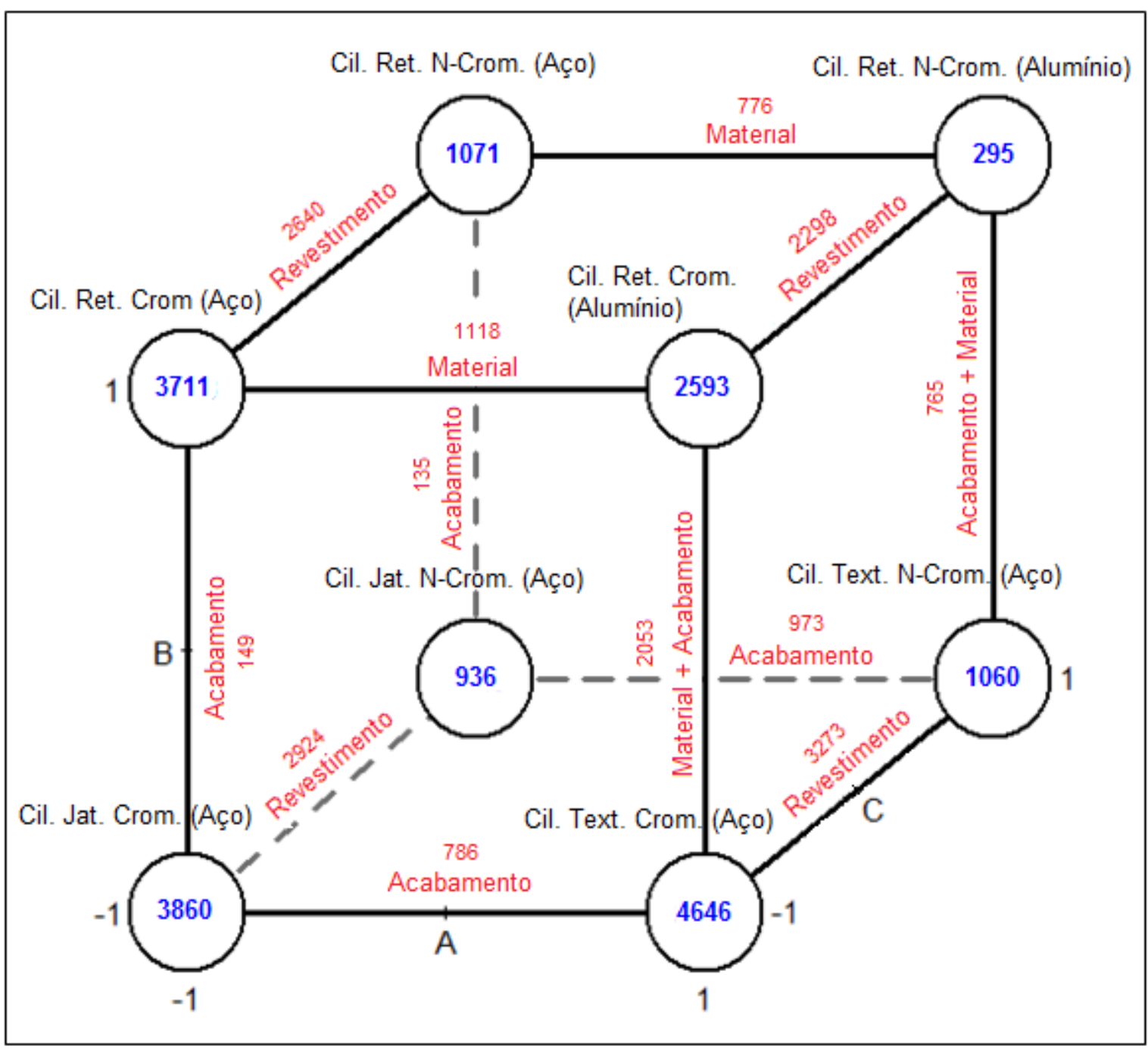

Fonte: (Autor - software portal Action) 


\section{Capítulo 10 - Conclusão}

A pesquisa desenvolvida ao longo deste trabalho buscou oferecer contribuições nas áreas: revestimento de cromo, rugosidade $3 \mathrm{D}$ e ferramentas de análise estatística e métodos de agrupamentos. Mais especificamente, este trabalho mostrou que estas ferramentas constituem recursos poderosos e promissores, quando aplicados ao processamento de materiais via conformação mecânica.

Uma característica importante nesta tese e que deve ser salientada, foi o uso de dados reais de cilindros de laminação com diferentes condições de laminação e em diferentes indústrias e materiais (aço, cobre e alumínio) para avaliar os resultados obtidos com a aplicação das ferramentas. Isto oferece um forte caráter experimental ao trabalho.

\section{0-1. Contribuições}

As conclusões relacionadas com 0 presente trabalho de pesquisa, serão apresentadas conforme sequência, a seguir:

I. Sobre a avaliação da influência do revestimento de cromo em relação à performance dos parâmetros de rugosidade: $S_{q}, S_{a}, S_{s k}, S_{k u}, S_{p}, S_{v}, V_{m p}, V_{m c}$, $v_{v c}, v_{v v}$.

Os resultados deste item I, estão referenciados à TABELA 9.17.

$\mathbf{S}_{\mathrm{a} \text { e }} \mathbf{S}_{\mathrm{q}}$ : Verificado queda da rugosidade aritmética ao longo da campanha tanto do cilindro cromado quanto não cromado, devido o processo natural de desgaste do cilindro. Os cilindros cromados apresentaram maior resistência ao desgaste em relação aos cilindros não cromados em todas as condições de laminação

$\mathbf{S}_{\mathbf{s k}}$ : Perfil da rugosidade em relação ao Skewness, com tendência no início da campanha apresentar o perfil de "pico" em relação ao "vale" e no final da campanha esta relação se inverte, com a maioria das condições de acabamento dos cilindros com perfil de vale. 
$\mathrm{S}_{\mathrm{ku}}$ : Perfil da rugosidade com tendência de picos mais agudos no início da campanha dos cilindros em todas as condições de acabamento e revestimento. $\mathrm{E}$ no final da campanha os cilindros apresentaram em $100 \%$ do material um perfil "achatado", ou seja, curtose < 3. O perfil com maior estabilização geométrica do pico, com tendência de curtose $>3$, foi verificado nos cilindros cromados.

$\mathbf{S}_{\mathrm{p} \text { : }}$ Perfil geométrico dos picos com tendência de picos agudos, sendo mais elevados para cilindros cromados.

$\mathbf{S}_{\mathrm{v}}$ : Comportamento tribológico do vale apresentando melhor performance para os cilindros cromados em todas as condições de laminação.

$\mathbf{V}_{\mathbf{m p}}$ : Menor perda volume e consequente menor perda de rugosidade nos cilindros que utilizaram o cilindro cromado.

$\mathbf{V}_{\mathbf{m c}}$ : Menor redução da estrutura do pico devido menor desgaste influenciado pelo revestimento de cromo.

$\mathbf{V}_{\mathbf{v c}}$ : Menor redução do volume de vazio do núcleo devido estabilização da estrutura do pico no cilindro cromado.

$\mathbf{V}_{\mathbf{v v}}$ : Menor redução do volume de vazio devido estabilização da estrutura do pico no cilindro cromado.

II. Sobre a avaliação da influência do revestimento de cromo em relação aos aspectos de qualidade da chapa, utilizando como referência a performance das variáveis de rugosidade.

Por meio dos modelos regressos enfocando as condições de processo experimentadas, pode-se concluir que o cilindro cromado seja, jateado, retificado ou texturizado para as chapas de aço, cobre ou alumínio, obtiveram os seguintes desempenhos:

- Cilindro retificado e cromado durante a laminação de chapa de aço, aumentou aproximadamente três vezes mais a campanha em relação ao cilindro retificado e não-cromado; 
- Cilindro jateado e cromado durante a laminação de chapa de aço, aumentou aproximadamente quatro vezes mais a campanha em relação ao cilindro jateado e não-cromado;

- Cilindro texturizado e cromado durante a laminação de chapa de aço, aumentou aproximadamente quatro vezes mais a campanha em relação ao cilindro texturizado e não-cromado;

- Cilindro retificado e cromado durante a laminação de chapa de cobre, aumentou aproximadamente quinze vezes mais a campanha em relação ao cilindro retificado e não-cromado;

- Cilindro retificado e cromado durante a laminação de chapa de alumínio, aumentou aproximadamente nove vezes mais a campanha em relação ao cilindro retificado e não-cromado.

III. Sobre a avaliação do mecanismo de agrupamento aplicado pelas ferramentas SPSS e SOM, em função dos parâmetros de rugosidade e condições de processo de laminação.

a) Conclusão com 2 Clusters: caracterizado pela dissimilaridade entre os clusters devido diferença de material (aço, cobre e alumínio).

Cluster 1: chapa aço com tendência de variáveis em níveis alto indicando robustez do pico e vale.

Cluster 2: chapa cobre com tendência variáveis em níveis baixos indicando fragilidade do pico e vale, no entanto consistência da campanha.

b) Conclusão com 3 Clusters: caracterizado pela dissimilaridade entre diferentes materiais (aço e cobre) e diferentes acabamentos (retificado e jateado).

Cluster 1: chapa aço com cilindro retificado com tendência variáveis em níveis elevados indicando robustez do pico e vale 
Cluster 2: chapa aço com cilindro jateado com tendência variáveis em níveis médio indicando menor robustez do pico e vale, no entanto maior consistência da campanha.

Cluster 3: chapa cobre com tendência variáveis em níveis baixos, no entanto Ssk e Sku elevados, caracterizando tendência maior vale que pico, com pico agudo mesmo com a estrutura do pico menor.

c) Conclusão com 5 clusters: caracterizado pela dissimilaridade entre diferentes materiais (aço, cobre e alumínio) e diferença de acabamento (retificado e jateado).

Cluster 1: chapa aço com cilindro jateado, alta campanha influenciado pelo Ssk baixo (tendência maior pico em relação a vale) e alto Sku (pico agudo)

Cluster 2: chapa aço com cilindro retificado, baixa campanha devido ao valor da rugosidade Sa médio e influenciado pela participação dos materiais não revestidos (Revestimento=1,37).

Cluster 3: chapa aço com cilindro retificado, média campanha.

Cluster 4: chapa cobre com tendência variáveis em níveis baixos, no entanto Ssk e Sku elevados caracterizando tendência maior vale que pico, com pico agudo mesmo com a estrutura do pico menor.

Cluster 5: chapa alumínio, baixa campanha influenciado pela baixa rugosidade, Ssk maior vale do que pico, baixa estrutura do pico (Vmp e Vmc)

d) Conclusão com10 Clusters: caracterizado pela dissimilaridade entre diferentes materiais (aço, cobre e alumínio), diferentes tipos de acabamento (retificado e jateado) e diferentes tipos de revestimento (cromado e não-cromado)

Cluster 1: Chapa cobre, campanha alta, revestimento de cromo, Sku alto (pico agudo), estrutura do núcleo e pico médio (Vmc e Vmp). 
Cluster 2: Chapa aço, campanha alta, revestimento de cromo, Ssk baixo (maior pico que vale), estrutura do núcleo e pico médio (Vmc, Vmp).

Cluster 3: Chapa aço, baixa campanha, sem revestimento cromo, com boa performance das variáveis não foi suficiente para garantia de boa performance da campanha.

Cluster 4: chapa cobre, campanha baixa, revestimento de cromo, baixa performance da maioria das variáveis.

Cluster 5: Chapa aço, baixa campanha, revestimento cromo, cilindro jateado, baixa performance.

Cluster 6: Chapa alumínio, sem cromo, retificado, média performance devido Sku alto (pico agudo) e o Ssk com tendência a ter um pico igual ao vale.

Cluster 7: Chapa aço, sem cromo, retificado, baixa performance campanha, com isso baixo Sa e Vmp.

Cluster 8: Chapa aço, cromo, jateado, média performance campanha, devido Sa, Sp Vmc médio

Cluster 9: Chapa aço, sem cromo, jateado, média performance campanha, devido Sp e Sv médio.

Cluster 10: Chapa alumínio, cromado, retificado, baixa performance campanha, devido Sa, Sku médio.

e) Conclusão com 15 Clusters: caracterizado pela dissimilaridade entre diferentes tipos de: materiais (aço, cobre e alumínio), acabamento (retificado e jateado), revestimento (cromado e não-cromado) e campanha (alto, médio e baixo).

Cluster 1: Chapa aço, cromado e retificado, campanha baixa, devido Sa, Sv e Vvv médio.

Cluster 2: Chapa aço, cromado e retificado, campanha baixa, devido Sa médio. 
Cluster 3: Chapa alumínio, cilindro cromado e retificado, campanha alta devido todas as variáveis performance média, exceto Vvc.

Cluster 4: Chapa alumínio, cilindro não-cromado e retificado, campanha baixa devido da maioria das variáveis.

Cluster 5: Chapa alumínio, cilindro cromado e retificado, campanha baixa devido valores baixos da maioria das variáveis.

Cluster 6: Chapa aço, cilindro cromado e jateado, campanha média devido valores médios do Sq, Sa, Sp, Vmc e Vvv.

Cluster 7: Chapa aço, cilindro jateado e cromado, campanha alta.

Cluster 8: Chapa cobre, retificado e cromado, campanha baixa devido maioria dos parâmetros baixo, exceto Ssk e Sku.

Cluster 9: Chapa aço, jateado e cromado, campanha alta devido cromo.

Cluster 10: Chapa aço, jateado e não-cromado, campanha média devido: Sp e Vvc.

Cluster 11: Chapa aço, retificado e não-cromado, campanha baixa devido: Sa, Vmp e Vmc.

Cluster 12: Chapa aço, jateado e cromado, campanha baixa devido maioria das variáveis média, exceto Vmc e Vvc.

Cluster 13: Chapa cobre, retificado e cromado, campanha baixa devido maioria dos parâmetros baixo, exceto Sku.

Cluster 14: Chapa aço, jateado e cromado, campanha alta devido: Vvc (alto).

Cluster 15: Chapa alumínio, retificado e cromado, campanha alta devido: Sku e Vmc. 
IV. Sobre a avaliação da inter-relação dos parâmetros de rugosidade $3 \mathrm{D}$ e aplicações típicas, na busca de limites operacionais do processo de laminação.

Os limites operacionais definidos pelos métodos e ferramentas convencionais, foram ampliadas neste estudo, com os novos métodos e ferramentas, com os seguintes benefícios:

- Constatação da efetiva melhora nos resultados das campanhas dos cilindros de laminação com a utilização do revestimento de cromo.

- O estudo introduziu duas ferramentas de monitoramento do processo de desgaste do cilindro que ajuda na tomada de decisão da troca de cilindros durante o processo de laminação, a saber: o interferômetro, gerando as variáveis Sq, Sa, Ssk, Sku, Sp, Sv, Vmp, Vmc, Vvc e Vvv e o SOM, na geração dos clusters.

- As medições de rugosidade medida em 2D através do rugosimetro convencional com informações somente da superfície do material em análise, foram substituídas pela rugosidade medida em 3D, o que proporcionou uma caracterização adequada da textura e topografia de superfície do material.

- Proposição de uso do SPSS na construção e validação dos clusters, corroborando com o SOM, com resultados melhores e mais consistentes. 


\section{REFERÊNCIAS}

1. AlegRE, E., ALAIZ-RODRÍGUEZ, R., BARREIRO, J., FIDALGO E., FERNÁNDEZ, L.; Surface Finish Control in Machining Processes Using Haralick Descriptors and Neuronal Networks, Computational Modeling of Objects Represented in Images Lecture Notes in Computer Science, vol. 6026, pp. 231-241, 2010.

1. AlVES, W. A. L., ARAUJO, S. A., Avaliação na utilização de dois diferentes modelos de redes neurais na classificação de imagens baseadas em características texturais, Exata, São Paulo, vol. 4, pp. 76-86, 2006.

2. AMERICAN SOCIETY FOR METALS. Handbook, Friction, Lubrication, and Wear Technology, v. 18, 1992.

3. ARAS, N.; OOMMEN, B.J.; ALTINEL, I.K. The Kohonen network incorporating explicit statistics and its application to the travelling salesman problem. Neural Networks no 12, pg.1273-1284, 1999.

4. AVCI, E., An Expert System Based On Wavelet Neural Network-Adaptive Norm Entropy For Scale Invariant Texture Classification, Expert Systems With Applications In Press, Corrected Proof, 2006.

5. AZAMBUJA, S. Estudo e Implementação da Análise de Agrupamento em Ambientes Virtuais de Aprendizagem. 2005. Dissertação (Mestrado em Informática). UFRJ. Orientadores: Cláudia Lage Rebello da Motta e Marcos da Fonseca Elia. Rio de Janeiro, RJ.

6. BASHAR, M. K.; TSUMOTO, T. M.; Y OHNISHI, N. Transform-based locally order less images for texture segmentation. Pattern Recognition Letters, vol. 24, pp. 2633-2650, 2003.

7. BASSAB, W. O.; MIAZAKI, É. S.; ANDRADE, D. F. Introdução à Análise de Agrupamentos. Associação Brasileira de Estatística - ABE. 9ำ Simpósio Nacional de Probabilidade e Estatística. São Paulo - Julho de 1990. 
8. BECH, J.; BAY, N.; ERIKSEN, M. A Study of Mechanisms of Liquid Lubrication in Metal Forming. CIRP Annals - Manufacturing Technology, v. 47, n. 1, p. 221-226, 1998. ISSN 0007-8506.

9. BECKER, E. P.; LUDEMA, K. C. A qualitative empirical model of cylinder bore wear. Wear, v. 225-229, Part 1, p. 387-404, 1999. ISSN 0043-1648. BELIN, M. Triboscopy: A new quantitative tool for microtribology. Wear, v. 168, n. 1-2, p. 7-12, 1993. ISSN 0043-1648.

10. BLUNT, L.; BILLS, P.; JIANG, X.; HARDAKER, C.; CHAKRABARTY, G. The role of tribology and metrology in the latest development of biomaterials. Elsevier, Wear, pp. 424-431, 2009.

11.BLUNT, L.; JIANG, X. Advanced techniques for assessment surface topography development of a basis for the 3D surface texture standards "SURFSTAND". Kogan Page Science, 2003.

12. BODGER, B. E.; MCGRANN, R. T. R.; SOMERVILLE, D. A. The evaluation of tungsten carbide thermal spray coatings as replacements for electrodeposited chrome plating on aircraft landing gear. Plating and Surface Finishing, v. 84, n. 9, p. 28-31, Sep 1997. ISSN 0360-3164.

13.BOLELLI, G.; CANNILLO, V.; LUSVARGHI, L.; RICCÒ, S. Mechanical and tribological properties of electrolytic hard chrome and HVOF-sprayed coatings. Surface and Coatings Technology, v. 200, n. 9, p. 2995-3009, 2006. ISSN 0257-8972. 126

14. BHUSHAN, B. Principles and applications of tribology. John Wiley \& Sons, Inc., New York, 1999.

15.BUSCH, M. L.; BIAUSSER, H.; BIARD, G.; LE BON, A.; GRUMBACH, M. Metallurgical and Mechanical Aspects of Temper Rolling Process. $4^{\text {th }}$ International Steel Rolling Conference - the Science and Technology on Flat Rolling. E: 48.1 -7 p. 1987.

16. CARKACIO-LU, A.; YARMAN-VURAL, F. SASI: A generic texture descriptor for Image Retrieval. Pattern Recognition, vol. 36, pp. 2615-2633, 2003. 
17. CHARALAMPIDIS, D.; KASPARIS, T. Wavelet-Based Rotational Invariant Roughness Features For Texture Classification And Segmentation. Image Processing, IEEE Transactions On, Aug 2002, vol. 11, n. 8, pp. 825- 837, 2002.

18. CHERNOFF, HERMAN. The Use of Faces to Represent Points in kdimensional Space Graphically. Journal of the American Statistical Association (JASA), № 68, pg. 361-368, 1973.

19. CHIU, L. H.; YANG, C. F.; HSIEH, W. C.; CHENG, A. S. Effect of contact pressure on wear resistance of AISI $\mathrm{H13}$ tool steels with chromium nitride and hard chromium coatings. Surface and Coatings Technology, v. 154, n. 23, p. 282-288, 2002. ISSN 0257-8972.

20. CLARK, J. R., GRANT, M. B. The effect of surface finish on component performance. Int. J. Mach. Tools Manufacturing. v. 32, n. 1/2, p. 57-66, 1992.

21. CONCl, A., AZEVEDO, E. e LETA, F. R. Computação Gráfica: Teoria e Prática. Rio de Janeiro: Elsevier, vol. 2, 2008.

22. CORTÊS, P. E. F. Desenvolvimento de acabamento rolled-on em aço inoxidável. 2009. 2009. 108 f. Dissertação de Mestrado - Universidade Federal de Minas Gerais, Belo Horizonte.

23. COSTA, H. L.; HUTCHINGS, I. M. Some innovative surface texturing techniques for tribological purposes. Proceedings of the Institution of Mechanical Engineers, Part J: Journal of Engineering Tribology, v. 229, n. 4, p. 429-448, April 2015.

24. COSTA, JOSÉ ALFREDO FERREIRA. Classificação Automática e Análise de Dados por Redes Neurais Auto-Organizáveis. Tese de Doutorado. Universidade Estadual de Campinas (UNICAMP), Faculdade de Engenharia Elétrica e de Computação, 1999.

25. CUI; P.; LI; J.; PAN Q.; ZHANG, H. Rotation And Scaling Invariant Texture Classification Based On Radon Transform And Multiscale Analysis. Pattern Recognition Letters, vol. 27, n. 5, pp. 408-413, 2006. 
26.DE MELLO, J. D. B.; GONÇALVES JR, J. L.; COSTA, H. L. Influence of surface texturing and hard chromium coating on the wear of steels used in cold rolling mill rolls. https://doi.org/10.1016/j. Wear. 2013.02.006.

27.DHANASEKAR, B.; RAMAMOORTHY, B. Digital speckle interferometry for assessment of surface roughness. Optics and Lasers in Engineering, pp. 272$280,2008$.

28. DIETER, G. E. Mechanical Metallurgy. McGraw Hill Book Company, 1988. p. DONG, W. P.; SULLIVAN, P. J.; STOUT, K. J. Comprehensive study of parameters for characterizing three- dimensional surface

29.DONG, W. P.; SULLIVAN, P.J.; STOUT K.J. Comprehensive study of parameters for characterizing three- dimensional surface topography: Parameters for characterizing amplitude and some functional properties. Wear, v. 178, n. 1-2, p. 29-43, 1994. ISSN 0043- 1648.

30.DUDA, R.O.; HART, P.E.; STORK, D.G. Pattern Classification. $2^{\text {nd }}$ edition. Wiley Interscience, 2000.

31. EL-AMOUSH, A. S.; ABU-ROB, A.; EDWAN, H.; ATRASH, K.; IGAB, M. Tribological properties of hard chromium coated 1010 mild steel under different sliding distances. Solid State Sciences, v. 13, n. 3, p. 529-533, 2011. ISSN 1293-2558.

32. ELKOCA, O. A study on the characteristics of electrical discharge textured skin pass millwork roll. Surface and Coatings Technology, v. 202, n. 12, p. 2765-2774, 2008. ISSN 0257-8972.

33.ERWIN, E.; OBERMAYER, K.; SCHULTEN, K. Self-Organizing Maps: Ordering, Convergence Properties and Energy Functions. Biological Cybernetics 67, pg. 47-55, 1992.

34. EVERITT, BRIAN. Cluster Analysis. $3^{\text {rd }}$ edition. London: Edward Arnold; New York: John Wiley, 1993.

35. EVERITT, B. Cluster Analysis. Heinemann Educational Books, London, 1974. 
36. FAYYAD, USAMA; PIATETSKY-SHAPIRO, GREGORY; SMYTH, PADHRAIC Knowledge Discovery and Data Mining: Towards a Unifying Framework. In: Proceedings of the $2^{\text {nd }}$ International Conference on Knowledge Discovery and Data Mining (KDD-96), AAAI Press, Menlo Park, CA, pg. 82-88, 1996. URL: http://research.microsoft.com. Recuperado 12/07/2000.

37. FAYYAD, USAMA; HAUSSLER, DAVID; STOLORZ, PAUL. Mining Scientific Data. Communications of the ACM, vol. 39, n. ${ }^{-11}$, pg. 51-57, 1996.

38. FLETCHER, D. I.; KAPOOR, A.; STEINHOFF, K.; SCHULEIT, N. Wear behavior and surface form evolution of a novel titanium carbide implanted surface under lubricated conditions. Proceedings of the Institution of Mechanical Engineers, Part J: Journal of Engineering Tribology, v. 214, n. 6, p. 597-610, June 1, 2000.

39.GONZALEZ, R. C., WOODS, R. E. Processamento de Imagens Digitais. Edgard Blueher, São Paulo, 509 p., 1992.

40.GOWER, J.C.; ROSS, G.J.S. Minimum Spanning Trees and single linkage cluster analysis. Applied Statistics no 18, pg 54-64, 1969.

41. HAIR, JR., J. F.; ANDERSON, R.; TATHAM, R. L.; BLACK, W. C. Análise Multivariada de Dados. 5ª Edição. Bookman. 2005. 593p.

42. HALLING, J. Principles of Tribology. The MacMillan Press. Ltda, 1983.

43. HAMMOUCHE, M. D.; POStAIRE, J. G. A Clustering Method Based On Multidimensional Texture Analysis. Pattern Recognition, vol. 39, n. 7, pp. 1265-1277, 2006.

44. HARALICK, R. M.; SHANMUGAN, K. Texture Features for Image Classification. IEEE Transaction On Systems, Man And Cybernetics (SMC-3), vol.6, n. 3, pp. 610-621, 1973.

45. HARALICK, R. M. Statistical and Structural Approaches to Texture. Proceedings of The IEEE, vol.67, n. 5, pp.786-800, 1979. 
46. HILGENBERG, K.; STEINHOFF, K. Texturing of skin-pass rolls by pulsed laser dispersing. Journal of Materials Processing Technology, v. 225, p. 84-92, 2015. ISSN 0924-0136.

47. HOLMBERG, K; KENEETH, H; MATTEWS, S; ALLAN. R.S. Coatings tribology, properties, mechanisms, Techniques and applications in surface engineering. S.I.: Elsevier, 2009.

48. HONKELA, TIMO; KASKI, SAMUEL; LAGUS, KRISTA; KOHONEN, TEUVO. Exploration of Full-Text Databases with Self-Organizing Maps. In: Proceedings of International Conference on Neural Networks (ICNN'96), vol. 1, IEEE Service Center, Piscataway, NJ, pg. 56-61, 1996. URL: http://websom.hut.fi/websom/doc/ps/honkela96.ps.gz.

49. JAIN, A. K. Fundamentals of Image. Prentice-Hall, Inc., NY, USA, 569 p., 1989.

50.JAIN, ANIL K.; MURTY, M.N.; FLYNN, P.J. Data Clustering: A Review. In: ACM Computing Surveys, vol. 31, nº 3, pg. 264-323, 1999.

51.JAIN, ANIL K.; DUBES, R. C. Algorithms for Clustering Data. Prentice-Hall, Englewood Cliffs, NJ, 1988.

52. JIANG, X. Standardization in surface metrology, Scientific Technical Committee "S" (Surface) meeting. International Academy of Production Engineering, 55th General Assembly, Kobe, Japan, 2006.

53. JOHNSON, R. A.; WICHERN, D. W. Applied Multivariate Statistical Analysis. Prentice Hall, New Jersey, USA, 1998, 816p.

54.KASKI, SAMUEL. Data Exploration using Self-Organizing Maps. Acta Polytechnica Scandinavica, Mathematics, Computing and Management in Engineering Series № 82. Dr. Tech Thesis, Helsinki University of Technology, Finland, 1997.

55. KAUFMAN, L., AZARIA, P., J. Finding Groups in Data: an Introduction to Cluster Analysis. $2^{\circ}$ ed., Wiley Interscience, 368, 2002. 
56. KOHONEN, T. Emergence of Invariant-Feature Detectors in the AdaptiveSubspace Self-Organizing Map. Biological Cybernetics 75, pg. 281-291, 1996.

57.KOHONEN, T.; KASKI, S. Self-Organized Formation of Various InvariantFeature Filters in the Adaptive-Subspace SOM. Neural Computation, vol. 9, № 6, pg. 1321-1344, 1997.

58. KOHONEN, T. Self-Organized Formation of Topologically Correct Feature Maps. Biol-Cybern, 43, pp. 59-69, 1982.

59. KUBAT, M. BRATKO, I.; MICHALSKI, R. S. A Review of Machine Learning Methods. In: Michalski, R.S.; Bratko, I.; Kubat, M. (editors) "Machine Learning and Data Mining. Methods and Applications". John Wiley \& Sons, cap. 1, pg. 366, 1998.

60. LEITE, M. V.; SANTOS, M. M. D.; MELLO, J. D. B. D.; LIMA, A. G. D.; RAMOS, G. P.; MACHADO, J. R.; SANTOS, N. L. D.; ROSÁRIO, C. S. D.; OLIVEIRA, A. F. D.; RAMPINELLI, M. E. G.; ROCHA, S. D. S.; FERREIRA, R. L. D. O.; LESSA, R. A. G. Mecanismos de Desgaste de Cilindros de Trabalho dos

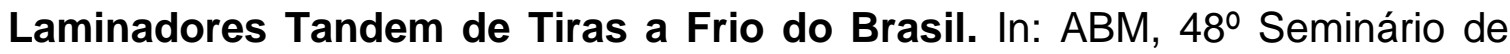
Laminação - Processos e Produtos Laminados e Revestidos, 2011. Santos - SP.

61. LESSMANN, M.; WURTZ, R. P. Image segmentation by a network of cortical macro columns with learned connection weights. IFIP - International Federation for Information Processing. Biologically Inspired Collaborative Computing, vol. 268, pp. 177-186, 2008.

62. LEWIS, D. G. Análise de Variância. São Paulo: Harbra, 1995.

63. LO, S.-W.; HORNG, T. C. Lubricant Permeation From Micro Oil Pits Under Intimate Contact Condition. Journal of Tribology, v. 121, n. 4, p. 633-638, 1999. ISSN 0742-4787.

64. LOURENÇO, A.; MATIAS, R. P. Estatística Multivariada. Instituto Superior de Engenharia do Porto, 2001. 
65. MARTINS, M. P.; GUIMARÃES, L. N. F.; FONSECA, L. M. G. Classificador De Texturas Por Redes Neurais. II Congresso Brasileiro de Computação - CB Comp., 2002.

66. MAROCO, J. Análise Estatística com utilização do SPSS. $1^{a}$ ed., Edições Silabo. Lisboa, 2003.

67.MCQUEEN, J. B. Some Methods for Classification and Analysis of Multivariate Observations. In: Le Cam, L.M. and Neyman, J. (editors) Proceedings of the Fifth Berkeley Symposium on Mathematical Statistics and Probability. University of California Press, vol. I, pg. 281- 297, 1967.

68. MENDES, J. L. T. Influência de Parâmetros Microestruturais no Comportamento Tribológico de Ligas Ferrosas Multicomponentes. 2007. 160 f. Doutorado em Engenharia Mecânica - Universidade Federal de Uberlândia, Uberlândia. Metals Handbook. 8. ASM International, 1973. p. ISBN 0378-3804.

69. MICHALSKI, RYSZARD S.; KAUFMAN, KENNETH A. Data Mining and Knowledge Discovery: A Review of Issues and a Must strategy Approach. In: Michalski, R.S.; Bratko, I.; Kubat, M. (editors) "Machine Learning and Data Mining. Methods and Applications". John Wiley \& Sons, cap. 2, pg. 71-105, 1998.

70. MÜNZENMAYER， C.; WILHARM， S.; HORNEGGER J.; WITTENBERG, T.; Illumination Invariant Color Texture Analysis Based on Sum - and Difference- Histograms, Springer, Lecture. Notes in Computer Science, vol.3663, pp. 17-24, 2005.

71. NEWBY, K. R. In: REIDENBACH, F. (Ed.). ASM Handbook: Surface Engineering. ASM International, v.5, 1994. p. 684-721. ISBN 0-87170-384-X.

72. PALM, C. Color texture classification by integrative co-occurrence matrices. Pattern Recognition, vol. 37, n. 5, pp. 965-976, 2004.

73. PARKER, J., R. Algorithms for Image Processing and Computer Vision. John Wiley and Sons, Toronto, pp. 432, 1997. 
74. PASCHOS, G.; PETROU, M. Histogram ratio features for color texture classification. Pattern Recognition Letters, vol. 24, pp. 309-314, 2003.

75.PAWELSKI, I. O.; RASP, I. W.; ZWICK, W.; NETTELBECK, I. H. J.; STEINHOFF, I. K. The influence of different work-roll texturing systems on the development of surface structure in the temper rolling process of steel sheet used in the automotive industry. Journal of Materials Processing Technology, v. 45, n. 1, p. 215-222, 1994. ISSN 0924-0136.

76. PEDRINI, H.; SCHUWARTZ, W. R. Análise de Imagens Digitais. Princípios, Algoritmos e Aplicações. São Paulo, Ed. Thompson Learning, 2008.

77. PESTANA, M. H.; GAGEIRO, J. N. Análise de Dados para Ciências Sociais: A complementaridade do SPSS. $2^{\mathrm{a}}$ ed., Editora Silabo, Lisboa, 2000.

78. PFESTORF, M.; ENGEL, U.; GEIGER, M. 3D Surface Parameters and their Application on Deterministic Textured Metal Sheets. International Journal of Machine Tools \& Manufacture. v. 38, p. 607-614, 1998.

79. RAMALHO, A.; MIRANDA, J. C. Friction and wear of electroless NiP and NiP + PTFE coatings. Wear, v. 259, n. 7-12, p. 828-834, 2005. ISSN 00431648.

80. RASTOGI, P. K. Digital Speckle Pattern Interferometry and Related Techniques. 384 p., 2000.

81. REINELT, G. TSPLIB - A Travelling Salesman Problem Library. 1991. URL: http://softlib.rice.edu/softlib/tsplib/. Recuperado em 17/07/2000.

82. Ritter, H. (1998). The handbook of brain theory and neural networks. In M. A. Arbib (Ed.), (pp. 846-851). MIT Press.

83. RUSHING, J.; A., RANGANA T.; H., HINKE, T.; H., GRAVES, S. J. Image Segmentation Using Association Rule Features. Image Processing, IEEE Transactions On, vol. 11, n. 5, pp. 558- 567, 2002. 
84. SENGUR, A.; TURKOGLU, I.; Y INCE, M. C. Wavelet packet neural networks for texture classification. Expert Systems with Applications. vol. 32, pp. 527533, 2007.

85. SHARMA, S. Applied Multivariate Techniques. Wiley, New York, 1996.

86. SHIBA, M. H.; SANTOS, R. L.; QUINTANILHA, J. A.; KIM, H. Y. Classificação de imagens de sensoriamento remoto pela aprendizagem por árvore de decisão: uma avaliação de desempenho. Anais XII Simpósio Brasileiro de Sensoriamento Remoto, Goiânia, Brasil, 16-21, INPE, pp. 4319-4326, 2005.

87. SIDOROVA, V. S. Clustering algorithm for texture data from remote sensing, Optoelectronics. Instrumentation and Data Processing, vol. 46, n 5, pp. 435-442, 2010.

88. SILVA, E. D.; FRANÇA, L. P.; NASCIMENTO, M. M. G. S.; ZOPELARO, R. M.; NETO, O. C.; SOARES, R. A. R.; GENESTRA, M. Propostas à Prevenção de Riscos Ambientais relacionados ao Tratamento de Superfície com Cromatos. UniFOA, V. Edição Especial, p. 48-58, Maio 20082008.

89. SIM, D. G.; KIM, H. K. A.; PARK, R. H. Invariant Texture Retrieval Using Modified. Zernike Moments, Mage and Vision Computing, vol. 22, n. 4, pp. 331-342, 2004.

90. SIMÃO, J.; ASPINWALL, D. K. Hard chromium plating of EDT Mill Work Rolls. Journal of Materials Processing Technology, v. 92-93, n. 0, p. 281-287, 1999. ISSN 0924-0136.

91. SIMÃO, J.; ASPINWALL, D. K.; WISE, M. L. H.; EL-MENSHAWY, M. F. Mill roll texturing using EDT. Journal of Materials Processing Technology, v. 45, n. 14, p. 207-214, 1994. ISSN 0924-0136. 129

92. SKLANSKY, J. Image Segmentation and Feature Extraction. IEEE Trans, on Computers, pp. 237-247, 1978.

93. SKLANSKY, J. On the Hough Technique for Curve Detection. IEEE Trans, on Computers, vol. C-27, pp. 923-926, 1978. 
94. SNEATH, P. H. A. Some Statistical Problems in Numerical Taxonomy. The Statistician, Vol. 17, Nr. 1 - 1967 - pp $1-12$ - Blackwell Publishing for the Royal Statistical Society

95. SNEATH, P. H. A.; SOKAL, R. R. Numerical Taxonomy - The Principles and Practice of Numerical Classification. W. H. Freeman and Company - $1973-$ $573 p$.

96. STAEVES, J. Avaliação da topografia de chapas no que diz respeito ao atrito durante a formação. 1998. Palestra sobre a dissertação. Universidade Técnica de Darmstadt. Instituto de Engenharia de Produção e Máquinas de Formação.

97. STEINER, M. T. A. Uma Metodologia para o Reconhecimento de Padrões Multivariados com Resposta Dicotômica. 1995. Tese (Doutorado em Engenharia), UFSC, Florianópolis.

98. STEINHOFF, K.; RASP, W.; PAWELSKI, O. Development of deterministicstochastic surface structures to improve the tribological conditions of sheet forming processes. Journal of Materials Processing Technology, v. 60, n. 1-4, p. 355-361, 1996. ISSN 0924-0136.

99. STOUT, K. Development of Methods for the Characterization of Roughness in Three Dimensions. Penton Press, 2000. p. ISBN 9781857180237.

100.STOUT, K. J.; SULLIVAN, P. J.; DONG, W. P.; MAINSAH, E.; LUO, N.; MATHIA, T.; ZAHYOUANI $H$. The development of methods for the characterization of roughness in three dimensions. Commission of the European Communities, 1993.

101. SUN, D.; YAO, L.; FAN, Q.; ZHANG, J. Research on Service Performances between Different Textured Cold Rolls. AISTech, 2006.

102. TAHERI, R.; OGUOCHA, I. N. A.; YANNACOPOULOS, S. The tribological characteristics of electroless NiP coatings. Wear, v. 249, n. 5-6, p. 389-396, 2001. ISSN 0043-1648. 
103. TAYLOR HOBSON, P. Guide to surface texture parameters. 2000.

104. THOMAS, R. T. Rough surfaces. 2nd edition, Imperial College Press, London, 1999.

105. TUKEY, J. W. Exploratory Data Analysis. Addison-Wesley, Reading, MA, 1977.

106. UNFER, R. K; BRESSAN, J.D. Evolution of Roughness on Straining of Interstitial Free - IF Steel Sheet. Key Engineering Materials, v. 504-506, p. 83-88, 2012. doi:10.4028/www.scientific.net/KEM.504-506.83.

107. UTSCH, M.; VINKE, P. EDT: Roll Texturing Technology as a Base of Modern Surfaces in Automotive Cold Mill Flat Products. Iron \& Steel technology, p. 50, April 2005.

108. VAN HULLE, MARK M. Faithful Representation and Topographic Maps: From Distortion to Information-Based Self-Organization. John Wiley \& Sons, 2000.

109. VESANTO, JUHA; ALHONIEMI, ESA. Clustering of the Self-Organizing Map. IEEE Transactions on Neural Networks, vol. 11, n.ำ 2, pg. 586-600, 2000.

110. WEIDEL, S.; ENGEL, U. Characterization of the flattening behavior of modelled asperities. Wear, v. 266, p. 596-599, 2009.

111. WILSON, R.; SPANN, M. Image Segmentation and Uncertainly. Research Studies Press, 190 p., 1988.

112. XIA, Y.; FENG, D.; ZHAO, R. Morphology-Based Multi-Actual Estimation For Texture Segmentation. Image Processing, IEEE Transactions On, vol. 15, n. 3, pp. 614- 623, 2006.

113. XIE, H. B.; JIANG, Z. Y.; YUEN, W. Y. D. Analysis of friction and surface roughness effects on edge crack evolution of thin strip during cold rolling. Tribology International, v. 44, n. 9, p. 971-979, 2011. ISSN 0301-679 
114. YANG, X; LIU, J. Maximum entropy random fields for texture analysis. Pattern Recognition Letters, vol. 23, pp. 93-101, 2002.

115.ZUM GAHR, K. H.; MATHIEU, M.; BRYLKA, B. Friction control by surface engineering of ceramic sliding pairs in water. Wear, v. 263, n. $7-12$, p. 920929, 2007. ISSN 0043-1648.

\section{APÊNDICE 1: MÉTODOS ALTERNATIVOS DE MEDIÇÃO}

\section{Métodos de não contato}

Esses métodos são caracterizados por não existir o contato com a área de medição, sendo realizados através da incidência de luz sobre a superfície, podendo ser um feixe de luz branca ou um feixe de laser, nestes casos estão incluídos os métodos de medição através dos microscópios, interferômetros, etc.

Os métodos de não contato, por meio dos microscópios permitem uma visão ampliada de uma parte da superfície examinada. Essa imagem possibilita observar o espaçamento e a largura das irregularidades, mas não sua altura o que impossibilitava estabelecer um valor numérico da rugosidade na FIGURA 2-13.

Figura 2-17. Rugosímetro 3D não contato
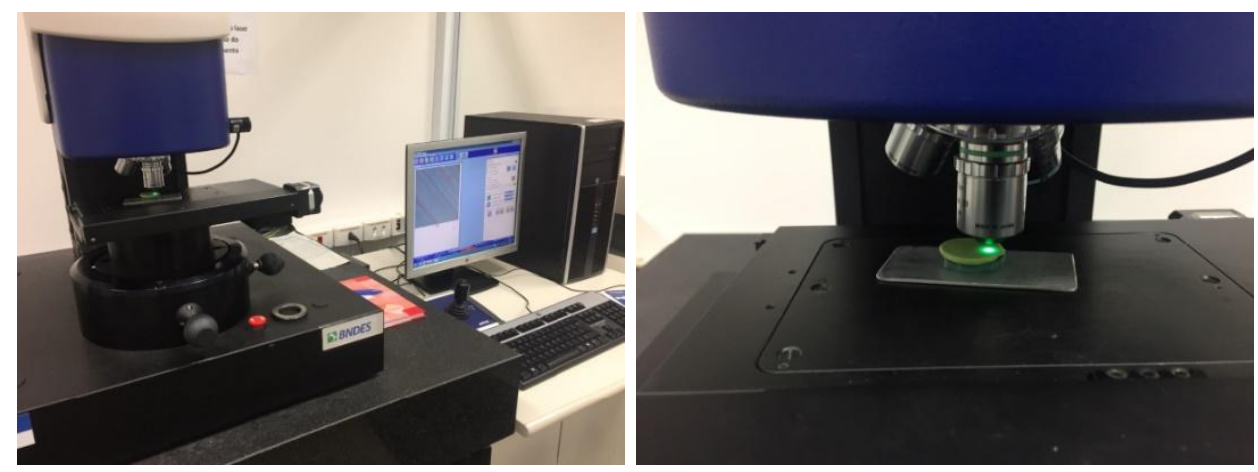

Fonte: (Autor - Equipamento CCl)

Havia, então, a necessidade de observar a superfície sob um corte vertical, para se poder também avaliar a altura das irregularidades. Foram, então, empregados sistemas de corte ótico que consistiam na incidência de uma lâmina de luz, obliquamente à superfície, e cuja reflexão era recebida por uma ocular ou mesmo 282 
uma tela de projeção, como ocorre, por exemplo, em alguns projetores de perfis atuais. Porém, a resolução e a velocidade de obtenção de resultados deste método não são satisfatórias para serem usados em processos industriais. O sistema de medição exige cálculos para a obtenção da rugosidade, tornando o método um dos mais demorados.

Os critérios para obtenção da rugosidade normalizados ou ainda em estudos para normalização são baseados no perfil da superfície. O principal motivo para essa escolha surgiu com a evolução da eletrônica, permitindo a fabricação de aparelhos que, a partir do perfil efetivo, podiam calcular os parâmetros com precisão e indicar rapidamente os seus valores num mostrador de fácil leitura.

Mais no transcorrer desta evolução e da necessidade de utilização de processos automatizados para ensaios mecânicos foi estudado e desenvolvido outro meio ótico que vem sendo muito utilizado que utiliza técnicas interferométricas. Comumente empregadas em mecânica, materiais, metalurgia, etc. Elas têm como principais qualidades, o fato de serem não destrutivas e de não contato. O princípio de interferência da luz permitiu observar e medir o espaçamento e a altura das irregularidades com exatidão. 


\section{APÊNDICE 2: BANCO DE DADOS ORIGINAL}

Mat $=$ material

Camp = campanha

Rev $=$ Revisão

$\mathrm{ACA}=$ Acabamento

Pos $=$ Posição

\begin{tabular}{|c|c|c|c|c|c|c|c|c|c|c|c|c|c|c|c|c|c|}
\hline Réplica & $\mathrm{Sq}$ & Sa & Ssk & Sku & $S p$ & Sv & $\mathrm{Sz}$ & $\begin{array}{c}\mathrm{Vm} \\
\mathrm{p}\end{array}$ & $\begin{array}{c}\mathrm{Vm} \\
\mathrm{c}\end{array}$ & Vv & Vvc & Vvv & $\begin{array}{c}\mathrm{Ma} \\
\mathrm{t}\end{array}$ & Camp & $\begin{array}{l}\operatorname{Re} \\
\mathrm{v}\end{array}$ & $\begin{array}{c}\mathrm{Ac} \\
\mathrm{a}\end{array}$ & $\begin{array}{c}\text { Po } \\
\text { S }\end{array}$ \\
\hline 1 & 1,02 & $\begin{array}{c}0,7 \\
6\end{array}$ & 1,60 & 6,45 & 9,24 & 9,67 & 18,92 & 0,09 & 0,75 & $\begin{array}{c}1,4 \\
6\end{array}$ & $\begin{array}{c}1,3 \\
9\end{array}$ & $\begin{array}{c}0,0 \\
7\end{array}$ & 2 & 0 & 1 & 2 & 1 \\
\hline 2 & 0,94 & $\begin{array}{c}0,7 \\
2\end{array}$ & 0,01 & 3,84 & 5,02 & 3,49 & 8,51 & 0,05 & 0,77 & $\begin{array}{c}1,1 \\
9\end{array}$ & $\begin{array}{c}1,0 \\
8\end{array}$ & $\begin{array}{c}0,1 \\
1\end{array}$ & 2 & 42 & 2 & 2 & 2 \\
\hline 3 & 2,66 & $\begin{array}{c}1,9 \\
6\end{array}$ & 0,56 & 6,26 & 11,95 & 18,86 & 30,81 & 0,14 & 2,01 & $\begin{array}{c}3,3 \\
2\end{array}$ & $\begin{array}{c}2,9 \\
6\end{array}$ & $\begin{array}{c}0,3 \\
6\end{array}$ & 1 & 14 & 1 & 1 & 1 \\
\hline 4 & 2,77 & $\begin{array}{c}2,0 \\
0\end{array}$ & 1,49 & 5,92 & 10,24 & 24,22 & 34,46 & 0,11 & 2,10 & $\begin{array}{c}3,2 \\
0\end{array}$ & $\begin{array}{c}2,8 \\
0\end{array}$ & $\begin{array}{c}0,4 \\
0\end{array}$ & 1 & 10 & 1 & 1 & 2 \\
\hline 5 & 2,49 & $\begin{array}{c}1,8 \\
6\end{array}$ & 0,18 & 4,77 & 12,25 & 9,61 & 21,86 & 0,16 & 1,93 & $\begin{array}{c}3,2 \\
7\end{array}$ & $\begin{array}{c}2,9 \\
9\end{array}$ & $\begin{array}{c}0,2 \\
8\end{array}$ & 1 & 30 & 1 & 1 & 1 \\
\hline 6 & 0,64 & $\begin{array}{c}0,4 \\
9\end{array}$ & 1,58 & 4,84 & 9,10 & 8,34 & 17,44 & 0,05 & 0,54 & $\begin{array}{c}0,9 \\
3\end{array}$ & $\begin{array}{c}0,8 \\
8\end{array}$ & $\begin{array}{c}0,0 \\
4 \\
\end{array}$ & 2 & 10 & 1 & 2 & 1 \\
\hline 7 & 0,66 & $\begin{array}{c}0,5 \\
2\end{array}$ & 1,08 & 5,06 & 8,88 & 9,00 & 17,88 & 0,04 & 0,57 & $\begin{array}{c}0,9 \\
3\end{array}$ & $\begin{array}{c}0,8 \\
8\end{array}$ & $\begin{array}{c}0,0 \\
5\end{array}$ & 2 & 14 & 1 & 2 & 1 \\
\hline 8 & 0,42 & $\begin{array}{c}0,3 \\
2\end{array}$ & 1,01 & 3,79 & 10,93 & 11,57 & 22,50 & 0,02 & 0,36 & $\begin{array}{c}0,5 \\
0\end{array}$ & $\begin{array}{c}0,4 \\
6\end{array}$ & $\begin{array}{c}0,0 \\
4\end{array}$ & 3 & 0 & 1 & 2 & 1 \\
\hline 9 & 0,79 & $\begin{array}{c}0,4 \\
5\end{array}$ & 0,66 & 3,56 & 8,02 & 7,32 & 15,34 & 0,01 & 0,42 & $\begin{array}{c}0,7 \\
1\end{array}$ & $\begin{array}{c}0,6 \\
7\end{array}$ & $\begin{array}{c}0,0 \\
5\end{array}$ & 3 & 50 & 1 & 2 & 2 \\
\hline 10 & 0,99 & $\begin{array}{c}0,7 \\
0\end{array}$ & 0,10 & 9,19 & 8,95 & 8,22 & 17,17 & 0,08 & 0,72 & $\begin{array}{c}1,1 \\
4\end{array}$ & $\begin{array}{c}1,0 \\
3\end{array}$ & $\begin{array}{c}0,1 \\
1\end{array}$ & 2 & 50 & 1 & 2 & 1 \\
\hline 11 & 3,00 & $\begin{array}{c}2,5 \\
0\end{array}$ & 1,33 & 4,55 & 13,96 & 8,56 & 22,52 & 0,15 & 2,98 & $\begin{array}{c}4,1 \\
3\end{array}$ & $\begin{array}{c}3,9 \\
3\end{array}$ & $\begin{array}{c}0,2 \\
0\end{array}$ & 1 & 0 & 1 & 1 & 2 \\
\hline 12 & 2,51 & $\begin{array}{c}2,0 \\
1\end{array}$ & 0,60 & 5,02 & 23,37 & 12,78 & 36,15 & 0,14 & 2,33 & $\begin{array}{c}3,3 \\
9\end{array}$ & $\begin{array}{c}3,1 \\
7\end{array}$ & $\begin{array}{c}0,2 \\
1\end{array}$ & 1 & 20 & 1 & 1 & 1 \\
\hline 13 & 0,97 & $\begin{array}{c}0,7 \\
5\end{array}$ & 0,74 & 6,41 & 4,48 & 5,86 & 10,34 & 0,05 & 0,82 & $\begin{array}{c}1,3 \\
9\end{array}$ & $\begin{array}{c}1,3 \\
0\end{array}$ & $\begin{array}{c}0,0 \\
9\end{array}$ & 2 & 50 & 1 & 2 & 2 \\
\hline 14 & 0,87 & $\begin{array}{c}0,6 \\
5\end{array}$ & 1,57 & 5,99 & 7,48 & 10,01 & 17,49 & 0,07 & 0,67 & $\begin{array}{c}1,2 \\
3\end{array}$ & $\begin{array}{c}1,1 \\
5\end{array}$ & $\begin{array}{c}0,0 \\
8\end{array}$ & 2 & 17 & 1 & 2 & 1 \\
\hline 15 & 1,16 & $\begin{array}{c}0,8 \\
0\end{array}$ & 0,67 & 3,59 & 5,42 & 2,28 & 7,70 & 0,09 & 0,79 & $\begin{array}{c}1,4 \\
6\end{array}$ & $\begin{array}{c}1,3 \\
5\end{array}$ & $\begin{array}{c}0,1 \\
1\end{array}$ & 2 & 54 & 1 & 2 & 2 \\
\hline 16 & 0,86 & $\begin{array}{c}0,6 \\
4\end{array}$ & 1,13 & 5,09 & 5,24 & 12,41 & 17,65 & 0,07 & 0,66 & $\begin{array}{c}1,0 \\
8\end{array}$ & $\begin{array}{c}1,0 \\
0\end{array}$ & $\begin{array}{c}0,0 \\
8\end{array}$ & 2 & 20 & 1 & 2 & 1 \\
\hline 17 & 1,94 & $\begin{array}{c}1,2 \\
7\end{array}$ & 0,74 & 5,00 & 4,29 & 6,67 & 10,97 & 0,15 & 1,10 & $\begin{array}{c}2,2 \\
2\end{array}$ & $\begin{array}{c}1,8 \\
9\end{array}$ & $\begin{array}{c}0,3 \\
3\end{array}$ & 2 & 63 & 1 & 2 & 2 \\
\hline 18 & 2,17 & $\begin{array}{c}1,6 \\
3\end{array}$ & 2,04 & 14,30 & 10,70 & 11,70 & 22,40 & 0,14 & 1,73 & $\begin{array}{c}2,8 \\
2\end{array}$ & $\begin{array}{c}2,5 \\
5\end{array}$ & $\begin{array}{c}0,2 \\
6\end{array}$ & 1 & 0 & 2 & 1 & 1 \\
\hline 19 & 3,06 & $\begin{array}{c}2,3 \\
8\end{array}$ & 0,27 & 3,76 & 14,00 & 19,93 & 33,93 & 0,14 & 2,64 & $\begin{array}{c}3,8 \\
8\end{array}$ & $\begin{array}{c}2,4 \\
8\end{array}$ & $\begin{array}{c}0,4 \\
0\end{array}$ & 1 & 0 & 2 & 1 & 2 \\
\hline 20 & 3,34 & $\begin{array}{c}2,5 \\
4\end{array}$ & 1,24 & 4,10 & 12,62 & 16,81 & 29,43 & 0,18 & 2,61 & $\begin{array}{c}4,2 \\
3\end{array}$ & $\begin{array}{c}3,7 \\
8\end{array}$ & $\begin{array}{c}0,4 \\
5\end{array}$ & 1 & 0 & 1 & 1 & 1 \\
\hline 21 & 2,46 & $\begin{array}{c}1,9 \\
0\end{array}$ & 0,91 & 3,63 & 10,55 & 14,29 & 24,84 & 0,15 & 2,03 & $\begin{array}{c}3,4 \\
1\end{array}$ & $\begin{array}{c}3,1 \\
5\end{array}$ & $\begin{array}{c}0,2 \\
6\end{array}$ & 1 & 25 & 1 & 1 & 2 \\
\hline 22 & 1,20 & $\begin{array}{c}0,8 \\
6\end{array}$ & 1,27 & 9,68 & 8,98 & 13,63 & 22,61 & 0,05 & 0,84 & $\begin{array}{c}1,3 \\
5\end{array}$ & $\begin{array}{c}1,1 \\
3\end{array}$ & $\begin{array}{c}0,2 \\
2\end{array}$ & 1 & 0 & 2 & 2 & 1 \\
\hline
\end{tabular}




\begin{tabular}{|c|c|c|c|c|c|c|c|c|c|c|c|c|c|c|c|c|c|}
\hline 23 & 0,94 & $\begin{array}{c}0,7 \\
2\end{array}$ & 0,22 & 4,52 & 8,20 & 5,88 & 14,08 & 0,05 & 0,78 & $\begin{array}{c}1,2 \\
0\end{array}$ & $\begin{array}{c}1,0 \\
8\end{array}$ & $\begin{array}{c}0,1 \\
2\end{array}$ & 1 & 10 & 2 & 2 & 2 \\
\hline 24 & 0,85 & $\begin{array}{c}0,6 \\
1\end{array}$ & 0,71 & 4,19 & 9,38 & 9,75 & 19,13 & 0,06 & 0,65 & $\begin{array}{c}1,0 \\
0\end{array}$ & $\begin{array}{c}0,9 \\
1\end{array}$ & $\begin{array}{c}0,1 \\
0\end{array}$ & 1 & 0 & 1 & 2 & 1 \\
\hline 25 & 0,84 & $\begin{array}{c}0,6 \\
4 \\
\end{array}$ & 0,46 & 6,15 & 3,76 & 6,41 & 14,17 & 0,06 & 0,69 & $\begin{array}{c}1,0 \\
8\end{array}$ & $\begin{array}{c}1,0 \\
0\end{array}$ & $\begin{array}{c}0,0 \\
8 \\
\end{array}$ & 1 & 0 & 1 & 2 & 2 \\
\hline 26 & 1,17 & $\begin{array}{c}0,8 \\
4\end{array}$ & 1,12 & 6,60 & 6,22 & 7,79 & 14,01 & 0,11 & 0,85 & $\begin{array}{c}1,4 \\
0\end{array}$ & $\begin{array}{c}1,2 \\
9\end{array}$ & $\begin{array}{c}0,1 \\
1\end{array}$ & 1 & 20 & 2 & 2 & 1 \\
\hline 27 & 1,49 & $\begin{array}{c}1,2 \\
0\end{array}$ & 0,90 & 6,82 & 6,58 & 10,52 & 17,10 & 0,07 & 1,35 & $\begin{array}{c}2,0 \\
8\end{array}$ & $\begin{array}{c}1,9 \\
3\end{array}$ & $\begin{array}{c}0,1 \\
5\end{array}$ & 1 & 0 & 1 & 2 & 1 \\
\hline 28 & 1,01 & $\begin{array}{c}0,7 \\
2 \\
\end{array}$ & 0,83 & 7,74 & 7,07 & 10,98 & 18,05 & 0,07 & 0,72 & $\begin{array}{c}1,2 \\
8 \\
\end{array}$ & $\begin{array}{c}1,1 \\
8 \\
\end{array}$ & $\begin{array}{c}0,1 \\
0 \\
\end{array}$ & 2 & 25 & 1 & 2 & 1 \\
\hline 29 & 1,40 & $\begin{array}{c}1,0 \\
0\end{array}$ & $-0,14$ & 1,84 & 3,36 & 3,00 & 6,35 & 0,11 & 0,98 & $\begin{array}{c}1,9 \\
3\end{array}$ & $\begin{array}{c}1,7 \\
7 \\
\end{array}$ & $\begin{array}{c}0,1 \\
5 \\
\end{array}$ & 2 & 100 & 2 & 2 & 2 \\
\hline 30 & 0,80 & $\begin{array}{c}0,6 \\
1 \\
\end{array}$ & $-0,95$ & 7,44 & 6,20 & 1,76 & 7,96 & 0,06 & 0,67 & $\begin{array}{c}1,0 \\
2 \\
\end{array}$ & $\begin{array}{c}0,9 \\
5\end{array}$ & $\begin{array}{c}0,0 \\
7 \\
\end{array}$ & 2 & 70 & 1 & 2 & 2 \\
\hline 31 & 2,27 & $\begin{array}{c}1,7 \\
3\end{array}$ & 1,36 & 4,75 & 11,28 & 11,93 & 23,21 & 0,09 & 1,85 & $\begin{array}{c}2,8 \\
3\end{array}$ & $\begin{array}{c}2,4 \\
7\end{array}$ & $\begin{array}{c}0,3 \\
6\end{array}$ & 3 & 20 & 1 & 2 & 1 \\
\hline 32 & 2,73 & $\begin{array}{c}2,0 \\
7\end{array}$ & 0,42 & 1,08 & 5,80 & 1,73 & 7,53 & 0,23 & 2,10 & $\begin{array}{c}3,9 \\
4\end{array}$ & $\begin{array}{c}3,7 \\
3\end{array}$ & $\begin{array}{c}0,2 \\
1\end{array}$ & 3 & 55 & 2 & 2 & 2 \\
\hline 33 & 1,79 & $\begin{array}{c}1,4 \\
2\end{array}$ & 0,32 & 3,35 & 7,63 & 11,13 & 18,77 & 0,09 & 1,48 & $\begin{array}{c}2,5 \\
3 \\
\end{array}$ & $\begin{array}{c}2,3 \\
7\end{array}$ & $\begin{array}{c}0,1 \\
7 \\
\end{array}$ & 3 & 0 & 2 & 2 & 1 \\
\hline 34 & 1,21 & $\begin{array}{c}0,9 \\
6 \\
\end{array}$ & 0,66 & 3,51 & 7,99 & 4,88 & 12,78 & 0,05 & 1,09 & $\begin{array}{c}1,6 \\
2 \\
\end{array}$ & $\begin{array}{c}1,4 \\
9 \\
\end{array}$ & $\begin{array}{c}0,1 \\
3 \\
\end{array}$ & 3 & 60 & 1 & 2 & 2 \\
\hline 35 & 2,26 & $\begin{array}{c}1,7 \\
8\end{array}$ & 0,54 & 3,27 & 11,72 & 10,33 & 22,06 & 0,13 & 1,89 & $\begin{array}{c}3,4 \\
4\end{array}$ & $\begin{array}{c}3,2 \\
5\end{array}$ & $\begin{array}{c}0,1 \\
9\end{array}$ & 3 & 5 & 2 & 2 & 1 \\
\hline 36 & 2,20 & $\begin{array}{c}1,7 \\
7\end{array}$ & 0,49 & 3,84 & 8,61 & 10,75 & 19,36 & 0,08 & 2,04 & $\begin{array}{c}2,8 \\
7\end{array}$ & $\begin{array}{c}2,5 \\
9\end{array}$ & $\begin{array}{c}0,2 \\
7\end{array}$ & 3 & 30 & 1 & 2 & 1 \\
\hline 37 & 1,77 & $\begin{array}{c}1,4 \\
8\end{array}$ & 0,23 & 1,39 & 5,24 & 1,64 & 6,89 & 0,06 & 1,73 & $\begin{array}{c}2,4 \\
4\end{array}$ & $\begin{array}{c}2,2 \\
7\end{array}$ & $\begin{array}{c}0,1 \\
6\end{array}$ & 3 & 60 & 2 & 2 & 2 \\
\hline 38 & 3,14 & $\begin{array}{c}2,5 \\
8\end{array}$ & 0,45 & 3,15 & 8,68 & 6,36 & 15,03 & 0,12 & 2,98 & $\begin{array}{c}4,2 \\
1\end{array}$ & $\begin{array}{c}3,8 \\
9\end{array}$ & $\begin{array}{c}0,3 \\
2\end{array}$ & 3 & 70 & 1 & 2 & 2 \\
\hline 39 & 1,06 & $\begin{array}{c}0,8 \\
4 \\
\end{array}$ & 0,19 & 5,33 & 6,24 & 7,60 & 13,84 & 0,05 & 0,96 & $\begin{array}{c}1,4 \\
1 \\
\end{array}$ & $\begin{array}{c}1,2 \\
9\end{array}$ & $\begin{array}{c}0,1 \\
2 \\
\end{array}$ & 1 & 40 & 2 & 2 & 1 \\
\hline 40 & 2,11 & $\begin{array}{c}1,6 \\
1\end{array}$ & 0,72 & 2,96 & 6,37 & 9,00 & 15,38 & 0,15 & 1,59 & $\begin{array}{c}2,9 \\
8\end{array}$ & $\begin{array}{c}2,7 \\
8\end{array}$ & $\begin{array}{c}0,1 \\
9\end{array}$ & 1 & 0 & 1 & 2 & 1 \\
\hline 41 & 1,38 & $\begin{array}{c}1,0 \\
2\end{array}$ & 0,70 & 5,42 & 5,03 & 9,68 & 14,71 & 0,13 & 1,05 & $\begin{array}{c}1,6 \\
7\end{array}$ & $\begin{array}{c}1,5 \\
4\end{array}$ & $\begin{array}{c}0,1 \\
2\end{array}$ & 1 & 0 & 1 & 2 & 1 \\
\hline 42 & 1,44 & $\begin{array}{c}1,0 \\
2\end{array}$ & 0,05 & 3,40 & 6,16 & 6,87 & 10,20 & 0,06 & 0,99 & $\begin{array}{c}1,8 \\
2\end{array}$ & $\begin{array}{c}1,5 \\
8\end{array}$ & $\begin{array}{c}0,2 \\
4\end{array}$ & 1 & 60 & 2 & 2 & 1 \\
\hline 43 & 1,53 & $\begin{array}{c}1,1 \\
6 \\
\end{array}$ & $-0,30$ & 1,83 & 3,97 & 6,17 & 10,14 & 0,07 & 1,29 & $\begin{array}{c}1,8 \\
1 \\
\end{array}$ & $\begin{array}{c}1,6 \\
1 \\
\end{array}$ & $\begin{array}{c}0,2 \\
0 \\
\end{array}$ & 1 & 0 & 1 & 2 & 1 \\
\hline 44 & 1,28 & $\begin{array}{c}1,0 \\
1\end{array}$ & 0,32 & 3,34 & 7,57 & 4,39 & 11,96 & 0,07 & 1,13 & $\begin{array}{c}1,7 \\
8\end{array}$ & $\begin{array}{c}1,6 \\
5\end{array}$ & $\begin{array}{c}0,1 \\
3 \\
\end{array}$ & 1 & 40 & 2 & 2 & 2 \\
\hline 45 & 0,77 & $\begin{array}{c}0,5 \\
9\end{array}$ & 0,28 & 5,62 & 9,86 & 4,11 & 13,97 & 0,05 & 0,60 & $\begin{array}{c}1,1 \\
2\end{array}$ & $\begin{array}{c}1,0 \\
5\end{array}$ & $\begin{array}{c}0,0 \\
7\end{array}$ & 1 & 50 & 1 & 2 & 2 \\
\hline 46 & 0,80 & $\begin{array}{c}0,6 \\
2 \\
\end{array}$ & 0,85 & 5,70 & 9,20 & 4,47 & 13,66 & 0,04 & 0,71 & $\begin{array}{c}1,0 \\
6 \\
\end{array}$ & $\begin{array}{c}0,9 \\
6 \\
\end{array}$ & $\begin{array}{c}0,0 \\
9\end{array}$ & 2 & 0 & 2 & 2 & 1 \\
\hline 47 & 0,96 & $\begin{array}{c}0,7 \\
5\end{array}$ & 0,52 & 4,32 & 5,49 & 6,95 & 12,44 & 0,06 & 0,78 & $\begin{array}{c}1,3 \\
4\end{array}$ & $\begin{array}{c}1,2 \\
5\end{array}$ & $\begin{array}{c}0,0 \\
9\end{array}$ & 2 & 30 & 1 & 2 & 1 \\
\hline 48 & 0,87 & $\begin{array}{c}0,6 \\
8 \\
\end{array}$ & $-1,11$ & 5,10 & 5,58 & 2,56 & 8,14 & 0,05 & 0,71 & $\begin{array}{c}1,3 \\
2\end{array}$ & $\begin{array}{c}1,2 \\
4\end{array}$ & $\begin{array}{c}0,0 \\
8 \\
\end{array}$ & 2 & 76 & 1 & 2 & 2 \\
\hline 49 & 0,58 & $\begin{array}{c}0,4 \\
6 \\
\end{array}$ & 0,04 & 3,31 & 5,58 & 2,40 & 7,98 & 0,03 & 0,51 & $\begin{array}{c}0,7 \\
9 \\
\end{array}$ & $\begin{array}{c}0,7 \\
2 \\
\end{array}$ & $\begin{array}{c}0,0 \\
6 \\
\end{array}$ & 1 & 80 & 2 & 2 & 1 \\
\hline 50 & 0,82 & $\begin{array}{c}0,6 \\
2\end{array}$ & $-0,01$ & 1,41 & 3,06 & 5,29 & 8,36 & 0,05 & 0,66 & $\begin{array}{c}1,1 \\
0\end{array}$ & $\begin{array}{c}1,0 \\
0\end{array}$ & $\begin{array}{c}0,1 \\
0\end{array}$ & 1 & 0 & 1 & 2 & 1 \\
\hline 51 & 11,13 & $\begin{array}{c}5,9 \\
2 \\
\end{array}$ & 3,20 & 16,81 & 82,69 & 65,61 & 48,30 & 2,13 & 3,31 & $\begin{array}{c}8,2 \\
9 \\
\end{array}$ & $\begin{array}{c}7,7 \\
4 \\
\end{array}$ & $\begin{array}{c}0,5 \\
6 \\
\end{array}$ & 1 & 10 & 1 & 1 & 1 \\
\hline 52 & 2,26 & $\begin{array}{c}1,7 \\
9\end{array}$ & 2,32 & 13,40 & 7,18 & 12,04 & 19,22 & 0,01 & 2,01 & $\begin{array}{c}2,9 \\
0\end{array}$ & $\begin{array}{c}2,6 \\
1 \\
\end{array}$ & $\begin{array}{c}0,2 \\
9 \\
\end{array}$ & 1 & 14 & 2 & 1 & 1 \\
\hline 53 & 2,46 & $\begin{array}{c}1,8 \\
9\end{array}$ & 0,33 & 4,45 & 10,75 & 10,05 & 20,80 & 0,12 & 2,06 & $\begin{array}{c}3,1 \\
3\end{array}$ & $\begin{array}{c}2,8 \\
1\end{array}$ & $\begin{array}{c}0,3 \\
1\end{array}$ & 1 & 34 & 1 & 1 & 1 \\
\hline
\end{tabular}




\begin{tabular}{|c|c|c|c|c|c|c|c|c|c|c|c|c|c|c|c|c|c|}
\hline 54 & 2,61 & $\begin{array}{c}2,0 \\
2\end{array}$ & 0,53 & 3,76 & 11,68 & 14,25 & 25,93 & 0,15 & 2,12 & $\begin{array}{c}3,6 \\
0\end{array}$ & $\begin{array}{c}3,3 \\
1\end{array}$ & $\begin{array}{c}0,2 \\
9\end{array}$ & 1 & 17 & 1 & 1 & 1 \\
\hline 55 & 3,55 & $\begin{array}{c}2,8 \\
4 \\
\end{array}$ & $-0,55$ & 3,85 & 11,77 & 18,72 & 30,50 & 0,15 & 3,24 & $\begin{array}{c}4,6 \\
3 \\
\end{array}$ & $\begin{array}{c}4,2 \\
0 \\
\end{array}$ & $\begin{array}{c}0,4 \\
3 \\
\end{array}$ & 1 & 0 & 1 & 3 & 1 \\
\hline 56 & 3,79 & $\begin{array}{c}2,9 \\
9\end{array}$ & $-0,57$ & 3,63 & 10,36 & 17,32 & 25,68 & 0,13 & 3,44 & $\begin{array}{c}4,7 \\
2 \\
\end{array}$ & $\begin{array}{c}4,2 \\
0\end{array}$ & $\begin{array}{c}0,5 \\
2\end{array}$ & 1 & 15 & 1 & 3 & 1 \\
\hline 57 & 3,83 & $\begin{array}{c}2,9 \\
9\end{array}$ & $-0,20$ & 3,09 & 8,01 & 16,51 & 20,52 & 0,17 & 3,35 & $\begin{array}{c}4,5 \\
8\end{array}$ & $\begin{array}{c}4,0 \\
4\end{array}$ & $\begin{array}{c}0,5 \\
4\end{array}$ & 1 & 30 & 1 & 3 & 1 \\
\hline 58 & 3,46 & $\begin{array}{c}2,7 \\
3\end{array}$ & $-0,46$ & 3,31 & 19,60 & 18,81 & 38,41 & 0,14 & 3,10 & $\begin{array}{c}, 3 \\
5 \\
\end{array}$ & $\begin{array}{c}3,8 \\
9 \\
\end{array}$ & $\begin{array}{c}0,4 \\
6 \\
\end{array}$ & 1 & 0 & 1 & 3 & 2 \\
\hline 59 & 3,98 & $\begin{array}{c}3,1 \\
6 \\
\end{array}$ & $-0,36$ & 3,19 & 13,74 & 14,61 & 28,34 & 0,15 & 3,60 & $\begin{array}{c}4,9 \\
6 \\
\end{array}$ & $\begin{array}{c}4,4 \\
1 \\
\end{array}$ & $\begin{array}{c}0,5 \\
5 \\
\end{array}$ & 1 & 30 & 1 & 3 & 2 \\
\hline 60 & 3,61 & $\begin{array}{c}2,8 \\
7 \\
\end{array}$ & 0,34 & 3,25 & 10,97 & 26,85 & 37,81 & 0,14 & 3,26 & $\begin{array}{c}, 5 \\
6 \\
\end{array}$ & $\begin{array}{c}4,1 \\
0\end{array}$ & $\begin{array}{c}0,4 \\
6 \\
\end{array}$ & 1 & 0 & 2 & 3 & 1 \\
\hline 61 & 2,66 & $\begin{array}{c}2,1 \\
1\end{array}$ & 0,38 & 3,37 & 10,85 & 18,12 & 28,97 & 0,17 & 2,18 & $\begin{array}{c}3,8 \\
6\end{array}$ & $\begin{array}{c}3,6 \\
9\end{array}$ & $\begin{array}{c}0,1 \\
8\end{array}$ & 1 & 20 & 2 & 3 & 1 \\
\hline 62 & 3,38 & $\begin{array}{c}2,6 \\
8\end{array}$ & 0,09 & 1,62 & 7,16 & 10,35 & 17,51 & 0,14 & 3,03 & $\begin{array}{c}4,3 \\
0\end{array}$ & $\begin{array}{c}3,8 \\
6\end{array}$ & $\begin{array}{c}0,4 \\
4\end{array}$ & 1 & 40 & 2 & 3 & 1 \\
\hline 63 & 3,77 & $\begin{array}{c}2,8 \\
4\end{array}$ & 0,38 & 3,70 & 5,25 & 5,93 & 11,20 & 0,15 & 3,16 & $\begin{array}{c}4,6 \\
0\end{array}$ & $\begin{array}{c}4,1 \\
2\end{array}$ & $\begin{array}{c}0,4 \\
8\end{array}$ & 1 & 0 & 2 & 3 & 2 \\
\hline 64 & 3,79 & $\begin{array}{c}3,0 \\
3\end{array}$ & 0,32 & 3,09 & 20,12 & 23,13 & 43,25 & 0,13 & 3,46 & $\begin{array}{c}4,9 \\
9\end{array}$ & $\begin{array}{c}4,5 \\
0\end{array}$ & $\begin{array}{c}0,4 \\
9\end{array}$ & 1 & 10 & 2 & 3 & 2 \\
\hline 65 & 3,71 & $\begin{array}{c}2,9 \\
6 \\
\end{array}$ & $-0,48$ & 3,14 & 11,05 & 16,78 & 27,83 & 0,12 & 3,41 & $\begin{array}{c}4,6 \\
5 \\
\end{array}$ & $\begin{array}{c}4,1 \\
5 \\
\end{array}$ & $\begin{array}{c}0,5 \\
0 \\
\end{array}$ & 1 & 20 & 2 & 3 & 2 \\
\hline 66 & 0,31 & $\begin{array}{c}0,2 \\
3\end{array}$ & $-0,47$ & 12,09 & 4,31 & 4,27 & 8,58 & 0,02 & 0,26 & $\begin{array}{c}0,3 \\
6 \\
\end{array}$ & $\begin{array}{c}0,3 \\
2\end{array}$ & $\begin{array}{c}0,0 \\
4\end{array}$ & 3 & 42 & 1 & 2 & 1 \\
\hline 67 & 0,30 & $\begin{array}{c}0,2 \\
2 \\
\end{array}$ & $-0,98$ & 7,94 & 1,45 & 3,17 & 4,61 & 0,01 & 0,24 & $\begin{array}{c}0,3 \\
7\end{array}$ & $\begin{array}{c}0,3 \\
2\end{array}$ & $\begin{array}{c}0,0 \\
4\end{array}$ & 3 & 42 & 1 & 2 & 2 \\
\hline 68 & 0,37 & $\begin{array}{c}0,2 \\
8\end{array}$ & $-0,94$ & 10,56 & 7,00 & 4,21 & 11,21 & 0,01 & 0,31 & $\begin{array}{c}0,4 \\
4 \\
\end{array}$ & $\begin{array}{c}0,3 \\
8 \\
\end{array}$ & $\begin{array}{c}0,0 \\
6\end{array}$ & 3 & 57 & 1 & 2 & 1 \\
\hline 69 & 0,37 & $\begin{array}{c}0,2 \\
8\end{array}$ & 0,74 & 15,50 & 7,31 & 1,83 & 9,14 & 0,02 & 0,30 & $\begin{array}{c}0,4 \\
4\end{array}$ & $\begin{array}{c}0,3 \\
9\end{array}$ & $\begin{array}{c}0,0 \\
5\end{array}$ & 3 & 57 & 1 & 2 & 2 \\
\hline 70 & 0,55 & $\begin{array}{c}0,4 \\
4 \\
\end{array}$ & 0,68 & 7,06 & 7,22 & 2,37 & 9,60 & 0,03 & 0,47 & $\begin{array}{c}0,7 \\
6 \\
\end{array}$ & $\begin{array}{c}0,7 \\
1 \\
\end{array}$ & $\begin{array}{c}0,0 \\
5 \\
\end{array}$ & 3 & 39 & 1 & 2 & 1 \\
\hline 71 & 0,42 & $\begin{array}{c}0,3 \\
3\end{array}$ & $-0,24$ & 3,84 & 2,75 & 2,51 & 5,25 & 0,02 & 0,37 & $\begin{array}{c}0,5 \\
3\end{array}$ & $\begin{array}{c}0,4 \\
8\end{array}$ & $\begin{array}{c}0,0 \\
5\end{array}$ & 3 & 39 & 1 & 2 & 2 \\
\hline 72 & 0,45 & $\begin{array}{c}0,3 \\
4 \\
\end{array}$ & 0,97 & 12,98 & 6,52 & 3,43 & 9,95 & 0,03 & 0,37 & $\begin{array}{c}0,5 \\
5\end{array}$ & $\begin{array}{c}0,5 \\
0 \\
\end{array}$ & $\begin{array}{c}0,0 \\
5\end{array}$ & 3 & 48 & 1 & 2 & 1 \\
\hline 73 & 0,38 & $\begin{array}{c}0,2 \\
9\end{array}$ & 0,73 & 14,14 & 5,83 & 1,45 & 7,28 & 0,02 & 0,32 & $\begin{array}{c}0,4 \\
8\end{array}$ & $\begin{array}{c}0,4 \\
3\end{array}$ & $\begin{array}{c}0,0 \\
5\end{array}$ & 3 & 48 & 1 & 2 & 2 \\
\hline 74 & 2,26 & $\begin{array}{c}1,8 \\
2 \\
\end{array}$ & 0,61 & 3,08 & 9,80 & 6,48 & 16,27 & 0,13 & 1,98 & $\begin{array}{c}3,3 \\
4 \\
\end{array}$ & $\begin{array}{c}3,1 \\
8 \\
\end{array}$ & $\begin{array}{c}0,1 \\
6 \\
\end{array}$ & 1 & 45 & 1 & 1 & 2 \\
\hline 75 & 2,22 & $\begin{array}{c}1,7 \\
5\end{array}$ & 0,88 & 3,79 & 11,14 & 5,53 & 16,67 & 0,15 & 1,87 & $\begin{array}{c}3,2 \\
8 \\
\end{array}$ & $\begin{array}{c}3,1 \\
3\end{array}$ & $\begin{array}{c}0,1 \\
5 \\
\end{array}$ & 1 & 50 & 1 & 1 & 2 \\
\hline 76 & 2,11 & $\begin{array}{c}1,6 \\
8\end{array}$ & 0,66 & 3,29 & 9,50 & 5,17 & 14,67 & 0,12 & 1,83 & $\begin{array}{c}3,1 \\
3\end{array}$ & $\begin{array}{c}2,9 \\
7\end{array}$ & $\begin{array}{c}0,1 \\
6\end{array}$ & 1 & 59 & 1 & 1 & 2 \\
\hline 77 & 1,75 & $\begin{array}{c}1,3 \\
7 \\
\end{array}$ & $-0,45$ & 2,52 & 8,78 & 4,30 & 13,08 & 0,11 & 1,49 & $\begin{array}{c}2,4 \\
8 \\
\end{array}$ & $\begin{array}{c}2,3 \\
2 \\
\end{array}$ & $\begin{array}{c}0,1 \\
6 \\
\end{array}$ & 1 & 90 & 1 & 1 & 1 \\
\hline 78 & 1,88 & $\begin{array}{c}1,4 \\
9\end{array}$ & $-0,46$ & 2,17 & 9,55 & 5,83 & 15,37 & 0,11 & 1,67 & $\begin{array}{c}2,6 \\
5 \\
\end{array}$ & $\begin{array}{c}2,4 \\
9 \\
\end{array}$ & $\begin{array}{c}0,1 \\
6 \\
\end{array}$ & 1 & 85 & 1 & 1 & 1 \\
\hline 79 & 1,89 & $\begin{array}{c}1,4 \\
7 \\
\end{array}$ & $-0,77$ & 3,09 & 9,30 & 7,90 & 17,20 & 0,14 & 1,58 & $\begin{array}{c}2,5 \\
9\end{array}$ & $\begin{array}{c}2,4 \\
4 \\
\end{array}$ & $\begin{array}{c}0,1 \\
5 \\
\end{array}$ & 1 & 78 & 1 & 1 & 1 \\
\hline 80 & 1,36 & $\begin{array}{c}1,0 \\
9\end{array}$ & $-0,32$ & 2,95 & 3,93 & 5,21 & 9,14 & 0,04 & 1,24 & $\begin{array}{c}1,8 \\
0\end{array}$ & $\begin{array}{c}1,6 \\
2\end{array}$ & $\begin{array}{c}0,1 \\
8 \\
\end{array}$ & 1 & 80 & 1 & 1 & 2 \\
\hline 81 & 1,27 & $\begin{array}{c}1,0 \\
0\end{array}$ & $-0,34$ & 3,50 & 5,11 & 5,77 & 10,88 & 0,05 & 1,13 & $\begin{array}{c}1,6 \\
4 \\
\end{array}$ & $\begin{array}{c}1,4 \\
8 \\
\end{array}$ & $\begin{array}{c}0,1 \\
6 \\
\end{array}$ & 1 & 80 & 1 & 1 & 1 \\
\hline 82 & 1,38 & $\begin{array}{c}1,1 \\
1\end{array}$ & $-0,30$ & 3,25 & 8,10 & 5,86 & 13,97 & 0,06 & 1,25 & $\begin{array}{c}1,7 \\
5\end{array}$ & $\begin{array}{c}1,5 \\
8 \\
\end{array}$ & $\begin{array}{c}0,1 \\
7 \\
\end{array}$ & 1 & 80 & 1 & 1 & 2 \\
\hline 83 & 1,21 & $\begin{array}{c}0,9 \\
6 \\
\end{array}$ & $-0,33$ & 3,42 & 6,86 & 6,62 & 13,48 & 0,05 & 1,11 & $\begin{array}{c}1,5 \\
5\end{array}$ & $\begin{array}{c}1,4 \\
0 \\
\end{array}$ & $\begin{array}{c}0,1 \\
5 \\
\end{array}$ & 1 & 85 & 1 & 1 & 1 \\
\hline 84 & 1,46 & $\begin{array}{c}1,1 \\
1 \\
\end{array}$ & $-0,85$ & 4,42 & 5,93 & 7,65 & 13,58 & 0,05 & 1,22 & $\begin{array}{c}1,7 \\
1 \\
\end{array}$ & $\begin{array}{c}1,4 \\
8\end{array}$ & $\begin{array}{c}0,2 \\
3 \\
\end{array}$ & 1 & 85 & 1 & 1 & 2 \\
\hline
\end{tabular}




\begin{tabular}{|c|c|c|c|c|c|c|c|c|c|c|c|c|c|c|c|c|c|}
\hline 85 & 1,13 & $\begin{array}{c}0,9 \\
1\end{array}$ & $-0,30$ & 3,19 & 3,24 & 6,23 & 9,46 & 0,04 & 1,03 & $\begin{array}{c}1,5 \\
1\end{array}$ & $\begin{array}{c}1,3 \\
7\end{array}$ & $\begin{array}{c}0,1 \\
4\end{array}$ & 1 & 80 & 1 & 1 & 1 \\
\hline 86 & 0,31 & $\begin{array}{c}0,2 \\
5\end{array}$ & 0,87 & 4,42 & 12,47 & 8,20 & 20,67 & 0,02 & 0,26 & $\begin{array}{c}0,4 \\
4\end{array}$ & $\begin{array}{c}0,4 \\
2\end{array}$ & $\begin{array}{c}0,0 \\
2\end{array}$ & 3 & 10 & 2 & 2 & 1 \\
\hline 87 & 0,32 & $\begin{array}{c}0,2 \\
5\end{array}$ & 0,44 & 1,31 & 6,79 & 1,16 & 7,95 & 0,02 & 0,26 & $\begin{array}{c}0,4 \\
4 \\
\end{array}$ & $\begin{array}{c}0,4 \\
1 \\
\end{array}$ & $\begin{array}{c}0,0 \\
2 \\
\end{array}$ & 3 & 65 & 2 & 2 & 2 \\
\hline 88 & 0,39 & $\begin{array}{c}0,2 \\
5\end{array}$ & 0,42 & 3,30 & 8,41 & 9,88 & 18,29 & 0,03 & 0,25 & $\begin{array}{c}0,4 \\
4\end{array}$ & $\begin{array}{c}0,4 \\
2\end{array}$ & $\begin{array}{c}0,0 \\
2\end{array}$ & 3 & 15 & 2 & 2 & 1 \\
\hline 89 & 1,80 & $\begin{array}{c}1,3 \\
7\end{array}$ & $-0,86$ & 4,09 & 6,30 & 7,83 & 14,12 & 0,07 & 1,49 & $\begin{array}{c}2,0 \\
0\end{array}$ & $\begin{array}{c}1,6 \\
9\end{array}$ & $\begin{array}{c}0,3 \\
1\end{array}$ & 1 & 90 & 1 & 1 & 2 \\
\hline 90 & 1,51 & $\begin{array}{c}1,1 \\
2 \\
\end{array}$ & $-1,16$ & 4,83 & 6,13 & 6,62 & 12,75 & 0,04 & 1,17 & $\begin{array}{c}1,6 \\
4 \\
\end{array}$ & $\begin{array}{c}1,3 \\
5 \\
\end{array}$ & $\begin{array}{c}0,2 \\
9 \\
\end{array}$ & 1 & 90 & 1 & 1 & 1 \\
\hline 91 & 1,81 & $\begin{array}{c}1,3 \\
7 \\
\end{array}$ & $-0,84$ & 4,14 & 8,01 & 8,72 & 16,73 & 0,07 & 1,52 & $\begin{array}{c}2,0 \\
6 \\
\end{array}$ & $\begin{array}{c}1,7 \\
5 \\
\end{array}$ & $\begin{array}{c}0,3 \\
2 \\
\end{array}$ & 1 & 94 & 1 & 1 & 2 \\
\hline 92 & 1,52 & $\begin{array}{c}1,1 \\
6 \\
\end{array}$ & $-0,90$ & 4,62 & 4,23 & 7,55 & 11,78 & 0,05 & 1,27 & $\begin{array}{c}1,8 \\
2 \\
\end{array}$ & $\begin{array}{c}1,5 \\
7\end{array}$ & $\begin{array}{c}0,2 \\
5\end{array}$ & 1 & 94 & 1 & 1 & 2 \\
\hline 93 & 1,36 & $\begin{array}{c}1,0 \\
5\end{array}$ & $-0,90$ & 4,54 & 3,80 & 8,02 & 11,83 & 0,04 & 1,18 & $\begin{array}{c}1,6 \\
2\end{array}$ & $\begin{array}{c}1,4 \\
1\end{array}$ & $\begin{array}{c}0,2 \\
1\end{array}$ & 1 & 96 & 1 & 1 & 1 \\
\hline 94 & 2,02 & $\begin{array}{c}1,4 \\
2\end{array}$ & $-1,99$ & 7,93 & 4,85 & 11,62 & 16,46 & 0,03 & 1,39 & $\begin{array}{c}1,8 \\
5\end{array}$ & $\begin{array}{c}1,4 \\
1\end{array}$ & $\begin{array}{c}0,4 \\
3\end{array}$ & 1 & 96 & 1 & 1 & 1 \\
\hline 95 & 1,45 & $\begin{array}{c}1,1 \\
0\end{array}$ & $-0,98$ & 4,65 & 3,70 & 7,52 & 11,22 & 0,04 & 1,19 & $\begin{array}{c}1,6 \\
9\end{array}$ & $\begin{array}{c}1,4 \\
5\end{array}$ & $\begin{array}{c}0,2 \\
4 \\
\end{array}$ & 1 & 96 & 1 & 1 & 2 \\
\hline 96 & 1,52 & $\begin{array}{c}1,1 \\
5\end{array}$ & $-1,22$ & 5,98 & 11,96 & 11,02 & 22,99 & 0,04 & 1,29 & $\begin{array}{c}1,6 \\
6 \\
\end{array}$ & $\begin{array}{c}1,4 \\
0 \\
\end{array}$ & $\begin{array}{c}0,2 \\
6 \\
\end{array}$ & 1 & 96 & 1 & 1 & 1 \\
\hline 97 & 1,88 & $\begin{array}{c}1,4 \\
7\end{array}$ & 0,69 & 4,51 & 9,46 & 6,13 & 15,59 & 0,14 & 1,55 & $\begin{array}{c}2,6 \\
3\end{array}$ & $\begin{array}{c}2,5 \\
0\end{array}$ & $\begin{array}{c}0,1 \\
2\end{array}$ & 1 & 78 & 1 & 1 & 2 \\
\hline 98 & 2,95 & $\begin{array}{c}2,2 \\
5\end{array}$ & 1,29 & 4,49 & 13,88 & 15,07 & 28,95 & 0,23 & 2,27 & $\begin{array}{c}4,6 \\
7\end{array}$ & $\begin{array}{c}4,5 \\
3\end{array}$ & $\begin{array}{c}0,1 \\
4\end{array}$ & 1 & 10 & 1 & 1 & 1 \\
\hline 99 & 2,70 & $\begin{array}{c}1,9 \\
7\end{array}$ & 1,65 & 6,68 & 15,41 & 7,99 & 23,40 & 0,28 & 1,86 & $\begin{array}{c}3,7 \\
7\end{array}$ & $\begin{array}{c}3,6 \\
3\end{array}$ & $\begin{array}{c}0,1 \\
4\end{array}$ & 1 & 17 & 1 & 1 & 2 \\
\hline 100 & 1,32 & $\begin{array}{c}1,0 \\
1\end{array}$ & $-0,65$ & 2,09 & 6,64 & 7,16 & 13,80 & 0,06 & 1,12 & $\begin{array}{c}1,5 \\
1\end{array}$ & $\begin{array}{c}1,3 \\
0\end{array}$ & $\begin{array}{c}0,2 \\
1\end{array}$ & 1 & 100 & 1 & 1 & 1 \\
\hline 101 & 1,64 & $\begin{array}{c}1,3 \\
0\end{array}$ & 0,17 & 3,67 & 8,47 & 4,98 & 13,45 & 0,09 & 1,39 & $\begin{array}{c}2,4 \\
0\end{array}$ & $\begin{array}{c}2,2 \\
5\end{array}$ & $\begin{array}{c}0,1 \\
4 \\
\end{array}$ & 3 & 80 & 1 & 2 & 2 \\
\hline 102 & 2,83 & $\begin{array}{c}2,1 \\
5\end{array}$ & 0,32 & 3,25 & 10,11 & 12,53 & 22,64 & 0,23 & 2,10 & $\begin{array}{c}4,4 \\
5\end{array}$ & $\begin{array}{c}4,3 \\
2\end{array}$ & $\begin{array}{c}0,1 \\
3\end{array}$ & 3 & 40 & 1 & 2 & 1 \\
\hline 103 & 0,84 & $\begin{array}{c}0,6 \\
3\end{array}$ & 0,37 & 2,71 & 7,97 & 8,11 & 16,08 & 0,05 & 0,66 & $\begin{array}{c}1,0 \\
8\end{array}$ & $\begin{array}{c}0,9 \\
7\end{array}$ & $\begin{array}{c}0,1 \\
1\end{array}$ & 3 & 20 & 2 & 2 & 1 \\
\hline 104 & 0,55 & $\begin{array}{c}0,4 \\
3\end{array}$ & 0,41 & 1,92 & 4,86 & 2,72 & 7,58 & 0,03 & 0,48 & $\begin{array}{c}0,7 \\
2\end{array}$ & $\begin{array}{c}0,6 \\
6\end{array}$ & $\begin{array}{c}0,0 \\
7\end{array}$ & 3 & 70 & 2 & 2 & 2 \\
\hline 105 & 0,68 & $\begin{array}{c}0,5 \\
2 \\
\end{array}$ & 0,85 & 3,15 & 8,38 & 5,57 & 13,95 & 0,05 & 0,54 & $\begin{array}{c}0,9 \\
6 \\
\end{array}$ & $\begin{array}{c}0,9 \\
0\end{array}$ & $\begin{array}{c}0,0 \\
5 \\
\end{array}$ & 3 & 25 & 2 & 2 & 1 \\
\hline 106 & 0,62 & $\begin{array}{c}0,4 \\
9\end{array}$ & 0,16 & 1,98 & 5,44 & 1,78 & 7,22 & 0,04 & 0,52 & $\begin{array}{c}0,8 \\
7\end{array}$ & $\begin{array}{c}0,8 \\
2 \\
\end{array}$ & $\begin{array}{c}0,0 \\
5 \\
\end{array}$ & 3 & 75 & 2 & 2 & 2 \\
\hline 107 & 0,35 & $\begin{array}{c}0,2 \\
6\end{array}$ & 0,46 & 2,92 & 7,24 & 1,14 & 8,37 & 0,03 & 0,26 & $\begin{array}{c}0,4 \\
7\end{array}$ & $\begin{array}{c}0,4 \\
4\end{array}$ & $\begin{array}{c}0,0 \\
2\end{array}$ & 3 & 30 & 2 & 2 & 1 \\
\hline 108 & 0,35 & $\begin{array}{c}0,2 \\
6 \\
\end{array}$ & 0,14 & 1,09 & 2,15 & 1,89 & 4,04 & 0,03 & 0,27 & $\begin{array}{c}0,4 \\
9 \\
\end{array}$ & $\begin{array}{c}0,4 \\
6 \\
\end{array}$ & $\begin{array}{c}0,0 \\
2 \\
\end{array}$ & 3 & 80 & 2 & 2 & 2 \\
\hline 109 & 0,34 & $\begin{array}{c}0,2 \\
6\end{array}$ & 0,80 & 2,13 & 6,15 & 1,07 & 7,22 & 0,03 & 0,27 & $\begin{array}{c}0,4 \\
8\end{array}$ & $\begin{array}{c}0,4 \\
5\end{array}$ & $\begin{array}{c}0,0 \\
3\end{array}$ & 3 & 35 & 2 & 2 & 1 \\
\hline 110 & 0,38 & $\begin{array}{c}0,2 \\
7 \\
\end{array}$ & 0,42 & 1,83 & 4,75 & 1,12 & 5,88 & 0,03 & 0,27 & $\begin{array}{c}0,5 \\
0 \\
\end{array}$ & $\begin{array}{c}0,4 \\
8 \\
\end{array}$ & $\begin{array}{c}0,0 \\
2 \\
\end{array}$ & 3 & 85 & 2 & 2 & 2 \\
\hline 111 & 0,57 & $\begin{array}{c}0,4 \\
4 \\
\end{array}$ & 0,75 & 2,91 & 6,81 & 1,86 & 8,67 & 0,03 & 0,48 & $\begin{array}{c}0,7 \\
8 \\
\end{array}$ & $\begin{array}{c}0,7 \\
1 \\
\end{array}$ & $\begin{array}{c}0,0 \\
7 \\
\end{array}$ & 3 & 40 & 2 & 2 & 1 \\
\hline 112 & 0,74 & $\begin{array}{c}0,5 \\
4\end{array}$ & 0,69 & 1,23 & 3,76 & 1,25 & 5,01 & 0,06 & 0,56 & $\begin{array}{c}0,9 \\
2\end{array}$ & $\begin{array}{c}0,8 \\
6\end{array}$ & $\begin{array}{c}0,0 \\
6\end{array}$ & 3 & 90 & 2 & 2 & 2 \\
\hline 113 & 0,61 & $\begin{array}{c}0,4 \\
9\end{array}$ & 0,56 & 1,84 & 5,23 & 1,63 & 6,86 & 0,04 & 0,54 & $\begin{array}{c}0,8 \\
5 \\
\end{array}$ & $\begin{array}{c}0,7 \\
9 \\
\end{array}$ & $\begin{array}{c}0,0 \\
5 \\
\end{array}$ & 3 & 45 & 2 & 2 & 1 \\
\hline 114 & 0,27 & $\begin{array}{c}0,2 \\
2\end{array}$ & 0,64 & 0,58 & 2,11 & 1,36 & 3,47 & 0,02 & 0,23 & $\begin{array}{c}0,4 \\
1 \\
\end{array}$ & $\begin{array}{c}0,4 \\
0 \\
\end{array}$ & $\begin{array}{c}0,0 \\
1 \\
\end{array}$ & 3 & 95 & 2 & 2 & 2 \\
\hline 115 & 0,30 & $\begin{array}{c}0,2 \\
3\end{array}$ & 0,51 & 1,32 & 4,90 & 1,03 & 5,93 & 0,02 & 0,24 & $\begin{array}{c}0,4 \\
6\end{array}$ & $\begin{array}{c}0,4 \\
4\end{array}$ & $\begin{array}{c}0,0 \\
2\end{array}$ & 3 & 50 & 2 & 2 & 1 \\
\hline
\end{tabular}




\begin{tabular}{|c|c|c|c|c|c|c|c|c|c|c|c|c|c|c|c|c|c|}
\hline 116 & 0,33 & $\begin{array}{c}0,2 \\
5\end{array}$ & 0,23 & 0,53 & 3,49 & 0,68 & 4,18 & 0,03 & 0,25 & $\begin{array}{c}0,4 \\
8\end{array}$ & $\begin{array}{c}0,4 \\
6\end{array}$ & $\begin{array}{c}0,0 \\
2\end{array}$ & 3 & 100 & 2 & 2 & 2 \\
\hline 117 & 0,80 & $\begin{array}{c}0,6 \\
1 \\
\end{array}$ & 0,50 & 4,60 & 7,10 & 2,99 & 10,09 & 0,07 & 0,63 & $\begin{array}{c}1,0 \\
8 \\
\end{array}$ & $\begin{array}{c}1,0 \\
4 \\
\end{array}$ & $\begin{array}{c}0,0 \\
5 \\
\end{array}$ & 2 & 34 & 1 & 2 & 1 \\
\hline 118 & 1,01 & $\begin{array}{c}0,7 \\
3\end{array}$ & $-1,15$ & 3,84 & 3,54 & 2,22 & 5,76 & 0,09 & 0,70 & $\begin{array}{c}1,4 \\
1\end{array}$ & $\begin{array}{c}1,3 \\
2\end{array}$ & $\begin{array}{c}0,0 \\
9\end{array}$ & 2 & 82 & 1 & 2 & 2 \\
\hline 119 & 0,91 & $\begin{array}{c}0,7 \\
2\end{array}$ & 0,54 & 3,68 & 7,27 & 3,80 & 11,07 & 0,06 & 0,75 & $\begin{array}{c}1,3 \\
2\end{array}$ & $\begin{array}{c}1,2 \\
7\end{array}$ & $\begin{array}{c}0,0 \\
5\end{array}$ & 2 & 40 & 1 & 2 & 1 \\
\hline 120 & 0,78 & $\begin{array}{c}8,1 \\
4\end{array}$ & $-0,69$ & 3,66 & 3,22 & 4,59 & 7,81 & 1,11 & 0,06 & $\begin{array}{c}0,0 \\
6\end{array}$ & $\begin{array}{c}1,0 \\
7\end{array}$ & $\begin{array}{c}0,0 \\
5\end{array}$ & 2 & 91 & 1 & 2 & 2 \\
\hline 121 & 0,83 & $\begin{array}{c}0,6 \\
5 \\
\end{array}$ & 0,70 & 4,15 & 4,00 & 4,04 & 8,03 & 0,06 & 0,75 & $\begin{array}{c}1,1 \\
2 \\
\end{array}$ & $\begin{array}{c}1,0 \\
6\end{array}$ & $\begin{array}{c}0,0 \\
6 \\
\end{array}$ & 2 & 45 & 1 & 2 & 1 \\
\hline 122 & 0,76 & $\begin{array}{c}0,6 \\
1 \\
\end{array}$ & $-0,99$ & 3,21 & 2,82 & 1,59 & 4,42 & 0,04 & 0,68 & $\begin{array}{c}1,0 \\
7 \\
\end{array}$ & $\begin{array}{c}1,0 \\
2 \\
\end{array}$ & $\begin{array}{c}0,0 \\
5 \\
\end{array}$ & 2 & 100 & 1 & 2 & 2 \\
\hline 123 & 1,42 & $\begin{array}{c}1,1 \\
3\end{array}$ & $-0,66$ & 3,25 & 4,78 & 6,88 & 11,66 & 0,04 & 1,32 & $\begin{array}{c}1,7 \\
2\end{array}$ & $\begin{array}{c}1,5 \\
1\end{array}$ & $\begin{array}{c}0,2 \\
1\end{array}$ & 1 & 25 & 1 & 1 & 1 \\
\hline 124 & 1,34 & $\begin{array}{c}1,0 \\
7\end{array}$ & $-0,48$ & 3,01 & 4,96 & 5,24 & 10,20 & 0,05 & 1,25 & $\begin{array}{c}1,6 \\
1\end{array}$ & $\begin{array}{c}1,4 \\
2\end{array}$ & $\begin{array}{c}0,1 \\
8\end{array}$ & 1 & 30 & 1 & 1 & 2 \\
\hline 125 & 1,46 & $\begin{array}{c}1,1 \\
7\end{array}$ & $-0,12$ & 2,74 & 4,93 & 5,19 & 10,12 & 0,07 & 1,37 & $\begin{array}{c}1,8 \\
5\end{array}$ & $\begin{array}{c}1,6 \\
7\end{array}$ & $\begin{array}{c}0,1 \\
8\end{array}$ & 1 & 20 & 1 & 1 & 1 \\
\hline 126 & 1,44 & $\begin{array}{c}1,1 \\
4\end{array}$ & $-0,77$ & 3,27 & 4,09 & 5,40 & 9,48 & 0,04 & 1,30 & $\begin{array}{c}1,6 \\
4\end{array}$ & $\begin{array}{c}1,4 \\
0\end{array}$ & $\begin{array}{c}0,2 \\
4\end{array}$ & 1 & 30 & 1 & 1 & 2 \\
\hline 127 & 1,29 & $\begin{array}{c}1,0 \\
2 \\
\end{array}$ & $-0,31$ & 3,22 & 4,90 & 6,76 & 11,66 & 0,06 & 1,15 & $\begin{array}{c}1,6 \\
1 \\
\end{array}$ & $\begin{array}{c}1,4 \\
3 \\
\end{array}$ & $\begin{array}{c}0,1 \\
8 \\
\end{array}$ & 1 & 30 & 1 & 1 & 1 \\
\hline 128 & 1,42 & $\begin{array}{c}1,1 \\
2\end{array}$ & $-0,56$ & 3,32 & 7,80 & 5,83 & 13,63 & 0,05 & 1,27 & $\begin{array}{c}1,7 \\
2\end{array}$ & $\begin{array}{c}1,5 \\
0\end{array}$ & $\begin{array}{c}0,2 \\
1\end{array}$ & 1 & 20 & 1 & 1 & 2 \\
\hline 129 & 0,71 & $\begin{array}{c}0,5 \\
6\end{array}$ & $-0,61$ & 4,89 & 8,49 & 3,44 & 11,93 & 0,02 & 0,65 & $\begin{array}{c}0,8 \\
1\end{array}$ & $\begin{array}{c}0,7 \\
0\end{array}$ & $\begin{array}{c}0,1 \\
1\end{array}$ & 2 & 50 & 1 & 2 & 1 \\
\hline 130 & 0,78 & $\begin{array}{c}0,6 \\
0\end{array}$ & $-0,86$ & 4,16 & 7,97 & 3,23 & 11,20 & 0,03 & 0,67 & $\begin{array}{c}0,8 \\
7\end{array}$ & $\begin{array}{c}0,7 \\
3\end{array}$ & $\begin{array}{c}0,1 \\
3\end{array}$ & 2 & 50 & 1 & 2 & 2 \\
\hline 131 & 0,91 & $\begin{array}{c}0,7 \\
0\end{array}$ & $-1,05$ & 3,97 & 1,76 & 3,76 & 5,52 & 0,02 & 0,80 & $\begin{array}{c}0,9 \\
9\end{array}$ & $\begin{array}{c}0,8 \\
2\end{array}$ & $\begin{array}{c}0,1 \\
6\end{array}$ & 2 & 76 & 1 & 2 & 1 \\
\hline 132 & 0,60 & $\begin{array}{c}0,4 \\
6 \\
\end{array}$ & $-0,52$ & 6,45 & 8,57 & 2,72 & 11,29 & 0,02 & 9,53 & $\begin{array}{c}0,6 \\
8 \\
\end{array}$ & $\begin{array}{c}0,5 \\
9\end{array}$ & $\begin{array}{c}0,0 \\
9 \\
\end{array}$ & 2 & 76 & 1 & 2 & 2 \\
\hline 133 & 0,73 & $\begin{array}{c}0,5 \\
8\end{array}$ & $-0,49$ & 3,49 & 5,43 & 3,30 & 8,73 & 0,02 & 0,65 & $\begin{array}{c}0,8 \\
7\end{array}$ & $\begin{array}{c}0,7 \\
6\end{array}$ & $\begin{array}{c}0,1 \\
1\end{array}$ & 2 & 70 & 1 & 2 & 1 \\
\hline 134 & 0,77 & $\begin{array}{c}0,5 \\
9\end{array}$ & $-0,81$ & 4,24 & 3,50 & 3,80 & 7,30 & 0,02 & 0,66 & $\begin{array}{c}0,9 \\
3\end{array}$ & $\begin{array}{c}0,8 \\
1\end{array}$ & $\begin{array}{c}0,1 \\
2\end{array}$ & 2 & 70 & 1 & 2 & 2 \\
\hline 135 & 1,91 & $\begin{array}{c}1,2 \\
6\end{array}$ & $-1,17$ & 3,54 & 10,74 & 4,51 & 15,25 & 0,16 & 1,52 & $\begin{array}{c}2,5 \\
8\end{array}$ & $\begin{array}{c}2,4 \\
4\end{array}$ & $\begin{array}{c}0,1 \\
4\end{array}$ & 1 & 74 & 1 & 1 & 1 \\
\hline 136 & 2,37 & $\begin{array}{c}1,8 \\
2\end{array}$ & 0,99 & 4,21 & 10,25 & 5,36 & 15,61 & 0,19 & 1,89 & $\begin{array}{c}3,3 \\
7 \\
\end{array}$ & $\begin{array}{c}3,2 \\
0\end{array}$ & $\begin{array}{c}0,1 \\
7 \\
\end{array}$ & 1 & 30 & 1 & 1 & 2 \\
\hline 137 & 2,17 & $\begin{array}{c}1,6 \\
8 \\
\end{array}$ & $-0,84$ & 3,68 & 8,98 & 6,65 & 15,62 & 0,16 & 1,77 & $\begin{array}{c}3,2 \\
1 \\
\end{array}$ & $\begin{array}{c}3,0 \\
4 \\
\end{array}$ & $\begin{array}{c}0,1 \\
6 \\
\end{array}$ & 1 & 63 & 1 & 1 & 1 \\
\hline 138 & 2,66 & $\begin{array}{c}2,0 \\
1\end{array}$ & 1,24 & 4,90 & 14,01 & 9,93 & 23,94 & 0,24 & 2,01 & $\begin{array}{c}3,7 \\
9\end{array}$ & $\begin{array}{c}3,6 \\
2\end{array}$ & $\begin{array}{c}0,1 \\
7\end{array}$ & 1 & 20 & 1 & 1 & 2 \\
\hline 139 & 2,45 & $\begin{array}{c}1,8 \\
7 \\
\end{array}$ & $-0,12$ & 4,94 & 13,59 & 7,03 & 20,62 & 0,21 & 1,96 & $\begin{array}{c}3,3 \\
6 \\
\end{array}$ & $\begin{array}{c}3,2 \\
0 \\
\end{array}$ & $\begin{array}{c}0,1 \\
6 \\
\end{array}$ & 1 & 40 & 1 & 1 & 1 \\
\hline 140 & 2,37 & $\begin{array}{c}1,8 \\
0 \\
\end{array}$ & 1,02 & 4,80 & 12,01 & 5,76 & 17,77 & 0,18 & 1,88 & $\begin{array}{c}3,3 \\
2 \\
\end{array}$ & $\begin{array}{c}3,1 \\
3\end{array}$ & $\begin{array}{c}0,1 \\
8 \\
\end{array}$ & 1 & 34 & 1 & 1 & 2 \\
\hline 141 & 2,51 & $\begin{array}{c}1,9 \\
9\end{array}$ & 0,24 & 3,20 & 9,83 & 10,17 & 20,00 & 0,14 & 2,16 & $\begin{array}{c}3,4 \\
8 \\
\end{array}$ & $\begin{array}{c}3,2 \\
2 \\
\end{array}$ & $\begin{array}{c}0,2 \\
6 \\
\end{array}$ & 1 & 25 & 1 & 1 & 1 \\
\hline 142 & 0,73 & $\begin{array}{c}0,5 \\
8 \\
\end{array}$ & 0,33 & 3,21 & 2,84 & 3,26 & 6,10 & 0,04 & 0,65 & $\begin{array}{c}1,0 \\
4 \\
\end{array}$ & $\begin{array}{c}0,9 \\
7\end{array}$ & $\begin{array}{c}0,0 \\
7 \\
\end{array}$ & 1 & 100 & 1 & 1 & 2 \\
\hline 143 & 1,93 & $\begin{array}{c}1,5 \\
1 \\
\end{array}$ & 0,11 & 3,97 & 7,67 & 5,86 & 13,53 & 0,13 & 1,60 & $\begin{array}{c}2,7 \\
5 \\
\end{array}$ & $\begin{array}{c}2,5 \\
9 \\
\end{array}$ & $\begin{array}{c}0,1 \\
7 \\
\end{array}$ & 3 & 90 & 1 & 2 & 2 \\
\hline 144 & 1,89 & $\begin{array}{c}1,4 \\
6 \\
\end{array}$ & 0,07 & 1,93 & 6,05 & 3,90 & 9,95 & 0,13 & 1,60 & $\begin{array}{c}2,7 \\
3 \\
\end{array}$ & $\begin{array}{c}2,5 \\
7\end{array}$ & $\begin{array}{c}0,1 \\
6 \\
\end{array}$ & 3 & 100 & 1 & 2 & 2 \\
\hline 145 & 2,35 & $\begin{array}{c}1,8 \\
2 \\
\end{array}$ & 0,86 & 4,04 & 10,41 & 5,99 & 16,39 & 0,18 & 1,93 & $\begin{array}{c}3,3 \\
2 \\
\end{array}$ & $\begin{array}{c}3,1 \\
4\end{array}$ & $\begin{array}{c}0,1 \\
8 \\
\end{array}$ & 1 & 40 & 1 & 1 & 2 \\
\hline 146 & 2,32 & $\begin{array}{c}1,8 \\
0\end{array}$ & $-0,07$ & 4,72 & 12,60 & 4,99 & 17,60 & 0,18 & 1,90 & $\begin{array}{c}3,2 \\
7 \\
\end{array}$ & $\begin{array}{c}3,1 \\
2 \\
\end{array}$ & $\begin{array}{c}0,1 \\
5 \\
\end{array}$ & 1 & 45 & 1 & 1 & 1 \\
\hline
\end{tabular}




\begin{tabular}{|c|c|c|c|c|c|c|c|c|c|c|c|c|c|c|c|c|c|}
\hline 147 & 2,74 & $\begin{array}{c}2,1 \\
2\end{array}$ & 1,17 & 4,48 & 13,73 & 5,83 & 19,56 & 0,21 & 2,15 & $\begin{array}{c}4,1 \\
8\end{array}$ & $\begin{array}{c}4,0 \\
3\end{array}$ & $\begin{array}{c}0,1 \\
5\end{array}$ & 1 & 14 & 1 & 1 & 2 \\
\hline 148 & 2,18 & $\begin{array}{c}1,6 \\
5\end{array}$ & $-1,21$ & 3,17 & 10,82 & 5,02 & 15,84 & 0,20 & 1,70 & $\begin{array}{c}2,9 \\
4\end{array}$ & $\begin{array}{c}2,8 \\
0\end{array}$ & $\begin{array}{c}0,1 \\
4\end{array}$ & 1 & 54 & 1 & 1 & 1 \\
\hline 149 & 2,10 & $\begin{array}{c}1,5 \\
9 \\
\end{array}$ & $-1,04$ & 2,93 & 10,95 & 5,07 & 16,02 & 0,18 & 1,64 & $\begin{array}{c}2,8 \\
6 \\
\end{array}$ & $\begin{array}{c}2,6 \\
9 \\
\end{array}$ & $\begin{array}{c}0,1 \\
7 \\
\end{array}$ & 1 & 70 & 1 & 1 & 1 \\
\hline 150 & 1,98 & $\begin{array}{c}1,4 \\
6\end{array}$ & 0,76 & 5,59 & 9,66 & 4,40 & 14,06 & 0,19 & 1,49 & $\begin{array}{c}2,5 \\
8\end{array}$ & $\begin{array}{c}2,4 \\
4\end{array}$ & $\begin{array}{c}0,1 \\
4\end{array}$ & 1 & 67 & 1 & 1 & 2 \\
\hline 151 & 2,25 & $\begin{array}{c}1,6 \\
8 \\
\end{array}$ & $-0,23$ & 5,31 & 11,59 & 5,38 & 16,97 & 0,21 & 1,71 & $\begin{array}{c}3,0 \\
3 \\
\end{array}$ & $\begin{array}{c}2,8 \\
8 \\
\end{array}$ & $\begin{array}{c}0,1 \\
5\end{array}$ & 1 & 50 & 1 & 1 & 1 \\
\hline 152 & 1,09 & $\begin{array}{c}0,8 \\
0 \\
\end{array}$ & 0,59 & 4,02 & 8,35 & 1,86 & 10,21 & 0,10 & 0,77 & $\begin{array}{c}1,4 \\
4 \\
\end{array}$ & $\begin{array}{c}1,3 \\
8 \\
\end{array}$ & $\begin{array}{c}0,0 \\
6\end{array}$ & 1 & 90 & 1 & 1 & 2 \\
\hline 153 & 1,28 & $\begin{array}{c}0,9 \\
0\end{array}$ & 2,44 & 12,36 & 9,80 & 1,90 & 11,70 & 0,14 & 0,79 & $\begin{array}{c}1,6 \\
7 \\
\end{array}$ & $\begin{array}{c}1,6 \\
3 \\
\end{array}$ & $\begin{array}{c}0,0 \\
5 \\
\end{array}$ & 1 & 23 & 2 & 1 & 1 \\
\hline 154 & 1,34 & $\begin{array}{c}0,9 \\
2 \\
\end{array}$ & 2,43 & 11,57 & 10,96 & 1,73 & 12,68 & 0,15 & 0,82 & $\begin{array}{c}1,7 \\
3 \\
\end{array}$ & $\begin{array}{c}1,6 \\
8 \\
\end{array}$ & $\begin{array}{c}0,0 \\
5 \\
\end{array}$ & 1 & 30 & 2 & 1 & 1 \\
\hline 155 & 1,05 & $\begin{array}{c}0,7 \\
2 \\
\end{array}$ & 2,74 & 17,65 & 14,34 & 1,41 & 15,75 & 0,11 & 0,70 & $\begin{array}{c}1,3 \\
7\end{array}$ & $\begin{array}{c}1,3 \\
3 \\
\end{array}$ & $\begin{array}{c}0,0 \\
4 \\
\end{array}$ & 1 & 100 & 2 & 1 & 2 \\
\hline 156 & 0,98 & $\begin{array}{c}0,7 \\
2 \\
\end{array}$ & 1,91 & 8,64 & 6,65 & 1,53 & 8,17 & 0,09 & 0,68 & $\begin{array}{c}1,3 \\
5 \\
\end{array}$ & $\begin{array}{c}1,3 \\
0 \\
\end{array}$ & $\begin{array}{c}0,0 \\
4 \\
\end{array}$ & 1 & 100 & 2 & 1 & 2 \\
\hline 157 & 1,33 & $\begin{array}{c}0,8 \\
7 \\
\end{array}$ & 1,12 & 12,30 & 12,96 & 1,85 & 14,81 & 0,16 & 0,76 & $\begin{array}{c}1,5 \\
6\end{array}$ & $\begin{array}{c}1,5 \\
1 \\
\end{array}$ & $\begin{array}{c}0,0 \\
5\end{array}$ & 1 & 34 & 2 & 1 & 1 \\
\hline 158 & 1,36 & $\begin{array}{c}0,9 \\
7 \\
\end{array}$ & 1,80 & 9,71 & 12,92 & 2,90 & 15,82 & 0,14 & 0,89 & $\begin{array}{c}1,7 \\
5 \\
\end{array}$ & $\begin{array}{c}1,6 \\
6 \\
\end{array}$ & $\begin{array}{c}0,0 \\
9 \\
\end{array}$ & 1 & 98 & 2 & 1 & 2 \\
\hline 159 & 1,35 & $\begin{array}{c}1,0 \\
1 \\
\end{array}$ & 1,56 & 10,98 & 7,19 & 2,64 & 9,83 & 0,13 & 0,94 & $\begin{array}{c}1,9 \\
3 \\
\end{array}$ & $\begin{array}{c}1,8 \\
6 \\
\end{array}$ & $\begin{array}{c}0,0 \\
7 \\
\end{array}$ & 1 & 41 & 2 & 1 & 1 \\
\hline 160 & 1,57 & $\begin{array}{c}1,1 \\
4 \\
\end{array}$ & 1,97 & 7,93 & 9,92 & 1,94 & 11,87 & 0,17 & 1,03 & $\begin{array}{c}2,2 \\
1 \\
\end{array}$ & $\begin{array}{c}2,1 \\
6 \\
\end{array}$ & $\begin{array}{c}0,0 \\
5 \\
\end{array}$ & 1 & 100 & 2 & 1 & 2 \\
\hline 161 & 1,33 & $\begin{array}{c}0,9 \\
3 \\
\end{array}$ & 0,80 & 8,19 & 9,71 & 2,74 & 12,45 & 0,15 & 0,89 & $\begin{array}{c}1,6 \\
5 \\
\end{array}$ & $\begin{array}{c}1,5 \\
6 \\
\end{array}$ & $\begin{array}{c}0,0 \\
9 \\
\end{array}$ & 1 & 56 & 2 & 1 & 1 \\
\hline 162 & 2,11 & $\begin{array}{c}1,5 \\
7\end{array}$ & 1,45 & 6,26 & 12,70 & 10,87 & 23,57 & 0,20 & 1,59 & $\begin{array}{c}2,8 \\
2\end{array}$ & $\begin{array}{c}2,6 \\
9\end{array}$ & $\begin{array}{c}0,1 \\
2\end{array}$ & 1 & 100 & 2 & 1 & 2 \\
\hline
\end{tabular}

